\title{
Estudio de la evolución de cargas en forjados y estructuras auxiliares de apuntalamiento durante \\ la construcción de edificios de hormigón in situ mediante procesos de cimbrado, clareado y descimbrado de plantas consecutivas
}



Departamento de Ingeniería de la Construcción y de Proyectos de Ingeniería Civil

ESTUDIO DE LA EVOLUCIÓN DE CARGAS EN FORJADOS Y ESTRUCTURAS AUXILIARES DE APUNTALAMIENTO

DURANTE LA CONSTRUCCIÓN DE EDIFICIOS DE HORMIGÓN IN SITU MEDIANTE PROCESOS DE CIMBRADO, CLAREADO Y DESCIMBRADO DE PLANTAS CONSECUTIVAS

TESIS DOCTORAL

Autora

$\mathrm{M}^{\mathrm{a}}$ Isabel Gasch Molina

\section{Directores}

Dr. Pedro A. Calderón García

Dr. Salvador Ivorra Chorro

Valencia, Abril de 2012 


\section{Colección Tesis Doctorales}

๑) Isabel Gasch Molina

( 1 2014, de la presente edición: Editorial Universitat Politècnica de València Telf.: 963877012 / www.lalibreria.upv.es

ISBN: 978-84-9048-197-4 (versión CD)

Queda prohibida la reproducción, distribución, comercialización, transformación, y en general, cualquier otra forma de explotación, por cualquier procedimiento, de todo o parte de los contenidos de esta obra sin autorización expresa y por escrito de sus autores. 
Cuando pares de buscar algo, lo encontrarás

(Murphy) 



\section{AGRADECIMIENTOS}

En primer lugar deseo expresar mi agradecimiento a mis directores de tesis, Pedro Calderón y Salvador Ivorra, por brindarme la oportunidad de realizar esta investigación, por el tiempo que me han dedicado, sus consejos y su inestimable ayuda sin la cual no hubiera sido posible la realización de esta Tesis Doctoral.

De igual forma, me gustaría darle las gracias a todo el grupo de investigación, empezando por Yezid, que fue quien me inició en esta investigación. Hemos compartido muchas horas de trabajo y se ha convertido en un amigo con el que he podido contar en todo momento. Gracias también a Benja, por estar siempre ahí para echarme una mano cuando ha hecho falta, por compartir horas de trabajo y por ser un gran amigo. Agradecer también a Nacho, Teresa, Fran, Jose Miguel, Ester y Vicente, quienes de igual manera, formaron parte del equipo de investigación aportando sus conocimientos y experiencias.

No me puedo olvidar de todas las personas que he podido conocer a lo largo de este tiempo como Andrea y Andrés C., compañeros y amigos, así como mis compañeros de FIPPU, en especial Cristina, Maite y Nuria, con las que he compartido buenos momentos e interminables conversaciones de desahogo.

Agradecer a toda mi familia el apoyo que me han brindado en todo momento. A Edwin, por el tiempo que le he robado, por estar ahí en los buenos y en los malos momentos dándome el ánimo necesario para seguir adelante. A mis padres Manolo e Isabel, por confiar siempre en mí, por todos sus consejos y enseñanzas que me han convertido en lo que soy. Tampoco me olvido de mi hermano Manolo ni de mi abuela Paquita, gracias por apoyarme en todo.

Por último, agradecer el apoyo económico de las empresas Encofrados J. ALSINA y SACYR sin el cual el desarrollo de esta tesis doctoral no habría sido posible, así como la financiación de la Generalitat Valenciana del proyecto GVPRE/2008/284. Así mismo, agradecer la colaboración de las empresas ACSA y ACCIONA. 



\section{RESUMEN}

Cada año se construyen miles de metros cuadrados de estructura y forjados de edificios mediante cimbrado y descimbrado de plantas sucesivas, produciéndose el mayor número de colapsos durante el proceso constructivo. Buscando mejorar los plazos de construcción y los costes, sin reducir la seguridad estructural, en España se utiliza una técnica conocida como clareado, o descimbrado parcial. Esta técnica consiste en retirar el encofrado y la mitad de los puntales que soportan el forjado unos días después de su hormigonado, pero sin que los puntales que permanecen pierdan en ningún momento su contacto con la estructura, reduciendo así el material necesario para el encofrado y el apuntalamiento.

Hasta la fecha han sido numerosos los estudios llevados a cabo sobre la transmisión de cargas entre forjados y puntales durante el proceso constructivo, pero pocos han sido los autores que han estudiado la técnica de clareado. Es por ello que uno de los principales objetivos de la presente Tesis Doctoral es el de realizar una investigación experimental y teórica en la que se estudie la transmisión de cargas entre forjados y puntales, utilizando un proceso de cimbrado-clareado-descimbrado, en las tipologías de forjados más comunes en edificación.

Para poder evaluar la transmisión de cargas entre forjados y puntales, durante la construcción de edificios de hormigón armado de plantas sucesivas, se ha llevado a cabo un estudio experimental en tres obras reales mediante la instrumentación de un número determinado de puntales. Las tres obras estudiadas abarcan las distintas tipologías de forjados más comunes en edificación, y en todas ellas se ha adoptado un proceso constructivo de cimbrado, clareado y descimbrado. El estudio experimental ha evidenciado que la transmisión de cargas entre forjados y puntales es diferente según el vano analizado. Esto se debe a que las condiciones de contorno y geometría del vano hacen particular la deformabilidad y/o la rigidez de cada uno de los vanos del forjado.

En otra fase de la investigación, se ha calibrado el modelo numérico desarrollado en investigaciones anteriores por el grupo de investigación, ajustándolo a las diferentes tipologías estructurales, y de las cuales se conoce su comportamiento experimental a través de las medidas de cargas en puntales y temperaturas tomadas en obra. Los resultados obtenidos de los modelos numéricos se ajustan satisfactoriamente a las mediciones experimentales.

Por último se ha validado un método simplificado, a partir de los resultados obtenidos, que permita, mediante coeficientes de carga, evaluar la transmisión de cargas durante el proceso de cimbrado, clareado y descimbrado de edificios con forjados consecutivos de hormigón in situ. El método que mejor grado de ajuste ha presentado, tanto con las medidas experimentales como con los modelos numéricos, ha sido el Nuevo Procedimiento Simplificado (Calderón et al., 2011).

Por otro lado, un efecto poco estudiado hasta la fecha es el que tienen los cambios de temperatura ambiente en la distribución de cargas entre forjados y puntales, pese a que algunos autores han registrado lo importante de su influencia. Es por ello que otro de los objetivos principales de la 
presente Tesis Doctoral es conocer las variaciones de temperatura de los diferentes elementos de la estructura durante su construcción y determinar su influencia en la variación de carga en los puntales.

Para evaluar el efecto que tiene la variación de la temperatura ambiente en los diferentes elementos de la estructura durante su construcción se ha desarrollado un estudio experimental donde se ha medido tanto la evolución de la temperatura ambiente como las variaciones de temperatura que se producían en el espesor de los forjados, observando la magnitud e importancia de los gradientes de temperatura en el forjado.

Posteriormente, mediante el desarrollo de un modelo teórico de elementos finitos, se ha realizado una aproximación numérica al efecto que producen los cambios de temperatura en la transmisión de cargas entre forjados y puntales. Los resultados obtenidos del modelo numérico de temperaturas muestran la importancia de las variaciones de temperatura en las cargas de puntales y forjados durante la construcción de edificios. Estos cambios en las cargas son producto de la combinación de dos efectos principales: los cambios de temperatura en los pilares y los puntales y la diferencia de temperatura entre las caras superior e inferior de los forjados.

Palabras Clave: Clareado; Cimbrado; Descimbrado; Puntal; Edificios de hormigón armado; Forjados; Estudio experimental; Modelo de elementos finitos; Modelo simplificado; Temperatura del hormigón. 


\section{RESUM}

Cada any es construeixen milers de metres quadrats d'estructura i forjats d'edificis mitjançant cintrat i descintrat de plantes successives, produint-se el major nombre de col-lapses durant el procés constructiu. Buscant millorar els terminis de construcció i els costos, sense reduir la seguretat estructural, a Espanya s'utilitza una tècnica coneguda com clarejat, o descintrat parcial. Aquesta tècnica consisteix a retirar l'encofrat i la meitat dels puntals que suporten el forjat uns dies després del formigonat, però sense que els puntals que romanen perden en cap moment el seu contacte amb l'estructura, reduint així el material necessari per l'encofrat i l'apuntalament.

Fins a la data han sigut nombrosos els estudis duts a terme sobre la transmissió de càrregues entre forjats i puntals durant el procés constructiu, però pocs han sigut els autors que han estudiat la tècnica de clarejat. És per això que un dels principals objectius de la present Tesi Doctoral és el de realitzar una investigació experimental i teòrica en la qual s'estudie la transmissió de càrregues entre forjats i puntals, utilitzant un procés de cintrat-clarejat-descintrat, en les tipologies de forjats més comuns en edificació.

Per a poder avaluar la transmissió de càrregues entre forjats i puntals, durant la construcció d'edificis de formigó armat de plantes successives, s'ha dut a terme un estudi experimental en tres obres reals mitjançant la instrumentació d'un nombre determinat de puntals. Les tres obres estudiades comprenen les distintes tipologies de forjats més comuns en edificació, i en totes elles s'ha adoptat un procés constructiu de cintrat, clarejat i descintrat. L'estudi experimental ha evidenciat que la transmissió de càrregues entre forjats i puntals és diferent segons el va analitzat. Açò és perquè les condicions de contorn i geometria del va fan particular la deformabilitat i/o la rigidesa de cada un dels vans del forjat.

En una altra fase de la investigació, s'ha calibrat el model numèric desenvolupat en investigacions anteriors pel grup d'investigació, ajustant-ho a les diferents tipologies estructurals, i de les quals es coneix el seu comportament experimental a través de les mesures de càrregues en puntals $\mathrm{i}$ temperatures preses en obra. Els resultats obtinguts dels models numèrics s'ajusten satisfactòriament als mesuraments experimentals.

Finalment s'ha validat un mètode simplificat, a partir dels resultats obtinguts, que permeta, per mitjà de coeficients de càrrega, avaluar la transmissió de càrregues durant el procés de cintrat, clarejat i descintrat d'edificis amb forjats consecutius de formigó in situ. El mètode que millor grau d'ajust ha presentat, tant amb les mesures experimentals com amb els models numèrics, ha sigut el Nou Procediment Simplificat (Calderón et al., 2011).

D'altra banda, un efecte poc estudiat fins ara és el que tenen els canvis de temperatura ambient en la distribució de càrregues entre forjats i puntals, tot i que alguns autors han registrat l'important de la seua influència. És per això que un altre dels objectius principals de la present Tesi Doctoral és conèixer les variacions de temperatura dels diversos elements de l'estructura durant la seua construcció i determinar la seua influència en la variació de càrrega en els puntals. 
Per avaluar l'efecte que té la variació de la temperatura ambient en els diversos elements de l'estructura durant la seua construcció s'ha desenvolupat un estudi experimental on s'ha mesurat tant l'evolució de la temperatura ambient com les variacions de temperatura que es produïen en l'espessor dels forjats, observant la magnitud i importància dels gradients de temperatura en el forjat.

Posteriorment, mitjançant el desenvolupament d'un model teòric d'elements finits, s'ha realitzat una aproximació numèrica a l'efecte que produeixen els canvis de temperatura en la transmissió de càrregues entre forjats i puntals. Els resultats obtinguts del model numèric de temperatures mostren la importància de les variacions de temperatura en les càrregues de puntals i forjats durant la construcció d'edificis. Estos canvis en les càrregues són producte de la combinació de dos efectes principals: els canvis de temperatura en els pilars i els puntals i la diferència de temperatura entre les cares superior i inferior dels forjats.

Paraules Claus: Clarejat; Cintrat; Descintrat; Puntal; Edificis de formigó armat; Forjats; Estudi experimental; Model de elements finits; Model simplificat; Temperatura del formigó. 


\section{SUMMARY}

Every year thousands of square meters of building structures and slabs are built, being the highest number of crashes during the construction process. Seeking to improve construction time and costs without reducing the structural safety, in Spain a technique known as clearing or partial striking is used. The technique consists of removing the formwork and 50\% of the slab-supporting shores several days after casting. This considerably reduces the material necessary for formwork and shoring, cuts costs and rationalizes the building process.

Several authors have carried out research studies to determine the load distribution during the construction process through theoretical models and experimental studies, but very few have studied the clearing technique. This is the reason that one of the main objectives of this $\mathrm{PhD}$ thesis is to carry out an experimental and theoretical research to study the load transmission between slabs and shores, using a construction process of shoring-clearing-striking, for the most common types of slab.

To be able to evaluate the load transmission between slabs and shores, during the construction of multistorey buildings, an experimental study in three real buildings has been carried out. All three buildings include the different types of slabs more common in construction and all of them have adopted a construction process of shoring, clearing and striking. The results showed that the load transmission varied according to the type of span studied, due to the different ways in which their deformability and/or stiffness are affected by their different geometries and boundary conditions.

In another phase of the research, the finite element model developed previously by the research group has been calibrated. The model has been adjusted to the different structural typologies, whose experimental behavior is known through the loads measured on shores. The FEM results showed a satisfactory fit with the readings obtained experimentally.

Finally, a simplified method to evaluate the load transmission between slabs and shores, during the process of shoring, clearing and striking of multistorey buildings, has been validated based on the experimental and numerical results. The method that has better fit with the experimental and numerical results is the New Simplified Procedure proposed by Calderón et al. (2011).

On the other hand, a factor that has received little attention to date is the effect of ambient temperature changes on load distribution between shores and floor slabs, even though certain authors have emphasized its importance. This is why the other main objective of this $\mathrm{PhD}$ Thesis is to evaluate the temperature changes of the different elements of the structure during construction and to determine their influence on the load distribution on shores.

To evaluate this effect, different building sites were monitored during construction in order to observe the temperature gradients inside reinforced concrete slabs during variations in the ambient temperature. It has been observed the magnitude and importance of temperature gradients in the slabs. 
The experimental results have been used to determine the influence of temperature changes on load variations on shores by developing a theoretical finite element model. The numerical results show the importance of temperature variations in the loads on shores and slabs during construction of multistory buildings. These changes in loads are the product of the combination of two main effects: temperature changes on columns and shores and the temperature difference between the upper and the lower surface of the slabs

Palabras Clave: Clareado; Cimbrado; Descimbrado; Puntal; Edificios de hormigón armado; Forjados; Estudio experimental; Modelo de los elementos finitos; Temperatura del hormigón.

Keywords: Clearing; Shoring; Striking; Shore; Reinforced concrete buildings; Slabs; Experimental study; Finite element method; Simplified model; Temperature of concrete. 


\section{INDICE GENERAL}

Pág.

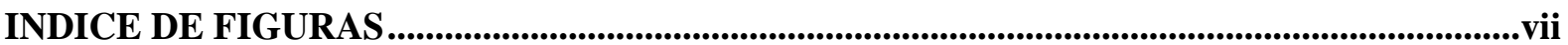

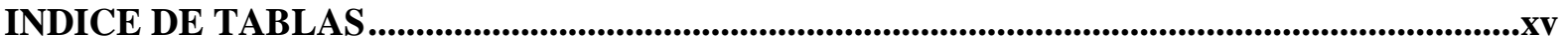

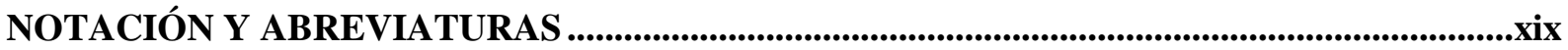

\section{CAPITULO 1. INTRODUCCIÓN Y OBJETIVOS}

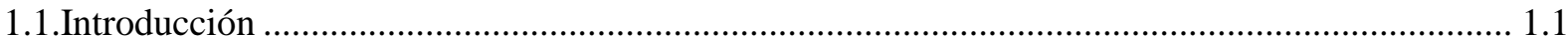

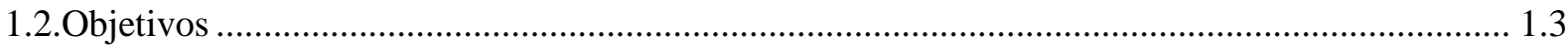

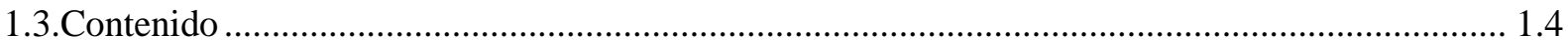

\section{CAPITULO 2. ANTECEDENTES Y ESTADO DEL ARTE}

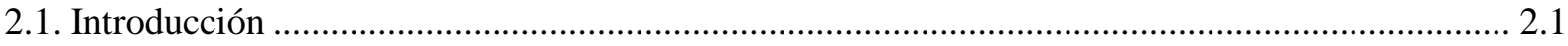

2.2. Procesos constructivos para edificios de hormigón armado de plantas consecutivas .................... 2.2

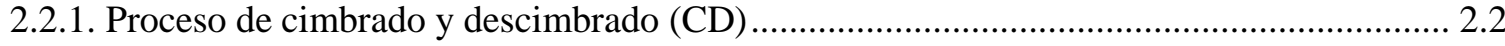

2.2.2. Proceso de cimbrado, recimbrado y descimbrado (CRD) .............................................. 2.2

2.2.3. Proceso de cimbrado, clareado y descimbrado (CCD) ........................................................ 2.3

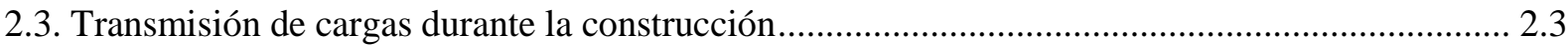

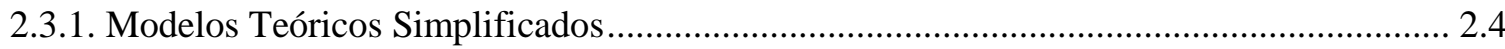

2.3.1.1. Método Simplificado (Grundy y Kabaila, 1963) ....................................................... 2.4

2.3.1.2. Método Refinado (Liu et al., 1985, 1986) ...................................................................... 2.7

2.3.1.3. Método Mejorado (El-Shahhat y Chen, 1992) ............................................................. 2.9

2.3.1.4. Método Simplificado Mejorado (Duan y Chen, 1995) ................................................2.10

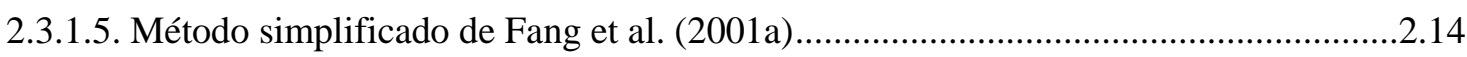

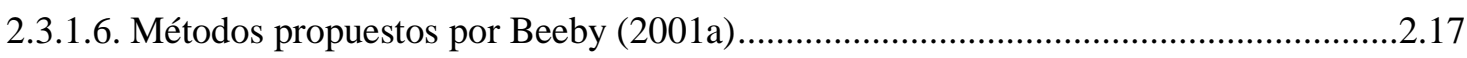

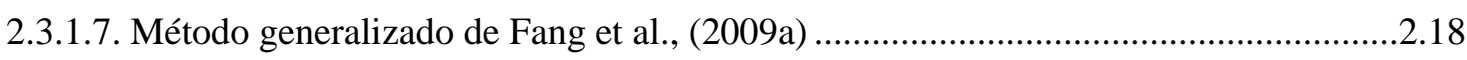

2.3.1.8. Nuevo Procedimiento Simplificado (Calderón et al., 2011) ..........................................19

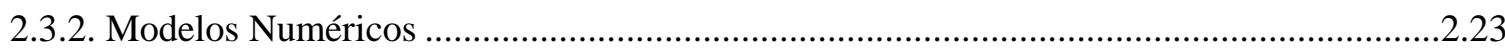


2.3.2.1. Equivalent Frame Method (Stivaros y Halvorsen, 1990) …..................................... 2.23

2.3.2.2. Modelo de Mosallam y Chen (1991) ……….............................................................. 2.27

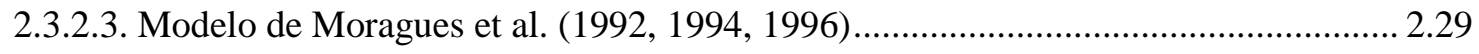

2.3.2.4. Modelo numérico de Kwak et al. (2006) ................................................................. 2.32

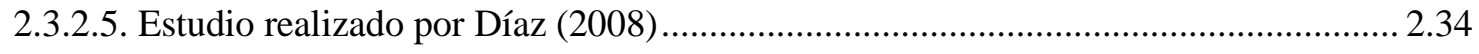

2.3.2.6. Modelo numérico de Alvarado et al. (2010) ............................................................ 2.35

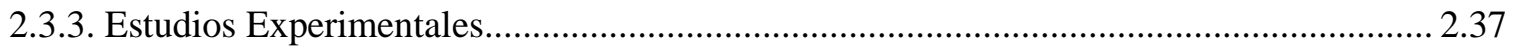

2.3.3.1. Medidas realizadas por Agarwal y Gardner (1974) ............................................... 2.37

2.3.3.2. Medidas realizadas por Lasisi y Ng (1979) .......................................................... 2.38

2.3.3.3. Medidas realizadas por Moragues (1992)............................................................. 2.38

2.3.3.4. Medidas realizadas por Ambrose et al. (1994) ....................................................... 2.39

2.3.3.5. Medidas realizadas por Rosowsky et al. (1997) ...................................................... 2.39

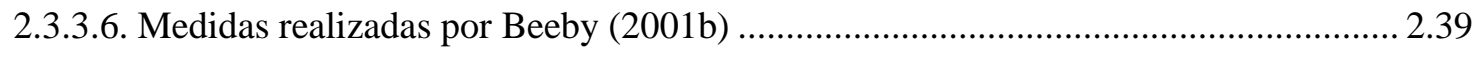

2.3.3.7. Medidas realizadas por Fang et al. (2001b) ......................................................... 2.40

2.3.3.8. Medidas realizadas por Puente et al. (2007) ....................................................... 2.41

2.3.3.9. Medidas realizadas por Alvarado et al. (2009) ....................................................... 2.42

2.4. Efecto de la temperatura en la transmisión de cargas entre forjados y puntales........................... 2.44

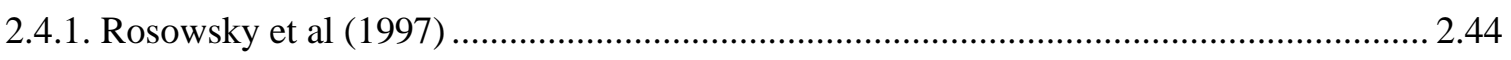

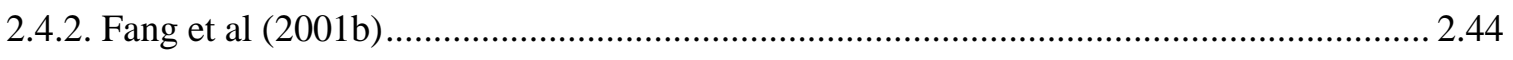

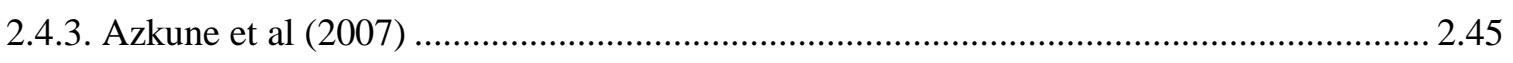

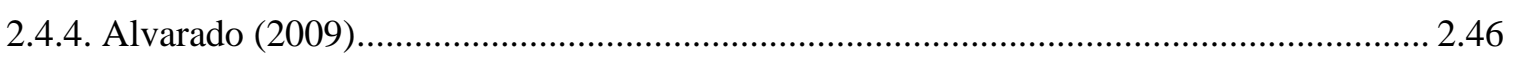

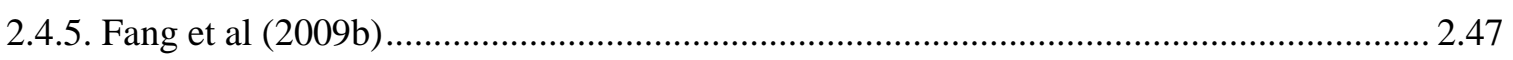

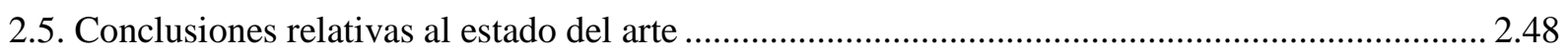

\section{CAPITULO 3. ESTUDIOS EXPERIMENTALES}

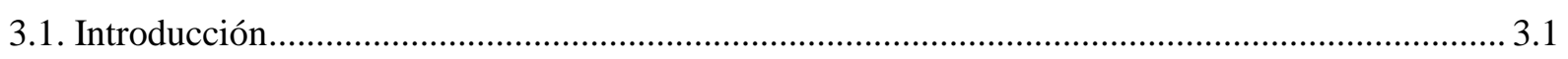

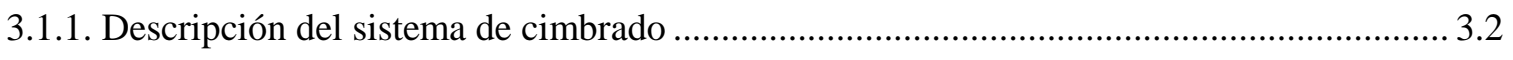

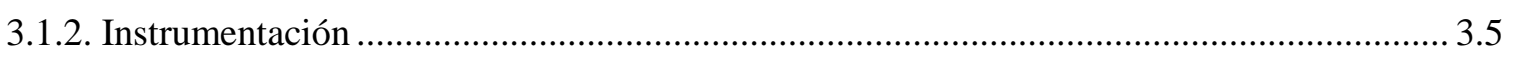

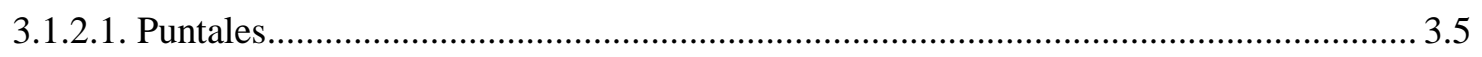

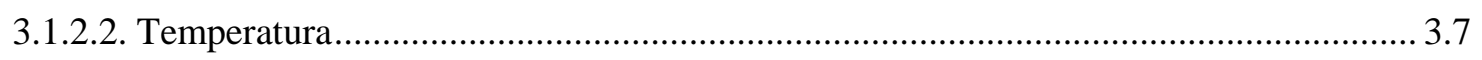

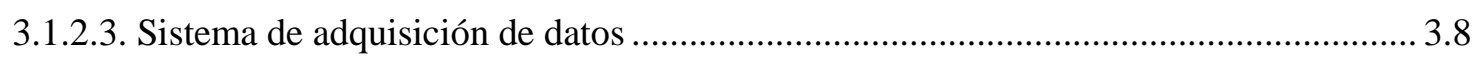

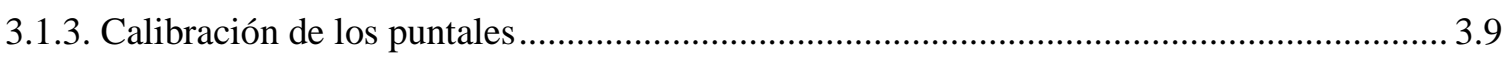




\section{Pág.}

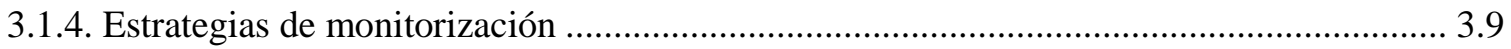

3.2. Estudio experimental de un edificio de forjado de losa maciza ....................................................10

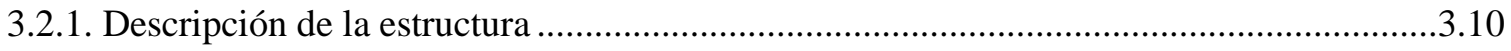

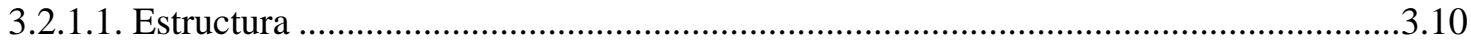

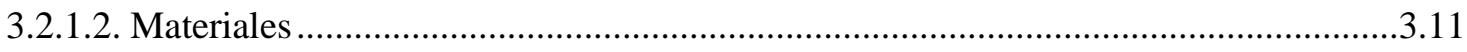

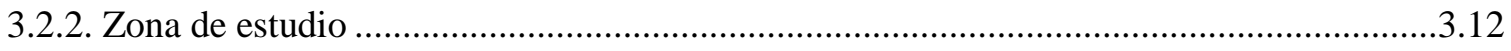

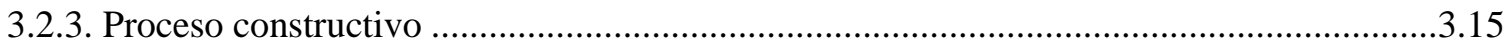

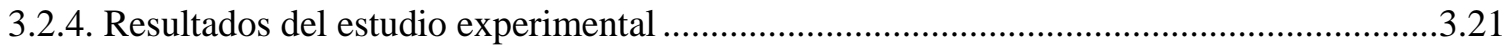

3.3. Estudio experimental de un edificio de forjado reticular de casetón perdido ................................3.28

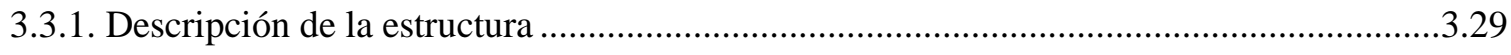

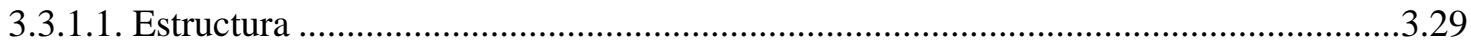

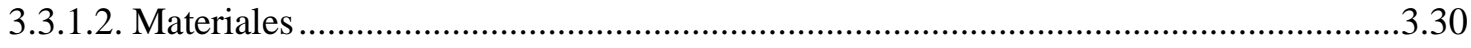

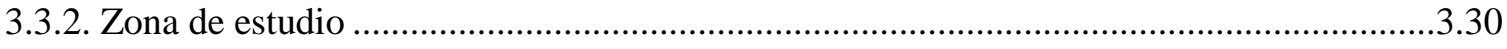

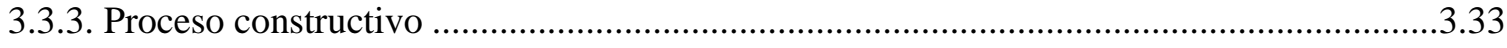

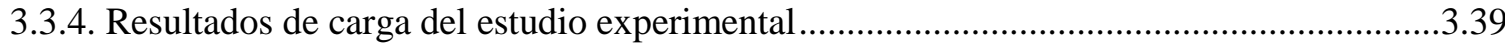

3.3.5. Resultados de temperatura del estudio experimental ............................................................

3.4. Estudio experimental de un edificio de forjado reticular de casetón recuperable ............................46

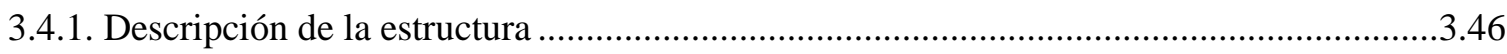

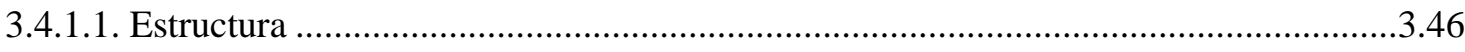

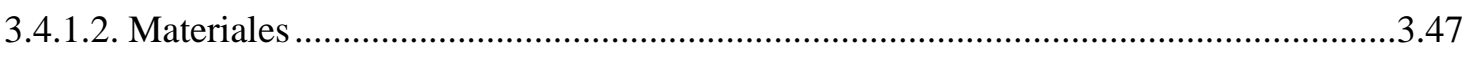

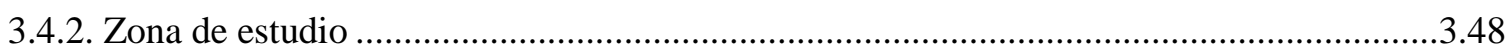

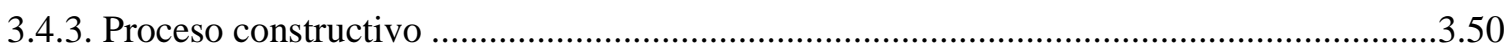

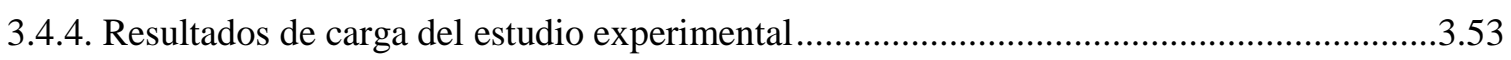

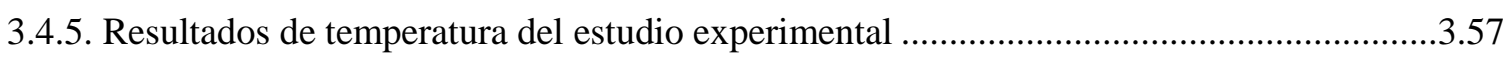

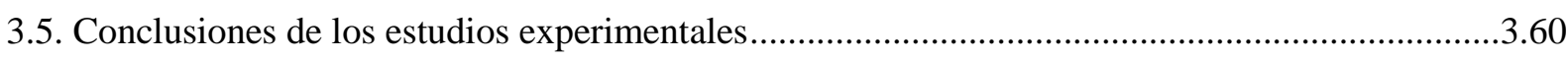

3.5.1. Conclusiones del estudio experimental del edificio de forjado de losa maciza ....................61

3.5.2. Conclusiones del estudio experimental del edificio de forjado reticular de casetón perdido..

3.5.3. Conclusiones del estudio experimental del edificio de forjado reticular de casetón

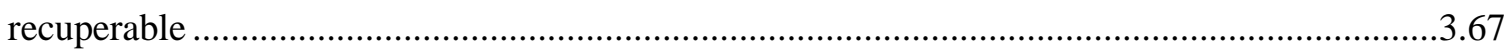

3.5.4. Comparación de las medidas experimentales de carga de los distintos edificios estudiados 
Pág.

\section{CAPITULO 4. MODELOS NUMÉRICOS}

4.1. Introducción 4.1

4.2. Modelo numérico del edificio de forjado de losa maciza ................................................... 4.1

4.2.1. Hipótesis consideradas .................................................................................... 4.2

4.2.2. Descripción del modelo de Elementos Finitos .............................................................. 4.3

4.2.2.1. Tipos de EF y mallado empleado ................................................................. 4.3

4.2.2.2. Simulación del proceso constructivo ............................................................... 4.4

4.2.3. Análisis de resultados del modelo y comparación con las medidas experimentales .......... 4.7

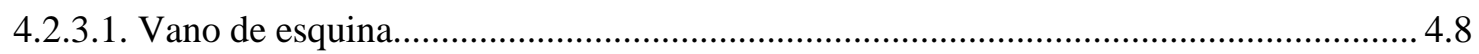

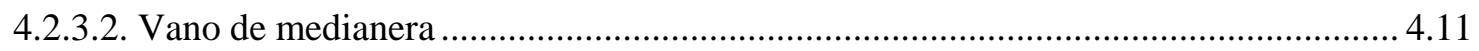

4.2.3.3. Resumen .......................................................................................... 4.14

4.2.4. Comparación de los resultados de los puntales de la sopanda con los de la totalidad de puntales del vano en el FEM ................................................................................. 4.14

4.3. Modelo numérico del edificio de forjado reticular de casetón recuperable..............................4.16

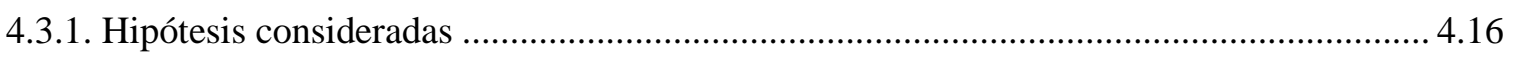

4.3.2. Descripción del modelo de Elementos Finitos ......................................................... 4.17

4.3.2.1. Tipos de EF y mallado empleado .................................................................. 4.17

4.3.2.2. Simulación del proceso constructivo .......................................................... 4.18

4.3.3. Análisis de resultados del modelo y comparación con las medidas experimentales ....... 4.19

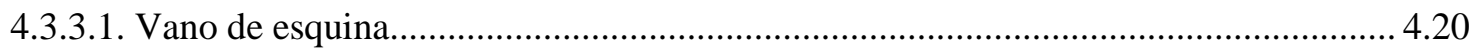

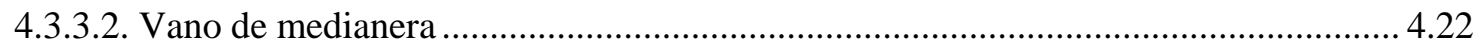

4.3.3.3. Resumen ........................................................................................ 4.24

4.4. Modelo numérico del edificio experimental de Alvarado (2009) considerando los efectos de la

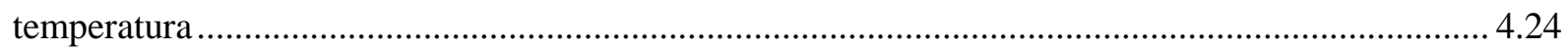

4.4.1. Breve descripción del edificio experimental de Alvarado (2009) ................................ 4.25

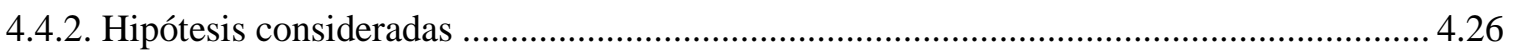

4.4.3. Descripción del modelo de Elementos Finitos ...................................................... 4.27

4.4.3.1. Tipos de EF y mallado empleado ................................................................ 4.27

4.4.3.2. Temperaturas consideradas................................................................... 4.27

4.4.3.3. Simulación del proceso constructivo .......................................................... 4.29

4.4.4. Análisis de resultados del modelo y comparación con las medidas experimentales ........ 4.30 


\section{CAPITULO 5. ESTUDIO COMPARATIVO DE DIVERSOS MÉTODOS SIMPLIFICADOS DE CÁLCULO DE TRANSMISIÓN DE CARGAS}

5.1. Introducción 5.1

5.2. Métodos simplificados considerados 5.1

5.2.1. Método Simplificado Mejorado (Duan y Chen, 1995) 5.2

5.2.2. Método Simplificado de Fang et al. (2001a) 5.2

5.2.3. Nuevo Procedimiento Simplificado (Calderón et al., 2011) 5.3

5.3. Aplicación de los métodos simplificados al edificio de forjado de losa maciza 5.3

5.3.1. Método Simplificado Mejorado (Duan y Chen, 1995)

5.3.1.1. Resultados de la aplicación del método

5.3.1.2. Comparación de los resultados

5.3.2. Método Simplificado de Fang et al. (2001a)

5.3.2.1. Resultados de la aplicación del método

5.3.2.2. Comparación de los resultados

5.3.3. Nuevo Procedimiento Simplificado (Calderón et al., 2011)

5.3.3.1. Resultados de la aplicación del método

5.3.3.2. Comparación de los resultados

5.4. Aplicación de los métodos simplificados al edificio de forjado reticular de casetón perdido ......5.19

5.4.1. Método Simplificado Mejorado (Duan y Chen, 1995)........................................................19

5.4.1.1. Resultados de la aplicación del método ....................................................................5.20

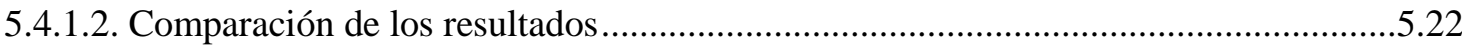

5.4.2. Método Simplificado de Fang et al. (2001a) .........................................................................23

5.4.2.1. Resultados de la aplicación del método .....................................................................5.23

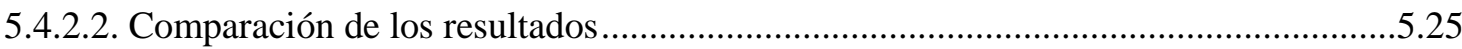

5.4.3. Nuevo Procedimiento Simplificado (Calderón et al., 2011) .............................................5.26

5.4.3.1. Resultados de la aplicación del método ………...........................................................5.26

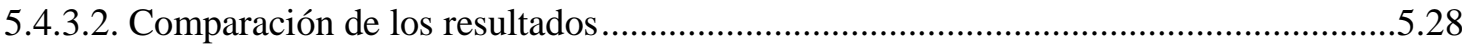

5.5. Aplicación de los métodos simplificados al edificio de forjado reticular de casetón recuperable..... 
5.5.1.1. Resultados de la aplicación del método .5 .30

5.5.1.2. Comparación de los resultados

5.5.2. Método Simplificado de Fang et al. (2001a)

5.5.2.1. Resultados de la aplicación del método.

5.5.2.2. Comparación de los resultados

5.5.3. Nuevo Procedimiento Simplificado (Calderón et al., 2011).............................................. 5.37

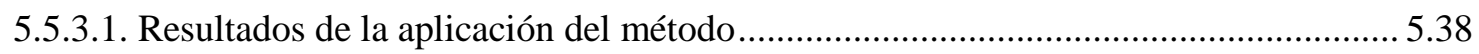

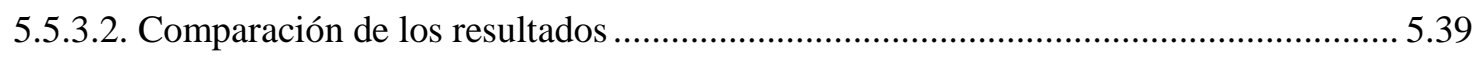

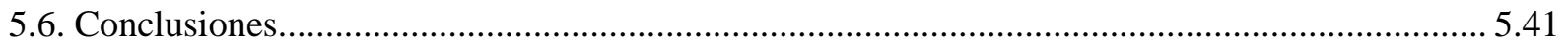

\section{CAPITULO 6. CONCLUSIONES Y FUTURAS LÍNEAS DE INVESTIGACIÓN}

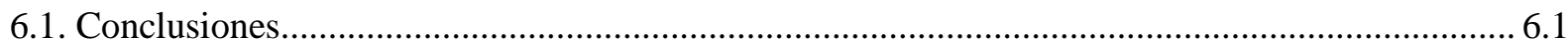

6.1.1. Medidas experimentales de la transmisión de cargas entre puntales y forjados.................. 6.1

6.1.2. Medidas experimentales de los cambios de temperatura en los distintos elementos........... 6.3

6.1.3. Verificación y calibración de los modelos numéricos de EF................................................. 6.3

6.1.3.1. Transmisión de cargas por operaciones constructivas .................................................. 6.3

6.1.3.2. Efectos de los cambios de temperatura en la transmisión de cargas.............................. 6.4

6.1.4. Comprobación de la validez de los métodos simplificados de determinación de transmisión de cargas

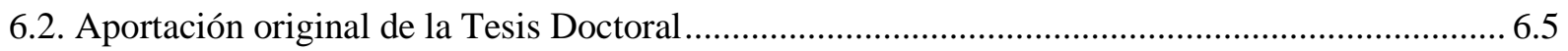

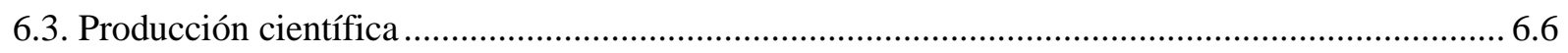

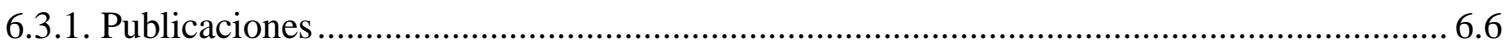

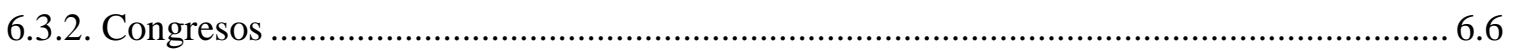

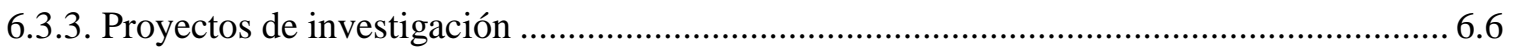

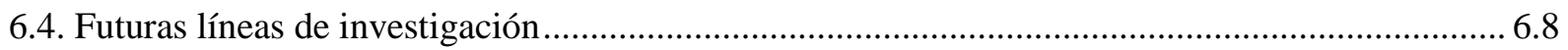

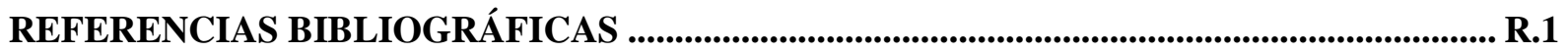

\section{APÉNDICES}

Apéndice I. Resultados de los estudios experimentales .................................................................... I.1

Apéndice II. Resultados de los modelos numéricos ................................................................................1

Apéndice III. Estimación del módulo de elasticidad del hormigón...................................................... III.1 


\section{INDICE DE FIGURAS}

Fig. 2.1 Porcentaje de las publicaciones científicas entre los años 1952 y 2011 según datos de Scopus Fig. 2.2 Evolución de las publicaciones científicas entre los años 1952 y 2011 según datos de Scopus

Fig. 2.3 Operaciones de cimbrado y descimbrado $n=3$

Fig. 2.4 Coeficientes de carga para puntales y forjados $n=2$

Fig. 2.5 Coeficientes de carga para puntales y forjados $n=3$

Fig. 2.6 Coeficientes de carga para puntales y forjados considerando la variación del módulo de elasticidad $\mathrm{n}=3$

Fig. 2.7 Evolución del módulo elástico con la edad (Grundy y Kabaila, 1963)

Fig. 2.8 Coeficientes de carga para puntales y forjados $n=2$ (Recimbrado).

Fig. 2.9 Modelo estructural Modelo de Liu et al. (1985)

Fig. 2.10 Operaciones de (a) Hormigonado del último forjado y (b) Descimbrado del primer forjado

Fig. 2.11 Modelo de la estructura (de 2D a 1D) para la fase de hormigonado (Fang et al., 2001a).

Fig. 2.12 Coeficiente de carga máxima en forjados para procesos constructivos con 2 niveles cimbrados y n recimbrados (Fang et al., 2001a).

Fig. 2.13 Coeficiente de carga máxima en forjados para procesos constructivos con 3 niveles cimbrados y $n$ recimbrados (Fang et al., 2001a).

Fig. 2.14 Operaciones de (a) Hormigonado del último forjado (b) Clareado del último forjado y (c) Descimbrado del primer forjado

Fig. 2.15 Idealización de la estructura para el EFM (Stivaros y Halvorsen, 1990)

Fig. 2.16 Planta característica del ejemplo usado en el modelo EFM (Stivaros y Halvorsen, 1990)

Fig. 2.17 Resultados del modelo EFM comparado con distintos modelos numéricos (Stivaros y Halvorsen, 1990)

Fig. 2.18 Coeficientes de carga máximos para un forjado cimbrado (Stivaros y Halvorsen, 1990)

Fig. 2.19 Coeficientes de carga máximos para dos forjados cimbrados (Stivaros y Halvorsen, 1990)

Fig. 2.20 Coeficientes de carga modelo Moragues et al. (1996) para dos plantas cimbradas

Fig. 2.21 Coeficientes de carga modelo Moragues et al. (1996) para tres plantas cimbradas

Fig. 2.22 Evolución de cargas en puntales medida por Fang et al.

Fig. 2.23 Evolución de carga en puntales medida por Azkune et al. (2007) en Getaria.

Fig. 2.24 Coeficiente de carga media en puntales entre el hormigonado y antes del clareado del forjado 1 (Alvarado, 2009).

Fig. 3.1 Sistema Alumecano (edificio de Sabadell)

Fig. 3.2 Sistema Alucubetas (edificio de Bellas Artes)

Fig. 3.3 Puntal empleado en los estudios experimentales

Fig. 3.4. Basculantes (edificio de Sabadell)

Fig. 3.5 Superficie del puntal una vez pulido

Fig. 3.6 Galga pegada en la superficie del puntal

Fig. 3.7 Protección utilizada para las bandas extensométricas

Fig. 3.8 Termopares tipo $\mathbf{J}$ (a) Termopares con conector mini tipo $\mathbf{J}$ (b) Termopares embebidos en el hormigón 
Fig. 3.9 Estación de medida empleada para la adquisición de datos

Fig. 3.10 Sección del edificio de forjado de losa maciza

Fig. 3.11 Zona de estudio del edificio de forjado de losa maciza

Fig. 3.12 Disposición de sopandas principales y secundarias planta baja del edificio de forjado de losa maciza

Fig. 3.13 Disposición de sopandas principales y secundarias plantas superiores del edificio de forjado de losa maciza

Fig. 3.14 Proceso constructivo día "0" (forjado de losa maciza)

Fig. 3.15 Proceso constructivo día "7" (forjado de losa maciza)

Fig. 3.16 Proceso constructivo día "10" (forjado de losa maciza)

Fig. 3.17 Proceso constructivo día "15" (forjado de losa maciza)

Fig. 3.18 Proceso constructivo día "16" (forjado de losa maciza)

Fig. 3.19 Proceso constructivo día "22" (forjado de losa maciza)

Fig. 3.20 Proceso constructivo día " 23 a" (forjado de losa maciza)

Fig. 3.21 Proceso constructivo día " 23 b" (forjado de losa maciza)

Fig. 3.22 Proceso constructivo día " 28 " (forjado de losa maciza)

Fig. 3.23 Proceso constructivo día "29" (forjado de losa maciza)

Fig. 3.24 Proceso constructivo día "30" (forjado de losa maciza)

Fig. 3.25 Proceso constructivo día " 35 " (forjado de losa maciza)

Fig. 3.26 Proceso constructivo día "36" (forjado de losa maciza)

Fig. 3.27 Proceso constructivo día "37" (forjado de losa maciza)

Fig. 3.28 Coeficientes de carga en el forjado 1 (Forjado de losa maciza - Vano de esquina)

Fig. 3.29 Coeficientes de carga en puntales bajo el forjado 1 (Forjado de losa maciza - Vano de esquina)

Fig. 3.30 Coeficientes de carga en el forjado 2 (Forjado de losa maciza - Vano de esquina)

Fig. 3.31 Coeficientes de carga en puntales bajo el forjado 2 (Forjado de losa maciza - Vano de esquina)

Fig. 3.32 Coeficientes de carga en el forjado 3 (Forjado de losa maciza - Vano de esquina)

Fig. 3.33 Coeficientes de carga en puntales bajo el forjado 3 (Forjado de losa maciza - Vano de esquina)

Fig. 3.34 Coeficientes de carga en el forjado 4 (Forjado de losa maciza - Vano de esquina)

Fig. 3.35 Coeficientes de carga en puntales bajo el forjado 4 (Forjado de losa maciza - Vano de esquina)

Fig. 3.36 Coeficientes de carga en el forjado 5 (Forjado de losa maciza - Vano de esquina)

Fig. 3.37 Coeficientes de carga en puntales bajo el forjado 5 (Forjado de losa maciza - Vano de esquina)

Fig. 3.38 Coeficientes de carga en el forjado 1 (Forjado de losa maciza - Vano de medianera)

Fig. 3.39 Coeficientes de carga en puntales bajo el forjado 1 (Forjado de losa maciza - Vano de medianera)

Fig. 3.40 Coeficientes de carga en el forjado 2 (Forjado de losa maciza - Vano de medianera)

Fig. 3.41 Coeficientes de carga en puntales bajo el forjado 2 (Forjado de losa maciza - Vano de medianera)

Fig. 3.42 Coeficientes de carga en el forjado 3 (Forjado de losa maciza - Vano de medianera) 
Fig. 3.43 Coeficientes de carga en puntales bajo el forjado 3 (Forjado de losa maciza - Vano de medianera)

Fig. 3.44 Coeficientes de carga en el forjado 4 (Forjado de losa maciza - Vano de medianera)

Fig. 3.45 Coeficientes de carga en puntales bajo el forjado 4 (Forjado de losa maciza - Vano de medianera)

Fig. 3.46 Coeficientes de carga en el forjado 5 (Forjado de losa maciza - Vano de medianera)

Fig. 3.47 Coeficientes de carga en puntales bajo el forjado 5 (Forjado de losa maciza - Vano de medianera)

Fig. 3.48 Sección del edificio de forjado reticular de casetón perdido

Fig. 3.49 Zona de estudio del edificio de forjado reticular de casetón perdido. Forjados 1 y 2

Fig. 3.50 Zona de estudio del edificio de forjado reticular de casetón perdido. Forjados superiores

Fig. 3.51 Disposición de sopandas principales y secundarias en los sótanos del edificio de forjado reticular de casetón perdido

Fig. 3.52 Disposición de sopandas principales y secundarias en el resto de plantas del edificio de forjado reticular de casetón perdido

Fig. 3.53. Termopares embebidos en el hormigón en la zona del ábaco (forjado reticular de casetón perdido).

Fig. 3.54 Proceso constructivo día "0" (forjado reticular de casetón perdido)

Fig. 3.55 Proceso constructivo día "6" (forjado reticular de casetón perdido)

Fig. 3.56 Proceso constructivo día "53" (forjado reticular de casetón perdido)

Fig. 3.57 Proceso constructivo día "59" (forjado reticular de casetón perdido)

Fig. 3.58 Proceso constructivo día "84" (forjado reticular de casetón perdido)

Fig. 3.59 Proceso constructivo día "89" (forjado reticular de casetón perdido)

Fig. 3.60 Proceso constructivo día "111 a" (forjado reticular de casetón perdido)

Fig. 3.61 Proceso constructivo día "111 b" (forjado reticular de casetón perdido)

Fig. 3.62 Proceso constructivo día "115" (forjado reticular de casetón perdido)

Fig. 3.63 Proceso constructivo día "137" (forjado reticular de casetón perdido)

Fig. 3.64 Proceso constructivo día "143a" (forjado reticular de casetón perdido)

Fig. 3.65 Proceso constructivo día "143b" (forjado reticular de casetón perdido)

Fig. 3.66 Proceso constructivo día "160a" (forjado reticular de casetón perdido)

Fig. 3.67 Proceso constructivo día "37" (forjado reticular de casetón perdido)

Fig. 3.68 Coeficientes de carga en el forjado 1 (forjado reticular de casetón perdido)

Fig. 3.69 Coeficientes de carga en puntales bajo el forjado 1 (forjado reticular de casetón perdido)

Fig. 3.70 Coeficientes de carga en el forjado 2 (forjado reticular de casetón perdido)

Fig. 3.71 Coeficientes de carga en puntales bajo el forjado 2 (forjado reticular de casetón perdido)

Fig. 3.72 Coeficientes de carga en el forjado 3 (forjado reticular de casetón perdido)

Fig. 3.73 Coeficientes de carga en puntales bajo el forjado 3 (forjado reticular de casetón perdido)

Fig. 3.74 Coeficientes de carga en el forjado 4 (forjado reticular de casetón perdido)

Fig. 3.75 Coeficientes de carga en puntales bajo el forjado 4 (forjado reticular de casetón perdido)

Fig. 3.76 Coeficientes de carga en el forjado 5 (forjado reticular de casetón perdido)

Fig. 3.77 Coeficientes de carga en puntales bajo el forjado 5 (forjado reticular de casetón perdido)

Fig. 3.78 Distribución de temperaturas en el espesor de la losa a lo largo del día para la losa de $0.20 \mathrm{~m}$ encofrada. Edificio de forjado reticular de casetón perdido 
Fig. 3.79 Distribución de temperaturas en el espesor de la losa a lo largo del día para la losa de $0.20 \mathrm{~m}$ desencofrada. Edificio de forjado reticular de casetón perdido

Fig. 3.80 Distribución de temperaturas en el espesor de la losa a lo largo del día para la losa de $0.32 \mathrm{~m}$ encofrada. Edificio de forjado reticular de casetón perdido.

Fig. 3.81 Distribución de temperaturas en el espesor de la losa a lo largo del día para la losa de $0.32 \mathrm{~m}$ desencofrada. Edificio de forjado reticular de casetón perdido.

Fig. 3.82 Sección del edificio de forjado reticular de casetón recuperable

Fig. 3.83 Zona de estudio del edificio de forjado reticular de casetón recuperable

Fig. 3.84 Disposición de sopandas principales y secundarias en el edificio de forjado reticular de casetón recuperable

Fig. 3.85 Termopares embebidos en el hormigón (forjado reticular de casetón recuperable)

Fig. 3.86 Proceso constructivo día "0" (forjado reticular de casetón recuperable)

Fig. 3.87 Proceso constructivo día "7" (forjado reticular de casetón recuperable)

Fig. 3.88 Proceso constructivo día "17" (forjado reticular de casetón recuperable)

Fig. 3.89 Proceso constructivo día "24a" (forjado reticular de casetón recuperable)

Fig. 3.90 Proceso constructivo día "24b" (forjado reticular de casetón recuperable)

Fig. 3.91 Proceso constructivo día "32" (forjado reticular de casetón recuperable)

Fig. 3.92 Proceso constructivo día "37" (forjado reticular de casetón recuperable)

Fig. 3.93 Proceso constructivo día " 38 " (forjado reticular de casetón recuperable)

Fig. 3.94 Proceso constructivo día "49" (forjado reticular de casetón recuperable)

Fig. 3.95 Coeficientes de carga en el forjado 1 (Forjado reticular de casetón recuperable - Vano de esquina)

Fig. 3.96 Coeficientes de carga en puntales bajo el forjado 1 (Forjado reticular de casetón recuperable - Vano de esquina)

Fig. 3.97 Coeficientes de carga en el forjado 2 (Forjado reticular de casetón recuperable - Vano de esquina)

Fig. 3.98 Coeficientes de carga en puntales bajo el forjado 2 (Forjado reticular de casetón recuperable - Vano de esquina)

Fig. 3.99 Coeficientes de carga en el forjado 3 (Forjado reticular de casetón recuperable - Vano de esquina)

Fig. 3.100 Coeficientes de carga en puntales bajo el forjado 3 (Forjado reticular de casetón recuperable - Vano de esquina)

Fig. 3.101 Coeficientes de carga en el forjado 1 (Forjado reticular de casetón recuperable - Vano de medianera)

Fig. 3.102 Coeficientes de carga en puntales bajo el forjado 1 (Forjado reticular de casetón recuperable - Vano de medianera)

Fig. 3.103 Coeficientes de carga en el forjado 2 (Forjado reticular de casetón recuperable - Vano de medianera)

Fig. 3.104 Coeficientes de carga en puntales bajo el forjado 2 (Forjado reticular de casetón recuperable - Vano de medianera)

Fig. 3.105 Coeficientes de carga en el forjado 3 (Forjado reticular de casetón recuperable - Vano de medianera)

Fig. 3.106 Coeficientes de carga en puntales bajo el forjado 3 (Forjado reticular de casetón recuperable - Vano de medianera) 
Fig. 3.107 Distribución de temperaturas en el espesor del forjado a lo largo del día para el forjado de $0.40 \mathrm{~m}$ encofrado. Edificio de forjado reticular de casetón recuperable.

Fig. 3.108 Distribución de temperaturas en el espesor del forjado a lo largo del día para el forjado de $0.40 \mathrm{~m}$ desencofrado con insolación directa. Edificio de forjado reticular de casetón recuperable.

Fig. 3.109 Distribución de temperaturas en el espesor del forjado a lo largo del día para el forjado de $0.40 \mathrm{~m}$ desencofrado sin insolación directa. Edificio de forjado reticular de casetón recuperable.

Fig. 4.1 Modelo de Elementos Finitos del edificio de forjado de losa maciza: (a) Sección (b) Forjado tipo

Fig. 4.2 Elemento SHELL63 (ANSYS 11.0, 2006)

Fig. 4.3 Elemento LINK 10 (ANSYS 11.0, 2006)

Fig. 4.4 Elemento BEAM 188 (ANSYS 11.0, 2006)

Fig. 4.5 Comparación coeficientes de carga en el forjado 1 (Forjado de losa maciza - Vano de esquina)

Fig. 4.6 Comparación coeficientes de carga en puntales bajo el forjado 1 (Forjado de losa maciza Vano de esquina)

Fig. 4.7 Comparación coeficientes de carga en el forjado 2 (Forjado de losa maciza - Vano de esquina)

Fig. 4.8 Comparación coeficientes de carga en puntales bajo el forjado 2 (Forjado de losa maciza Vano de esquina)

Fig. 4.9 Comparación coeficientes de carga en el forjado 3 (Forjado de losa maciza - Vano de esquina)

Fig. 4.10 Comparación coeficientes de carga en puntales bajo el forjado 3 (Forjado de losa maciza Vano de esquina)

Fig. 4.11 Comparación coeficientes de carga en el forjado 4 (Forjado de losa maciza - Vano de esquina)

Fig. 4.12 Comparación coeficientes de carga en puntales bajo el forjado 4 (Forjado de losa maciza Vano de esquina)

Fig. 4.13 Comparación coeficientes de carga en el forjado 5 (Forjado de losa maciza - Vano de esquina)

Fig. 4.14 Comparación coeficientes de carga en puntales bajo el forjado 5 (Forjado de losa maciza Vano de esquina)

Fig. 4.15 Comparación coeficientes de carga en el forjado 1 (Forjado de losa maciza - Vano de medianera)

Fig. 4.16 Comparación coeficientes de carga en puntales bajo el forjado 1 (Forjado de losa maciza Vano de medianera)

Fig. 4.17 Comparación coeficientes de carga en el forjado 2 (Forjado de losa maciza - Vano de medianera)

Fig. 4.18 Comparación coeficientes de carga en puntales bajo el forjado 2 (Forjado de losa maciza Vano de medianera)

Fig. 4.19 Comparación coeficientes de carga en el forjado 3 (Forjado de losa maciza - Vano de medianera)

Fig. 4.20 Comparación coeficientes de carga en puntales bajo el forjado 3 (Forjado de losa maciza Vano de medianera)

Fig. 4.21 Comparación coeficientes de carga en el forjado 4 (Forjado de losa maciza - Vano de medianera) 
Fig. 4.22 Comparación coeficientes de carga en puntales bajo el forjado 4 (Forjado de losa maciza Vano de medianera)

Fig. 4.23 Comparación coeficientes de carga en el forjado 5 (Forjado de losa maciza - Vano de medianera)

Fig. 4.24 Comparación coeficientes de carga en puntales bajo el forjado 5 (Forjado de losa maciza Vano de medianera)

Fig. 4.25 Modelo de Elementos Finitos del edificio de forjado reticular de casetón recuperable: (a) Sección (b) Forjado tipo

Fig. 4.26 Sección correspondiente a los nervios del emparrillado.

Fig. 4.27 Comparación coeficientes de carga en el forjado 1 (Forjado reticular de casetón recuperable Vano de esquina)

Fig. 4.28 Comparación coeficientes de carga en puntales bajo el forjado 1 (Forjado reticular de casetón recuperable - Vano de esquina)

Fig. 4.29 Comparación coeficientes de carga en el forjado 2 (Forjado reticular de casetón recuperable Vano de esquina)

Fig. 4.30 Comparación coeficientes de carga en puntales bajo el forjado 2 (Forjado reticular de casetón recuperable - Vano de esquina)

Fig. 4.31 Comparación coeficientes de carga en el forjado 3 (Forjado reticular de casetón recuperable Vano de esquina)

Fig. 4.32 Comparación coeficientes de carga en puntales bajo el forjado 3 (Forjado reticular de casetón recuperable - Vano de esquina)

Fig. 4.33 Comparación coeficientes de carga en el forjado 1 (Forjado reticular de casetón recuperable Vano de medianera)

Fig. 4.34 Comparación coeficientes de carga en puntales bajo el forjado 1 (Forjado reticular de casetón recuperable - Vano de medianera)

Fig. 4.35 Comparación coeficientes de carga en el forjado 2 (Forjado reticular de casetón recuperable Vano de medianera)

Fig. 4.36 Comparación coeficientes de carga en puntales bajo el forjado 2 (Forjado reticular de casetón recuperable - Vano de medianera

Fig. 4.37 Comparación coeficientes de carga en el forjado 3 (Forjado reticular de casetón recuperable Vano de medianera)

Fig. 4.38 Comparación coeficientes de carga en puntales bajo el forjado 3 (Forjado reticular de casetón recuperable - Vano de medianera)

Fig. 4.39 Operación no controlada realizada antes del Clareado del Forjado 3

Fig. 4.40 Edificio experimental (Alvarado, 2009)

Fig. 4.41 Temperatura medida en el hormigón, puntales y ambiente para el Forjado 1 del edificio experimental. (Alvarado, 2009)

Fig. 4.42 Temperatura medida en el hormigón, puntales y ambiente para el Forjado 2 del edificio experimental. (Alvarado, 2009)

Fig. 4.43 Evolución del coeficiente de carga en puntales del forjado 1

Fig. 4.44 Evolución del coeficiente de carga en puntales del forjado 2

Fig. 4.45 Deformaciones medidas experimentalmente en el forjado 1 (Alvarado, 2009)

Fig. 4.46 Deformaciones medidas experimentalmente en el forjado 2 (Alvarado, 2009)

Fig. 4.47 Deformaciones que sufre el forjado en el MEF (Paso de carga 8) 
Fig. 4.48 Deformaciones que sufre el forjado en el MEF (Paso de carga 9)

Fig. 4.49 Deformaciones que sufre el forjado en el MEF (Paso de carga 10)

Fig. 4.50 Deformaciones que sufre el forjado en el MEF (Paso de carga 11)

Fig. 4.51 Deformaciones que sufre el forjado en el MEF (Paso de carga 12)

Fig. 4.52 Deformaciones que sufre el forjado en el MEF (Paso de carga 13)

Fig. 4.53 Deformaciones que sufre el forjado en el MEF (Paso de carga 14)

Fig. 4.54 Deformaciones que sufre el forjado en el MEF (Paso de carga 15)

Fig. 4.55 Deformaciones que sufre el forjado en el MEF (Paso de carga 16)

Fig. 4.56 Deformaciones que sufre el forjado en el MEF (Paso de carga 17)

Fig. 4.57 Deformación del forjado e incrementos de carga en puntales debidos a los cambios de temperatura entre los pasos de carga 14 y 15

Fig. 5.1 Coeficientes de carga estimados con el método de Duan y Chen (1995) (Forjado de losa maciza)

Fig. 5.2 Coeficientes de carga estimados con el método de Fang et al. (2001a) (Forjado de losa maciza)

Fig. 5.3 Coeficientes de carga estimados con el método de Calderón et al. (2011) (Forjado de losa maciza)

Fig. 5.4 Coeficientes de carga estimados con el método de Duan y Chen (1995) (Forjado reticular de casetón perdido)

Fig. 5.5 Coeficientes de carga estimados con el método de Fang et al. (2001a) (Forjado reticular de casetón perdido)

Fig. 5.6 Coeficientes de carga estimados con el método de Calderón et al. (2011) (Forjado reticular de casetón perdido)

Fig. 5.7 Coeficientes de carga estimados con el método de Duan y Chen (1995) (Forjado reticular de casetón recuperable)

Fig. 5.8 Coeficientes de carga estimados con el método de Fang et al. (2001a) (Forjado reticular de casetón recuperable)

Fig. 5.9 Coeficientes de carga estimados con el método de Calderón et al. (2011) (Forjado reticular de casetón recuperable)

Fig. 5.10 Comparación entre los métodos simplificados y las medidas experimentales (Edificio de forjado de losa maciza - vano de esquina)

Fig. 5.11 Comparación entre los métodos simplificados y los resultados del MEF (Edificio de forjado de losa maciza vano - de esquina)

Fig. 5.12 Comparación entre los métodos simplificados y las medidas experimentales (Edificio de forjado de losa maciza - vano de medianera)

Fig. 5.13 Comparación entre los métodos simplificados y los resultados del MEF (Edificio de forjado de losa maciza vano - de medianera)

Fig. 5.14 Comparación entre los métodos simplificados y las medidas experimentales (Edificio de reticular de casetón perdido)

Fig. 5.15 Comparación entre los métodos simplificados y las medidas experimentales (Edificio de reticular de casetón recuperable - vano de esquina)

Fig. 5.16 Comparación entre los métodos simplificados y los resultados del MEF (Edificio de reticular de casetón recuperable - vano de esquina) 
Fig. 5.17 Comparación entre los métodos simplificados y las medidas experimentales (Edificio de reticular de casetón recuperable - vano de medianera)

Fig. 5.18 Comparación entre los métodos simplificados y los resultados del MEF (Edificio de reticular de casetón recuperable - vano de medianera) 


\section{INDICE DE TABLAS}

Tabla 2.1 Coeficientes máximos en puntales modelos Liu, Chen y Bowman (1985)

Tabla 2.2 Comparación de coeficientes de carga en puntales para diferentes métodos y para el Método Mejorado (1992) para el caso de un forjado aislado.

Tabla 2.3 Comparación de coeficientes de carga en forjados y puntales para el Método Simplificado de Grundy y Kabaila (1963) y para el Método Simplificado Mejorado de Duan y Chen (1995) para el caso de dos forjados cimbrados y uno recimbrado.

Tabla 2.4 Comparación de coeficientes de carga en forjados para diferentes métodos y el modelo de Fang et al. (2001a), para el caso de dos forjados cimbrados y uno recimbrado

Tabla 2.5 Porcentaje de distribución de cargas durante el proceso constructivo (Beeby, 2001a)

Tabla 2.6 Comparación de los resultados del Nuevo Procedimiento Simplificado (Calderón et al. 2011) con otros métodos (Unidades: $\mathrm{kN} / \mathrm{m} 2$ )

Tabla 2.7 Comparación de coeficientes de carga en forjados y puntales para el Método Simplificado (1963) y el Modelo Mosallam y Chen (1991) para el caso de tres plantas cimbradas.

Tabla 2.8 Coeficientes máximos de carga en forjados

Tabla 2.9 Coeficientes máximos de carga en puntales (Cimentación)

Tabla 2.10 Coeficientes máximos de carga en puntales (Casos Restantes)

Tabla 2.11 Comparación de coeficientes de carga en forjados para diferentes métodos y el modelo de Kwak et al. (2006), para el caso de dos forjados cimbrados y uno recimbrado. $\mathrm{S}=1.5 \mathrm{~m}$

Tabla 2.12 Validación del modelo numérico de Alvarado et al. (2010) con los resultados experimentales de Alvarado et al. (2009)

Tabla 2.13 Coeficientes de cargas en puntales de los resultados experimentales y los obtenidos con el Método de Beeby (2001 a).

Tabla 2.14 Coeficientes de carga en puntales medidos por Fang et al. (2001b)

Tabla 2.15 Comparación entre las medidas experimentales de Puente et al. (2007) con diferentes métodos de estimación de cargas

Tabla 2.16 Comparación entre las medidas experimentales de Alvarado et al. (2009) con otros métodos

Tabla 2.17 Resumen de los estudios experimentales

Tabla 3.1 Características geométricas de los puntales empleados en los estudios experimentales

Tabla 3.2 Resistencia de los puntales según la atura de uso

Tabla 3.3 Características de las bandas extensométricas

Tabla 3.4 Resumen medición experimental. Forjado de losa maciza - Vano de esquina

Tabla 3.5 Resumen medición experimental. Forjado de losa maciza - Vano de medianera

Tabla 3.6. Resumen medición experimental. Forjado reticular de casetón perdido

Tabla 3.7. Incrementos de temperatura $\left({ }^{\circ} \mathrm{C}\right)$, máximos y mínimos, entre la cara superior e inferior del forjado registrados en el edificio de forjado reticular de casetón perdido.

Tabla 3.8. Resumen medición experimental. Forjado reticular de casetón recuperable - Vano de esquina 
Tabla 3.9. Resumen medición experimental. Forjado reticular de casetón recuperable - Vano de medianera

Tabla 3.10. Incrementos de temperatura $\left({ }^{\circ} \mathrm{C}\right)$, máximos y mínimos, entre la cara superior e inferior del forjado registrados en edificio de forjado reticular de casetón recuperable.

Tabla 4.1. Edades del hormigón y módulos elásticos para cada paso de carga (modelo del edificio de forjado de losa maciza).

Tabla 4.2. Comparación entre las medidas experimentales y los resultados del modelo numérico (Forjado de losa maciza - Vano de esquina)

Tabla 4.3. Comparación entre las medidas experimentales y los resultados del modelo numérico (Forjado de losa maciza - Vano de medianera)

Tabla 4.4. Comparación entre los resultados del modelo numérico considerando sólo los puntales monitorizados y los correspondientes a la totalidad de puntales del vano.

Tabla 4.5. Edades del hormigón y módulos elásticos para cada paso de carga (modelo del edificio de forjado reticular de casetón recuperable).

Tabla 4.6. Comparación entre las medidas experimentales y los resultados del modelo numérico (Forjado reticular de casetón recuperable - Vano de esquina)

Tabla 4.7. Comparación entre las medidas experimentales y los resultados del modelo numérico (Forjado reticular de casetón recuperable - Vano de medianera)

Tabla 4.8. Características geométricas y mecánicas de los puntales considerados en el modelo

Tabla 4.9. Diferencias de temperatura $\left({ }^{\circ} \mathrm{C}\right)$, máximas y mínimas, entre la cara superior e inferior de la losa consideradas en el modelo

Tabla 4.10. Deformación en centro de vano según MEF para los pasos de carga 8-17.

Tabla 5.1 Parámetros del forjado para el método simplificado de Duan y Chen (1995) (Forjado losa maciza - Vano de esquina)

Tabla 5.2 Parámetros de los puntales para el método simplificado de Duan y Chen (1995) (Forjado losa maciza - Vano de esquina)

Tabla 5.3 Parámetros del forjado para el método simplificado de Duan y Chen (1995) (Forjado losa maciza - Vano de medianera)

Tabla 5.4 Parámetros de los puntales para el método simplificado de Duan y Chen (1995) (Forjado losa maciza - Vano de medianera)

Tabla 5.5 Comparación entre los coeficientes de carga estimados con el método de Duan y Chen (1995) con las medidas experimentales y con los resultados del modelo de EF, para el vano de esquina (Forjado de losa maciza)

Tabla 5.6 Comparación entre los coeficientes de carga estimados con el método de Duan y Chen (1995) con las medidas experimentales y con los resultados del modelo de EF, para el vano de medianera (Forjado de losa maciza)

Tabla 5.7 Parámetros del forjado para el método simplificado de Fang et al. (2001a). (Forjado losa maciza - Vano de esquina)

Tabla 5.8 Parámetros de los puntales para el método simplificado de Fang et al. (2001a). (Forjado losa maciza - Vano de esquina)

Tabla 5.9 Parámetros del forjado para el método simplificado de Fang et al. (2001a) (Forjado losa maciza - Vano de medianera)

Tabla 5.10 Parámetros de los puntales para el método simplificado de Fang et al. (2001a) (Forjado losa maciza - Vano de medianera) 
Tabla 5.11 Comparación entre los coeficientes de carga estimados con el método de Fang et al. (2001a) con las medidas experimentales y con los resultados del modelo de EF, para el vano de esquina. (Forjado de losa maciza)

Tabla 5.12 Comparación entre los coeficientes de carga estimados con el método de Fang et al. (2001a) con las medidas experimentales y con los resultados del modelo de EF, para el vano de medianera (Forjado de losa maciza)

Tabla 5.13 Parámetros del forjado para el nuevo procedimiento simplificado de Calderón et al. (2011) (Forjado losa maciza - Vano de esquina)

Tabla 5.14 Parámetros de los puntales para el nuevo procedimiento simplificado de Calderón et al. (2011) (Forjado losa maciza - Vano de esquina)

Tabla 5.15 Parámetros del forjado para el nuevo procedimiento simplificado de Calderón et al. (2011) (Forjado losa maciza - Vano de medianera)

Tabla 5.16 Parámetros de los puntales para el nuevo procedimiento simplificado de Calderón et al. (2011) (Forjado losa maciza - Vano de medianera)

Tabla 5.17 Comparación entre los coeficientes de carga estimados con el método de Calderón et al. (2011) con las medidas experimentales y con los resultados del modelo de EF, para el vano de esquina. (Forjado de losa maciza)

Tabla 5.18 Comparación entre los coeficientes de carga estimados con el método de Calderón et al. (2011) con las medidas experimentales y con los resultados del modelo de EF, para el vano de medianera. (Forjado de losa maciza)

Tabla 5.19 Parámetros del forjado para el método simplificado de Duan y Chen (1995) (Forjado reticular de casetón perdido)

Tabla 5.20 Parámetros de los puntales para el método simplificado de Duan y Chen (1995) (Forjado reticular de casetón perdido)

Tabla 5.21 Comparación entre los coeficientes de carga estimados con el método de Duan y Chen (1995) con las medidas experimentales (Forjado reticular de casetón perdido)

Tabla 5.22 Parámetros del forjado para el método simplificado de Fang et al. (2001a). (Forjado reticular de casetón perdido)

Tabla 5.23 Parámetros de los puntales para el método simplificado de Fang et al. (2001a). (Forjado reticular de casetón perdido)

Tabla 5.24 Comparación entre los coeficientes de carga estimados con el método de Fang et al. (2001a) con las medidas experimentales (Forjado reticular de casetón perdido)

Tabla 5.25 Parámetros del forjado para el nuevo procedimiento simplificado de Calderón et al. (2011) (Forjado reticular de casetón perdido)

Tabla 5.26 Parámetros de los puntales para el nuevo procedimiento simplificado de Calderón et al. (2011) (Forjado reticular de casetón perdido)

Tabla 5.27 Comparación entre los coeficientes de carga estimados con el método de Calderón et al. (2011) y con las medidas experimentales. (Forjado reticular de casetón perdido)

Tabla 5.28 Parámetros del forjado para el método simplificado de Duan y Chen (1995) (Forjado reticular de casetón recuperable - Vano de esquina)

Tabla 5.29 Parámetros de los puntales para el método simplificado de Duan y Chen (1995) (Forjado reticular de casetón recuperable - Vano de esquina)

Tabla 5.30 Parámetros del forjado para el método simplificado de Duan y Chen (1995) (Forjado reticular de casetón recuperable - Vano de medianera) 
Tabla 5.31 Parámetros de los puntales para el método simplificado de Duan y Chen (1995) (Forjado reticular de casetón recuperable - Vano de medianera)

Tabla 5.32 Comparación entre los coeficientes de carga estimados con el método de Duan y Chen (1995) con las medidas experimentales y con los resultados del modelo de EF, para el vano de esquina (Forjado reticular de casetón recuperable)

Tabla 5.33 Comparación entre los coeficientes de carga estimados con el método de Duan y Chen (1995) con las medidas experimentales y con los resultados del modelo de EF, para el vano de medianera (Forjado reticular de casetón recuperable)

Tabla 5.34 Parámetros del forjado para el método simplificado de Fang et al. (2001a). (Forjado reticular de casetón recuperable - Vano de esquina)

Tabla 5.35 Parámetros de los puntales para el método simplificado de Fang et al. (2001a). (Forjado reticular de casetón recuperable - Vano de esquina)

Tabla 5.36 Parámetros del forjado para el método simplificado de Fang et al. (2001a) (Forjado reticular de casetón recuperable - Vano de medianera)

Tabla 5.37 Parámetros de los puntales para el método simplificado de Fang et al. (2001a) (Forjado reticular de casetón recuperable - Vano de medianera)

Tabla 5.38 Comparación entre los coeficientes de carga estimados con el método de Fang et al. (2001a) con las medidas experimentales y con los resultados del modelo de EF, para el vano de esquina. (Forjado reticular de casetón recuperable)

Tabla 5.39 Comparación entre los coeficientes de carga estimados con el método de Fang et al. (2001a) con las medidas experimentales y con los resultados del modelo de EF, para el vano de medianera (Forjado reticular de casetón recuperable)

Tabla 5.40 Parámetros del forjado para el nuevo procedimiento simplificado de Calderón et al. (2011) (Forjado reticular de casetón recuperable - Vano de esquina)

Tabla 5.41 Parámetros de los puntales para el nuevo procedimiento simplificado de Calderón et al. (2011) (Forjado reticular de casetón recuperable - Vano de esquina)

Tabla 5.42 Parámetros del forjado para el nuevo procedimiento simplificado de Calderón et al. (2011) (Forjado reticular de casetón recuperable - Vano de medianera)

Tabla 5.43 Parámetros de los puntales para el nuevo procedimiento simplificado de Calderón et al. (2011) (Forjado reticular de casetón recuperable - Vano de medianera)

Tabla 5.44 Comparación entre los coeficientes de carga estimados con el método de Calderón et al. (2011) con las medidas experimentales y con los resultados del modelo de EF, para el vano de esquina. (Forjado reticular de casetón recuperable)

Tabla 5.46 Comparación entre los coeficientes de carga estimados con el método de Calderón et al. (2011) con las medidas experimentales y con los resultados del modelo de EF, para el vano de medianera. (Forjado reticular de casetón recuperable) 


\section{NOTACIÓN}

A

A

A

$A_{\text {Cimbrado }}$

$A_{\text {Clareado }}$

$A_{\text {shore }, i}$

$A_{t}$

$A_{\text {total }}$

$C_{D \& C}$

$C_{\text {exp }}$

$C_{\text {Fang }}$

$C_{M E F}$

$C_{N P S}$

$C_{f}$

$C_{p, \max }$

$C_{p}$

$d$

E

$E_{c i}$

$E_{c m}$

$E_{c m}(\mathrm{t})$

$E_{c, t, f}$

$E_{c, t, p}$

$E_{j}$

$E_{s h}$

$E_{\text {sh }}$

Área de todos los puntales (según Duan y Chen 1995)

Área de todos los puntales (según Calderón et al. 2011)

Constante denominada factor de frecuencia

Sumatoria del área de los puntales en la fase de cimbrado

Sumatoria del área de los puntales en la fase de clareado

Área de la sección transversal de los puntales (según Fang et al. 2001)

Área tributaria del puntal considerado

Área del forjado instrumentada

Coeficiente de carga Método Simplificado Mejorado de Duan y Chen

Coeficiente de carga media, medido experimentalmente

Coeficiente de carga Método Simplificado de Fang et al.

Coeficiente de carga obtenido en el modelo de elementos finitos

Coeficiente de carga Nuevo Procedimiento Simplificado de Calderón et al.

Coeficiente de carga en forjados que resulta de la relación entre la carga media del forjado y el peso propio del forjado $\left(Q_{f} / W_{f}\right)$

Coeficiente de carga máxima en puntales

Coeficiente de carga en puntales que resulta de la relación entre la carga media en puntales y el peso propio del forjado $\left(Q_{p} / W_{f}\right)$.

Días

Energía de activación

Módulo de elasticidad del hormigón del forjado $i$ (según Fang et al. 2001)

Módulo de elasticidad del hormigón a los 28 días

Módulo de elasticidad del hormigón a los $t$ días

Módulo de elasticidad del hormigón del forjado a los $t$ días

Módulo de elasticidad del hormigón de los pilares a los $t$ días

Módulo de elasticidad del hormigón del forjado $j$ (según Duan y Chen 1995)

Módulo de elasticidad de los puntales (según Duan y Chen 1995)

Módulo de elasticidad de los puntales (según Calderón et al. 2011) 
$E_{\text {shore }, i} \quad$ Módulo de elasticidad de los puntales ubicados en el forjado $i$ (según Fang et al. 2001)

F

$f_{c k}$

$f_{c m}$

$f_{c m}(t)$

H

H

I

I

$I_{i}$

$i$

j

j

K

$\bar{K}_{J}$

$K_{s h, j}$

$K_{\text {shore }, i}$

$K_{\text {slab }, i}$

$K_{\text {slab }, 28}$

$k$

$L$

$L$

$L_{\text {shore }, i}$

$L_{\text {slab }}$

$m_{i, 1}$

n

$P$

$P_{i}$

Incrementos de carga en puntales (según Duan y Chen 1995)

Resistencia característica del hormigón a compresión

Resistencia media a compresión del hormigón a 28 días

Resistencia media a compresión del hormigón a una edad de $j$ días

Altura del puntal (según Duan y Chen 1995)

Altura del puntal (según Calderón et al. 2011)

Momento de inercia suponiendo un ancho unitario (según Duan y Chen 1995)

Momento de inercia bruta de la sección de la banda considerada (según Calderón et al. 2011)

Momento de inercia de la franja de forjado $i$ (según Fang et al. 2001)

Número del forjado considerado (según Fang et al. 2001)

Número del forjado considerado (según Duan y Chen 1995)

Tiempo equivalente (según Freiesleben Hansen y Pedersen 1977)

Deformación del elemento estructural bajo la acción de una carga unitaria (según Duan y Chen 1995)

Deformación media del forjado bajo la acción de una carga unitaria (según Calderón et al. 2011)

Deformación de los puntales, ubicados en el nivel $j$, bajo la acción de una carga unitaria (según Calderón et al. 2011)

Rigidez del sistema de cimbrado ubicado en el forjado $i$ (según Fang et al. 2001, Fang et al. 2009a)

Rigidez del forjado $i$ (según Fang et al. 2001)

Rigidez del forjado a los 28 días (Fang et al. 2009a)

Constante de velocidad

Luz del vano más largo del forjado (según Duan y Chen 1995)

Luz entre caras de pilares (según Calderón et al. 2011)

Longitud de los puntales (según Fang et al. 2001)

Luz del forjado (según Fang et al. 2001)

Relación de carga soportada por el forjado del nivel $i$ y la carga soportada por el primer forjado (según Fang et al. 2001)

Número de plantas consecutivas cimbradas

Peso propio del forjado recién hormigonado (según Duan y Chen 1995)

Carga instantánea en el puntal " $i$ " 


\begin{tabular}{|c|c|}
\hline$P_{\max , M E F}$ & Axil del puntal más cargado en el modelo de elementos finitos \\
\hline$P_{\max , \exp }$ & Axil del puntal más cargado medida experimentalmente \\
\hline$P_{\max }$ & Axil del puntal más cargado \\
\hline$Q_{j}$ & Incremento de carga en forjados (según Calderón et al. 2011) \\
\hline$\overline{Q_{J}}$ & Incremento de carga media en forjados (según Calderón et al. 2011) \\
\hline$Q_{f}$ & Carga media en el forjado $\left(W_{f}-Q_{p}\right)$ \\
\hline$Q_{p}$ & Carga media en puntales \\
\hline$q$ & Peso propio del forjado (según Grundy y Kabaila 1963) \\
\hline$q$ & Peso propio del forjado superior (según Fang et al. 2001) \\
\hline$q_{i}$ & Carga soportada por el forjado $i$ (según Fang et al. 2001) \\
\hline$q_{\max }$ & Axil del puntal más cargado por unidad de superficie $\left(P_{\max } / A_{t}\right)$ \\
\hline$q_{m e d, M E F}$ & $\begin{array}{l}\text { Carga media en puntales por unidad de superficie en el modelo de elementos } \\
\text { finitos }\end{array}$ \\
\hline$q_{m e d, e x p}$ & Carga media en puntales por unidad de superficie medida experimentalmente \\
\hline$q_{\text {med }}$ & $\begin{array}{l}\text { Carga media en puntales por unidad de superficie que resulta de la relación entre } \\
\text { la sumatoria de las cargas en puntales y el área del forjado instrumentada } \\
\left(\sum P_{i} / A_{\text {total }}\right)\end{array}$ \\
\hline$R$ & Constante de los gases perfectos \\
\hline$S_{b}$ & Rigidez de los puntales (según Beeby 2001) \\
\hline$S_{S}$ & $\begin{array}{l}\text { Rigideces del forjado considerando su variación con el tiempo (según Beeby } \\
\text { 2001) }\end{array}$ \\
\hline$S_{j}$ & Incremento de carga en puntales (según Calderón et al. 2011) \\
\hline$s$ & Número de puntales instalados bajo el vano considerado (según Fang et al. 2001) \\
\hline$s$ & Coeficiente que depende de la velocidad de endurecimiento del cemento \\
\hline$T$ & Temperatura ambiente en el momento de ejecución de la operación constructiva \\
\hline$T_{i}$ & Temperatura en el intervalo de tiempo $\Delta t_{i}$ \\
\hline$T_{R}$ & Temperatura de referencia \\
\hline$u_{i, j}$ & $\begin{array}{l}\text { Coeficiente que relaciona la rigidez del forjado } i \text { con la rigidez de los puntales } \\
\text { (según Fang et al. 2001) }\end{array}$ \\
\hline$v_{i, j}$ & $\begin{array}{l}\text { Coeficiente que relaciona la rigidez de dos forjados consecutivos (según Fang et } \\
\text { al. 2001) }\end{array}$ \\
\hline$W_{f}$ & Peso propio del forjado de los estudios experimentales \\
\hline$w_{b 1}$ & Carga en los puntales de la planta inferior cimbrada (según Beeby 2001) \\
\hline$w_{p}$ & Carga en los puntales que soportan el encofrado (según Beeby 2001) \\
\hline$\alpha$ & Ratio de cargas entre dos forjados consecutivos (según Duan y Chen 1995) \\
\hline
\end{tabular}


$\alpha$

$\beta_{c c}$

$\gamma$

$\gamma$

$\lambda_{i}$

$\rho_{i}$

$\Delta_{i}$

$\Delta_{j}$

$\overline{\Delta_{J}}$

$\Delta_{s h, j}$

$\overline{\Delta_{s h, J-1}}$

CCD

CD

CRD

EDM

EF

EFM

MEF

ICITECH
Ratio de cargas entre dos forjados consecutivos (según Calderón et al. 2011)

Factor reductor de la resistencia del hormigón asociado a una edad temprana Coeficiente que depende de las condiciones de contorno y la relación largo ancho del forjado (según Duan y Chen 1995)

Parámetro estructural característico (según Fang et al. 2009a)

Coeficiente que considera las condiciones de contorno del forjado $i$ y la naturaleza de las cargas (según Fang et al. 2001)

Coeficiente que considera las cargas desiguales en los puntales (según Fang et al. 2001)

Deformación del forjado $i$ (según Fang et al. 2001)

Flecha en el centro del forjado $j$ (según Duan y Chen 1995)

Deformación media del forjado $j$ (según Calderón et al. 2011)

Deformación media de los puntales ubicados sobre el forjado $j$ (según Duan y Chen 1995)

Deformación media de los puntales ubicados en el nivel $j-1$ (según Calderón et al. 2011)

Cimbrado, clareado y descimbrado

Cimbrado y descimbrado

Cimbrado, recimbrado y descimbrado

Estación de medida

Elemento/s finito/s

Equivalent frame method

Método de los elementos finitos

Instituto de Ciencia y Tecnología del hormigón 


\section{CAPITULO 1. INTRODUCCIÓN Y OBJETIVOS}

\subsection{Introducción}

El proceso de construcción de un edificio exige considerar, de forma equilibrada, aspectos como la seguridad, el tiempo de ejecución y el coste, que deben ser compaginados para conseguir un proceso óptimo. En edificios con forjados hormigonados "in situ", todos estos parámetros dependen en gran medida de los sistemas y procesos de cimbrado. Es por ello que una buena planificación del uso de estos sistemas, que permita recuperar la mayor parte de los componentes utilizados en el menor tiempo posible, puede disminuir los costes, así como mejorar los plazos de ejecución.

Con este objetivo se emplea en España un método conocido como clareado o descimbrado parcial, que consiste en la retirada del encofrado y de más del $50 \%$ de los puntales que soportan el forjado pocos días después de su hormigonado. Esta técnica permite reducir el material necesario para el encofrado y cimbrado, mejorar notablemente la economía y racionalizar el proceso constructivo.

Sin embargo, no hay que olvidarse de otro factor importante, la seguridad. Durante el proceso constructivo no deben sobrepasarse las capacidades resistentes de forjados y puntales. Si el ritmo de construcción es demasiado rápido y se realiza un clareado o descimbrado de forma prematura, los forjados pueden quedar sometidos a solicitaciones superiores a sus capacidades resistentes, pudiendo provocar el derrumbe de la estructura. De hecho, un porcentaje significativo de los colapsos de edificios se producen durante su cimbrado-descimbrado, tal y como se muestra en diversas publicaciones, p.e. Eldukair y Ayyub (1991), Kaminetzky y Stivaros (1994), Feld y Carper (1997) o Epaarachchi et al. (2002).

Para poder descimbrar toda la estructura, o parte de ella, lo más rápidamente posible y usar así el mínimo número de elementos, es necesario tener muy en cuenta el plazo de descimbrado, el cual depende de diversos factores, entre otros, el sistema y el proceso de construcción empleado, las propias características de la estructura a construir (tipo de hormigón y cargas de cálculo), y las condiciones ambientales bajo las que se realicen los trabajos (temperatura y humedad).

Las normas y recomendaciones internacionales que abordan el estudio del plazo de descimbrado lo hacen de forma muy general y habitualmente con criterios muy conservadores. En 1952, Nielsen publicó una de las primeras investigaciones desarrolladas para determinar la carga que soportan los forjados y los puntales durante el proceso constructivo. Años más tarde, Grundy y Kabaila (1963) desarrollaron un método simplificado de muy fácil aplicación en el que se asume que la rigidez de los puntales es infinita con respecto a la de los forjados, todos los forjados tienen la misma rigidez, y la cimentación es infinitamente rígida. Este método es fácil de aplicar y en la mayoría de los casos está del lado de la seguridad. 
Autores como Mossallam y Chen (1991) o Duan y Chen (1995) han propuesto modificaciones para el método de Grundy y Kabaila (1963) para tener en cuenta tanto la rigidez real de los forjados como la redistribución de cargas durante el proceso constructivo. Beeby (2001) también propone algunas modificaciones al método propuesto por Grundy y Kabaila (1963), éstas se basan en considerar la rigidez real de los puntales, y que los forjados tienen un comportamiento elástico con una rigidez dependiente del tiempo.

Diversos autores como Moragues et al. (1996), Liu et al. (1985), Stivaros y Halvorsen (1990), ElShahhat y Chen, Fang et al (2001a) o Alvarado et al. (2010), han desarrollado modelos numéricos complejos en dos y tres dimensiones, buscando representar las diferentes variables que interactúan durante el proceso constructivo.

La validación experimental de estas investigaciones ha sido llevada a cabo por diversos autores. Por ejemplo, en 1974 Agarwall y Gardner realizaron una investigación experimental en la que estudiaron la validez del método simplificado de Grundy y Kabaila (1963), concluyendo que la aplicación de este método era adecuada para el caso particular que habían estudiado. Existen investigaciones experimentales posteriores, p.e. Taylor (1967), Moragues et al. (1992), Beeby (2001b), Fang et al. (2001b) o Alvarado (2009), basadas en la instrumentación de edificios durante su construcción, donde se ha medido la distribución de cargas entre puntales y forjados.

De todos los estudios realizados hasta la fecha relacionados con el proceso de cimbrado y descimbrado de forjados consecutivos, los únicos autores que han estudiado la técnica del clareado son Moragues et al. (1992, 1994, 1996), Alvarado (2009) y Alvarado et al. (2010). El clareado, o descimbrado parcial, es una técnica muy utilizada en España que consiste en la retirada del encofrado y la mitad de los puntales que soportan la losa unos días después de su hormigonado, pero sin que los puntales que permanecen pierdan en ningún momento su contacto con la estructura. Con este proceso se consigue reducir el material necesario para el encofrado y el apuntalamiento, dado que los forjados comienzan a asumir parte de su peso propio y las sobrecargas que se presentan sobre ellos.

En investigaciones anteriores realizadas en el Instituto de Ciencia y Tecnología del Hormigón de la Universidad Politécnica de Valencia (Alvarado (2009) y Alvarado et al. (2010)), se ha desarrollado un modelo numérico que permite simular el proceso constructivo. Como continuación de este trabajo se ha planteado un estudio en detalle de la transmisión de cargas entre forjado y puntales en un proceso de cimbrado y descimbrado a través de la medición de cargas en puntales durante el proceso constructivo de varios edificios con distintas tipologías de forjados. El objetivo de este procedimiento experimental ha sido la calibración del modelo numérico desarrollado, para diferentes tipologías estructurales.

Otro efecto poco estudiado hasta la fecha es el que tienen los cambios de temperatura ambiente en la distribución de cargas entre forjados y puntales, pese a que algunos autores han registrado lo importante de su influencia. Rosowsky et al. (1997) registraron la evolución de cargas en puntales durante los días posteriores al hormigonado, obteniendo fluctuaciones cíclicas diarias que atribuyeron a los cambios medioambientales que se produjeron en la obra. Además de estas fluctuaciones, también observaron un carácter decreciente de las cargas durante el proceso de curado del forjado. 
Fang et al. (2001b) midieron también las cargas en puntales durante el curado de la losa. Al igual que Rosowsky et al. (1997), establecieron que la evolución de cargas en puntales está influenciada por las variaciones diarias de temperatura e igualmente detectaron que durante el curado del forjado se producía un descenso en las cargas.

En 2007, Azkune et al. realizaron un estudio de la influencia de la temperatura en la trasmisión de cargas en diferentes edificios. Los autores observaron que las fluctuaciones de temperatura diarias podían producir una variación de carga en puntales de hasta un 30\% de la carga.

Posteriormente, Fang et al. (2009b) llevaron a cabo un estudio analítico para conocer la influencia de la temperatura (entre otras variables) en la redistribución de cargas de los forjados. De este estudio concluyeron que las variaciones de la temperatura ambiente provocan fluctuaciones de carga en el forjado, incrementando su carga máxima.

Por su parte Alvarado (2009) detectó, durante la medición continua en el edificio experimental, que las variaciones de temperatura ambiente tenían una gran influencia sobre las cargas en los puntales durante el proceso constructivo. Estos cambios de temperatura afectaban a los diferentes elementos de la estructura durante su construcción (forjados, pilares, puntales, tableros de encofrado y sopandas), afectando finalmente a la variación de carga en los puntales.

Debido a la importancia que los diversos autores han demostrado que tienen las variaciones de temperatura ambiente en la distribución de cargas entre forjados y puntales, se planteó la necesidad de conocer mejor cómo afecta la temperatura ambiente a los diferentes elementos de la estructura y con ello estudiar su influencia en la variación de carga en los puntales.

En la presente Tesis Doctoral se exponen los diferentes estudios experimentales llevados a cabo para analizar la transmisión de cargas entre forjados y puntales en las distintas tipologías de forjados más comunes en edificación, analizando también el efecto que tiene la variación de la temperatura ambiente en los diferentes elementos de la estructura durante su construcción. Por otra parte se calibra el modelo numérico propuesto por Alvarado et al. (2010) y se valida el método simplificado propuesto por Calderón et al. (2011) para la estimación de la transmisión de cargas entre forjados y puntales durante el proceso constructivo.

\subsection{Objetivos}

El objetivo principal de esta Tesis Doctoral es realizar una investigación experimental y teórica en la que se estudien la transmisión de cargas entre forjados y puntales en las tipologías de forjados más comunes en edificación. En los edificios monitorizados se empleó la técnica del clareado, que introduce fuertes variaciones de la rigidez del apuntalamiento en el proceso constructivo. Con este estudio se pretende verificar la influencia de esta operación en el reparto de cargas entre forjados y puntales. Por otro lado se busca también comprobar la validez de modelos simplificados de cálculo para representar el comportamiento de un sistema donde la correcta estimación de las rigideces de puntales y forjados es crucial. 
Así mismo, se pretende, mediante el desarrollo de un estudio experimental, conocer las variaciones de temperatura de los diferentes elementos de la estructura durante su construcción y determinar su influencia en la variación de carga en los puntales mediante el desarrollo de un modelo teórico de elementos finitos.

A nivel más concreto, se plantean los objetivos específicos que se enumeran a continuación:

- Preparación de un estado del arte que se mantendrá al día recopilando y analizando las nuevas aportaciones científico-técnicas de interés que surjan durante el desarrollo de la investigación. Para ello, se revisarán continuamente las principales bases de datos de documentación científica.

- Estudio experimental de la transmisión de cargas entre forjados y puntales, llevado a cabo en tres obras reales, que abarquen las distintas tipologías más comunes en edificación, instrumentado un número determinado de puntales.

- Estudio experimental de la influencia de la operación de clareado en la transmisión de cargas entre forjados y puntales durante el proceso constructivo.

- Estudio experimental del efecto que tiene la variación de la temperatura ambiente en los diferentes elementos de la estructura durante su construcción (forjados, pilares, puntales, tableros de encofrado y sopandas).

- Calibración del modelo numérico desarrollado en investigaciones anteriores por el grupo de investigación, ajustándolo a las diferentes tipologías estructurales definidas con anterioridad, y de las cuales se conoce su comportamiento experimental a través de las medidas de cargas en puntales y temperaturas tomadas en obra.

- Aproximación numérica al efecto que producen los cambios de temperatura en la transmisión de cargas entre forjados y puntales.

- Validación de un método simplificado, a partir de los resultados obtenidos, que permita, mediante coeficientes de carga, evaluar la transmisión de cargas durante el proceso de cimbrado, clareado y descimbrado de edificios con forjados consecutivos de hormigón in situ.

\subsection{Contenido}

La presente Tesis Doctoral está estructurada de la siguiente forma:

- Capítulo 1. Introducción y objetivos.

- Capítulo 2. Antecedentes y estado del arte.

- Capítulo 3. Estudios experimentales.

- Capítulo 4. Modelos numéricos.

- Capítulo 5. Estudio comparativo de diversos métodos simplificados de cálculo de transmisión de cargas. 
- Capítulo 6. Conclusiones y propuesta de nuevas investigaciones.

- Bibliografía

- Apéndices

En el Capítulo 1 se justifica la realización de la presente Tesis Doctoral, exponiendo los objetivos, tanto el general como los específicos, que se pretenden alcanzar.

El Capítulo 2 muestra, a partir de una exhaustiva revisión bibliográfica, el estado del arte relativo al tema planteado. En una primera parte se describen brevemente los sistemas y procesos de cimbrado de uso común en edificación. Posteriormente, se estudian en detalle las diversas investigaciones de carácter experimental y numérico relativas a la transmisión de cargas entre forjados y puntales durante el proceso constructivo de edificios de hormigón armado de plantas sucesivas. Finalmente se hace una recopilación de los estudios que han considerado el efecto de la temperatura en la transmisión de cargas entre forjados y puntales.

En el Capítulo 3 se describen los distintos estudios experimentales. Además, se muestran y analizan los resultados, tanto a nivel de carga como de temperatura, obtenidos en cada uno de dichos estudios.

En el Capítulo 4 se calibra el modelo numérico desarrollado en estudios anteriores por el grupo de investigación, ajustándolo a diferentes tipologías estructurales. La calibración del modelo se realiza a partir de las mediciones experimentales. Por otro lado, se realiza una aproximación numérica al efecto que producen los cambios de temperatura en la transmisión de cargas entre forjados y puntales.

En el Capítulo 5 se evalúan distintos métodos simplificados que permitan considerar un proceso de cimbrado, clareado y descimbrado, buscando validar un método simplificado que permita, mediante coeficientes de carga, evaluar la transmisión de cargas durante dicho proceso.

El Capítulo 6 recoge las conclusiones acerca del trabajo desarrollado en la presente Tesis Doctoral, así como los nuevos aportes que ésta hace al estudio del tema en cuestión. Además, expone la producción científica derivada de la investigación y las líneas futuras de investigación que se extraen de las experiencias realizadas.

Finalmente se recogen varios Apéndices que contienen información que complementa la investigación desarrollada. 



\section{CAPITULO 2. ANTECEDENTES Y ESTADO DEL ARTE}

\subsection{Introducción}

En la construcción de edificios de hormigón armado de plantas sucesivas, las cargas generadas en los forjados hormigonados más recientemente se transmiten hacia forjados previamente hormigonados por medio de sistemas de apuntalamiento. Las cargas que se producen durante este proceso constructivo son debidas principalmente al peso del hormigón fresco, de la armadura colocada, de los encofrados, el peso de los trabajadores, el peso del equipamiento y el impacto por el vertido del hormigón. También las variaciones térmicas o, en menor medida, los efectos reológicos pueden tener influencia sobre el reparto y magnitud de las cargas en forjados y puntales.

Dichas cargas, que se reparten entre los forjados interconectados entre sí por puntales, suelen ser menores que las cargas de servicio de los forjados, pero, en algunos casos, pueden sobrepasar la capacidad resistente de estos, pudiéndose producir un colapso en la estructura. Se debe tener en consideración, además, que las cargas de construcción se aplican a forjados de edades inferiores a 28 días, los cuales, en el momento de soportarlas, no han adquirido aún la capacidad resistente para la cual fueron diseñados. Esto hace que sea necesario prestar una especial atención a los valores de carga transmitidos durante la construcción.

Diferentes autores han realizado trabajos de investigación para intentar determinar la distribución de cargas durante el proceso constructivo a través de modelos teóricos, considerando la evolución de la transmisión de cargas sobre el forjado y sobre los puntales, las cargas actuantes, la variación del esquema estructural y la evolución de las propiedades del hormigón. Sin embargo, la validación experimental de dichos modelos teóricos es más bien escasa. Tal y como se muestra en la Figura 2.1, sólo un $29 \%$ de las investigaciones llevadas a cabo hasta la fecha (según datos recogidos de Scopus) se refieren a estudios experimentales.

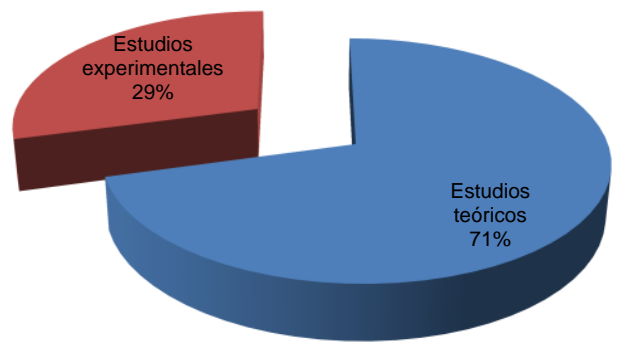

Fig. 2.1 Porcentaje de las publicaciones científicas entre los años 1952 y 2011 según datos de Scopus

En este capítulo se exponen los antecedentes y estado actual de conocimiento que motivan el desarrollo de la presente Tesis Doctoral, centrándose exclusivamente en el estudio de la trasmisión de cargas entre forjados y puntales. En una primera parte, se describen brevemente los diferentes 
procesos constructivos para edificios de hormigón armado de plantas consecutivas. A continuación, se hace una evaluación de los diferentes modelos teóricos existentes para determinar la transmisión de cargas durante los procesos de cimbrado de forjados consecutivos y se describen las mediciones reales en obra efectuadas por diversos autores. Por último se hace una recopilación de los estudios que han considerado el efecto de la temperatura en la transmisión de cargas entre forjados y puntales.

\subsection{Procesos constructivos para edificios de hormigón armado de plantas consecutivas}

Durante la ejecución de un edificio de hormigón de varias plantas pueden presentarse las siguientes operaciones:

$\checkmark$ Cimbrado: operación en la que se coloca el sistema de cimbrado (encofrado, puntales, sopandas) previa al hormigonado.

$\checkmark$ Clareado o descimbrado parcial: consiste en la retirada del encofrado y del $50 \%$ de los puntales que soportan el forjado pocos días después de su hormigonado, pero sin que los puntales que permanecen pierdan en ningún momento su contacto con la estructura.

$\checkmark$ Recimbrado: consiste en retirar el sistema de apuntalamiento de una planta determinada permitiendo así una redistribución de carga entre los forjados. Posteriormente se vuelven a colocar los puntales asegurando el contacto entre estos y los forjados, de forma que los puntales colaboren con los futuros incrementos de carga. Mediante el empleo de esta técnica se reducen considerablemente las cargas en los puntales.

$\checkmark$ Descimbrado: fase de recuperación de la cimbra para volver a hacer uso de ella en la planta superior.

Combinando las distintas operaciones se pueden distinguir tres procesos constructivos principales que se exponen a continuación (Alvarado, 2009).

\subsubsection{Proceso de cimbrado y descimbrado (CD)}

En el proceso de cimbrado y descimbrado (en adelante proceso de $\mathrm{CD}$ ) sólo intervienen dos etapas claramente definidas, la colocación de la cimbra donde se vierte el hormigón, y la retirada de esta cimbra. En este proceso existirán cuantos juegos de cimbras sean necesarios por cada planta, pudiendo tener dos, tres, o más plantas consecutivas cimbradas.

\subsubsection{Proceso de cimbrado, recimbrado y descimbrado (CRD)}

En 1967 Taylor desarrolla el proceso de cimbrado, recimbrado y descimbrado (en adelante proceso de CRD). Que consiste en descimbrar determinadas plantas, descargando completamente los puntales correspondientes, redistribuyendo de esta forma la carga entre los forjados. A continuación se apuntala de nuevo, asegurando el contacto entre los puntales y forjados, de forma que los puntales colaboren 
con los futuros incrementos de carga. De esta forma se consigue que los forjados, a edades cortas, y en el momento de ser recimbrados, deban soportar única y exclusivamente su peso propio.

\subsubsection{Proceso de cimbrado, clareado y descimbrado (CCD)}

El clareado o descimbrado parcial es una operación de uso habitual en España. Al retirar el encofrado y más del $50 \%$ de los puntales que soportan el forjado pocos días después de su hormigonado, se reduce notablemente el material necesario para el encofrado y cimbrado. Esta técnica mejora notablemente la economía y racionaliza el proceso constructivo. Esta técnica permite reducir el material necesario para el encofrado y cimbrado, mejora notablemente la economía y racionaliza el proceso constructivo.

\subsection{Transmisión de cargas durante la construcción}

Para poder evaluar si los forjados son capaces de soportar con suficiente seguridad y sin deformaciones excesivas, los esfuerzos a los que va estar sometido durante el proceso de construcción, es necesario conocer la distribución de cargas en la estructura.

Diversos autores han llevado a cabo investigaciones, tanto teóricas como experimentales, sobre la distribución de las cargas en los forjados y puntales originadas durante la construcción, obteniéndose modelos teóricos que permiten estimar dicha distribución de cargas.

En la Figura 2.2 se muestra la evolución del porcentaje de publicaciones relacionadas con modelos simplificados, estudios analíticos, modelos numéricos y estudios experimentales (como valor medio de los datos recogidos de Scopus) desde los años 50 hasta la actualidad. Se observa que es a partir de los años 90 cuando se acentúa la investigación en la transmisión de cargas entre forjados y puntales durante la construcción.

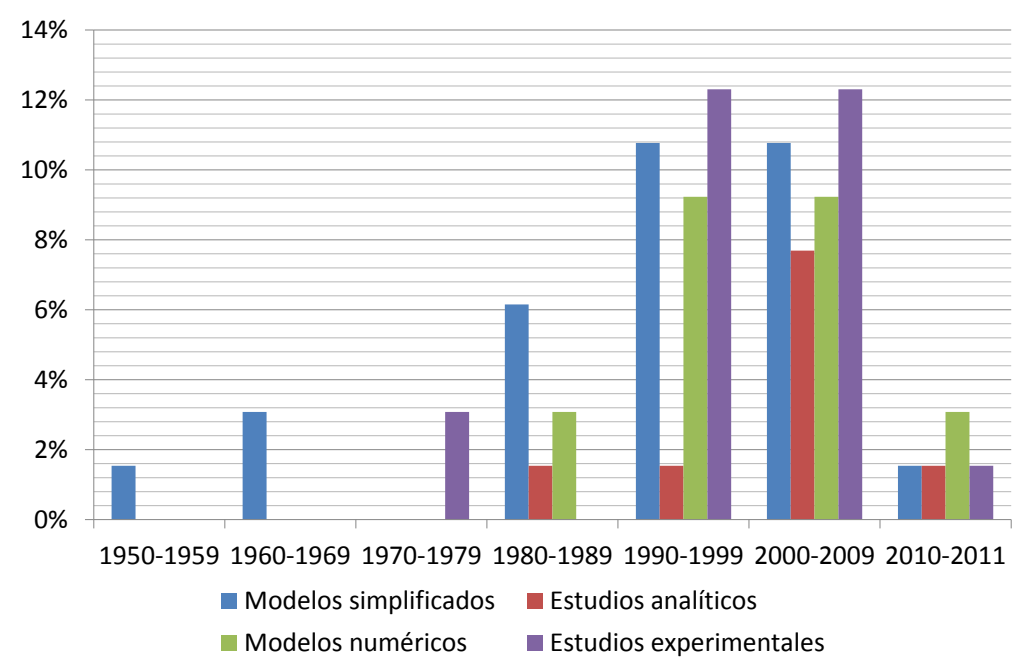

Fig. 2.2 Evolución de las publicaciones científicas entre los años 1952 y 2011 según datos de Scopus 


\subsubsection{Modelos Teóricos Simplificados}

En el presente apartado se describen algunos de los principales métodos teóricos simplificados para el cálculo de la distribución de cargas en forjados y puntales durante la construcción de forjados sucesivos de hormigón in situ.

\subsubsection{Método Simplificado (Grundy y Kabaila, 1963)}

El primer documento de investigación relacionado con esta área fue publicado en 1952 por K. Nielsen. En él, Nielsen propone un método bastante complejo donde estudia la interacción de las cargas entre la losa y los puntales durante el proceso de construcción de edificios de hormigón de varias plantas.

Años más tarde, en 1963, Grundy y Kabaila, desarrollaron el que hoy se conoce como Método Simplificado. En éste se asumen los siguientes supuestos:

$\checkmark$ La rigidez de los puntales es infinita en comparación con la resistencia a flexión del forjado.

$\checkmark$ La cimentación se considera también infinitamente rígida.

$\checkmark$ La carga de los puntales sobre el forjado se puede tratar como carga distribuida.

$\checkmark$ Se asume que todos los forjados tienen la misma resistencia a flexión, a pesar de las diferencias de edad del hormigón en cada uno de ellos.

$\checkmark$ Se desprecian los efectos de retracción y fluencia.

Estas hipótesis hacen que el método sea claro y fácil de aplicar en cualquier caso.

Las dos operaciones básicas a considerar en el proceso constructivo son:

a) El hormigonado de un nuevo forjado (operación A). En esta operación, si hay $n$ plantas cimbradas, cuando se hormigona un nuevo forjado, la carga $q\left(\mathrm{kN} / \mathrm{m}^{2}\right)$, correspondiente a su peso propio y a la sobrecarga de construcción, se reparte entre $\operatorname{los} n$ forjados inferiores, correspondiendo a cada uno de ellos una carga de:

$\frac{q}{n} k N / m^{2}$

b) El descimbrado del nivel más bajo de puntales (operación B). Si hay $n$ plantas cimbradas, al descimbrar la inferior, la diferencia entre la carga total que recibía $\mathrm{q}_{1}\left(\mathrm{kN} / \mathrm{m}^{2}\right)$, y su peso propio $\mathrm{q}$ $\left(\mathrm{kN} / \mathrm{m}^{2}\right)$, se reparte entre los $\mathrm{n}$ forjados superiores correspondiendo a cada uno de ellos:

$$
\frac{q_{1}-q}{n} k N / m^{2}
$$

En la Figura 2.3 se muestra para un número de plantas cimbradas $n=3$ las dos operaciones. 

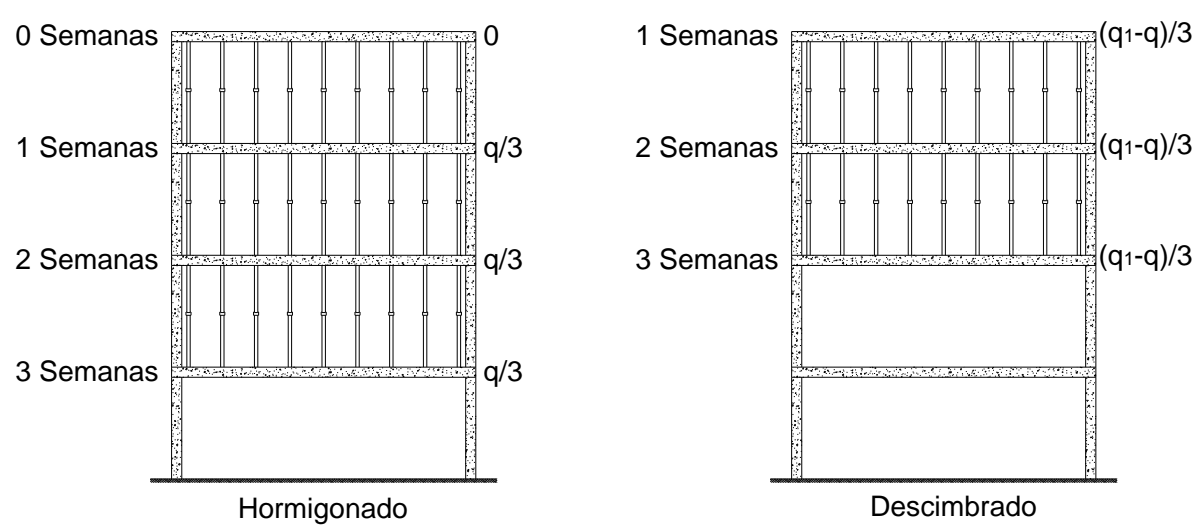

Fig. 2.3 Operaciones de cimbrado y descimbrado $n=3$

De esta forma, se obtienen coeficientes de carga, que se definen como la relación entre la carga de construcción y el peso propio del forjado más la sobrecarga de construcción. Usando estos coeficientes se pueden determinar las cargas actuantes en los forjados y puntales en las operaciones de cimbrado y descimbrado. En las Figuras 2.4 y 2.5 se muestran, para 2 y 3 juegos de puntales respectivamente, los coeficientes de carga, considerando un ciclo de construcción de $d$ días por planta y $d_{l}$ días para el descimbrado de una planta, y el montaje de puntales y sopandas a la nueva planta superior.

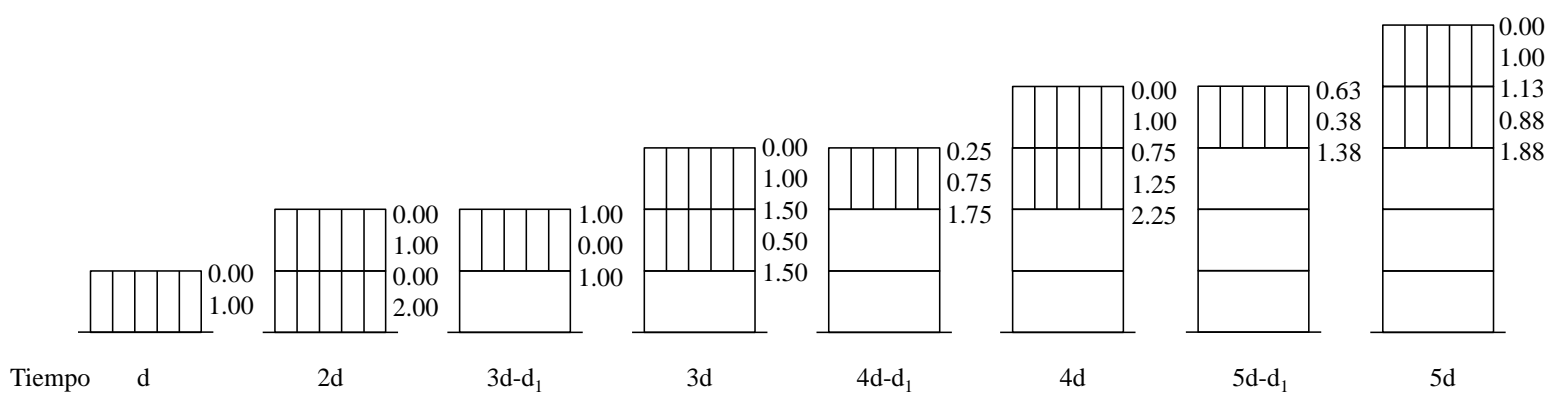

Fig. 2.4 Coeficientes de carga para puntales y forjados $n=2$

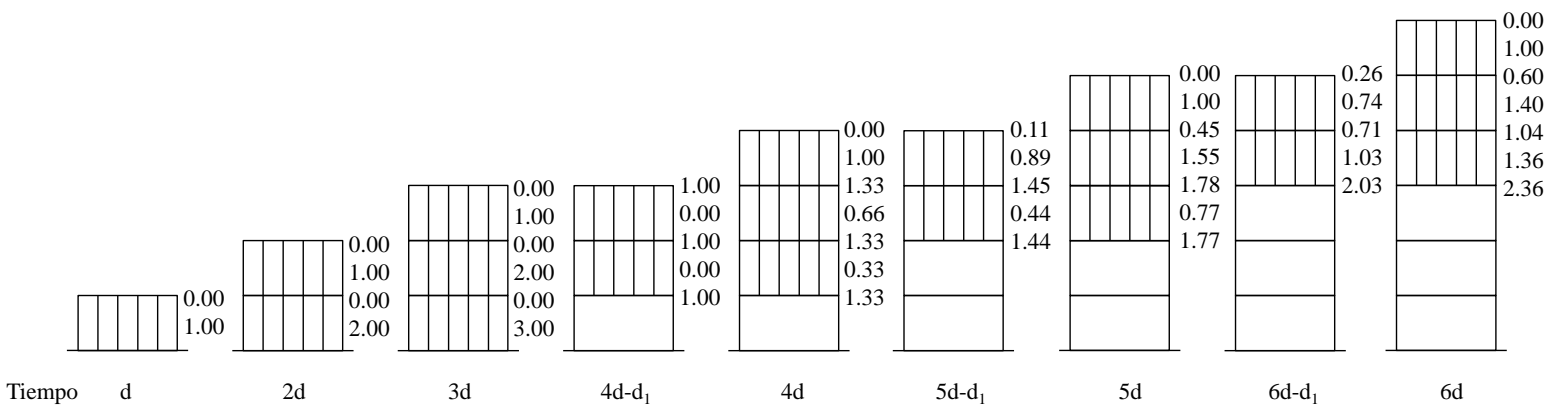

Fig. 2.5 Coeficientes de carga para puntales y forjados $n=3$ 
Como se puede observar, el coeficiente de carga máximo en forjado tiene un valor de 2.25 , en el caso de 2 juegos de cimbras, y se produce en el segundo forjado al hormigonar el cuarto. Para 3 juegos de cimbras, se da en el tercer forjado al hormigonar el sexto, con un valor de 2.36 .

En la realidad, la carga no se reparte por igual entre los forjados debido a sus distintas rigideces. La Figura 2.6 muestra, para $n=3$ y considerando un ciclo de construcción de una semana por planta $(d=$ 7 y $d_{1}=2$ días), los coeficientes de cimbrado y descimbrado, determinados por Grundy y Kabaila (1963), teniendo en cuenta esta diferencia de rigideces. Se supone que la situación de los forjados corresponde a no fisuración o fisuración reducida, con lo cual equivale a hacer el reparto de las cargas en proporción a los valores del módulo de elasticidad del hormigón a las distintas edades. La evolución del módulo de elasticidad considerada para el estudio es la que se ,muestra en la Figura 2.7.

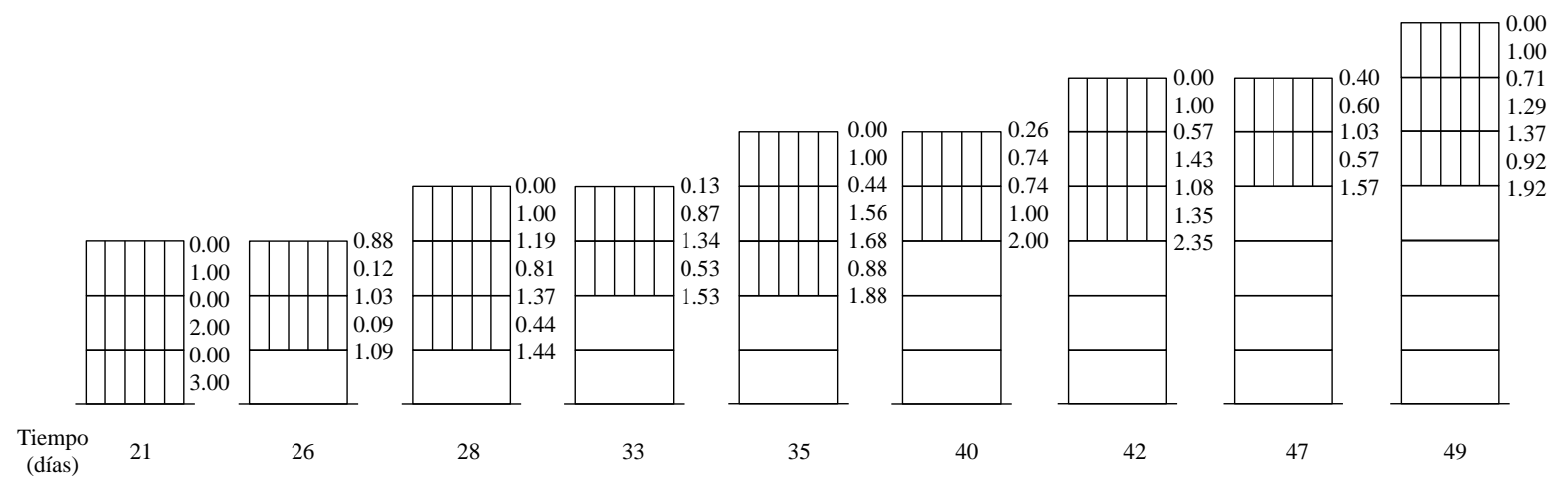

Fig. 2.6 Coeficientes de carga para puntales y forjados considerando la variación del módulo de elasticidad $n=3$

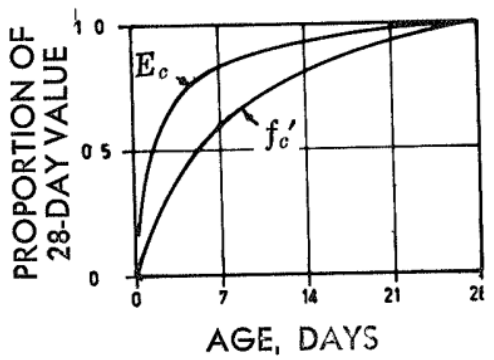

Fig. 2.7 Evolución del módulo elástico con la edad (Grundy y Kabaila, 1963)

Los coeficientes obtenidos para forjados de rigidez constante no difieren mucho de los obtenidos considerando la variación del módulo elástico, teniendo ésta una influencia despreciable en el reparto de cargas en los procesos de cimbrado y descimbrado, según Grundy y Kabaila.

En 1967, Taylor aplica este método para el cálculo de coeficientes de carga en forjados y puntales cuando existe recimbrado, consiguiendo así reducir los coeficientes obtenidos con el Método Simplificado (Grundy y Kabaila, 1963) puro. La Figura 2.8 muestra los coeficientes carga en forjados y puntales para un proceso de recimbrado, para dos juegos de puntales. 


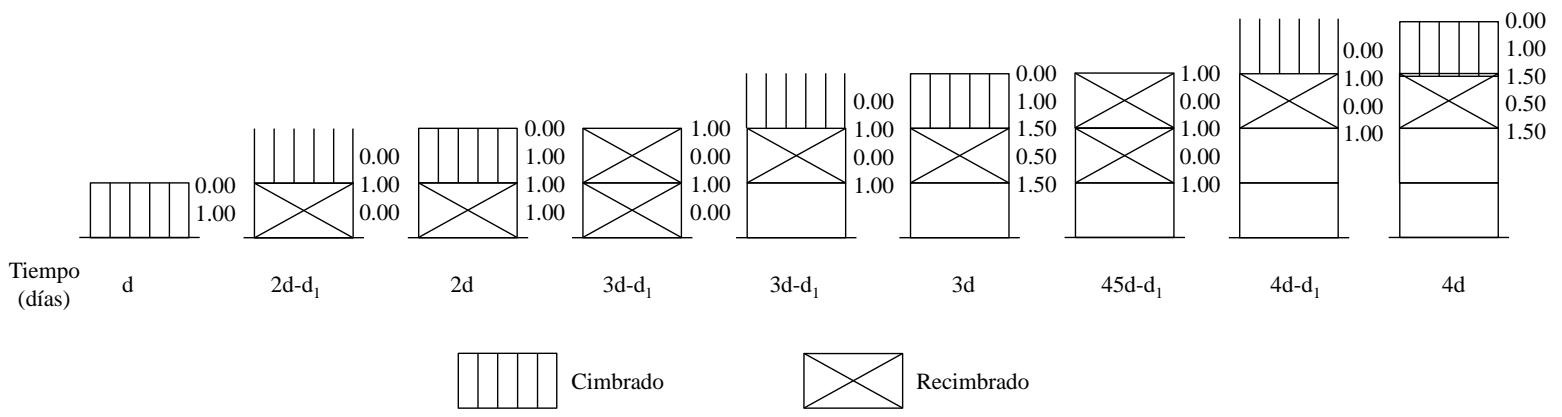

Fig. 2.8 Coeficientes de carga para puntales y forjados $n=2$ (Recimbrado).

\subsubsection{Método Refinado (Liu et al., 1985, 1986)}

En el año 1985, Liu et al (1985) desarrollaron el Método Refinado que intentaba mejorar el Método Simplificado de Grundy y Kabaila. Este nuevo método sí que considera la rigidez real de los puntales y la variación en el tiempo de la rigidez de las losas, debido a la madurez del hormigón.

Inicialmente, este método se basó en un modelo bidimensional. Posteriormente, para verificar su exactitud y determinar la influencia de diversos parámetros en la distribución de cargas, se desarrolló también un modelo tridimensional.

En el análisis se consideraron las siguientes hipótesis:

$\checkmark$ Se asume que los forjados tienen un comportamiento elástico y que su rigidez depende del tiempo.

$\checkmark$ Se desprecia la deformación del forjado que se produce en la unión de éste con el pilar.

$\checkmark \quad$ El peso y los detalles estructurales de cada planta se asume que son similares.

$\checkmark$ Los puntales se comportan como soportes elásticos ideales continuos con igual rigidez axial.

$\checkmark$ La unión entre los puntales y los forjados se considera articulada.

$\checkmark$ La cimentación se considera rígida e indeformable.

Liu et al. (1985, 1986) compararon los resultados obtenidos con los modelos 2D y 3D y el Método Simplificado (Grundy y Kabaila, 1963). Para ello consideraron el modelo tridimensional que se muestra en la Figura 2.9. 


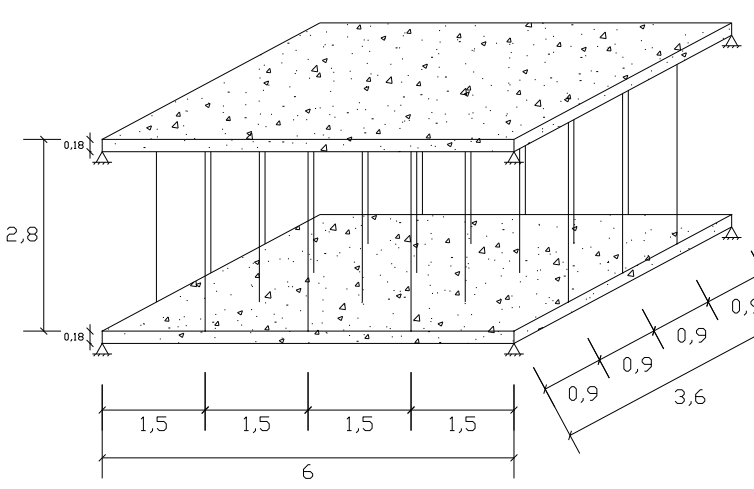

Fig. 2.9 Modelo estructural Modelo de Liu et al. (1985)

Las características consideradas en el análisis fueron las siguientes:

- Resistencia característica del hormigón: $41 \mathrm{MPa}$.

- Módulo de elasticidad del hormigón a los 28 días: 35 GPa.

- Los puntales son de madera con una sección rectangular de 50 x $100 \mathrm{~mm}$.

- Resistencia a compresión de la madera: 5.6 MPa.

- Módulo elástico de la madera: 7.75 GPa.

- El ciclo constructivo considerado fue de dos plantas cimbradas y una recimbrada, con un ritmo de ejecución de un forjado por semana.

El estudio se realizó para cuatro condiciones de contorno del forjado distintas: la primera considerando al forjado continuo en todas sus direcciones, la segunda y la tercera considerándolo continuo en una dirección y extremo en la otra dirección, y la cuarta considerando un forjado aislado. En la Tabla 2.1, se muestran los coeficientes de carga máxima en puntales obtenidos por Liu et al. (1985) en modelos de 2 y 3 dimensiones, comparados con los coeficientes del Método Simplificado (Grundy y Kabaila, 1963), para un proceso de construcción con dos plantas cimbradas y una recimbrada, hormigonando una planta por semana.

Tabla 2.1 Coeficientes máximos en puntales modelos Liu, Chen y Bowman (1985)

\begin{tabular}{|c|c|c|c|c|c|}
\hline \multirow[b]{2}{*}{ No. } & \multirow[b]{2}{*}{$\begin{array}{c}\text { Condiciones de } \\
\text { Contorno del Forjado }\end{array}$} & \multicolumn{3}{|c|}{ Carga Máxima en Puntales } & \multirow[b]{2}{*}{$\mathbf{M}_{3 \mathrm{D}} / \mathbf{M}_{\mathrm{S}}$} \\
\hline & & $\begin{array}{c}\text { Método } \\
\text { Simplificado }\left(M_{S}\right) \\
\end{array}$ & $\begin{array}{c}\text { Método Refinado } \\
\text { 2D }\left(M_{2 D}\right)\end{array}$ & $\begin{array}{c}\text { Método Refinado } \\
\text { 3D }\left(\mathbf{M}_{3 \mathrm{D}}\right) \\
\end{array}$ & \\
\hline 1 & $i$ & 2.00 & 1.83 & 1.86 & 0.93 \\
\hline 2 & \begin{tabular}{l|} 
\\
1 \\
1
\end{tabular} & 2.00 & 1.83 & 1.97 & 0.99 \\
\hline 3 & & 2.00 & 2.07 & 2.06 & 1.03 \\
\hline 4 & & 2.00 & 2.07 & 2.07 & 1.04 \\
\hline
\end{tabular}


Por otra parte, Liu et al. (1985), estudiaron la influencia de otras hipótesis como la rigidez de la cimentación, la deformabilidad de los pilares y la relación largo-ancho del forjado. De este estudio concluyeron que las tres nuevas hipótesis planteadas tenían poca influencia a la hora de determinar la carga máxima en los puntales.

Finalmente Liu et al. $(1985,1986)$ concluyen que el Método Simplificado de Grundy y Kabaila (1963) predice de forma adecuada la etapa constructiva y la ubicación donde las cargas máximas ocurren, pero, generalmente, subestima los valores de carga reales. Por ello, recomiendan usar un coeficiente de modificación que varíe entre 1.05 y 1.10 y corrija así los coeficientes de carga.

\subsubsection{Método Mejorado (El-Shahhat y Chen, 1992)}

En 1992, El-Shahhat y Chen desarrollan un nuevo método para el análisis de la trasmisión de cargas durante la construcción de edificios. El modelo asume las siguientes hipótesis básicas:

Los forjados se comportan de forma elástica y su rigidez depende del tiempo.

$\checkmark$ Los puntales, tanto en el cimbrado como en el recimbrado, actúan como soportes elásticos con una rigidez finita e independiente del tiempo.

$\checkmark$ La cimentación es rígida.

$\checkmark$ Se tienen en cuenta distintas condiciones de contorno del forjado: forjado aislado o con continuidad.

$\checkmark$ La unión entre los puntales y los forjados se considera articulada.

$\checkmark$ Se considera que los puntales, tanto en el cimbrado como en el recimbrado, sólo resisten cargas de compresión.

$\checkmark$ Se aplica el principio de superposición para calcular los desplazamientos acumulados debidos a los sucesivos estados de carga (hormigonado, recimbrado, descimbrado).

La técnica divide el análisis en dos partes. La primera parte utiliza el Método Refinado (Liu et al., 1985) para las operaciones de hormigonado. Mientras que la segunda, empleada en las operaciones de recimbrado o descimbrado, consiste en calcular la carga de los puntales basándose en la aplicación de la compatibilidad de desplazamientos.

El-Shahhat y Chen (1992) realizaron un estudio paramétrico utilizando el modelo bidimensional descrito por Liu et al. (1986). Consideraron dos condiciones de contorno distintas: un forjado continuo en todas sus direcciones y un forjado aislado.

En la Tabla 2.2 se muestran los coeficientes en puntales, para un forjado aislado, obtenidos a partir del Método Mejorado (El-Shahhat y Chen, 1992) y la comparación con el Método Simplificado (Grundy y Kabaila, 1963) y con el Método Refinado (Liu et al., 1985 y 1986). 
Tabla 2.2 Comparación de coeficientes de carga en puntales para diferentes métodos y para el Método Mejorado (1992) para el caso de un forjado aislado.

\begin{tabular}{|c|c|c|c|c|c|c|}
\hline Paso & Nivel & $\begin{array}{c}\text { Método } \\
\text { Simplificado } \\
\left(\mathbf{M}_{\mathrm{S}}\right)\end{array}$ & $\begin{array}{c}\text { Método } \\
\text { Refinado } \\
\left(\mathbf{M}_{\mathbf{R}}\right)\end{array}$ & $\begin{array}{c}\text { Métodos } \\
\text { Mejorado } \\
\left(\mathbf{M}_{\mathbf{M}}\right)\end{array}$ & $\mathbf{M}_{\mathbf{S}} / \mathbf{M}_{\mathbf{M}}$ & $\mathbf{M}_{\mathbf{R}} / \mathbf{M}_{\mathbf{M}}$ \\
\hline 1 & 1 & 1.00 & 1.00 & 1.00 & 1.00 & 1.00 \\
\hline \multirow{2}{*}{2} & 2 & 1.00 & 1.00 & 1.00 & 1.00 & 1.00 \\
\hline & 1 & 2.00 & 1.88 & 1.88 & 1.06 & 1.00 \\
\hline \multirow{2}{*}{3,4} & 2 & 0.00 & 0.16 & 0.17 & 0.00 & 0.94 \\
\hline & 1 & 0.00 & 0.00 & 0.00 & - & - \\
\hline \multirow{3}{*}{5} & 3 & 1.00 & 1.00 & 1.00 & 1.00 & 1.00 \\
\hline & 2 & 1.00 & 0.93 & 0.93 & 1.08 & 1.00 \\
\hline & 1 & 1.00 & 0.73 & 0.73 & 1.38 & 1.00 \\
\hline \multirow{2}{*}{6} & 3 & 0.67 & 0.81 & 0.90 & 0.74 & 0.90 \\
\hline & 2 & 0.33 & 0.55 & 0.57 & 0.58 & 0.97 \\
\hline \multirow{2}{*}{7,8} & 3 & 0.50 & 0.57 & 0.64 & 0.78 & 0.89 \\
\hline & 2 & 0.00 & 0.00 & 0.00 & - & - \\
\hline \multirow{3}{*}{9} & 4 & 1.00 & 1.00 & 1.00 & 1.00 & 1.00 \\
\hline & 3 & 1.17 & 1.19 & 1.27 & 0.92 & 0.94 \\
\hline & 2 & 0.34 & 0.30 & 0.30 & 1.13 & 1.00 \\
\hline \multirow{2}{*}{10} & 4 & 0.89 & 0.92 & 1.02 & 0.87 & 0.90 \\
\hline & 3 & 0.95 & 1.02 & 1.13 & 0.84 & 0.90 \\
\hline
\end{tabular}

Los resultados obtenidos con este método son muy semejantes a los obtenidos con el Método Refinado. La comparación con los resultados del Método Simplificado muestra una buena predicción de la etapa y el nivel donde se produce la carga máxima, pero los autores consideran que la hipótesis del Método Simplificado de considerar los puntales como soportes rígidos resulta inadecuada puesto que la deformación axial de estos influye en el comportamiento de la estructura.

\subsubsection{Método Simplificado Mejorado (Duan y Chen, 1995)}

Buscando un nuevo procedimiento, que al igual que el Método Simplificado (Grundy y Kabaila, 1963) no necesitara un software de análisis estructural, en 1995, Duan y Chen desarrollaron el Método Simplificado Mejorado. Este método, a diferencia del Método Simplificado (Grundy y Kabaila, 1963), considera que los puntales tienen una rigidez finita.

La Figura 2.10 muestra la discretización estructural de las fases de hormigonado y descimbrado consideradas por Duan y Chen (1995), donde $P$ es el peso propio del forjado recién hormigonado $(n)$, que se reparte entre los forjados inferiores hormigonados previamente y conectados mediante puntales.

Los incrementos de carga en los puntales $F_{j}$, producidos por las cargas de los forjados $P_{j}$ son los siguientes:

$F_{1}=P_{1}$

$F_{2}=P_{1}+P 2$

$\dddot{F_{j}}=P_{1}+P_{2}+\ldots+P_{j}$

$F_{n}=P_{1}+P_{2}+P_{3}+\ldots+P_{n}=P$ 


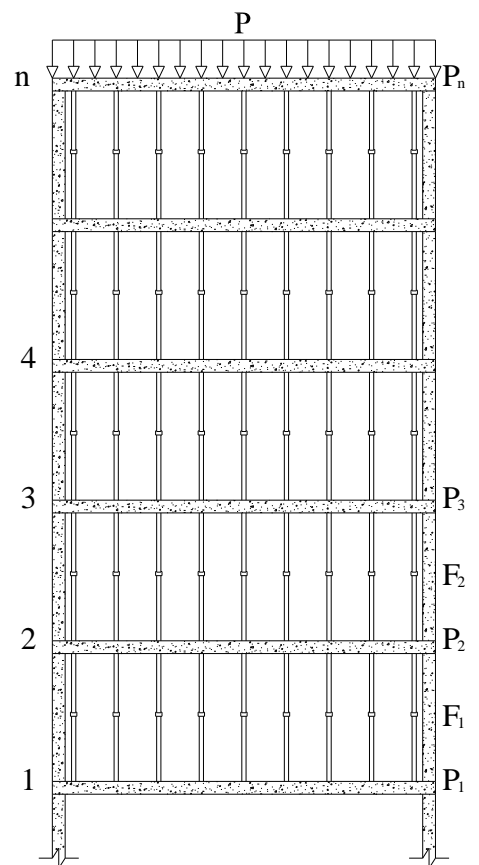

(a)

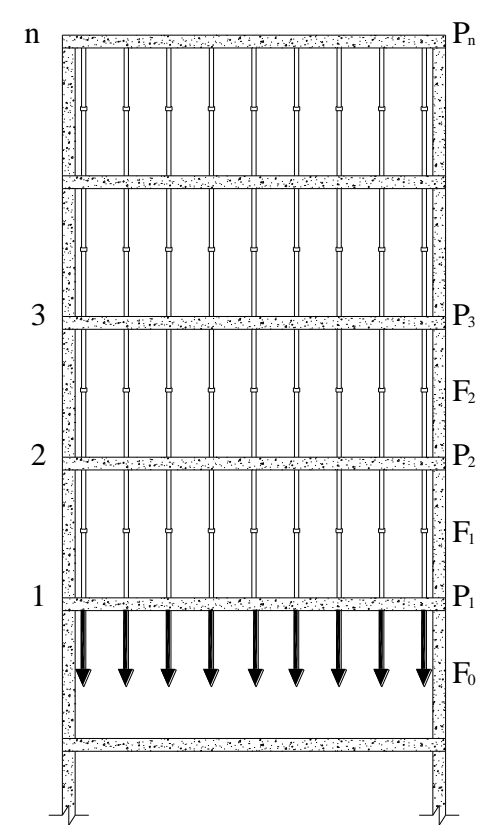

(b)

Fig. 2.10 Operaciones de (a) Hormigonado del último forjado y (b) Descimbrado del primer forjado

Asumiendo que las cargas transmitidas a los puntales son uniformemente distribuidas, Duan y Chen (1995) determinaron que la deformación de los puntales ubicados en la parte central del vano, es igual a la deformación media de los puntales ubicados en el mismo nivel. De esta forma, aplicando la compatibilidad de desplazamientos para la parte central de los forjados ubicados en $j$ y $j-l$ se tiene:

$\Delta_{j}=\Delta_{j-1}+\Delta_{s h, j-1}$

donde $\Delta_{j}$ y $\Delta_{j-1}$ son las flechas en el centro de los forjados $j$ y $j-1$ respectivamente. $\Delta_{s h, j-1}$ la deformación media de los puntales ubicados en el nivel $j$-1. Sustituyendo deformaciones por esfuerzos, expresando las cargas en puntales en función de las solicitaciones en los forjados, tenemos:

$K_{j} \cdot P_{j}=K_{j-1} \cdot P_{j-1}+K_{s h, j-1}\left(P_{1}+P_{2}+\ldots+P_{j-1}\right)$

donde los factores $K$ se definen como las deformaciones del elemento estructural bajo la acción de una carga unitaria ya sea forjado o puntal. Para el cálculo de estos factores se emplean las siguientes expresiones (la expresión 2.6 para forjados y la expresión 2.7 para puntales):

$K_{j}=\gamma \cdot \frac{L^{2}}{E_{j} \cdot I}$

$K_{s h, j-1}=\frac{H}{E_{s h} \cdot A}$

donde $\gamma$ es un coeficiente que depende de las condiciones de contorno y la relación largo/ancho del forjado. $E_{j}$ el módulo de elasticidad de los forjados y $E_{s h}$ es el módulo de elasticidad de los puntales. $L$ 
es la longitud del vano más largo del forjado e $I$ el momento de inercia del forjado suponiendo un ancho unitario. $H$ es la altura de los puntales y $A$ el área de todos los puntales.

Una vez calculados los coeficientes $K$ de forjados y puntales, se definen los ratios de cargas entre dos forjados consecutivos:

$$
\begin{aligned}
& \alpha_{21}=\frac{P_{2}}{P_{1}}=\frac{K_{1}}{K_{2}}+\frac{K_{s h}}{K_{2}} \\
& \alpha_{32}=\frac{P_{3}}{P_{2}}=\frac{K_{2}}{K_{3}}+\frac{K_{s h}}{K_{3}}\left(1+\frac{1}{\alpha_{21}}\right) \\
& \alpha_{43}=\frac{P_{4}}{P_{3}}=\frac{K_{3}}{K_{4}}+\frac{K_{s h}}{K_{4}}\left(1+\frac{1}{\alpha_{32}}+\frac{1}{\alpha_{21} \cdot \alpha_{32}}\right) \\
& \ldots . . \\
& \alpha_{n n-1}=\frac{P_{n}}{P_{n-1}}=\frac{K_{n-1}}{K_{n}}+\frac{K_{s h}}{K_{n}}\left(1+\frac{1}{\alpha_{n-1} n-2}+\frac{1}{\alpha_{n-1 n-2} \cdot \alpha_{n-2 n-3}}+\ldots\right)
\end{aligned}
$$

Además, sabiendo que el peso propio $P$ del forjado recién hormigonado se reparte entre los forjados inferiores conectados por puntales, se cumple que:

$\sum_{j=1}^{n} P_{j}=P$

Así, las solicitaciones de carga en los forjados se pueden calcular por las siguientes expresiones:

$$
\begin{aligned}
& P_{1}=\frac{P}{1+\alpha_{21}+\alpha_{21} \cdot \alpha_{32}+\alpha_{21} \cdot \alpha_{32} \cdot \alpha_{43}+\ldots+\alpha_{21} \cdot \alpha_{32} \cdot \alpha_{n-1 n-2}} \\
& P_{j}=\alpha_{j j-1} \cdot P_{j-1}
\end{aligned}
$$

La operación de descimbrado equivale a aplicar una fuerza equivalente con la misma magnitud que las fuerzas transmitidas por los puntales retirados y en sentido descendente. Es por ello que las fórmulas aplicadas para el descimbrado son análogas a las del hormigonado, pero teniendo en cuenta que la transmisión de cargas se realiza en sentido contrario.

De esta manera, para el caso de descimbrado presentado en la Figura 2.10 (b) las relaciones entre los incrementos de carga en los forjados $P_{j}$ y los incrementos de carga en los puntales $F_{j}$, son las siguientes:

$F_{1}=-\left(P_{2}+P_{3}+\ldots+P_{n}\right)$

$F_{2}=-\left(P_{3}+P_{4}+\ldots+P_{n}\right)$

...

$F_{j}=-\left(P_{j+1}+P_{j+2}+\ldots+P_{n}\right)$

...

$F_{n-l}=-P_{n}$ 


$$
\sum_{j=1}^{n} P_{j}=F_{0}
$$

Las ecuaciones de compatibilidad de desplazamientos son similares tanto en el caso de hormigonado como en el caso de descimbrado. Así, se cumple que la carga transmitida por los puntales retirados se reparte entre los forjados superiores cimbrados, validando la expresión 2.13.

En la Tabla 2.3 se muestran los resultados a manera de coeficiente de carga del método desarrolladopor Duan y Chen (1995) comparándolos con el método simplificado de Grundy y Kabaila (1963).

Tabla 2.3 Comparación de coeficientes de carga en forjados y puntales para el Método Simplificado de Grundy y Kabaila (1963) y para el Método Simplificado Mejorado de Duan y Chen (1995) para el caso de dos forjados cimbrados y uno recimbrado.

\begin{tabular}{|c|c|c|c|c|c|}
\hline \multirow[t]{2}{*}{ Paso } & \multirow[t]{2}{*}{ Nivel } & \multicolumn{2}{|c|}{$\begin{array}{l}\text { Método Simplificado } \\
\text { (Grundy y Kabaila) }\end{array}$} & \multicolumn{2}{|c|}{$\begin{array}{c}\text { Método Simplificado } \\
\text { Mejorado (Duan y Chen) }\end{array}$} \\
\hline & & Puntales & Forjado & Puntales & Forjado \\
\hline 1 & 1 & 1.00 & 0.00 & 1.00 & 0.00 \\
\hline \multirow{2}{*}{2} & 2 & 1.00 & 0.00 & 1.00 & 0.00 \\
\hline & 1 & 2.00 & 0.00 & 1.65 & 0.35 \\
\hline \multirow{2}{*}{3,4} & 2 & 0.00 & 1.00 & 0.39 & 0.61 \\
\hline & 1 & 0.00 & 1.00 & 0.00 & 1.39 \\
\hline \multirow{3}{*}{5} & 3 & 1.00 & 0.00 & 1.00 & 0.00 \\
\hline & 2 & 1.00 & 1.00 & 0.97 & 1.07 \\
\hline & 1 & 1.00 & 1.00 & 0.33 & 1.59 \\
\hline \multirow{3}{*}{6} & 3 & 0.67 & 0.33 & 0.95 & 0.05 \\
\hline & 2 & 0.33 & 1.34 & 0.78 & 1.16 \\
\hline & 1 & 0.00 & 1.33 & 0.00 & 1.78 \\
\hline \multirow{3}{*}{7,8} & 3 & 0.50 & 0.50 & 0.66 & 0.34 \\
\hline & 2 & 0.00 & 1.50 & 0.00 & 1.65 \\
\hline & 1 & 0.00 & 1.00 & 0.00 & 1.00 \\
\hline \multirow{4}{*}{9} & 4 & 1.00 & 0.00 & 1.00 & 0.00 \\
\hline & 3 & 1.17 & 0.83 & 1.14 & 0.86 \\
\hline & 2 & 0.34 & 1.83 & 0.19 & 1.94 \\
\hline & 1 & 0.00 & 1.34 & 0.00 & 1.19 \\
\hline \multirow{4}{*}{10} & 4 & 0.89 & 0.11 & 0.97 & 0.03 \\
\hline & 3 & 0.95 & 0.94 & 1.06 & 0.91 \\
\hline & 2 & 0.00 & 1.95 & 0.00 & 2.05 \\
\hline & 1 & 0.00 & 1.00 & 0.00 & 1.00 \\
\hline
\end{tabular}

De los resultados obtenidos, Duan y Chen (1995) concluyeron lo siguiente:

- El método simplificado de Grundy y Kabaila subestima las solicitaciones de los forjados, debido a que considera los puntales como infinitamente rígidos.

- Para el cálculo de los ratios de cargas muertas en la construcción de forjados, se recomienda usar el Método Simplificado (Grundy y Kabaila, 1963) para unas rigideces de forjado/puntal menores que 0.40, para el resto de los casos cabría usar el Método Simplificado Mejorado (Duan y Chen, 1995). 
- Para el cálculo de los ratios de sobrecargas en la construcción de forjados, se recomienda usar el Método Simplificado (Grundy y Kabaila, 1963) para unas rigideces de forjado/puntal menores que 0.20, para el resto de los casos el Método Simplificado Mejorado (Duan y Chen, 1995).

\subsubsection{Método simplificado de Fang et al. (2001a)}

En el año 2001, Fang et al. instrumentaron un edificio en Beijing y tras analizar los resultados observaron que durante el curado del hormigón la rigidez de los elementos estructurales varía significativamente y en consecuencia los esfuerzos en la estructura tienen que redistribuirse, especialmente en forjados recién hormigonados. Es por ello que propusieron un nuevo método para el cálculo de la transmisión de cargas en la construcción de edificios en altura donde se tenía en cuenta dicha redistribución de cargas.

El modelo de Fang et al. (2001a) considera las siguientes hipótesis:

$\checkmark$ El modelo es bidimensional.

$\checkmark \quad$ La unión entre puntales y forjado es considerada como una articulación.

$\checkmark$ Se considera la variación del módulo de elasticidad con el tiempo de los elementos de hormigón.

$\checkmark$ La cimentación se considera como infinitamente rígida.

$\checkmark$ El modelo es incremental. Esto significa que considera la acumulación de cargas y desplazamientos.

$\checkmark$ El forjado recién hormigonado evoluciona desde una situación en que no soporta ninguna carga, hasta soportar parte de su peso propio. Esto produce una redistribución del peso propio del forjado proporcional a su rigidez y a la rigidez del sistema de apuntalamiento.

A continuación se describe el procedimiento para determinar la redistribución de cargas, el cual se basa en expresiones que reparten la carga en función de la relación de rigideces entre los forjados y la cimbra.

La rigidez del forjado en el nivel $i$ se calcula mediante la siguiente expresión:

$K_{\text {slab }, i}=\frac{\lambda_{i} \cdot E_{c i} \cdot I_{i}}{L_{\text {slab }}^{4}} \quad i=1,2, \ldots, n$

donde, $n$ es el número de forjados conectados por puntales, $\lambda_{i}$ el coeficiente que considera las condiciones de contorno de los forjados y la naturaleza de las cargas (diferente para cargas puntuales y cargas distribuidas), $E_{c i}$ módulo de elasticidad del hormigón dependiente del tiempo, $I_{i}$ el momento de inercia de la franja de forjado considerado y $L_{\text {slab }}$ la luz del forjado. 
La rigidez del sistema de cimbrado ubicado en el nivel $i$ se calcula mediante la siguiente expresión:

$K_{\text {shore }, i}=\frac{\rho_{i} \cdot s \cdot E_{\text {shore }, i} \cdot A_{\text {shore }, i}}{L_{\text {shore }, i} \cdot L_{\text {slab }}} \quad i=1,2, \ldots, n-1$

siendo, $s$ el número de puntales instalados en el vano considerado, $\rho_{i}$ el coeficiente que considera las cargas desiguales en los puntales, $E_{\text {Shore }, i}$ el módulo de elasticidad de los puntales ubicados en el nivel $i, A_{\text {shore }, i}$ el área de la sección transversal de los puntales, $L_{\text {shore }, i}$ la longitud de los puntales y $L_{\text {slab }}$ la luz del forjado.

Asumiendo que el peso propio del forjado superior es $q$, que la carga soportada por el forjado inferior es $q_{i}$, y que la deformación del forjado $i$ es $\Delta_{i}$, entonces:

$\Delta_{i}=\frac{q_{i}}{K_{\text {slab }, i}}$

$\Delta_{i+1}-\Delta_{i}=\sum_{j=1}^{i} \frac{q_{j}}{K_{\text {shore }, i}}$

$\sum_{i=1}^{n} q_{i}=q$

de la ecuación 2.16 se cumple que:

$\Delta_{1}=\frac{q_{1}}{K_{\text {slab }, 1}}$

$\Delta_{2}=\frac{q_{2}}{K_{\text {slab }, 2}}$

$\Delta_{2}-\Delta_{1}=\frac{q_{1}}{K_{\text {shore }, 1}}$

entonces:

$q_{2}=q_{1}\left(\frac{K_{\text {slab }, 2}}{K_{\text {slab }, 1}}+\frac{K_{\text {slab }, 2}}{K_{\text {shore }, 1}}\right)=m_{2,1} \cdot q_{1}$

$v_{i, j}=\frac{K_{\text {slab }, i}}{K_{\text {slab }, j}}$

$u_{i, j}=\frac{K_{\text {slab }, i}}{K_{\text {shore }, j}}$

El coeficiente $m_{i, 1}$ representa la relación de carga soportada por el forjado del nivel $i$ y la carga soportada por el primer forjado. Los coeficientes $v_{i, j}$ y $u_{i, j}$ definen la relación de rigidez entre dos forjados, y entre el forjado y puntal respectivamente. 
Así se tiene que la carga soportada por el forjado del tercer nivel será:

$$
\begin{gathered}
q_{3}=q_{2}\left(\frac{K_{\text {slab }, 3}}{K_{\text {slab }, 2}}+\frac{K_{\text {slab }, 3}}{K_{\text {shore }, 2}}\right)+q_{1} \cdot \frac{K_{\text {slab }, 3}}{K_{\text {shore }, 2}}=m_{2,1} \cdot q_{1}\left(v_{3,2}+u_{3,2}\right)+u_{3,2} \cdot q_{1} \\
=m_{3,1} \cdot q_{1}
\end{gathered}
$$

La carga soportada por el forjado del nivel $i$ se puede expresar de la siguiente forma:

$q_{i}=m_{i, 1} \cdot q_{1}$

$m_{i, 1}=m_{i-1,1} \cdot v_{i, i-1}+u_{i, i-1} \cdot \sum_{j=1}^{i-1} m_{j, 1} \quad i=2,3, \ldots, n$

$q_{i}=q \cdot \frac{m_{i, 1}}{\sum_{j=1}^{n} m_{j, 1}}$

$$
i=1,2, \ldots, n
$$

Si se considera el peso propio del forjado superior como unitario $(q=1)$, se pueden establecer los coeficientes de carga. La Tabla 2.4 muestra una comparación entre los coeficiente de carga obtenidos con el modelo de Fang et al. y algunos de los modelos descritos anteriormente.

\begin{tabular}{|c|c|c|c|c|c|c|}
\hline Paso & Nivel & $\begin{array}{c}\text { Método } \\
\text { Simplificado } \\
\text { (Grundy y } \\
\text { Kabaila) }\end{array}$ & $\begin{array}{c}\text { Método } \\
\text { Refinado } \\
\text { (Liu et al.) }\end{array}$ & $\begin{array}{l}\text { Modelo de } \\
\text { Mosallam y } \\
\text { Chen }\end{array}$ & $\begin{array}{c}\text { Método } \\
\text { Simplificado } \\
\text { Mejorado } \\
\text { (Duan y Chen) }\end{array}$ & $\begin{array}{c}\text { Método } \\
\text { Simplificado } \\
\text { de Fang et } \\
\text { al. }\end{array}$ \\
\hline 1 & 1 & 0.00 & 0.00 & 0.00 & 0.00 & 0.00 \\
\hline \multirow{2}{*}{2} & 2 & 0.00 & 0.00 & 0.00 & 0.00 & 0.00 \\
\hline & 1 & 0.00 & 0.37 & 0.86 & 0.35 & 0.38 \\
\hline \multirow{2}{*}{3,4} & 2 & 1.00 & 0.62 & 0.97 & 0.61 & 0.67 \\
\hline & 1 & 1.00 & 1.38 & 1.07 & 1.39 & 1.33 \\
\hline \multirow{3}{*}{5} & 3 & 0.00 & 0.00 & 0.00 & 0.00 & 0.00 \\
\hline & 2 & 1.00 & 1.08 & 1.41 & 1.07 & 1.10 \\
\hline & 1 & 1.00 & 1.58 & 1.32 & 1.59 & 1.51 \\
\hline \multirow{3}{*}{6} & 3 & 0.33 & 0.06 & 0.51 & 0.05 & 0.20 \\
\hline & 2 & 1.34 & 1.17 & 1.31 & 1.16 & 1.14 \\
\hline & 1 & 1.33 & 1.77 & 1.27 & 1.78 & 1.66 \\
\hline \multirow{3}{*}{7,8} & 3 & 0.50 & 0.36 & 0.59 & 0.34 & 0.44 \\
\hline & 2 & 1.50 & 1.66 & 1.47 & 1.65 & 1.56 \\
\hline & 1 & 1.00 & 1.00 & 1.00 & 1.00 & 1.00 \\
\hline \multirow{4}{*}{9} & 4 & 0.00 & 0.00 & 0.00 & 0.00 & 0.00 \\
\hline & 3 & 0.83 & 0.86 & 1.10 & 0.86 & 0.93 \\
\hline & 2 & 1.83 & 1.95 & 1.80 & 1.94 & 1.86 \\
\hline & 1 & 1.34 & 1.19 & 1.22 & 1.19 & 1.20 \\
\hline \multirow{4}{*}{10} & 4 & 0.11 & 0.03 & 0.51 & 0.03 & 0.30 \\
\hline & 3 & 0.94 & 0.91 & 0.91 & 0.91 & 0.84 \\
\hline & 2 & 1.95 & 2.06 & 1.63 & 2.05 & 1.86 \\
\hline & 1 & 1.00 & 1.00 & 1.00 & 1.00 & 1.00 \\
\hline
\end{tabular}

Tabla 2.4 Comparación de coeficientes de carga en forjados para diferentes métodos y el modelo de Fang et al. (2001a), para el caso de dos forjados cimbrados y uno recimbrado

De esta comparación de resultados, Fang et al. (2001a) concluyeron que los resultados de su nuevo modelo se ajustan a los resultados obtenidos por el Modelo de Mosallam y Chen (1991), y a los 
resultados obtenidos por el Método Simplificado Mejorado (Duan y Chen, 1995). Al analizar un ciclo constructivo de tres plantas apuntaladas Fang et al. (2001a) consideraron que el Modelo de Mosallam y Chen (1991) y el Método Simplificado Mejorado (Duan y Chen, 1995), no estiman adecuadamente las solicitaciones de carga máxima en los forjados.

\subsubsection{Métodos propuestos por Beeby (2001a)}

Beeby (2001a) propone la aplicación de dos métodos prácticos que permiten la estimación de la transmisión de cargas durante el proceso constructivo, dependiendo del nivel de exactitud buscado.

El primer método consiste en establecer un porcentaje de cargas transmitidas en el conjunto de la estructura. Se trata de un método simple y, en general, conservador. La Tabla 2.5 muestra los porcentajes de cargas establecidos por Beeby (2001a) considerando procesos constructivos con dos y tres juegos de cimbras.

Tabla 2.5 Porcentaje de distribución de cargas durante el proceso constructivo (Beeby, 2001a)

\begin{tabular}{|c|c|c|c|c|c|c|}
\hline \multirow{2}{*}{ Localización } & \multirow{2}{*}{ Carga } & \multirow{2}{*}{$\begin{array}{c}\begin{array}{c}1 \text { Juego de } \\
\text { cimbra }\end{array} \\
\text { Forjado } \\
\end{array}$} & \multicolumn{2}{|c|}{2 Juegos de cimbras } & \multicolumn{2}{|c|}{3 Juegos de cimbras } \\
\hline & & & Forjado & Puntales & Forjado & Puntales \\
\hline $\begin{array}{l}\text { Forjado recién } \\
\text { hormigonado }\end{array}$ & Total $\mathrm{w}_{\mathrm{p}}$ & $100 \%$ & $100 \%$ & & $100 \%$ & \\
\hline Cimbras & & $100 \%$ & & $100 \%$ & & $100 \%$ \\
\hline Forjado 1 & & $100 \%$ & $70 \% \mathrm{w}_{\mathrm{p}}$ & & $65 \% \mathrm{w}_{\mathrm{p}}$ & \\
\hline Cimbras & $\mathrm{w}_{\mathrm{b} 1}$ & & & $30 \% \mathrm{w}_{\mathrm{p}}$ & & $35 \% \mathrm{w}_{\mathrm{p}}$ \\
\hline Forjado2 & & & $30 \% \mathrm{w}_{\mathrm{p}}$ & & $23 \% \mathrm{w}_{\mathrm{p}}$ & \\
\hline Cimbras & $\mathrm{w}_{\mathrm{b} 2}$ & & & & & $12 \% \mathrm{w}_{\mathrm{p}}$ \\
\hline Forjado 3 & & & & & $12 \% \mathrm{w}_{\mathrm{p}}$ & \\
\hline
\end{tabular}

El segundo método consiste en una variación del Método Simplificado de Grundy y Kabaila (1963), considerando que los forjados tienen un comportamiento elástico con una rigidez dependiente del tiempo y que los puntales tienen una rigidez finita. Para dos niveles de cimbrado, la carga en los puntales de la planta inferior cimbrada se corresponde con:

$w_{b 1}=\frac{w_{p}}{\left(1+\frac{S_{s 1}}{S_{s 2}}+\frac{S_{s 1}}{S_{b}}\right)}$

siendo $w_{p}$ la carga en los puntales que soportan el encofrado, $w_{b 1}$ la carga en los puntales de la planta inferior cimbrada, $S_{s 1}$ y $S_{s 2}$ las rigideces de los forjados considerando su variación con el tiempo y $S_{b}$ la rigidez de los puntales.

Para tres niveles de cimbrado, las cargas en los puntales de las plantas inferiores cimbradas se corresponden con: 
$w_{b 1}=\frac{w_{p}}{\left(1+\frac{S_{s 1}}{S_{s 2}}+\frac{S_{s 1}}{S_{b}}\right)-\left[\frac{\left(\frac{S_{s 1}}{S_{S 2}}\right)}{\left(1+\frac{S_{s 2}}{S_{s 3}}+\frac{S_{S 2}}{S_{b}}\right)}\right]}$

$w_{b 2}=\frac{w_{b 1}}{\left(1+\frac{S_{s 2}}{S_{s 3}}+\frac{S_{s 2}}{S_{b}}\right)}$

En el caso de puntales apoyados en la cimentación, se considera la cimentación como infinitamente rígida y son de aplicación las ecuaciones 2.29 y $2.30\left(S_{S 2}=\infty, S_{S 3}=\infty\right)$.

\subsubsection{Método generalizado de Fang et al., (2009a)}

En 2009, Fang et al. realizan una reformulación del Método Simplificado de Fang et al. (2001a). El modelo considerado en este análisis pasa de ser bidimensional a tener 1D (Fig. 2.11).

La estructura se considera como un sistema de muelles en 1D, cuya distribución de cargas está en función de la rigidez relativa y la compatibilidad de deformaciones de la estructura. Además considera que las cargas aplicadas en los forjados son uniformemente distribuidas y que todos los forjados tienen la misma rigidez después de 28 días.

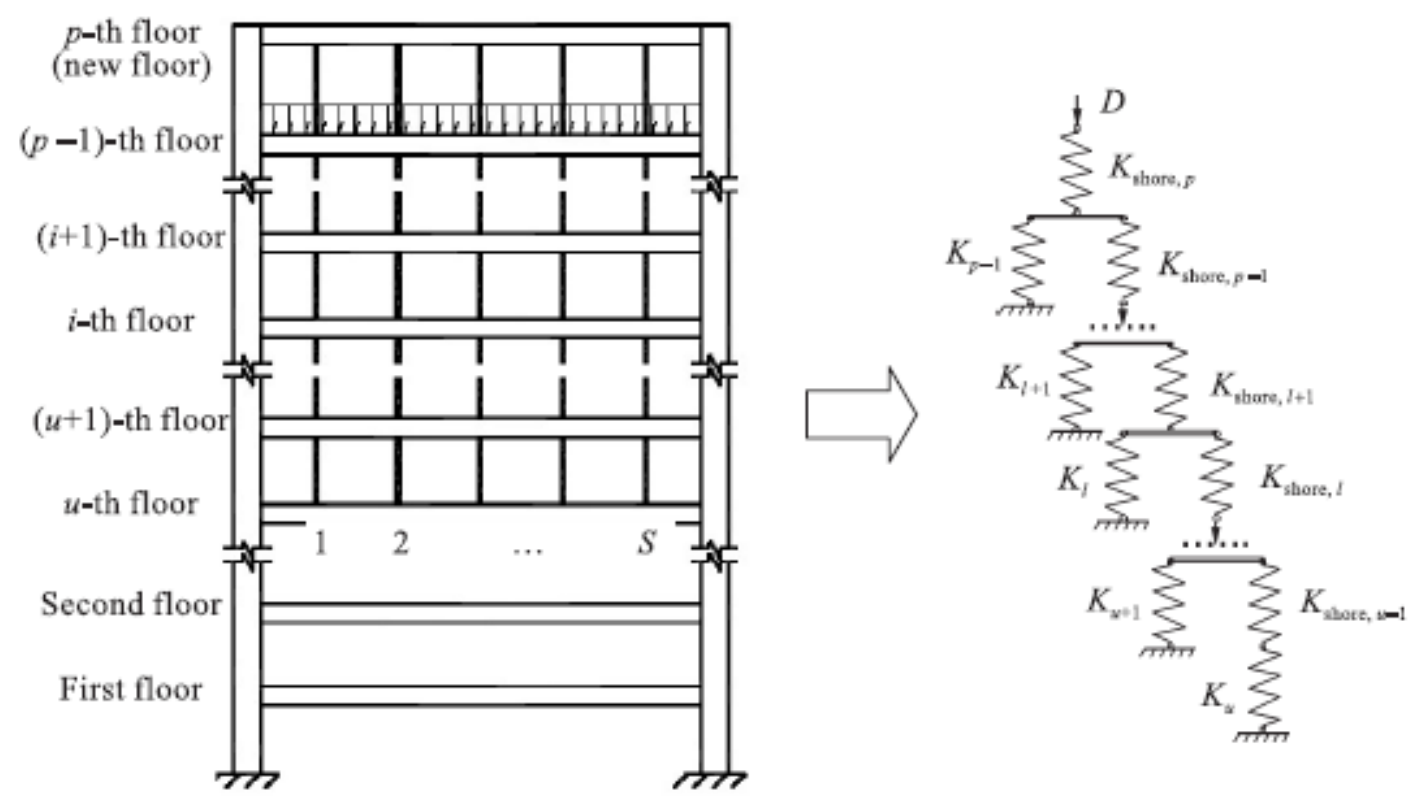

Fig. 2.11 Modelo de la estructura (de 2D a 1D) para la fase de hormigonado (Fang et al., 2001a).

En este estudio, Fang et al. (2009a) denominan a la relación de rigidez entre el forjado y puntal $\left(u_{i, j}\right)$ (ecuación 2.24) a los 28 días como parámetro estructural característico $(\gamma)$. 
$u_{i, j}=\gamma=\frac{K_{\text {slab }, 28}}{K_{\text {shore }}}$

A partir de este parámetro y la aplicación del modelo teórico, los autores calcularon la carga máxima en los forjados para 20 procesos constructivos distintos. En las Figuras 2.12 y 2.13 se muestra la carga máxima en función del parámetro estructural característico $(\gamma)$ y para distintos procesos de constructivos.

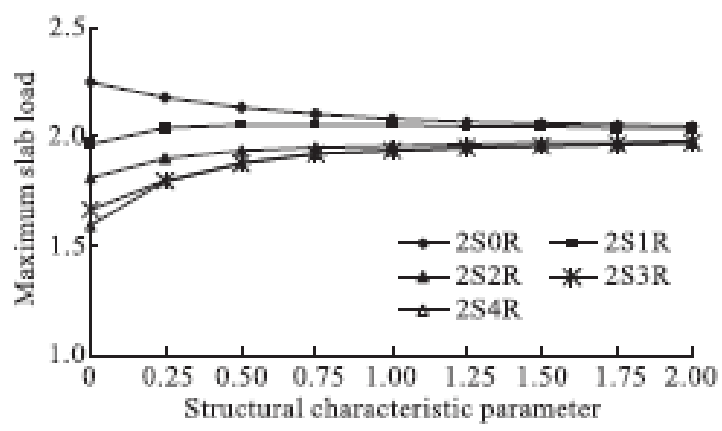

Fig. 2.12 Coeficiente de carga máxima en forjados para procesos constructivos con 2 niveles cimbrados y $n$ recimbrados (Fang et al., 2001a).

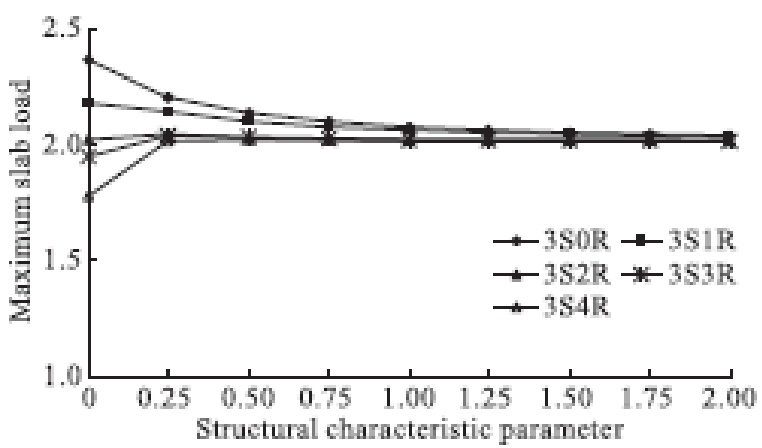

Fig. 2.13 Coeficiente de carga máxima en forjados para procesos constructivos con 3 niveles cimbrados y $n$ recimbrados (Fang et al., 2001a).

Posteriormente, compararon los resultados con los obtenidos a partir del Método Simplificado (Grundy y Kabaila, 1963). Del estudio concluyeron que la distribución de cargas y la carga máxima en forjados dependen en gran medida del proceso constructivo y del parámetro estructural característico $(\gamma)$. Así mismo, verificaron que el Método Simplificado (Grundy y Kabaila, 1963) subestima o sobrestima la carga máxima en forjados, dependiendo del proceso constructivo elegido.

\subsubsection{Nuevo Procedimiento Simplificado (Calderón et al., 2011)}

Recientemente, Calderón et. al (2011) han desarrollado un nuevo procedimiento simplificado que permite estimar la transmisión de cargas entre forjados y puntales en el proceso de cimbrado, clareado y descimbrado. Este método ha sido validado de forma experimental y numérica empleando los resultados obtenidos por Alvarado (2009) y Alvarado et al. (2009, 2010). 
De forma análoga a los métodos desarrollados por Duan y Chen (1995), y Fang et al. (2001), el Nuevo Método Simplificado se basa en considerar que los puntales tienen una rigidez finita y en considerar la compatibilidad de deformaciones entre forjados y puntales durante el proceso constructivo. Su principal novedad estriba en que permite estimar la carga en cualquiera de los puntales bajo el forjado, permitiendo así determinar las deformaciones y cargas medias sobre puntales y forjados.

Las hipótesis consideradas en el nuevo procedimiento simplificado son las siguientes:

$\checkmark$ Se considera la variación del módulo de elasticidad con el tiempo de los elementos de hormigón.

$\checkmark$ La cimentación se considera como infinitamente rígida.

$\checkmark$ El modelo es incremental. Esto significa que considera la acumulación de cargas y desplazamientos.

$\checkmark$ Se considera a los puntales como elementos con un comportamiento elástico y de rigidez finita.

$\checkmark$ Se considera que las cargas transmitidas por los puntales a los forjados son uniformemente distribuidas.

$\checkmark$ Se considera que la deformación del forjado en cualquier punto coincide con la del puntal situado en ese punto. Así, la deformación media del forjado coincide con la deformación media de los puntales dispuestos bajo este forjado.

$\checkmark$ Se consideran diferentes condiciones de contorno del forjado, estimando su deformabilidad mediante la aplicación del método de Scanlon y Murray (1982).

$\checkmark$ Se desprecian los efectos de retracción y fluencia.

La Figura 2.14 muestra la discretización estructural para las fases de hormigonado, clareado y descimbrado, donde $Q$ es el peso propio del forjado recién hormigonado $(n)$. 


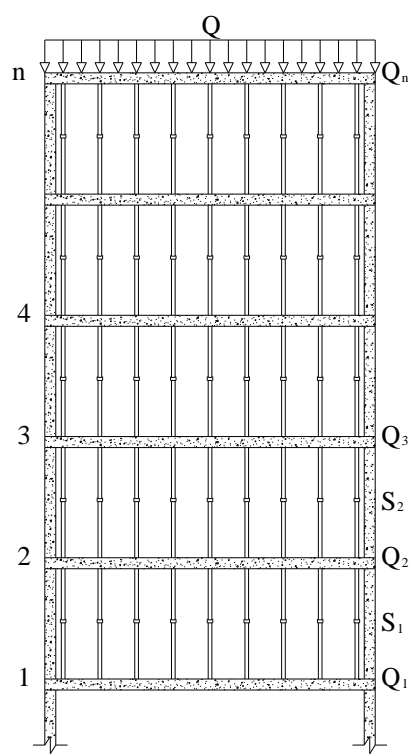

a

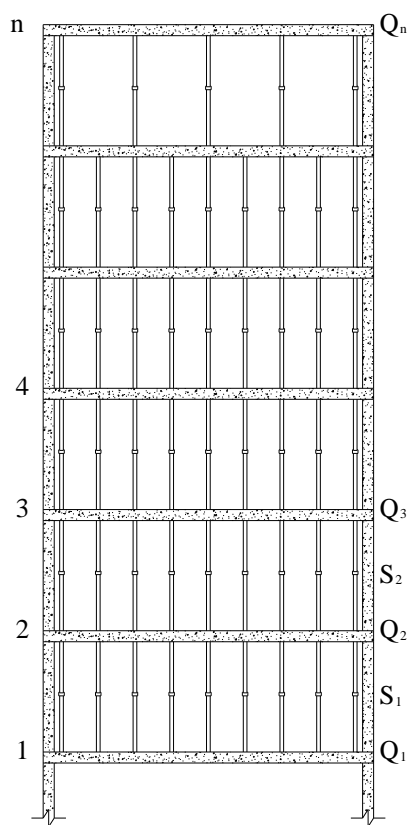

b

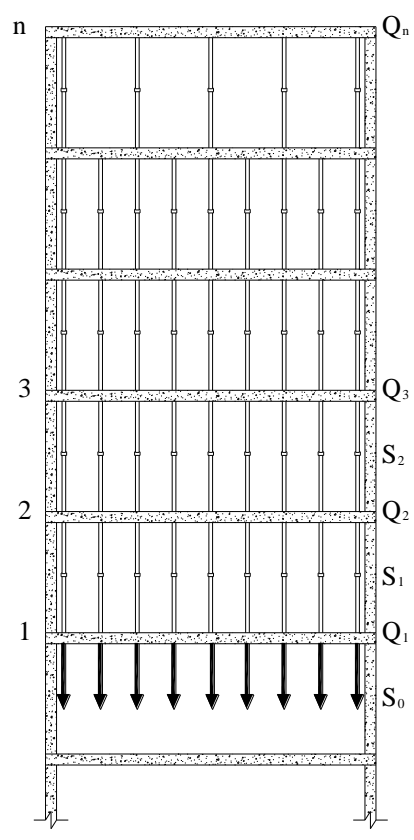

Fig. 2.14 Operaciones de (a) Hormigonado del último forjado (b) Clareado del último forjado y (c) Descimbrado del primer forjado

Los incrementos de carga en los puntales $S_{j}$, producidos por los incrementos de cargas en los forjados $Q_{j}$ en las operaciones de hormigonado y clareado son los siguientes:

$S_{1}=Q_{1}$

$S_{2}=Q_{1}+Q_{2}$

$S_{j}=Q_{1}+Q_{2}+\ldots+Q_{j}$

$\stackrel{S}{S}_{n}=Q_{1}+Q_{2}+Q_{3}+\ldots+Q_{n}$

Asumiendo que las cargas transmitidas a los puntales son uniformemente distribuidas, se tiene que la deformación media del forjado coincide con la deformación media de los puntales dispuestos bajo dicho forjado. De esta forma aplicando compatibilidad de desplazamientos para la deformación media de los forjados ubicados en $j$ y $j-1$ se tiene:

$\overline{\Delta_{j}}=\overline{\Delta_{j-1}}+\overline{\Delta_{s h, j-1}}$

donde $\overline{\Delta_{j}}$ y $\overline{\Delta_{j-1}}$ son las flechas medias de los forjados $j$ y $j-1$ respectivamente. $\overline{\Delta_{s h, j-1}}$ la deformación media de los puntales ubicados en el nivel $j-1$.

Transformando las deformaciones en esfuerzos, expresando las cargas en puntales en función de los incrementos medios de carga producidos en un forjado $\left(\overline{Q_{j}}\right)$, se tiene: 
$\overline{K_{j}} \cdot \overline{Q_{j}}=\overline{K_{j-1}} \cdot \overline{Q_{j-1}}+K_{s h, j-1} \cdot\left(\overline{Q_{1}}+\overline{Q_{2}}+\ldots+\overline{Q_{j-1}}\right)$

donde los factores $K$ se definen como las deformaciones del elemento estructural bajo la acción de una carga unitaria ya sea de forjado o de puntal.

A partir de la ecuación (2.35) se pueden definir los ratios de carga entre dos forjados consecutivos:

$$
\begin{aligned}
& \alpha_{21}=\frac{\overline{Q_{2}}}{\overline{Q_{1}}}=\frac{\overline{K_{1}}}{\overline{K_{2}}}+\frac{K_{s h}}{\overline{K_{2}}} \\
& \alpha_{32}=\frac{\overline{Q_{3}}}{\overline{Q_{2}}}=\frac{\overline{K_{2}}}{\overline{K_{3}}}+\frac{K_{s h}}{\overline{K_{3}}}\left(1+\frac{1}{\alpha_{21}}\right) \\
& \alpha_{43}=\frac{\overline{Q_{4}}}{\overline{Q_{3}}}=\frac{\overline{K_{3}}}{\overline{K_{4}}}+\frac{K_{s h}}{\overline{K_{4}}}\left(1+\frac{1}{\alpha_{32}}+\frac{1}{\alpha_{21} \cdot \alpha_{32}}\right) \\
& \alpha_{n n-1}=\frac{\overline{Q_{n}}}{\overline{Q_{n-1}}}=\frac{\overline{K_{n-1}}}{\overline{K_{n}}}+\frac{K_{s h}}{\overline{K_{n}}}\left(1+\frac{1}{\alpha_{n-1 n-2}}+\frac{1}{\alpha_{n-1 n-2} \cdot \alpha_{n-2 n-3}}+\ldots\right)
\end{aligned}
$$

Por otro lado, el incremento de carga que se produce en una nueva fase de hormigonado o clareado se reparte entre los forjados inferiores conectados por puntales, de donde:

$$
\sum_{j=1}^{n} \bar{Q}_{j}=Q
$$

Así, los incrementos de carga en los forjados que se producen en las fases de hormigonado o clareado se pueden calcular por las siguientes expresiones:

$\overline{Q_{1}}=\frac{Q}{1+\alpha_{21}+\alpha_{21} \cdot \alpha_{32}+\alpha_{21} \cdot \alpha_{32} \cdot \alpha_{43}+\ldots+\alpha_{21} \cdot \alpha_{32} \cdot \alpha_{n-1 n-2}}$

$\overline{Q_{j}}=\alpha_{j-1} \cdot \overline{Q_{j-1}}$

La operación de descimbrado resulta equivalente a la aplicación de una fuerza equivalente en sentido descendente con la misma magnitud que las fuerzas transmitidas por los puntales retirados (ver Fig. 2.14 (c)). Así, las formulas aplicadas para el descimbrado son análogas al hormigonado y al clareado, teniendo en cuenta que la transmisión de cargas se realiza en sentido contrario.

En la Tabla 2.6 se muestran los resultados obtenidos aplicando el Nuevo Procedimiento Simplificado (Calderón et al., 2011) al edificio experimental desarrollado por Alvarado (2009) y resultados del modelo numérico de dicho edificio (Alvarado, 2009 y Alvarado et al., 2010) y se comparan con los resultados obtenidos aplicando el Método Simplificado Mejorado (Duan y Chen, 1995) y el Método simplificado de Fang et al. (2001) al mismo edificio. 
Tabla 2.6 Comparación de los resultados del Nuevo Procedimiento Simplificado (Calderón et al. 2011) con otros métodos (Unidades: $\mathrm{kN} / \mathrm{m}^{2}$ )

\begin{tabular}{lccccc}
\hline $\begin{array}{l}\text { Etapa de } \\
\text { construcción }\end{array}$ & Nivel & $\begin{array}{c}\text { Modelo } \\
\text { Numérico }\end{array}$ & $\begin{array}{c}\text { Nuevo } \\
\text { Procedimiento } \\
\text { Simplificado } \\
\text { Calderón et al.) }\end{array}$ & $\begin{array}{c}\text { Método } \\
\text { Simplificado } \\
\text { Mejorado } \\
\text { (Duan y } \\
\text { Chen) }\end{array}$ & $\begin{array}{c}\text { Método } \\
\text { Simplificado } \\
\text { de Fang et al. }\end{array}$ \\
\hline $\begin{array}{l}\text { Hormigonado } \\
\text { Nivel 1 }\end{array}$ & 1 & 5.52 & 5.64 & 5.64 & 5.64 \\
\hline Clareado Nivel 1 & 1 & 3.41 & 4.23 & 4.51 & 4.62 \\
\hline Hormigonado & 2 & 5.80 & 5.64 & 5.64 & 5.64 \\
Nivel 2 & 1 & 6.60 & 8.36 & 8.91 & 8.97 \\
\hline Clareado Nivel 2 & 2 & 2.90 & 3.48 & 4.40 & 3.84 \\
\hline Descimbrado & 1 & 5.33 & 6.47 & 7.90 & 7.50 \\
\hline Nivel 1 & 2 & 1.39 & 1.02 & 0.79 & 0.68 \\
\hline Hormigonado & 3 & 5.80 & 5.64 & 5.64 & 5.64 \\
Nivel 3 & 2 & 3.04 & 3.12 & 3.33 & 3.21 \\
\hline Clareado Nivel 3 & 3 & 2.77 & 3.08 & 3.27 & 3.27 \\
\hline Carga Nivel 3 & 2 & 2.19 & 2.02 & 2.26 & 2.14 \\
\hline Descimbrado & 3 & 5.37 & 5.75 & 6.49 & 6.43 \\
Nivel 2 & 3 & 3.36 & 3.38 & 3.67 & 3.55 \\
\hline
\end{tabular}

Los autores concluyeron que las estimaciones realizadas con el Método Simplificado Mejorado (Duan y Chen, 1995) y con el Método simplificado de Fang et al. (2001a), en la mayoría de las operaciones constructivas sobreestiman las cargas en puntales. Esto es debido a considerar que la deformación media del conjunto de puntales bajo un forjado coincide con la deformación de un puntual situado en el centro del vano. El Nuevo Procedimiento Simplificado (Calderón et al., 2011) presenta un mejor grado de ajuste que los dos métodos simplificados estudiados para el edificio estudiado por Alvarado (2009).

\subsubsection{Modelos Numéricos}

En el presente apartado se describen algunos modelos más complejos, basados en modelizaciones por el método de los elementos finitos en dos y tres dimensiones, para el cálculo de la distribución de cargas en forjados y puntales durante la construcción de forjados sucesivos de hormigón in situ.

\subsubsection{Equivalent Frame Method (Stivaros y Halvorsen, 1990)}

Stivaros y Halvorsen propusieron, en el año 1990, el Equivalent Frame Method (EFM) para llevar a cabo el estudio las cargas de construcción durante el cimbrado y recimbrado en edificios de hormigón armado de varias plantas y con el fin de intentar mejorar métodos anteriores.

En este caso, el edificio a estudiar se modela como una estructura porticada de dos dimensiones, y que puede ser de uno o varios vanos. 
Las hipótesis consideradas en este análisis son las siguientes:

$\checkmark$ Los puntales se reemplazan por un número igual de soportes elásticos, con una rigidez equivalente a la rigidez total de los puntales correspondientes.

$\checkmark$ Se supone que en el recimbrado los puntales no reciben carga en el momento de su instalación, por lo que los forjados se deforman libremente hasta la colocación de aquellos.

$\checkmark$ El peso del hormigón recién vertido se aplica a los puntales del forjado inferior en forma de cargas puntuales.

$\checkmark$ Se asume que las uniones entre losas y puntales son articulaciones.

$\checkmark$ Se asume que los puntales se apoyan sobre una cimentación infinitamente rígida.

En la Figura 2.15 se muestra una idealización del modelo estructural bidimensional utilizado.

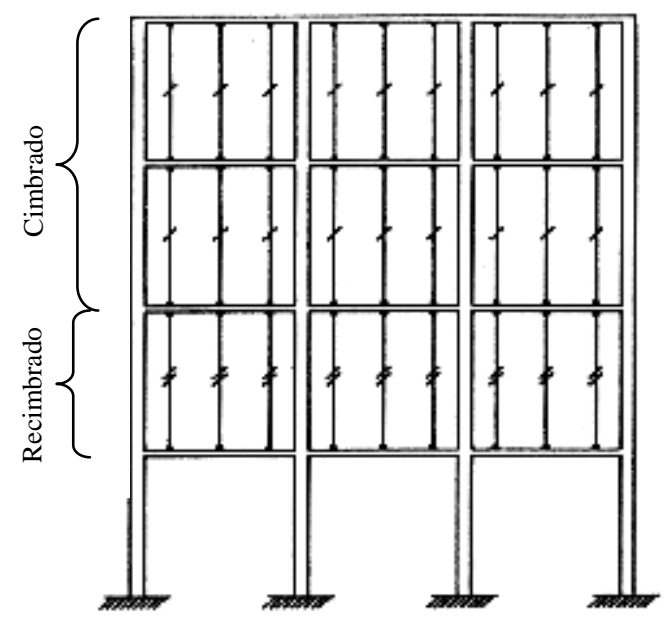

Fig. 2.15 Idealización de la estructura para el EFM (Stivaros y Halvorsen, 1990)

Para evaluar las fuerzas en los diferentes elementos del pórtico, incluyendo las cargas axiales en los puntales, se analiza éste elásticamente usando procedimientos de rigidez convencionales.

En la Figura 2.16 se muestra la planta característica utilizada en el ejemplo que estudiaron. Se idealizaron los puntales, tanto en el cimbrado como en el descimbrado, como series de elementos verticales tipo barra con una rigidez equivalente a la rigidez de los puntales de cada fila. Las losas son representadas con elementos tipo viga, con un ancho igual a la luz entre pilares y canto igual al canto real de la losa. Los pilares se consideran como elementos tipo viga con una sección igual a la sección real. 


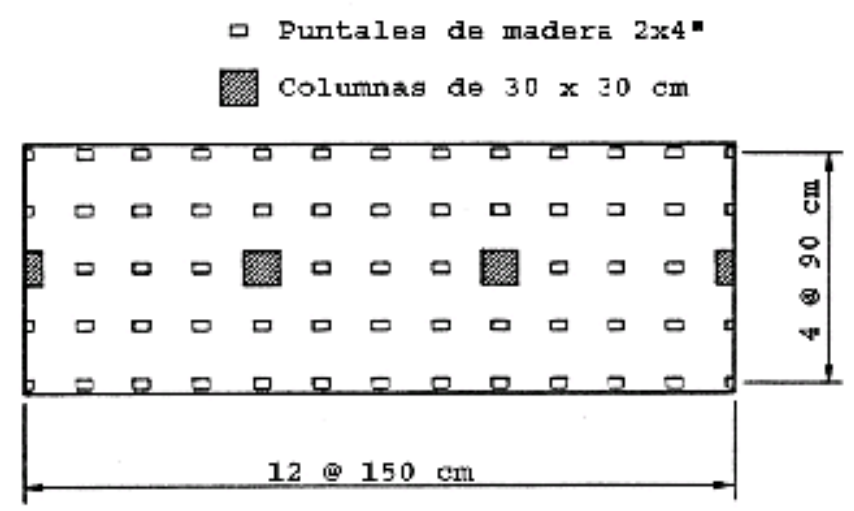

Fig. 2.16 Planta característica del ejemplo usado en el modelo EFM (Stivaros y Halvorsen, 1990)

Se supuso un proceso de construcción con dos plantas cimbradas y una recimbrada, con un ritmo de ejecución de una planta por semana.

Las operaciones de construcción se denotan con una serie de dos números. El primero representa el nivel del forjado que se está edificando. El segundo, señala la fase de construcción; donde 1 representa el hormigonado del forjado más alto, 2 hace referencia a la retirada de los puntales reapuntalados del nivel más bajo, y 3 denota la extracción de puntales del nivel inferior.

Comparando este método con el Método Simplificado (Grundy y Kabaila, 1963) y el Refinado (Liu et al., 1985), se observa que todos los modelos predicen igual el lugar y la etapa de construcción en donde se produce la carga máxima (operación 4-2, correspondiente a la planta 4 y retirada de los puntales de la planta recimbrada). También se observó que después de retirar los puntales de la planta baja (recimbrada), todos los métodos tienden a converger.

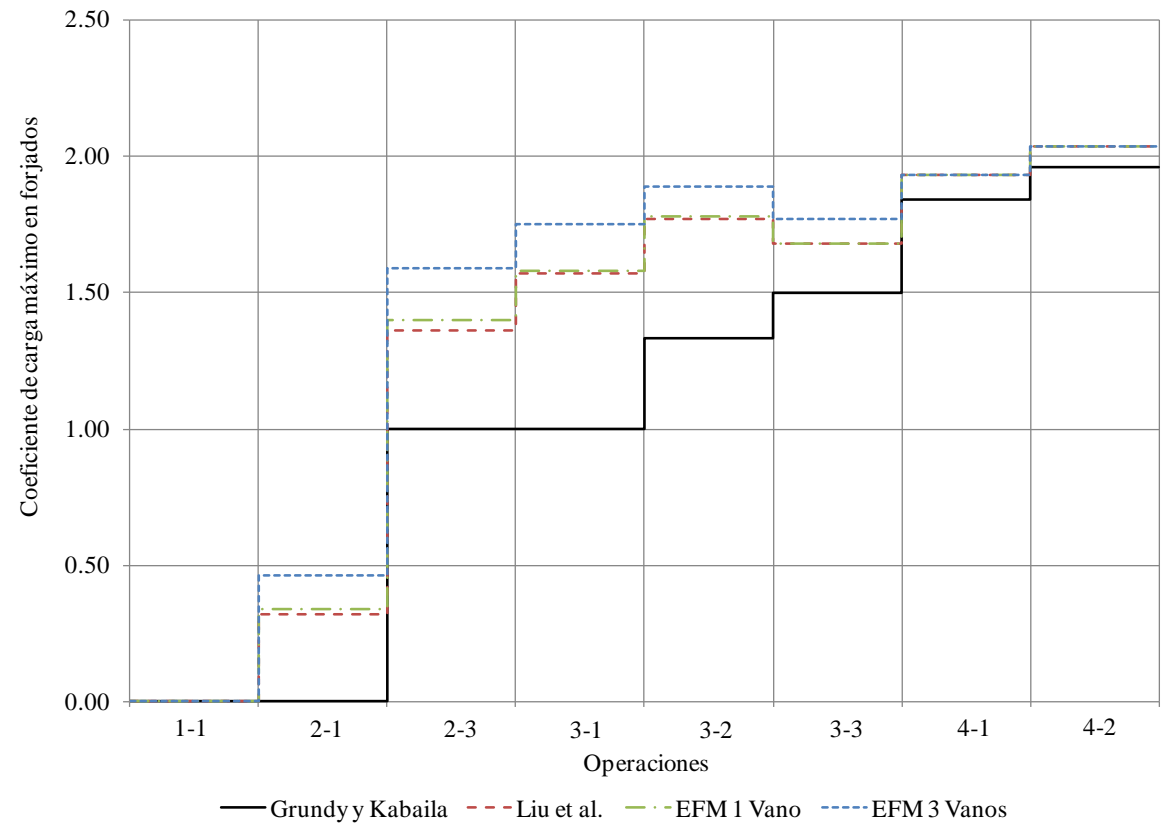

Fig. 2.17 Resultados del modelo EFM comparado con distintos modelos numéricos (Stivaros y Halvorsen, 1990) 
Al comparar el EFM (Stivaros y Halvorsen, 1990) con el Método Simplificado (Grundy y Kabaila, 1963) se concluyó que la carga máxima no difiere en más de un 5\%, pero esta diferencia aumenta en otras etapas de construcción. Las diferencias registradas entre ambos métodos se atribuyeron principalmente a la suposición básica en el Método Simplificado (Grundy y Kabaila, 1963) de la rigidez infinita de puntales

Stivaros y Halvorsen (1990) señalaron que estos resultados corresponden a un proceso constructivo determinado, y que las diferencias podrían ser mayores en otros esquemas constructivos. Es por ello que decidieron estudiar varias secuencias constructivas cambiando el número de forjados que se encontraban cimbrados y recimbrados. Los resultados de las cargas máximas para diferentes combinaciones constructivas se presentan en las Figuras 2.18 y 2.19 .

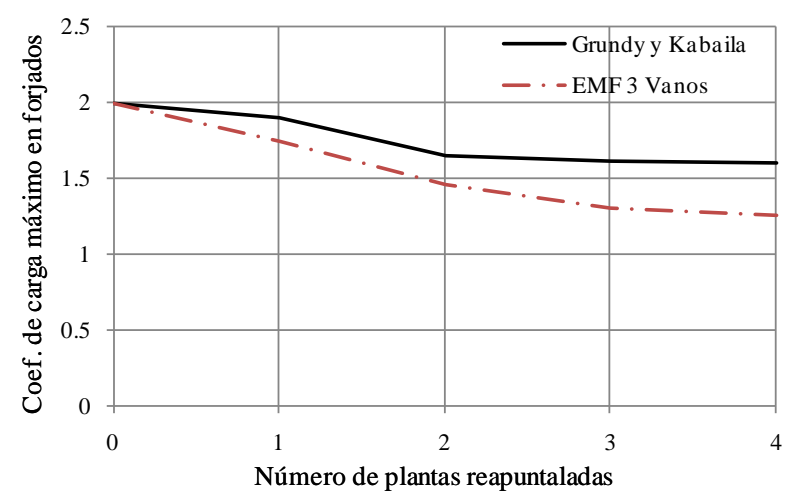

Fig. 2.18 Coeficientes de carga máximos para un forjado cimbrado (Stivaros y Halvorsen, 1990)

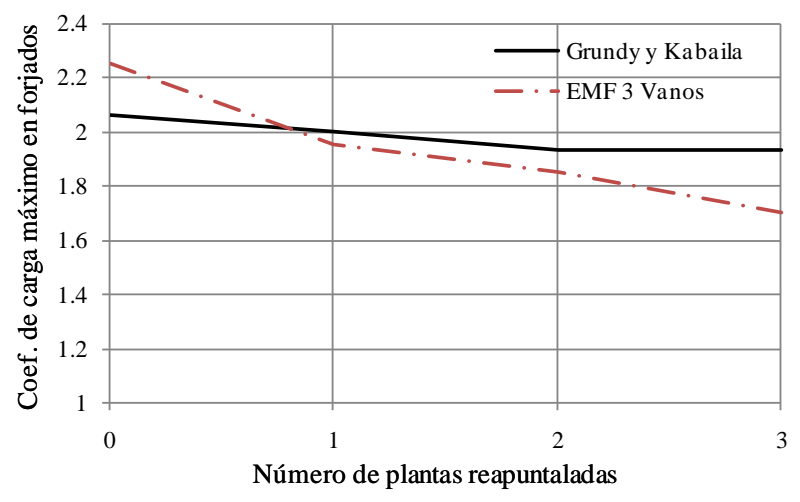

Fig. 2.19 Coeficientes de carga máximos para dos forjados cimbrados (Stivaros y Halvorsen, 1990)

Tal y como se observa en las Figuras 2.16 y 2.17 la carga máxima varía dependiendo del esquema constructivo utilizado. La diferencia entre el EFM (Stivaros y Halvorsen, 1990) y el Método Simplificado (Grundy y Kabaila, 1963) es en algunos casos mayor al 5\%. Estas diferencias aumentan a medida que se aumenta el número de plantas recimbradas, llegando a diferencias de hasta un 30\% para el caso de una planta cimbrada y cuatro recimbradas. Por este motivo, Stivaros y Halvorsen (1990) 
señalan que el coeficiente de corrección de entre 5 y $10 \%$ sugerido por Liu et al. $(1985,1986)$ no es adecuado para todos los sistemas de apuntalamiento.

\subsubsection{Modelo de Mosallam y Chen (1991)}

En 1991, Mosallam y Chen crearon un nuevo modelo bidimensional que pretendía mejorar el desarrollado anteriormente por Liu et al. $(1985,1986)$, así como comparar los resultados con los del Método Simplificado (Grundy y Kabaila, 1963).

Mossallam y Chen (1991) sugieren que la distribución de cargas varía continuamente entre una etapa de la construcción y la siguiente, y por tanto hay que tener en cuenta dicha variación, ya que los métodos anteriores no lo tienen en cuenta y proporcionan una distribución de carga para cada etapa.

Las suposiciones básicas que se realizan en este modelo son las siguientes:

$\checkmark$ Tanto los forjados como los pilares se comportan de forma elástica, asumiendo su rigidez dependiente del tiempo.

$\checkmark$ Los puntales, tanto en el cimbrado como en el recimbrado, actúan como soportes elásticos con una rigidez finita.

$\checkmark$ La unión entre los puntales y los forjados se considera articulada.

$\checkmark$ La rigidez de la cimentación se considera como la correspondiente a la de una losa de cimentación de las mismas características que los forjados.

$\checkmark$ Se asume que los pilares se hormigonan una semana antes que el forjado inmediatamente superior.

$\checkmark \quad$ La distribución de cargas de construcción en puntales y forjados se considera cambiante durante el periodo de tiempo definido entre el hormigonado de forjados consecutivos.

Para el estudio utilizaron un modelo bidimensional igual al empleado por Liu et al. (1985), pero considerando los pilares como elementos de hormigón armado de sección cuadrada de 0.5 x 0.5 m.

Tuvieron en cuenta dos procesos constructivos distintos: tres plantas cimbradas, y dos plantas cimbradas y una recimbrada. En la Tabla 2.7 se muestra la comparativa entre este método con el Método Simplificado (Grundy y Kabaila, 1963) para el caso de tres plantas cimbradas. 
Tabla 2.7 Comparación de coeficientes de carga en forjados y puntales para el Método Simplificado (1963) y el Modelo Mosallam y Chen (1991) para el caso de tres plantas cimbradas.

\begin{tabular}{|c|c|c|c|c|c|c|c|}
\hline \multirow[b]{2}{*}{ Paso } & \multirow[b]{2}{*}{ Nivel } & \multicolumn{2}{|c|}{ Método Simplificado } & \multicolumn{2}{|c|}{ Modelo Mosallam y Chen } & \multicolumn{2}{|c|}{ Comparación } \\
\hline & & $\begin{array}{c}\text { Puntales } \\
\left(\mathbf{P}_{\mathrm{S}}\right)\end{array}$ & $\begin{array}{c}\text { Forjado } \\
\left(\mathbf{F}_{\mathrm{S}}\right)\end{array}$ & $\begin{array}{c}\text { Puntales } \\
\left(\mathbf{P}_{\mathrm{MyC}}\right)\end{array}$ & $\begin{array}{c}\text { Forjado } \\
\left(\mathbf{F}_{\mathrm{My}} \mathrm{C}\right) \\
\end{array}$ & $\mathbf{P}_{\mathrm{S}} / \mathbf{P}_{\mathrm{MyC}}$ & $\mathbf{F}_{\mathrm{S}} / \mathbf{F}_{\mathrm{MyC}}$ \\
\hline 1 & 1 & 1.00 & 0.00 & 1.00 & 0.00 & 1.00 & - \\
\hline \multirow{2}{*}{2} & 2 & 1.00 & 0.00 & 1.00 & 0.00 & 1.00 & - \\
\hline & 1 & 2.00 & 0.00 & 1.51 & 0.86 & 1.32 & 0.00 \\
\hline \multirow{3}{*}{3} & 3 & 1.00 & 0.00 & 1.00 & 0.00 & 1.00 & - \\
\hline & 2 & 2.00 & 0.00 & 1.08 & 1.15 & 1.85 & 0.00 \\
\hline & 1 & 3.00 & 0.00 & 1.34 & 0.85 & 2.24 & 0.00 \\
\hline \multirow{3}{*}{4} & 3 & 0.00 & 1.00 & 0.08 & 0.94 & 0.00 & 1.06 \\
\hline & 2 & 0.00 & 1.00 & 0.06 & 1.03 & 0.00 & 0.97 \\
\hline & 1 & & 1.00 & & 1.07 & & 0.93 \\
\hline \multirow{4}{*}{5} & 4 & 1.00 & 0.00 & 1.00 & 0.00 & 1.00 & - \\
\hline & 3 & 0.66 & 1.34 & 0.70 & 1.42 & 0.94 & 0.94 \\
\hline & 2 & 0.33 & 1.33 & 0.32 & 1.36 & 1.03 & 0.98 \\
\hline & 1 & & 1.33 & & 1.29 & & 1.03 \\
\hline \multirow{4}{*}{6} & 4 & 0.89 & 0.11 & 0.09 & 0.94 & 9.89 & 0.12 \\
\hline & 3 & 0.44 & 1.45 & 0.06 & 1.03 & 7.33 & 1.41 \\
\hline & 2 & & 1.44 & & 1.07 & & 1.34 \\
\hline & 1 & & 1.00 & & 1.00 & & 1.00 \\
\hline \multirow{4}{*}{7} & 5 & 1.00 & 0.00 & 1.00 & 0.00 & 1.00 & - \\
\hline & 4 & 1.55 & 0.45 & 0.71 & 1.41 & 2.18 & 0.32 \\
\hline & 3 & 0.77 & 1.78 & 0.33 & 1.35 & 2.33 & 1.32 \\
\hline & 2 & & 1.78 & & 1.28 & & 1.39 \\
\hline \multirow{4}{*}{8} & 5 & 0.74 & 0.26 & 0.10 & 0.93 & 7.40 & 0.28 \\
\hline & 4 & 1.03 & 0.71 & 0.07 & 1.02 & 14.70 & 0.70 \\
\hline & 3 & & 2.03 & & 1.05 & & 1.93 \\
\hline & 2 & & 1.00 & & 1.00 & & 1.00 \\
\hline \multirow{4}{*}{9} & 6 & 1.00 & 0.00 & 1.00 & 0.00 & 1.00 & - \\
\hline & 5 & 1.40 & 0.60 & 0.72 & 1.40 & 1.94 & 0.43 \\
\hline & 4 & 1.36 & 1.04 & 0.34 & 1.34 & 4.00 & 0.78 \\
\hline & 3 & & 2.36 & & 1.27 & & 1.86 \\
\hline \multirow{4}{*}{10} & 6 & 0.54 & 0.46 & 0.11 & 0.93 & 4.91 & 0.49 \\
\hline & 5 & 0.49 & 1.05 & 0.08 & 1.01 & 6.13 & 1.04 \\
\hline & 4 & & 1.49 & & 1.05 & & 1.42 \\
\hline & 3 & & 1.00 & & 1.00 & & 1.00 \\
\hline
\end{tabular}

En la Tabla anterior se observa que el Método Simplificado (Grundy y Kabaila, 1963) sobreestima las cargas que se presentan durante el proceso constructivo, en relación a los coeficientes obtenidos por el Modelo de Mosallam y Chen (1991). Debido a estas diferencias los autores decidieron determinar la influencia que tienen, en la distribución de cargas en forjados y puntales, las distintas hipótesis contempladas en el modelo.

A continuación se resumen las conclusiones a las que los autores llegaron:

- Considerar que la cimentación es infinitamente rígida, tal y como se hace en el Método Simplificado (Grundy y Kabaila, 1963), tiene un efecto despreciable en la distribución de cargas en forjados. Sin embargo, en la distribución de cargas en puntales existe un incremento de carga de aproximadamente un $11 \%$. 
- Se observó que la influencia que tiene considerar el módulo de elasticidad del hormigón como variable o constante, en la distribución de cargas de construcción en los forjados, es muy pequeña.

- El Método Simplificado (Grundy y Kabaila, 1963) considera los puntales como infinitamente rígidos mientras que el Modelo de Mosallam y Chen (1991) considera que los puntales tienen una rigidez finita. Estos últimos autores observaron que al incrementar la rigidez de los puntales la carga máxima en forjados tiende a disminuir en un 3\%, y la carga máxima en puntales tiende a incrementarse en un 98\%, para el caso de tres plantas cimbradas. En el caso de dos plantas cimbradas y una recimbrada se incrementa la carga máxima un $7 \%$ en forjados y un $50 \%$ puntales.

- El Método Simplificado (Grundy y Kabaila, 1963) asume que la distribución de cargas de construcción se mantiene constante durante el hormigonado de forjados consecutivos. Esta hipótesis lleva a sobreestimar la carga máxima en forjados en un 43\%, y la carga máxima en puntales en un $42 \%$ para el caso de tres plantas cimbradas. Del mismo modo, para el caso de dos plantas cimbradas y una recimbrada, se sobreestima la carga máxima en forjados en un $17 \%$, y en un $16 \%$ la carga máxima en puntales.

\subsubsection{Modelo de Moragues et al. (1992, 1994, 1996)}

En 1994, Moragues et al. (1994) plantearon un modelo numérico bidimensional tras el análisis de los resultados obtenidos en la instrumentación de dos edificios durante su fase constructiva, . Las hipótesis consideradas en el modelo son las siguientes:

$\checkmark$ Comportamiento lineal de los materiales.

Todos los forjados tienen la misma rigidez.

$\checkmark$ La cimentación se considera como infinitamente rígida.

Se consideran puntales metálicos de rigidez conocida.

No se considera el peso propio de los puntales.

Los puntales se consideran apoyados en sus extremos.

$\checkmark$ Se desprecian los efectos de retracción y fluencia.

$\checkmark$ La estructura tipo analizada tiene tres vanos y ocho alturas.

Además, en un segundo paso, se consideraron las siguientes variantes:

Supuesto básico.

$\checkmark$ Variación del módulo de elasticidad del hormigón con la edad.

Descimbrado parcial o clareado.

Variación del módulo de elasticidad del hormigón con la edad y clareado. 
Estos son los primeros autores que estudian la técnica del clareado o recimbrado parcial, la cual es de uso habitual en España. Esta técnica permite la retirada del encofrado y la mitad de los puntales, sin dejar de apuntalar el forjado..

En las Figuras 2.20 y 2.21 se muestran los coeficientes de carga obtenidos con el Modelo de Moragues et al. (1996) para dos y tres juegos de cimbras, respectivamente, y considerando el clareado y la variación del módulo elástico del hormigón con la edad.

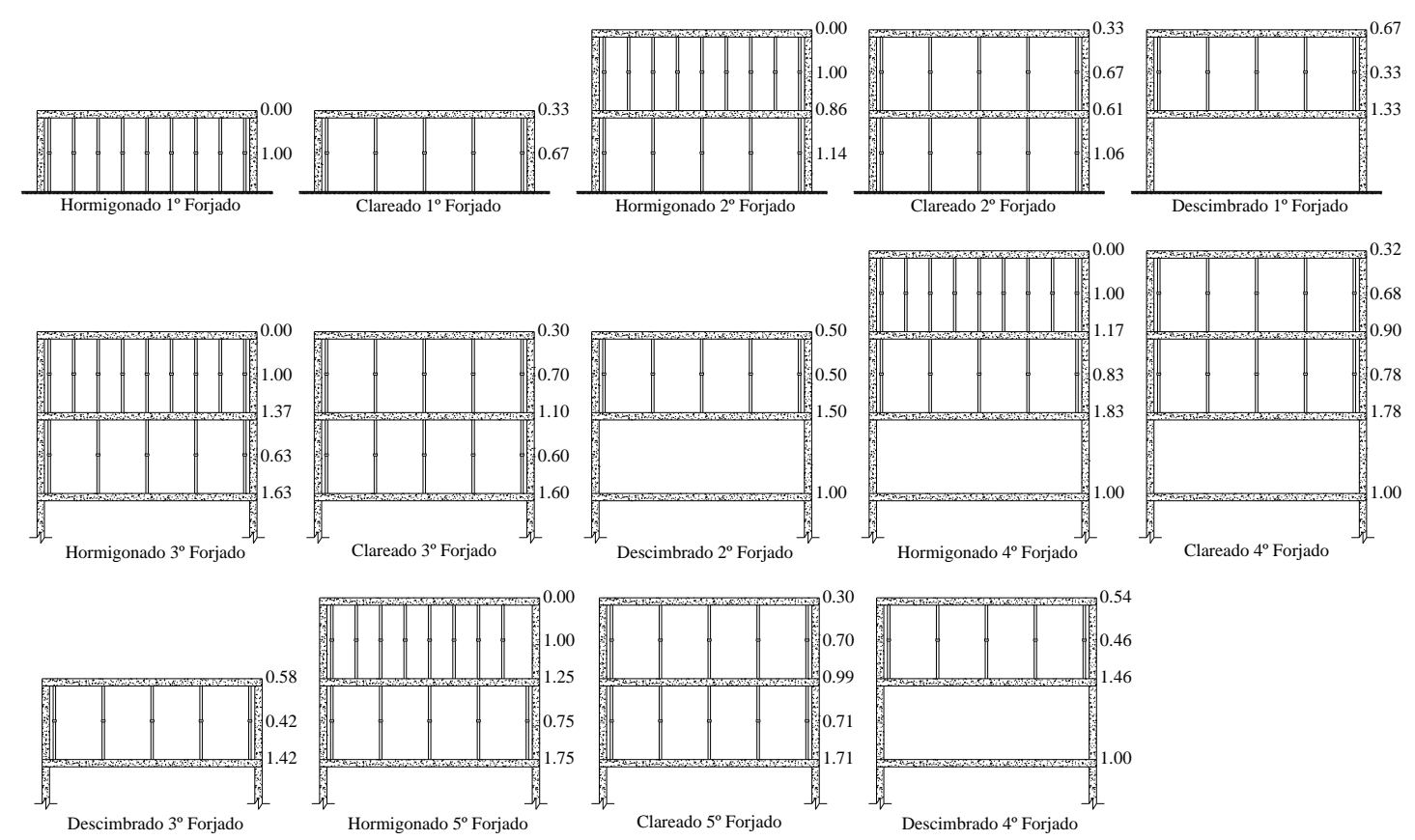

Fig. 2.20 Coeficientes de carga modelo Moragues et al. (1996) para dos plantas cimbradas 


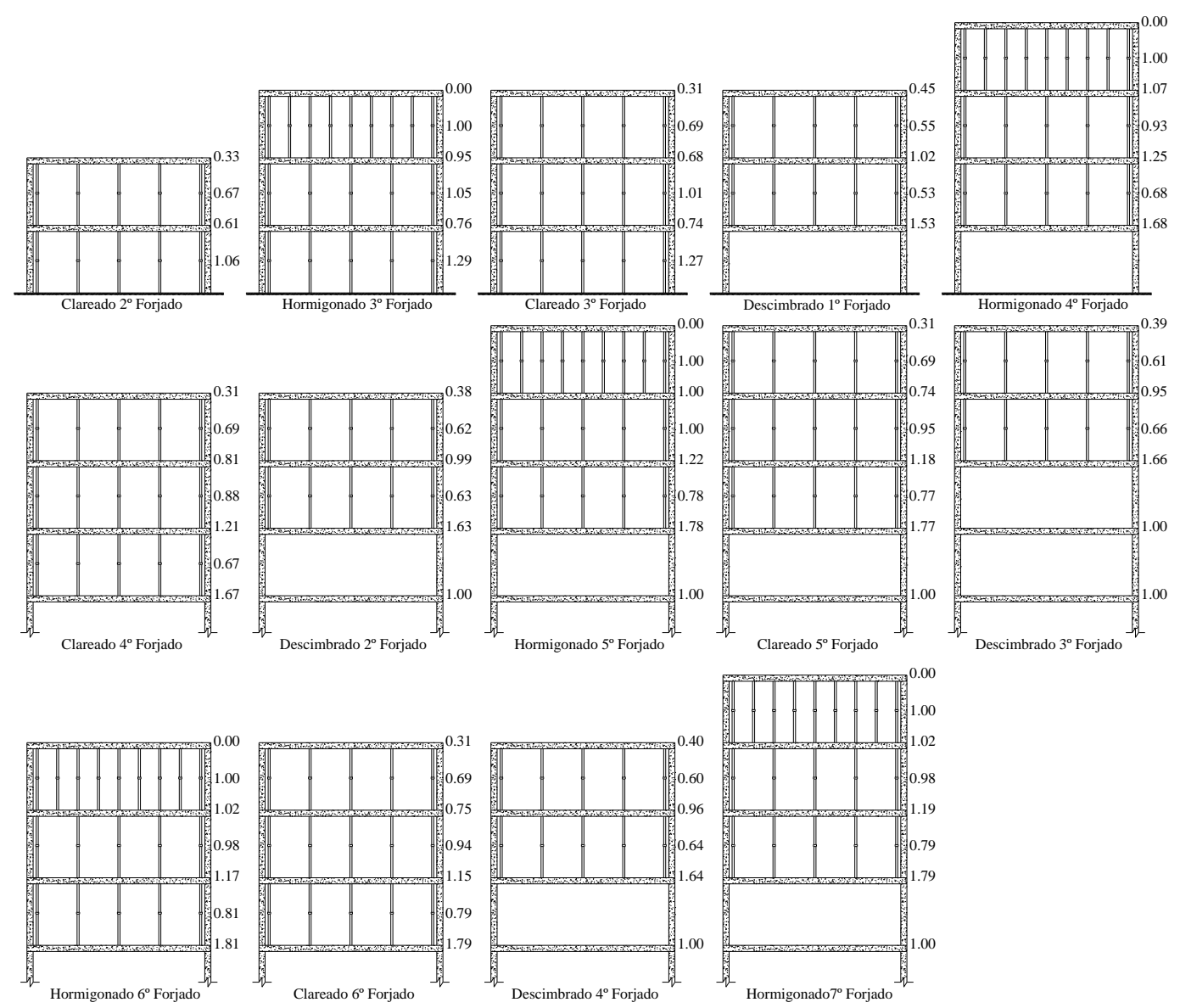

Fig. 2.21 Coeficientes de carga modelo Moragues et al. (1996) para tres plantas cimbradas

A continuación se muestran los resultados y conclusiones obtenidas con las diferentes modelizaciones numéricas realizadas por Moragues et al. $(1994,1996)$ y su comparación con las mediciones realizadas en obra:

- Como indica el Método Simplificado (Grundy y Kabaila, 1963), el forjado más solicitado corresponde a la última planta que fue hormigonada con puntales hasta la cimentación, cuando se tiene sobre él un número de plantas cimbradas igual a los juegos de cimbras que se utilicen. En la Tabla 2.8 se muestran los coeficientes máximos de carga en forjados.

Tabla 2.8 Coeficientes máximos de carga en forjados

\begin{tabular}{ccccccc}
\hline \multirow{2}{*}{ N } & \multicolumn{7}{c}{ Hipótesis } \\
\cline { 2 - 7 } & $\begin{array}{c}\text { Método } \\
\text { Simplificado }\end{array}$ & $\begin{array}{c}\text { No clareado } \\
\text { No E Variable }\end{array}$ & $\begin{array}{c}\text { No Clareado } \\
\text { E Variable }\end{array}$ & $\begin{array}{c}\text { Clareado } \\
\text { No E Variable }\end{array}$ & $\begin{array}{c}\text { Clareado } \\
\text { E Variable }\end{array}$ & $\begin{array}{c}\text { Mediciones } \\
\text { en obra }\end{array}$ \\
\hline 2 & 2.25 & 2.12 & 2.14 & 1.77 & 1.83 & - \\
3 & 2.36 & 2.18 & 2.22 & 1.77 & 1.81 & 1.84 \\
\hline
\end{tabular}

- Las cargas máximas en puntales aparecen siempre en los que apoyan en la cimentación, cuando tienen todos los juegos de cimbra sobre ellos (Tabla 2.9). Una vez retirados los puntales inferiores 
apoyados sobre la cimentación, las cargas máximas en puntales aparecen sobre la última planta que fue cimbrada hasta la cimentación, cuando se hormigona la planta " $n$ " situada sobre ella (Tabla 2.10).

Tabla 2.9 Coeficientes máximos de carga en puntales (Cimentación)

\begin{tabular}{ccccccc}
\hline \multirow{6}{*}{$\mathbf{N}$} & \begin{tabular}{c} 
Método \\
\cline { 2 - 7 } \\
\cline { 2 - 7 }
\end{tabular} & $\begin{array}{c}\text { No clareado } \\
\text { No E Variable }\end{array}$ & $\begin{array}{c}\text { No Clareado } \\
\text { E Variable }\end{array}$ & $\begin{array}{c}\text { Clareado } \\
\text { No E Variable }\end{array}$ & $\begin{array}{c}\text { Clareado } \\
\text { E Variable }\end{array}$ & $\begin{array}{c}\text { Mediciones } \\
\text { en obra }\end{array}$ \\
\hline 2 & 2.00 & 1.54 & 1.73 & 2.78 & 2.96 & - \\
3 & 3.00 & 1.85 & 2.13 & 3.15 & 3.35 & 3.38 \\
\hline
\end{tabular}

Tabla 2.10 Coeficientes máximos de carga en puntales (Casos Restantes)

\begin{tabular}{ccccccc}
\hline & \multicolumn{5}{c}{ Hipótesis } \\
\cline { 2 - 7 } N & $\begin{array}{c}\text { Método } \\
\text { Simplificado }\end{array}$ & $\begin{array}{c}\text { No clareado } \\
\text { No E Variable }\end{array}$ & $\begin{array}{c}\text { No Clareado } \\
\text { E Variable }\end{array}$ & $\begin{array}{c}\text { Clareado } \\
\text { No E Variable }\end{array}$ & $\begin{array}{c}\text { Clareado } \\
\text { E Variable }\end{array}$ & $\begin{array}{c}\text { Mediciones } \\
\text { en obra }\end{array}$ \\
\hline 2 & 1.12 & 1.16 & 2.01 & 2.15 & - & 1.25 \\
3 & 1.34 & 1.44 & 2.49 & 2.60 & 2.40 & 1.55 \\
\hline
\end{tabular}

- La influencia de considerar el incremento del módulo de elasticidad del hormigón con la edad es escasa.

- Los autores consideran la necesidad de realizar más investigaciones que tengan en cuenta aspectos como las deformaciones producidas por el proceso constructivo, la posible fisuración del hormigón joven y la influencia que pueden tener las deformaciones de retracción y térmicas durante el proceso constructivo.

\subsubsection{Modelo numérico de Kwak et al. (2006)}

En 2006, Kwak et al. desarrollaron un modelo numérico para simular el comportamiento dependiente del tiempo de una estructura de hormigón armado teniendo en cuenta el proceso constructivo.

Este modelo numérico tiene en cuenta:

$\checkmark$ La no linealidad del material, incluyendo la fisuración del hormigón y la plastificación de las barras de refuerzo.

$\checkmark$ La no linealidad geométrica debida al efecto P- $\Delta$.

$\checkmark \quad$ La fluencia del hormigón.

$\checkmark$ La variación de las propiedades del hormigón con el tiempo.

Para el estudio utilizaron un modelo bidimensional similar al empleado por Liu et al. (1985), pero con las siguientes variaciones: 
- La deformación axial de los pilares es tenida en cuenta. Estos presentan diferentes dimensiones para las distintas plantas.

- La carga soportada por el forjado se considera como una carga distribuida aplicada en la viga y con valor de $26.46 \mathrm{kN} / \mathrm{m}$.

- Resistencia media a compresión del hormigón a 28 días: $27.5 \mathrm{MPa}$.

- Coeficiente de fluencia último: $\phi_{\mathrm{cr}}^{\infty}=2.5$

- Coeficiente de retracción último: $\varepsilon_{\mathrm{sh}}^{\infty}=300 \cdot 10^{-6}$

- Se considera el efecto de la distancia entre puntales. El estudio se realiza para distancias entre puntales de $\mathrm{S}=0.6,1.0$ y $1.5 \mathrm{~m}$.

- Puntales de madera con una sección rectangular de 100 x 100 mm.

- Módulo elástico de la madera: 7.75 GPa.

- Puntales de acero con una sección circular hueca de $858 \mathrm{~mm}^{2}$.

- Módulo elástico del acero: $2.1 \cdot 10^{5} \mathrm{MPa}$.

- Se consideran diversos ciclos constructivos.

La Tabla 2.11 muestra una comparación entre los coeficiente de carga obtenidos con algunos de los modelos descritos anteriormente y el modelo de Kwak et al. (2006) considerando: (A) la edad del hormigón y puntales de madera y (B) la edad del hormigón, la retracción y fluencia, y puntales de madera.

Tabla 2.11 Comparación de coeficientes de carga en forjados para diferentes métodos y el modelo de Kwak et al. (2006), para el caso de dos forjados cimbrados y uno recimbrado. $\mathrm{S}=1.5 \mathrm{~m}$

\begin{tabular}{|c|c|c|c|c|c|c|c|c|}
\hline \multirow[b]{2}{*}{ Paso } & \multirow[b]{2}{*}{ Nivel } & \multirow[b]{2}{*}{$\begin{array}{c}\text { Método } \\
\text { Simplificado } \\
\text { (Grundy y } \\
\text { Kabaila) }\end{array}$} & \multicolumn{2}{|c|}{ Forjado continuo } & \multicolumn{2}{|c|}{ Forjado aislado } & \multirow[b]{2}{*}{$\begin{array}{l}\text { Método } \\
\text { numérico } \\
\text { de Kwak } \\
\text { et al. (A) }\end{array}$} & \multirow[b]{2}{*}{$\begin{array}{l}\text { Método } \\
\text { numérico } \\
\text { de Kwak } \\
\text { et al. (B) }\end{array}$} \\
\hline & & & $\begin{array}{c}\text { Método } \\
\text { Refinado } \\
\text { (Liu et al.) }\end{array}$ & $\begin{array}{l}\text { Método } \\
\text { Mejorado } \\
\text { (El- } \\
\text { Shahhat y } \\
\text { Chen) }\end{array}$ & $\begin{array}{c}\text { Método } \\
\text { Refinado } \\
\text { (Liu et al.) }\end{array}$ & $\begin{array}{c}\text { Método } \\
\text { Mejorado } \\
\text { (El- } \\
\text { Shahhat y } \\
\text { Chen) }\end{array}$ & & \\
\hline 1 & 1 & 0.00 & 0.00 & 0.00 & 0.00 & 0.00 & 0.00 & 0.00 \\
\hline \multirow{2}{*}{2} & 2 & 0.00 & 0.00 & 0.00 & 0.00 & 0.00 & 0.00 & 0.00 \\
\hline & 1 & 0.00 & 0.37 & 0.37 & 0.07 & 0.07 & 0.15 & 0.14 \\
\hline \multirow{2}{*}{3,4} & 2 & 1.00 & 0.67 & 0.61 & 0.88 & 0.88 & 0.92 & 0.98 \\
\hline & 1 & 1.00 & 1.41 & 1.39 & 1.12 & 1.12 & 1.10 & 1.01 \\
\hline \multirow{3}{*}{5} & 3 & 0.00 & 0.00 & 0.00 & 0.00 & 0.00 & 0.00 & 0.00 \\
\hline & 2 & 1.00 & 1.09 & 1.08 & 1.03 & 1.02 & 0.99 & 1.05 \\
\hline & 1 & 1.00 & 1.60 & 1.59 & 1.20 & 1.21 & 1.16 & 1.07 \\
\hline \multirow{3}{*}{6} & 3 & 0.33 & 0.06 & 0.12 & 0.20 & 0.14 & 0.34 & 0.61 \\
\hline & 2 & 1.34 & 1.19 & 1.29 & 1.27 & 1.32 & 1.25 & 1.14 \\
\hline & 1 & 1.33 & 1.78 & 1.73 & 1.52 & 1.54 & 1.44 & 1.21 \\
\hline \multirow{3}{*}{7,8} & 3 & 0.50 & 0.37 & 0.35 & 0.45 & 0.40 & 0.53 & 0.74 \\
\hline & 2 & 1.50 & 1.67 & 1.78 & 1.55 & 1.60 & 1.8 & 1.29 \\
\hline & 1 & 1.00 & 1.00 & 1.00 & 1.00 & 1.00 & 0.99 & 0.96 \\
\hline \multirow{4}{*}{9} & 4 & 0.00 & 0.00 & 0.00 & 0.00 & 0.00 & 0.00 & 0.00 \\
\hline & 3 & 0.83 & 0.87 & 0.89 & 0.80 & 0.75 & 0.87 & 1.07 \\
\hline & 2 & 1.83 & 1.95 & 1.93 & 1.88 & 1.93 & 1.82 & 1.64 \\
\hline & 1 & 1.34 & 1.21 & 1.21 & 1.31 & 1.31 & 1.33 & 1.41 \\
\hline \multirow{4}{*}{10} & 4 & 0.11 & 0.03 & 0.14 & 0.02 & 0.02 & 0.37 & 0.42 \\
\hline & 3 & 0.94 & 0.92 & 0.92 & 0.86 & 0.86 & 0.85 & 1.01 \\
\hline & 2 & 1.95 & 2.06 & 2.24 & 2.12 & 2.12 & 1.79 & 1.59 \\
\hline & 1 & 1.00 & 1.00 & 1.00 & 1.00 & 1.00 & 0.99 & 0.97 \\
\hline
\end{tabular}


Los autores concluyeron que si no se tiene en cuenta la variación de las deformaciones del hormigón con el tiempo en el diseño del sistema de apuntalamiento, se producen resultados conservadores para las cargas de los forjados, mientras que se subestiman las cargas de los puntales. Además, tras estudiar diferentes ciclos constructivos llegaron a la conclusión que el sistema más efectivo era el de 2 plantas cimbradas y una recimbrada.

\subsubsection{Estudio realizado por Díaz (2008)}

En 2008, Díaz (2008) realizó el análisis en 2D de un pórtico de estructura de edificación con vigas planas de 5 vanos y 9 plantas, que recibe un forjado autoportante de $6 \mathrm{~m}$. de luz en las dos direcciones, con un ritmo de ejecución de una semana por planta con tres niveles de cimbrado. Dicho análisis lo llevó a cabo mediante el programa de elementos finitos SAP 2000,

El autor estudió el cimbrado de plantas consecutivas, considerando cuatro diferentes hipótesis:

$\checkmark$ Los puntales tienen una rigidez infinita y están apoyados sobre un suelo de rigidez infinita.

$\checkmark$ Los puntales tienen una rigidez finita y están apoyados sobre un suelo de rigidez infinita.

$\checkmark$ Los puntales tienen una rigidez infinita y están apoyados sobre un suelo de rigidez finita

$\checkmark$ Los puntales tienen una rigidez finita y están apoyados sobre un suelo de rigidez finita.

Además, Díaz (2008) considera que todas las plantas de hormigón tienen el mismo módulo elástico, excepto la recién hormigonada cuyo módulo se considera como nulo.

De los resultados del estudio el autor concluyó que:

$\checkmark$ Al considerar que la cimentación tiene una rigidez finita, aumentan las cargas sobre los forjados de los tres primeros niveles respecto a los casos de considerar la cimentación como infinitamente rígida. Sin embargo, los valores del coeficiente de carga son inferiores a los que se producen en los mismos tramos, una vez que se retiran los puntales que llegan hasta la cimentación.

$\checkmark$ Suponer rigidez finita en los puntales disminuye los valores máximos de los coeficientes de carga en los forjados, ya que produce un mayor reparto de las cargas entre los forjados que soportan puntales. Esto conduce a que los forjados situados en los niveles superiores de cada fase de hormigonado, estén sometidos a mayores cargas que en el caso de suponer rigidez infinita en los puntales.

$\checkmark$ Las cargas actuantes sobre las plantas durante las fases de construcción, alcanzan los siguientes valores:

- Si se considera rigidez infinita en los puntales, el valor máximo es un 9\% superior al valor mayorado de la carga considerada en proyecto para el cálculo de la estructura.

- Si se considera rigidez finita en los puntales, el valor máximo es un $24 \%$ inferior al valor mayorado de la carga considerada en proyecto para el cálculo de la estructura. 
Díaz (2008) también estudió la influencia de algunos factores como la variación del módulo de elasticidad del hormigón con la edad, la variación en las dimensiones de los pilares, variación de rigidez de los puntales comerciales, descimbrado de dos vanos consecutivos manteniendo cimbrados otros tres y el descimbrado de un vano desde el centro hacia los apoyos, encontrando que se alcanza como máximo un $4 \%$ de variación frente a los resultados obtenidos en el caso general.

\subsubsection{Modelo numérico de Alvarado et al. (2010)}

Alvarado et al. (2010) desarrollaron un modelo numérico en 3D, no lineal, en el que se incluye un cálculo evolutivo, cuyo objeto es simular el proceso constructivo considerando la evolución de las propiedades del hormigón con el tiempo.

En una primera fase se consideró un proceso de CCD, para poder así verificar el modelo de elementos finitos con los resultados obtenidos del estudio experimental realizado por Alvarado ${ }^{1}$ (2009) y Alvarado et al. (2009).

Las hipótesis adoptadas para realizar el modelo de elementos finitos fueron las siguientes:

Se asume un comportamiento elástico y lineal del forjado de hormigón armado, considerando la variación de su rigidez en el tiempo.

$\checkmark$ Los pilares se simulan con un comportamiento elástico y lineal, y se considera la variación de su rigidez con respecto al tiempo.

$\checkmark$ Los puntales de acero son considerados como elementos elásticos con una rigidez finita, apoyados en sus extremos. Tienen una sección transversal de $289 \mathrm{~mm}^{2}$ y un módulo de elasticidad de 210 GPa.

$\checkmark$ Los tableros de encofrado son considerados como elementos con un comportamiento elástico y lineal y de rigidez finita. Los tableros son de madera, con un espesor de $27 \mathrm{~mm}$ y un módulo de elasticidad de $10 \mathrm{GPa}$.

$\checkmark$ Las sopandas son simuladas como elementos con un comportamiento elástico y lineal, con una rigidez finita. Las sopandas son de acero, con una sección transversal de $406 \mathrm{~mm}^{2}$ y un módulo de elasticidad de $210 \mathrm{GPa}$.

$\checkmark \quad$ La cimentación se considera infinitamente rígida. Esta hipótesis se adopta a partir de establecer que el conjunto de puntales del primer forjado apoyan directamente sobre la losa de cimentación.

$\checkmark$ No se consideran los efectos de fluencia y retracción en el hormigón, ni los cambios de temperatura en los diferentes elementos de la estructura.

Los resultados del modelo se verificaron con los resultados del estudio experimental realizado por Alvarado et al. (2009). En la Tabla 2.12 se muestra la comparación entre ambos.

\footnotetext{
${ }^{1}$ La descripción de este estudio experimental se detalla en el apartado 2.3.2.9
} 
Tabla 2.12 Validación del modelo numérico de Alvarado et al. (2010) con los resultados experimentales de Alvarado et al. (2009)

\begin{tabular}{lcccc}
\hline \multicolumn{1}{c}{ Operación } & Nivel & $\begin{array}{c}\text { (a) Carga media } \\
\text { experimental } \\
\left(\mathbf{K N} / \mathbf{m}^{\mathbf{2}}\right)\end{array}$ & $\begin{array}{c}\text { (b) Carga media } \\
\text { modelo numérico } \\
\left(\mathbf{K N} / \mathbf{m}^{\mathbf{2}}\right)\end{array}$ & $(\boldsymbol{a}) /(\boldsymbol{b})$ \\
\hline Hormigonado Forjado 1 & 1 & 5.46 & 5.52 & 0.99 \\
\hline Clareado Forjado 1 & 1 & 3.07 & 3.41 & 0.90 \\
\hline Hormigonado Forjado 2 & 2 & 5.60 & 5.80 & 0.97 \\
& 1 & 4.48 & 6.60 & 0.68 \\
\hline Clareado Forjado 2 & 2 & 2.91 & 2.90 & 1.00 \\
& 1 & 3.86 & 5.33 & 0.72 \\
\hline Descimbrado Forjado 1 & 2 & 1.57 & 1.39 & 1.13 \\
\hline Hormigonado Forjado 3 & 3 & 5.50 & 5.80 & 0.95 \\
& 2 & 3.07 & 3.04 & 1.01 \\
\hline Clareado Forjado 3 & 3 & 3.12 & 2.77 & 1.13 \\
& 2 & 2.78 & 2.19 & 1.27 \\
\hline Carga sobre Forjado 3 & 3 & 4.33 & 5.37 & 0.81 \\
& 2 & 3.38 & 3.36 & 1.01 \\
\hline Descimbrado Forjado 2 & 3 & 3.67 & 4.23 & 0.87 \\
\hline
\end{tabular}

Tras validar el modelo numérico con los resultados de Alvarado et al. (2009), el siguiente paso del estudio fue realizar modelos de elementos finitos similares al planteado, con el objeto de analizar los procesos CD y CRD para el modelo experimental.

En ambos casos se consideran, al igual que en el estudio experimental, 2 juegos de puntales. El proceso constructivo simulado fue el de 2 plantas cimbradas, en el caso de $\mathrm{CD}$, y de una planta cimbrada y otra recimbrada, para el proceso de CRD,

De la comparación entre el proceso de CCD y el proceso de CD los autores concluyeron que:

- Al realizar la operación de clareado dentro de un proceso de $\mathrm{CCD}$, los forjados asumen una fracción importante de carga. Esto reduce la carga media que soportan los puntales.

- La carga media máxima en puntales, para ambos procesos, se presenta en los puntales del forjado 1 , en el momento del hormigonado del forjado 2.

- El conjunto de la carga asumida por los puntales es inferior en el proceso CCD que en el CD aunque, al reducirse a menos de la mitad el número de puntales en una planta en el CCD, las cargas individuales por puntal pueden ser mayores.

- El proceso CCD emplea un 53\% de tableros de encofrado y un $66 \%$ de puntales y sopandas, menos respecto de los que precisa el proceso $\mathrm{CD}$.

De la comparación entre el proceso de CCD y el proceso de CRD concluyeron que:

- Las cargas medias en puntales son superiores para el proceso CCD que en el proceso de CRD. Por otro lado, el número puntales en el proceso de CCD es del orden del 50\% de los puntales en un 
proceso de CRD. Por este motivo, las cargas individuales en puntales serán superiores en el proceso CCD.

- Los puntales en el proceso de CRD nunca asumen una carga superior al peso propio de cada uno de los forjados. En el proceso CCD llegan a asumir, en el peor momento, una carga del orden del $118 \%$ del peso propio de un forjado (forjado 1 tras hormigonado del forjado 2).

- El proceso CCD emplea un $67 \%$ de los puntales y un $133 \%$ de las sopandas que precisa el proceso CRD.

\subsubsection{Estudios Experimentales}

A continuación se muestran algunos de los estudios experimentales basados en la distribución de carga entre forjados y puntales durante la construcción de forjados consecutivos hormigonados in situ. Estos estudios han buscado la validación de algunos de los modelos expuestos en el apartado anterior.

\subsubsection{Medidas realizadas por Agarwal y Gardner (1974)}

En 1974, Agarwal y Gardner instrumentaron dos edificios en Canadá con el fin de conocer mejor las cargas que se producían en los puntales durante el proceso constructivo.

El primero de los edificios estaba situado en Alta Vista Drive, Ottawa, y constaba de 22 plantas destinadas a apartamentos. Los forjados eran de losa maciza de $0.20 \mathrm{~m}$ de canto y las luces máximas de los vanos eran de $6.25 \mathrm{~m}$. En su construcción se utilizaron tres niveles de forjados cimbrados y cuatro recimbrados. El ritmo de construcción era de dos plantas por semana. La primera medición se realizó en la $7^{\mathrm{a}}$ planta, terminando el estudio en la $13^{\mathrm{a}}$, completando así un ciclo total de construcción. Las mediciones se realizaron con bandas extensométricas de $5 \mathrm{~mm}$ de longitud colocadas en el cuerpo de los puntales.

El segundo edificio, destinado a oficinas, estaba ubicado en la Place du Portage en Hull, Quebec. Tenía 27 alturas, con forjados de los maciza de hormigón armado de $0.25 \mathrm{~m}$ de canto hasta la planta decimocuarta, y de $0.20 \mathrm{~m}$ en el resto. La luz máxima era de $7.62 \mathrm{~m}$. El ritmo de construcción fue de una planta por semana con tres juegos de cimbra (sin recimbrado). Las mediciones se realizaron desde la planta $19^{\mathrm{a}}$ hasta la $22^{\mathrm{a}}$, completando el ciclo de construcción. Al igual que en el otro edificio, se utilizaron bandas extensométricas adheridas a los puntales como elemento de medida.

De la comparación de las mediciones experimentales con los resultados obtenidos a partir del Método Simplificado (Grundy y Kabaila, 1963), los autores concluyeron que dicho método podía considerarse adecuado para la estimación de cargas en forjados y puntales durante el proceso constructivo, ya que las diferencias obtenidas eran de un 5-10\%. Sin embargo, consideran que sería necesario realizar más investigaciones teniendo en cuenta las diferentes variables que aparecen durante el proceso constructivo. 


\subsubsection{Medidas realizadas por Lasisi y $\mathrm{Ng}$ (1979)}

Unos años más tarde, en 1979, Lasisi y Ng instrumentaron el edificio $\mathrm{N}^{\circ} 5$ del Gobierno de Canadá en Ottawa. Se trataba de un edificio de oficinas de 15 plantas con forjados de losa maciza de hormigón armado de 0.25-0.28 m de canto. Entre el hormigonado de una planta y el hormigonado de la planta inmediatamente superior transcurría un plazo de 10 días. Se utilizaron tres juegos de cimbras, con una planta cimbrada y dos recimbradas. Las medidas se tomaron desde el hormigonado de la $7^{\mathrm{a}}$ planta hasta el descimbrado de la $11^{\text {a }}$. Se utilizaron cuatro células de carga instaladas bajo los puntales metálicos para la instrumentación de un vano interior.

Lasisi (1979) propuso una pequeña modificación al Método Simplificado (Grundy y Kabaila, 1963) que consistía en considerar las sobrecargas de construcción durante las fases de hormigonado. Comparando las medidas experimentales con las teóricas, obtuvo buenas aproximaciones para las cargas máximas en puntales. Sin embargo, observó que las cargas en puntales que se produjeron en el recimbrado eran considerablemente menores que las obtenidas teóricamente.

\subsubsection{Medidas realizadas por Moragues (1992)}

Moragues et al. (1992) decidieron estudiar las cargas que se producen en la construcción de un edificio, considerando los medios habituales usados en España, mediante la instrumentación de dos edificios ubicados en Benidorm (Alicante) y Alicante.

El primero de ellos, situado en Benidorm (Alicante), se trataba de un edificio de apartamentos de 28 plantas, con forjados reticulares de $0.28 \mathrm{~m}$ de canto y pantallas de arriostramiento frente a esfuerzos de viento. La cimbra estaba formada por puntales metálicos arriostrados, con una sección transversal de $181 \mathrm{~mm}^{2}$, posicionados en una retícula de $0.80 \times 0.80 \mathrm{~m}$, igual a la retícula del forjado. El sistema de cimbrado dispone de un dispositivo en la cabeza del puntal que permite retirar el tablero de encofrado y la mitad de los puntales sin dejar de apuntalar el edificio, realizando así un descimbrado parcial o clareado.

En el proceso constructivo se mantenía una planta cimbrada y dos clareadas. Se obtuvieron datos desde la cimentación hasta el hormigonado de la $9^{a}$ planta. Para la medición se utilizaron un total de 12 células de carga (4 por planta) situadas en la base de los puntales.

Analizando las mediciones, los autores determinaron que la carga máxima en puntales se produce cuando están todos los juegos de cimbras, hasta la cimentación. Este valor difiere del teórico esperado al aplicar el método de Grundy y Kabaila (1963), puesto que, de cargar hasta tres veces el peso propio del forjado, se pasó a medir un coeficiente de 1.69. En cuanto a las cargas sobre forjados, se obtuvo que el caso más desfavorable se presenta en el forjado que fue cimbrado hasta la cimentación, cuando sobre él existen tantos forjados como juegos de cimbras utilizados. La diferencia con el Método Simplificado de Grundy y Kabaila (1963), es que el coeficiente de carga que se obtuvo fue de 1.84 veces el peso propio, bastante alejado del valor 2.36 propuesto por Grundy y Kabaila (1963).

En las Tablas 2.8, 2.9 y 2.10, del apartado 2.3.2.3 se muestra una comparación de los coeficientes máximos de carga medidos en obra, y los teóricos esperados (estos coeficientes siempre se corresponden a tomar como unidad el peso propio del forjado). 
El segundo edificio instrumentado por Moragues et al. (1992), estaba situado en la Avda. General Marvá de Alicante. Consistía en una estructura de forjados reticulares, de $27+4 \mathrm{~cm}$ de canto con nervios cada $0.80 \mathrm{~m}$, con un total de 12 forjados. En el proceso constructivo se mantenía una planta cimbrada y dos clareadas, con un ritmo de construcción de 1 planta cada 10 días. Se realizaron mediciones a partir del hormigonado del forjado 6 , utilizando células de carga.

Los resultados obtenidos en este edificio fueron muy semejantes a los obtenidos en el edificio de Benidorm aunque con una ligera mayor dispersión. Moragues et al. (1992) atribuye este hecho a que en este edificio la cimbra no tenía unas condiciones de modulación estrictas, por lo que la distribución de puntales no era del todo uniforme.

\subsubsection{Medidas realizadas por Ambrose et al. (1994)}

Durante la construcción de un edificio en Burlington (Vermont), Ambrose et al. (1994) instrumentaron puntales bajo un forjado recién hormigonado, instalando células de carga en la base de dichos puntales. El objetivo de la experimentación consistía en medir la evolución de las cargas en los puntales en el tiempo durante las primeras 72 horas posteriores al hormigonado del forjado.

Una vez transcurridas las 72 horas, las cargas en los puntales descendieron hasta llegar a un $75 \%$ de su carga inicial, debido al aumento de rigidez de la losa de hormigón. De esta forma Ambrose et al. (1994), concluyeron que durante el proceso de curado del hormigón se presenta una redistribución del peso propio del forjado, considerando que el forjado va asumiendo un mayor porcentaje de carga hasta que termina el proceso de curado.

\subsubsection{Medidas realizadas por Rosowsky et al. (1997)}

En 1997, Rosowsky et al. realizaron un análisis cualitativo de las mediciones realizadas durante la construcción de un edificio penitenciario en Beckley (West Virginia) un año antes. Se instrumentaron tres áreas distintas. Dos zonas más pequeñas donde se colocaron cuatro puntales instrumentados por zona, y un área mayor donde 8 de 16 puntales se encontraban instrumentados.

Rosowsky et al. (1997) estudiaron la evolución de cargas en puntales durante los tres o cuatro primeros días después del hormigonado del forjado, controlando que las sobrecargas de ejecución aplicadas sobre el forjado fueran relativamente bajas. Las variaciones registradas durante este periodo de tiempo fueron diferentes según la zona instrumentada, presentándose mayores variaciones en la zona con una mayor área. En ambas zonas las variaciones de carga en los puntales fueron de carácter cíclico (diario) aunque con una tendencia decreciente con el tiempo. Además, los autores concluyeron que la carga de diseño (incluyendo sobrecargas) sugerida por el American Concrete Institute (ACI, 1988, 1989) era adecuada para el caso estudiado.

\subsubsection{Medidas realizadas por Beeby (2001b)}

Beeby (2001b) realizó mediciones de la distribución de cargas en puntales y forjados durante la construcción del edificio European Concrete Building Project. Este edificio de siete plantas situado en Cardington (Reino Unido) fue construido en condiciones controladas de laboratorio y con fines exclusivamente de investigación. 
Todos los forjados eran losas de hormigón armado de $0.25 \mathrm{~m}$ de canto y con un peso propio de 6.25 $\mathrm{kN} / \mathrm{m}^{2}$ (densidad del hormigón $2500 \mathrm{~kg} / \mathrm{m}^{3}$ ). También se consideró una sobrecarga de construcción de $0.75 \mathrm{kN} / \mathrm{m}^{2}$. Se instrumentaron dos vanos, uno interior y otro de medianera. Los ciclos de construcción de la estructura quedaron definidos, para dos juegos de cimbras, con una planta cimbrada y una planta recimbrada.

En la Tabla 2.13 se muestran, para la operación de hormigonado, los coeficientes de carga medidos en puntales, así como una comparación con el método desarrollado por Beeby (2001a).

Tabla 2.13 Coeficientes de cargas en puntales de los resultados experimentales y los obtenidos con el Método de Beeby (2001 a).

\begin{tabular}{cccccc}
\hline \multirow{2}{*}{ Operación } & \multirow{2}{*}{ Nivel } & \multicolumn{2}{c}{ Medición } & \multicolumn{2}{c}{$\begin{array}{c}\text { Valor estimado Beeby } \\
\text { (2001a) }\end{array}$} \\
\cline { 3 - 6 } & & Vano 1 & Vano 2 & Vano 1 & Vano 2 \\
\hline Hormigonado Forjado 3 & 2 & 0.273 & 0.244 & 0.320 & 0.252 \\
\hline Hormigonado Forjado 4 & 3 & 0.362 & 0.303 & 0.343 & 0.274 \\
\hline Hormigonado Forjado 5 & 2 & 0.116 & 0.080 & 0.117 & 0.078 \\
\hline Hormigonado Forjado 6 & 4 & 0.354 & 0.387 & 0.379 & 0.340 \\
\hline Hormigonado Forjado 7 & 5 & 0.348 & 0.281 & 0.315 & 0.261 \\
\hline
\end{tabular}

\subsubsection{Medidas realizadas por Fang et al. (2001b)}

Fang et al. (2001b) realizaron uno de los programas experimentales más extensos hasta ese momento durante la construcción de un edificio de hormigón armado de plantas sucesivas en Beijing (China). Para poder realizar las medidas colocaron 2 bandas extensométricas de forma simétrica en la caña del puntal. Instrumentaron un total de 52 puntales distribuidos en 2 plantas (26 puntales instrumentados por planta).

Los forjados estaban constituidos por losas macizas de hormigón armado y vigas. El canto del forjado era de $0.11 \mathrm{~m}$ con un hormigón de $22 \mathrm{MPa}$, y una luz entre pilares de $3.60 \mathrm{~m}$. El ciclo constructivo consistió en mantener dos forjados cimbrados consecutivos, con un ritmo de ejecución de 15 días por planta.

Se realizaron mediciones desde el hormigonado del segundo forjado hasta el cuarto. La Tabla 2.14 muestra las cargas obtenidas en cada fase constructiva considerando como la unidad el peso propio del forjado. 
Tabla 2.14 Coeficientes de carga en puntales medidos por Fang et al. (2001b)

\begin{tabular}{cccc}
\hline Paso & Operación & Nivel & Puntales \\
\hline \multirow{2}{*}{1} & Hormigonado & 2 & 0.752 \\
& Forjado 2 & 1 & Sin datos \\
\hline \multirow{2}{*}{2} & 1 día después & 2 & 0.580 \\
& hormigonado forjado 2 & 1 & Sin datos \\
\hline 3 & Descimbrado forjado 1 & 2 & 0.460 \\
\hline \multirow{2}{*}{4} & Hormigonado forjado & 3 & 0.783 \\
& 3 & 2 & 0.777 \\
\multirow{2}{*}{5} & 1 día después & 3 & 0.697 \\
& hormigonado forjado 3 & 2 & 0.748 \\
\hline \multirow{2}{*}{6} & Descimbrado forjado 2 & 3 & 0.456 \\
\hline \multirow{2}{*}{8} & Hormigonado forjado & 4 & 0.895 \\
& 4 & 3 & 0.769 \\
\hline 9 & hormigonado forjado 4 & 3 & 0.658 \\
\hline
\end{tabular}

Los autores observaron que durante el curado del hormigón, en los forjados recién hormigonados, la carga de los puntales desciende, empezando a soportar el forjado parte de su peso propio.

Además, Fang et al. (2001b) compararon los resultados experimentales con las cargas estimadas usando el Método Simplificado (Grundy y Kabaila, 1963), encontrando diferencias de hasta un 27.2\% en la estimación de la cargas en los forjados. También compararon sus resultados con su modelo numérico (descrito en el apartado 2.3.1.8), encontrando que las estimaciones realizadas con este método diferían sólo un 5.3\%, considerándolo como aceptable para estimar la distribución de cargas tanto en puntales como en los forjados.

\subsubsection{Medidas realizadas por Puente et al. (2007)}

Puente et al. (2007) midieron las cargas en puntales durante la construcción de un edificio situado en Getaria (Guipúzcoa, España) con el objetivo de conocer las cargas reales transmitidas por los puntales. El ciclo constructivo llevado a cabo fue de 3 plantas cimbradas.

El edificio estaba constituido por 7 plantas de viviendas más 4 sótanos. Se instrumentaron únicamente los sótanos con 34 puntales instrumentados por planta. Los puntales fueron instrumentados mediante 4 bandas extensométricas por puntal, conectadas a puente completo de forma que dos de ellas están activas en ramas opuestas del puente de Wheatsone, eliminando de este modo la influencia de la deformación por flexión del puntal. Las otras dos bandas se situaron en las ramas libres del puente para realizar una compensación por temperatura.

La Tabla 2.15 muestra una comparación entre los resultados obtenidos con diferentes métodos de estimación de cargas con los registrados experimentalmente en la obra de Getaria (considerando como unidad el peso propio del forjado). 
Tabla 2.15 Comparación entre las medidas experimentales de Puente et al. (2007) con diferentes métodos de estimación de cargas

\begin{tabular}{|c|c|c|c|c|c|c|c|c|}
\hline Operación & Nivel & $\begin{array}{c}\text { Método } \\
\text { Simplificado } \\
\text { (Grundy y } \\
\text { Kabaila) } \\
\end{array}$ & $\begin{array}{c}\text { Método } \\
\text { Refinado } \\
\text { 2D (Liu et } \\
\text { al) } \\
\end{array}$ & $\begin{array}{c}\text { Método } \\
\text { Refinado } \\
\text { 3D (Liu et } \\
\text { al) } \\
\end{array}$ & $\begin{array}{c}\text { Modelo } \\
\text { Mosallam y } \\
\text { Chen 2D }\end{array}$ & $\begin{array}{c}\text { Modelo } \\
\text { Mosallam y } \\
\text { Chen 3D }\end{array}$ & $\begin{array}{c}\text { Método } \\
\text { Simplificado } \\
\text { Mejorado } \\
\text { (Duan y Chen) } \\
\end{array}$ & $\begin{array}{c}\text { Medida } \\
\text { Experimenta }\end{array}$ \\
\hline $\begin{array}{c}\text { Hormigón } \\
\text { sótano -4 }\end{array}$ & -4 & 1.00 & 1.00 & 1.00 & 1.00 & 1.00 & 1.00 & 0.99 \\
\hline Hormigón & -3 & 1.00 & 1.00 & 1.00 & 1.00 & 1.00 & 1.00 & 1.02 \\
\hline sótano -3 & -4 & 2.00 & 1.41 & 1.51 & 1.10 & 0.97 & 1.59 & 1.35 \\
\hline \multirow{3}{*}{$\begin{array}{c}\text { Hormigón } \\
\text { sótano -2 }\end{array}$} & -2 & 1.00 & 1.00 & 1.00 & 1.00 & 1.00 & 1.00 & 1.07 \\
\hline & -3 & 2.00 & 1.33 & 1.41 & 0.95 & 0.83 & 1.48 & 1.35 \\
\hline & -4 & 3.00 & 1.58 & 1.73 & 1.05 & 1.03 & 1.86 & 1.53 \\
\hline \multirow{2}{*}{$\begin{array}{l}\text { Descimb. } \\
\text { sótano }-4\end{array}$} & -2 & 0.00 & 0.84 & 0.79 & 0.37 & 0.31 & 0.75 & 0.95 \\
\hline & -3 & 0.00 & 0.84 & 0.79 & 0.30 & 0.31 & 0.74 & 0.84 \\
\hline \multirow{3}{*}{$\begin{array}{l}\text { Hormigón } \\
\text { sótano -1 }\end{array}$} & -1 & 1.00 & 1.00 & 1.00 & 1.00 & 1.00 & 1.00 & 0.94 \\
\hline & -2 & 0.67 & 1.17 & 1.17 & 0.82 & 0.70 & 1.21 & 1.23 \\
\hline & -3 & 0.33 & 0.95 & 0.93 & 0.45 & 0.49 & 0.91 & 0.96 \\
\hline \multirow{2}{*}{$\begin{array}{l}\text { Descimb. } \\
\text { sótano -3 }\end{array}$} & -1 & 0.89 & 0.92 & 0.89 & 0.34 & 0.32 & 0.87 & 0.81 \\
\hline & -2 & 0.44 & 0.91 & 0.88 & 0.38 & 0.36 & 0.84 & 0.86 \\
\hline $\begin{array}{l}\text { Descimb. } \\
\text { sótano -2 }\end{array}$ & -1 & 0.67 & 0.70 & 0.63 & 0.26 & 0.21 & 0.58 & 0.64 \\
\hline
\end{tabular}

Al comparar los resultados obtenidos de esta investigación con los diferentes métodos de cálculo de transmisión de cargas, los autores concluyeron que:

- En general, todos los modelos teóricos predicen correctamente la posición de la carga máxima durante el proceso de construcción.

- Los métodos desarrollados por Liu et al. (1985), son los más acertados en la predicción de los valores de carga, sin embargo, son métodos cuya aplicación resulta compleja.

- El Método Simplificado Mejorado (Duan y Chen, 1995) predice con una precisión razonable las cargas originadas en los puntales durante la construcción de una estructura de hormigón.

\subsubsection{Medidas realizadas por Alvarado et al. (2009)}

Con el fin de estudiar la transmisión de cargas entre forjados y puntales durante los procesos de cimbrado y descimbrado Alvarado et al. (2009) instrumentaron un edificio construido en las instalaciones del laboratorio del Instituto de Ciencia y Tecnología del Hormigón (ICITECH), en el Campus de Vera de la Universidad Politécnica de Valencia, con fines únicamente de investigación.

El edificio estaba formado por 3 forjados resueltos mediante losa de hormigón armado de $0.25 \mathrm{~m}$ de canto y una resistencia característica a compresión del hormigón de $25 \mathrm{MPa}$. La luz entre pilares era de $6.00 \mathrm{~m}$ y había un voladizo de $1.80 \mathrm{~m}$.

En la construcción de cada forjado se diferenciaron las fases de: cimbrado, clareado, y descimbrado. El ciclo de construcción quedó definido por un forjado cimbrado y otro clareado. Con el objeto de simular la ejecución de otro forjado más, en el último forjado se aplicó, mediante balsas de plástico 
llenas de agua, una carga uniformemente repartida. Junto con Moragues (1992), son los únicos autores que estudian la operación del clareado.

Se instrumentaron un total de 80 puntales. En cada uno de ellos, a una altura de $1.25 \mathrm{~m}$. de la base del puntal, se colocaron 3 bandas extensométricas, dispuestas con un ángulo de $120^{\circ}$. La carga a la que estaban sometidos dichos puntales se calculó a partir del valor medio de la deformación de las tres bandas. Con el objeto de medir el efecto de la temperatura ambiente sobre: los puntales, las galgas extensométricas y el equipo de adquisición de datos, se utilizaron 3 puntales como referencia. Sobre estos puntales no se impuso ningún tipo de coacción en sus extremos, por lo que no formaron parte del sistema de cimbrado del edificio.

En la Tabla 2.16 se muestra una comparación entre los coeficientes de carga obtenidos en cada fase durante la construcción del edificio, los obtenidos mediante el modelo numérico (Alvarado et al., 2010) ( $\mathrm{C}_{\mathrm{FEM}}$ ) y coeficientes teóricos propuestos por el Método Simplificado (Grundy y Kabaila, 1963) $\left(C_{\mathrm{G \& K}}\right)$, por Moragues et al. (1996) $\left(C_{\mathrm{M}}\right)$, por el Método Simplificado Mejorado (Duan y Chen, 1995) $\left(C_{\mathrm{D} \& \mathrm{C}}\right)$, por el Método Simplificado de Fang et al. (2001a) $\left(C_{\mathrm{Fang}}\right)$ y los obtenidos mediante los Métodos Propuestos por Beeby (2001a) $\left(C_{\text {Beeby }}\right)$. Todos los métodos, a excepción del Método Simplificado, consideran la rigidez real de los forjados y puntales.

Tabla 2.16 Comparación entre las medidas experimentales de Alvarado et al. (2009) con otros métodos

\begin{tabular}{lcccccccc}
\hline \multicolumn{1}{c}{ Operación } & Nivel & $\boldsymbol{C}_{\boldsymbol{e x p}}$ & $\boldsymbol{C}_{\boldsymbol{M E F}}$ & $\boldsymbol{C}_{\mathbf{G \& K}}$ & $\boldsymbol{C}_{\mathbf{M}}$ & $\boldsymbol{C}_{\boldsymbol{D} \& \boldsymbol{C}}$ & $\boldsymbol{C}_{\boldsymbol{F a n g}}$ & $\boldsymbol{C}_{\boldsymbol{B e e b y}}$ \\
\hline $\begin{array}{l}\text { Hormigonado } \\
\text { Forjado 1 }\end{array}$ & 1 & 0.97 & 0.98 & 1.00 & 1.00 & 1.00 & 1.00 & 1.00 \\
\hline Clareado Forjado 1 & 1 & 0.54 & 0.60 & 1.00 & 0.67 & 0.54 & 0.66 & 0.88 \\
\hline Hormigonado & 2 & 0.99 & 1.00 & 1.00 & 1.00 & 1.00 & 1.00 & 1.00 \\
Forjado 2 & 1 & 0.79 & 1.17 & 2.00 & 1.14 & 1.07 & 1.18 & 1.75 \\
\hline Clareado Forjado 2 & 2 & 0.52 & 0.51 & 1.00 & 0.67 & 0.44 & 0.43 & 0.78 \\
& 1 & 0.68 & 0.95 & 2.00 & 1.06 & 0.77 & 0.87 & 1.55 \\
\hline Descimbrado Forjado & 2 & 0.28 & 0.25 & 0.00 & 0.33 & 0.17 & 0.15 & 0.09 \\
1 & 3 & 0.98 & 1.00 & 1.00 & 1.00 & 1.00 & 1.00 & 1.00 \\
\hline Hormigonado & 2 & 0.54 & 0.54 & 0.50 & 0.63 & 0.52 & 0.50 & 0.56 \\
Forjado 3 & 3 & 0.55 & 0.49 & 1.00 & 0.70 & 0.42 & 0.42 & 0.62 \\
Clareado Forjado 3 & 2 & 0.49 & 0.39 & 0.50 & 0.60 & 0.31 & 0.29 & 0.38 \\
\hline Carga sobre Forjado & 3 & 0.77 & 0.95 & 1.66 & 1.08 & 0.83 & 0.83 & 1.23 \\
3 & 2 & 0.60 & 0.60 & 0.83 & 0.75 & 0.45 & 0.43 & 0.67 \\
\hline Descimbrado Forjado & 3 & 0.65 & 0.75 & 1.25 & 0.71 & 0.66 & 0.68 & 0.94 \\
2 & & & & & & & \\
\hline
\end{tabular}

El coeficiente de carga $\left(\mathrm{C}_{\text {esp }}\right)$ se corresponde a la relación entre la carga media medida en los puntales $\left(\mathrm{Q}_{\mathrm{med}}\right)$ y el peso propio estimado del forjado.

Las mediciones realizadas permitieron conocer cómo se transmitieron las cargas entre forjados y puntales durante la construcción del edificio experimental en un proceso de cimbrado, clareado y descimbrado. 
Del análisis de la medición instantánea los autores concluyeron que al realizar la operación de clareado, los forjados asumen una fracción importante de carga. Para el caso estudiado, el valor medio de los porcentajes de carga que asumieron los forjados, en relación a su peso propio, una vez clareados, fue de un 46\%. Esto implica que una vez realizada la operación de clareado se produce una reducción de la carga media por unidad de área del sistema de apuntalamiento en todos los forjados.

Para poder simular la operación de clareado, es necesario que el método teórico a aplicar considere los puntales como elementos con un comportamiento elástico y de rigidez finita. Por ello, los autores concluyeron que la reducción de carga producida por el clareado no es posible de evaluar con el Método Simplificado (Grundy y Kabaila, 1963).

El resto de métodos simplificados mostrados en la Tabla 2.16 sí son de aplicación, concluyendo los autores que en general el método que presenta un mejor ajuste con las medidas experimentales y los resultados del modelo numérico (Alvarado et al., 2010) es el Método Simplificado Mejorado (Duan y Chen, 1995).De los resultados del estudio experimental, los autores también observaron que al realizar las operaciones de clareado, descimbrado y hormigonado sobre un forjado ya endurecido, el reparto de cargas en los puntales no era uniforme. Este reparto dependía de la deformación del forjado, correspondiendo las cargas máximas en los puntales con puntos donde la flecha del forjado era máxima.

\subsection{Efecto de la temperatura en la transmisión de cargas entre forjados y puntales}

Un efecto poco estudiado hasta la fecha es el que tienen los cambios de temperatura ambiente en la distribución de cargas entre forjados y puntales, pese a que algunos autores han registrado lo importante de su influencia.

\subsubsection{Rosowsky et al (1997)}

En el estudio experimental llevado a cabo por Rosowsky et al. (1997) (ver apartado 2.3.2.5) se registró la evolución de cargas en puntales durante los días posteriores al hormigonado. Los autores obtuvieron fluctuaciones cíclicas diarias en la carga de los puntales que atribuyeron a los cambios medioambientales (variaciones de temperatura) que se produjeron en la obra. Además de estas fluctuaciones, también observaron un carácter decreciente de las cargas durante el proceso de curado del forjado, que asociaron con efectos de fluencia y ganancia de rigidez del hormigón.

\subsubsection{Fang et al (2001b)}

Fang et al. (2001b) midieron las cargas en puntales durante la construcción de un edificio en Beijing, tal y como se explica en el aparatado 2.3.2.7.

Adicionalmente, durante la construcción del tercer forjado de dicho edificio, Fang et al. (2001b) monitorizaron de forma continua las cargas en los puntales después de la fase de hormigonado y durante los siguientes dos días. Los autores observaron una tendencia decreciente y cíclica de las cargas en los puntales (Fig. 2.22), sin que ninguna carga adicional fuera aplicada o retirada. Fang et al. 
(2001b), al igual que Rosowsky (1997), concluyeron que estos efectos eran debidos a los cambios de la temperatura ambiente (se registraron variaciones diarias de hasta $10^{\circ} \mathrm{C}$ ) y a la fluencia y aumento de rigidez de los forjados, que empiezan a soportar parte de su peso propio.

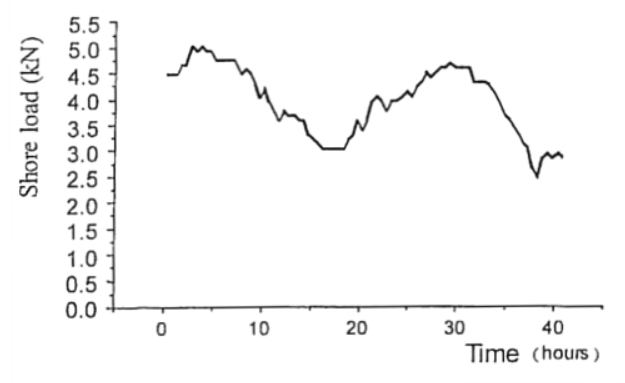

Fig. 2.22 Evolución de cargas en puntales medida por Fang et al.

\subsubsection{Azkune et al (2007)}

Azkune et al. (2007) realizaron un estudio de la influencia de la temperatura en la trasmisión de cargas en diferentes edificios, entre ellos el descrito en el apartado 2.3.2.8. La temperatura utilizada en el análisis no se midió directamente en obra, sino que los datos se extrajeron de una estación meteorológica próxima. La Figura 2.23 muestra la variación por temperatura en algunos de los puntales instrumentados.

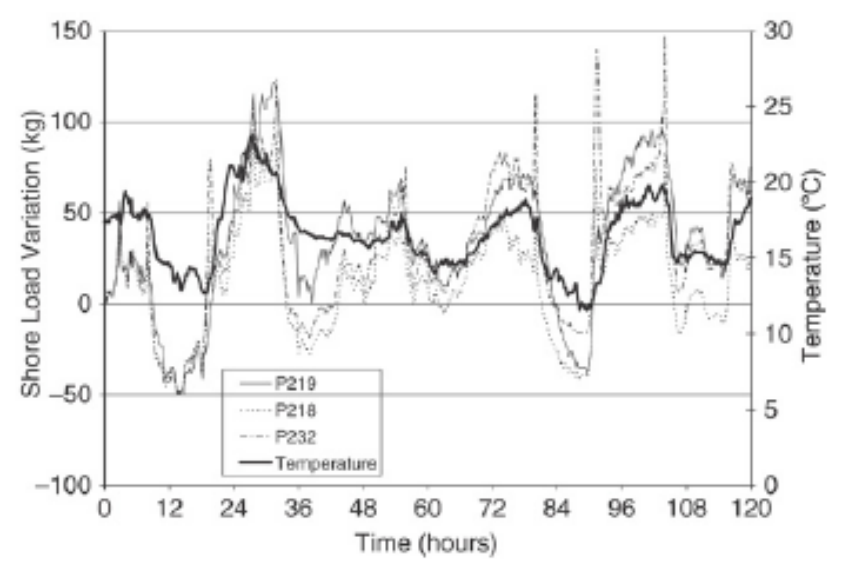

Fig. 2.23 Evolución de carga en puntales medida por Azkune et al. (2007) en Getaria.

Los autores observaron que las fluctuaciones de temperaturas diarias podían producir cambios en los valores de carga en puntales de hasta $300 \mathrm{Kg}$ (30\% de la carga).

A la vista de la importancia que tenían las variaciones de temperatura ambiente en la distribución de cargas, Azkune et al. (2007) propusieron modificaciones en los métodos Refinado (Liu et al. 1985) y Simplificado Mejorado (Duan y Chen, 1995) con el fin de incluir el efecto de la temperatura. Posteriormente compararon los resultados obtenidos con estos métodos y los medidos en obra. 
Del análisis de estas comparaciones, los autores concluyeron que ambos métodos, siendo modificados, predicen el mismo comportamiento frente a variaciones de temperatura que el observado en obra, pero tienden a sobrestimar la carga.

\subsubsection{Alvarado (2009)}

Tal y como se ha indicado en el apartado 2.3.3.9, Alvarado et al. (2009) instrumentaron un edificio construido en las instalaciones del laboratorio del ICITECH, en el recinto de la Universidad Politécnica de Valencia, con fines únicamente de investigación.

Durante la construcción de dicho edificio, además de las mediciones instantáneas (medidas de los incrementos de carga tomadas una vez ejecutada cada una de las operaciones del proceso constructivo), ya analizadas en el aparatado 2.3.3.9, se realizaron mediciones continuas, tomando medidas cada 5 segundos durante las fases críticas del ensayo, es decir, durante el clareado y hormigonado de los forjados. Mientras que en las fases intermedias a las anteriormente mencionadas las medidas se tomaron cada 5 minutos.

El efecto de la temperatura sobre los puntales y los sistemas de medida, se corrigió utilizando puntales de referencia sobre los que no se impuso ningún tipo de coacción en sus extremos, por lo que no formaban parte del sistema de cimbrado del edificio.

Además de las mediciones de carga, durante todo el proceso constructivo, se controló la evolución de la temperatura en obra. Se registró, de forma continua, la temperatura ambiente en el emplazamiento de la obra, y se midió la evolución de temperaturas en el hormigón de cada uno de los forjados, en probetas cilíndricas normalizadas de hormigón y en puntales.

Para el registro de las temperaturas se utilizaron termopares tipo $\mathrm{J}$ con un diámetro de $3 \mathrm{~mm}$ y $150 \mathrm{~mm}$ de largo. Para poder determinar la temperatura media en las losas de hormigón, se embebieron 3 termopares, en cada uno de los forjados, y se realizaron medidas cada 3 minutos.

En la Figura 2.24 se muestra la variación del coeficiente de carga media en puntales entre el hormigonado del forjado $1 \mathrm{y}$ antes del clareado de éste y la variación de la temperatura ambiente durante dicho periodo.

Al analizar los registros obtenidos mediante la medición continua, Alvarado (2009) detectó la importancia que las variaciones de temperatura ambiente tenían sobre las cargas en los puntales durante el proceso constructivo. Estos cambios de temperatura afectaban a los diferentes elementos de la estructura durante su construcción (forjados, pilares, puntales, tableros de encofrado y sopandas), afectando finalmente a la variación de carga en los puntales. 


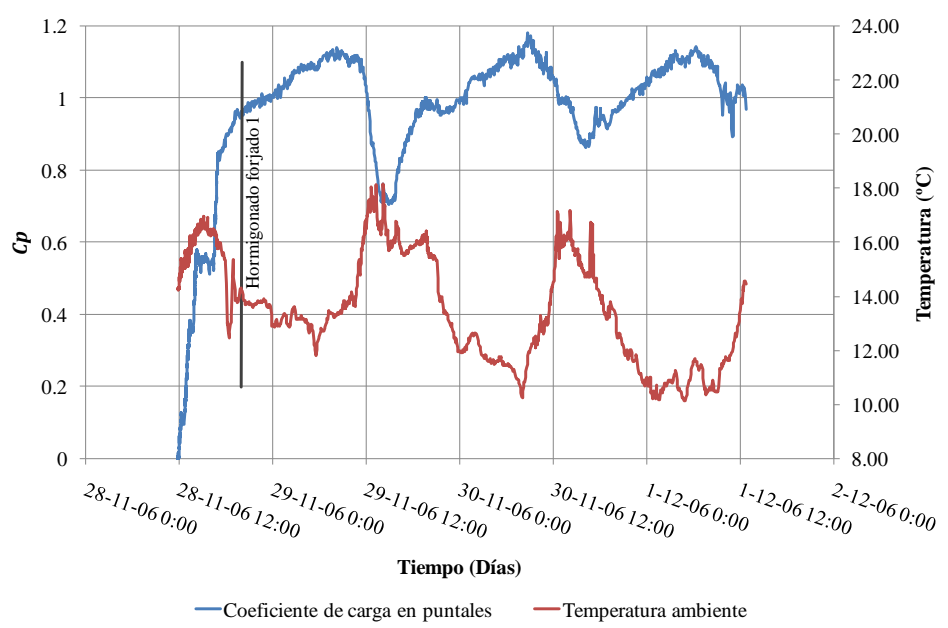

Fig. 2.24 Coeficiente de carga media en puntales entre el hormigonado y antes del clareado del forjado 1 (Alvarado, 2009).

De los resultados obtenidos Alvarado (2009) concluyó que:

- Durante la medición continua, la carga en cada uno de los puntales presentaba variaciones significativas (entre el 13 y el 50\% de su carga inicial). Dichas variaciones seguían una misma pauta de comportamiento que dependía de las variaciones de temperatura ambiente en la obra. La pauta de comportamiento de dicha variación, se corresponde con un aumento de la carga en los puntales al descender la temperatura, y a un descenso de carga en los puntales al aumentar la temperatura.

- La variación de carga en los puntales, debido a la variación de temperatura, cobraba una mayor importancia cuando el forjado estaba completamente cimbrado.

- Un vez hormigonados los forjados, la variación de carga media por unidad de superficie debido a los cambios de temperatura, fue de $\pm 0.34 \mathrm{kN} / \mathrm{m}^{2}$ en el forjado $1 \mathrm{y} \mathrm{de} \pm 0.21 \mathrm{kN} / \mathrm{m}^{2}$ en los forjados 2 y 3 para variaciones de temperatura de $\pm 1^{\circ} \mathrm{C}$.

- Al estar los forjados clareados, la variación de la carga media por unidad de superficie debido a los cambios de temperatura, fue de $\pm 0.10 \mathrm{kN} / \mathrm{m}^{2}$ en el forjado $1 \mathrm{y} \mathrm{de} \pm 0.13 \mathrm{kN} / \mathrm{m}^{2}$ en los forjados 2 y 3 para variaciones de temperatura de $\pm 1^{\circ} \mathrm{C}$.

\subsubsection{Fang et al (2009b)}

En 2009, Fang et al. llevaron a cabo un estudio analítico para conocer la influencia de la temperatura (entre otras variables) en la redistribución de cargas de los forjados.

Para el estudio, los autores consideran que, en el caso de los puntales, el incremento de temperatura es igual al de la temperatura ambiente, ya que el acero tiene un coeficiente de dilatación térmica alto y la sección del puntal es relativamente pequeña. El hormigón, en cambio, tiene un coeficiente de expansión térmica menor y su volumen (forjados, pilares) es bastante mayor, por lo tanto los elementos de hormigón tardarán más tiempo en alcanzar la temperatura ambiente. Fang et al. (2009b) 
consideran que estos elementos tienen un comportamiento similar al de la temperatura ambiente, pero sin llegar a alcanzar los máximos y mínimos que ésta presenta y con un decalaje en el tiempo.

A partir de estas consideraciones Fang et al (2009b) calculan el cambio de longitud relativa del puntal en función de la temperatura e introduciendo este parámetro en el modelo teórico desarrollado por Fang et al. (2009a) obtienen la distribución de cargas en los forjados teniendo en cuenta las variaciones de temperatura.

De este estudio, los autores concluyeron que las variaciones diarias de la temperatura ambiente provocan fluctuaciones de carga en el forjado, incrementando su carga máxima. El aumento de la carga máxima del forjado, como consecuencia de las variaciones diarias de temperatura, puede llegar a ser un 22.5\% mayor que las predicciones utilizando el Método Simplificado (Grundy y Kabaila, 1963). Por lo tanto, se debería prestar especial atención a la influencia de la temperatura, sobre todo cuando existan variaciones de temperatura relativamente altas.

\subsection{Conclusiones relativas al estado del arte}

En la construcción de edificios en altura, es necesario apoyar la cimbra sobre forjados que no suelen tener la resistencia suficiente para soportar las cargas del forjado superior mientras se está construyendo. Estos forjados pueden estar sometidos a solicitaciones de carga superiores a las de servicio, haciendo evidente la necesidad de conocer cómo se transmiten las cargas entre los forjados y los puntales

Para resolver este problema se han desarrollado diversas investigaciones de carácter teórico y experimental, explicadas en el apartado 2.3, que han intentado determinar cómo se efectúa la transmisión de cargas entre los forjados y los puntales.

En 1963 Grundy y Kabaila propusieron un método simplificado que se sigue empleando en la actualidad para determinar las cargas en puntales y forjados. Este método es de fácil aplicación y está, en la mayoría de los casos, del lado de la seguridad.

Posteriormente, autores como Duan y Chen (1995), Fang et al. (2001a, 2009a), Beeby (2001a) o Calderón et al. (2010) entre otros, han desarrollado metodologías simplificadas que permiten estimar la distribución de cargas en forjados y puntales durante la construcción de edificios de plantas sucesivas. Dichos modelos se basan, principalmente, en considerar a los puntales como elementos de rigidez finita y en considerar la ganancia de rigidez del forjado de hormigón con el tiempo.

También se han desarrollado modelos teóricos más complejos basados en modelaciones por el método de los elementos finitos en dos y tres dimensiones como los desarrollados por Liu et al. (1985), Stivaros y Halvorsen (1990), Mosallam y Chen (1991), Moragues et al. (1996), Díaz (2008) y Alvarado et al. (2010). Sin embargo, dichos modelos requieren de un software de cálculo especializado, lo cual los convierte en métodos de una limitada aplicación práctica.

Todos los autores anteriores coinciden en afirmar que el método simplificado de Grundy y Kabaila (1963) sobreestima las cargas que se transmiten a los puntales y forjados. Esta sobreestimación es 
debida, principalmente, a que Grundy y Kabaila (1963) consideran los puntales como elementos infinitamente rígidos.

La validación experimental de dichos modelos teóricos ha sido desarrollada posteriormente e incluso, en la mayoría de los casos, por otros autores. El desarrollo de estos estudios experimentales se ha basado en la instrumentación de edificios durante su construcción midiendo las cargas en los puntales. Esto implica que la toma de datos sea una tarea compleja, debido a que se requiere adaptar toda la organización y control que requiere un estudio experimental al ritmo de la obra. Se destacan las mediciones experimentales realizadas por Agarwal y Gardner (1974), Moragues et al. (1992), Rosowsky et al. (1997), Fang et al. (2001) y Alvarado et al. (2009). En la Tabla 2.17 se muestra un resumen de los estudios experimentales realizados hasta la fecha. En general, las instrumentaciones se realizaron en una zona concreta del vano con unos pocos puntales instrumentados. Únicamente los últimos estudios de Fang et al. (2001) y Alvarado et al. (2009), llevados a cabo en edificios experimentales en condiciones controladas, y los de Puente et al. (2006) instrumentaron la totalidad del vano. Además, como se observa en dicha tabla, todas las medidas experimentales, excepto las efectuadas por Moragues (1992), se realizaron en edificios con forjado de losa maciza, quedando un vacío en el estudio de la transmisión de cargas entre forjados y puntales en edificios de forjado reticular.

Cabe destacar que han sido pocos los autores que han estudiado la técnica del clareado. Tan sólo Moragues et al. (1992, 1994, 1996), Alvarado et al. (2009, 2010) y Alvarado (2009) han llevado a cabo estudios experimentales (Tabla 2.17) y teóricos de la aplicación de esta técnica a los procesos de cimbrado y descimbrado. Esto pese a que dicho proceso es de uso habitual en España. Tanto Moragues et al. (1992, 1994, 1996) como Alvarado et al. (2009, 2010) y Alvarado (2009) concluyen en sus investigaciones que al realizar el clareado se produce una reducción de la carga media por unidad de área del sistema de apuntalamiento, comenzando los forjados a soportar una fracción importante de la carga que actúa sobre éstos. Esta reducción de carga, que se produce en el sistema de apuntalamiento, no es posible de evaluar con el Método Simplificado (Grundy y Kabaila, 1963), pero sí en aquellos métodos donde se considere la rigidez finita de los puntales.

Otro efecto poco estudiado hasta la fecha es el que tienen los cambios de temperatura ambiente en la distribución de cargas entre forjados y puntales, pese a que algunos autores han registrado lo importante de su influencia. Rosowsky et al. (1997) registraron la evolución de cargas en puntales durante los días posteriores al hormigonado, obteniendo fluctuaciones cíclicas diarias que atribuyeron a los cambios medioambientales que se produjeron en la obra. Además de estas fluctuaciones, también observaron un carácter decreciente de las cargas durante el proceso de curado del forjado debido a efectos de fluencia y a la ganancia de rigidez del forjado.

Fang et al. (2001b) midieron también las cargas en puntales durante el curado de la losa. Al igual que Rosowsky et al. (1997), establecieron que la evolución de cargas en puntales está influenciada por las variaciones diarias de temperatura e igualmente detectaron que durante el curado del forjado se producía un descenso en las cargas de los puntales debido a que el forjado empezaba a asumir parte de su peso propio. 
Estudio de la evolución de cargas en forjados y puntales durante el proceso constructivo

Tabla 2.17 Resumen de los estudios experimentales

\begin{tabular}{|c|c|c|c|c|c|c|c|}
\hline Medidas realizadas por: & $\begin{array}{l}\text { Tipo de Forjado } \\
\text { (Canto (m)) }\end{array}$ & $\begin{array}{c}\text { Proceso } \\
\text { constructivo }\end{array}$ & $\begin{array}{c}\text { Ciclo de } \\
\text { construcción }\end{array}$ & $\begin{array}{c}\text { Núm. Puntales } \\
\text { instrumentados por } \\
\text { planta }\end{array}$ & $\begin{array}{l}\text { Núm. Plantas } \\
\text { Instrumentadas }\end{array}$ & $\begin{array}{c}\text { Tiempo de } \\
\text { instrumentación }\end{array}$ & $\begin{array}{l}\text { Elemento de } \\
\text { medida }\end{array}$ \\
\hline Agarwal y Gardner (1974) & Losa $(0.20)$ & CRD & $\begin{array}{c}3 \text { plantas cimbradas } \\
\text { y } 4 \text { recimbradas }\end{array}$ & 8 & 7 & 1 ciclo constructivo & $\begin{array}{c}\text { Bandas } \\
\text { extensométricas }\end{array}$ \\
\hline Agarwal y Gardner (1974) & Losa $(0.25 / 0.20)$ & $\mathrm{CD}$ & 3 plantas cimbradas & 9 & 3 & 1 ciclo constructivo & $\begin{array}{c}\text { Bandas } \\
\text { extensométricas }\end{array}$ \\
\hline Lasisi y Ng (1979) & Losa $(0.25 / 0.28)$ & CRD & $\begin{array}{c}1 \text { planta cimbrada y } \\
2 \text { recimbradas }\end{array}$ & 4 & 3 & $\begin{array}{l}\text { Horm. F7 - } \\
\text { Desc. F11 }\end{array}$ & Células de carga \\
\hline Moragues (1992) & Reticular (0.28) & CCD & $\begin{array}{c}1 \text { planta cimbrada y } \\
2 \text { clareadas }\end{array}$ & 4 & 3 & $\begin{array}{l}\text { Horm. F1 - } \\
\text { Horm. F9 }\end{array}$ & Células de carga \\
\hline Moragues (1992) & Reticular (0.31) & CCD & $\begin{array}{c}1 \text { planta cimbrada y } \\
2 \text { clareadas }\end{array}$ & 7 & 1 & $\begin{array}{l}\text { Horm. F6 - } \\
\text { Horm- F12 }\end{array}$ & Células de carga \\
\hline Ambrose et al. (1994) & - & - & - & 2 & 1 & 72 horas & Células de carga \\
\hline Rosowsky et al. (1997) & Losa $(0.20)$ & $\mathrm{CD}$ & - & 16 & 1 & 4 días & \\
\hline Beeby (2001b) & Losa $(0.25)$ & CRD & $\begin{array}{l}1 \text { planta cimbrada y } \\
1 \text { recimbradas }\end{array}$ & & 2 & $\begin{array}{l}\text { Horm. F1 - } \\
\text { Desc. F7 }\end{array}$ & Células de carga \\
\hline Fang et al. (2001b) & Losa $(0.11)$ & $\mathrm{CD}$ & 2 plantas cimbradas & 26 & 2 & $\begin{array}{c}\text { Horm. F2 - } \\
\text { Horm. F4 }\end{array}$ & $\begin{array}{c}\text { Bandas } \\
\text { extensométricas }\end{array}$ \\
\hline Puente et al. (2007) & Losa $(0.25)$ & $\mathrm{CD}$ & 3 plantas cimbradas & 34 & 3 & $\begin{array}{l}\text { Horm. Sótano } 4 \text { - } \\
\text { Desc. Sótano } 2\end{array}$ & $\begin{array}{c}\text { Bandas } \\
\text { extensométricas }\end{array}$ \\
\hline Alvarado et al. (2009) & Losa $(0.25)$ & CCD & $\begin{array}{c}1 \text { planta cimbrada y } \\
1 \text { clareada }\end{array}$ & $80 / 48$ & 2 & $\begin{array}{l}\text { Horm. F1 - } \\
\text { Desc. F2 }\end{array}$ & $\begin{array}{c}\text { Bandas } \\
\text { extensométricas }\end{array}$ \\
\hline
\end{tabular}


Alvarado (2009) instrumentó un edificio de forma continua durante su construcción, detectando la importancia que las variaciones de temperatura ambiente tenían sobre las cargas en los puntales durante el proceso constructivo. Estos cambios de temperatura afectaban a los diferentes elementos de la estructura durante su construcción, afectando finalmente a la variación de carga en los puntales.

Posteriormente, Fang et al. (2009b) llevaron a cabo un estudio analítico para conocer la influencia de la temperatura (entre otras variables) en la redistribución de cargas de los forjados. De este estudio concluyeron que las variaciones de la temperatura ambiente provocan fluctuaciones de carga en el forjado, incrementando su carga máxima.

Llegados a este punto, se advierte la necesidad de un estudio pormenorizado de la transmisión de cargas entre forjados y puntales para un proceso constructivo de $\mathrm{CCD}$, así como del efecto de las temperaturas en dicha transmisión de cargas.

Mediante el presente trabajo se pretende continuar con la investigación iniciada por Alvarado (2009), planteando para ello:

- Estudio experimental de la transmisión de cargas entre forjados y puntales, llevado a cabo en tres obras reales, donde se instrumentan:

- Vanos con distintas condiciones de contorno.

- Diversas tipologías de forjados: losa, reticular de casetón perdido y reticular de casetón recuperable.

- Calibración del modelo numérico desarrollado en investigaciones anteriores por el grupo de investigación, ajustándolo a las diferentes tipologías estructurales definidas con anterioridad.

- Validación de un método simplificado, a partir de los resultados obtenidos, que permita evaluar la transmisión de cargas durante el proceso de CCD.

- Estudio experimental del efecto que tiene la variación de la temperatura ambiente en los diferentes elementos de la estructura durante su construcción

- Aproximación numérica al efecto que producen los cambios de temperatura en la transmisión de cargas entre forjados y puntales. 



\section{CAPITULO 3. ESTUDIOS EXPERIMENTALES}

\subsection{Introducción}

Tal y como se ha observado en el Capítulo 2 de la presente Tesis Doctoral, han sido pocos los autores que han estudiado la técnica del clareado, pese a ser una técnica de uso habitual en España. Por tanto, surge la necesidad de realizar un estudio experimental pormenorizado de la transmisión de cargas entre forjados y puntales para un proceso constructivo de Cimbrado-Clareado-Descimbrado (CCD). Así mismo, pese a que algunos autores han registrado la importancia del efecto de las temperaturas en dicha transmisión de cargas, son pocos los estudios llevados a cabo hasta la fecha.

Con el objetivo de contribuir a paliar estas carencias y estudiar la transmisión de cargas entre forjados y puntales, en un proceso de $\mathrm{CCD}$, en las distintas tipologías de forjados más comunes en edificación, así como analizar el efecto que tiene la variación de la temperatura ambiente en los diferentes elementos de la estructura durante su construcción, se ha llevado a cabo la monitorización de tres obras reales.

Las obras se escogieron con el objetivo de cubrir el rango de tipologías de forjados bidireccionales de hormigón hormigonados "in situ": forjado de losa maciza, forjado reticular de casetón perdido y forjado reticular de casetón recuperable. Los estudios experimentales fueron llevados a cabo gracias a la financiación de convenios con las empresas Sacyr Vallehermoso (en el caso del primer estudio experimental) y Encofrados Alsina (en los otros dos estudios).

En todas las obras se realizaron mediciones instantáneas, consistentes en tomar medidas antes y después de cada una de las operaciones constructivas (hormigonado, clareado y descimbrado). Dichas medidas permiten conocer los incrementos de carga en puntales y forjados debido a la ejecución de cada una de las operaciones constructivas.

El primero de los estudios experimentales se realizó en un edificio de forjado de losa maciza situado en Madrid. Se trata de un edificio destinado a viviendas con 4 sótanos y 14 plantas. Se instrumentaron 2 vanos consecutivos, uno de esquina y otro de medianera, con 6 puntales instrumentados por cada vano. La medición se realizó desde el hormigonado del forjado correspondiente a planta baja (forjado 1), hasta el hormigonado del forjado correspondiente al techo de la quinta planta (forjado 6).

El siguiente estudio experimental se realizó en Sabadell (Barcelona), en un edificio de forjado reticular de casetón perdido. Consta de 5 plantas y 2 sótanos y también está destinado a viviendas. Se instrumentaron 2 sopandas principales por planta, pertenecientes ambas al mismo vano, con un total de 8 puntales instrumentados por sopanda. El estudio se llevó a cabo desde el hormigonado del forjado de techo de sótano 2 (forjado 1) hasta el hormigonado del forjado correspondiente al techo de la tercera planta (forjado 6). Además, para poder determinar la variación de la temperatura en el forjado de 
hormigón y evaluar el gradiente térmico que se producía, se instalaron termopares a diferentes profundidades del forjado.

El último de los estudios experimentales se hizo en un edificio de forjado reticular de casetón recuperable situado en Valencia y destinado a acoger la Facultad de Bellas Artes en el campus de Vera de la Universidad Politécnica de Valencia. El edificio consta de 7 forjados (6 plantas y 1 sótano). Al igual que en el edificio de losa maciza, se instrumentaron dos vanos consecutivos, uno de esquina y otro de medianera, con un total de 11 puntales por planta. La monitorización se realizó desde el hormigonado del forjado de techo del sótano (forjado 1) hasta el hormigonado del forjado de techo de la segunda planta (forjado 4). Así mismo, se instrumentaron, con termopares, 2 nervios de dos forjados consecutivos para poder estudiar el gradiente térmico que se producía en el forjado de hormigón.

En el presente capítulo se describen los distintos estudios experimentales y se presentan y analizan los resultados obtenidos, tanto en lo que se refiere a las cargas generadas en el proceso constructivo, como a las temperaturas, y las relaciones entre ambos.

\subsubsection{Descripción del sistema de cimbrado}

En edificios de losa maciza y forjado reticular de casetón perdido, se empleó el sistema Alumecano suministrado por la empresa Encofrados J. Alsina S.A (Fig. 3.1). Este sistema está formado por puntales, sopandas principales, sopandas secundarias, portasopandas y tableros de encofrado. Alumecano está formado por un sistema de mecano estructural de acero con un basculante de aluminio y una superficie encofrante de tableros de madera. El sistema permite, por su diseño, realizar la operación de clareado manteniendo el forjado apuntalado en todo momento. Se recupera el $80 \%$ de los elementos: portasopandas, sopandas intermedias, basculantes y los tableros con sus respectivos puntales de apoyo, quedando sólo las líneas de sopandas principales.

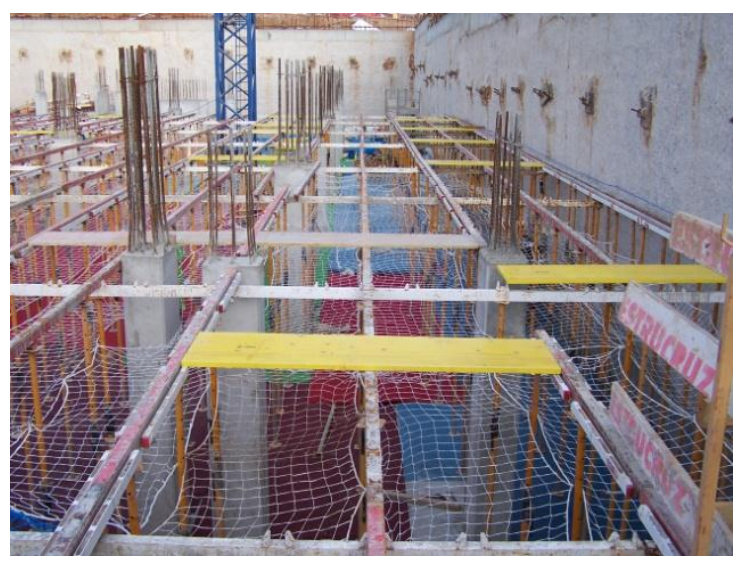

Fig. 3.1 Sistema Alumecano (edificio de Sabadell)

En el caso del edificio de forjado reticular de casetón recuperable, se utilizó el sistema Alucubetas, suministrado también por la empresa Encofrados J. Alsina S.A (Fig. 3.2). Este sistema está formado por cubetas y elementos del sistema Alumecano (puntales, sopandas principales y secundarias, portasopandas, basculantes y tableros). Al utilizar parte de los componentes del Alumecano, también permite la realización del clareado estando siempre la estructura apuntalada. 


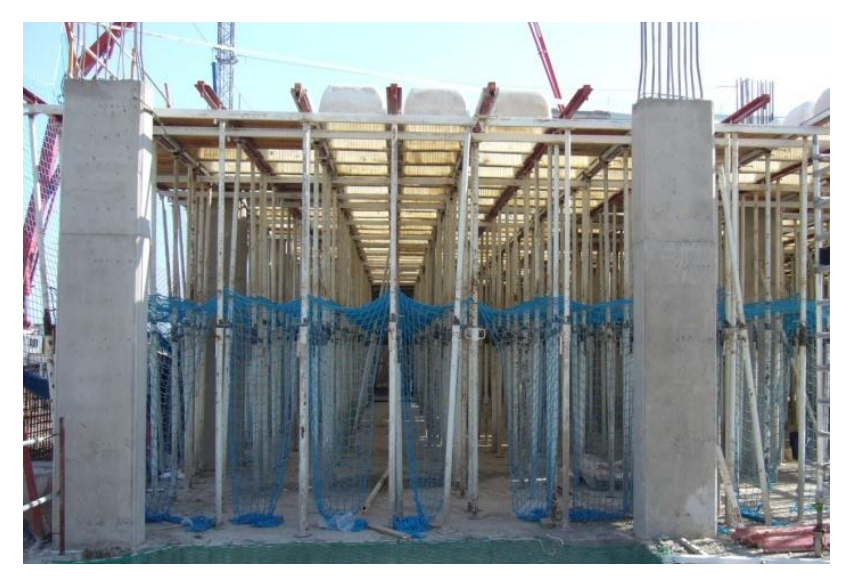

Fig. 3.2 Sistema Alucubetas (edificio de Bellas Artes, Valencia)

A continuación se describen cada uno de los componentes del sistema de cimbrado empleado en la construcción de los distintos edificios.

\section{Puntales}

Alsina dispone de puntales telescópicos con medidas comprendidas entre 1.5 y $6 \mathrm{~m}$. Los puntales empleados para la construcción de los edificios fueron los correspondientes a unas alturas máximas de 3, 4 y $5 \mathrm{~m}$. Estos puntales están fabricados con un tubo de acero de alta calidad S275JR (ST-44). Las bases, la rosca y el pasador son también de acero, y el cuerpo y la caña del puntal están pintados con pintura de poliéster para protegerlos de la intemperie y alargar su uso en la obra (Fig. 3.3).

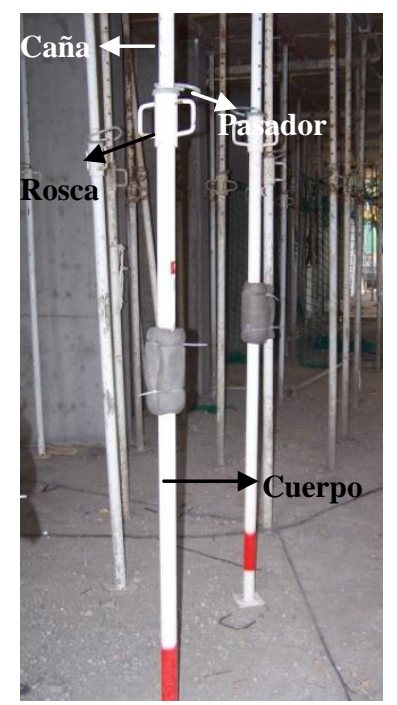

Fig. 3.3 Puntal empleado en los estudios experimentales

Las características geométricas y de resistencia de los puntales utilizados en las distintas obras se muestran en las Tablas 3.1 y 3.2, respectivamente. 
Estudio de la evolución de cargas en forjados y puntales durante el proceso constructivo

Tabla 3.1 Características geométricas de los puntales empleados en los estudios experimentales

\begin{tabular}{lllllll}
\hline $\begin{array}{l}\text { Tipo de } \\
\text { puntal }\end{array}$ & $\begin{array}{l}\text { Longitud del } \\
\text { cuerpo }(\mathbf{m})\end{array}$ & $\begin{array}{l}\text { Diámetro del } \\
\text { cuerpo }(\mathbf{m m})\end{array}$ & $\begin{array}{l}\text { Espesor } \\
\text { cuerpo }(\mathbf{m m})\end{array}$ & $\begin{array}{l}\text { Diámetro } \\
\text { caña }(\mathbf{m m})\end{array}$ & $\begin{array}{l}\text { Espesor caña } \\
(\mathbf{m m})\end{array}$ & Peso (N) \\
\hline Puntal 3 m. & 1.54 & 48 & 2 & 41 & 2.5 & 93.29 \\
Puntal 4 m. & 1.88 & 48 & 2 & 41 & 2.5 & 110.36 \\
Puntal 5 m. & 1.84 & 60 & 2 & 52 & 2.5 & 182.27 \\
\hline
\end{tabular}

Tabla 3.2 Resistencia de los puntales según la atura de uso

\begin{tabular}{lllllll}
\hline \multirow{2}{*}{$\begin{array}{l}\text { Tipo de } \\
\text { puntal }\end{array}$} & $\begin{array}{l}\text { Altura } \\
(\mathrm{m})\end{array}$ & $\begin{array}{l}\text { Máx. carga } \\
\text { admisible a } \\
\text { compresión }(\mathrm{kN})\end{array}$ & $\begin{array}{l}\text { Altura } \\
(\mathrm{m})\end{array}$ & $\begin{array}{l}\text { Máx. carga } \\
\text { admisible a } \\
\text { compresión }(\mathrm{kN})\end{array}$ & $\begin{array}{l}\text { Altura } \\
(\mathrm{m})\end{array}$ & $\begin{array}{l}\text { Máx. carga } \\
\text { admisible a } \\
\text { compresión }(\mathrm{kN})\end{array}$ \\
\hline Puntal 3 m. & 1.80 & 21.59 & 2.40 & 18.64 & 3.10 & 12.75 \\
\hline Puntal $4 \mathrm{~m}$. & 2.45 & 17.17 & 3.20 & 11.77 & 4.00 & 8.53 \\
\hline Puntal $5 \mathrm{~m}$. & 3.55 & 17.17 & 4.25 & 12.26 & 5.20 & 8.14 \\
\hline
\end{tabular}

\section{Sopandas principales}

Las sopandas principales son elementos resistentes de sección prácticamente rectangular, de acero y de longitudes variables entre 2 y $4 \mathrm{~m}$. Las sopandas principales están distanciadas entre sí 1.6 o 2 metros (longitud del tablero) aunque se dispongan sopandas secundarias entre ellas. En estas sopandas se colocan los basculantes.

\section{Sopandas secundarias}

Su sección y dimensiones son iguales a las de las sopandas principales, pero los tableros apoyan sobre ellas de forma directa, sin ningún elemento intermedio como los basculantes.

\section{Basculantes}

Se colocan en las sopandas principales. Trabajan siempre apoyados en los dos extremos. El primero de los apoyos recae sobre un puntal mientras que el segundo se realiza mediante un pasador de acero situado a $18 \mathrm{~cm}$ del siguiente puntal. Estos elementos son los que permiten la retirada de los tableros de fondo de encofrado manteniendo los puntales y las sopandas principales (Fig. 3.4). 


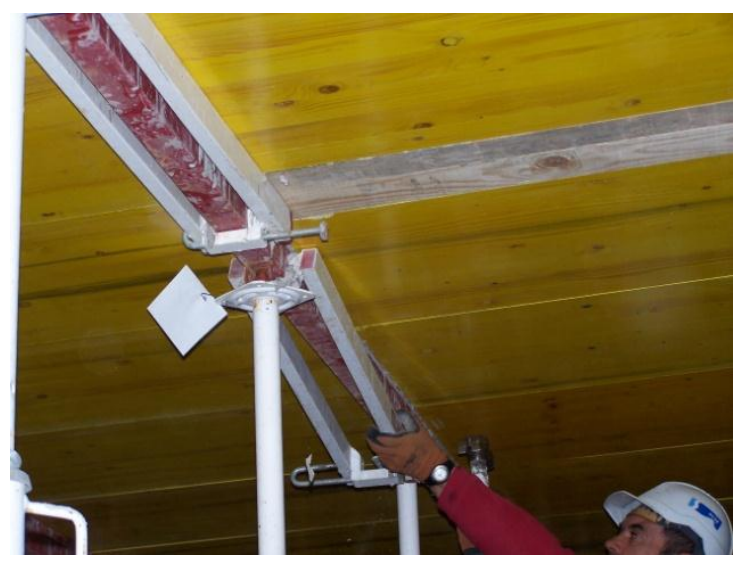

Fig. 3.4. Basculantes (edificio de Sabadell)

\section{Tableros de encofrado}

Los tableros de encofrado son de madera de $0.50 \mathrm{~m}$ de ancho, $2 \mathrm{~m}$ de largo y $27 \mathrm{~mm}$ de espesor, en el caso de los forjados de losa maciza y reticular de casetón perdido, y de $0.40 \mathrm{~m}$ de ancho, $0.80 \mathrm{~m}$ de largo y $35 \mathrm{~mm}$ de espesor, en el caso de los forjados reticulares de casetón recuperable. Los tableros de encofrado se apoyan sobre basculantes enganchados a las sopandas principales que permiten retirar dichos tableros, manteniendo así siempre el contacto entre sopandas y el forjado de hormigón.

\section{Portasopandas}

Son elementos que sirven de guía para el conjunto de sopandas principales y secundarias. Las portasopandas no cumplen ninguna función resistente.

\section{Cubetas}

Son elementos de polipropeno inyectado para la realización de forjados reticulares de casetón recuperable. Se apoyan sobre los basculantes.

\subsubsection{Instrumentación}

A continuación se describe la instrumentación de puntales, la medida de temperatura del hormigón de los forjados y el sistema de adquisición de datos.

\subsubsection{Puntales}

El número de puntales instrumentados varió para cada una de las obras. Cada puntal se instrumentó con tres bandas extensométricas o galgas, dispuestas al mismo nivel, para conocer exactamente los esfuerzos a los que estaban sometidos en cada una de las fases de construcción de la estructura. Además se utilizaron puntales como referencia con el objeto de medir el efecto de la temperatura ambiente sobre: los puntales, las galgas extensométricas y el equipo de adquisición de datos. Sobre estos puntales no se impuso ningún tipo de coacción en sus extremos, por lo que no formaron parte del sistema de cimbrado del edificio. 
El proceso de instrumentación de cada puntal se describe a continuación:

$\checkmark \quad$ Pulido de la superficie del puntal

La superficie donde iban a ser pegadas las galgas se pulió para quitar la pintura del puntal, dejando al descubierto una superficie lisa de acero (Fig. 3.5).

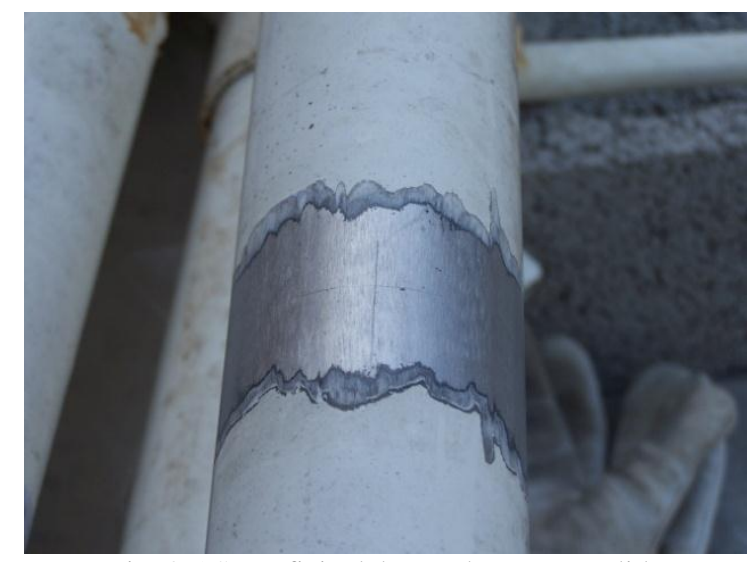

Fig. 3.5 Superficie del puntal una vez pulido

\section{$\checkmark$ Replanteo de bandas extensométricas y limpieza de la superficie del puntal}

Con el objetivo de instalar las bandas extensométricas, se realizó el replanteo de las tres galgas a una altura de $2.50 \mathrm{~m}$. de la base del puntal, distribuidas cada una a $120^{\circ}$ en el perímetro de éste. Para garantizar el perfecto contacto entre la superficie del puntal y la superficie de la galga, fue necesario limpiar la superficie del puntal con acetona. El montaje de las galgas extensométricas se realizó a 1/2 puente.

$\checkmark \quad$ Pegado de bandas extensométricas

Las bandas extensométricas, se pegaron con un adhesivo especial para acero (PU-120 suministrado por HBM). La Figura 3.6 muestra una de las bandas extensométricas pegada en la superficie del puntal.

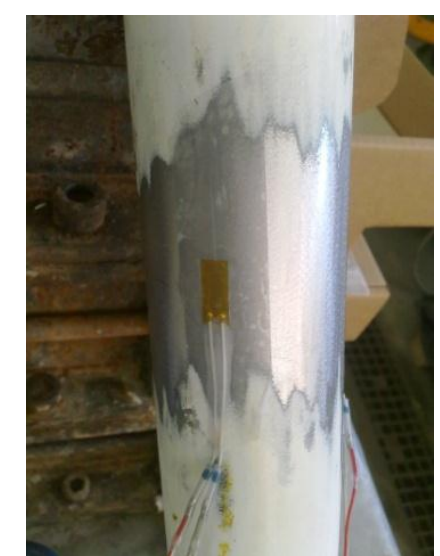

Fig. 3.6 Galga pegada en la superficie del puntal 
La totalidad de bandas extensométricas empleadas en el estudio experimental, fueron suministradas por HBM, con las siguientes características:

Tabla 3.3 Características de las bandas extensométricas

\begin{tabular}{ccccc}
\hline Tipo & Resistencia & $\begin{array}{c}\text { Factor de } \\
\text { galga }\end{array}$ & $\begin{array}{c}\text { Sensibilidad } \\
\text { transversal }\end{array}$ & Rango de temperatura \\
\hline $6 / 120 \mathrm{LY} 41-3-0.5 \mathrm{M}$ & $120 \Omega \pm 0.35 \%$ & Variable & $-0.1 \%$ & $-10 \ldots+45^{\circ} \mathrm{C}$ \\
\hline
\end{tabular}

Al tener distintos lotes de galga, estos tenían un factor de galga diferente. Cada puntal se numeró y se instrumentó con tres bandas extensométricas con el mismo factor de galga. Posteriormente se creó una base de datos con todos los puntales y el factor de galga de sus bandas extensométricas.

\section{Protección de las bandas extensométricas}

Con el fin de proteger las bandas extensométricas frente a agentes externos como la humedad, se empleó un esmalte de poliuretano suministrado por HBM. Adicionalmente las galgas se protegieron frente a posibles golpes mediante armaflex, un aislamiento térmico de espuma elastomérica a base de caucho sintético flexible, de estructura celular cerrada (Fig. 3.7).

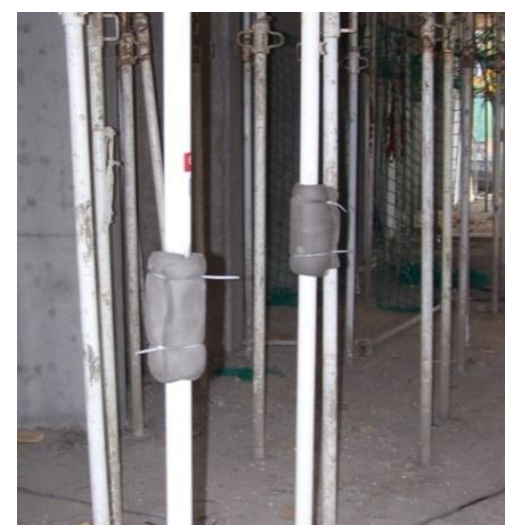

Fig. 3.7 Protección utilizada para las bandas extensométricas

\subsubsection{Temperatura}

Para poder determinar la variación de la temperatura en el forjado de hormigón y evaluar el gradiente térmico que se produce, se instalaron termopares embebidos en el hormigón a diferentes profundidades del forjado, tanto en el edificio de Sabadell como en el de Valencia. Asimismo, se midió la temperatura ambiente mediante un termopar libre.

Para el registro de las temperaturas se utilizaron termopares tipo $\mathrm{J}$ con un diámetro de $3 \mathrm{~mm}$ y largos de 50, 150, 200 y $300 \mathrm{~mm}$. Para su conexión se usaron conectores mini tipo J y cables especiales de prolongación para transmitir los datos al sistema de adquisición de datos (Fig. 3.8). 


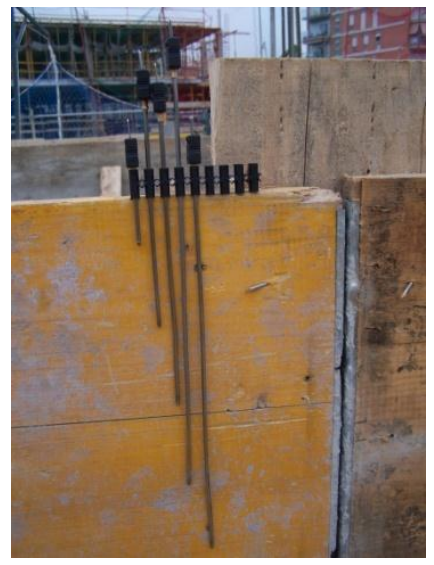

(a)

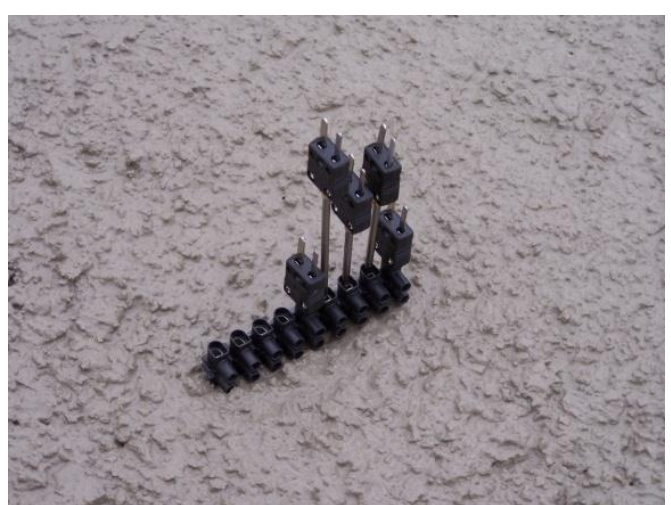

(b)

Fig. 3.8 Termopares tipo J (a) Termopares con conector mini tipo J (b) Termopares embebidos en el hormigón

\subsubsection{Sistema de adquisición de datos}

El sistema de adquisición de datos consistió en tres Estaciones de Medida (EDM) compuesta por equipos para la lectura de las bandas extensométricas y de un ordenador para almacenar los datos recopilados. Estas EDM tienen alimentación eléctrica empleando baterías de litio para cada una de ellas.

Para la lectura de las deformaciones proporcionadas por las bandas extensométricas se utilizaron módulos marca NATIONAL INSTRUMENTS, con referencia SG-140, permitiendo recopilar los datos de las tres bandas extensométricas de cada uno de los puntales. También se utilizó un módulo marca NATIONAL INSTRUMENTS, con referencia TC-120 para poder tomar datos de temperatura. Junto a los módulos de galgas y de temperatura, se utilizaron módulos de red marca NATIONAL INSTRUMENTS, con referencia FP-1601, que permiten transmitir los datos recopilados a los ordenadores portátiles. En la Figura 3.9 se muestra una de las EDM empleadas en la adquisición de datos.

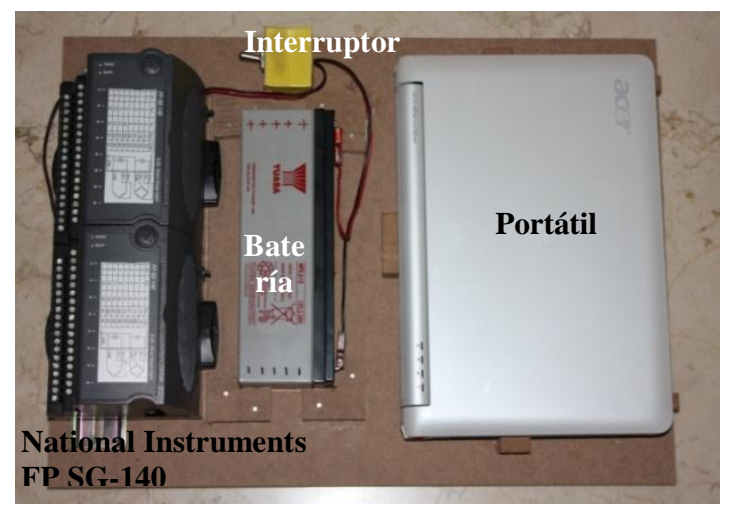

Fig. 3.9 Estación de medida empleada para la adquisición de datos

Los datos recopilados por el equipo de adquisición de datos fueron almacenados empleando un software desarrollado por D. Vicente Miguel Sosa, miembro de ICITECH. 


\subsubsection{Calibración de los puntales}

Con el fin de evaluar la precisión y dar por válida la utilización de las bandas extensométricas en los puntales, se ensayaron hasta la rotura 3 puntales sometidos a cargas de compresión centrada (Alvarado, 2009). Estos ensayos verificaron la validez del uso de las galgas para medir cargas en puntales durante la construcción de forjados hormigonados in situ.

\subsubsection{Estrategias de monitorización}

Además de estudiar distintas tipologías de forjados, las monitorizaciones se han realizado en vanos con distintas condiciones de contorno.

En el caso de los edificios de forjado de losa maciza y forjado reticular de casetón recuperable, se estudiaron dos vanos continuos, uno de esquina y otro de medianera. En cada uno de estos vanos se monitorizó una sopanda principal, la central, asumiendo que la carga media de dicha sopanda se puede considerar como la carga media del forjado. Este hecho queda demostrado en el Capítulo 4 (apartado 4.2.4) de la presente Tesis Doctoral.

En el edificio de forjado reticular de casetón perdido, se monitorizó un vano de medianera en los dos sótanos (forjados 1 y 2), que pasaba a tener continuidad en una sola dirección a partir del forjado 3 . En este caso, sólo existían 3 sopandas principales en el vano. Como una de ellas estaba pegada al muro en los forjados inferiores y en los siguientes quedaba bastante extrema, se decidió monitorizar las otras dos sopandas principales del vano (Figs. 3.52 y 3.53 ).

Puesto que lo que se pretendía en estos estudios experimentales era conocer los incrementos de carga en puntales y forjados debido a la ejecución de cada una de las operaciones constructivas, las medidas que se realizaron fueron mediciones instantáneas. Éstas consisten en tomar medidas antes y después de cada una de las operaciones constructivas (hormigonado, clareado y descimbrado). Las mediciones eran realizadas por dos personas equipadas cada una de ellas con una EDM. Con cada EDM se medían individualmente los puntales de una sopanda. La medición de un vano se llevaba a cabo en unos 10-15 minutos.

Adicionalmente, se tomaban medidas de los puntales dispuestos para compensar la temperatura. Estos puntales no tenían impuesto ningún tipo de coacción y por lo tanto su deformación era debida únicamente al efecto de la temperatura ambiente sobre los puntales, las galgas extensométricas y el equipo de adquisición de datos.

El valor medio de la deformación de las tres bandas extensométricas colocadas en cada puntal permite establecer con precisión la carga a la que estaba sometido cada uno de los puntales durante la construcción de la estructura. A partir de estas cargas se puede obtener la carga media $\left(\mathrm{q}_{\mathrm{med}}\right)$ sobre los puntales $\left(\mathrm{kN} / \mathrm{m}^{2}\right)$. Ésta se obtiene como la suma de la carga total de los puntales instrumentados dividida entre el área de influencia total de dichos puntales. 


\subsection{Estudio experimental de un edificio de forjado de losa maciza}

El edificio objeto de estudio se encuentra en la parcela IX del "Bulevar Arroyo de los Pinos", Madrid. Se trata de un edificio de forjado de losa maciza con 4 sótanos y 14 plantas con una altura de coronación de 45.10 metros.

La medición se realizó en dos vanos consecutivos, uno de esquina y otro de medianera, disponiendo una sopanda con 6 puntales instrumentados por cada vano. El vano de esquina tenía una luz entre pilares de $3.50 \times 4.50 \mathrm{~m}$, mientras que en el vano de medianera las luces eran de $5.40 \times 5.20 \mathrm{~m}$.

Las mediciones se realizaron desde el hormigonado del Forjado 1 (puntales apoyados en planta baja), hasta el hormigonado del Forjado 6 (puntales apoyados en el Forjado 5). Se midieron cargas hasta el hormigonado del Forjado 6 ya que en esta operación es donde en teoría se presenta la mayor solicitación de cargas sobre los forjados inferiores donde se apoyan puntales.

Los ciclos de construcción de la estructura quedaron definidos, para tres juegos de cimbras, con una planta cimbrada y dos clareadas, con un ritmo de ejecución de 7 días por planta.

La definición del estudio experimental se realizó el 13 de Marzo de 2009. A partir de esta fecha se inició con la primera fase del planteamiento de estudio experimental, donde quedó definida el área objeto de estudio y el número de plantas a instrumentar. El traslado de los puntales instrumentados y de los equipos de adquisición de datos se realizó el 4 de Junio de 2009. El estudio experimental inició el 8 de Junio de 2009 con el hormigonado del Forjado 1 y finalizó el 15 de Julio de 2009 con el hormigonado del Forjado 6.

\subsubsection{Descripción de la estructura}

Se trata de un edificio con 4 sótanos y 14 plantas. La planta baja tiene una altura de $3.65 \mathrm{~m}$, mientras que en el resto de plantas la altura entre pisos es de $3.05 \mathrm{~m}$. En los sótanos la altura entre pisos es de $3.00 \mathrm{~m}$, excepto en el primer sótano que es de $3.43 \mathrm{~m}$. La estructura se resuelve mediante losas de hormigón armado, más pantallas, pilares y vigas, también de hormigón armado.

\subsubsection{Estructura}

La estructura de hormigón armado tiene las siguientes características:

$\checkmark$ Cimentación: Dadas las condiciones del terreno de cimentación se proyectaron losas de hormigón armado de 1.50 y $0.60 \mathrm{~m}$ de canto.

$\checkmark$ Sótanos: los forjados de sótano se resolvieron mediante losas de hormigón armado de $0.30 \mathrm{~m}$ de canto. La altura entre pisos es de $3.43 \mathrm{~m}$ para el primer sótano y de $3.00 \mathrm{~m}$ para el resto.

$\checkmark$ Planta Baja: el forjado de planta baja se resuelve mediante una losa de hormigón armado de 0.60 $\mathrm{m}$ de canto. Además dicho forjado cuenta con vigas de cuelgue de hasta $1.00 \mathrm{~m}$ de canto.

$\checkmark$ Forjados 01-12 y 14-15: los forjados se resolvieron mediante losas macizas de hormigón de armado de $0.22 \mathrm{~m}$ de canto.

$\checkmark$ Forjado 13: el forjado se resolvió mediante una losa de hormigón de $0.30 \mathrm{~m}$ de canto. 
En la Figura 3.10 se muestra una sección del edificio.

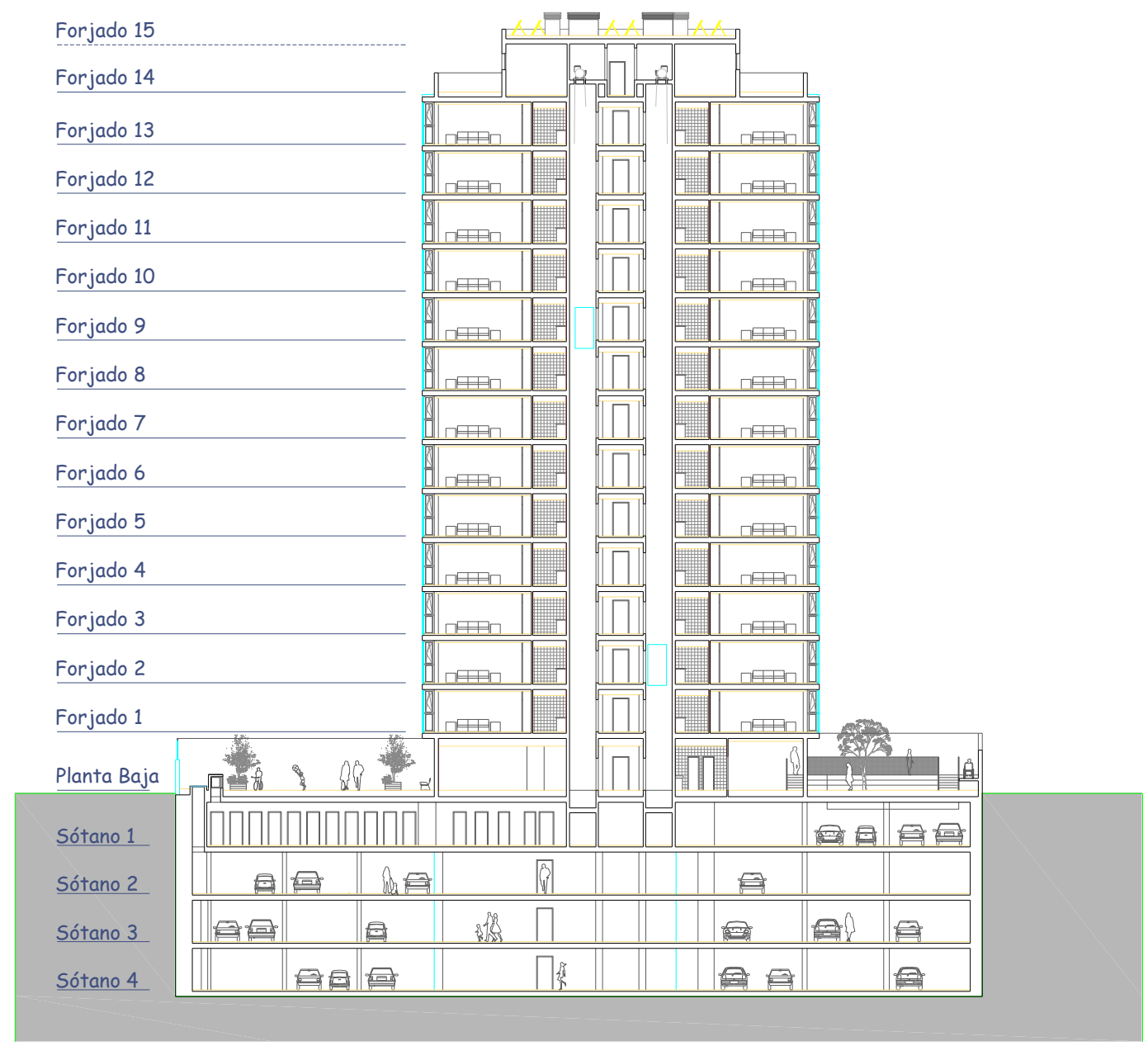

Fig. 3.10 Sección del edificio de forjado de losa maciza

\subsubsection{Materiales}

Los materiales empleados en la construcción de este edificio se describen a continuación:

$\checkmark$ El hormigón de la losa de cimentación es HA-30/B/40/IIa+Qa

- Resistencia característica a compresión $30 \mathrm{MPa}$.

- Consistencia: Blanda.

- Tamaño máximo del árido: $40 \mathrm{~mm}$.

- Clase general de exposición: IIa+Qa Elementos enterrados en ambientes con contenidos de sustancias químicas capaces de provocar alteración del hormigón con velocidad lenta.

$\checkmark$ El hormigón de las pantallas es HA-30/F/20/IIa+Qa

- Resistencia característica a compresión $30 \mathrm{MPa}$. 
- Consistencia: Fluida.

- Tamaño máximo del árido: $20 \mathrm{~mm}$.

- Clase general de exposición: IIa+Qa Elementos enterrados en ambientes con contenidos de sustancias químicas capaces de provocar alteración del hormigón con velocidad lenta.

$\checkmark$ El hormigón de los pilares es HA-35/B/20/IIa

- Resistencia característica a compresión $35 \mathrm{MPa}$.

- Consistencia: Blanda.

- Tamaño máximo del árido: $20 \mathrm{~mm}$.

- Clase general de exposición: IIA Interiores sometidos a humedades relativas medias altas.

$\checkmark$ El hormigón de los forjados es HA-25/B/40/IIa

- Resistencia característica a compresión $25 \mathrm{MPa}$.

- Consistencia: Blanda.

- Tamaño máximo del árido: $40 \mathrm{~mm}$.

- Clase general de exposición: IIA Interiores sometidos a humedades relativas medias altas.

Acero para armar: B-500-S

\subsubsection{Zona de estudio}

La zona de estudio se observa en la Fig. 3.11. Se eligieron los vanos de esquina y medianera que es donde se espera que se den las cargas máximas en puntales. 


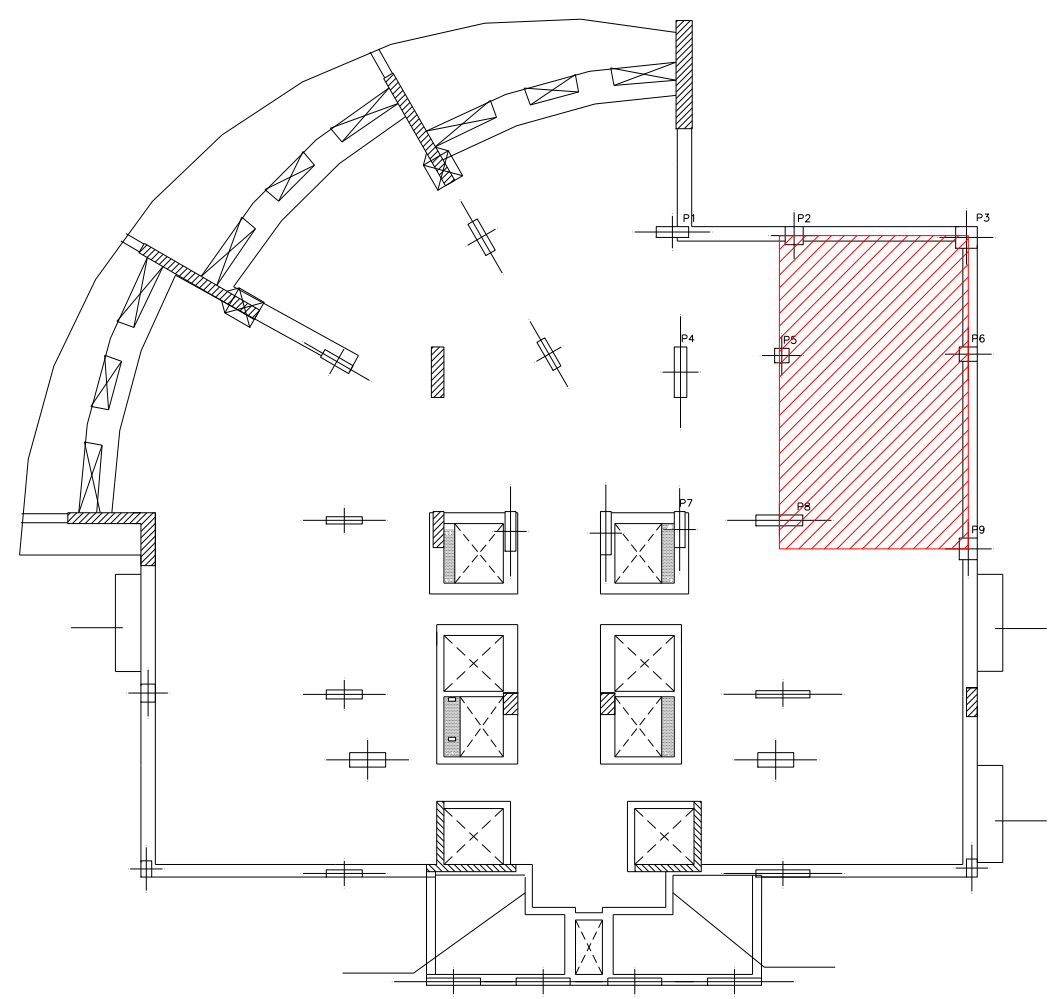

Fig. 3.11 Zona de estudio del edificio de forjado de losa maciza

Por cada planta se instrumentó un total de 12 puntales (6 por cada uno de los vanos). Su disposición es la que se muestra en las Figuras 3.12 y 3.13. Cada puntal se instrumentó con tres bandas extensométricas, para conocer exactamente los esfuerzos a los que estaban sometidos en cada una de las fases de construcción de la estructura. Adicionalmente 3 puntales fueron utilizados como referencia, con el objeto de medir el efecto de la temperatura ambiente sobre: los puntales, las galgas extensométricas y el equipo de adquisición de datos. Sobre estos puntales no se impuso ningún tipo de coacción en sus extremos, por lo que no formaron parte del sistema de cimbrado del edificio. 


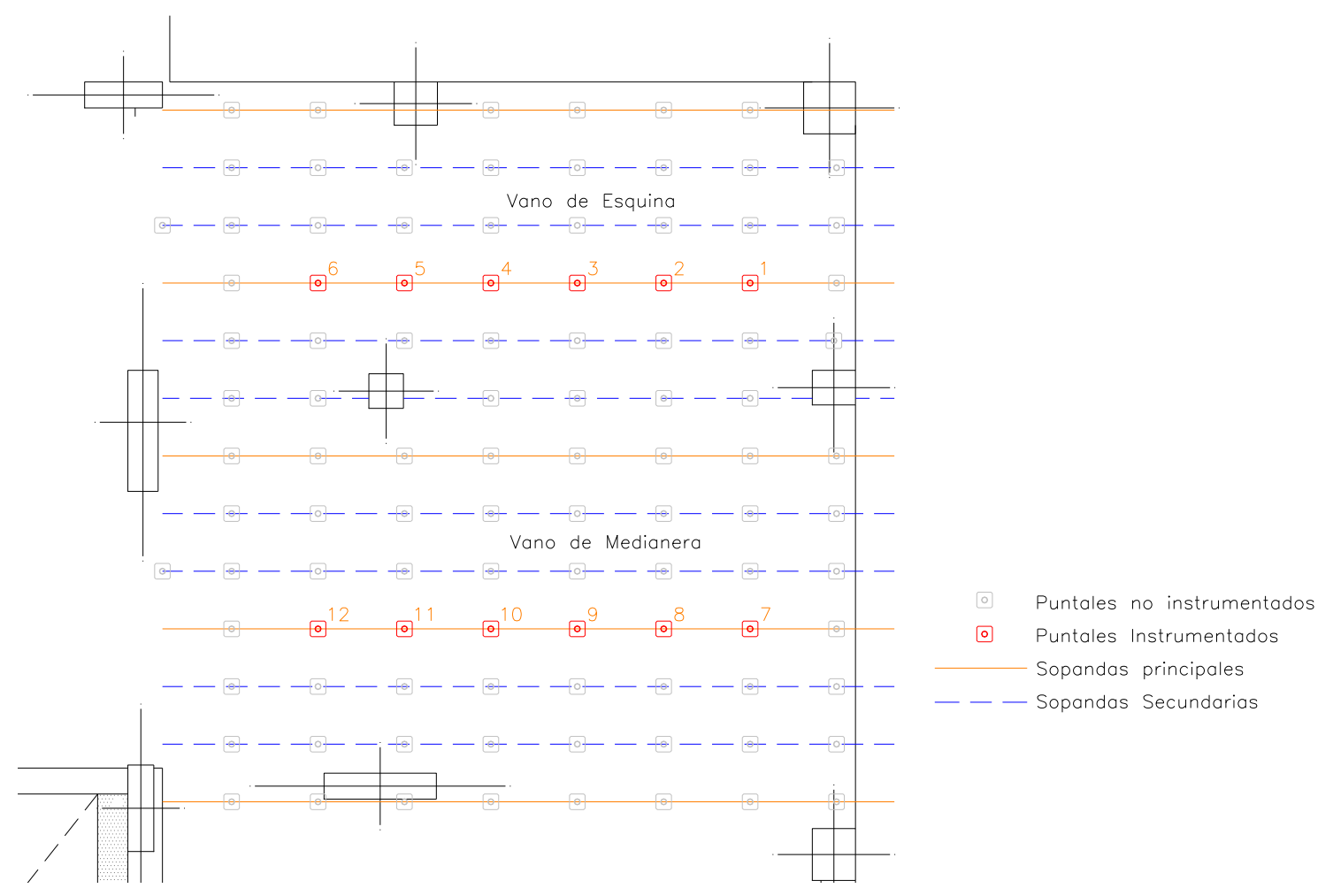

Fig. 3.12 Disposición de sopandas principales y secundarias sobre planta baja del edificio de forjado de losa maciza

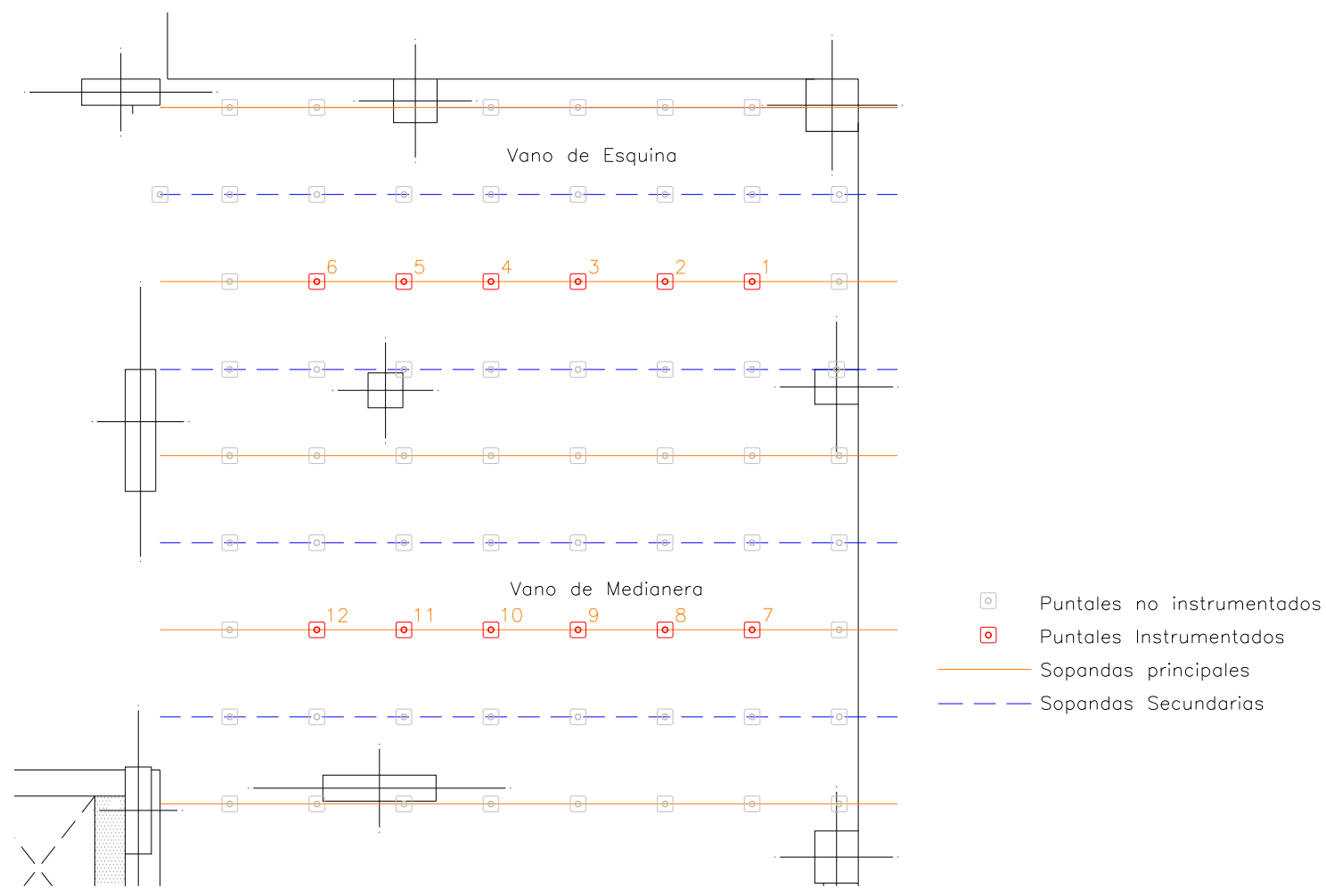

Fig. 3.13 Disposición de sopandas principales y secundarias plantas superiores del edificio de forjado de losa maciza 
La instrumentación se realizó desde el hormigonado del Forjado 1 hasta el hormigonado del Forjado 6. El Forjado de planta baja, al tener un canto de $0.60 \mathrm{~m}$ y vigas de cuelgue de hasta $1.00 \mathrm{~m}$ de canto, se puede considerar como infinitamente rígido en comparación al conjunto de puntales.

Se midieron cargas hasta el forjado 6 debido a que se utilizaron 3 juegos de puntales. Cuando se hormigona dicho forjado se cumple un ciclo completo del sistema de puntales y encofrado, lo cual permite evaluar cuáles son las cargas máximas a las que estarán sometidos los forjados y los puntales.

\subsubsection{Proceso constructivo}

El proceso constructivo adoptado para la construcción del edificio consistió en mantener dos plantas clareadas y una cimbrada, es decir utilizando 3 juegos de puntales. Las medidas experimentales fueron tomadas desde el hormigonado del forjado 1 hasta el hormigonado del forjado 6.

Las operaciones constructivas en las que se midieron las cargas en puntales son las siguientes:

Día "0" (8 de Junio de 2009): una vez hormigonado el forjado de planta baja y los pilares de la planta baja se instaló el sistema de cimbrado y encofrado para el hormigonado del primer forjado (Fig. 3.14).
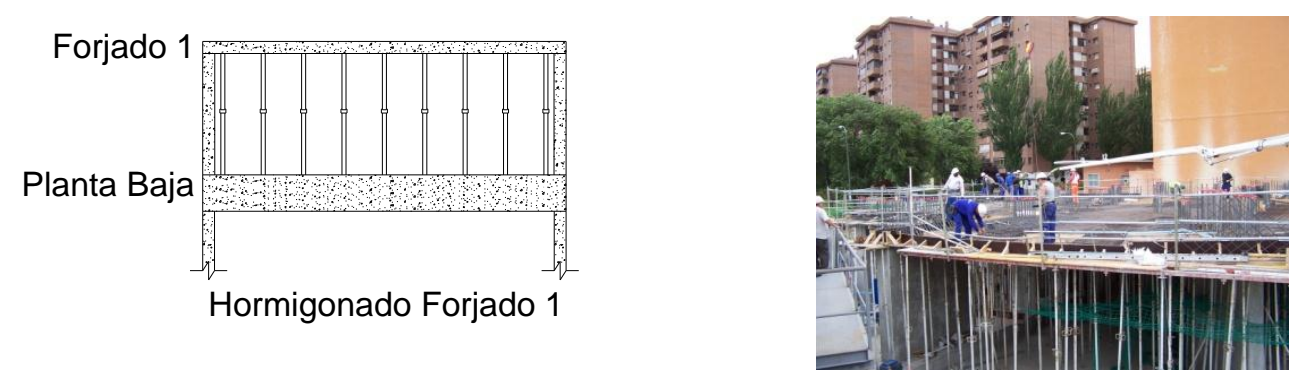

Fig. 3.14 Proceso constructivo día " 0 " (forjado de losa maciza)

Día "7" (15 de Junio de 2009): al cabo de siete días del hormigonado del primer forjado, se procedió a la retirada de fondos de encofrado y al clareado de puntales (Fig. 3.15).
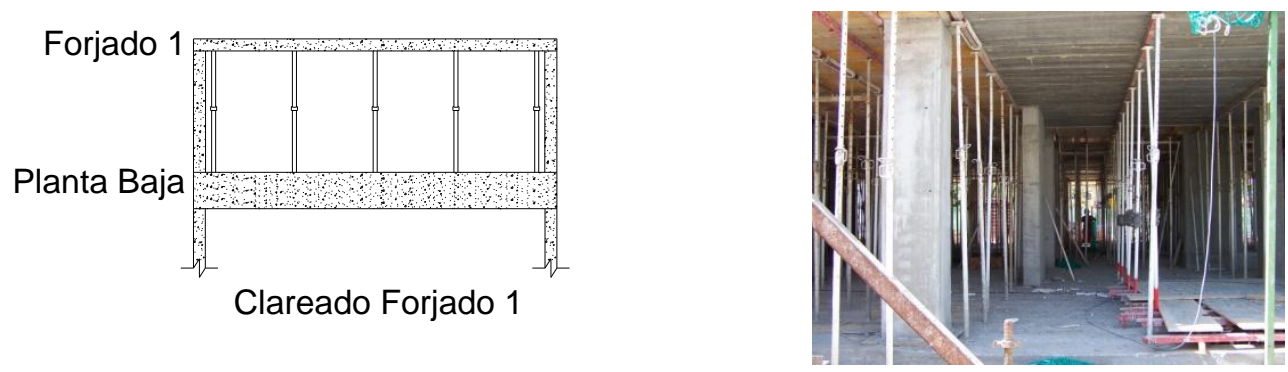

Fig. 3.15 Proceso constructivo día "7" (forjado de losa maciza) 
$\checkmark$ Día "10" (18 de Junio de 2009): una vez preparado el sistema de encofrado y cimbrado del segundo forjado se ejecutó su hormigonado (Fig. 3.16).
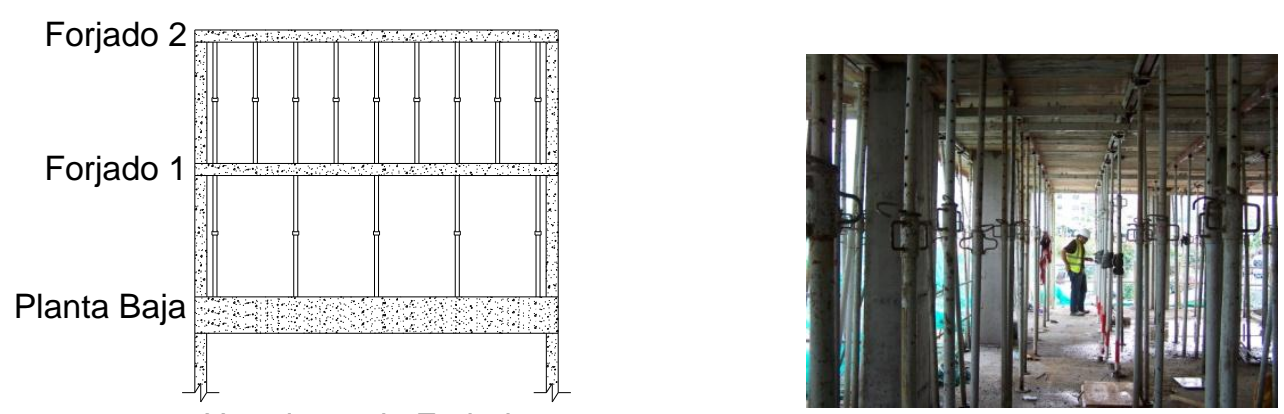

Hormigonado Forjado 2

Fig. 3.16 Proceso constructivo día "10" (forjado de losa maciza)

$\checkmark$ Día "15" (23 de Junio de 2009): transcurridos cinco días de hormigonado del segundo forjado, se retiraron los fondos de encofrado y se realizó el clareado de puntales (Fig. 3.17).
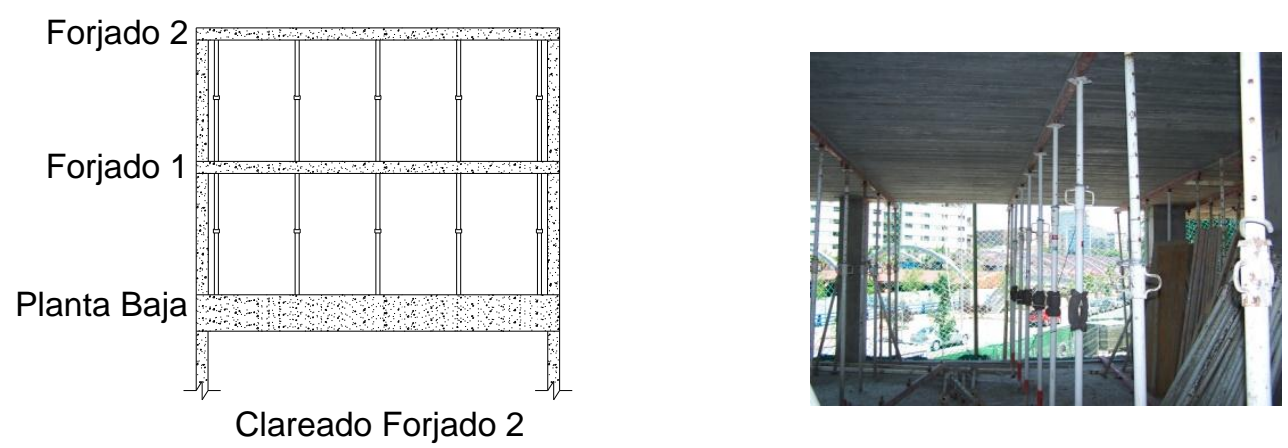

Fig. 3.17 Proceso constructivo día "15" (forjado de losa maciza)

$\checkmark$ Día "16" (24 de Junio de 2009): una vez instalado el sistema de encofrado y cimbrado se procedió a hormigonar el tercer forjado (Fig. 3.18).
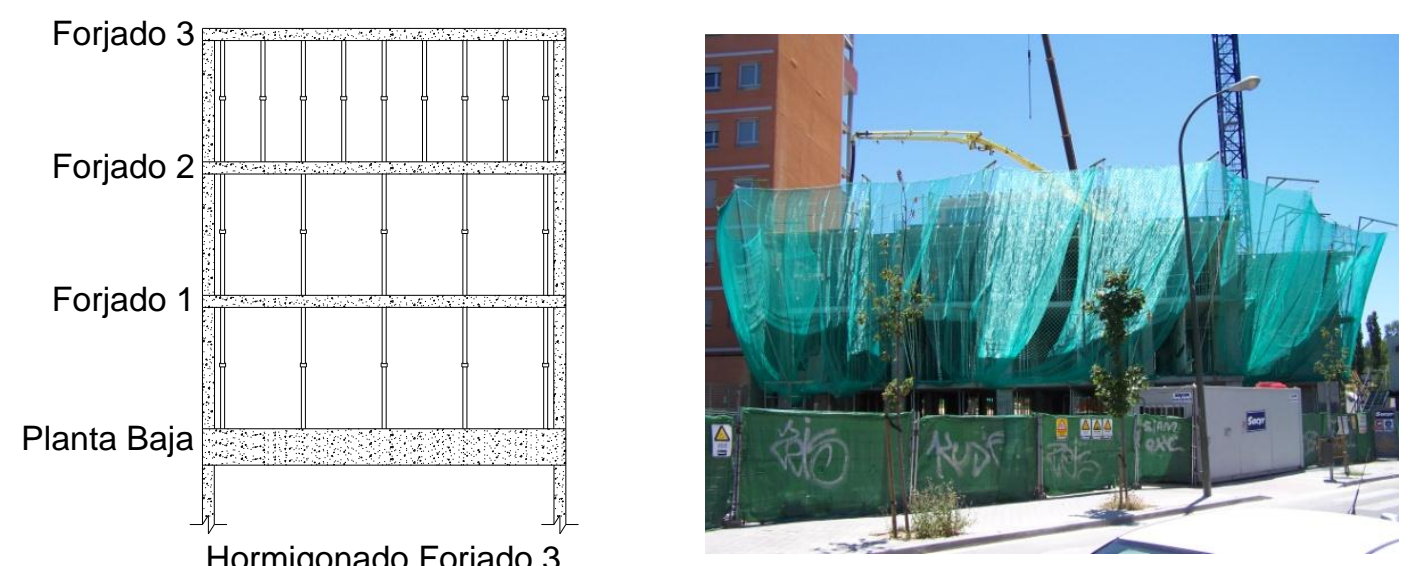

Fig. 3.18 Proceso constructivo día "16" (forjado de losa maciza) 
Día "22" (30 de Junio de 2009): seis días después de su hormigonado se procedió al clareado del forjado 3 (Fig. 3.19).
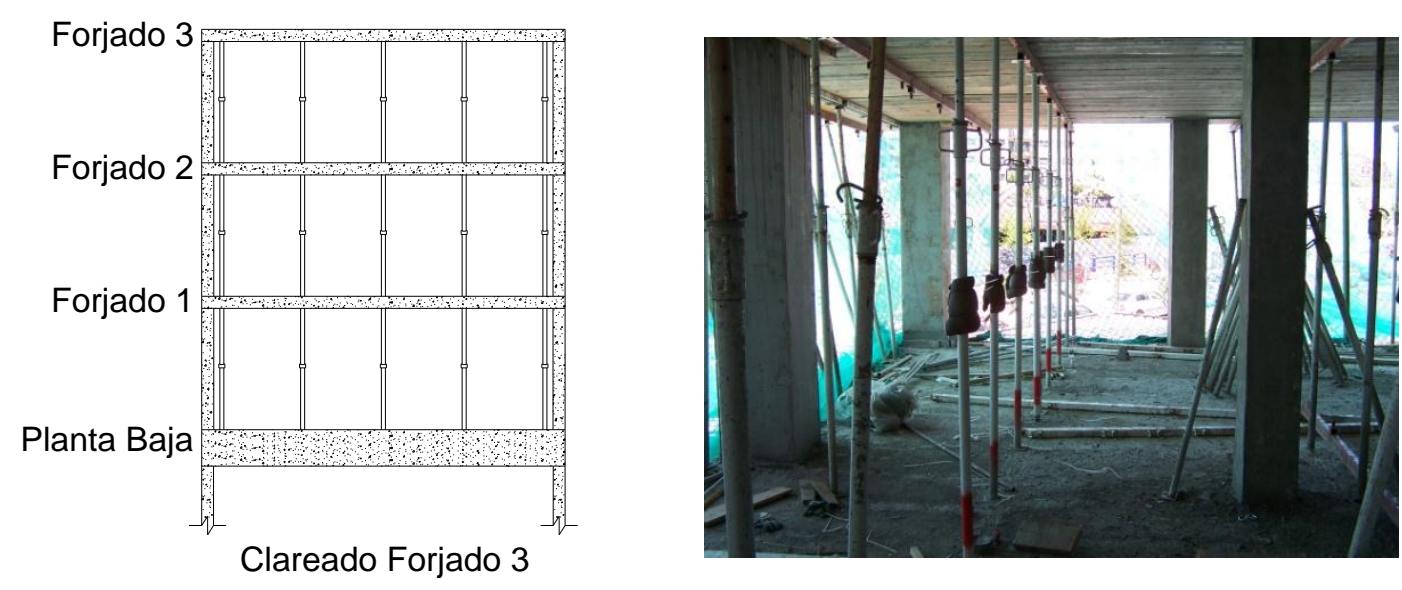

Fig. 3.19 Proceso constructivo día "22" (forjado de losa maciza)

Día “23 a” (1 de Julio de 2009): en esta fase se procedió al descimbrado del forjado 1 (Fig. 3.20).
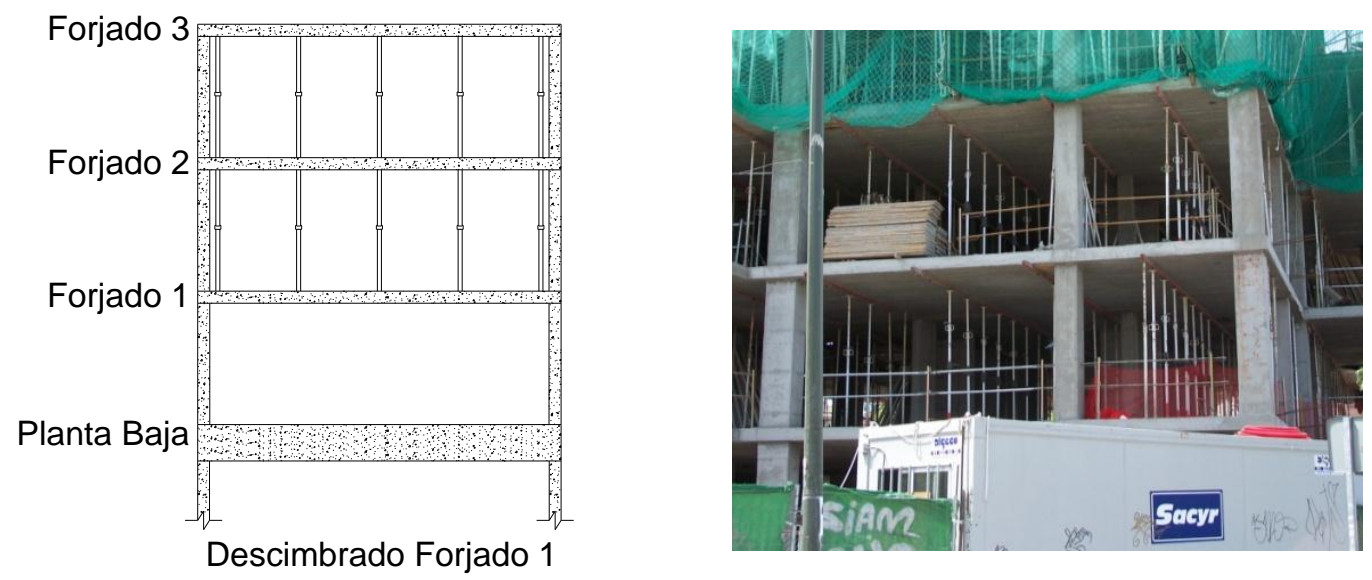

Fig. 3.20 Proceso constructivo día "23 a" (forjado de losa maciza) 
$\checkmark$ Día "23 b" (1 de Julio de 2009): Instalado el sistema de cimbrado y encofrado se procedió al hormigonado del forjado 4 (Fig. 3.21).
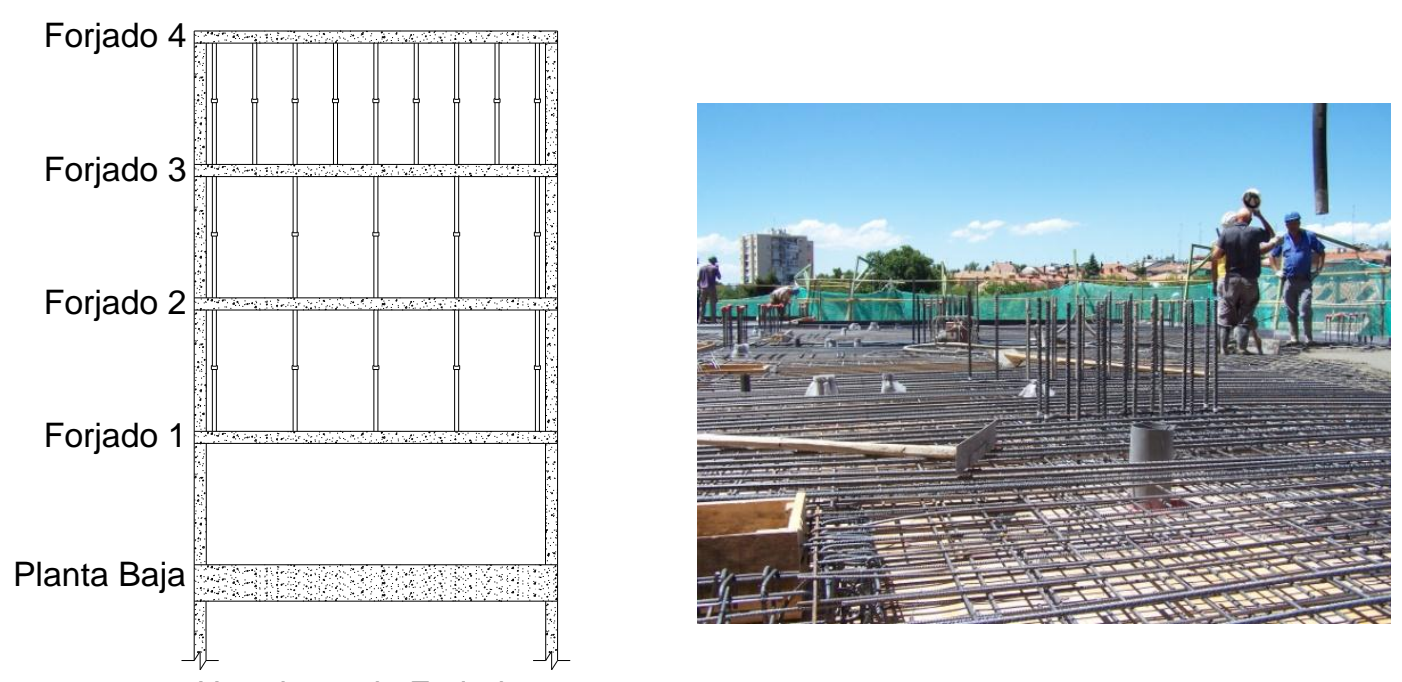

Hormigonado Forjado 4

Fig. 3.21 Proceso constructivo día "23 b" (forjado de losa maciza)

Antes de realizar el hormigonado del forjado 4 se informó por parte del encargado de la obra que algunos de los puntales bajo el forjado 3 fueron aflojados (los únicos no aflojados según el encargado de obra fueron los puntales instrumentados), lo cual produce un efecto de recimbrado parcial que se podrá reflejar en una reducción de carga en los forjados 2 y 1 antes del hormigonado del forjado 4.

$\checkmark$ Día "28" (6 de Julio de 2009): 5 días después de su hormigonado se procedió al clareado del forjado 4 (Fig. 3.22).
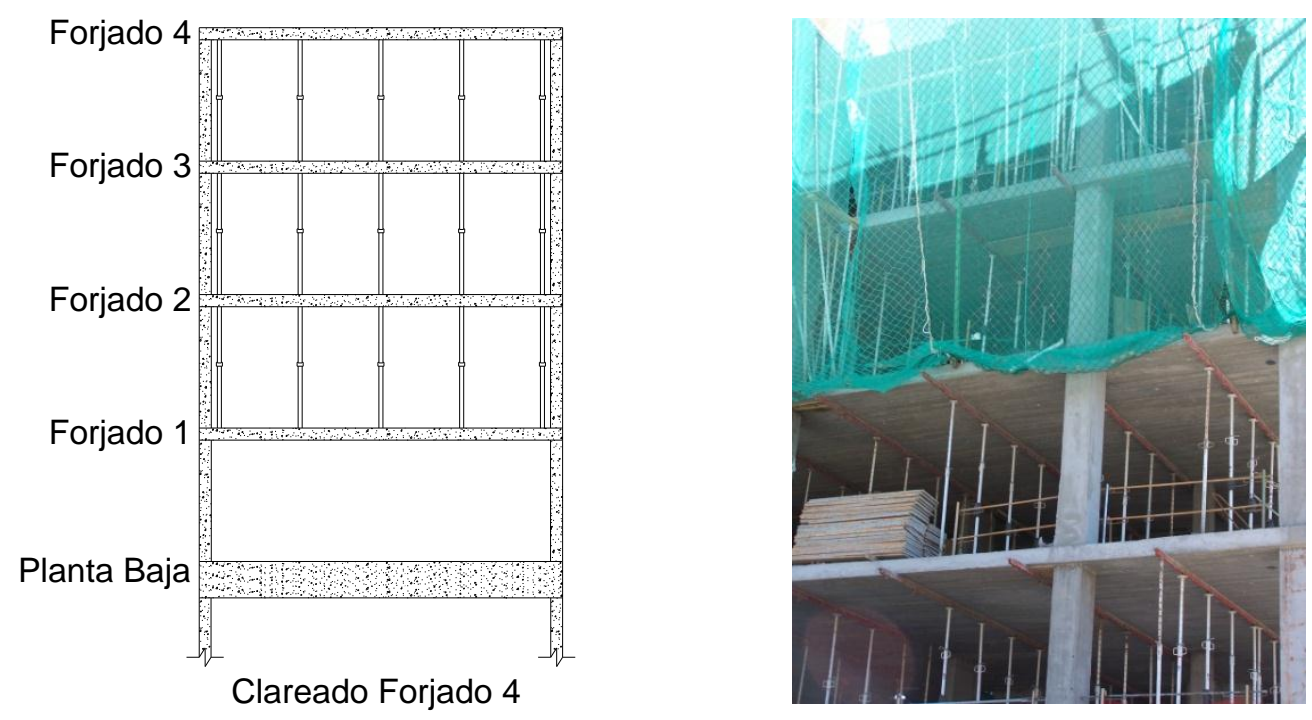

Fig. 3.22 Proceso constructivo día "28" (forjado de losa maciza) 
Día “29” (7 de Julio de 2009): en esta fase se realizó el descimbrado del forjado 2 (Fig. 3.23)
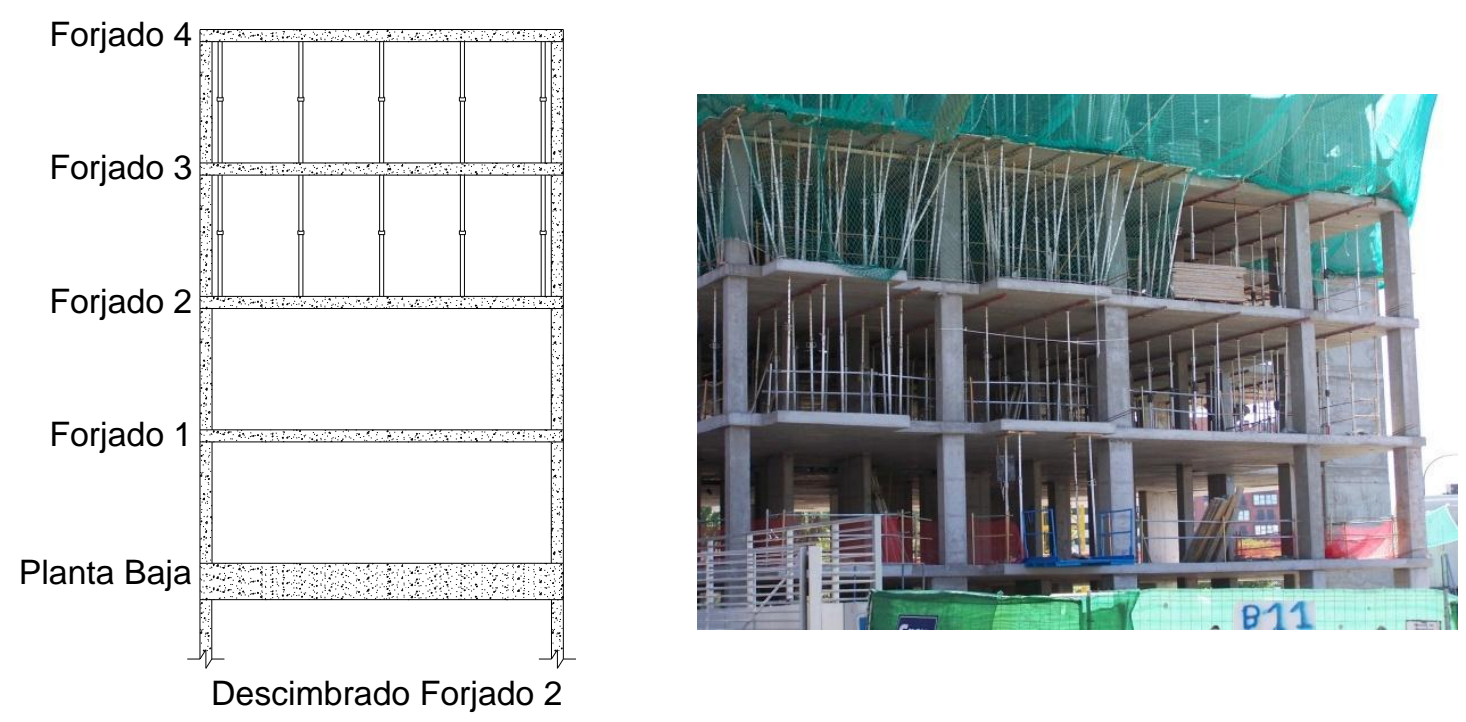

Fig. 3.23 Proceso constructivo día "29” (forjado de losa maciza)

Día “30” (8 de Julio de 2009): en el día “30” se procedió al hormigonado del 5 forjado (Fig. 3.24).
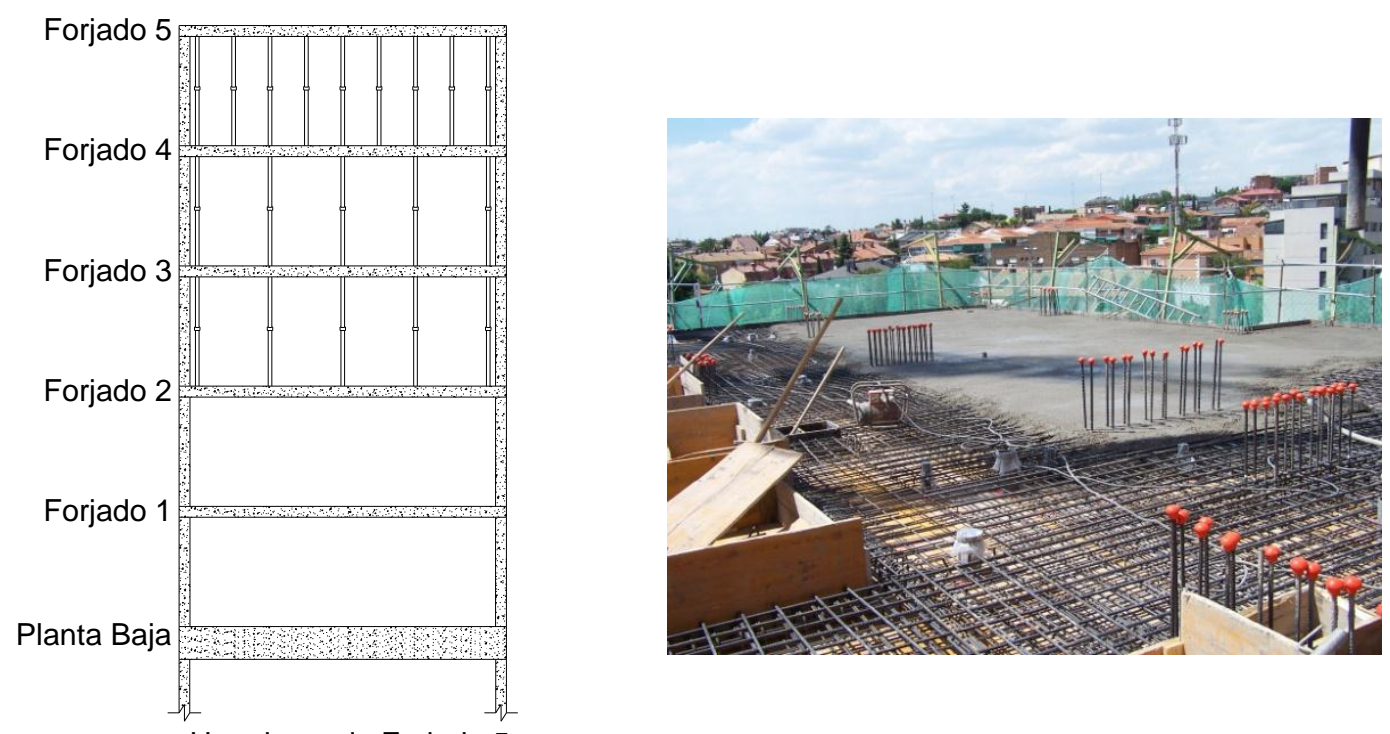

Hormigonado Forjado 5

Fig. 3.24 Proceso constructivo día “30” (forjado de losa maciza) 
$\checkmark$ Día "35" (13 de Julio de 2009): una vez hormigonado el forjado 5, a los cinco días se procedió con su clareado (Fig. 3.25).
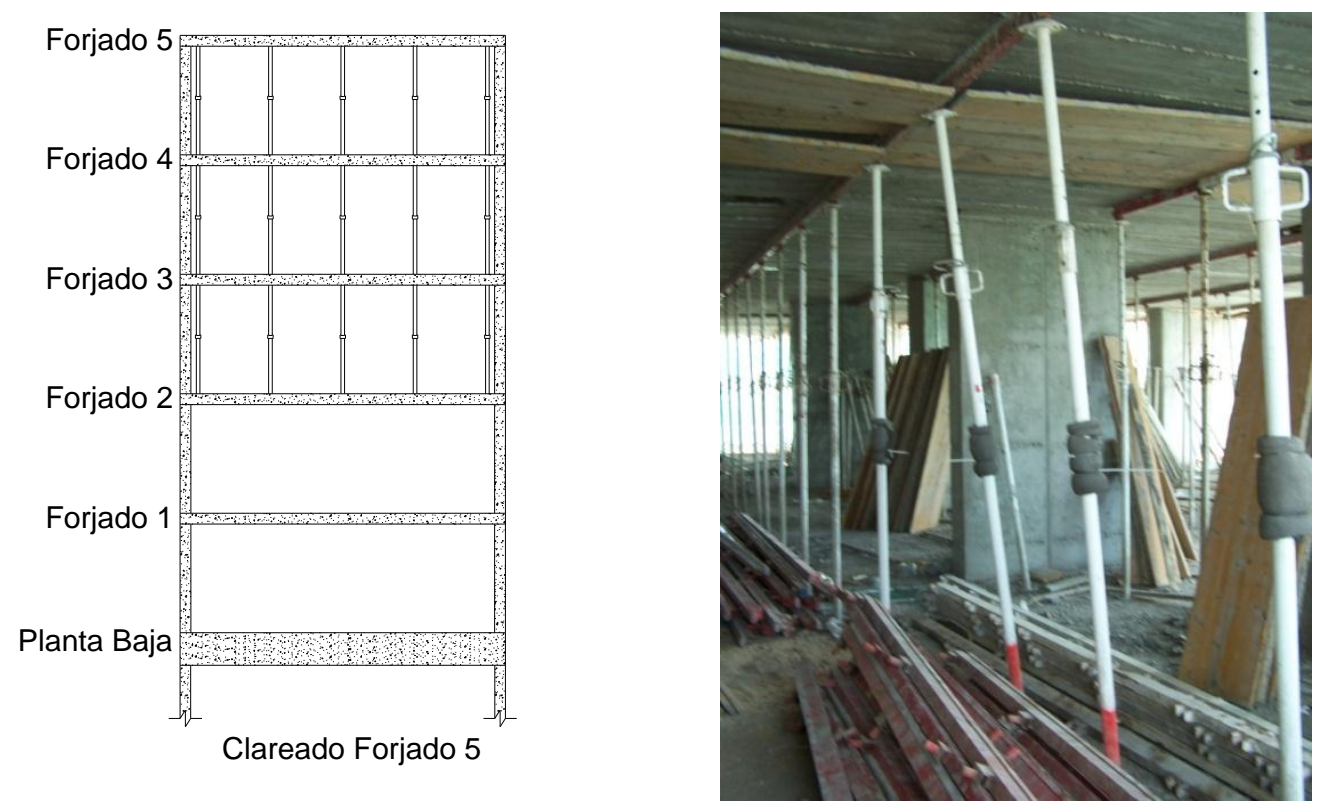

Fig. 3.25 Proceso constructivo día “35” (forjado de losa maciza)

Durante el clareado del forjado 5, se informó por parte del encargado de obra, que los puntales del forjado 3 (inclusive los puntales instrumentados) fueron apretados debido a que se detectó que los puntales de una de las sopandas se encontraban poco ajustados.

$\checkmark$ Día "36" (14 de Julio de 2009): esta operación constructiva consistió en el descimbrado del forjado 3 (Fig. 3.26).
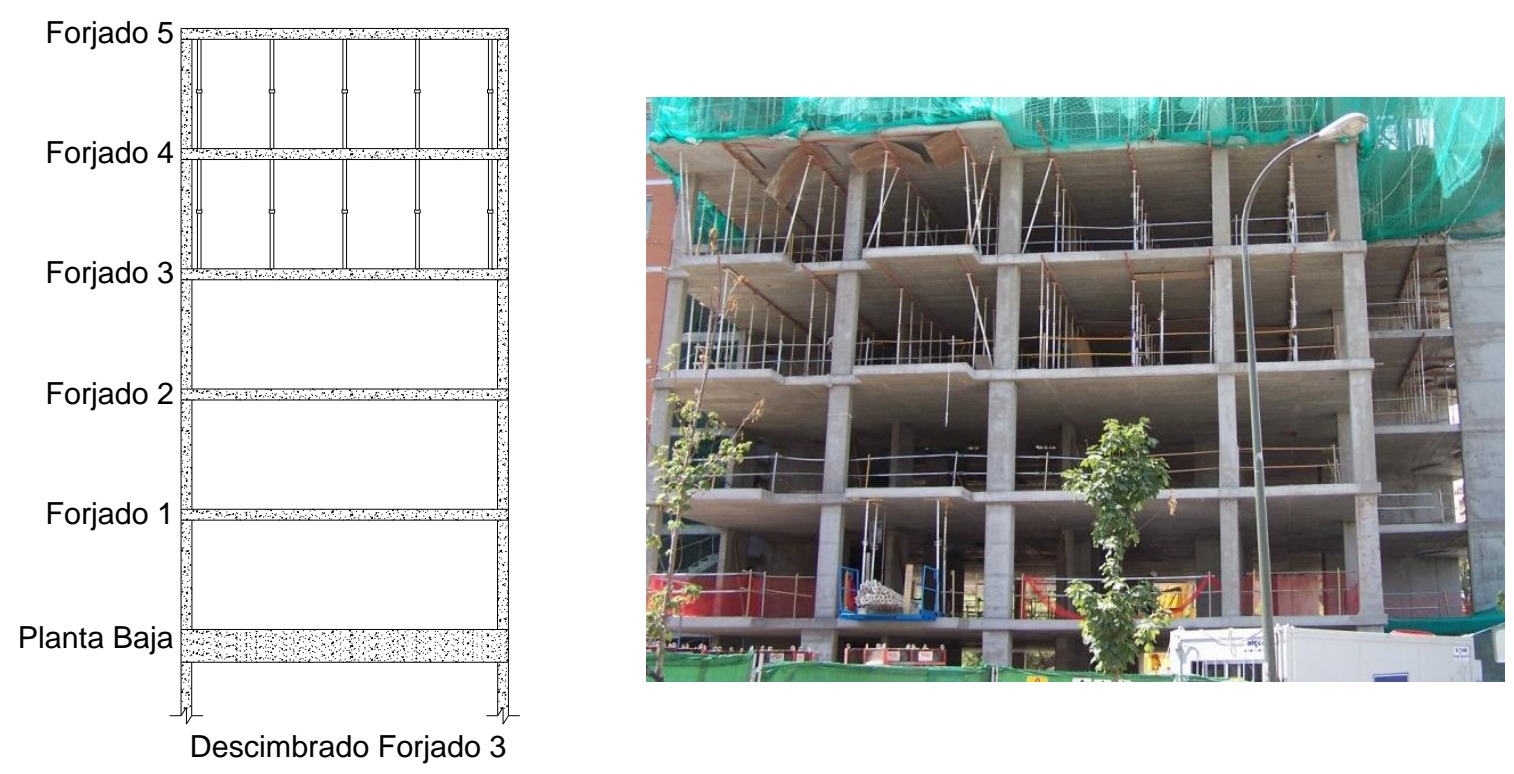

Fig. 3.26 Proceso constructivo día "36” (forjado de losa maciza) 
$\checkmark$ Día “37” (15 de Julio de 2009): la última operación constructiva estudiada consistió en el hormigonado del forjado 6 (Fig. 3.27).
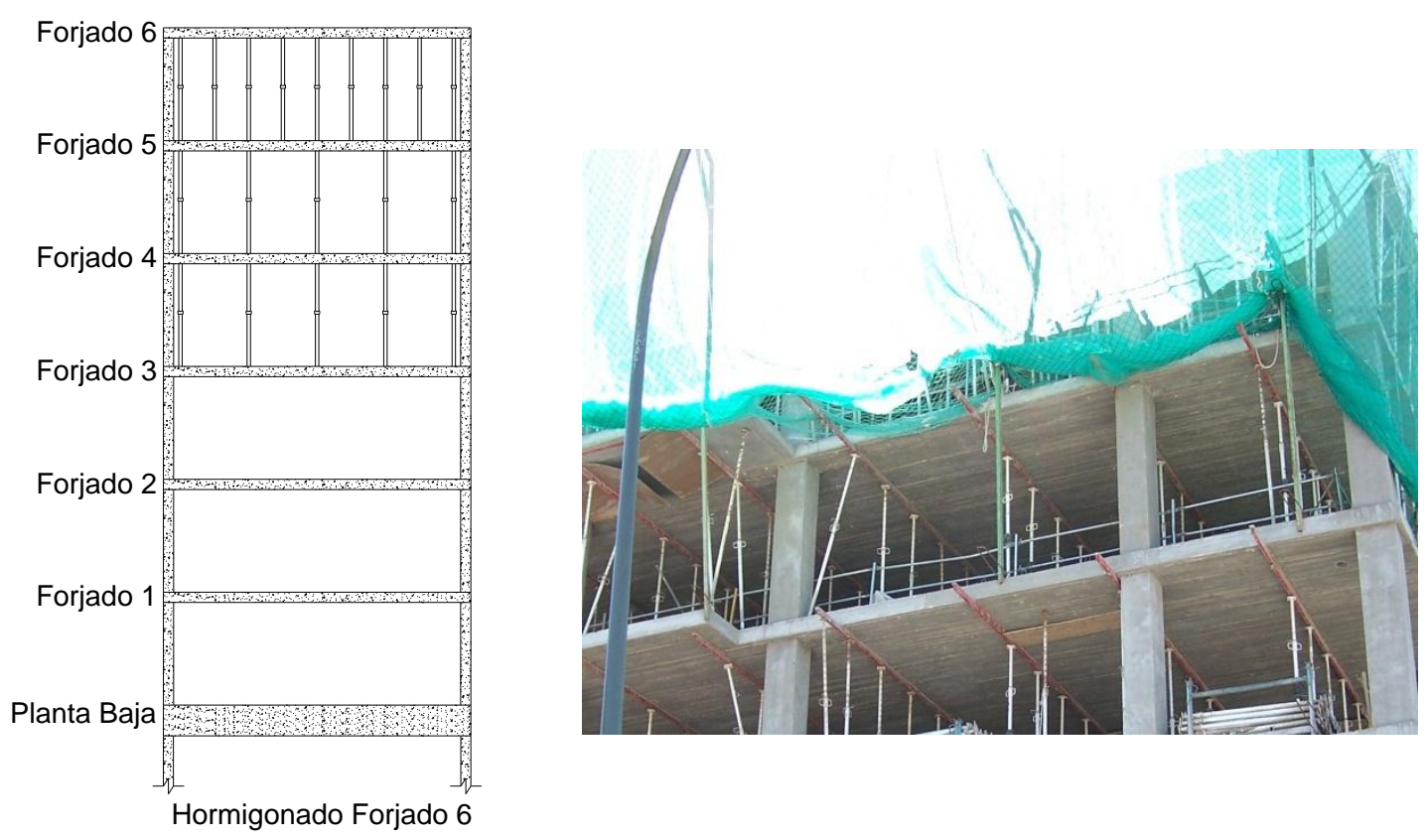

Fig. 3.27 Proceso constructivo día "37” (forjado de losa maciza)

\subsubsection{Resultados del estudio experimental}

Se instrumentaron 2 sopandas correspondientes a 2 vanos consecutivos, uno de esquina y otro de medianera (véase Figs. 3.12 y 3.13). Se realizaron medidas instantáneas, es decir, medidas tomadas una vez ejecutada cada una de las fases del proceso constructivo (hormigonado, clareado, descimbrado), desde el hormigonado del Forjado 1 hasta el hormigonado del Forjado 6.

La medición de cargas instantáneas durante la construcción del edificio experimental, permite analizar cómo se transmiten las cargas entre forjados y puntales debido a las operaciones constructivas de hormigonado, clareado y descimbrado de un forjado. En el Apéndice I se muestran, de forma amplia, los resultados obtenidos de dicha medición instantánea.

A continuación se resumen las mediciones del estudio experimental para cada uno de los vanos. Estos resultados se expresan en coeficientes de carga, siendo el coeficiente de carga en forjados $\left(\mathrm{C}_{\mathrm{f}}\right)$ la relación entre la carga media que soporta el forjado en un determinado momento y el peso propio del forjado y el coeficiente de carga en puntales $\left(\mathrm{C}_{\mathrm{p}}\right)$ la relación entre la carga media en puntales y el peso propio del forjado

\section{$\checkmark$ Vano de esquina}

Las Figuras 3.28 y 3.29 muestran la evolución del coeficiente de carga para el forjado 1 y para los puntales bajo este forjado durante todo el proceso constructivo. Las Figuras 3.30 y 3.31 muestran la evolución del coeficiente de carga para el forjado 2 y para los puntales bajo este forjado durante todo 
el proceso constructivo. Las Figuras 3.32 y 3.33 muestran la evolución del coeficiente de carga para el forjado 3 y para los puntales bajo este forjado durante todo el proceso constructivo. Las Figuras $3.34 \mathrm{y}$ 3.35 muestran la evolución del coeficiente de carga para el forjado 4 y para los puntales bajo este forjado durante todo el proceso constructivo. Por último, las Figuras 3.36 y 3.37 muestran la evolución del coeficiente de carga para el forjado 5 y para los puntales bajo este forjado durante todo el proceso constructivo. No se muestra una evolución del coeficiente de carga en el forjado 6 y en los puntales bajo este forjado debido a que únicamente fue objeto de medición el hormigonado de dicho forjado (operación en la cual concluyó el estudio experimental).

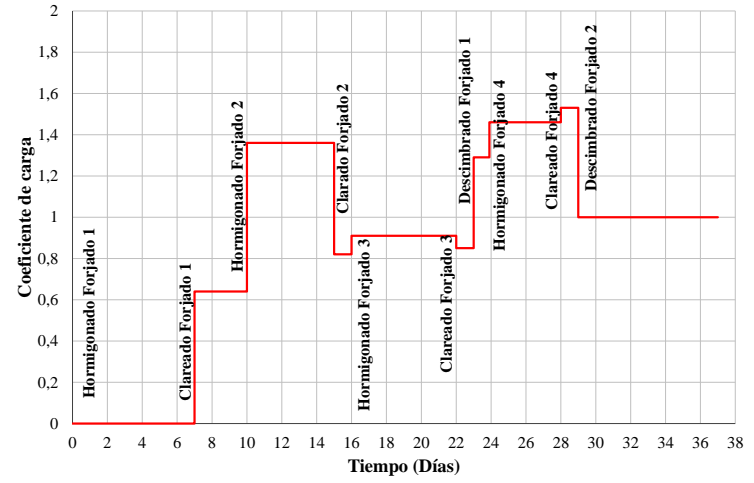

Fig. 3.28 Coeficientes de carga en el forjado 1 (Forjado de losa maciza - Vano de esquina)

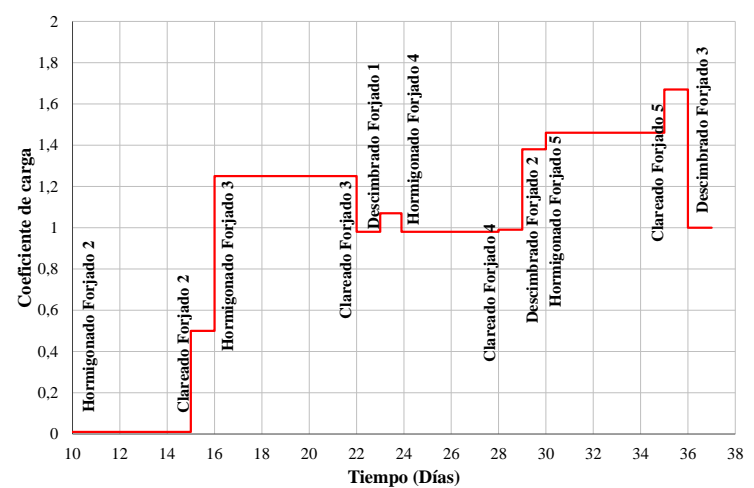

Fig. 3.30 Coeficientes de carga en el forjado 2 (Forjado de losa maciza - Vano de esquina)

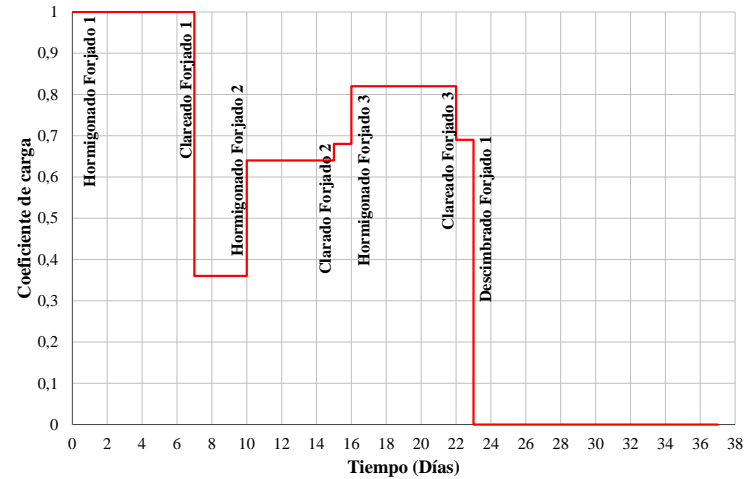

Fig. 3.29 Coeficientes de carga en puntales bajo el forjado 1 (Forjado de losa maciza - Vano de esquina)

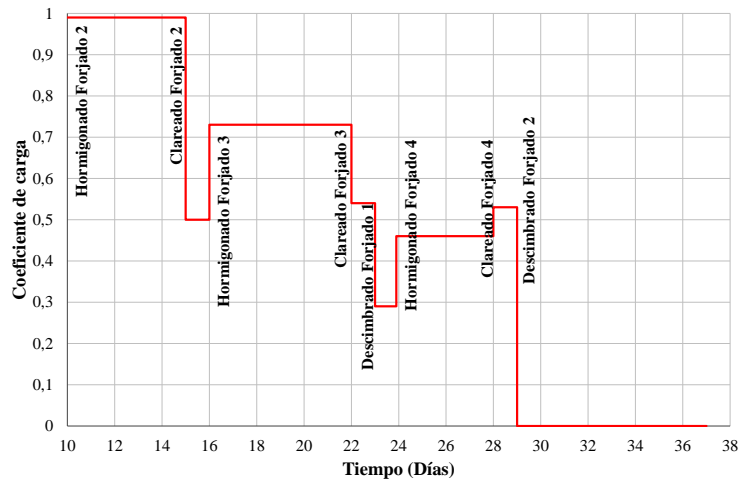

Fig. 3.31 Coeficientes de carga en puntales bajo el forjado 2 (Forjado de losa maciza - Vano de esquina) 


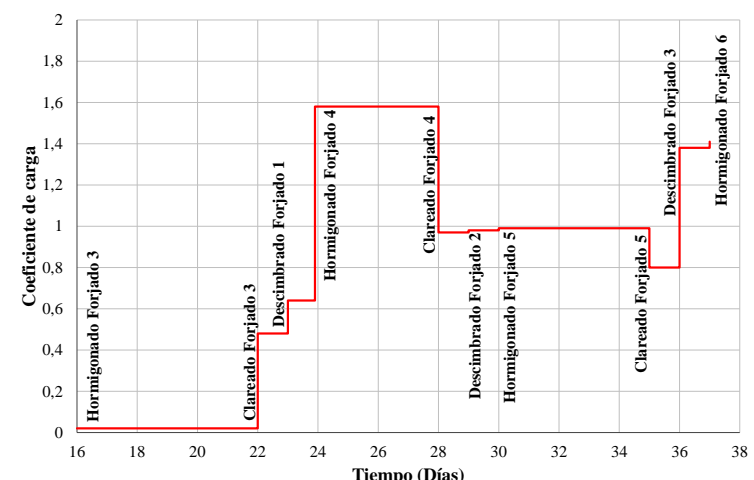

Fig. 3.32 Coeficientes de carga en el forjado 3 (Forjado de losa maciza - Vano de esquina)

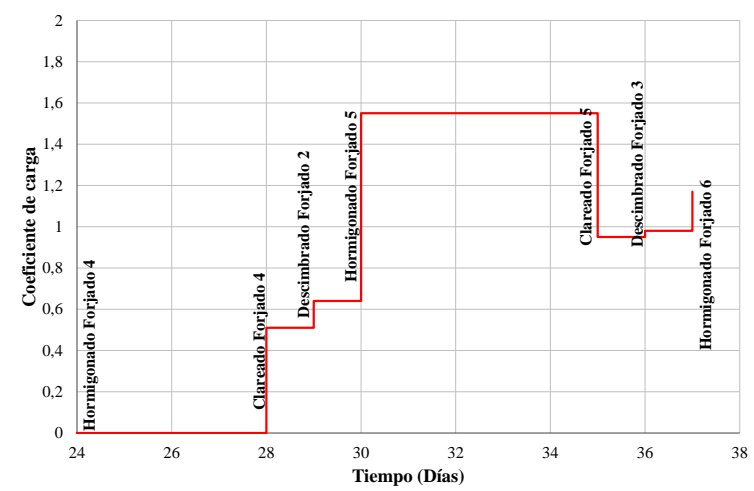

Fig. 3.34 Coeficientes de carga en el forjado 4 (Forjado de losa maciza - Vano de esquina)

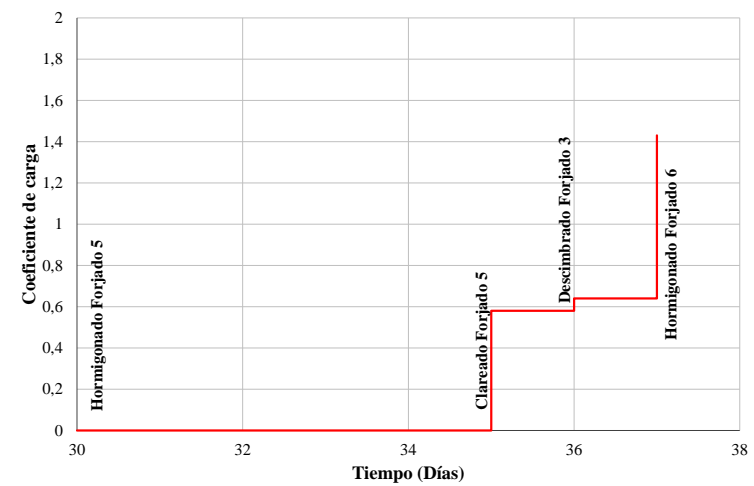

Fig. 3.36 Coeficientes de carga en el forjado 5 (Forjado de losa maciza - Vano de esquina)

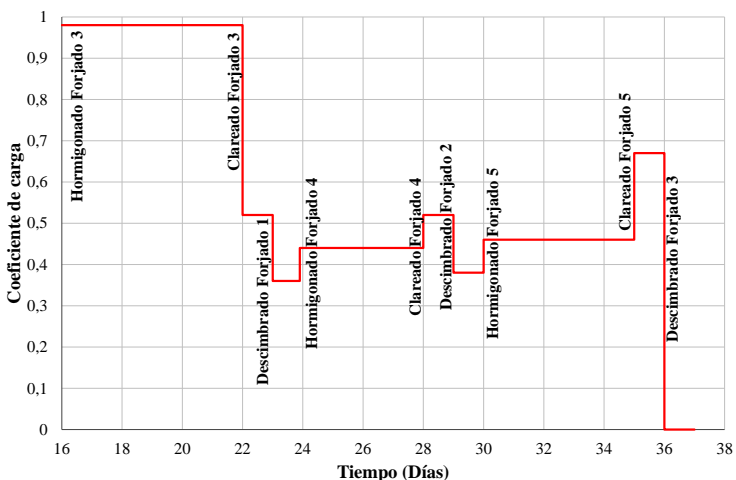

Fig. 3.33 Coeficientes de carga en puntales bajo el forjado 3 (Forjado de losa maciza - Vano de esquina)

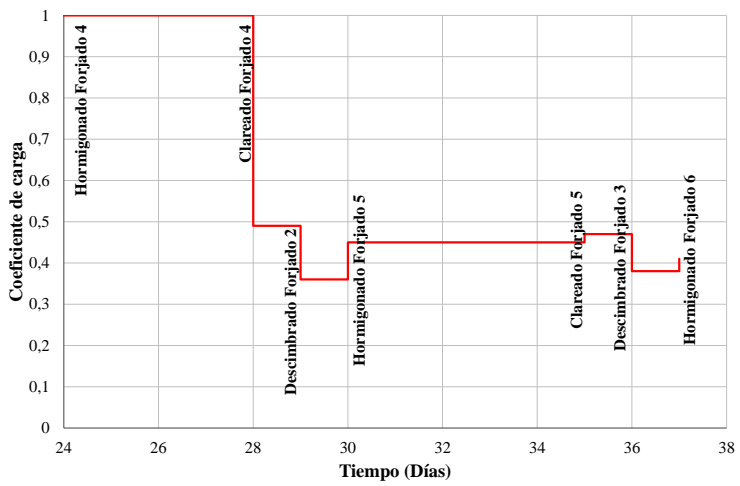

Fig. 3.35 Coeficientes de carga en puntales bajo el forjado 4 (Forjado de losa maciza - Vano de esquina)

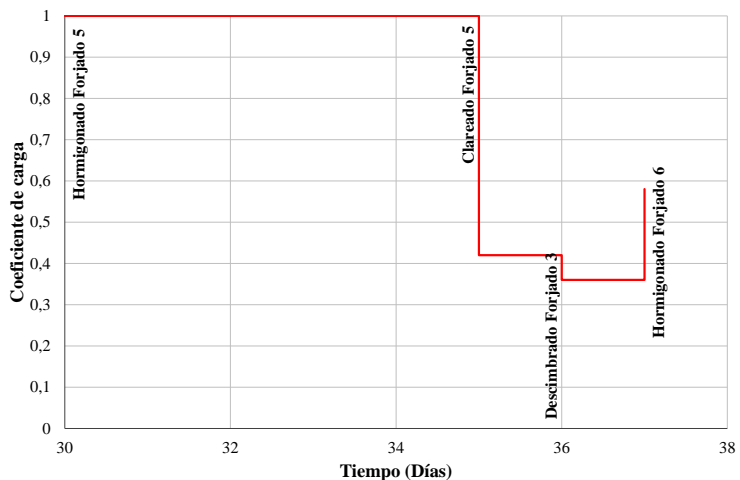

Fig. 3.37 Coeficientes de carga en puntales bajo el forjado 5 (Forjado de losa maciza - Vano de esquina)

Además la Tabla 3.4 muestra los coeficientes de carga, las cargas medias y las cargas máximas obtenidas en la medición instantánea para el vano de esquina. 
Estudio de la evolución de cargas en forjados y puntales durante el proceso constructivo

Tabla 3.4 Resumen medición experimental. Forjado de losa maciza - Vano de esquina

\begin{tabular}{|c|c|c|c|c|c|c|c|c|}
\hline \multirow{2}{*}{ Operación } & \multirow{2}{*}{ Nivel } & \multirow{2}{*}{$\underset{\left(\mathrm{kN} / \mathrm{m}^{2}\right)}{\boldsymbol{q}_{\boldsymbol{m e d}}}$} & \multicolumn{2}{|c|}{ Para $q_{m e d}$} & \multirow{2}{*}{$\begin{array}{l}\text { Puntal más } \\
\text { cargado }\end{array}$} & \multirow{2}{*}{$\begin{array}{c}\boldsymbol{P}_{\max } \\
(\mathrm{kN})\end{array}$} & \multirow{2}{*}{$\underset{\left(\mathrm{kN} / \mathrm{m}^{2}\right)}{\boldsymbol{q}_{\max }}$} & \multirow{2}{*}{$C_{p, \max }$} \\
\hline & & & $C_{p}$ & $C_{f}$ & & & & \\
\hline $\begin{array}{l}\text { Hormigonado } \\
\text { forjado } 1\end{array}$ & 1 & 4.95 & 1.00 & 0.00 & 5 & 3.40 & 5.10 & 1.03 \\
\hline $\begin{array}{l}\text { Clareado } \\
\text { forjado } 1\end{array}$ & 1 & 1.77 & 0.36 & 0.64 & 3 & 5.29 & 2.52 & 0.51 \\
\hline \multirow{2}{*}{$\begin{array}{l}\text { Hormigonado } \\
\text { forjado } 2\end{array}$} & 2 & 4.90 & 0.99 & 0.01 & 3 & 5.40 & 5.40 & 1.09 \\
\hline & 1 & 3.16 & 0.64 & 1.36 & 1 & 7.01 & 3.34 & 0.67 \\
\hline \multirow{2}{*}{$\begin{array}{l}\text { Clareado } \\
\text { forjado } 2\end{array}$} & 2 & 2.50 & 0.50 & 0.50 & 2 & 7.01 & 3.34 & 0.67 \\
\hline & 1 & 3.36 & 0.68 & 0.82 & 2 & 8.26 & 3.93 & 0.79 \\
\hline \multirow{3}{*}{$\begin{array}{l}\text { Hormigonado } \\
\text { forjado } 3\end{array}$} & 3 & 4.86 & 0.98 & 0.02 & 3 & 5.20 & 5.20 & 1.05 \\
\hline & 2 & 3.61 & 0.73 & 1.25 & 5 & 10.75 & 5.12 & 1.03 \\
\hline & 1 & 4.09 & 0.82 & 0.91 & 3 & 11.09 & 5.28 & 1.06 \\
\hline \multirow{3}{*}{$\begin{array}{l}\text { Clareado } \\
\text { forjado } 3\end{array}$} & 3 & 2.56 & 0.52 & 0.48 & 2 & 6.16 & 2.94 & 0.59 \\
\hline & 2 & 2.68 & 0.54 & 0.98 & 1 & 7.57 & 3.61 & 0.73 \\
\hline & 1 & 3.42 & 0.69 & 0.85 & 5 & 10.07 & 4.80 & 0.97 \\
\hline \multirow{3}{*}{$\begin{array}{l}\text { Descimbrado } \\
\text { forjado } 1\end{array}$} & 3 & 1.79 & 0.36 & 0.64 & 4 & 4.90 & 2.33 & 0.47 \\
\hline & 2 & 1.44 & 0.29 & 1.07 & 5 & 4.98 & 2.37 & 0.48 \\
\hline & 1 & & & 1.29 & & & & \\
\hline \multirow{4}{*}{$\begin{array}{l}\text { Hormigonado } \\
\text { forjado } 4\end{array}$} & 4 & 5.05 & 1.02 & 0.00 & 5 & 5.27 & 5.27 & 1.06 \\
\hline & 3 & 2.18 & 0.44 & 1.58 & 5 & 5.84 & 2.78 & 0.56 \\
\hline & 2 & 2.28 & 0.46 & 0.98 & 1 & 6.47 & 3.08 & 0.62 \\
\hline & 1 & & & 1.46 & & & & \\
\hline \multirow{4}{*}{$\begin{array}{l}\text { Clareado } \\
\text { forjado } 4\end{array}$} & 4 & 2.42 & 0.49 & 0.51 & 5 & 6.38 & 3.04 & 0.61 \\
\hline & 3 & 2.58 & 0.52 & 0.97 & 1 & 8.44 & 4.02 & 0.81 \\
\hline & 2 & 2.63 & 0.53 & 0.99 & 1 & 7.81 & 3.72 & 0.75 \\
\hline & 1 & & & 1.53 & & & & \\
\hline \multirow{3}{*}{$\begin{array}{l}\text { Descimbrado } \\
\text { forjado } 2\end{array}$} & 4 & 1.79 & 0.36 & 0.64 & 5 & 5.00 & 2.38 & 0.48 \\
\hline & 3 & 1.88 & 0.38 & 0.98 & 4 & 5.01 & 2.39 & 0.48 \\
\hline & 2 & & & 1.38 & & & & \\
\hline \multirow{4}{*}{$\begin{array}{l}\text { Hormigonado } \\
\text { forjado } 5\end{array}$} & 5 & 4.96 & 1.00 & 0.00 & 3 & 5.06 & 5.06 & 1.02 \\
\hline & 4 & 2.23 & 0.45 & 1.55 & 5 & 5.84 & 2.78 & 0.56 \\
\hline & 3 & 2.28 & 0.46 & 0.99 & 4 & 6.15 & 2.93 & 0.59 \\
\hline & 2 & & & 1.46 & & & & \\
\hline \multirow{4}{*}{$\begin{array}{l}\text { Clareado } \\
\text { forjado } 5\end{array}$} & 5 & 2.09 & 0.42 & 0.58 & 3 & 7.13 & 3.39 & 0.68 \\
\hline & 4 & 2.33 & 0.47 & 0.95 & 1 & 7.50 & 3.57 & 0.72 \\
\hline & 3 & 3.32 & 0.67 & 0.80 & 1 & 7.18 & 3.42 & 0.69 \\
\hline & 2 & & & 1.67 & & & & \\
\hline \multirow{3}{*}{$\begin{array}{l}\text { Descimbrado } \\
\text { forjado } 3\end{array}$} & 5 & 1.79 & 0.36 & 0.64 & 4 & 4.80 & 2.29 & 0.46 \\
\hline & 4 & 1.88 & 0.38 & 0.98 & 5 & 5.02 & 2.39 & 0.48 \\
\hline & 3 & & & 1.38 & & & & \\
\hline \multirow{4}{*}{$\begin{array}{l}\text { Hormigonado } \\
\text { forjado } 6\end{array}$} & 6 & 5.01 & 1.01 & 0.00 & 3 & 5.06 & 5.06 & 1.02 \\
\hline & 5 & 2.88 & 0.58 & 1.43 & 3 & 8.44 & 4.02 & 0.81 \\
\hline & 4 & 2.03 & 0.41 & 1.17 & 5 & 5.63 & 2.68 & 0.54 \\
\hline & 3 & & & 1.41 & & & & \\
\hline
\end{tabular}


Donde:

$\checkmark q_{\text {med }}$ : carga media en puntales por unidad de superficie que resulta de la relación entre la sumatoria de las cargas en puntales y el área del forjado instrumentada $\left(\sum P_{i} / A_{\text {total }}\right)$ $\left(\mathrm{kN} / \mathrm{m}^{2}\right)$. Siendo: $P_{i}$ la carga instantánea en el puntal “ $i$ ” $(\mathrm{kN})$ y $A_{\text {total }}$ el área del forjado instrumentada $\left(\mathrm{m}^{2}\right)$.

$\checkmark C_{p}$ : coeficiente de carga en puntales que resulta de la relación entre la carga media en puntales $\left(Q_{p}\right)$ y el peso propio del forjado $\left(W_{f}=4.96 \mathrm{kN} / \mathrm{m}^{2}\right) .\left(Q_{p} / W_{f}\right)$.

$\checkmark \quad C_{f}$ : coeficiente de carga en forjados que resulta de la relación entre la carga media del forjado $\left(Q_{f}\right)$ y el peso propio del forjado $\left(W_{f}=4.96 \mathrm{kN} / \mathrm{m}^{2}\right) .\left(Q_{f} / W_{f}\right)$.

$\checkmark \quad P_{\text {max }}$ : axil del puntal más cargado $(\mathrm{kN})$.

$\checkmark \quad q_{\max }$ : axil del puntal más cargado por unidad de superficie $\left(P_{\max } / A_{t}\right)\left(\mathrm{kN} / \mathrm{m}^{2}\right)$. Siendo $A_{t}$ el área tributaria del puntal considerado $\left(\mathrm{m}^{2}\right)$.

$\checkmark C_{p, \text { max }}$ : coeficiente de carga del puntal más cargado que resulta de la relación entre la carga máxima en puntales $\left(q_{\max }\right)$ y el peso propio del forjado $\left(W_{f}=4.96 \mathrm{kN} / \mathrm{m}^{2}\right) .\left(q_{\max } / W_{f}\right)$.

\section{$\checkmark \quad$ Vano de medianera}

Las Figuras 3.38 y 3.39 muestran la evolución del coeficiente de carga para el forjado 1 y para los puntales bajo este forjado durante todo el proceso constructivo. Las Figuras 3.40 y 3.41 muestran la evolución del coeficiente de carga para el forjado 2 y para los puntales bajo este forjado durante todo el proceso constructivo. Las Figuras 3.42 y 3.43 muestran la evolución del coeficiente de carga para el forjado 3 y para los puntales bajo este forjado durante todo el proceso constructivo. Las Figuras 3.44 y 3.45 muestran la evolución del coeficiente de carga para el forjado 4 y para los puntales bajo este forjado durante todo el proceso constructivo. Por último, las Figuras 3.46 y 3.47 muestran la evolución del coeficiente de carga para el forjado 5 y para los puntales bajo este forjado durante todo el proceso constructivo. No se muestra una evolución del coeficiente de carga en el forjado 6 y en los puntales bajo este forjado debido a que únicamente fue objeto de medición el hormigonado de dicho forjado (operación en la cual se terminó el estudio experimental).

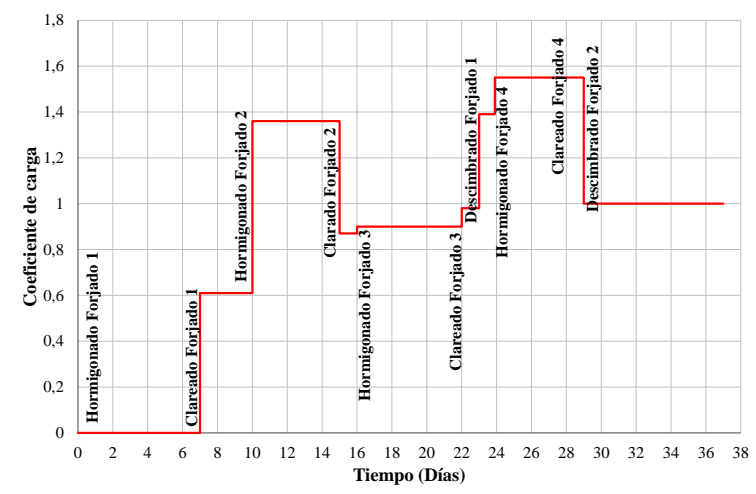

Fig. 3.38 Coeficientes de carga en el forjado 1 (Forjado de losa maciza - Vano de medianera)

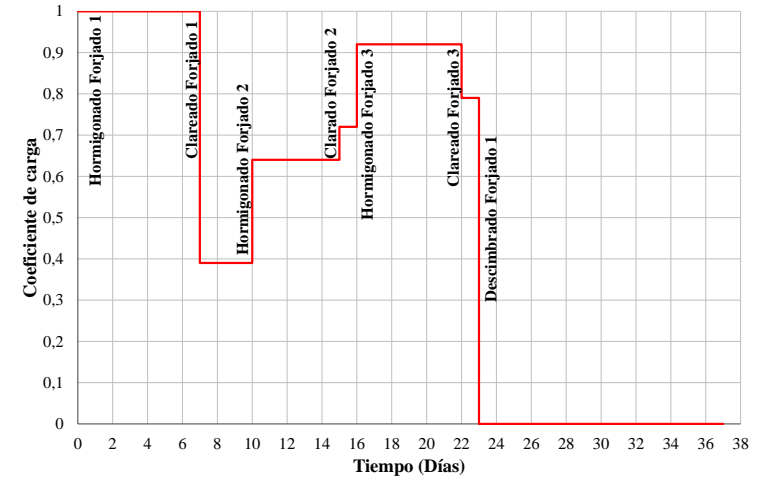

Fig. 3.39 Coeficientes de carga en puntales bajo el forjado 1 (Forjado de losa maciza - Vano de medianera) 


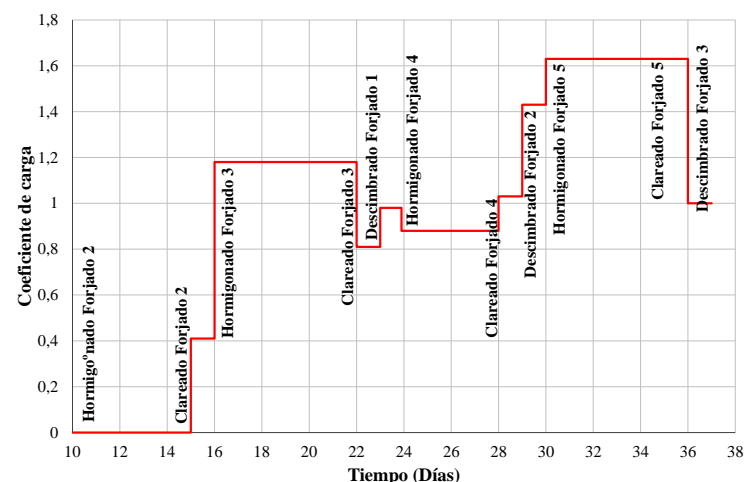

Fig. 3.40 Coeficientes de carga en el forjado 2 (Forjado de losa maciza - Vano de medianera)

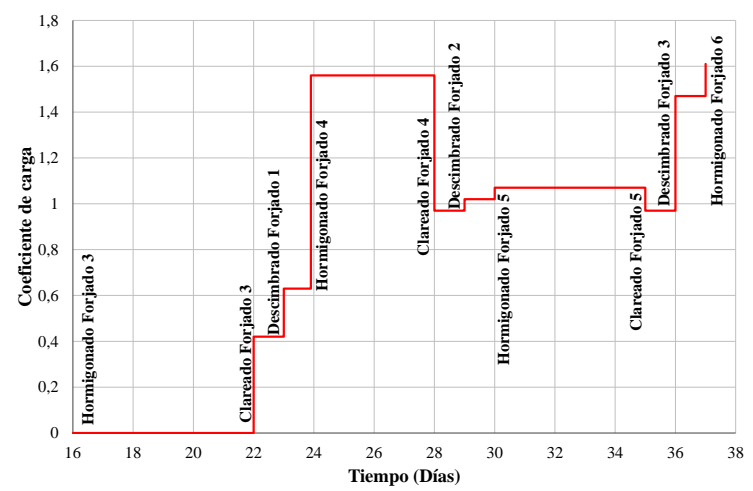

Fig. 3.42 Coeficientes de carga en el forjado 3 (Forjado de losa maciza - Vano de medianera)

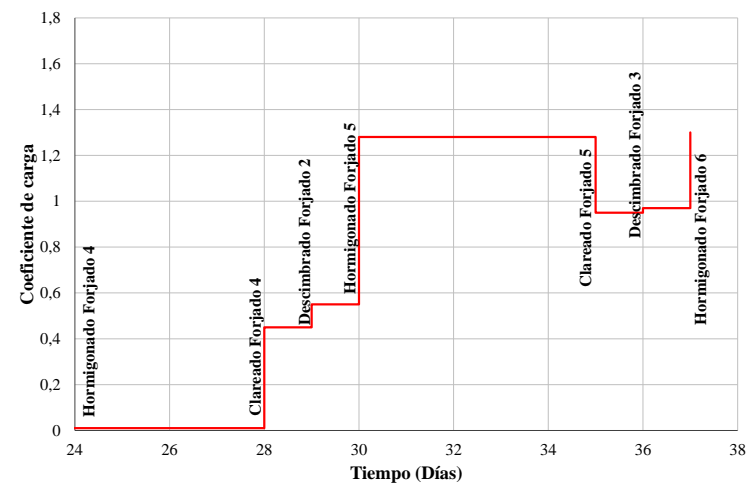

Fig. 3.44 Coeficientes de carga en el forjado 4 (Forjado de losa maciza - Vano de medianera)

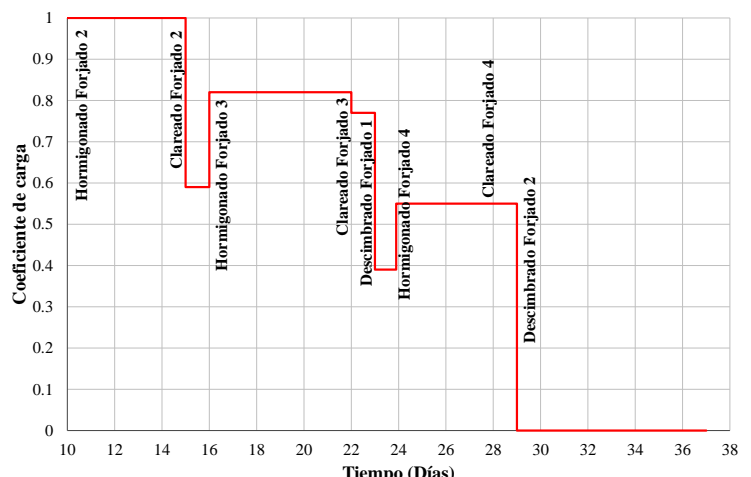

Fig. 3.41 Coeficientes de carga en puntales bajo el forjado 2 (Forjado de losa maciza - Vano de medianera)

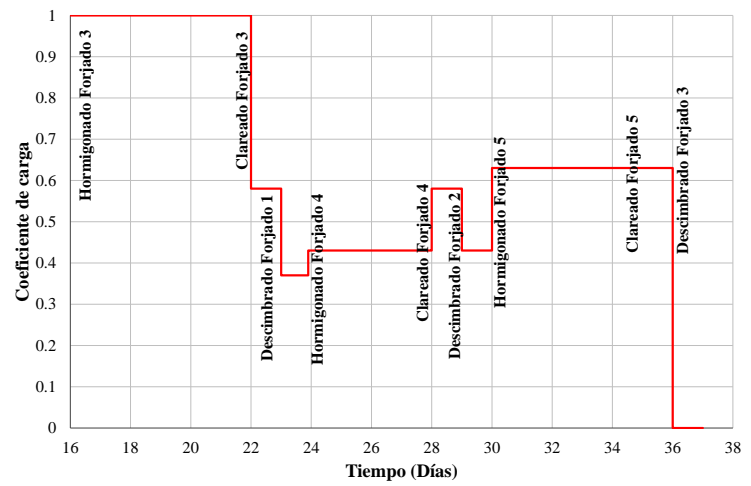

Fig. 3.43 Coeficientes de carga en puntales bajo el forjado 3 (Forjado de losa maciza - Vano de medianera)

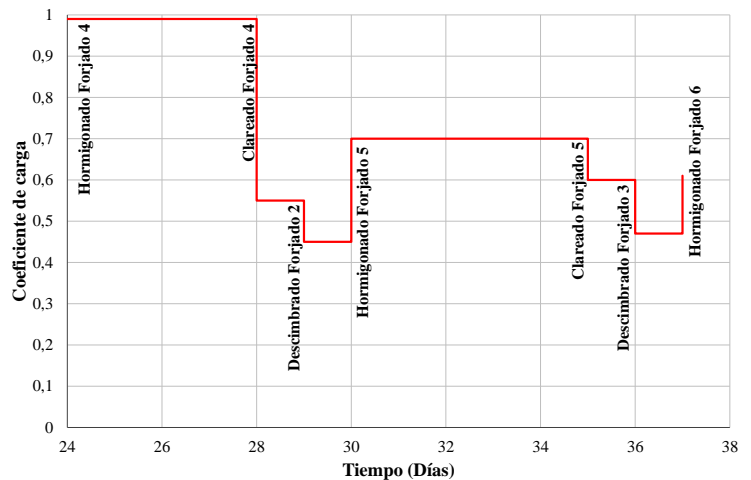

Fig. 3.45 Coeficientes de carga en puntales bajo el forjado 4 (Forjado de losa maciza - Vano de medianera) 


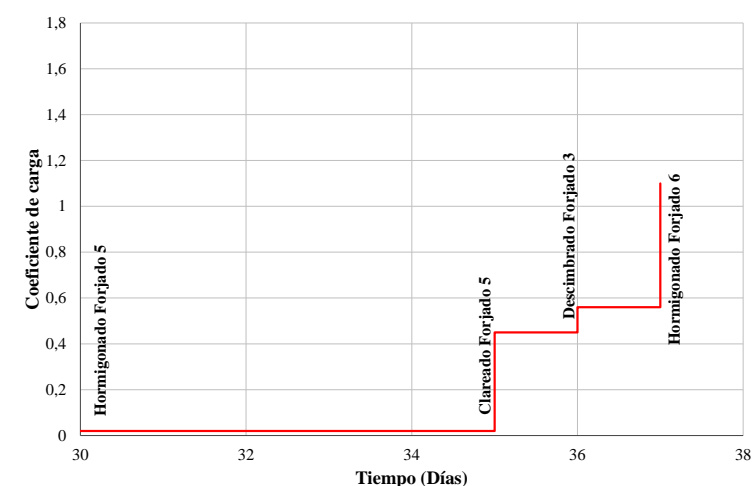

Fig. 3.46 Coeficientes de carga en el forjado 5 (Forjado de losa maciza - Vano de medianera)

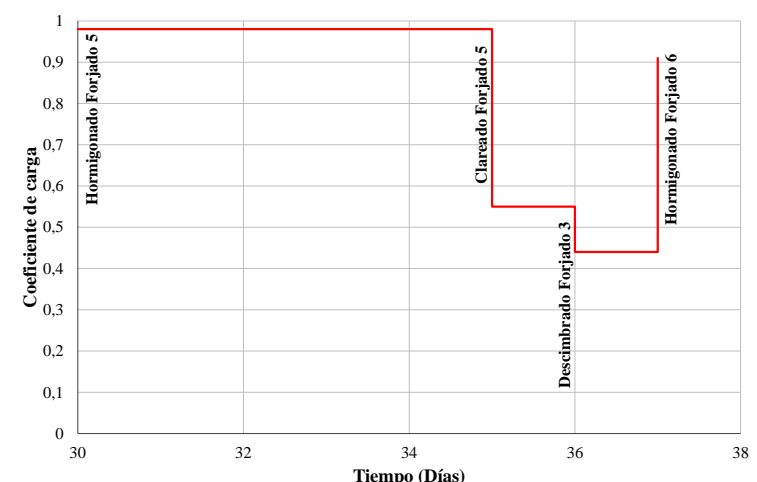

Fig. 3.47 Coeficientes de carga en puntales bajo el forjado 5 (Forjado de losa maciza - Vano de medianera)

Además, la Tabla 3.5 muestra los coeficientes de carga, las cargas medias y las cargas máximas obtenidas en la medición instantánea para el vano de medianera.

Tabla 3.5 Resumen medición experimental. Forjado de losa maciza - Vano de medianera

\begin{tabular}{|c|c|c|c|c|c|c|c|c|}
\hline \multirow{2}{*}{ Operación } & \multirow{2}{*}{ Nivel } & \multirow{2}{*}{$\underset{\left(\mathrm{kN} / \mathrm{m}^{2}\right)}{\left.\boldsymbol{q}_{\boldsymbol{m}}\right)}$} & \multicolumn{2}{|c|}{ Para $q_{m e d}$} & \multirow{2}{*}{$\begin{array}{l}\text { Puntal más } \\
\text { cargado }\end{array}$} & \multirow{2}{*}{$\begin{array}{c}\boldsymbol{P}_{\max } \\
(\mathrm{kN})\end{array}$} & \multirow{2}{*}{$\underset{\left(\mathrm{kN} / \mathrm{m}^{2}\right)}{\boldsymbol{q}_{\max }}$} & \multirow{2}{*}{$C_{p, \max }$} \\
\hline & & & $C_{p}$ & $C_{f}$ & & & & \\
\hline $\begin{array}{l}\text { Hormigonado } \\
\text { forjado } 1\end{array}$ & 1 & 4.96 & 1.00 & 0.00 & 9 & 3.40 & 5.10 & 1.03 \\
\hline $\begin{array}{l}\text { Clareado } \\
\text { forjado } 1\end{array}$ & 1 & 1.95 & 0.39 & 0.61 & 8 & 6.04 & 3.02 & 0.61 \\
\hline \multirow{2}{*}{$\begin{array}{l}\text { Hormigonado } \\
\text { forjado } 2\end{array}$} & 2 & 5.00 & 1.01 & 0.00 & 10 & 5.29 & 5.29 & 1.07 \\
\hline & 1 & 3.17 & 0.64 & 1.36 & 8 & 10.07 & 5.04 & 1.01 \\
\hline \multirow{2}{*}{$\begin{array}{l}\text { Clareado } \\
\text { forjado } 2\end{array}$} & 2 & 2.95 & 0.59 & 0.41 & 9 & 6.87 & 3.43 & 0.69 \\
\hline & 1 & 3.57 & 0.72 & 0.87 & 8 & 12.37 & 6.18 & 1.25 \\
\hline \multirow{3}{*}{$\begin{array}{l}\text { Hormigonado } \\
\text { forjado } 3\end{array}$} & 3 & 4.95 & 1.00 & 0.00 & 7 & 5.06 & 5.06 & 1.02 \\
\hline & 2 & 4.06 & 0.82 & 1.18 & 9 & 9.22 & 4.61 & 0.93 \\
\hline & 1 & 4.56 & 0.92 & 0.90 & 8 & 13.34 & 6.67 & 1.34 \\
\hline \multirow{3}{*}{$\begin{array}{l}\text { Clareado } \\
\text { forjado } 3\end{array}$} & 3 & 2.87 & 0.58 & 0.42 & 11 & 6.68 & 3.34 & 0.67 \\
\hline & 2 & 3.84 & 0.77 & 0.81 & 9 & 9.79 & 4.89 & 0.99 \\
\hline & 1 & 3.92 & 0.79 & 0.98 & 11 & 11.79 & 5.90 & 1.19 \\
\hline \multirow{3}{*}{$\begin{array}{l}\text { Descimbrado } \\
\text { forjado } 1\end{array}$} & 3 & 1.84 & 0.37 & 0.63 & 11 & 4.48 & 2.24 & 0.45 \\
\hline & 2 & 1.93 & 0.39 & 0.98 & 9 & 4.42 & 2.24 & 0.45 \\
\hline & 1 & & & 1.39 & & & & \\
\hline \multirow{4}{*}{$\begin{array}{l}\text { Hormigonado } \\
\text { forjado } 4\end{array}$} & 4 & 4.91 & 0.99 & 0.01 & 10 & 5.06 & 5.06 & 1.02 \\
\hline & 3 & 2.13 & 0.43 & 1.56 & 9 & 6.74 & 3.37 & 0.68 \\
\hline & 2 & 2.73 & 0.55 & 0.88 & 9 & 6.44 & 3.22 & 0.65 \\
\hline & 1 & & & 1.55 & & & & \\
\hline \multirow{4}{*}{$\begin{array}{l}\text { Clareado } \\
\text { forjado } 4\end{array}$} & 4 & 2.72 & 0.55 & 0.45 & 11 & 8.14 & 4.07 & 0.82 \\
\hline & 3 & 2.88 & 0.58 & 0.97 & 9 & 7.74 & 3.87 & 0.78 \\
\hline & 2 & 2.73 & 0.55 & 1.03 & 9 & 5.96 & 2.98 & 0.60 \\
\hline & 1 & & & 1.55 & & & & \\
\hline
\end{tabular}




\begin{tabular}{|c|c|c|c|c|c|c|c|c|}
\hline \multirow{2}{*}{ Operación } & \multirow{2}{*}{ Nivel } & \multirow{2}{*}{$\underset{\left(\mathrm{kN} / \mathrm{m}^{2}\right)}{\boldsymbol{q}_{\boldsymbol{m e d}}}$} & \multicolumn{2}{|c|}{ Para $q_{m e d}$} & \multirow{2}{*}{$\begin{array}{l}\text { Puntal más } \\
\text { cargado }\end{array}$} & \multirow{2}{*}{$\begin{array}{c}\boldsymbol{P}_{\max } \\
(\mathrm{kN})\end{array}$} & \multirow{2}{*}{$\underset{\left(\mathrm{kN} / \mathrm{m}^{2}\right)}{\boldsymbol{q}_{\max }}$} & \multirow{2}{*}{$C_{p, \max }$} \\
\hline & & & $C_{p}$ & $C_{f}$ & & & & \\
\hline \multirow{3}{*}{$\begin{array}{l}\text { Descimbrado } \\
\text { forjado } 2\end{array}$} & 4 & 2.23 & 0.45 & 0.55 & 11 & 5.10 & 2.55 & 0.51 \\
\hline & 3 & 2.13 & 0.43 & 1.02 & 10 & 5.20 & 2.60 & 0.52 \\
\hline & 2 & & & 1.43 & & & & \\
\hline \multirow{4}{*}{$\begin{array}{l}\text { Hormigonado } \\
\text { forjado } 5\end{array}$} & 5 & 4.87 & 0.98 & 0.02 & 11 & 5.06 & 5.06 & 1.02 \\
\hline & 4 & 3.47 & 0.70 & 1.28 & 11 & 7.04 & 3.52 & 0.71 \\
\hline & 3 & 3.12 & 0.63 & 1.07 & 9 & 9.72 & 4.86 & 0.98 \\
\hline & 2 & & & 1.63 & & & & \\
\hline \multirow{4}{*}{$\begin{array}{l}\text { Clareado } \\
\text { forjado } 5\end{array}$} & 5 & 2.75 & 0.55 & 0.45 & 11 & 6.63 & 3.32 & 0.67 \\
\hline & 4 & 2.98 & 0.60 & 0.95 & 9 & 6.24 & 3.12 & 0.63 \\
\hline & 3 & 3.12 & 0.63 & 0.97 & 9 & 8.64 & 4.32 & 0.87 \\
\hline & 2 & & & 1.63 & & & & \\
\hline \multirow{3}{*}{$\begin{array}{l}\text { Descimbrado } \\
\text { forjado } 3\end{array}$} & 5 & 2.18 & 0.44 & 0.56 & 11 & 5.14 & 2.57 & 0.52 \\
\hline & 4 & 2.33 & 0.47 & 0.97 & 11 & 5.63 & 2.82 & 0.57 \\
\hline & 3 & & & 1.47 & & & & \\
\hline \multirow{4}{*}{$\begin{array}{l}\text { Hormigonado } \\
\text { forjado } 6\end{array}$} & 6 & 5.00 & 1.01 & 0.00 & 9 & 5.03 & 5.03 & 1.01 \\
\hline & 5 & 4.51 & 0.91 & 1.10 & 8 & 10.52 & 5.26 & 1.06 \\
\hline & 4 & 3.03 & 0.61 & 1.30 & 11 & 9.32 & 4.66 & 0.94 \\
\hline & 3 & & & 1.61 & & & & \\
\hline
\end{tabular}

\subsection{Estudio experimental de un edificio de forjado reticular de casetón perdido}

El edificio donde se llevó a cabo el estudio está situado en Sabadell, Barcelona. Se trata de un edificio de forjado reticular de casetón perdido con muro de sótano, de 5 plantas y 2 sótanos, destinado a viviendas, donde la altura entre plantas varía entre $2.65 \mathrm{~m}$ y $4.45 \mathrm{~m}$.

Se instrumentaron 2 sopandas de un vano exterior, con un total de 15 puntales instrumentados en cada uno de los sótanos y 16 puntales por forjado en el resto de plantas. El vano instrumentado tenía unas dimensiones de $4.40 \times 7.00 \mathrm{~m}$, en los sótanos y de $4.60 \times 7.00 \mathrm{~m}$ con un voladizo de $1.70 \mathrm{~m}$ en el resto de plantas.

Se realizaron mediciones desde el hormigonado del Forjado 1 (techo de sótano 2), hasta el hormigonado del Forjado 6 (techo de la tercera planta). Se midieron cargas hasta el hormigonado del Forjado 6 ya que en esta operación es donde en teoría se presenta la mayor solicitación de cargas sobre los forjados inferiores donde se apoyan puntales.

Los ciclos de construcción de la estructura quedaron definidos, para tres juegos de cimbras, con una planta cimbrada y dos clareadas.

Además de las mediciones de carga, se llevaron a cabo mediciones de temperatura en el interior del forjado colocando termopares a distintas profundidades. Estas mediciones se realizaron en diferentes días, una vez el hormigón había curado, y con diferentes condiciones del forjado (encofrado o desencofrado). 
La definición del estudio experimental se realizó en Octubre de 2009. A partir de esta fecha se comenzó con la primera fase del planteamiento de estudio experimental, donde quedó definida el área objeto de estudio y el número de plantas a instrumentar, así como el número de termopares. El estudio experimental inició el 4 de Diciembre de 2009 con el hormigonado del Forjado 1 y finalizó el 13 de Mayo de 2010 con el hormigonado del Forjado 6.

\subsubsection{Descripción de la estructura}

El edificio objeto de este estudio consta de un total de 5 plantas y 2 sótanos, destinados a vivienda.

\subsubsection{Estructura}

Todas las plantas tienen forjado reticular de casetón perdido de $0.32 \mathrm{~m}$ de canto $(25+7)$, con un nervio de $0.15 \mathrm{~m}$ y casetón prefabricado de hormigón de $0.70 \mathrm{~m}$. Los balcones se resuelven con losa maciza de hormigón de $0.20 \mathrm{~m}$ de canto.

La altura entre plantas es de $2.65 \mathrm{~m}$ en el segundo sótano y de $2.80 \mathrm{~m}$ en el primer sótano. La planta baja tiene una altura libre de $4.15 \mathrm{~m}$ y en el resto de plantas de $2.70 \mathrm{~m}$. En la Figura 3.48 se muestra una sección del edificio. Las figuras 3.49 y 3.50 muestran las planos de planta.

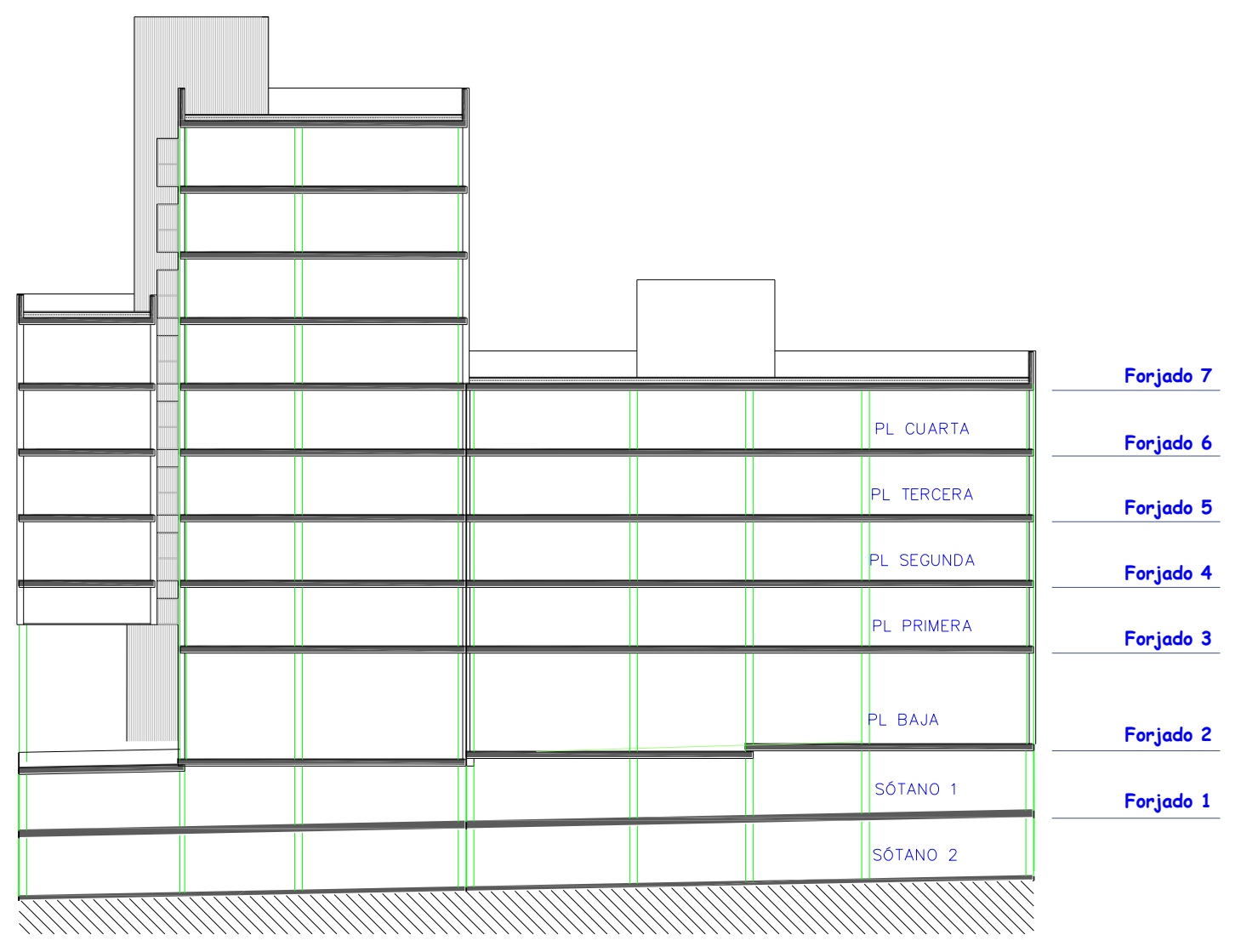

Fig. 3.48 Sección del edificio de forjado reticular de casetón perdido 


\subsubsection{Materiales}

Los materiales empleados en la construcción de este edificio se describen a continuación:

$\checkmark$ El hormigón del primer y segundo forjado (techo de sótano 2 y sótano 1) es HA-25/B/20/IIa

- Resistencia característica a compresión $25 \mathrm{MPa}$.

- Consistencia: Blanda.

- Tamaño máximo del árido: $20 \mathrm{~mm}$.

- Clase general de exposición: IIa Interiores sometidos a humedades relativas medias altas.

$\checkmark$ El hormigón del resto de los forjados es HA-25/B/20/I

- Resistencia característica a compresión $25 \mathrm{MPa}$.

- Consistencia: Blanda.

- Tamaño máximo del árido: $20 \mathrm{~mm}$.

- Clase general de exposición: I Interiores de edificios.

$\checkmark$ Acero para armar: B-500-S

\subsubsection{Zona de estudio}

En la Figura 3.49 se muestra la zona de estudio correspondiente a los forjados 1 y 2, mientras que en la Figura 3.50 la correspondiente a los forjados superiores. Se monitorizó un único vano, con dos sopandas principales por vano. La disposición de las sopandas y los puntales instrumentados es la que se muestra en las Figuras 3.51 y 3.52. Como se observa en las Figuras 3.49 y 3.51, en los sótanos existe un muro de sótano paralelo a las sopandas. Además de los puntales instrumentados para la medición de carga, se utilizó un puntal de referencia por planta para poder medir el efecto de la temperatura ambiente sobre los puntales, las galgas extensométricas y el equipo de adquisición de datos. 


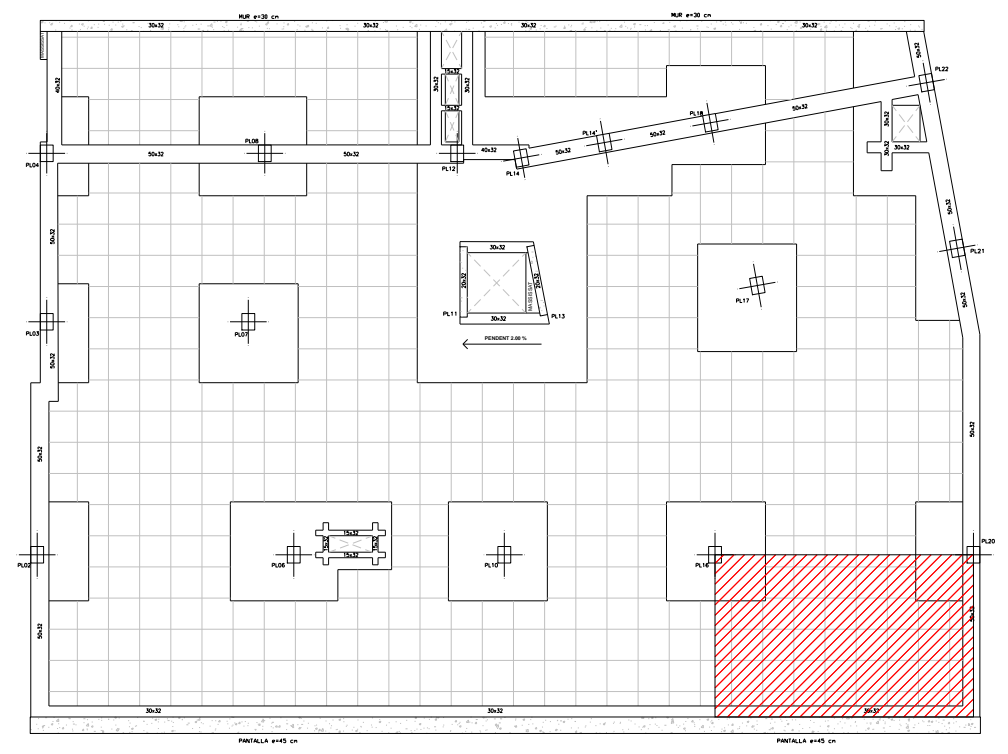

Fig. 3.49 Zona de estudio del edificio de forjado reticular de casetón perdido. Forjados 1 y 2

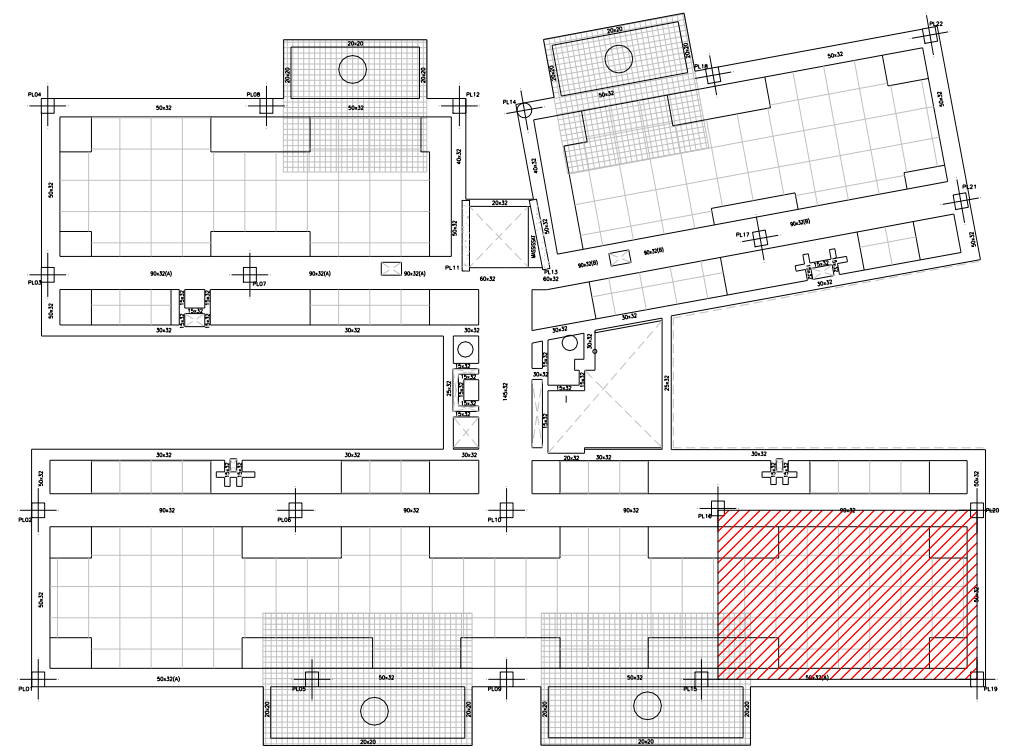

Fig. 3.50 Zona de estudio del edificio de forjado reticular de casetón perdido. Forjados superiores 


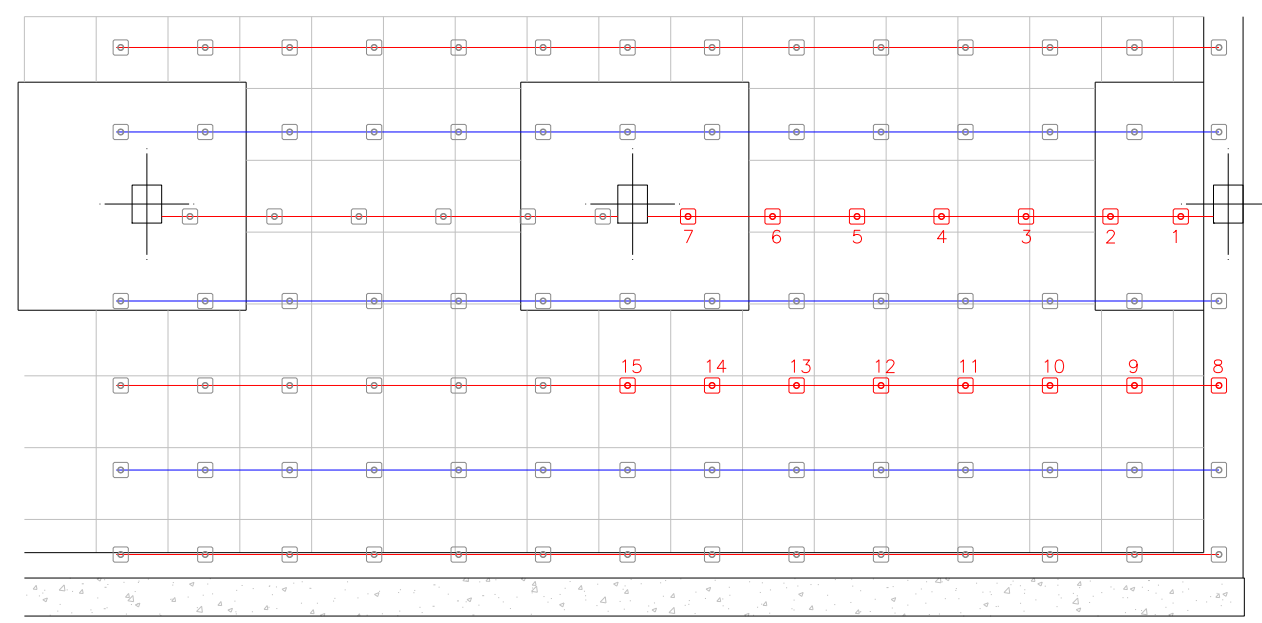

Puntales instrumentados

Puntales no instrumentados

Sopandas principales

Sopandas secundarias

Fig. 3.51 Disposición de sopandas principales y secundarias en los sótanos del edificio de forjado reticular de casetón perdido

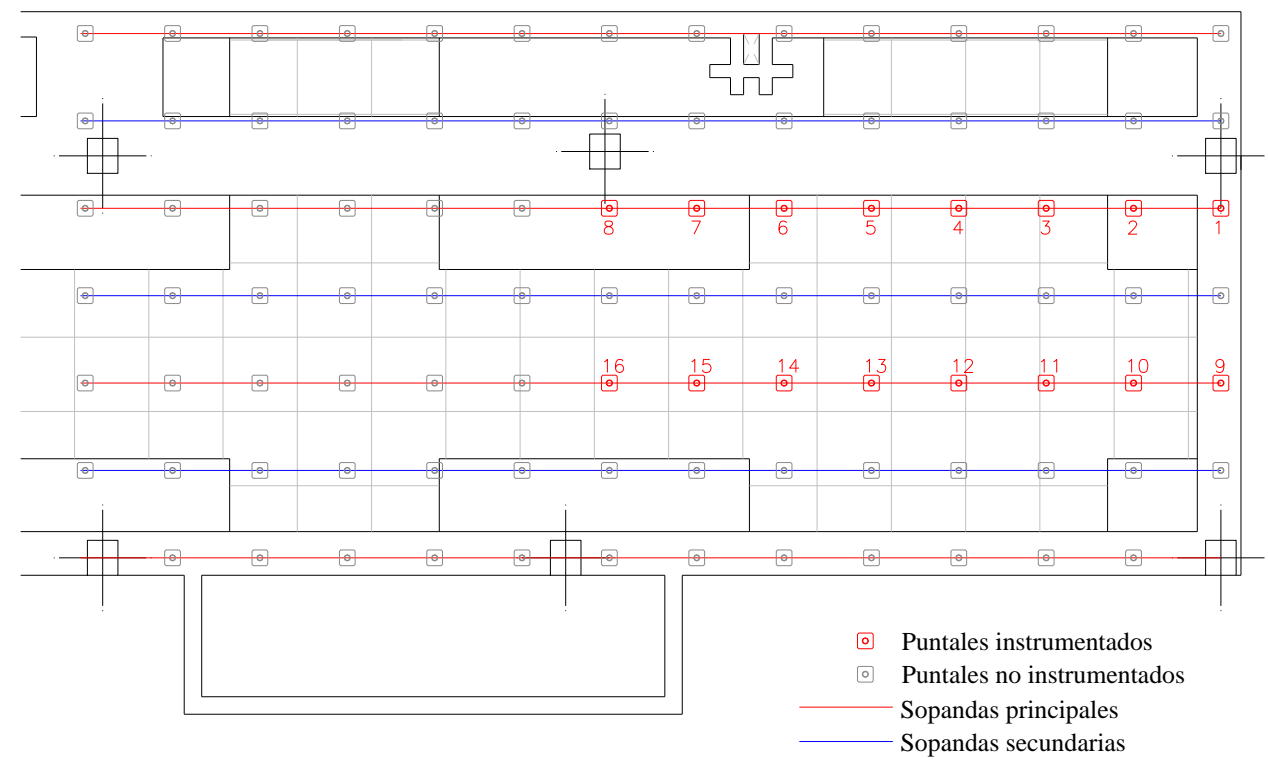

Fig. 3.52 Disposición de sopandas principales y secundarias en el resto de plantas del edificio de forjado reticular de casetón perdido

Adicionalmente, para poder determinar la variación de la temperatura en el forjado de hormigón y evaluar el gradiente térmico que se producía, se instrumentó un ábaco del Forjado 4 instalando termopares a diferentes profundidades. Un total de 5 termopares a una distancia de $0.05,0.10,0.175$, 0.25 y $0.30 \mathrm{~m}$. de la cara superior del forjado fueron embebidos durante el hormigonado del forjado (Fig. 3.53). 

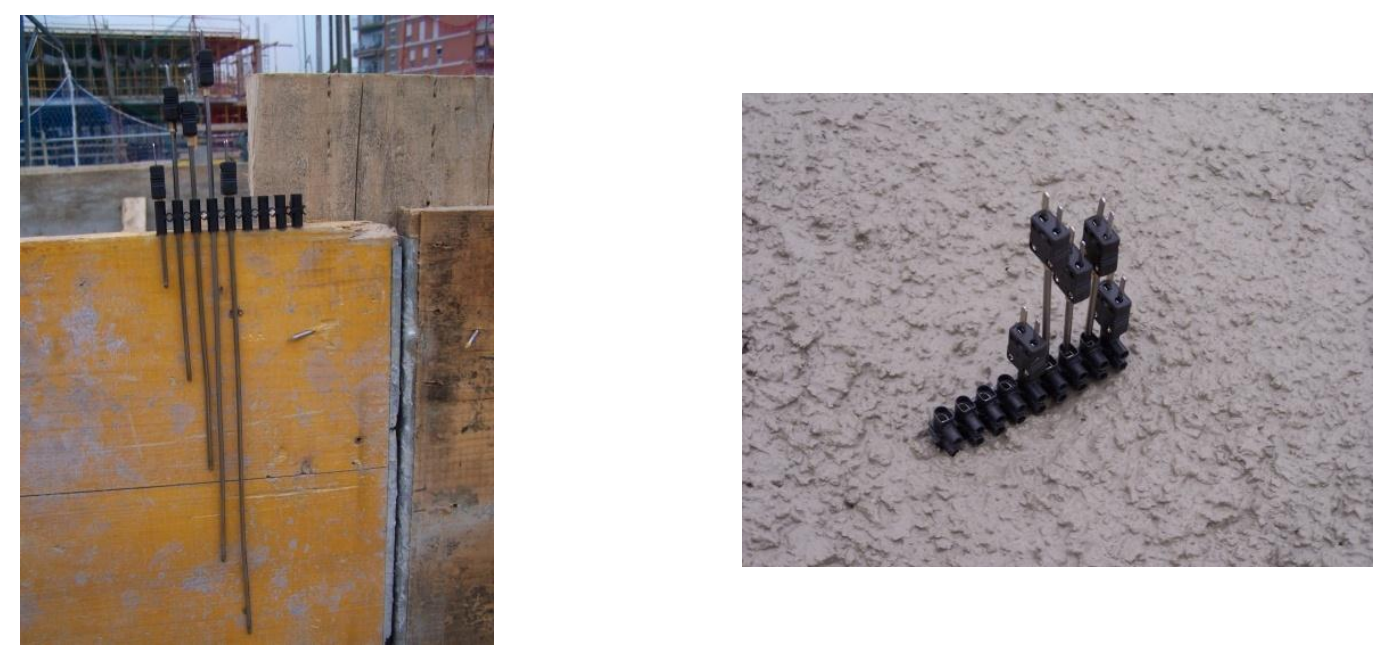

Fig. 3.53. Termopares embebidos en el hormigón en la zona del ábaco (forjado reticular de casetón perdido).

También se instrumentó la losa maciza $(0.20 \mathrm{~m})$ correspondiente a uno de los balcones del Forjado 4 del edificio. En ella se instalaron 3 termopares, a $0.05,0.10$ y $0.15 \mathrm{~m}$ de profundidad.

Así mismo, se tomaron medidas de la temperatura ambiente mediante un termopar libre.

\subsubsection{Proceso constructivo}

El proceso constructivo adoptado para la construcción del edificio se definió a partir de 3 juegos de puntales, manteniendo dos plantas clareadas y una cimbrada. Las medidas experimentales fueron tomadas desde el hormigonado del Forjado 1 hasta el hormigonado del Forjado 6.

Las operaciones constructivas en donde se midieron las cargas en puntales son las siguientes:

$\checkmark$ Día "0" (4 de Diciembre de 2009): una vez hormigonada la losa de cimentación y los pilares del segundo sótano, se instaló el sistema de cimbrado y encofrado para el hormigonado del primer forjado (Fig. 3.54).
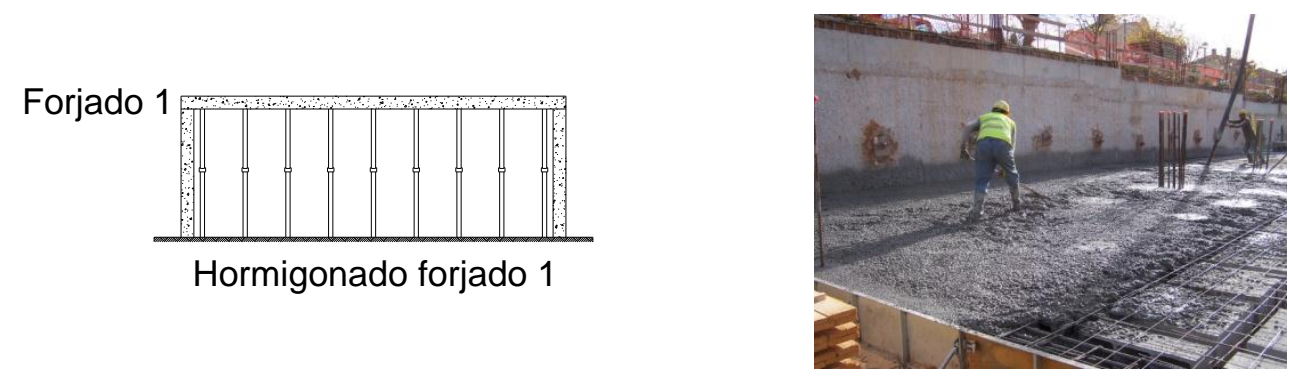

Fig. 3.54 Proceso constructivo día "0" (forjado reticular de casetón perdido) 
$\checkmark$ Día "6" (10 de Diciembre de 2009): al cabo de seis días del hormigonado del primer forjado, se procedió a la retirada de fondos de encofrado y al clareado de puntales (Fig. 3.55).
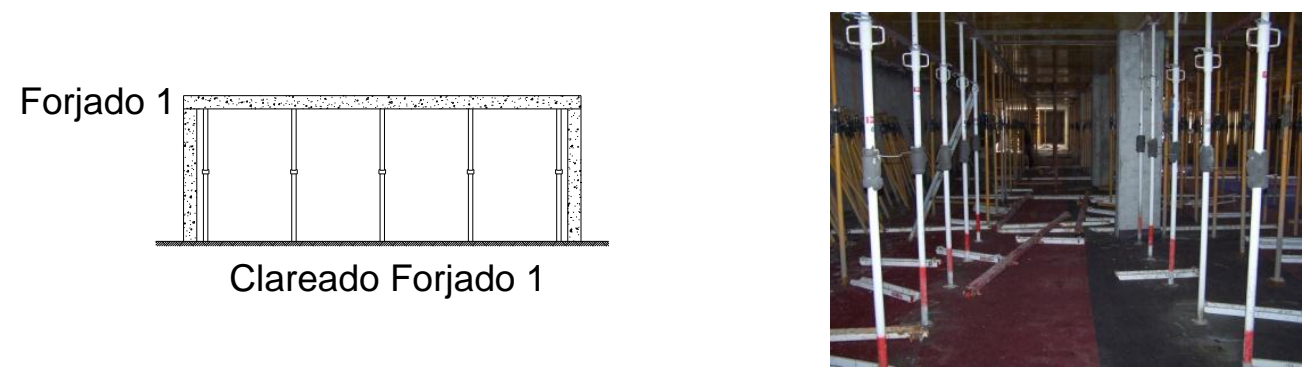

Fig. 3.55 Proceso constructivo día “6” (forjado reticular de casetón perdido)

$\checkmark$ Día "53" (26 de Enero de 2010): una vez preparado el sistema de encofrado y cimbrado del segundo forjado se ejecutó su hormigonado (Fig. 3.56).
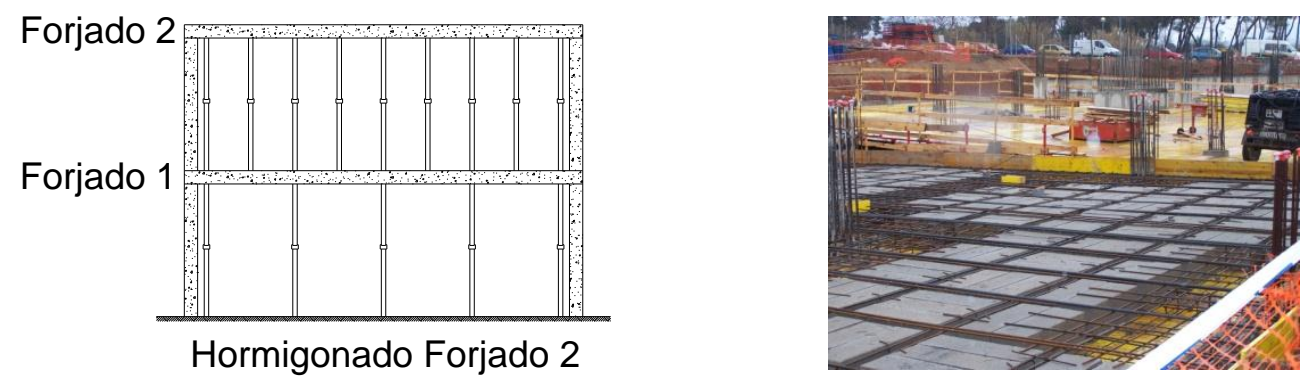

Fig. 3.56 Proceso constructivo día "53" (forjado reticular de casetón perdido)

$\checkmark$ Día "59" (1 de Febrero de 2010): transcurridos seis días de hormigonado del segundo forjado, se retiraron los fondos de encofrado y se realizó el clareado de puntales (Fig. 3.57).
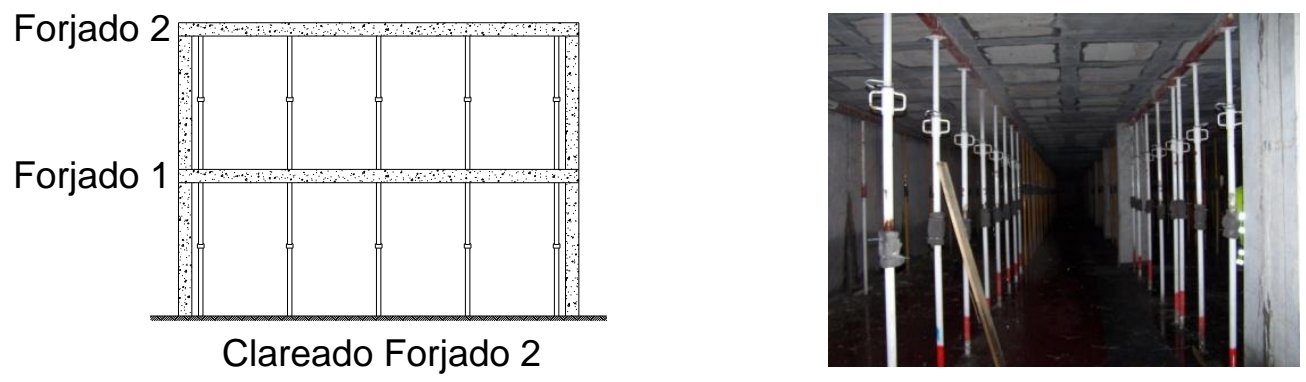

Fig. 3.57 Proceso constructivo día “59” (forjado reticular de casetón perdido)

$\checkmark$ Día "84" (26 de Febrero de 2010): una vez instalado el sistema de encofrado y cimbrado se procedió a hormigonar el tercer forjado (Fig. 3.58). 

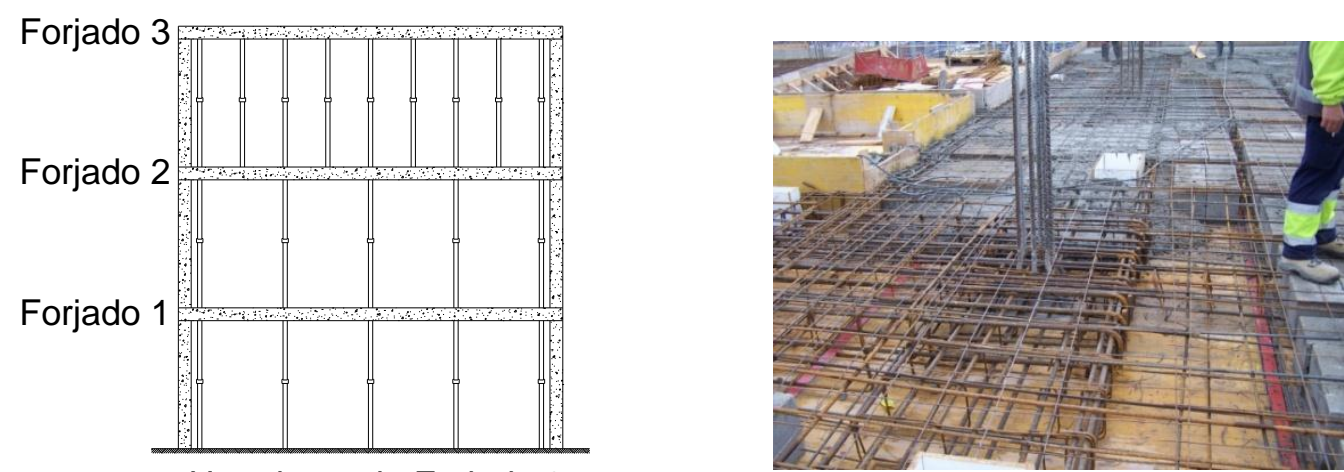

Hormigonado Forjado 3

Fig. 3.58 Proceso constructivo día "84" (forjado reticular de casetón perdido)

Día "89" (3 de Marzo de 2010): cinco días después de su hormigonado se procedió al clareado del forjado 3 (véase Fig. 3.59).
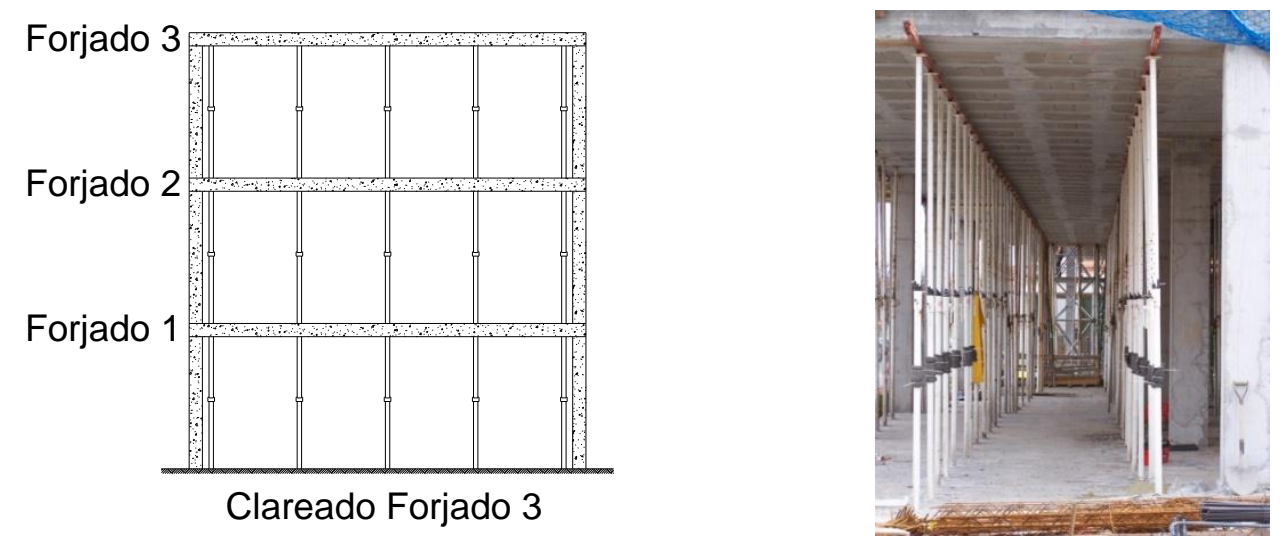

Fig. 3.59 Proceso constructivo día "89" (forjado reticular de casetón perdido)

Día "111 a" (25 de Marzo de 2010): en esta fase se procedió al descimbrado del forjado 1 (véase Fig. 3.60).
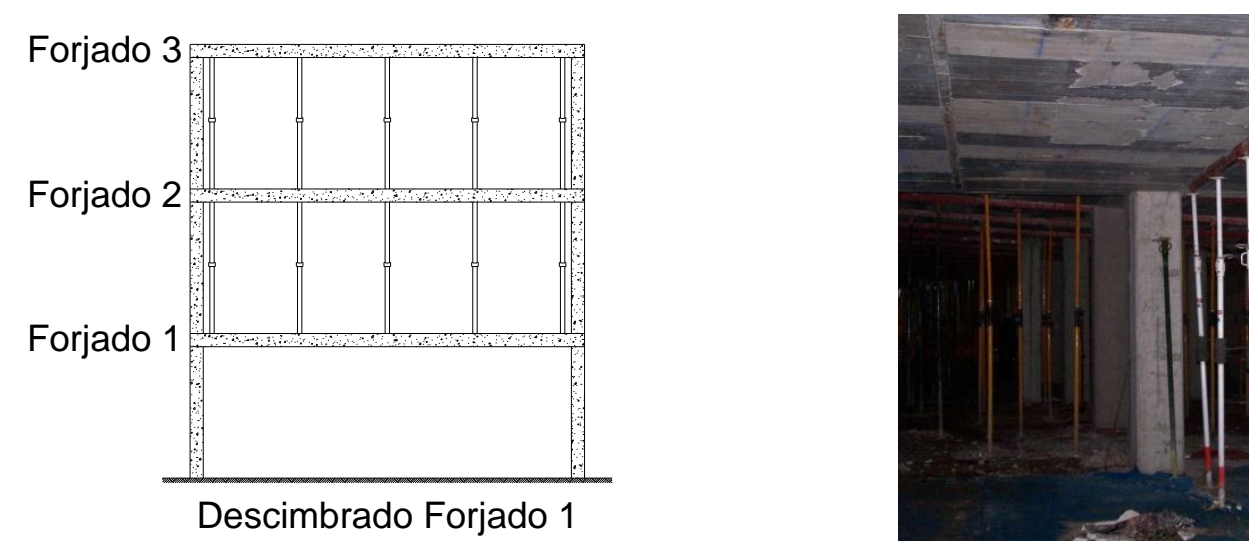

Fig. 3.60 Proceso constructivo día "111 a" (forjado reticular de casetón perdido) 
$\checkmark$ Día "111 b" (25 de Marzo de 2010): preparado el sistema de cimbrado y encofrado se procedió al hormigonado del forjado 4 (Fig. 3.61).
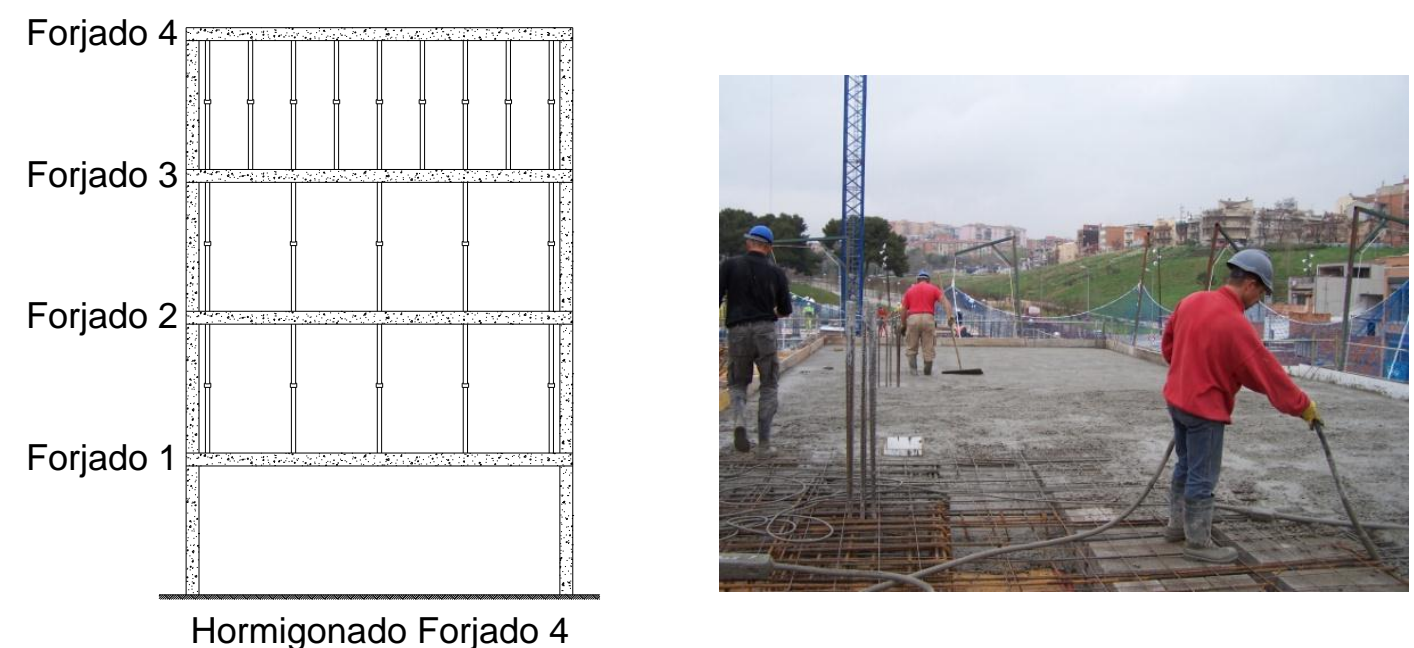

Fig. 3.61 Proceso constructivo día "111 b" (forjado reticular de casetón perdido)

$\checkmark$ Día “115” (29 de Marzo de 2010): 4 días después de su hormigonado se procedió al clareado del forjado 4 (Fig. 3.62).
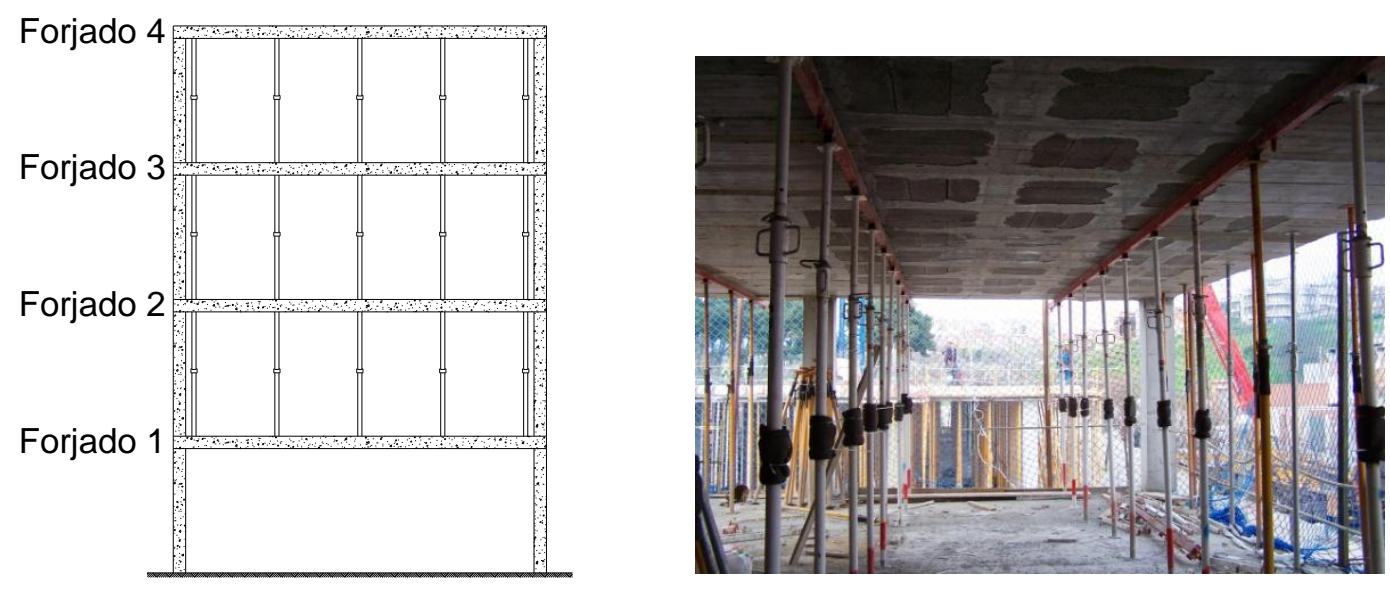

Clareado Forjado 4

Fig. 3.62 Proceso constructivo día "115" (forjado reticular de casetón perdido) 
Día "137” (20 de Abril de 2010): en el día “137” se procedió al hormigonado del 5 forjado (Fig. 3.63).
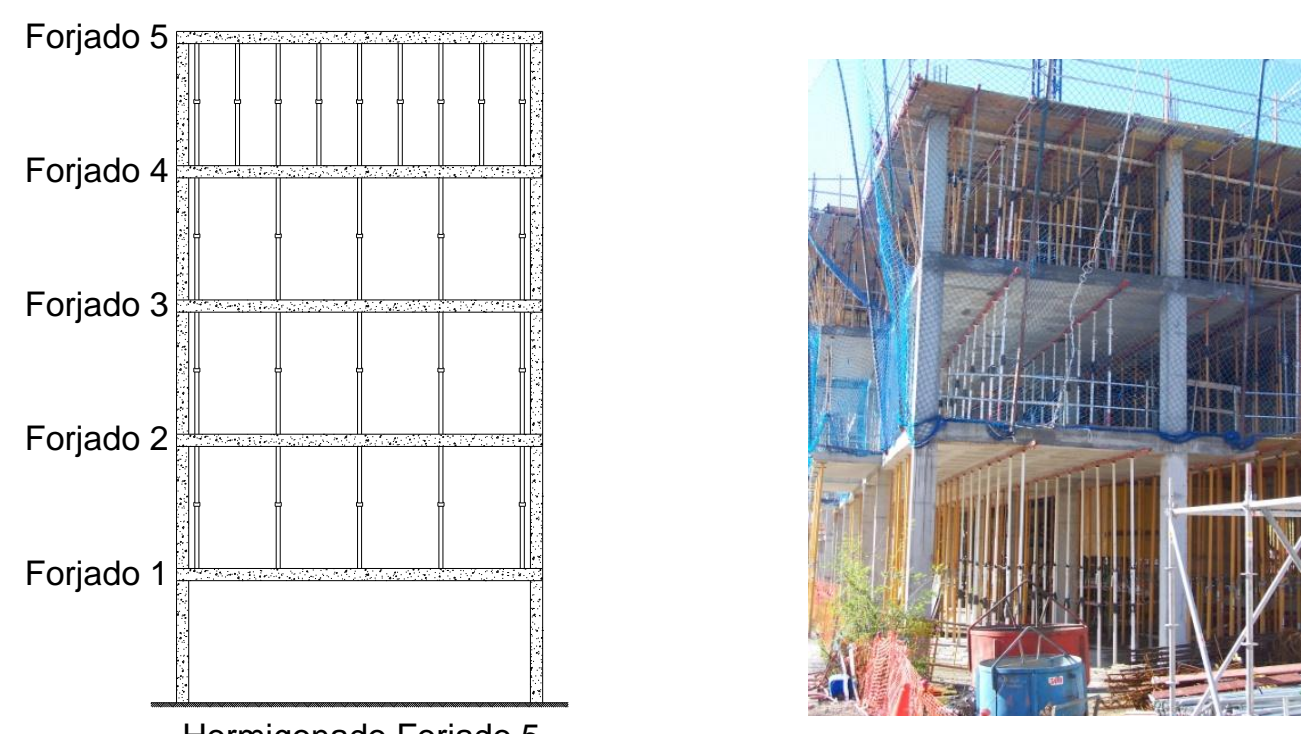

Fig. 3.63 Proceso constructivo día “137” (forjado reticular de casetón perdido)

Día "143a" (26 de Abril de 2010): en esta fase se realizó el descimbrado del forjado 2 (Fig. 3.64)
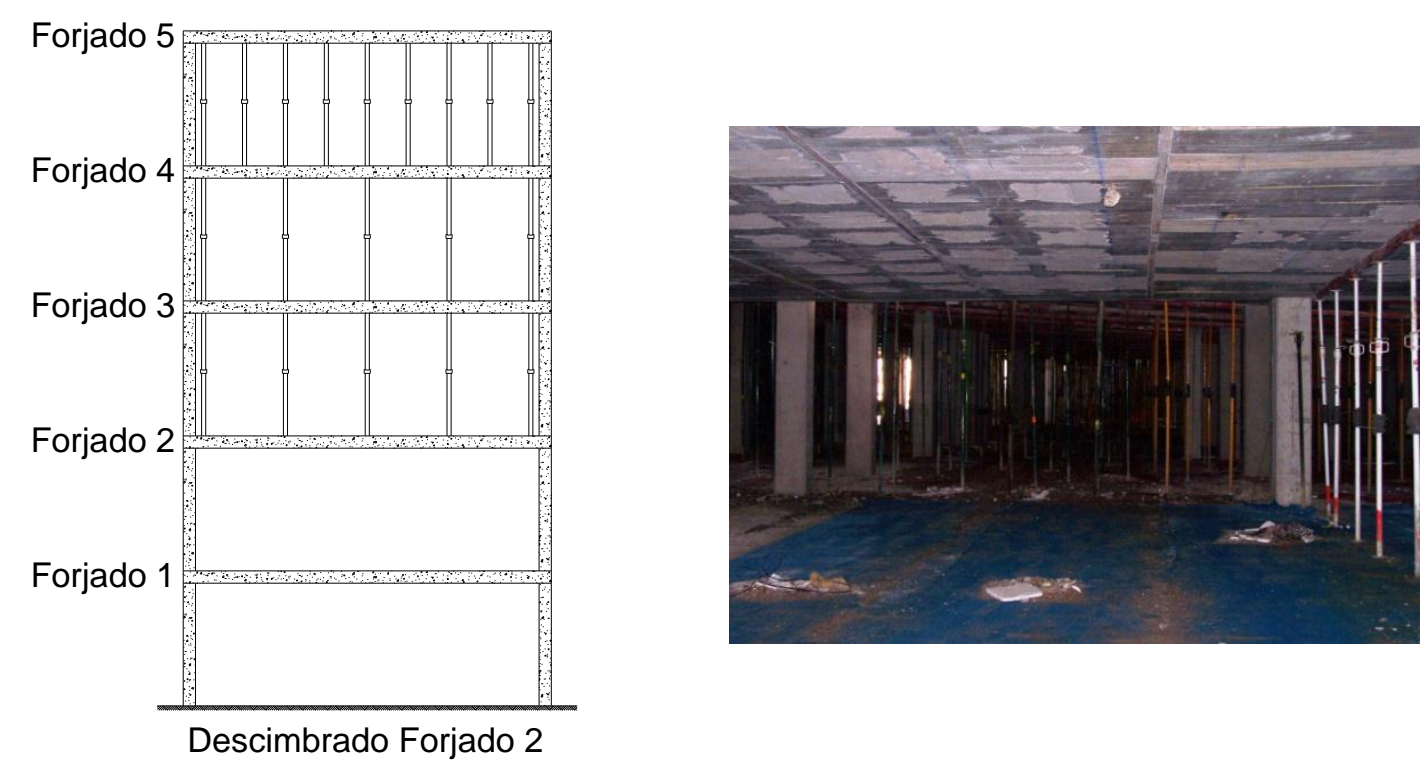

Fig. 3.64 Proceso constructivo día "143a" (forjado reticular de casetón perdido) 
$\checkmark$ Día "143b" (26 de Abril de 2010): una vez hormigonado el forjado 5, a los seis días se procedió a su clareado (Fig. 3.65).
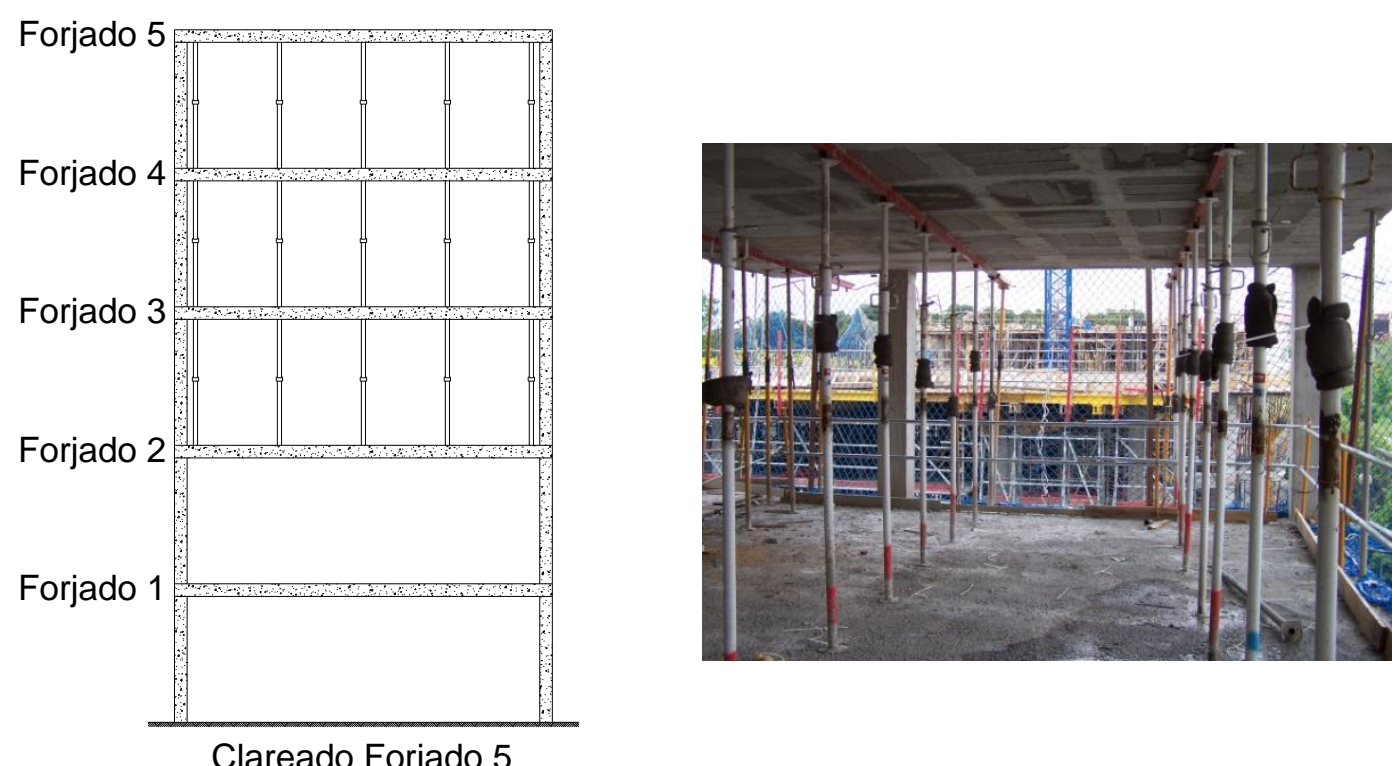

Clareado Forjado 5

Fig. 3.65 Proceso constructivo día "143b" (forjado reticular de casetón perdido)

$\checkmark$ Día "160a" (13 de Mayo de 2010): esta operación constructiva consistió en el descimbrado del forjado 3 (Fig. 3.66).
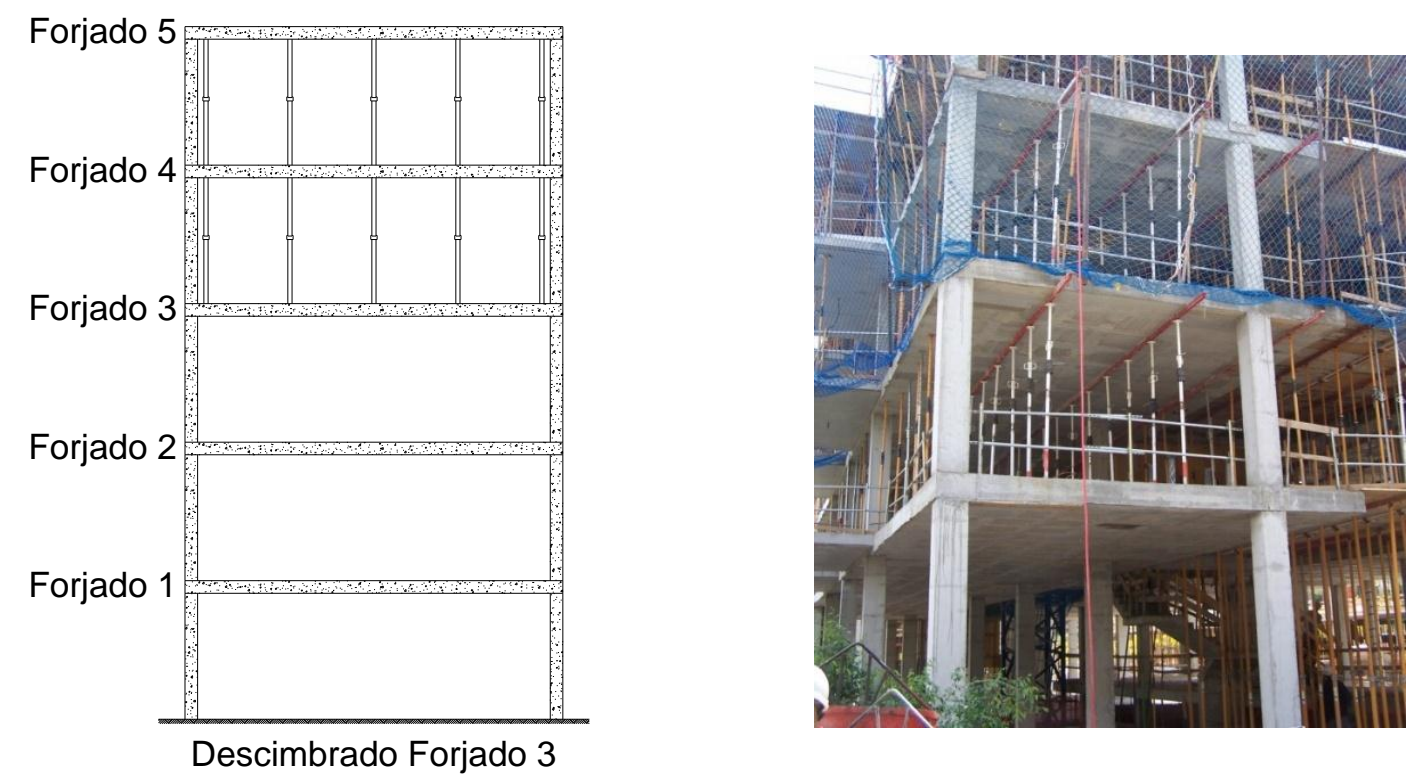

Fig. 3.66 Proceso constructivo día “160a” (forjado reticular de casetón perdido) 
Día "160b" (13 de Mayo de 2010): la última operación constructiva estudiada consistió en el hormigonado del forjado 6 (Fig. 3.67).
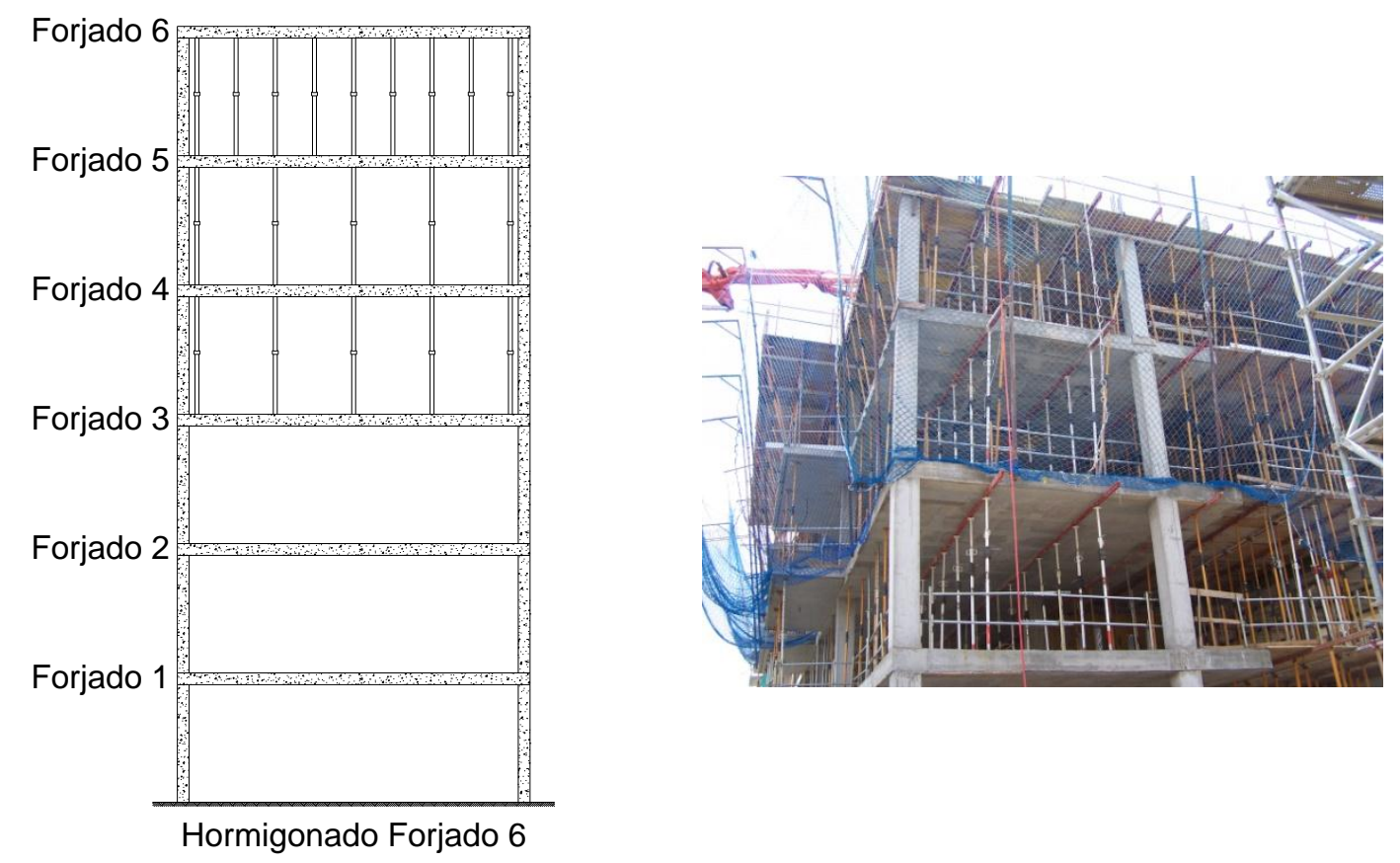

Fig. 3.67 Proceso constructivo día “37” (forjado reticular de casetón perdido)

\subsubsection{Resultados de carga del estudio experimental}

Se instrumentaron 2 sopandas de un único vano (véanse Figs. 3.51 y 3.52). Se dispusieron un total de 15 puntales instrumentados por vano en los sótanos y 16 puntales instrumentados por vano en el resto de plantas.

Se realizaron medidas instantáneas, es decir, medidas tomadas una vez ejecutada cada una de las fases del proceso constructivo (hormigonado, clareado, descimbrado), desde el hormigonado del Forjado 1 hasta el hormigonado del Forjado 6. Estas medidas permiten analizar cómo se transmiten las cargas entre forjados y puntales debido a las operaciones constructivas de hormigonado, clareado y descimbrado de un forjado. En el Apéndice I se muestran, de forma amplia, los resultados obtenidos de dicha medición instantánea.

A modo de resumen del estudio experimental de cargas, las Figuras 3.68 y 3.69 muestran la evolución del coeficiente de carga para el forjado 1 y para los puntales bajo este forjado durante todo el proceso constructivo. Las Figuras 3.70 y 3.71 muestran la evolución del coeficiente de carga para el forjado 2 y para los puntales bajo este forjado durante todo el proceso constructivo. Las Figuras 3.72 y 3.73 muestran la evolución del coeficiente de carga para el forjado 3 y para los puntales bajo este forjado durante todo el proceso constructivo. Las Figuras 3.74 y 3.75 muestran la evolución del coeficiente de carga para el forjado 4 y para los puntales bajo este forjado durante todo el proceso constructivo. Por último, las Figuras 3.76 y 3.77 muestran la evolución del coeficiente de carga para el forjado 5 y para los puntales bajo este forjado durante todo el proceso constructivo. No se muestra una evolución del 
coeficiente de carga en el forjado 6 y en los puntales bajo este forjado debido a que únicamente fue objeto de medición el hormigonado de dicho forjado (operación en la cual concluyó el estudio experimental).

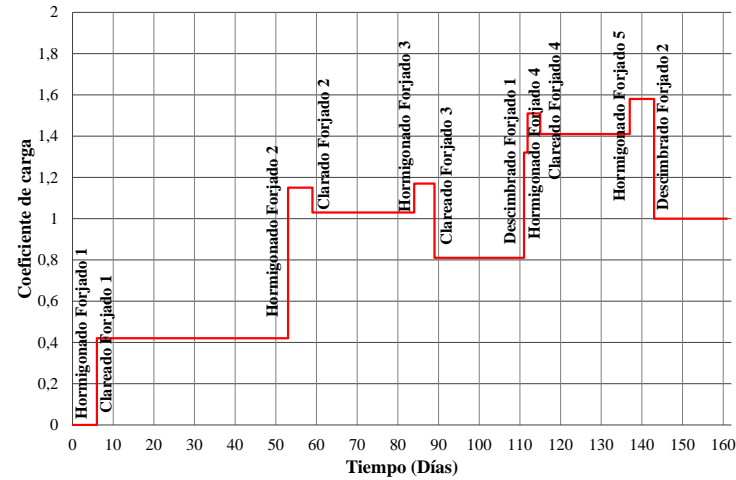

Fig. 3.68 Coeficientes de carga en el forjado 1 (forjado reticular de casetón perdido)

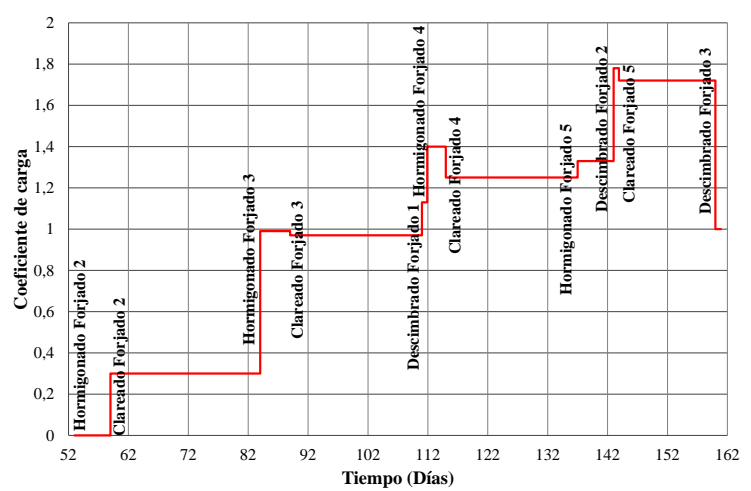

Fig. 3.70 Coeficientes de carga en el forjado 2 (forjado reticular de casetón perdido)

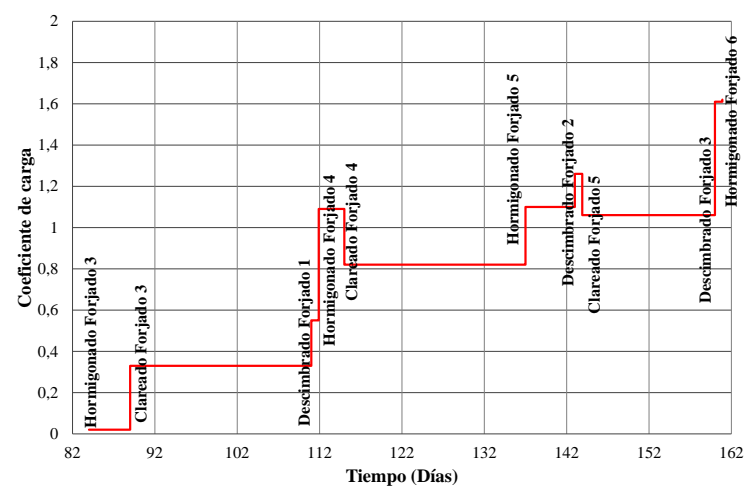

Fig. 3.72 Coeficientes de carga en el forjado 3 (forjado reticular de casetón perdido)

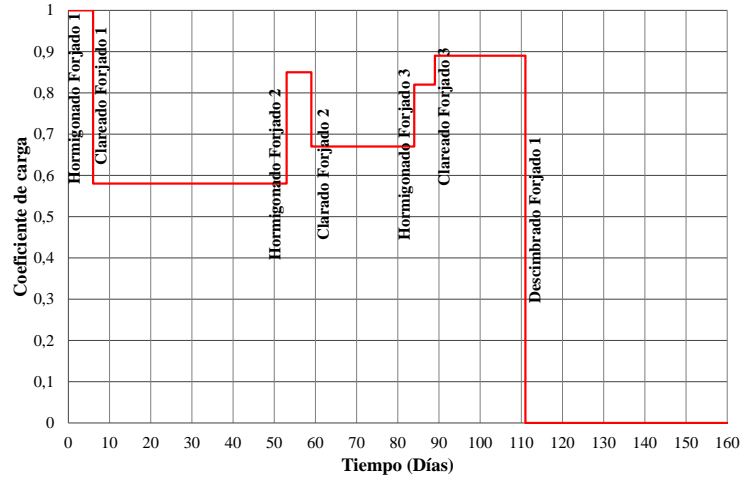

Fig. 3.69 Coeficientes de carga en puntales bajo el forjado 1 (forjado reticular de casetón perdido)

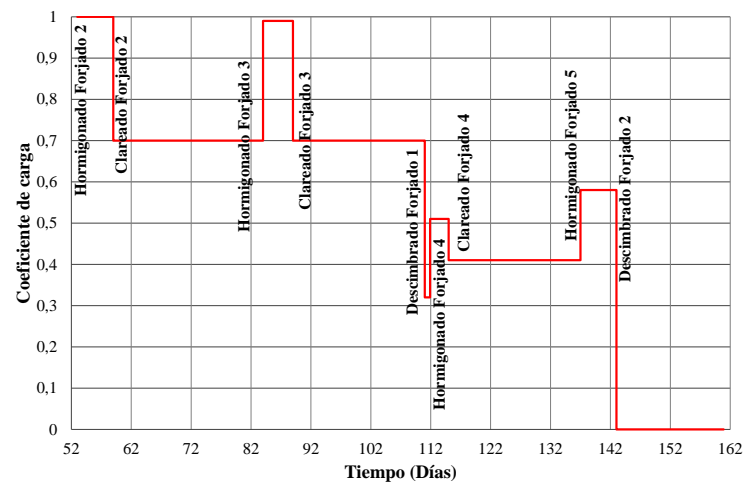

Fig. 3.71 Coeficientes de carga en puntales bajo el forjado 2 (forjado reticular de casetón perdido)

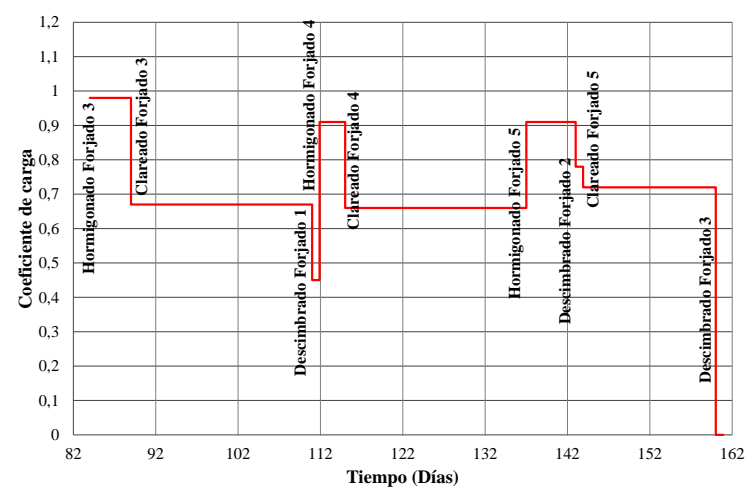

Fig. 3.73 Coeficientes de carga en puntales bajo el forjado 3 (forjado reticular de casetón perdido) 


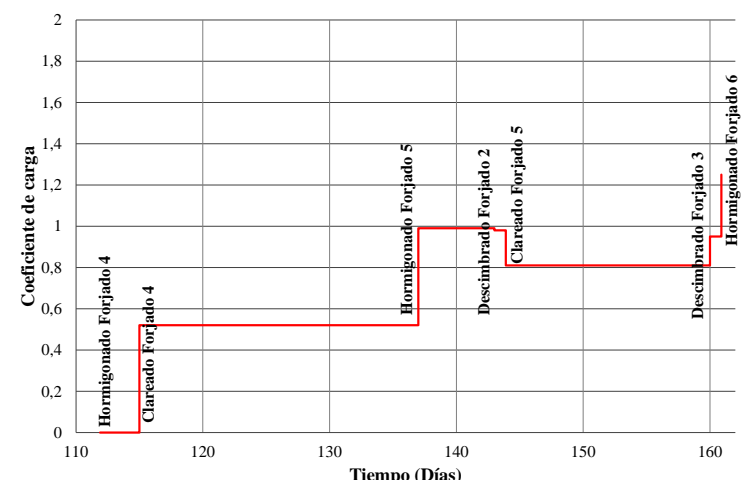

Fig. 3.74 Coeficientes de carga en el forjado 4 (forjado reticular de casetón perdido)

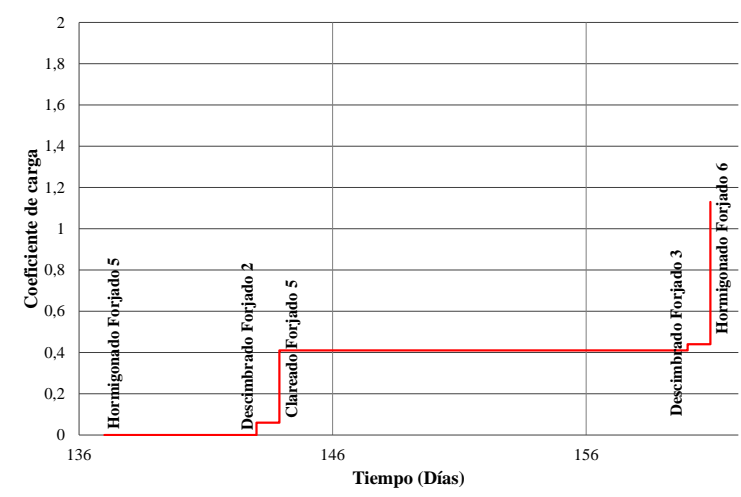

Fig. 3.76 Coeficientes de carga en el forjado 5 (forjado reticular de casetón perdido)

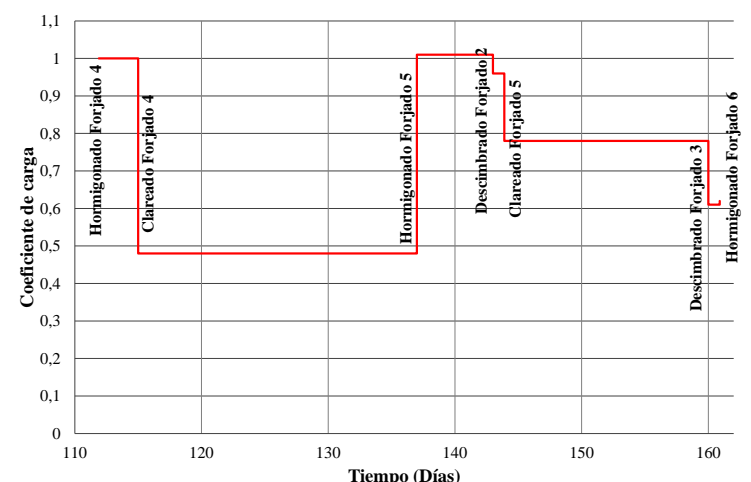

Fig. 3.75 Coeficientes de carga en puntales bajo el forjado 4 (forjado reticular de casetón perdido)

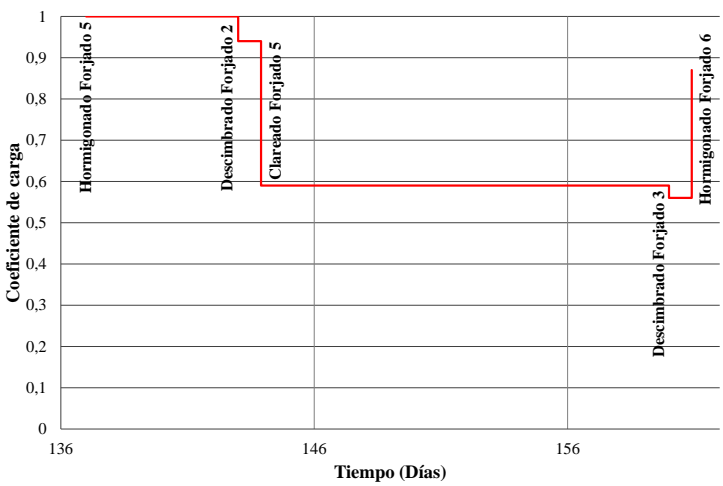

Fig. 3.77 Coeficientes de carga en puntales bajo el forjado 5 (forjado reticular de casetón perdido)

La Tabla 3.6 muestra los coeficientes de carga, las cargas medias y las cargas máximas obtenidas en la medición instantánea para el vano de esquina. Donde:

$\checkmark q_{\text {med }}$ : carga media en puntales por unidad de superficie que resulta de la relación entre la sumatoria de las cargas en puntales y el área del forjado instrumentada $\left(\sum P_{i} / A_{\text {total }}\right)$ $\left(\mathrm{kN} / \mathrm{m}^{2}\right)$. Siendo: $P_{i}$ la carga instantánea en el puntal “ $i$ ” $(\mathrm{kN})$ y $A_{\text {total }}$ el área del forjado instrumentada $\left(\mathrm{m}^{2}\right)$.

$\checkmark C_{p}$ : coeficiente de carga en puntales que resulta de la relación entre la carga media en puntales $\left(Q_{p}\right)$ y el peso propio del forjado $\left(W_{f}=3.39 \mathrm{kN} / \mathrm{m}^{2}\right) .\left(Q_{p} / W_{f}\right)$.

$\checkmark \quad C_{f}$ : coeficiente de carga en forjados que resulta de la relación entre la carga media del forjado $\left(Q_{f}\right)$ y el peso propio del forjado $\left(W_{f}=3.39 \mathrm{kN} / \mathrm{m}^{2}\right) .\left(Q_{f} / W_{f}\right)$.

$\checkmark \quad P_{\text {max }}$ : axil del puntal más cargado $(\mathrm{kN})$.

$\checkmark \quad q_{\max }$ : axil del puntal más cargado por unidad de superficie $\left(P_{\max } / A_{t}\right)\left(\mathrm{kN} / \mathrm{m}^{2}\right)$. Siendo $A_{t}$ el área tributaria del puntal considerado $\left(\mathrm{m}^{2}\right)$.

$\checkmark \quad C_{p, \text { max }}$ : coeficiente de carga del puntal más cargado que resulta de la relación entre la carga máxima en puntales $\left(q_{\max }\right)$ y el peso propio del forjado $\left(W_{f}=4.96 \mathrm{kN} / \mathrm{m}^{2}\right) .\left(q_{\max } / W_{f}\right)$. 
Estudio de la evolución de cargas en forjados y puntales durante el proceso constructivo

Tabla 3.6. Resumen medición experimental. Forjado reticular de casetón perdido

\begin{tabular}{|c|c|c|c|c|c|c|c|c|}
\hline \multirow{2}{*}{ Operación } & \multirow{2}{*}{ Nivel } & \multirow{2}{*}{$\underset{\left(\mathrm{kN} / \mathrm{m}^{2}\right)}{\boldsymbol{q}_{\boldsymbol{m} \boldsymbol{e}}}$} & \multicolumn{2}{|c|}{ Para $q_{m e d}$} & \multirow{2}{*}{$\begin{array}{l}\text { Puntal más } \\
\text { cargado }\end{array}$} & \multirow{2}{*}{$\begin{array}{r}P_{\max } \\
(\mathrm{kN})\end{array}$} & \multirow{2}{*}{$\underset{\left(\mathrm{kN} / \mathrm{m}^{2}\right)}{\boldsymbol{q}_{\max }}$} & \multirow{2}{*}{$C_{p, \max }$} \\
\hline & & & $C_{p}$ & $C_{f}$ & & & & \\
\hline $\begin{array}{l}\text { Hormigonado } \\
\text { forjado } 1\end{array}$ & 1 & 3.40 & 1.00 & 0.00 & 13 & 3.69 & 3.62 & 1.07 \\
\hline $\begin{array}{l}\text { Clareado } \\
\text { forjado } 1\end{array}$ & 1 & 1.97 & 0.58 & 0.42 & 5 & 4.98 & 2.52 & 0.74 \\
\hline \multirow{2}{*}{$\begin{array}{l}\text { Hormigonado } \\
\text { forjado } 2\end{array}$} & 2 & 3.40 & 1.00 & 0.00 & 12 & 3.55 & 3.41 & 1.01 \\
\hline & 1 & 2.88 & 0.85 & 1.15 & 13 & 8.03 & 3.96 & 1.17 \\
\hline \multirow{2}{*}{$\begin{array}{l}\text { Clareado } \\
\text { forjado } 2\end{array}$} & 2 & 2.37 & 0.70 & 0.30 & 11 & 6.84 & 3.35 & 0.99 \\
\hline & 1 & 2.27 & 0.67 & 1.03 & 13 & 6.48 & 3.19 & 0.94 \\
\hline \multirow{3}{*}{$\begin{array}{l}\text { Hormigonado } \\
\text { forjado } 3\end{array}$} & 3 & 3.32 & 0.98 & 0.02 & 13 & 3.90 & 3.38 & 1.00 \\
\hline & 2 & 3.36 & 0.99 & 0.99 & 11 & 10.52 & 5.16 & 1.52 \\
\hline & 1 & 2.78 & 0.82 & 1.17 & 11 & 7.56 & 3.56 & 1.05 \\
\hline \multirow{3}{*}{$\begin{array}{l}\text { Clareado } \\
\text { forjado } 3\end{array}$} & 3 & 2.27 & 0.67 & 0.33 & 13 & 6.58 & 3.25 & 0.96 \\
\hline & 2 & 2.37 & 0.70 & 0.97 & 11 & 8.14 & 3.99 & 1.18 \\
\hline & 1 & 3.02 & 0.89 & 0.81 & 11 & 8.47 & 4.00 & 1.18 \\
\hline \multirow{3}{*}{$\begin{array}{l}\text { Descimbrado } \\
\text { forjado } 1\end{array}$} & 3 & 1.53 & 0.45 & 0.55 & 13 & 5.56 & 2.75 & 0.81 \\
\hline & 2 & 1.08 & 0.32 & 1.13 & 11 & 5.04 & 2.47 & 0.73 \\
\hline & 1 & & & 1.32 & & & & \\
\hline \multirow{4}{*}{$\begin{array}{l}\text { Hormigonado } \\
\text { forjado } 4\end{array}$} & 4 & 3.39 & 1.00 & 0.00 & 13 & 3.60 & 3.43 & 1.01 \\
\hline & 3 & 3.08 & 0.91 & 1.09 & 13 & 8.77 & 4.34 & 1.28 \\
\hline & 2 & 1.73 & 0.51 & 1.40 & 11 & 3.94 & 1.93 & 0.57 \\
\hline & 1 & & & 1.51 & & & & \\
\hline \multirow{4}{*}{$\begin{array}{l}\text { Clareado } \\
\text { forjado } 4\end{array}$} & 4 & 1.62 & 0.48 & 0.52 & 3 & 4.68 & 2.15 & 0.63 \\
\hline & 3 & 2.24 & 0.66 & 0.82 & 13 & 4.93 & 2.44 & 0.72 \\
\hline & 2 & 1.39 & 0.41 & 1.25 & 11 & 3.88 & 1.90 & 0.56 \\
\hline & 1 & & & 1.41 & & & & \\
\hline \multirow{5}{*}{$\begin{array}{l}\text { Hormigonado } \\
\text { forjado } 5\end{array}$} & 5 & 3.40 & 1.00 & 0.00 & 14 & 3.45 & 3.45 & 1.02 \\
\hline & 4 & 3.41 & 1.01 & 0.99 & 3 & 9.13 & 4.28 & 1.26 \\
\hline & 3 & 3.08 & 0.91 & 1.10 & 2 & 7.22 & 3.49 & 1.03 \\
\hline & 2 & 1.97 & 0.58 & 1.33 & 11 & 4.18 & 2.05 & 0.60 \\
\hline & 1 & & & 1.58 & & & & \\
\hline \multirow{4}{*}{$\begin{array}{l}\text { Descimbrado } \\
\text { forjado } 2\end{array}$} & 5 & 3.20 & 0.94 & 0.06 & 6 & 4.43 & 4.43 & 1.31 \\
\hline & 4 & 3.27 & 0.96 & 0.98 & 3 & 8.22 & 3.86 & 1.14 \\
\hline & 3 & 2.38 & 0.78 & 1.26 & 2 & 6.10 & 2.95 & 0.87 \\
\hline & 2 & & & 1.78 & & & & \\
\hline \multirow{4}{*}{$\begin{array}{l}\text { Clareado } \\
\text { forjado } 5\end{array}$} & 5 & 2.00 & 0.59 & 0.41 & 14 & 5.89 & 3.47 & 1.02 \\
\hline & 4 & 2.64 & 0.78 & 0.81 & 10 & 6.92 & 3.99 & 1.18 \\
\hline & 3 & 2.44 & 0.72 & 1.06 & 2 & 5.34 & 2.58 & 0.76 \\
\hline & 2 & & & 1.72 & & & & \\
\hline \multirow{3}{*}{$\begin{array}{l}\text { Descimbrado } \\
\text { forjado } 3\end{array}$} & 5 & 1.91 & 0.56 & 0.44 & 14 & 6.03 & 3.54 & 1.04 \\
\hline & 4 & 2.08 & 0.61 & 0.95 & 10 & 8.59 & 4.96 & 1.46 \\
\hline & 3 & & & 1.61 & & & & \\
\hline \multirow{4}{*}{$\begin{array}{l}\text { Hormigonado } \\
\text { forjado } 6\end{array}$} & 6 & 3.40 & 1.00 & 0.00 & 13 & 3.48 & 3.48 & 1.03 \\
\hline & 5 & 2.96 & 0.87 & 1.13 & 2 & 8.01 & 4.01 & 1.18 \\
\hline & 4 & 2.09 & 0.62 & 1.25 & 7 & 5.06 & 2.48 & 0.73 \\
\hline & 3 & & & 1.62 & & & & \\
\hline
\end{tabular}




\subsubsection{Resultados de temperatura del estudio experimental}

Para poder determinar el gradiente térmico del forjado, se instrumentó la zona de un ábaco y una de las losas macizas de los balcones, de $0.20 \mathrm{~m}$ de espesor. Se instalaron 5 termopares a una profundidad de $0.05,0.10,0.175,0.25$ y $0.30 \mathrm{~m}$, en el caso del ábaco y 3 termopares a $0.05,0.10$ y $0.15 \mathrm{~m}$ de profundidad, en el caso de la losa. Así mismo, se tomaron medidas de la temperatura ambiente mediante un termopar libre. Las medidas se realizaron distintos días y con diferentes condiciones del forjado (encofrado, desencofrado).

En las Figuras 3.78 - 3.81, se observa la distribución de temperaturas en el espesor de la losa a lo largo del día. Las Figuras 3.78 y 3.80 se corresponden con las losas de 0.20 m y $0.32 \mathrm{~m}$, respectivamente, cuando se encontraban encofradas, mientras que las figuras 3.79 y 3.81 se corresponden con dichas losas cuando se encontraban desencofradas.

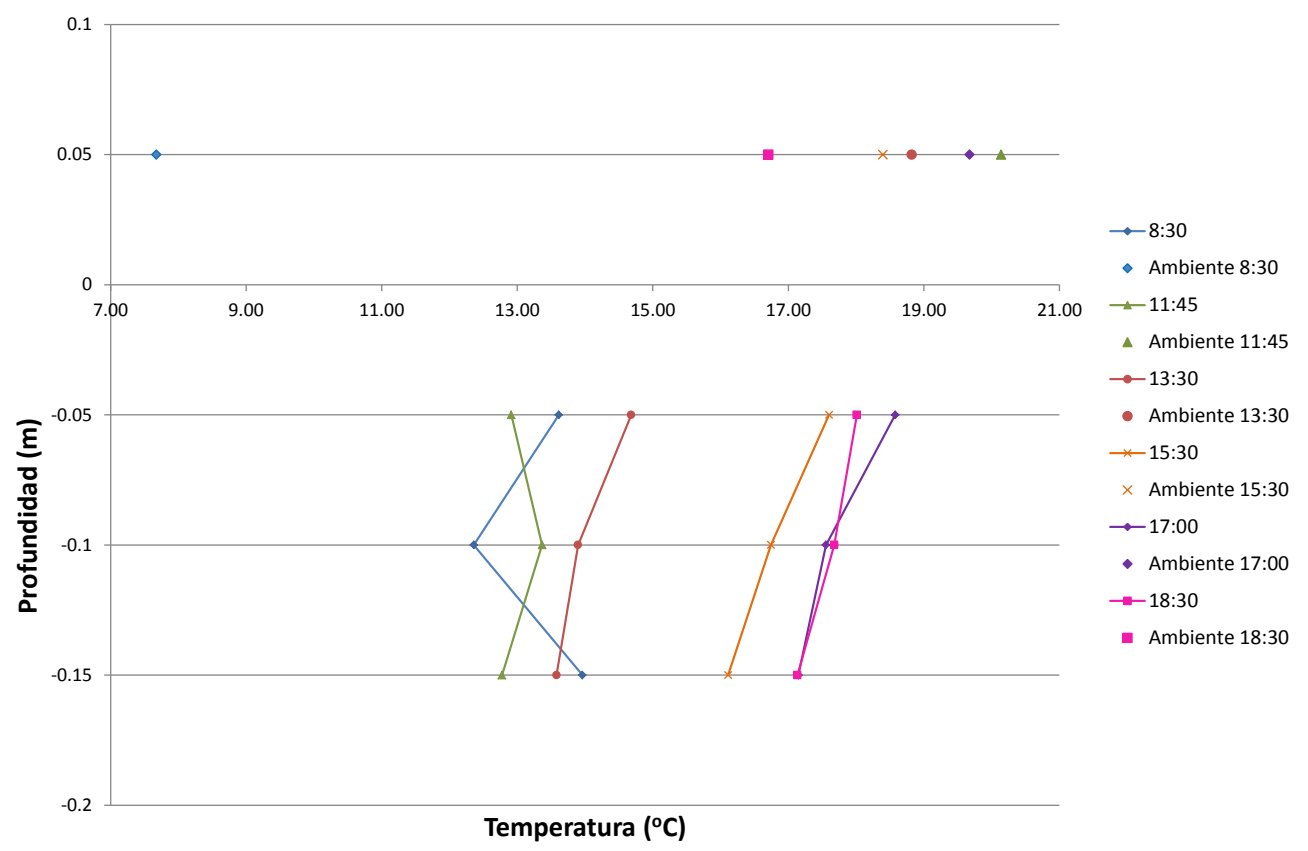

Fig. 3.78 Distribución de temperaturas en el espesor de la losa a lo largo del día para la losa de 0.20 m encofrada. Edificio de forjado reticular de casetón perdido 
Estudio de la evolución de cargas en forjados y puntales durante el proceso constructivo

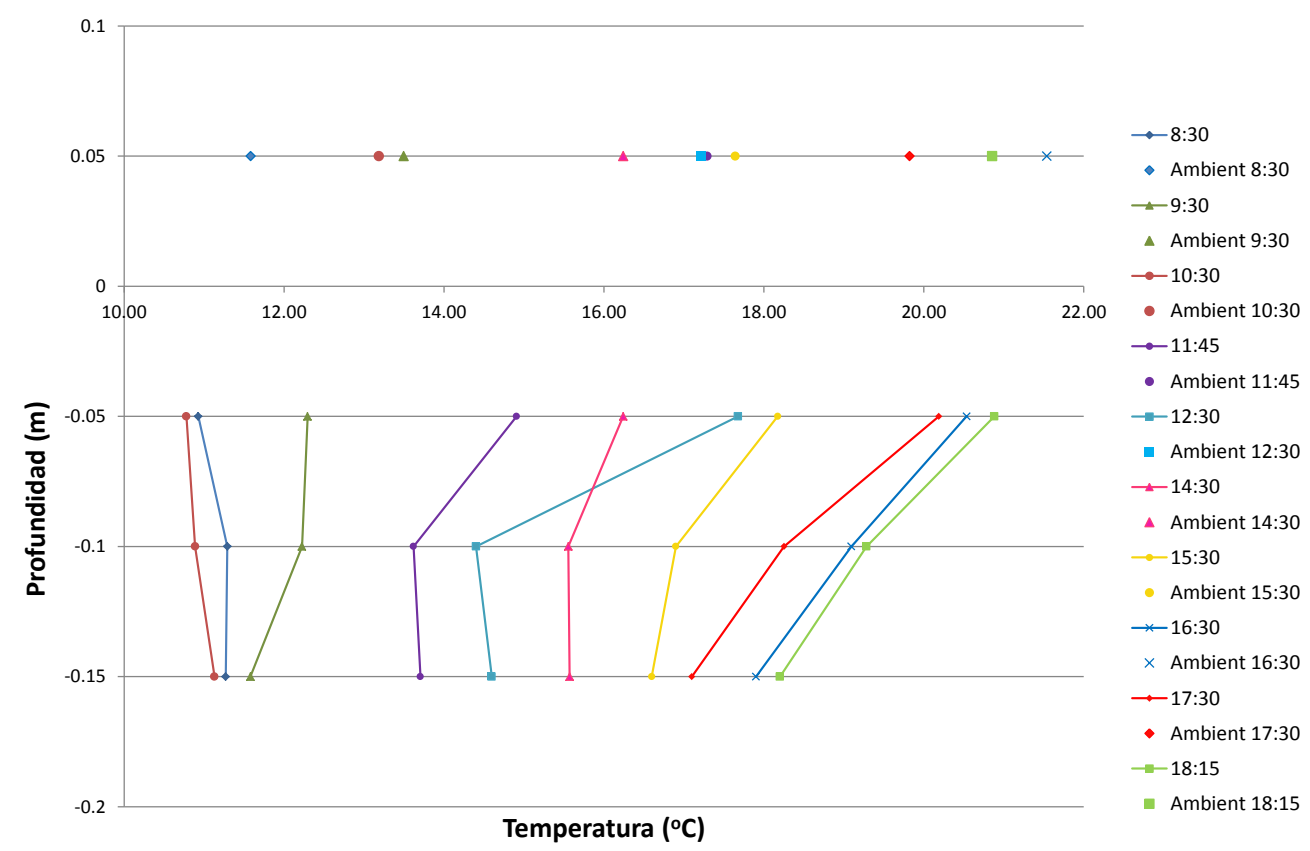

Fig. 3.79 Distribución de temperaturas en el espesor de la losa a lo largo del día para la losa de 0.20m desencofrada. Edificio de forjado reticular de casetón perdido

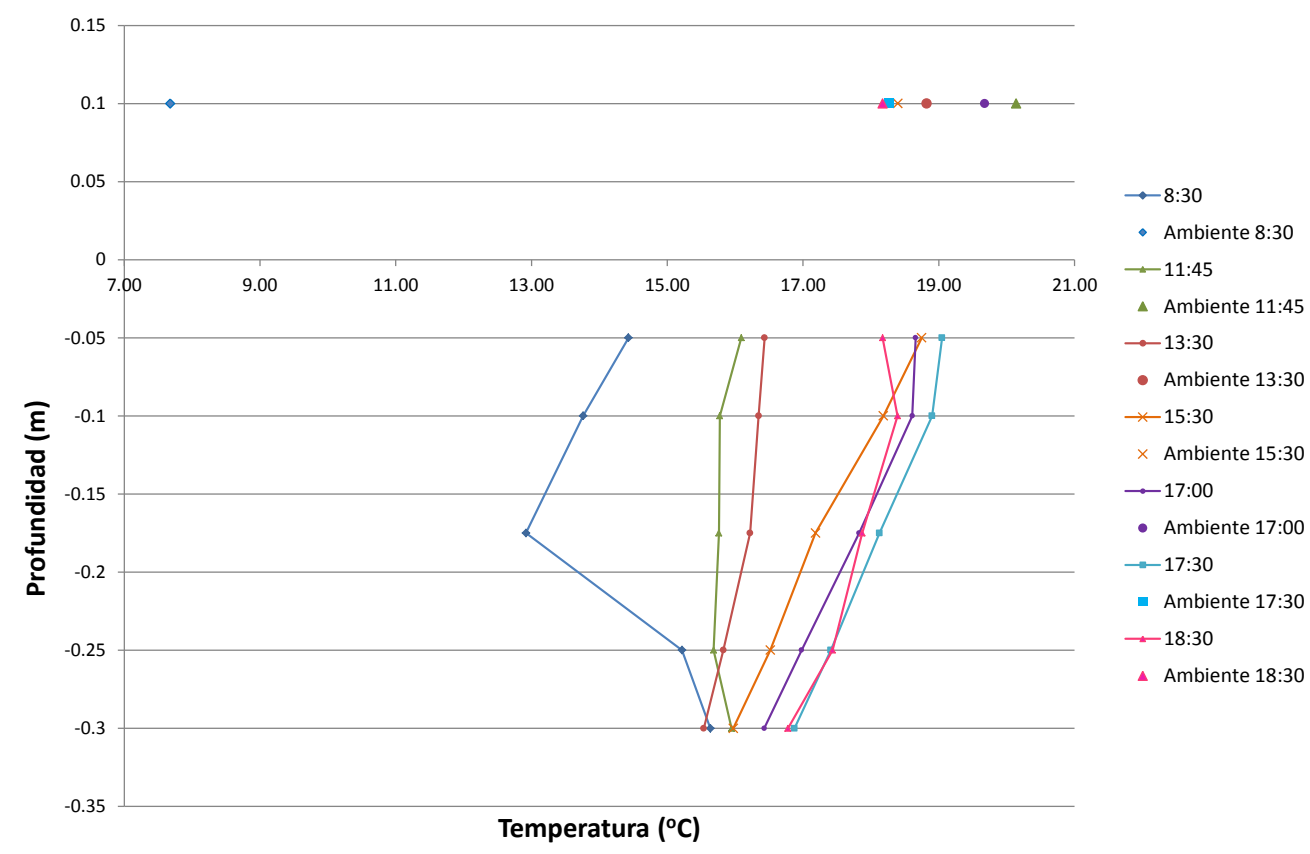

Fig. 3.80 Distribución de temperaturas en el espesor de la losa a lo largo del día para la losa de 0.32m encofrada. Edificio de forjado reticular de casetón perdido. 


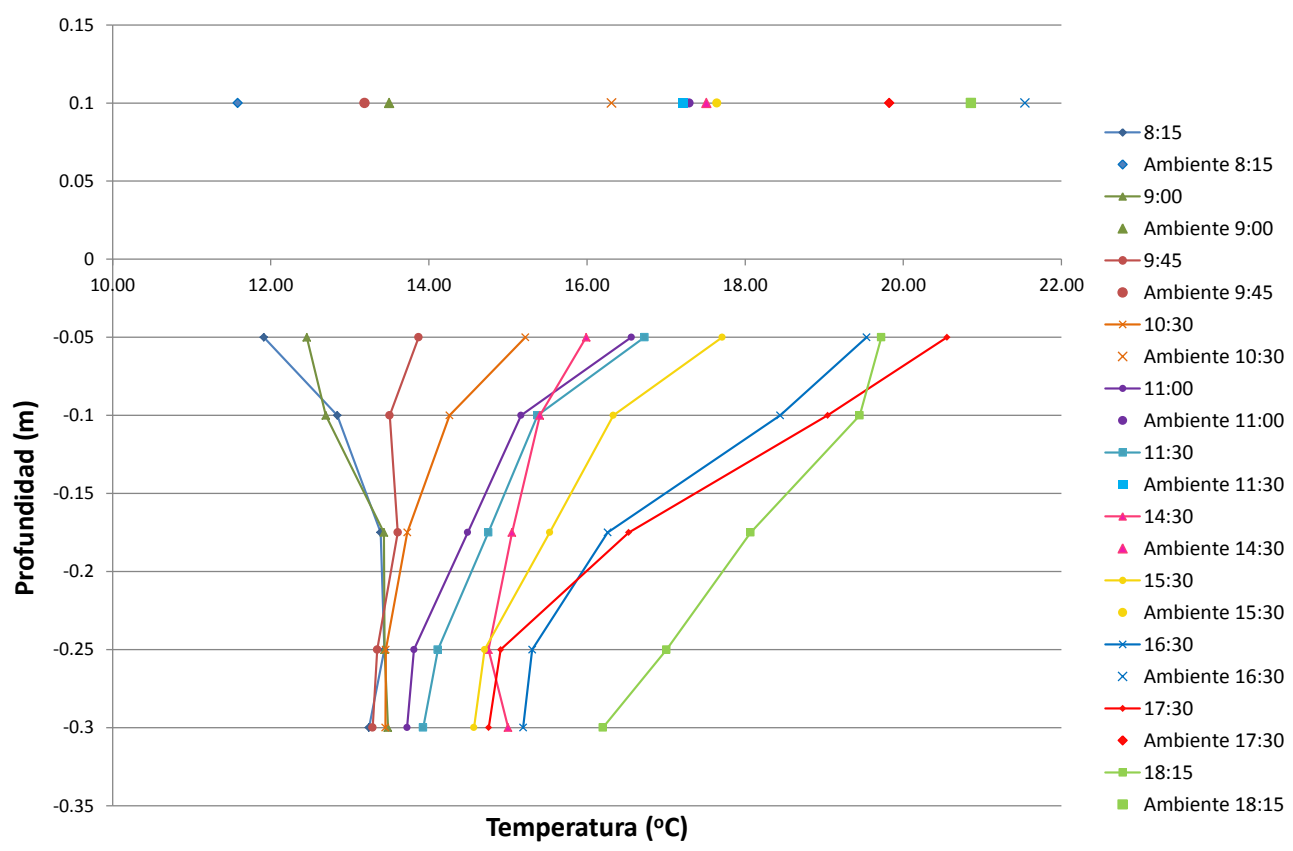

Fig. 3.81 Distribución de temperaturas en el espesor de la losa a lo largo del día para la losa de 0.32m desencofrada. Edificio de forjado reticular de casetón perdido.

En todos los casos se observa que a primera hora de la mañana, cuando la temperatura es menor, la cara inferior de la losa tiene una mayor temperatura que la cara superior. Conforme va avanzando el día y va aumentando la temperatura, este fenómeno se invierte, quedando la cara superior de la losa más caliente que la inferior.

Las variaciones de temperatura, máximas y mínimas, entre la cara superior e inferior de la losa registradas en cada uno de los forjados, variaron en función de si éstos estaban encofrados o ya habían sido desencofrados. Los valores de dichos incrementos pueden verse en la Tabla 3.7. Durante los días en que se realizaron las mediciones de temperatura, se registraron diferencias térmicas ambientales de hasta $12.5^{\circ} \mathrm{C}$.

Tabla 3.7. Incrementos de temperatura $\left({ }^{\circ} \mathrm{C}\right)$, máximos y mínimos, entre la cara superior e inferior del forjado registrados en el edificio de forjado reticular de casetón perdido.

\begin{tabular}{ccccc}
\hline & \multicolumn{2}{c}{ Forjado encofrado } & \multicolumn{2}{c}{ Forjado desencofrado } \\
\hline & Incremento min & Incremento máx. & Incremento min & Incremento máx. \\
\hline Losa $0.20 \mathrm{~m}$ & -0.35 & 1.49 & -0.77 & 3.79 \\
Ábaco $0.32 \mathrm{~m}$ & -1.21 & 2.77 & -1.87 & 5.80 \\
\hline
\end{tabular}




\subsection{Estudio experimental de un edificio de forjado reticular de casetón recuperable}

El último edificio donde se realizaron mediciones se encuentra situado en Valencia, dentro del recinto de la Universidad Politécnica de Valencia, y se corresponde con la ampliación de la facultad de Bellas Artes. Se trata de un edificio de forjado reticular de casetón recuperable con 1 sótano y 6 plantas. En el sótano existía un muro perimetral paralelo a las sopandas.

Se instrumentaron dos vanos consecutivos, uno de esquina y otro de medianera. El vano de medianera tenía una luz entre pilares de 5.5 × $8.0 \mathrm{~m}$, mientras que el vano de esquina era un vano irregular con dimensiones mínimas de 5.5 x $5.0 \mathrm{~m}$.

El estudio se llevó a cabo desde el hormigonado del Forjado 1 (techo de sótano) hasta el hormigonado del Forjado 4 (techo de $2^{\mathrm{a}}$ planta). Se midieron cargas hasta dicho hormigonado puesto que, al utilizar dos juegos de cimbras (una planta cimbrada y una clareada), es en esta operación donde se esperaba que se presentase la mayor solicitación de cargas sobre los forjados inferiores donde se apoyan puntales.

También se realizaron mediciones de temperatura en el interior del forjado colocando termopares a distintas profundidades. Estas mediciones se realizaron en diferentes días, una vez el hormigón había curado, y con diferentes condiciones del forjado (encofrado o desencofrado, con insolación directa o sin insolación directa).

La definición del estudio experimental se realizó a finales de Mayo de 2010. A partir de ahí se procedió a definir los vanos y número de plantas a instrumentar, el número de puntales y la distribución de los termopares en el forjado. El estudio experimental inició el 14 de Junio de 2010 con el hormigonado del Forjado 1 y finalizó el 2 de Agosto de 2010 con el hormigonado del Forjado 4.

\subsubsection{Descripción de la estructura}

El edificio consta de 7 forjados (6 plantas y 1 sótano) destinado a la Facultad de Bellas Artes y situado dentro del recinto de la Universidad Politécnica de Valencia.

\subsubsection{Estructura}

Todos los forjados se resolvieron mediante forjado reticular de casetón recuperable de $0.40 \mathrm{~m}$ de canto (35+5), $0.15 \mathrm{~m}$ de nervio y con un intereje de $0.83 \mathrm{~m}$.

La altura entre plantas es de $2.9 \mathrm{~m}$ en el caso del sótano, $4.0 \mathrm{~m}$ en el caso de planta baja y $3.6 \mathrm{~m}$ en el resto.

En la Figura 3.82 se muestra una sección del edificio. 


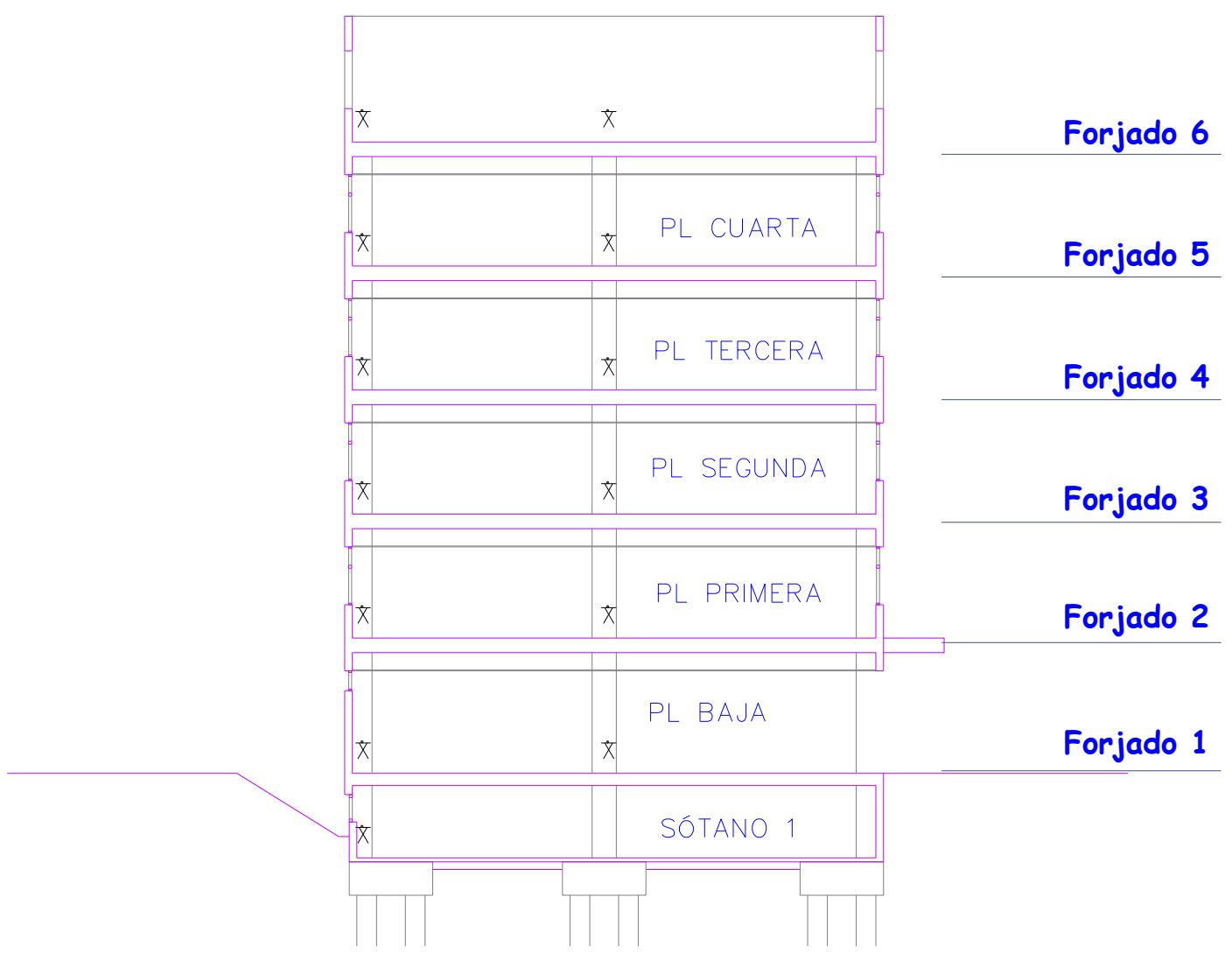

Fig. 3.82 Sección del edificio de forjado reticular de casetón recuperable

\subsubsection{Materiales}

Los materiales empleados en la construcción de este edificio se describen a continuación:

El hormigón de la losa de cimentación es HA-30/B/40/IIIb

- Resistencia característica a compresión $30 \mathrm{MPa}$.

- Consistencia: Blanda.

- Tamaño máximo del árido: 20/30 mm.

- Clase general de exposición: IIIb Elementos de estructuras marinas sumergidas permanentemente, por debajo del nivel mínimo de bajamar.

$\checkmark$ El hormigón de los pilares es HA-30/B/20/IIa

- Resistencia característica a compresión $30 \mathrm{MPa}$.

- Consistencia: Blanda.

- Tamaño máximo del árido: 20/25 mm.

- Clase general de exposición: IIa Interiores sometidos a humedades relativas medias altas.

El hormigón de los forjados es HA-30/B/20/IIa 
- Resistencia característica a compresión 30 MPa.

- Consistencia: Blanda.

- Tamaño máximo del árido: $15 / 20 \mathrm{~mm}$.

- Clase general de exposición: IIa Interiores sometidos a humedades relativas medias altas.

$\checkmark$ Acero para armar: B-500-S

\subsubsection{Zona de estudio}

Se instrumentaron los puntales de una sopanda principal de dos vanos consecutivos, uno de esquina y otro de medianera. El vano de esquina es un vano irregular, cuyas dimensiones mínimas son 5.5 x 5.0 $\mathrm{m}$, mientras que el vano de medianera es un vano regular de 5.5 x $8.0 \mathrm{~m}$. La zona sombreada de la Figura 3.83 muestra la zona instrumentada. En la figura 3.84 se muestra la distribución de los puntales instrumentados. En total se colocaron 12 puntales instrumentados por planta. Además, se dispusieron otros dos puntales de referencia, por cada planta, con el objeto de medir el efecto de la temperatura ambiente sobre los puntales, las galgas extensométricas y el equipo de adquisición de datos. Estos puntales estaban libres y por lo tanto no formaban parte del sistema de cimbrado.

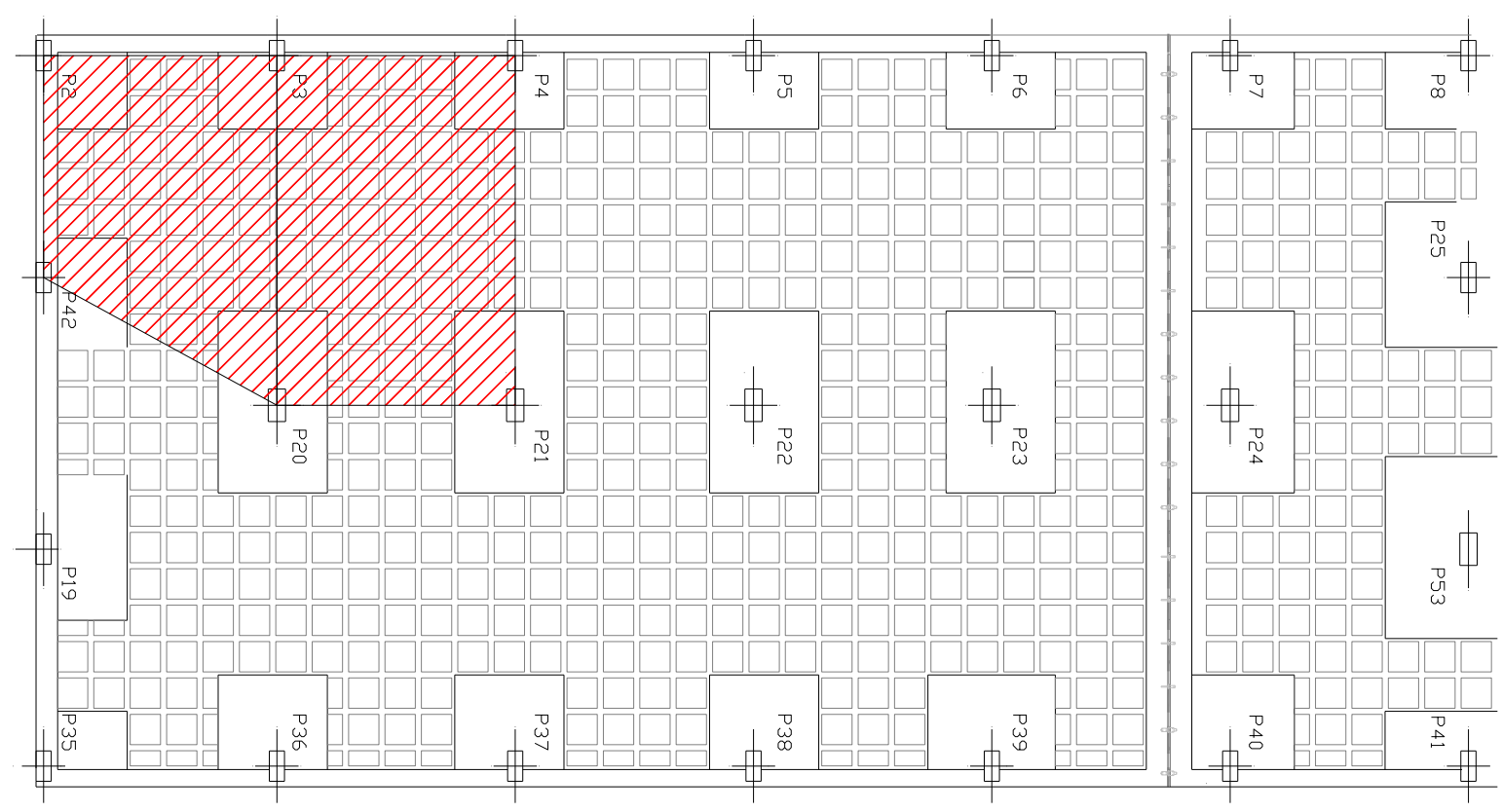

Fig. 3.83 Zona de estudio del edificio de forjado reticular de casetón recuperable 


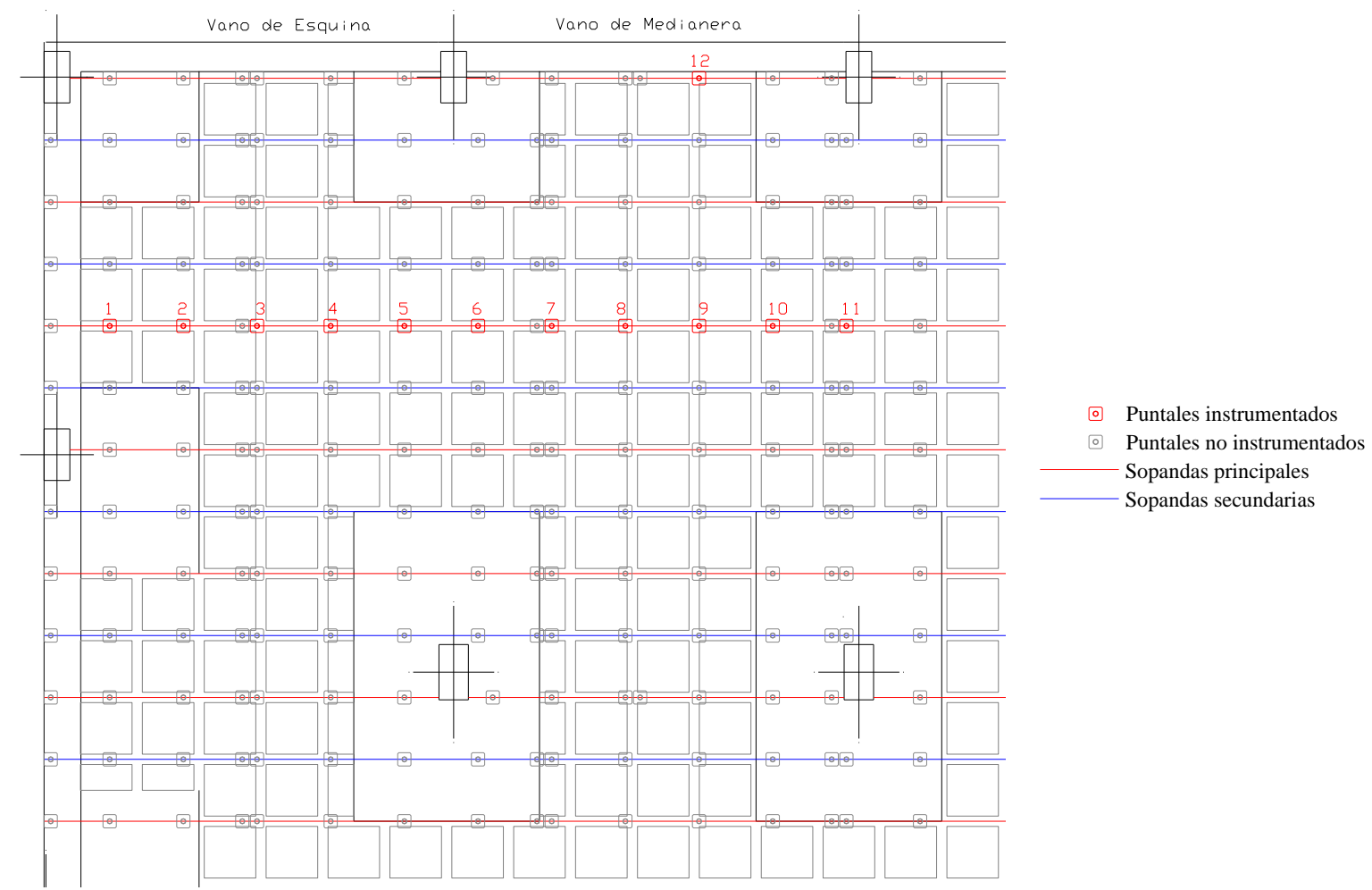

Fig. 3.84 Disposición de sopandas principales y secundarias en el edificio de forjado reticular de casetón recuperable

Para poder estudiar el gradiente térmico que se producía en el forjado de hormigón, se instrumentaron con termopares 2 nervios de dos forjados consecutivos (forjado 1 y forjado 2), véase Fig. 3.85. En cada uno de estos nervios, se embebieron 4 termopares a $0.05,0.10,0.20$ y $0.30 \mathrm{~m}$ de profundidad. También se tomaron medidas de la temperatura ambiente mediante un termopar libre.
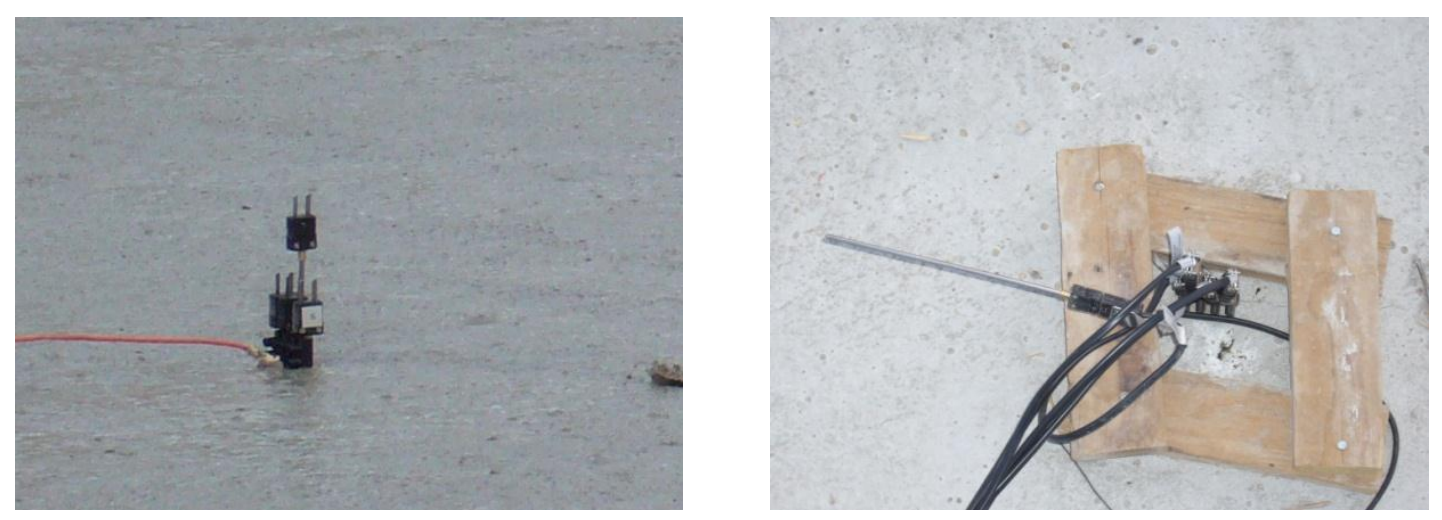

Fig. 3.85 Termopares embebidos en el hormigón (forjado reticular de casetón recuperable) 


\subsubsection{Proceso constructivo}

El proceso constructivo adoptado para la construcción del edificio consistió en mantener una planta clareada y una cimbrada, es decir utilizando 2 juegos de puntales. Las medidas experimentales fueron tomadas desde el hormigonado del Forjado 1 hasta el hormigonado del Forjado 4.

Las operaciones constructivas en donde se midieron las cargas en puntales son las siguientes:

$\checkmark$ Día “0” (14 de Junio de 2010): una vez hormigonada la losa de cimentación, el muro de sótano y los pilares del sótano se instaló el sistema de cimbrado y encofrado para el hormigonado del primer forjado (Fig. 3.86).
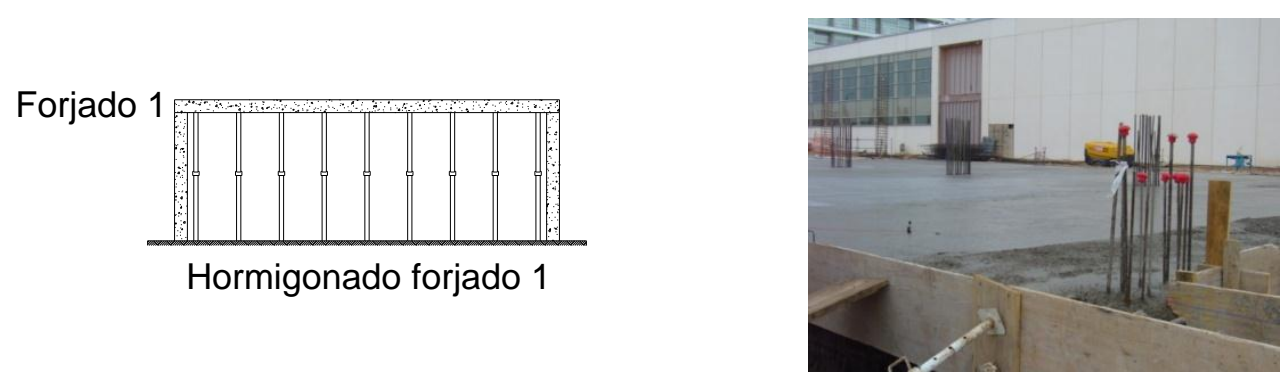

Fig. 3.86 Proceso constructivo día " 0 " (forjado reticular de casetón recuperable)

$\checkmark$ Día "7" (21 de Junio de 2010): al cabo de siete días del hormigonado del primer forjado, se procedió a la retirada de fondos de encofrado y al clareado de puntales (Fig. 3.87).
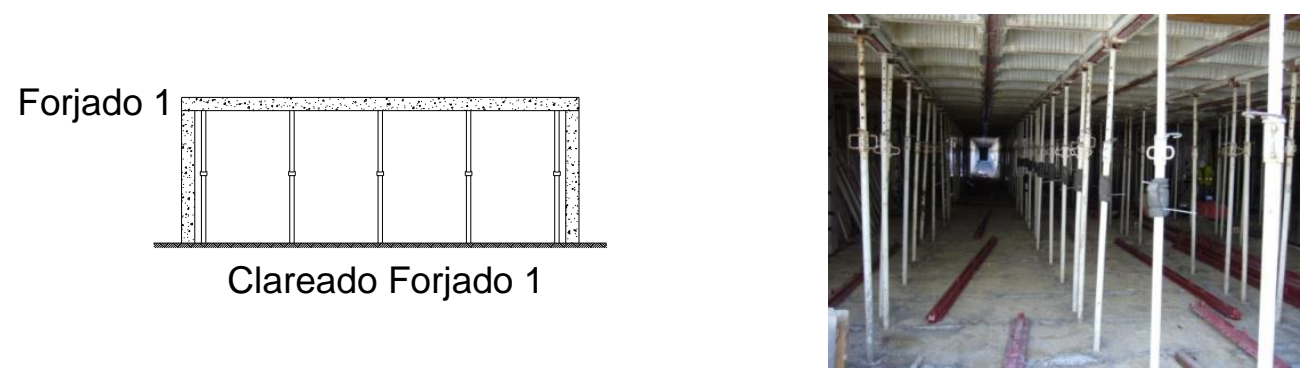

Fig. 3.87 Proceso constructivo día “7” (forjado reticular de casetón recuperable)

$\checkmark$ Día "17" (1 de Julio de 2010): una vez preparado el sistema de encofrado y cimbrado del segundo forjado se ejecutó su hormigonado (Fig. 3.88).
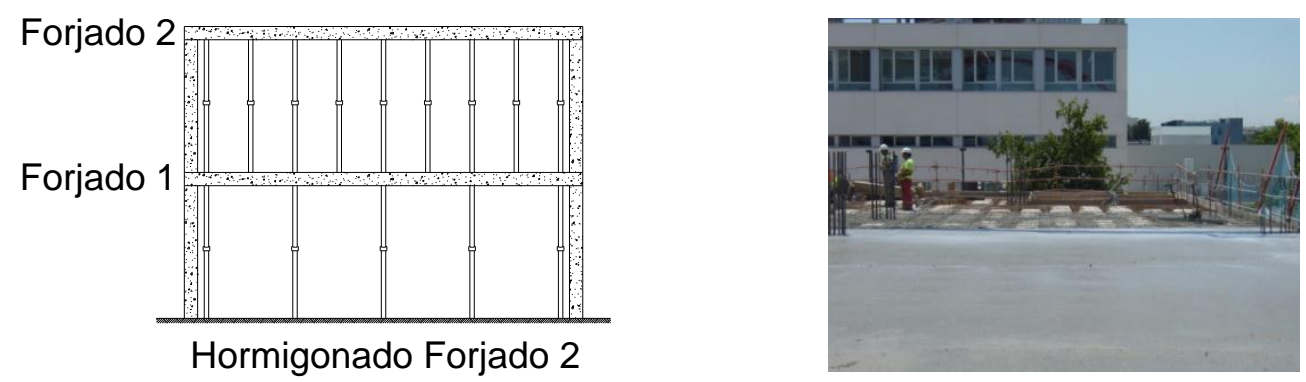

Fig. 3.88 Proceso constructivo día "17” (forjado reticular de casetón recuperable) 
$\checkmark$ Día "24a" (8 de Julio de 2010): siete días después del hormigonado del segundo forjado, se retiraron los fondos de encofrado y se realizó el clareado de puntales (Fig. 3.89).
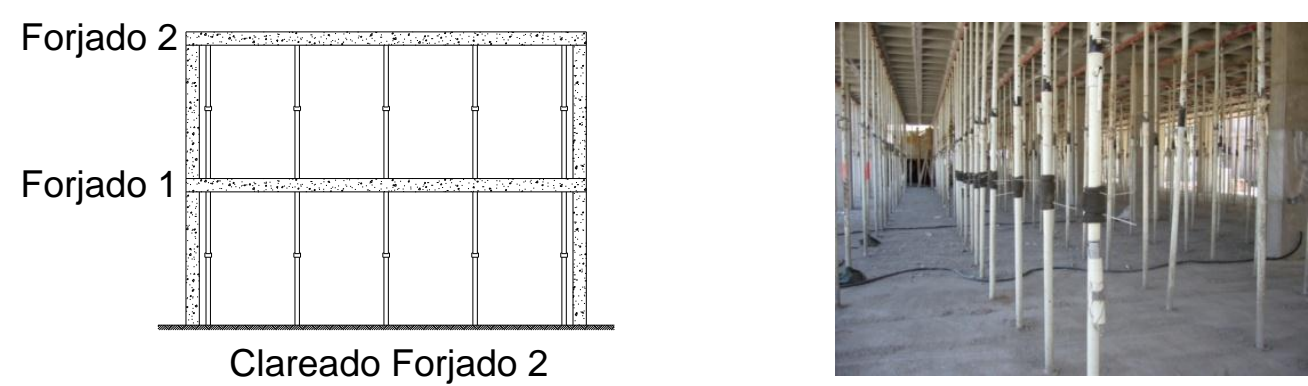

Fig. 3.89 Proceso constructivo día "24a” (forjado reticular de casetón recuperable)

Día "24b" (8 de Julio de 2010): simultáneamente al clareado del forjado 2, se realizó el descimbrado del forjado 1 (Fig. 3.90)
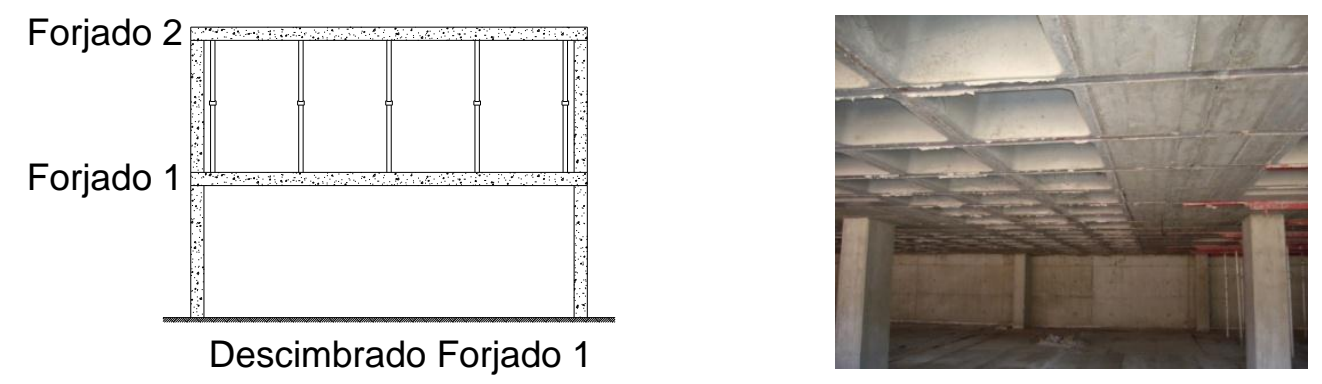

Fig. 3.90 Proceso constructivo día “24b” (forjado reticular de casetón recuperable)

Día "32" (16 de Julio de 2010): una vez instalado el sistema de encofrado y cimbrado se procedió a hormigonar el tercer forjado (Fig. 3.91).
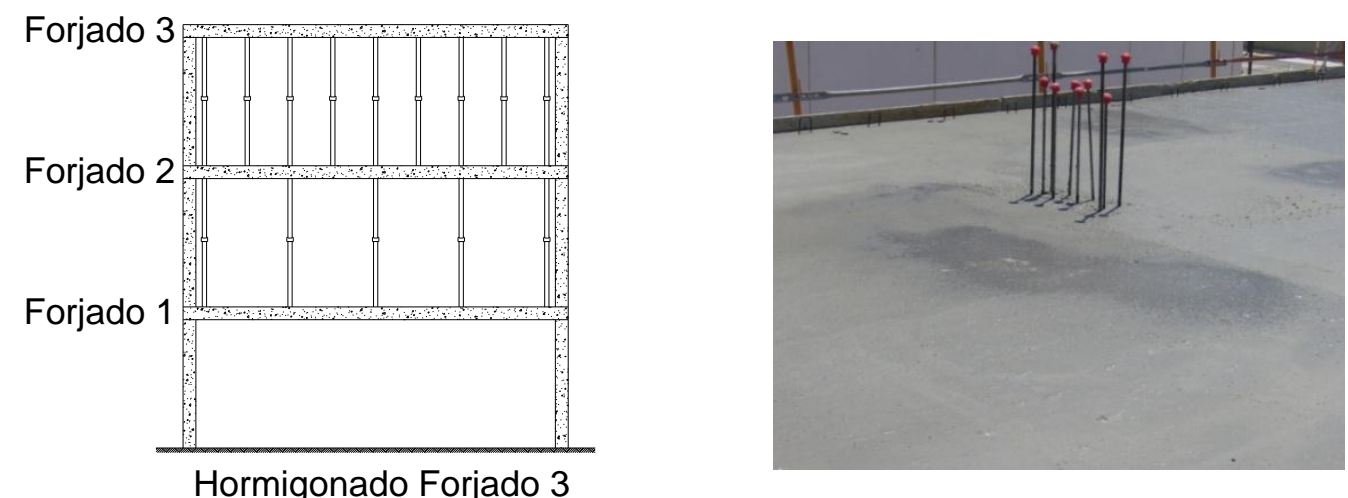

Fig. 3.91 Proceso constructivo día "32" (forjado reticular de casetón recuperable) 
$\checkmark$ Día "37" (21 de Julio de 2010): transcurridos cinco días de hormigonado del tercer forjado, se retiraron los fondos de encofrado y se realizó el clareado de puntales (Fig. 3.92).
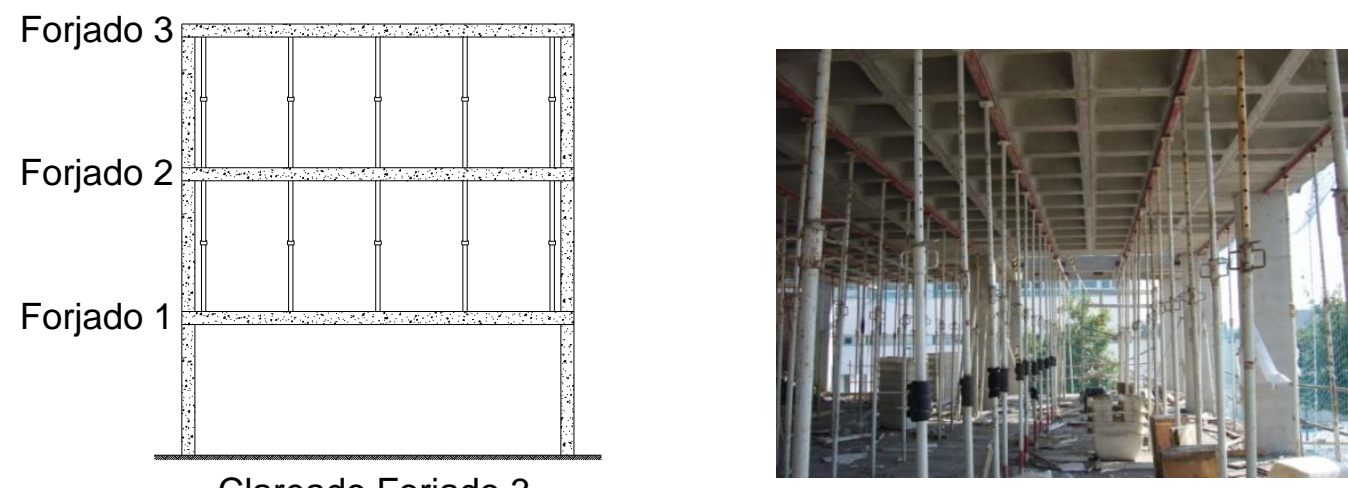

Clareado Forjado 3

Fig. 3.92 Proceso constructivo día “37” (forjado reticular de casetón recuperable)

$\checkmark$ Día “38” (22 de Julio de 2010): en esta fase se procedió al descimbrado del forjado 2 (Fig. 3.93).
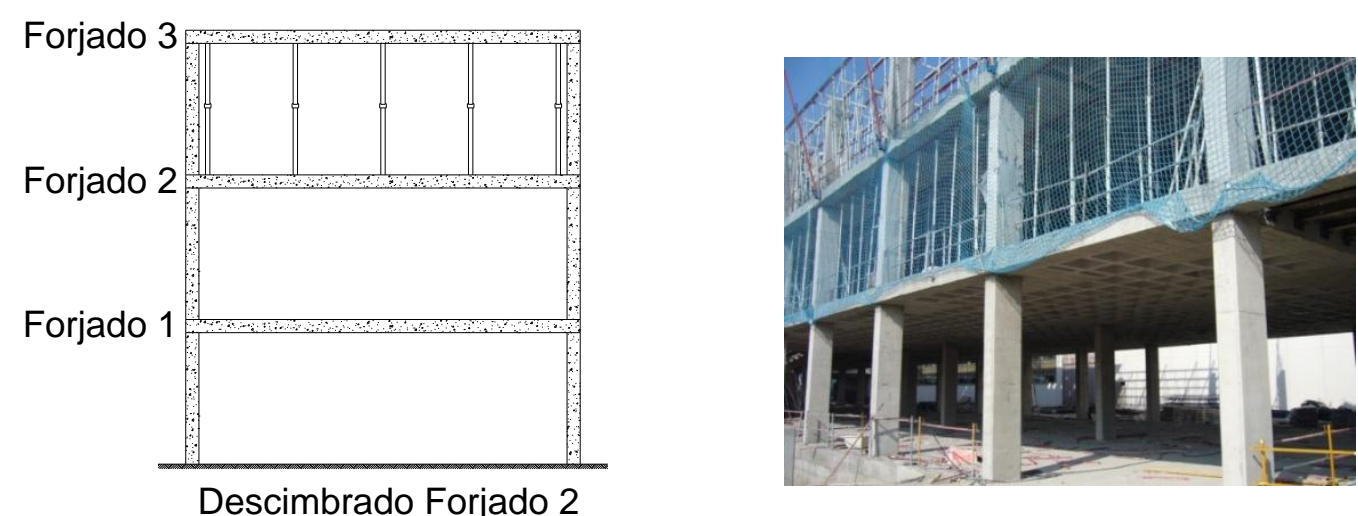

Fig. 3.93 Proceso constructivo día "38” (forjado reticular de casetón recuperable) 
Día "49" (2 de Agosto de 2010): instalado el sistema de cimbrado y encofrado se procedió al hormigonado del forjado 4 (Fig. 3.94).
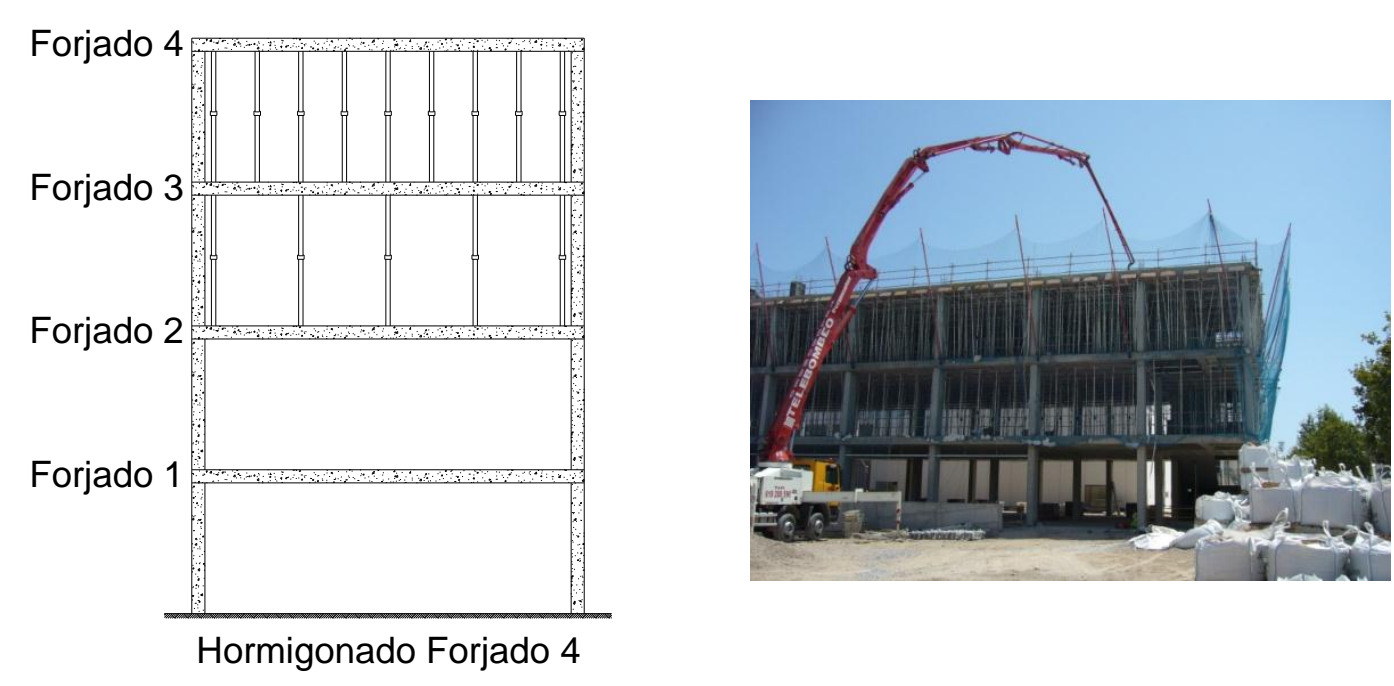

Fig. 3.94 Proceso constructivo día “49” (forjado reticular de casetón recuperable)

\subsubsection{Resultados de carga del estudio experimental}

Se instrumentó una sopanda principal abarcando 2 vanos consecutivos, uno de esquina y otro de medianera (Fig. 3.84). En total se colocaron 12 puntales instrumentados por planta.

Se tomaron medidas instantáneas en una cada una de las operaciones constructivas (hormigonado, clareado, descimbrado), desde el hormigonado del Forjado 1 hasta el hormigonado del Forjado 4. En el Apéndice I se muestran, de forma amplia, los resultados obtenidos de dicha medición instantánea.

A continuación se resumen las mediciones del estudio experimental para cada uno de los vanos:

\section{$\checkmark$ Vano de esquina}

Las Figuras 3.95 y 3.96 muestran la evolución del coeficiente de carga para el forjado 1 y para los puntales bajo este forjado durante todo el proceso constructivo. Las Figuras 3.94 y 3.98 muestran la evolución del coeficiente de carga para el forjado 2 y para los puntales bajo este forjado durante todo el proceso constructivo. Las Figuras 3.99 y 3.100 muestran la evolución del coeficiente de carga para el forjado 3 y para los puntales bajo este forjado durante todo el proceso constructivo. No se muestra una evolución del coeficiente de carga en el forjado 4 y en los puntales bajo este forjado debido a que únicamente fue objeto de medición el hormigonado de dicho forjado (operación en la cual se terminó el estudio experimental). 


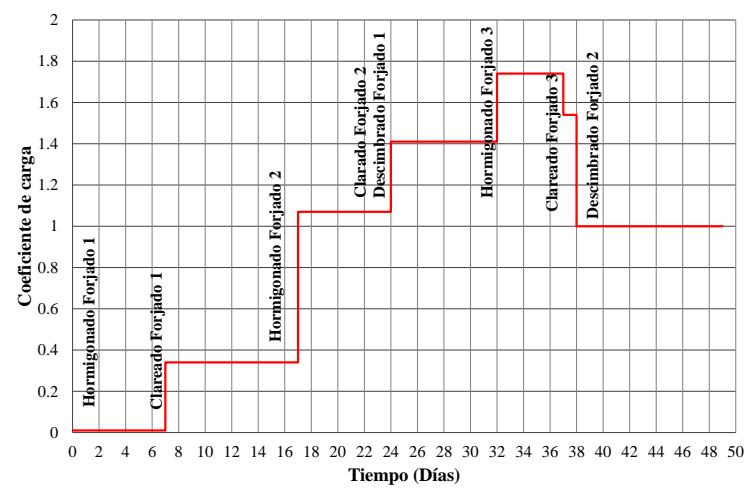

Fig. 3.95 Coeficientes de carga en el forjado 1 (Forjado reticular de casetón recuperable - Vano de esquina)

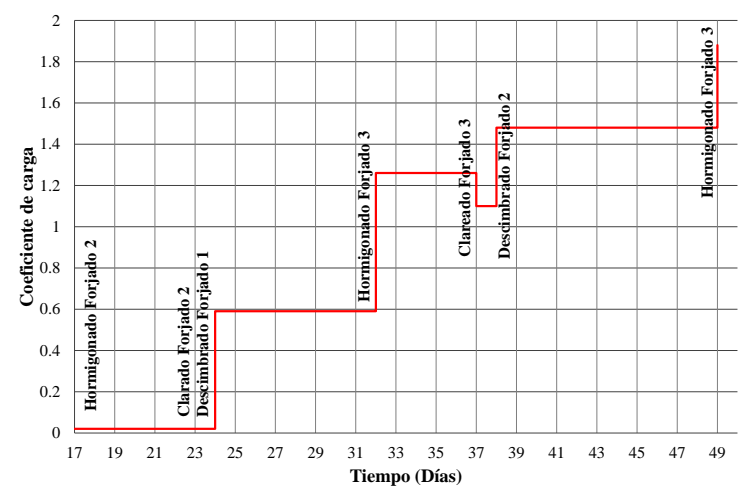

Fig. 3.97 Coeficientes de carga en el forjado 2 (Forjado reticular de casetón recuperable - Vano de esquina)

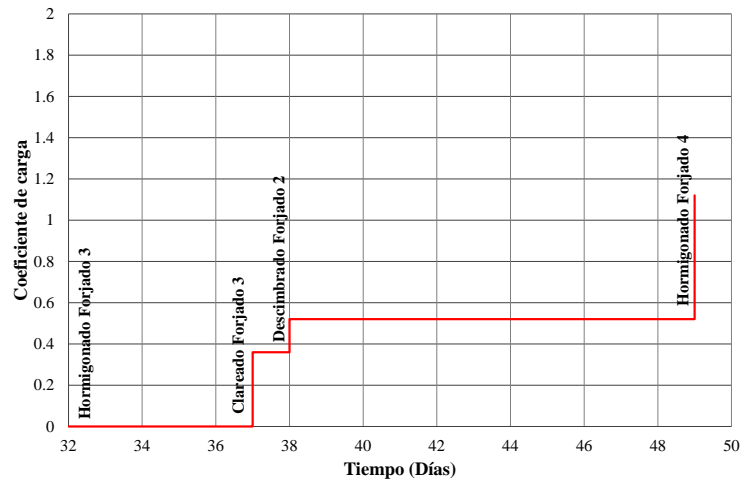

Fig. 3.99 Coeficientes de carga en el forjado 3 (Forjado reticular de casetón recuperable - Vano de esquina)

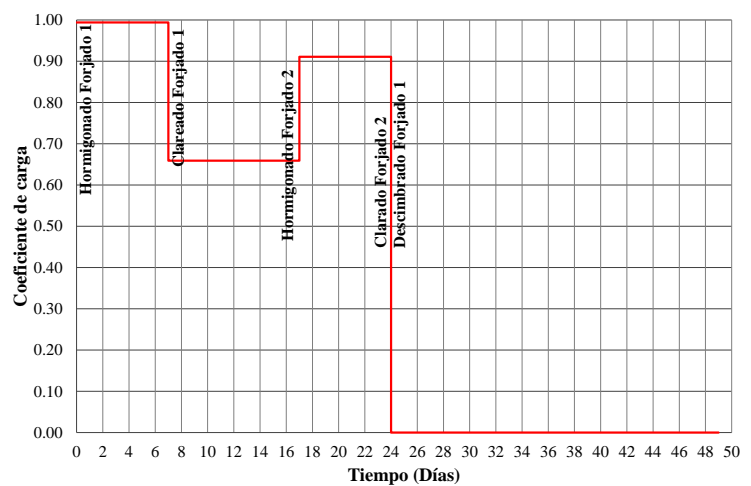

Fig. 3.96 Coeficientes de carga en puntales bajo el forjado 1 (Forjado reticular de casetón recuperable - Vano de esquina)

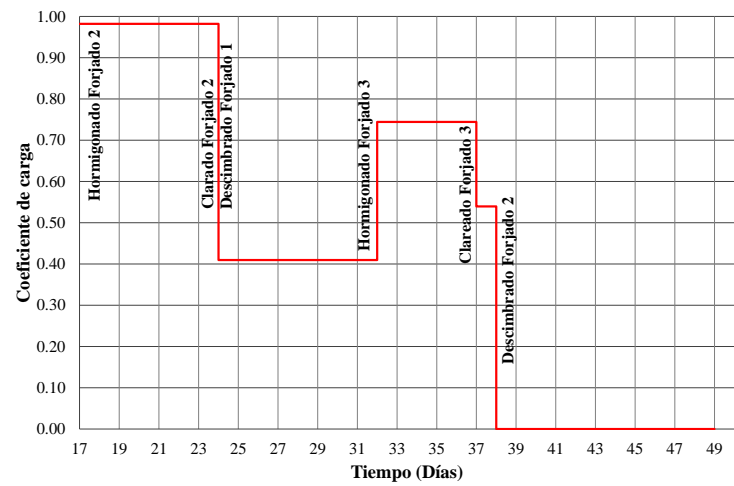

Fig. 3.98 Coeficientes de carga en puntales bajo el forjado 2 (Forjado reticular de casetón recuperable - Vano de esquina)

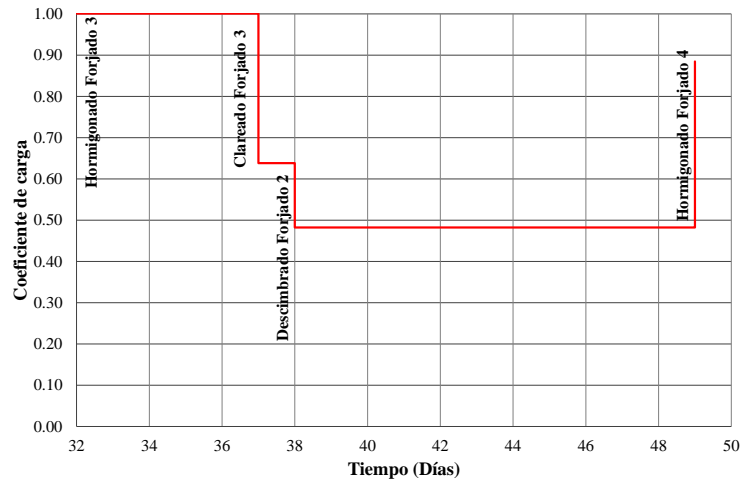

Fig. 3.100 Coeficientes de carga en puntales bajo el forjado 3 (Forjado reticular de casetón recuperable - Vano de esquina) 
La Tabla 3.8 muestra los coeficientes de carga, las cargas medias y las cargas máximas obtenidas en la medición instantánea para el vano de esquina.

Tabla 3.8. Resumen medición experimental. Forjado reticular de casetón recuperable - Vano de esquina

\begin{tabular}{|c|c|c|c|c|c|c|c|c|}
\hline \multirow{2}{*}{ Operación } & \multirow{2}{*}{ Nivel } & \multirow{2}{*}{$\underset{\left(\mathrm{kN} / \mathrm{m}^{2}\right)}{\boldsymbol{q}_{\boldsymbol{m}} \boldsymbol{d}}$} & \multicolumn{2}{|c|}{ Para $q_{m e d}$} & \multirow{2}{*}{$\begin{array}{l}\text { Puntal más } \\
\text { cargado }\end{array}$} & \multirow{2}{*}{$\begin{array}{c}\boldsymbol{P}_{\max } \\
(\mathrm{kN})\end{array}$} & \multirow{2}{*}{$\underset{\left(\mathrm{kN} / \mathrm{m}^{2}\right)}{\boldsymbol{q}_{\max }}$} & \multirow{2}{*}{$C_{p, \max }$} \\
\hline & & & $C_{p}$ & $C_{f}$ & & & & \\
\hline $\begin{array}{l}\text { Hormigonado } \\
\text { forjado } 1\end{array}$ & 1 & 5.73 & 0.99 & 0.01 & 5 & 4.80 & 5.78 & 1.00 \\
\hline $\begin{array}{l}\text { Clareado } \\
\text { forjado } 1\end{array}$ & 1 & 3.80 & 0.66 & 0.34 & 5 & 7.19 & 4.33 & 0.75 \\
\hline \multirow{2}{*}{$\begin{array}{l}\text { Hormigonado } \\
\text { forjado } 2\end{array}$} & 2 & 5.66 & 0.98 & 0.02 & 1 & 7.00 & 5.62 & 0.98 \\
\hline & 1 & 5.25 & 0.91 & 1.07 & 5 & 9.44 & 5.69 & 0.99 \\
\hline \multirow{2}{*}{$\begin{array}{l}\text { Descimbrado } \\
\text { forjado } 1\end{array}$} & 2 & 2.36 & 0.41 & 0.59 & 1 & 5.65 & 2.27 & 0.39 \\
\hline & 1 & & & 1.41 & & & & \\
\hline \multirow{3}{*}{$\begin{array}{l}\text { Hormigonado } \\
\text { forjado } 3\end{array}$} & 3 & 5.77 & 1.00 & 0.00 & 5 & 4.97 & 5.99 & 1.04 \\
\hline & 2 & 4.29 & 0.74 & 1.26 & 3 & 8.65 & 5.21 & 0.90 \\
\hline & 1 & & & 1.74 & & & & \\
\hline \multirow{3}{*}{$\begin{array}{l}\text { Clareado } \\
\text { forjado } 3\end{array}$} & 3 & 3.68 & 0.64 & 0.36 & 4 & 7.86 & 4.73 & 0.82 \\
\hline & 2 & 3.11 & 0.54 & 1.10 & 5 & 5.16 & 3.11 & 0.54 \\
\hline & 1 & & & 1.54 & & & & \\
\hline \multirow{2}{*}{$\begin{array}{l}\text { Descimbrado } \\
\text { forjado } 2\end{array}$} & 3 & 2.78 & 0.48 & 0.52 & 3 & 6.26 & 3.77 & 0.65 \\
\hline & 2 & & & 1.48 & & & & \\
\hline \multirow{3}{*}{$\begin{array}{l}\text { Hormigonado } \\
\text { forjado } 4\end{array}$} & 4 & 5.75 & 1.00 & 0.00 & 5 & 4.90 & 5.90 & 1.02 \\
\hline & 3 & 5.10 & 0.88 & 1.12 & 4 & 10.72 & 6.46 & 1.12 \\
\hline & 2 & & & 1.88 & & & & \\
\hline
\end{tabular}

Donde:

$\checkmark \quad q_{m e d}$ : carga media en puntales por unidad de superficie que resulta de la relación entre la sumatoria de las cargas en puntales y el área del forjado instrumentada $\left(\sum P_{i} / A_{\text {total }}\right)$ $\left(\mathrm{kN} / \mathrm{m}^{2}\right)$. Siendo: $P_{i}$ la carga instantánea en el puntal “ $i$ ” $(\mathrm{kN})$ y $A_{\text {total }}$ el área del forjado instrumentada $\left(\mathrm{m}^{2}\right)$.

$\checkmark \quad C_{p}$ : coeficiente de carga en puntales que resulta de la relación entre la carga media en puntales $\left(Q_{p}\right)$ y el peso propio del forjado $\left(W_{f}=5.76 \mathrm{kN} / \mathrm{m}^{2}\right) .\left(Q_{p} / W_{f}\right)$.

$\checkmark C_{f}$ : coeficiente de carga en forjados que resulta de la relación entre la carga media del forjado $\left(Q_{f}\right)$ y el peso propio del forjado $\left(W_{f}=5.76 \mathrm{kN} / \mathrm{m}^{2}\right) .\left(Q_{f} / W_{f}\right)$.

$\checkmark \quad P_{\text {max }}$ : axil del puntal más cargado $(\mathrm{kN})$.

$\checkmark \quad q_{\max }$ : axil del puntal más cargado por unidad de superficie $\left(P_{\max } / A_{t}\right)\left(\mathrm{kN} / \mathrm{m}^{2}\right)$. Siendo $A_{t}$ el área tributaria del puntal considerado $\left(\mathrm{m}^{2}\right)$.

$\checkmark \quad C_{p, \text { max }}$ : coeficiente de carga del puntal más cargado que resulta de la relación entre la carga máxima en puntales $\left(q_{\max }\right)$ y el peso propio del forjado $\left(W_{f}=4.96 \mathrm{kN} / \mathrm{m}^{2}\right) .\left(q_{\max } / W_{f}\right)$. 


\section{$\checkmark \quad$ Vano de medianera}

Las Figuras 3.101 y 3.102 muestran la evolución del coeficiente de carga para el forjado 1 y para los puntales bajo este forjado durante todo el proceso constructivo. Las Figuras 3.103 y 3.104 muestran la evolución del coeficiente de carga para el forjado 2 y para los puntales bajo este forjado durante todo el proceso constructivo. Las Figuras 3.105 y 3.106 muestran la evolución del coeficiente de carga para el forjado 3 y para los puntales bajo este forjado durante todo el proceso constructivo. No se muestra una evolución del coeficiente de carga en el forjado 4 y en los puntales bajo este forjado debido a que únicamente fue objeto de medición el hormigonado de dicho forjado (operación en la cual se terminó el estudio experimental).

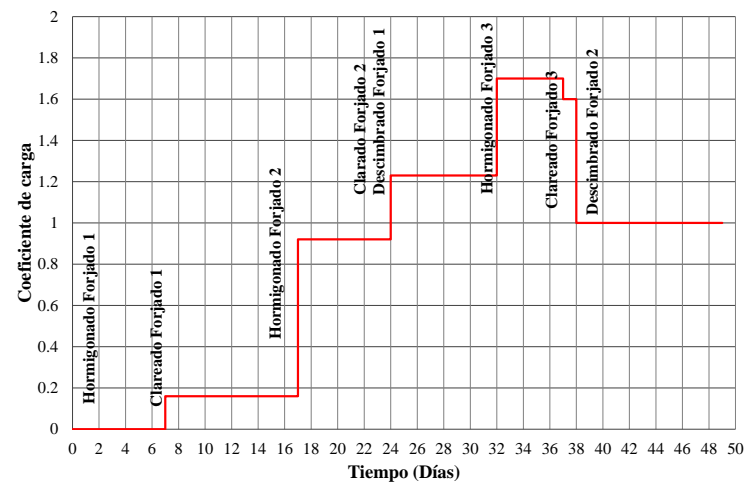

Fig. 3.101 Coeficientes de carga en el forjado 1 (Forjado reticular de casetón recuperable - Vano de medianera)

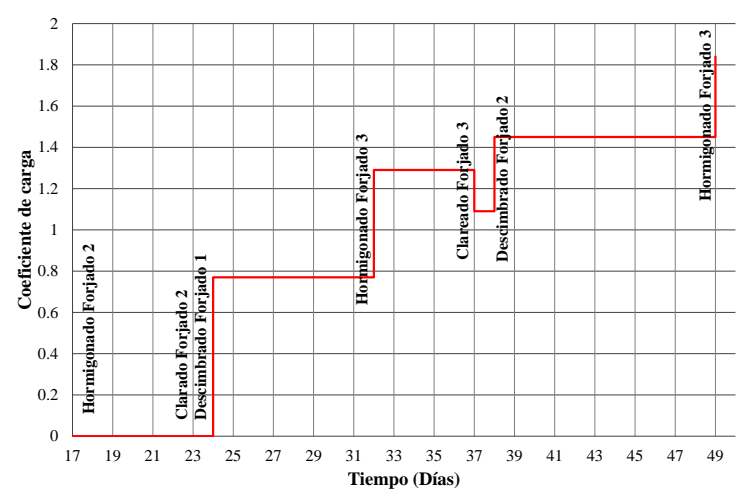

Fig. 3.103 Coeficientes de carga en el forjado 2 (Forjado reticular de casetón recuperable - Vano de medianera)

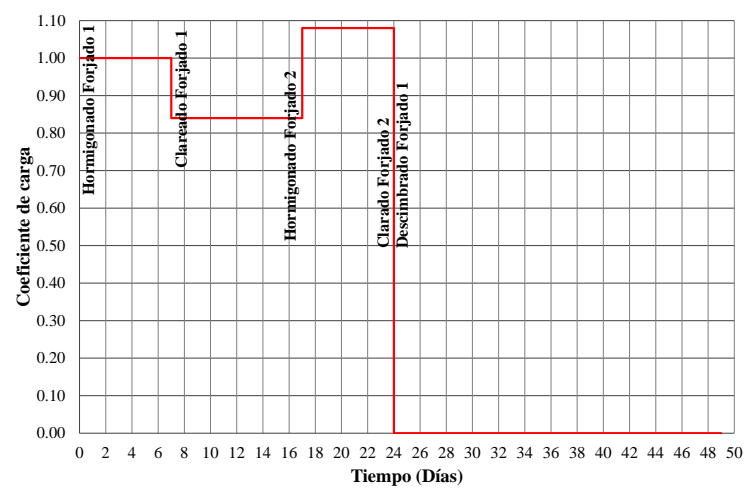

Fig. 3.102 Coeficientes de carga en puntales bajo el forjado 1 (Forjado reticular de casetón recuperable - Vano de medianera)

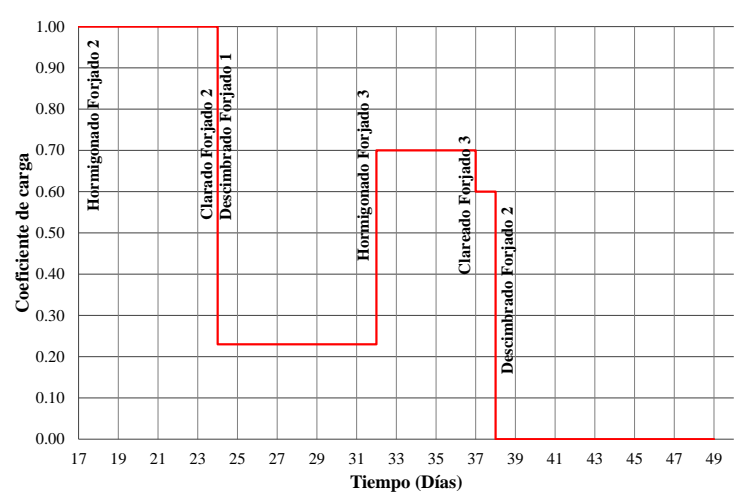

Fig. 3.104 Coeficientes de carga en puntales bajo el forjado 2 (Forjado reticular de casetón recuperable - Vano de medianera) 


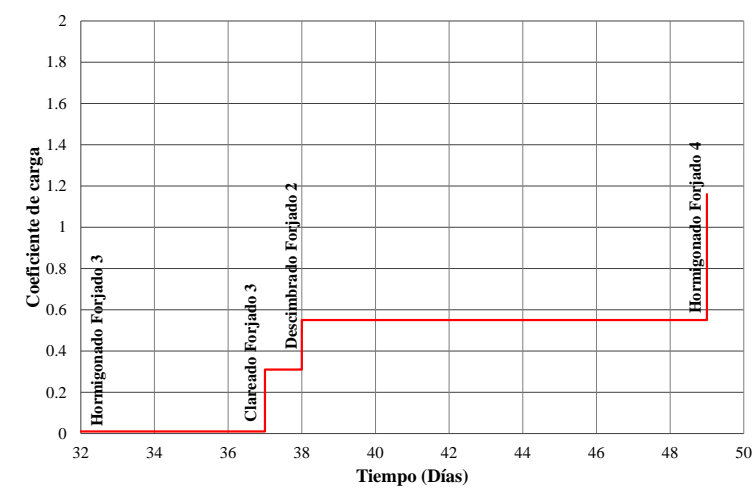

Fig. 3.105 Coeficientes de carga en el forjado 3 (Forjado reticular de casetón recuperable - Vano de medianera)

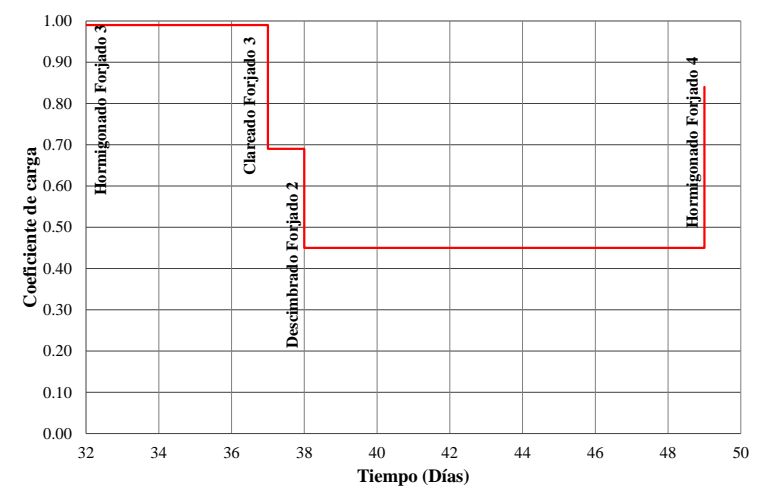

Fig. 3.106 Coeficientes de carga en puntales bajo el forjado 3 (Forjado reticular de casetón recuperable - Vano de medianera)

Además, la Tabla 3.9 muestra los coeficientes de carga, las cargas medias y las cargas máximas obtenidas en la medición instantánea para el vano de medianera.

Tabla 3.9. Resumen medición experimental. Forjado reticular de casetón recuperable - Vano de medianera

\begin{tabular}{|c|c|c|c|c|c|c|c|c|}
\hline \multirow{2}{*}{ Operación } & \multirow{2}{*}{ Nivel } & \multirow{2}{*}{$\underset{\left(\mathrm{kN} / \mathrm{m}^{2}\right)}{\boldsymbol{q}_{\boldsymbol{m}}}$} & \multicolumn{2}{|c|}{ Para $q_{m e d}$} & \multirow{2}{*}{$\begin{array}{l}\text { Puntal más } \\
\text { cargado }\end{array}$} & \multirow{2}{*}{$\underset{(\mathrm{kN})}{\boldsymbol{P}_{\max }}$} & \multirow{2}{*}{$\underset{\left(\mathrm{kN} / \mathrm{m}^{2}\right)}{\boldsymbol{q}_{\max }}$} & \multirow{2}{*}{$C_{p, \max }$} \\
\hline & & & $C_{p}$ & $C_{f}$ & & & & \\
\hline $\begin{array}{l}\text { Hormigonado } \\
\text { forjado } 1\end{array}$ & 1 & 5.79 & 1.00 & 0.00 & 8 & 4.75 & 5.72 & 0.99 \\
\hline $\begin{array}{l}\text { Clareado } \\
\text { forjado } 1\end{array}$ & 1 & 4.84 & 0.84 & 0.16 & 9 & 9.28 & 5.59 & 0.97 \\
\hline \multirow{2}{*}{$\begin{array}{l}\text { Hormigonado } \\
\text { forjado } 2\end{array}$} & 2 & 5.77 & 1.00 & 0.00 & 6 & 4.98 & 6.01 & 1.04 \\
\hline & 1 & 6.23 & 1.08 & 0.92 & 9 & 11.92 & 7.18 & 1.25 \\
\hline \multirow{2}{*}{$\begin{array}{l}\text { Descimbrado } \\
\text { forjado } 1\end{array}$} & 2 & 1.34 & 0.23 & 0.77 & 6 & 3.59 & 2.16 & 0.38 \\
\hline & 1 & & & 1.23 & & & & \\
\hline \multirow{3}{*}{$\begin{array}{l}\text { Hormigonado } \\
\text { forjado } 3\end{array}$} & 3 & 5.72 & 0.99 & 0.01 & 9 & 4.92 & 5.93 & 1.03 \\
\hline & 2 & 4.03 & 0.70 & 1.29 & 10 & 9.77 & 5.89 & 1.02 \\
\hline & 1 & & & 1.70 & & & & \\
\hline \multirow{3}{*}{$\begin{array}{l}\text { Clareado } \\
\text { forjado } 3\end{array}$} & 3 & 3.97 & 0.69 & 0.31 & 8 & 8.11 & 4.89 & 0.85 \\
\hline & 2 & 3.48 & 0.60 & 1.09 & 10 & 8.64 & 5.20 & 0.90 \\
\hline & 1 & & & 1.60 & & & & \\
\hline \multirow{2}{*}{$\begin{array}{l}\text { Descimbrado } \\
\text { forjado } 2\end{array}$} & 3 & 2.61 & 0.45 & 0.55 & 6 & 6.74 & 4.06 & 0.70 \\
\hline & 2 & & & 1.45 & & & & \\
\hline \multirow{3}{*}{$\begin{array}{l}\text { Hormigonado } \\
\text { forjado } 4\end{array}$} & 4 & 5.75 & 1.00 & 0.00 & 9 & 4.87 & 5.87 & 1.02 \\
\hline & 3 & 4.87 & 0.84 & 1.16 & 6 & 10.91 & 6.57 & 1.14 \\
\hline & 2 & & & 1.84 & & & & \\
\hline
\end{tabular}

\subsubsection{Resultados de temperatura del estudio experimental}

Con el fin de estudiar el gradiente térmico que se producía en el forjado, se instrumentaron 2 nervios de dos forjados consecutivos en los forjados de la $1^{\mathrm{a}}$ y la $2^{\mathrm{a}}$ planta. En cada uno de estos nervios, se embebieron 4 termopares a $0.05,0.10,0.20$ y $0.30 \mathrm{~m}$ de profundidad. También se tomaron medidas de 
la temperatura ambiente mediante un termopar libre. Las medidas se realizaron días distintos y con diferentes condiciones del forjado (encofrado, desencofrado con insolación directa y desencofrado con insolación indirecta).

Las Figuras 3.107, 3.108 y 3.109 muestran la distribución de temperaturas en el espesor del forjado a lo largo del día. La Figura 3.107 hace referencia al forjado antes de retirar el encofrado, en la Figura 3.108 se muestran los datos del forjado desencofrado y con insolación directa, y la Figura 3.109 se corresponde con las mediciones realizadas con el forjado desencofrado y sin insolación directa (hay un forjado superior). Estas últimas mediciones se realizaron conjuntamente con otras de termopares situados en el forjado superior. Debido a que el equipo utilizado permitía únicamente medir simultáneamente 7 termopares, se decidió que se tomarían medidas de los 4 termopares del forjado superior, 2 termopares (los situados a 0.05 y a $0.30 \mathrm{~m}$ de profundidad) del forjado inferior y la ambiente.

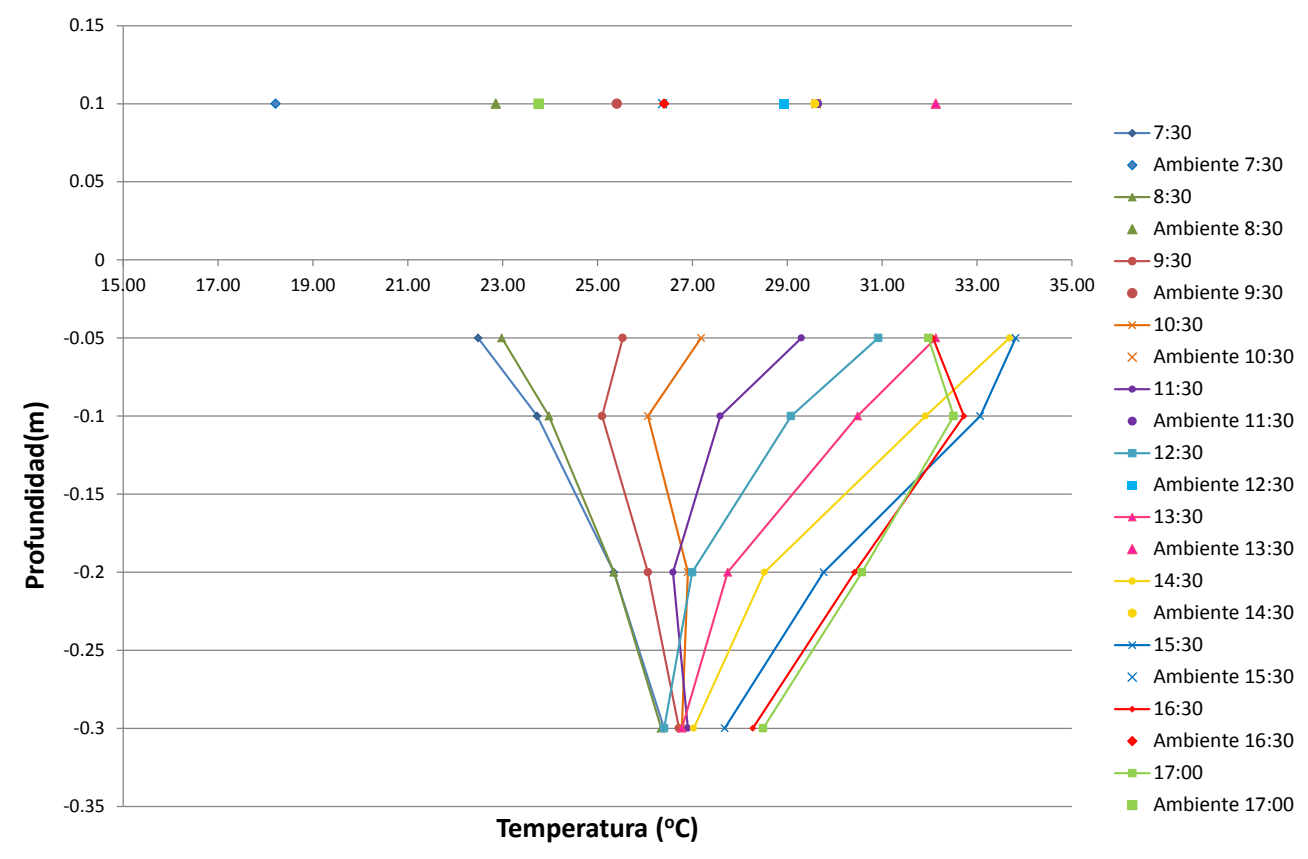

Fig. 3.107 Distribución de temperaturas en el espesor del forjado a lo largo del día para el forjado de 0.40 m encofrado. Edificio de forjado reticular de casetón recuperable. 


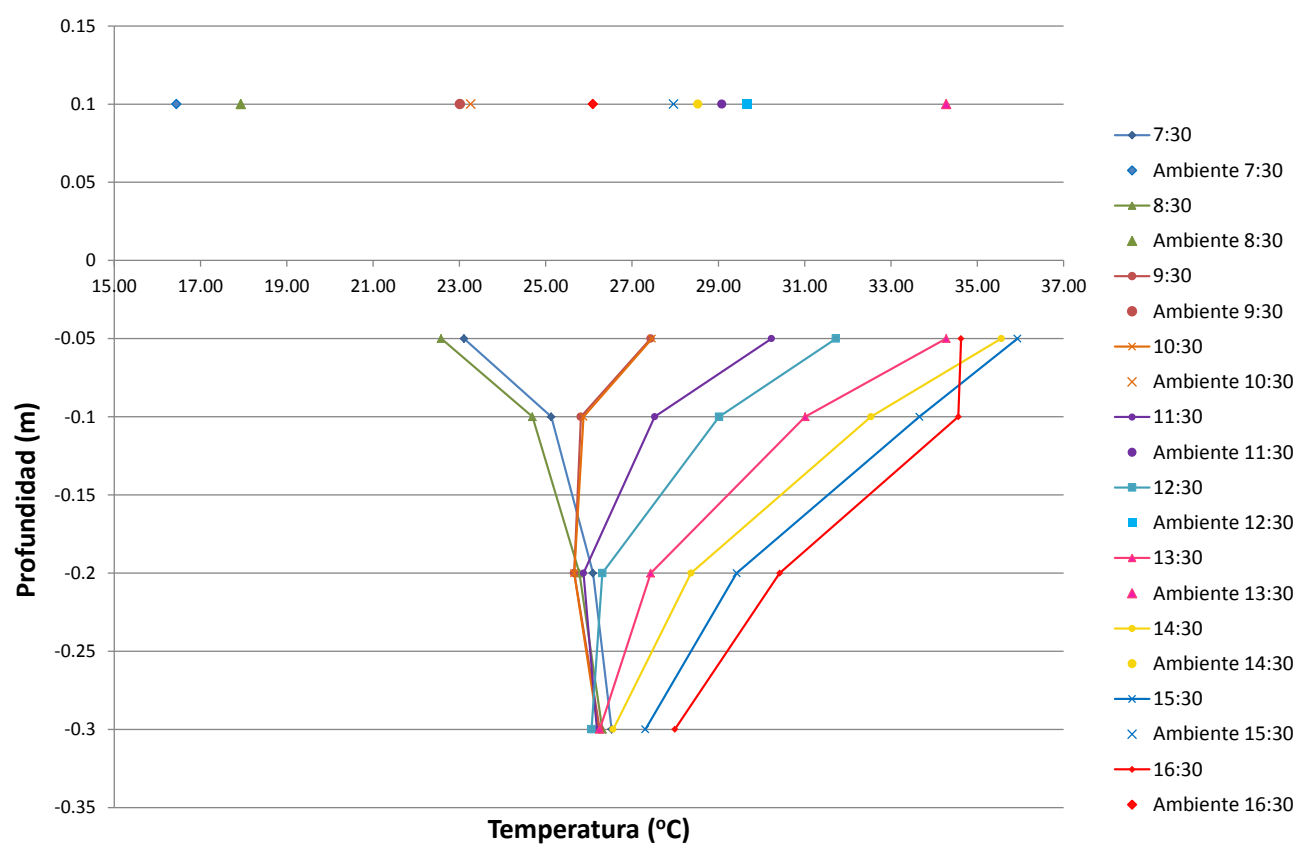

Fig. 3.108 Distribución de temperaturas en el espesor del forjado a lo largo del día para el forjado de $0.40 \mathrm{~m}$ desencofrado con insolación directa. Edificio de forjado reticular de casetón recuperable.

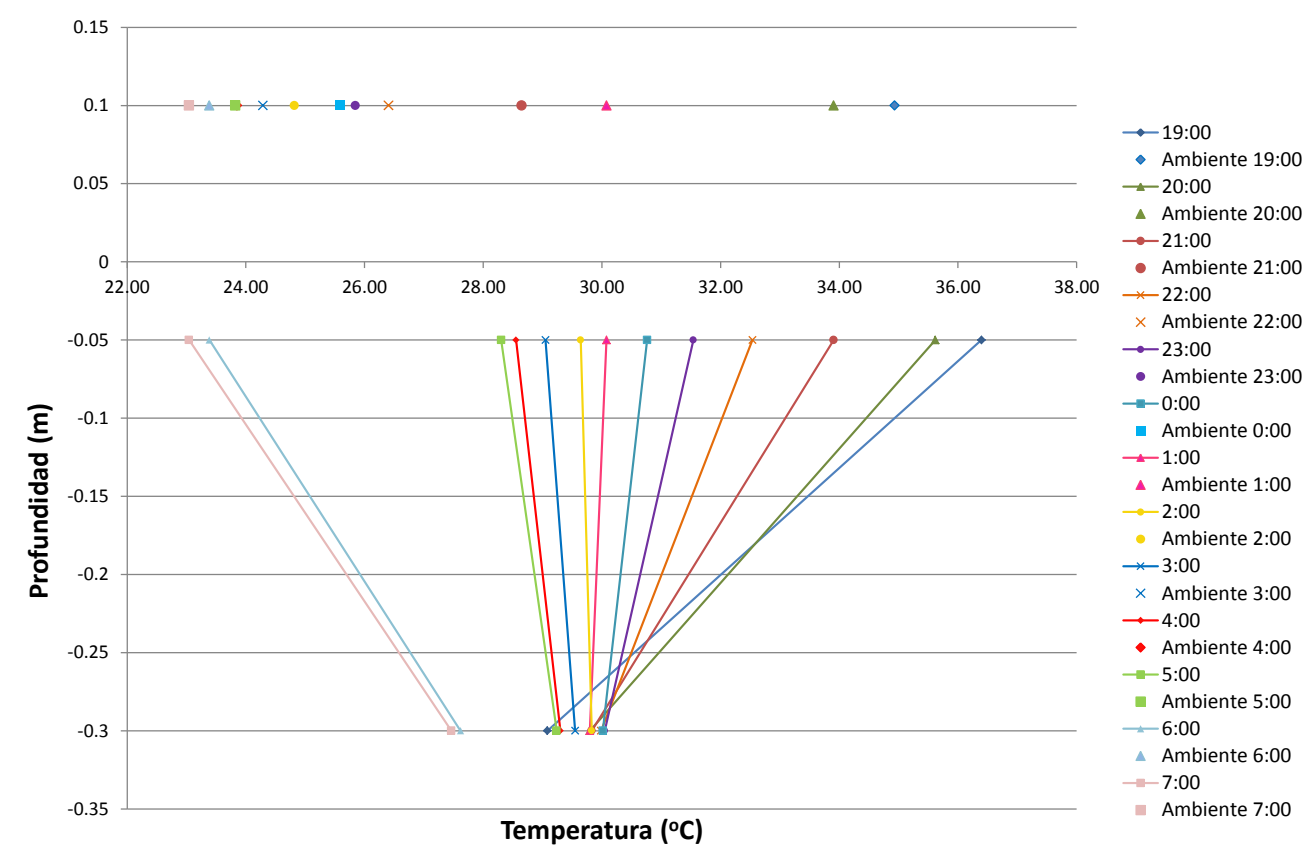

Fig. 3.109 Distribución de temperaturas en el espesor del forjado a lo largo del día para el forjado de 0.40m desencofrado sin insolación directa. Edificio de forjado reticular de casetón recuperable. 
Tal y como se refleja en todos los casos, durante la noche y a primera hora de la mañana, cuando la temperatura ambiente es menor, la parte inferior del forjado tiene una temperatura mayor que la parte superior. Este comportamiento se invierte conforme va aumentando la temperatura.

En la Tabla 3.10 se muestran las variaciones de temperatura entre la cara superior e inferior de la losa registrados en el edificio de Valencia. Dichas variaciones están en función de si el forjado está encofrado o desencofrado. También se diferencia si la insolación es directa o si por el contrario el forjado donde se realizan las mediciones tiene un forjado superior que no permite la insolación directa. Durante los días en que se realizaron las mediciones de temperatura, se registraron diferencias térmicas ambientales entre el día y la noche de hasta $12^{\circ} \mathrm{C}$.

Tabla 3.10. Incrementos de temperatura $\left({ }^{\circ} \mathrm{C}\right)$, máximos y mínimos, entre la cara superior e inferior del forjado registrados en edificio de forjado reticular de casetón recuperable.

\begin{tabular}{cccccc}
\hline \multicolumn{2}{c}{ Forjado encofrado } & \multicolumn{4}{c}{ Forjado desencofrado } \\
\hline & & \multicolumn{2}{c}{ Con insolación directa } & \multicolumn{2}{c}{ Sin insolación directa } \\
\hline $\begin{array}{c}\text { Incremento } \\
\text { min }\end{array}$ & $\begin{array}{c}\text { Incremento } \\
\text { máx. }\end{array}$ & $\begin{array}{c}\text { Incremento } \\
\text { min }\end{array}$ & $\begin{array}{c}\text { Incremento } \\
\text { máx. }\end{array}$ & $\begin{array}{c}\text { Incremento } \\
\text { min }\end{array}$ & $\begin{array}{c}\text { Incremento } \\
\text { máx. }\end{array}$ \\
\hline-2.96 & 6.94 & -3.86 & 9.56 & -1.31 & 7.32 \\
\hline
\end{tabular}

\subsection{Conclusiones de los estudios experimentales}

En este capítulo se han descrito los distintos estudios experimentales llevados a cabo con el fin de estudiar la transmisión de cargas entre forjados y puntales en las distintas tipologías de forjados más comunes en edificación, y analizar el efecto de la variación de la temperatura en diferentes elementos de la estructura durante la construcción. Así mismo, se han presentado y analizado los resultados, tanto a nivel de carga como de temperatura, obtenidos en cada uno de dichos estudios.

Los puntales utilizados en todos los estudios se instrumentaron mediante bandas extensométricas instaladas en su superficie. En cada puntal se dispusieron 3 bandas extensométricas. Para corregir el efecto que la temperatura ambiente tiene sobre las bandas extensométricas y los equipos de adquisición de datos, se instalaron puntales de referencia en cada una de las plantas. Estos puntales no estaban sometidos a carga y por lo tanto no formaban parte del sistema de cimbrado.

La medición experimental realizada durante la construcción de los edificios se basa en medidas instantáneas. La medición instantánea consiste en tomar medidas antes y después de cada una de las operaciones constructivas (hormigonado, clareado y descimbrado). Dichas medidas permiten conocer los incrementos de carga en puntales y forjados debido a la ejecución de cada una de las operaciones constructivas.

Para poder medir la temperatura en el interior del forjado, y conocer el gradiente en éste, se instalaron termopares embebidos en el hormigón a diferentes profundidades del forjado, tanto en el edificio de forjado reticular de casetón perdido como en el de forjado reticular de casetón recuperable. Asimismo, se midió la temperatura ambiente mediante un termopar libre. 
Para la adquisición de datos se utilizaron Estaciones de Medida (EDM) cada una de ellas compuesta por un equipo para la lectura de las bandas extensométricas, una batería de litio para su alimentación eléctrica y de un ordenador para almacenar los datos recopilados.

A continuación se resumen las principales conclusiones de los estudios experimentales. En primer lugar se presentan por separado las conclusiones relativas a cada uno de los edificios estudiados, y finalmente se realiza una comparativa de todos ellos.

\subsubsection{Conclusiones del estudio experimental del edificio de forjado de losa maciza}

Este estudio experimental se realizó en un edificio de forjado de losa maciza, con 4 sótanos y 14 plantas, destinado a viviendas y situado en Madrid.

Las medidas experimentales fueron tomadas desde el hormigonado del forjado 1 hasta el hormigonado del forjado 6. Las cargas fueron medidas hasta el hormigonado del forjado 6, debido a que se utilizaron 3 juegos de puntales, cumpliéndose con esta operación un ciclo completo del sistema de puntales y encofrado.

Se instrumentaron dos vanos consecutivos en cada uno de los forjados, uno de esquina y otro de medianera. En cada uno de los vanos se instrumentó una sopanda, cada una de éstas con 6 puntales instrumentados.

De la medición instantánea realizada se concluye para el vano de esquina:

$\checkmark$ Al hormigonar cada forjado, la totalidad de la carga fue transmitida a los puntales. Por ejemplo, al hormigonar el forjado 1 la carga media en los puntales $\left(q_{\text {med }}\right)$ fue de $4.95 \mathrm{kN} / \mathrm{m}^{2}$ valor que difiere menos de un $1 \%$ del peso propio teórico del forjado $\left(4.96 \mathrm{kN} / \mathrm{m}^{2}\right)$. Lo mismo sucede en el hormigonado de cada uno de los forjados superiores. Esto refleja el grado de precisión de las medidas obtenidas durante el ensayo.

$\checkmark$ Al realizar la operación de clareado, los cinco forjados en los que se midió esta operación asumieron una fracción importante de carga. Esto se presentó en los diferentes forjados de la siguiente forma:

- Una vez clareado el primer forjado, donde los puntales estaban apoyados en la planta baja, el forjado asumió el $64 \%$ de la carga en relación a su peso propio, y los puntales asumieron el $36 \%$ de esta carga.

- Al clarear el segundo forjado, donde los puntales estaban apoyados en el primer forjado, el forjado asumió el 50\% de la carga en relación a su peso propio, y los puntales asumieron el $50 \%$ de esta carga.

- En el clareado del tercer forjado, donde los puntales estaban apoyados en el segundo forjado, el forjado asumió el $48 \%$ de la carga en relación a su peso propio, y los puntales asumieron el $52 \%$ de esta carga.

- Al clarear el cuarto forjado, donde los puntales estaban apoyados en el tercer forjado, el forjado asumió el $51 \%$ de la carga en relación a su peso propio, y los puntales asumieron el $49 \%$ de esta carga. 
- En el clareado del quinto forjado, donde los puntales estaban apoyados en el cuarto forjado, el forjado asumió el 58\% de la carga en relación a su peso propio, y los puntales asumieron el $42 \%$ de esta carga.

Al hormigonar un forjado superior sobre forjados inferiores ya clareados, una fracción importante de carga es asumida por el forjado sobre el que se apoyan los puntales del forjado hormigonado. Esto se presentó de la siguiente manera:

- Al hormigonar el forjado 2, la carga transmitida por los puntales colocados bajo dicho forjado fue asumida en un $72 \%$ por el forjado 1. El $28 \%$ de carga restante fue asumida por forjados inferiores conectados con puntales.

- Al hormigonar el forjado 3, la carga transmitida por los puntales colocados bajo dicho forjado fue asumida en un $75 \%$ por el forjado 2 . El $25 \%$ de carga restante fue asumida por forjados inferiores conectados con puntales.

- Al hormigonar el forjado 4, la carga transmitida por los puntales colocados bajo dicho forjado fue asumida en un 94\% por el forjado 3. El 6\% de carga restante fue asumida por forjados inferiores conectados con puntales. Al hormigonar este forjado, el conjunto de puntales ya no apoya en la cimentación.

- Al hormigonar el forjado 5, la carga transmitida por los puntales colocados bajo dicho forjado fue asumida en un $91 \%$ por el forjado 4 . El $9 \%$ de carga restante fue asumida por forjados inferiores conectados con puntales.

- Al hormigonar el forjado 6, la carga transmitida por los puntales colocados bajo dicho forjado fue asumida en un $79 \%$ por el forjado 5 . El $21 \%$ de carga restante fue asumida por forjados inferiores conectados con puntales. En este hormigonado se produce un cambio de tendencia el cual viene provocado por operaciones no controladas llevadas a cabo durante la construcción.

Al retirar los puntales de un forjado o descimbrarlo, la carga que asumían dichos puntales se reparte entre los forjados superiores conectados por puntales. En el descimbrado de los forjados 1, 2 y 3 la carga se repartió de la siguiente manera:

- Al retirar los puntales bajo el forjado 1, la carga que tenían dichos puntales fue asumida en un $64 \%$ por el forjado 1 y el $36 \%$ restante por los forjados superiores conectados por puntales.

- En el descimbrado del forjado 2, la carga que tenían los puntales retirados fue asumida en un $73 \%$ por el forjado 2 y el $27 \%$ restante por los forjados superiores conectados por puntales.

- En el descimbrado del forjado 3, la carga que tenían los puntales retirados fue asumida en un $87 \%$ por el forjado 3 y el $13 \%$ restante por los forjados superiores conectados por puntales. 
De la medición instantánea realizada se concluye para el vano de medianera:

$\checkmark$ Al hormigonar cada forjado, la totalidad de la carga fue transmitida a los puntales. Por ejemplo, al hormigonar el forjado 4 la carga media en los puntales $\left(q_{m e d}\right)$ fue de $4.91 \mathrm{kN} / \mathrm{m}^{2}$ valor que difiere en un $1 \%$ del peso propio teórico del forjado $\left(4.96 \mathrm{kN} / \mathrm{m}^{2}\right)$. Lo mismo sucede en el hormigonado de cada uno de los forjados superiores. Esto refleja el grado de precisión de las medidas obtenidas durante el ensayo.

$\checkmark$ Al realizar la operación de clareado los cinco forjados, en los que se midió esta operación, asumieron una fracción importante de carga. La carga asumida fue muy similar a la registrada en el vano de esquina. Esto se presentó en los diferentes forjados de la siguiente forma:

- Una vez clareado el primer forjado, donde los puntales estaban apoyados en la planta baja, el forjado asumió el $61 \%$ de la carga en relación a su peso propio, y los puntales asumieron el $39 \%$ de esta carga.

- Al clarear el segundo forjado, donde los puntales estaban apoyados en el primer forjado, el forjado asumió el $41 \%$ de la carga en relación a su peso propio, y los puntales asumieron el $59 \%$ de esta carga.

- En el clareado del tercer forjado, donde los puntales estaban apoyados en el segundo forjado, el forjado asumió el $42 \%$ de la carga en relación a su peso propio, y los puntales asumieron el $58 \%$ de esta carga.

- Al clarear el cuarto forjado, donde los puntales estaban apoyados en el tercer forjado, el forjado asumió el $45 \%$ de la carga en relación a su peso propio, y los puntales asumieron el $55 \%$ de esta carga.

- En el clareado del quinto forjado, donde los puntales estaban apoyados en el cuarto forjado, el forjado asumió el $45 \%$ de la carga en relación a su peso propio, y los puntales asumieron el 55\% de esta carga.

$\checkmark$ Al hormigonar un forjado superior sobre forjados inferiores ya clareados, una fracción importante de carga es asumida por el forjado sobre el que se apoyan los puntales del forjado hormigonado. Se observa un comportamiento muy similar al del vano de esquina, excepto en los forjados 5 y 6 . Este cambio se debe a operaciones no registradas y que fueron llevadas a cabo durante la construcción del edificio.

- Al hormigonar el forjado 2, la carga transmitida por los puntales colocados bajo dicho forjado fue asumida en un $75 \%$ por el forjado 1 . El $25 \%$ de carga restante fue asumida por forjados inferiores conectados con puntales.

- Al hormigonar el forjado 3, la carga transmitida por los puntales colocados bajo dicho forjado fue asumida en un $77 \%$ por el forjado 2. El 23\% de carga restante fue asumida por forjados inferiores conectados con puntales.

- Al hormigonar el forjado 4, la carga transmitida por los puntales colocados bajo dicho forjado fue asumida en un $93 \%$ por el forjado 3. El 7\% de carga restante fue asumida por forjados inferiores conectados con puntales. Al hormigonar este forjado, el conjunto de puntales ya no apoya en la cimentación. 
- Al hormigonar el forjado 5, la carga transmitida por los puntales colocados bajo dicho forjado fue asumida en un $73 \%$ por el forjado 4 . El $27 \%$ de carga restante fue asumida por forjados inferiores conectados con puntales.

- Al hormigonar el forjado 6, la carga transmitida por los puntales colocados bajo dicho forjado fue asumida en un 54\% por el forjado 5. El $46 \%$ de carga restante fue asumida por forjados inferiores conectados con puntales.

Al retirar los puntales de un forjado o descimbrarlo, la carga que asumían dichos puntales se reparte entre los forjados superiores conectados por puntales. En el descimbrado de los forjados 1, 2 y 3 la carga se repartió de la siguiente manera:

- Al retirar los puntales bajo el forjado 1, la carga que tenían dichos puntales fue asumida en un $52 \%$ por el forjado $1 \mathrm{y}$ el $48 \%$ restante por los forjados superiores conectados por puntales.

- En el descimbrado del forjado 2, la carga que tenían los puntales retirados fue asumida en un $73 \%$ por el forjado 2 y el $27 \%$ restante por los forjados superiores conectados por puntales.

- En el descimbrado del forjado 3, la carga que tenían los puntales retirados fue asumida en un $79 \%$ por el forjado 3 y el $21 \%$ restante por los forjados superiores conectados por puntales.

En los resultados anteriores se puede apreciar que el forjado del vano de esquina es el que más carga soporta en las distintas fases constructivas. Podría pensarse que esto no es correcto puesto que un vano de esquina es menos rígido (más deformable) que uno de medianera, pero esto es así si ambos tienen las mismas luces.

En este caso, el vano de esquina tiene unas dimensiones menores que el vano de medianera, lo que lo hace más rígido y por lo tanto presenta una mayor solicitación de carga.

El reparto de cargas entre puntales no es uniforme. En general en los puntales de centro de vano se presentan los valores de carga máxima para cada una de las operaciones constructivas.

En las operaciones constructivas del hormigonado del forjado $4 \mathrm{y}$ del clareado del forjado 5 , el proceso constructivo sufrió algunas alteraciones por necesidades de obra. En el hormigonado del forjado 4 se aflojaron y retiraron momentáneamente algunos de los puntales de forjado 3 debido al tránsito de material en obra. Esto produce un descenso en la solicitación de carga en el forjado 2 al hormigonar el forjado 4, lo cual altera la transmisión de cargas entre forjados y puntales para esta operación y para operaciones constructivas posteriores.

En el clareado del forjado 5, los puntales del forjado 3 fueron apretados debido a que se detectó que los puntales de una sopanda se encontraban poco ajustados. Esto conlleva a un aumento de carga en los puntales del forjado 3 .

Además, de dichas alteraciones en el proceso constructivo, se produjeron operaciones no controladas llevadas a cabo durante la construcción que no pudieron ser detectadas.

Este tipo de operaciones no previstas dentro del proceso constructivo modifican notablemente la transmisión esperada de cargas entre forjados y puntales. 


\subsubsection{Conclusiones del estudio experimental del edificio de forjado reticular de casetón perdido}

Otro de los estudios experimentales es el realizado en un edificio de forjado reticular de casetón perdido situado en Sabadell. Se trata de un edificio de 5 plantas y 2 sótanos destinado a viviendas.

El estudio experimental se llevó a cabo desde el hormigonado del forjado 1 hasta el hormigonado del forjado 6. Al igual que sucedía en el estudio anterior, al utilizar 3 juegos de cimbras, con el hormigonado del forjado 6 se cierra un ciclo completo del sistema de cimbrado.

Se instrumentó un único vano por planta con 2 sopandas principales. Dicho vano se corresponde con un vano de esquina en los forjados de sótano, donde además existe un muro perimetral paralelo a las sopandas, y con un vano extremo con voladizo en el resto de forjados. En cada una de las sopandas se dispusieron un total de 8 puntales instrumentados.

De la medición instantánea se concluye:

$\checkmark$ Al hormigonar cada forjado, la totalidad de la carga fue transmitida a los puntales. Por ejemplo, al hormigonar el forjado 1 la carga media en los puntales $\left(\mathrm{q}_{\mathrm{med}}\right)$ fue de $3.40 \mathrm{kN} / \mathrm{m} 2$ valor que difiere menos de un $1 \%$ del peso propio teórico del forjado $(3.39 \mathrm{kN} / \mathrm{m} 2)$. Lo mismo sucede en el hormigonado de cada uno de los forjados superiores. Esto refleja el grado de precisión de las medidas obtenidas durante el ensayo.

$\checkmark$ Al realizar la operación de clareado los cinco forjados, en los que se midió esta operación, asumieron una fracción importante de carga. Esto se presentó en los diferentes forjados de la siguiente forma:

- Una vez clareado el primer forjado, donde los puntales estaban apoyados en la planta baja, el forjado asumió el $42 \%$ de la carga en relación a su peso propio, y los puntales asumieron el $58 \%$ de esta carga.

- Al clarear el segundo forjado, donde los puntales estaban apoyados en el primer forjado, el forjado asumió el $30 \%$ de la carga en relación a su peso propio, y los puntales asumieron el $70 \%$ de esta carga.

- En el clareado del tercer forjado, donde los puntales estaban apoyados en el segundo forjado, el forjado asumió el 33\% de la carga en relación a su peso propio, y los puntales asumieron el $67 \%$ de esta carga.

- Al clarear el cuarto forjado, donde los puntales estaban apoyados en el tercer forjado, el forjado asumió el 52\% de la carga en relación a su peso propio, y los puntales asumieron el $48 \%$ de esta carga.

- En el clareado del quinto forjado, donde los puntales estaban apoyados en el cuarto forjado, el forjado asumió el $41 \%$ de la carga en relación a su peso propio, y los puntales asumieron el 59\% de esta carga. 
Al hormigonar un forjado superior sobre forjados inferiores ya clareados, una fracción importante de carga es asumida por el forjado sobre el que se apoyan los puntales del forjado hormigonado. Esto se presentó de la siguiente manera:

- Al hormigonar el forjado 2, la carga transmitida por los puntales colocados bajo dicho forjado fue asumida en un $73 \%$ por el forjado 1 . El $27 \%$ de carga restante fue asumida por los puntales bajo dicho forjado.

- Al hormigonar el forjado 3, la carga transmitida por los puntales colocados bajo dicho forjado fue asumida en un $69 \%$ por el forjado 2. El $31 \%$ de carga restante fue asumida por forjados inferiores conectados con puntales.

- Al hormigonar el forjado 4, la carga transmitida por los puntales colocados bajo dicho forjado fue asumida en un 54\% por el forjado 3. El $46 \%$ de carga restante fue asumida por forjados inferiores conectados con puntales. Al hormigonar este forjado, el conjunto de puntales ya no apoya en la cimentación.

- Al hormigonar el forjado 5, la carga transmitida por los puntales colocados bajo dicho forjado fue asumida en un $47 \%$ por el forjado 4 . El $53 \%$ de carga restante fue asumida por forjados inferiores conectados con puntales.

- Al hormigonar el forjado 6, la carga transmitida por los puntales colocados bajo dicho forjado fue asumida en un $69 \%$ por el forjado 5. El $31 \%$ de carga restante fue asumida por forjados inferiores conectados con puntales.

Al retirar los puntales de un forjado o descimbrarlo, la carga que asumían dichos puntales se reparte entre los forjados superiores conectados por puntales. En el descimbrado de los forjados 1, 2 y 3 la carga se repartió de la siguiente manera:

- Al retirar los puntales bajo el forjado 1, la carga que tenían dichos puntales fue asumida en un $57 \%$ por el forjado 1 y el $43 \%$ restante por los forjados superiores conectados por puntales.

- En el descimbrado del forjado 2, la carga que tenían los puntales retirados fue asumida en un $67 \%$ por el forjado 2 y el $33 \%$ restante por los forjados superiores conectados por puntales.

- En el descimbrado del forjado 3, la carga que tenían los puntales retirados fue asumida en un $76 \%$ por el forjado 3 y el $24 \%$ restante por los forjados superiores conectados por puntales.

Al igual que sucedía en el caso anterior, el reparto de cargas entre puntales no es uniforme en todo el vano, siendo en los puntales de centro de vano donde, en general, se presenta la carga máxima.

Además de las mediciones de carga en puntales, para poder determinar la variación de la temperatura en el forjado de hormigón y evaluar el gradiente térmico que se producía, se instalaron termopares a diferentes profundidades del forjado. Se tomaron medidas de temperatura diferentes días estando el forjado tanto encofrado como desencofrado. 
De las mediciones de temperatura se puede concluir que como pauta general, se aprecia que por la noche y a primera hora de la mañana, cuando la temperatura ambiente es menor, la cara inferior del forjado tiene mayor temperatura que la superior. Conforme va aumentando la temperatura ambiente, este fenómeno se invierte, quedando la cara superior del forjado con una temperatura mayor que la cara inferior.

Se aprecia asimismo que las variaciones de temperatura son distintas dependiendo de si el forjado se encuentra encofrado o desencofrado, presentándose en este último caso un incremento de temperaturas mayor entre la cara superior y la inferior del forjado que estando encofrado el forjado En este último caso -y para el forjado de $0.32 \mathrm{~m}$. de canto- los incrementos mínimo y máximo medidos fueron de $-1.87^{\circ} \mathrm{C}$ y $5.80^{\circ} \mathrm{C}$, respectivamente, con una diferencia máxima de temperatura ambiente de unos $12^{\circ} \mathrm{C}$.

\subsubsection{Conclusiones del estudio experimental del edificio de forjado reticular de casetón recuperable}

El último de los estudios experimentales se realizó en un edificio de forjado reticular de casetón recuperable situado dentro del recinto de la Universidad Politécnica de Valencia. El edificio consta de 7 forjados (6 plantas y 1 sótano) y es la ampliación de la Facultad de Bellas Artes. En el sótano existía un muro perimetral paralelo a las sopandas.

La monitorización se realizó desde el hormigonado del forjado 1 hasta el hormigonado del forjado 4. En este caso, el ciclo se completa con esta operación puesto que se utilizaron 2 juegos de cimbras.

Se instrumentaron dos vanos consecutivos, uno de esquina y otro de medianera, con un total de 11 puntales por planta.

De la medición instantánea, para el vano de esquina, se puede concluir:

$\checkmark$ Al hormigonar cada forjado, la totalidad de la carga se transmite a los puntales. Por ejemplo, al hormigonar el forjado 2 la carga media en los puntales (Qmed) fue de $5.66 \mathrm{kN} / \mathrm{m} 2$, valor que difiere sólo en un $2 \%$ del peso propio teórico del forjado $(5.76 \mathrm{kN} / \mathrm{m} 2)$. Lo mismo sucede en el hormigonado del resto de los forjados. Esto refleja el grado de precisión de las medidas obtenidas durante la construcción.

$\checkmark$ Al realizar la operación de clareado los dos forjados, en los que se midió esta operación, asumieron una fracción importante de carga. Una vez clareado el primer forjado, donde los puntales estaban apoyados en la losa de cimentación, el forjado asumió el 34\% de la carga en relación a su peso propio, y los puntales asumieron el 66\% de esta carga. En el clareado del tercer forjado, donde los puntales estaban apoyados en el segundo forjado, el forjado asumió el $36 \%$ de la carga en relación a su peso propio, y los puntales asumieron el $64 \%$ de esta carga. El clareado del forjado 2 se realizó de forma conjunta con el descimbrado del forjado 1 por necesidades de la obra.

$\checkmark$ Al hormigonar forjados superiores sobre inferiores ya clareados, el reparto de cargas fue el siguiente: 
- Al hormigonar el forjado 2, la carga transmitida por los puntales colocados bajo dicho forjado fue asumida en un $73 \%$ por el forjado 1. El $27 \%$ de carga restante fue asumida por los puntales bajo el forjado 1 transmitiéndola a la losa de cimentación.

- La carga al hormigonar el forjado 3 se repartió entre los forjados 1 y 2. Así, la carga asumida por el forjado 1 fue del 33\% mientras que la carga asumida por el forjado 2 fue del $67 \%$ del peso propio del forjado 3 . Al hormigonar este forjado, el conjunto de puntales ya no apoya en la cimentación.

- Al hormigonar el forjado 4, la carga transmitida por los puntales colocados bajo dicho forjado fue asumida en un $40 \%$ por el forjado 2 y el $60 \%$ de carga restante fue asumida el forjado 3 .

$\checkmark$ Al descimbrar un forjado, la carga que asumían dichos puntales se reparte entre los forjados superiores conectados por puntales. En el descimbrado del forjado 2, la carga que tenían los puntales retirados fue asumida en un $70 \%$ por el forjado 2 y el $30 \%$ restante por el forjado 3 .

$\checkmark$ Al realizar de forma conjunta, las operaciones de clareado del forjado 2 y descimbrado del forjado 1, la carga que soportaban los puntales del forjado 1 fue asumida en un $37 \%$ por el forjado 1 y un $63 \%$ por el forjado 2 .

De la medición instantánea, para el vano de medianera, se puede concluir:

$\checkmark$ Al hormigonar cada forjado, la totalidad de la carga fue transmitida a los puntales. Por ejemplo, al hormigonar el forjado 1 la carga media en los puntales $\left(Q_{\mathrm{med}}\right)$ fue de $5.79 \mathrm{kN} / \mathrm{m}^{2}$ valor que difiere en menos de un $1 \%$ del peso propio teórico del forjado $\left(5.76 \mathrm{kN} / \mathrm{m}^{2}\right)$. Lo mismo sucede en el hormigonado de los forjados superiores. Esto refleja el grado de precisión de las medidas obtenidas durante la construcción.

$\checkmark$ Al realizar la operación de clareado los dos forjados, en los que se midió esta operación, asumieron una fracción importante de carga. Una vez clareado el primer forjado, donde los puntales estaban apoyados en la losa de cimentación, el forjado asumió el 16\% de la carga en relación a su peso propio, y los puntales asumieron el $84 \%$ de esta carga. Al clarear el tercer forjado, donde los puntales estaban apoyados en el segundo forjado, el forjado asumió el $31 \%$ de la carga en relación a su peso propio, y los puntales asumieron el 69\% de esta carga. El clareado del forjado 2 se realizó de forma conjunta con el descimbrado del forjado 1 por necesidades de la obra.

$\checkmark$ Al hormigonar un forjado superior sobre forjados inferiores ya clareados, una fracción importante de carga es asumida por el forjado sobre el que se apoyan los puntales del forjado hormigonado. Esto se presentó de la siguiente manera:

- Al hormigonar el forjado 2, la carga transmitida por los puntales colocados bajo dicho forjado fue asumida en un $76 \%$ por el forjado 1 . El $24 \%$ de carga restante fue asumida por los puntales situados bajo el forjado 1 y trasmitida a la losa de cimentación.

- Al hormigonar el forjado 3, la carga transmitida por los puntales colocados bajo dicho forjado fue asumida en un $47 \%$ por el forjado 1 . El 53\% de carga restante fue asumida por 
el forjado 2. Al hormigonar este forjado, el conjunto de puntales ya no apoya en la cimentación.

- Al hormigonar el forjado 4, la carga se repartió entre los forjados 2 y 3. La carga asumida por el forjado 2 fue del 39\%, asumiendo el forjado 3 el $61 \%$ restante.

$\checkmark$ Al retirar los puntales de un forjado o descimbrarlo, la carga que asumían dichos puntales se reparte entre los forjados superiores conectados por puntales. Para el caso estudiado, al retirar los puntales bajo el forjado 2, la carga que tenían dichos puntales fue asumida en un $60 \%$ por el forjado 2 y el $40 \%$ restante por el forjado 3.

$\checkmark \quad$ Tras la realización de las operaciones de clareado del forjado 2 y descimbrado del forjado 1, la carga que tenían los puntales del forjado 1 fue asumida en un $32 \%$ por el forjado $1 \mathrm{y}$ un $68 \%$ por el forjado 2 .

Como en los casos anteriores, no existió un reparto uniforme de las cargas en los puntales, dándose la carga máxima en los puntales de centro de vano.

Así mismo, se instrumentaron, con termopares, 2 nervios de dos forjados consecutivos para poder estudiar el gradiente térmico que se producía en el forjado de hormigón. Se tomaron medidas de temperatura diferentes días estando el forjado, encofrado, desencofrado con insolación directa y desencofrado con insolación indirecta.

De las mediciones de temperatura se puede concluir que, al igual que sucedía en el forjado reticular de casetón perdido, cuando la temperatura ambiente es menor, por la noche y a primera hora de la mañana, la cara inferior del forjado tiene mayor temperatura que la superior. Conforme va aumentando la temperatura ambiente, este fenómeno se invierte, quedando la cara superior del forjado con una temperatura mayor que la cara inferior.

También se observa que las diferencias de temperatura entre la cara superior e inferior del forjado son distintas dependiendo de si el forjado se encuentra encofrado o desencofrado, y si existe insolación directa. Los mayores incrementos se produjeron cuando el forjado estaba desencofrado y la insolación era directa. En este último caso los incrementos mínimo y máximo medidos fueron de $-3.86^{\circ} \mathrm{C}$ y $9.56^{\circ} \mathrm{C}$, respectivamente, con una diferencia máxima de temperatura ambiente de unos $12^{\circ} \mathrm{C}$.

\subsubsection{Comparación de las medidas experimentales de carga de los distintos edificios estudiados}

A continuación se realiza una comparativa del comportamiento, frente a la transmisión de carga entre forjados y puntales, de cada una de las tipologías de forjados estudiadas de acuerdo con los resultados obtenidos experimentalmente.

En todos los edificios, independientemente del tipo de vano estudiado, se observó que al hormigonar cada forjado, la totalidad de la carga fue transmitida a los puntales. 
$\checkmark$ Al realizar la operación de clareado, los forjados clareados asumen una fracción importante de carga. El porcentaje de carga transmitida a los forjados en la operación de clareado varió entre:

- Edificio de forjado de losa maciza.

- Vano de esquina: $48-64 \%$ del peso propio del forjado.

- Vano de medianera: $41-61 \%$ del peso propio del forjado.

- Edificio de forjado reticular de casetón perdido.

- Vano de esquina (forjados 1 y 2): 30-42\% del peso propio del forjado

- Vano extremo con voladizo (resto de forjados): $33-52 \%$ del peso propio del forjado

- Edificio de forjado reticular de casetón recuperable.

- Vano de esquina: $34-36 \%$ del peso propio del forjado.

- Vano de medianera: $16-31 \%$ del peso propio del forjado.

$\checkmark$ Al hormigonar un forjado superior sobre forjados inferiores ya clareados, una fracción importante de carga es asumida por el forjado sobre el que se apoyan los puntales del forjado hormigonado. En general, el porcentaje de carga asumido por dicho forjado varió entre:

- Edificio de forjado de losa maciza.

- Vano de esquina: 72 - 94\% del peso propio del forjado

- Vano de medianera: 54 - 93\% del peso propio del forjado

- Edificio de forjado reticular de casetón perdido.

- Vano de esquina (forjados 1 y 2): $69-73 \%$ del peso propio del forjado

- Vano extremo con voladizo (resto de forjados): 47-69\% del peso propio del forjado

- Edificio de forjado reticular de casetón recuperable.

- Vano de esquina: 60 - $73 \%$ del peso propio del forjado.

- Vano de medianera: $53-76 \%$ del peso propio del forjado.

$\checkmark$ Al retirar los puntales de un forjado o descimbrarlo, la carga que asumían dichos puntales se reparte entre los forjados superiores conectados por puntales. La carga asumida por el forjado inmediatamente superior al forjado descimbrado varió entre:

- Edificio de forjado de losa maciza.

- Vano de esquina: $64-87 \%$ de la carga que tenían los puntales retirados.

- Vano de medianera: $52-79 \%$ de la carga que tenían los puntales retirados.

- Edificio de forjado reticular de casetón perdido.

- Vano de esquina (forjados 1 y 2): $57-67 \%$ de la carga que tenían los puntales retirados.

- Vano extremo con voladizo (resto de forjados): $76 \%$ de la carga que tenían los puntales retirados. 
- Edificio de forjado reticular de casetón recuperable.

- Vano de esquina: 70\% de la carga que tenían los puntales retirados.

- Vano de medianera: $60 \%$ de la carga que tenían los puntales retirados.

Las medidas experimentales han evidenciado que la transmisión de cargas entre forjados y puntales es diferente según el vano y la tipología de forjado analizada. Esto se debe a que las condiciones de contorno y geometría del vano hacen particular la deformabilidad y/o la rigidez de cada uno de los vanos del forjado. A pesar de esto, también se observan unas pautas generales de comportamiento muy marcadas para cada una de las operaciones constructivas (hormigonado, clareado y descimbrado), independientemente del tipo de vano o forjado. 



\section{CAPITULO 4. MODELOS NUMÉRICOS}

\subsection{Introducción}

El presente capítulo tiene dos objetivos claramente diferenciados. Por un lado, se pretende calibrar el modelo numérico desarrollado en investigaciones anteriores por el grupo de investigación, ajustándolo a diferentes tipologías estructurales y de las cuales se conoce su comportamiento experimental a través de las medidas de cargas en puntales tomadas en obra. Por otro lado, se pretende obtener una aproximación numérica al efecto que producen los cambios de temperatura en la transmisión de cargas entre forjados y puntales.

Para la calibración del modelo numérico se han planteado dos modelos de Elementos Finitos distintos para simular los edificios de forjado de losa maciza y de forjado reticular de casetón recuperable, así como sus procesos constructivos, descritos en el capítulo anterior. Para ello se ha seguido el mismo procedimiento propuesto por Alvarado et al. (2010). Se asume un cálculo no lineal, evolutivo que considera tanto las fases constructivas como la variación de las características mecánicas de hormigón durante cada etapa constructiva. En estos modelos no se han considerado los efectos de los cambios de temperatura.

Por otra parte, debido a la importancia que se ha demostrado que tienen las variaciones de temperatura ambiente sobre las cargas en los puntales durante el proceso constructivo (véase apartado 2.4 de la presente Tesis Doctoral), en el presente capítulo se plantea un modelo de Elementos Finitos basado en el propuesto por Alvarado et al. (2010) que pretende simular el edificio experimental estudiado por Alvarado (2009), considerando los cambios de temperatura que se producen tanto en el ambiente, como en la losa, puntales y pilares. Se han considerado las características geométricas y mecánicas de cada uno de los elementos que intervienen en la construcción del edificio. Además, se ha tenido en cuenta el proceso constructivo seguido mediante un cálculo evolutivo.

Para realizar los distintos modelos numéricos se ha empleado el software comercial ANSYS 11.0 (2006).

\subsection{Modelo numérico del edificio de forjado de losa maciza}

Se plantea un modelo de numérico con el que se simula el edificio de forjado de losa maciza y el proceso constructivo de dicho edificio descrito en el capítulo anterior (véase apartado 3.2). La modelización se ha realizado con el software comercial ANSYS 11.0 (2006). Se ha seguido el mismo procedimiento propuesto por Alvarado et al. (2010), asumiendo un cálculo no lineal, evolutivo que considera tanto las fases constructivas como la variación de las características mecánicas del hormigón durante cada etapa constructiva. 
Dado que el análisis experimental se ciñe a un vano de esquina y a su contiguo de medianera se ha optado por modelizar únicamente una parte del edificio. La continuidad del forjado se ha simulado mediante voladizos que producen, en la línea de pilares, un momento flector similar al que se produce, por los vanos adyacentes, en la realidad. En la Figura 4.1a y 4.1b se observa una sección del edificio completo modelizado y una planta tipo, respectivamente.

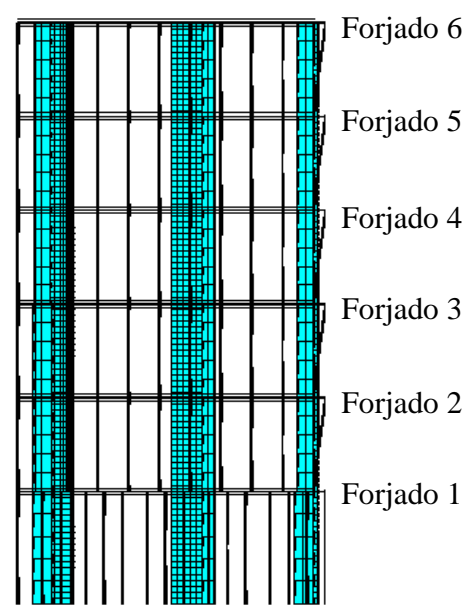

(a)

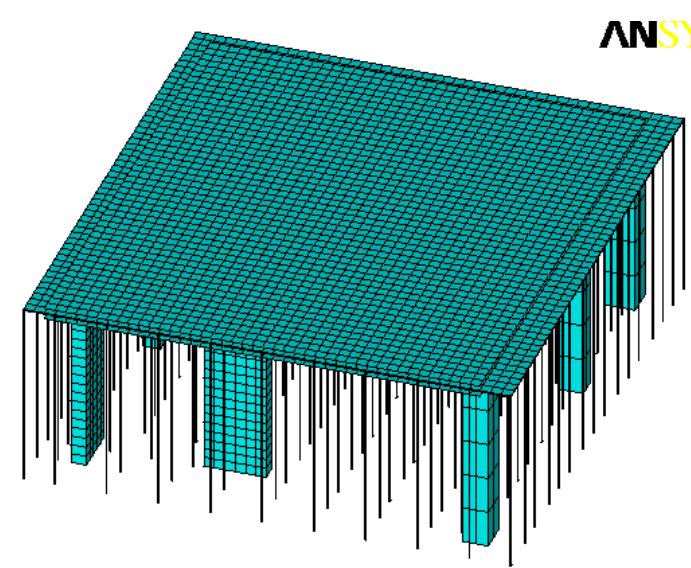

(b)

Fig. 4.1 Modelo de Elementos Finitos del edificio de forjado de losa maciza: (a) Sección (b) Forjado tipo

\subsubsection{Hipótesis consideradas}

Las características geométricas de los elementos que forman el modelo experimental son las descritas en el capítulo anterior (véase apartado 3.2.1). Por otro lado, el proceso constructivo se ha modelizado siguiendo las fases indicadas en el apartado 3.2.3.

Las hipótesis adoptadas para realizar el modelo de EF son:

$\checkmark$ Se asume un comportamiento elástico y lineal del forjado de hormigón armado, considerando la variación de su rigidez en el tiempo. Todos los forjados tienen un canto de $0.22 \mathrm{~m}$.

$\checkmark$ Los pilares se simulan con un comportamiento elástico y lineal, y se considera la variación de su rigidez con respecto al tiempo. Se asume que los pilares de planta baja están empotrados en su base.

$\checkmark$ Los puntales de acero son considerados como elementos elásticos con una rigidez finita, apoyados en sus extremos. Tienen una sección transversal de $289 \mathrm{~mm}^{2}$ y un módulo de elasticidad de 210 $\mathrm{GPa}$.

$\checkmark$ Los tableros de encofrado son considerados como elementos con un comportamiento elástico y lineal y de rigidez finita. Los tableros son de madera, con un espesor de $27 \mathrm{~mm}$ y un módulo de elasticidad de $10 \mathrm{GPa}$. 
$\checkmark$ Se asume que la losa de $0.60 \mathrm{~m}$ de canto, junto con las vigas de cuelgue de $1.00 \mathrm{~m}$, sobre la que apoyan los puntales dispuestos en planta baja se asemeja a una losa infinitamente rígida respecto a la rigidez de los forjados superiores.

$\checkmark$ No se consideran los efectos de fluencia y retracción en el hormigón, ni los cambios de temperatura en los diferentes elementos de la estructura. Se considera que esta hipótesis es válida ya que se analizan los incrementos de carga producidos en cada fase constructiva, siendo cada una de éstas de corta duración (medidas instantáneas).

\subsubsection{Descripción del modelo de Elementos Finitos}

El modelo de EF se realizó con el software comercial ANSYS 11 (2006). Para la discretización de cada una de las partes de la estructura se utilizaron EF tipo SHELL, BEAM y LINK (ANSYS, 2006). En los apartados siguientes se explica el tipo y el uso de cada uno de estos elementos. De igual forma se describe cómo se simula el proceso de cálculo evolutivo del edificio.

\subsubsection{Tipos de EF y mallado empleado}

Los forjados de hormigón y los tableros de encofrado de madera se modelizan mediante elementos bidimensionales SHELL63. Este elemento está formado por 4 nodos, con 6 grados de libertad por nodo (traslaciones y giros en X, Y, Z). El elemento SHELL63 admite realizar un cálculo evolutivo mediante el uso de la opción Birth and Death y el comando MPCHG, que permiten considerar la aparición de nuevos elementos en el cálculo y variar las propiedades de los materiales en el tiempo. Estas opciones se explicarán con detalle en apartados posteriores (véase apartado 4.2.2.2). La Figura 4.2 incluye la geometría y localización de los nodos del elemento.

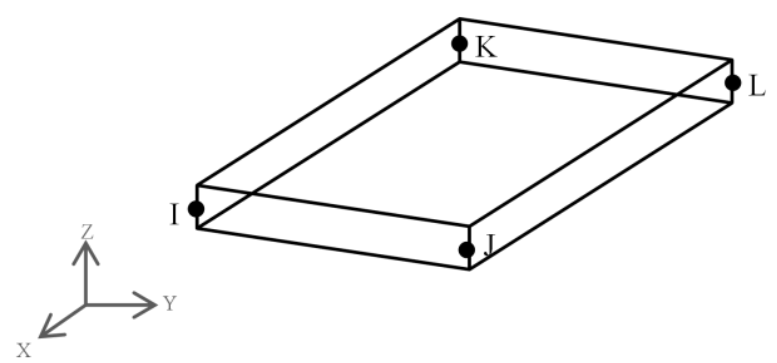

Fig. 4.2 Elemento SHELL63 (ANSYS 11.0, 2006)

Los puntales de acero se modelizan mediante elementos unidimensionales de 2 nodos LINK10. Este elemento tiene 3 grados de libertad en cada nodo (traslaciones en X, Y, Z). Dentro de sus opciones, se permite considerar que sólo estará sometido a esfuerzos de compresión, siendo ideal para modelar los puntales. El elemento LINK10 también permite el empleo de la opción Birth and Death que posibilita, para el caso de los puntales, modelar las operaciones de cimbrado, clareado y descimbrado. La Figura 4.3 muestra la geometría y localización de los nodos del elemento. 


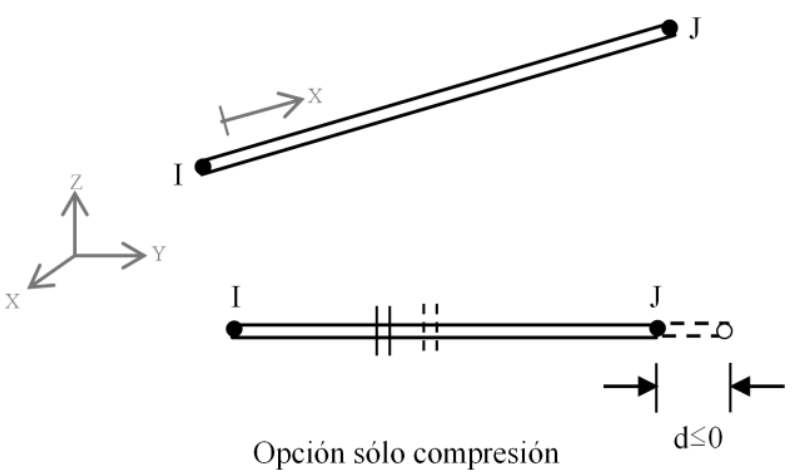

Fig. 4.3 Elemento LINK 10 (ANSYS 11.0, 2006)

Para modelizar los pilares de hormigón se emplean elementos BEAM188 y elementos SHELL63. Estos últimos se utilizan en el caso de los pilares apantallados. El elemento BEAM188 tiene dos nodos (I, J) y un tercer nodo opcional $(\mathrm{K})$ que define la orientación del elemento. Este elemento cuenta con 6 grados de libertad por nodo (traslaciones y giros en X, Y, Z). Dicho elemento permite desplazar sus nodos a partir del eje de la sección (ideal para desplazar los nodos al punto de crecimiento de cada uno de los pilares). Al igual que el resto de elementos empleados en el modelo de EF, el elemento BEAM188 admite la opción Birth and Death y el comando MPCHG. En la Figura 4.4 se observa la geometría y disposición de los nodos de dicho elemento.

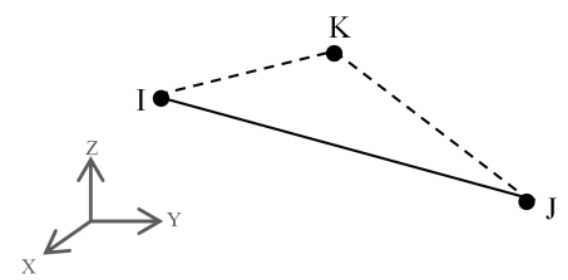

Fig. 4.4 Elemento BEAM 188 (ANSYS 11.0, 2006)

El tamaño de la malla de los forjados está condicionado por sus dimensiones y por la distribución de los componentes del sistema de cimbrado y encofrado. Buscando obtener un grado de aproximación adecuado, el tamaño de malla de EF para el forjado es de $0.20 \times 0.20 \mathrm{~m}^{2}$. Para los elementos del encofrado, así como para los pilares apantallados, el tamaño de la malla es también de 0.20 x $0.20 \mathrm{~m}^{2}$. El tamaño de la malla del resto de los pilares de hormigón es de $0.61 \mathrm{~m}$.

\subsubsection{Simulación del proceso constructivo}

Para simular el proceso constructivo del edificio en el modelo de Elementos Finitos se hace necesario considerar un modelo de estructura de carácter evolutivo. Es decir, las condiciones de apoyo (puntales y encofrado) y las características mecánicas del hormigón son cambiantes con el tiempo. ANSYS 11.0 permite realizar un cálculo evolutivo a través de diferentes pasos de carga (load steps).

Un paso de carga consiste en calcular la estructura para unas características mecánicas y geométricas determinadas. Una vez resuelto el primer paso de carga, el cálculo del segundo, toma como datos de partida de deformación y esfuerzos los obtenidos en el primer paso de carga. Para simular las distintas 
fases constructivas, se tendrán que definir tantos pasos de carga como fases de construcción del edificio.

Para poder realizar un cálculo evolutivo, ANSYS 11.0 dispone de las opciones Birth and Death y el comando MPCHG. La primera consiste en activar o desactivar los elementos deseados en un paso de carga. Cuando se desactiva un elemento el programa multiplica la rigidez de este elemento por 1.0E-6 (valor que se puede modificar) e igualmente, las cargas asociadas a dicho elemento se convierten en nulas. Cuando se vuelve a activar un elemento, el programa vuelve a asignarle la rigidez que le corresponde y se reactivan las cargas asociadas.

El comando MPCHG permite cambiar el material asignado a un elemento. En el modelo de Elementos Finitos, se simula la evolución del módulo de elasticidad del hormigón en el tiempo creando materiales con módulos de elasticidad correspondientes a la edad del hormigón de cada uno de los forjados, en cada una de las fases de construcción. Posteriormente, en cada uno de los pasos de carga, el módulo de elasticidad de los elementos de los forjados se cambia dependiendo de la edad del hormigón para la fase constructiva considerada.

El módulo de elasticidad del hormigón se estima de acuerdo con la formulación propuesta en la Instrucción de Hormigón Estructural EHE-08 (2008). El Apéndice III muestra el proceso de cálculo del módulo elástico.

Los distintos pasos de carga considerados en el modelo de Elementos Finitos son los siguientes:

- Paso de carga 1: Hormigonado del forjado 1. El cálculo de este paso de carga consiste en dejar activados únicamente los elementos del forjado 1 con su sistema de cimbrado, desactivando los elementos de los forjados superiores, incluidos los puntales y encofrado.

- Paso de carga 2: Clareado del forjado 1. Para el cálculo de este paso de carga se desactivan los elementos del encofrado y los puntales correspondientes a las sopandas intermedias correspondientes al sistema de cimbrado del forjado 1 .

- Paso de carga 3: Hormigonado del forjado 2. En este paso de carga se activan el conjunto de elementos del forjado 2 incluidos pilares, encofrado y puntales.

- Paso de carga 4: Clareado del forjado 2. En el paso de carga 4 se desactivan el encofrado y los puntales correspondientes a las sopandas intermedias del sistema de cimbrado del forjado 2.

- Paso de carga 5: Hormigonado del forjado 3. Para realizar este paso de carga, se activan los elementos del forjado 3, incluyendo el sistema de apuntalamiento.

- Paso de carga 6: Clareado del forjado 3. En este paso de carga se desactivan los puntales correspondientes a las sopandas intermedias así como el encofrado del sistema de cimbrado del forjado 3 .

- Paso de carga 7: Descimbrado del forjado 1. En este paso de carga se desactivan los puntales situados bajo el forjado 1, quedando los puntales bajo los forjados 2 y 3 . 
- Paso de carga 8: Hormigonado del forjado 4. En el paso de carga 8 se activan los elementos del forjado 4 incluyendo sus pilares y su sistema de cimbrado (encofrado y puntales).

- Paso de carga 9: Clareado del forjado 4. Para el cálculo de éste paso de carga se desactivan el encofrado, puntales de las sopandas intermedias, simulando de ésta forma el clareado del tercer forjado

- Paso de carga 10: Descimbrado del forjado 2. Para simular el descimbrado del forjado 2 se desactivan los puntales bajo el forjado 2 .

- Paso de carga 11: Hormigonado del forjado 5. En el paso de carga 11, se activan los elementos del forjado 5, incluyendo el sistema de apuntalamiento (encofrado y puntales).

- Paso de carga 12: Clareado del forjado 5. En este paso de carga se desactivan los puntales correspondientes a las sopandas intermedias así como el encofrado del sistema de cimbrado del forjado 5 .

- Paso de carga 7: Descimbrado del forjado 3. En este paso de carga se desactivan los puntales situados bajo el forjado 3, quedando puntales bajo los forjados 4 y 5 .

- Paso de carga 14: Hormigonado del forjado 6. El último paso de carga consiste en el hormigonado del forjado 6. Para realizar el cálculo de este paso de carga se activan los elementos del forjado 6 con su sistema de cimbrado.

En la Tabla 4.1 se muestran las edades del hormigón y los módulos de elasticidad correspondientes para cada uno de los pasos de carga. Se considera una temperatura media en obra de $25.3^{\circ} \mathrm{C}$.

Tabla 4.1. Edades del hormigón y módulos elásticos ${ }^{1}$ para cada paso de carga (modelo del edificio de forjado de losa maciza).

\begin{tabular}{cccccc}
\hline \multirow{2}{*}{ Paso de carga } & \multirow{2}{*}{ Nivel } & \multicolumn{2}{c}{ Forjado } & \multicolumn{2}{c}{ Pilares } \\
\cline { 3 - 6 } & & Edad (días) & $\mathbf{E}_{\mathbf{c}, \mathbf{t}, \mathbf{f}}(\mathbf{G P a})$ & Edad (días) & $\mathbf{E}_{\mathbf{c}, \mathbf{t}, \mathbf{p}}(\mathbf{G P a})$ \\
\hline 1 & 1 & 0 & 0.00 & 12 & 26.55 \\
\hline 2 & 1 & 7 & 25.72 & 19 & 27.11 \\
\hline \multirow{2}{*}{3} & 2 & 0 & 0.00 & 8 & 25.95 \\
& 1 & 10 & 26.29 & 22 & 27.26 \\
\hline \multirow{2}{*}{4} & 2 & 5 & 25.10 & 13 & 26.65 \\
& 1 & 15 & 26.83 & 27 & 27.46 \\
\hline \multirow{2}{*}{5} & 3 & 0 & 0.00 & 4 & 24.64 \\
& 2 & 6 & 25.45 & 14 & 26.75 \\
& 1 & 16 & 26.91 & 28 & 27.49 \\
\hline \multirow{2}{*}{6} & 3 & 12 & 25.45 & 10 & 26.29 \\
& 2 & 22 & 26.55 & 20 & 27.16 \\
& 1 & & 27.26 & 34 & 27.49 \\
\hline
\end{tabular}

\footnotetext{
${ }^{1}$ Para edades del hormigón superiores a 28 días se considera un módulo elástico igual al considerado a los 28
} días. 


\begin{tabular}{|c|c|c|c|c|c|}
\hline \multirow{2}{*}{ Paso de carga } & \multirow{2}{*}{ Nivel } & \multicolumn{2}{|c|}{ Forjado } & \multicolumn{2}{|c|}{ Pilares } \\
\hline & & Edad (días) & $\mathbf{E}_{\mathrm{c}, \mathrm{t,f}, \mathrm{GPa})}$ & Edad (días) & $\mathbf{E}_{\mathrm{c}, \mathrm{t}, \mathrm{p}}(\mathbf{G P a})$ \\
\hline \multirow{3}{*}{7} & 3 & 7 & 25.72 & 11 & 26.43 \\
\hline & 2 & 13 & 26.65 & 21 & 27.21 \\
\hline & 1 & 23 & 27.31 & 35 & 27.49 \\
\hline \multirow{4}{*}{8} & 4 & 0 & 0.00 & 5 & 25.10 \\
\hline & 3 & 7 & 25.72 & 11 & 26.43 \\
\hline & 2 & 13 & 26.65 & 21 & 27.21 \\
\hline & 1 & 23 & 27.31 & 35 & 27.49 \\
\hline \multirow{4}{*}{9} & 4 & 5 & 25.10 & 10 & 26.29 \\
\hline & 3 & 12 & 26.55 & 16 & 26.91 \\
\hline & 2 & 18 & 27.05 & 26 & 27.43 \\
\hline & 1 & 28 & 27.49 & 40 & 27.49 \\
\hline \multirow{4}{*}{10} & 4 & 6 & 25.45 & 11 & 26.43 \\
\hline & 3 & 13 & 26.65 & 17 & 26.98 \\
\hline & 2 & 19 & 27.11 & 27 & 27.46 \\
\hline & 1 & 29 & 27.49 & 41 & 27.49 \\
\hline \multirow{5}{*}{11} & 5 & 0 & 0.00 & 5 & 25.10 \\
\hline & 4 & 7 & 25.72 & 12 & 26.55 \\
\hline & 3 & 14 & 26.75 & 18 & 27.05 \\
\hline & 2 & 20 & 27.16 & 28 & 27.49 \\
\hline & 1 & 30 & 27.49 & 42 & 27.49 \\
\hline \multirow{5}{*}{12} & 5 & 5 & 25.10 & 10 & 26.29 \\
\hline & 4 & 12 & 26.55 & 17 & 26.98 \\
\hline & 3 & 19 & 27.11 & 23 & 27.31 \\
\hline & 2 & 25 & 27.39 & 33 & 27.49 \\
\hline & 1 & 35 & 27.49 & 47 & 27.49 \\
\hline \multirow{5}{*}{13} & 5 & 6 & 25.45 & 11 & 26.43 \\
\hline & 4 & 13 & 26.65 & 18 & 27.05 \\
\hline & 3 & 20 & 27.16 & 24 & 27.35 \\
\hline & 2 & 26 & 27.43 & 34 & 27.49 \\
\hline & 1 & 36 & 27.49 & 48 & 27.49 \\
\hline \multirow{6}{*}{14} & 6 & 0 & 0.00 & 5 & 25.10 \\
\hline & 5 & 7 & 25.72 & 12 & 26.55 \\
\hline & 4 & 14 & 26.75 & 19 & 27.11 \\
\hline & 3 & 21 & 27.21 & 25 & 27.39 \\
\hline & 2 & 27 & 27.46 & 35 & 27.49 \\
\hline & 1 & 37 & 27.49 & 49 & 27.49 \\
\hline
\end{tabular}

\subsubsection{Análisis de resultados del modelo y comparación con las medidas experimentales}

Puesto que únicamente se instrumentó una sopanda por cada vano, para realizar la comparación con las mediciones experimentales, del modelo de Elementos Finitos se han extraído únicamente los resultados correspondientes a los puntales que están situados en las mismas sopandas donde estaban los puntales instrumentados.

A continuación se muestra un resumen de los resultados obtenidos con el modelo de Elementos Finitos, validándolos con las mediciones del modelo experimental expuestas en el capítulo anterior (véase apartado 3.2.4). 


\subsubsection{Vano de esquina}

Las Figuras 4.5 y 4.6 muestran la evolución del coeficiente de carga para el forjado 1 y para los puntales bajo este forjado durante todo el proceso constructivo. Las Figuras 4.7 y 4.8 muestran la evolución del coeficiente de carga para el forjado 2 y para los puntales bajo este forjado durante todo el proceso constructivo. Las Figuras 4.9 y 4.10 muestran la evolución del coeficiente de carga para el forjado 3 y para los puntales bajo este forjado durante todo el proceso constructivo. Las Figuras $4.11 \mathrm{y}$ 4.12 muestran la evolución del coeficiente de carga para el forjado 4 y para los puntales bajo este forjado durante todo el proceso constructivo. Por último, las Figuras 4.13 y 4.14 muestran la evolución del coeficiente de carga para el forjado 5 y para los puntales bajo este forjado durante todo el proceso constructivo. No se muestra una evolución del coeficiente de carga en el forjado 6 y en los puntales bajo este forjado debido a que únicamente fue objeto de medición el hormigonado de dicho forjado (operación en la cual se terminó el estudio experimental). En todas las figuras se muestra tanto el coeficiente de carga obtenido a partir de los resultados del modelo de Elementos Finitos como el obtenido a partir de las medidas experimentales.

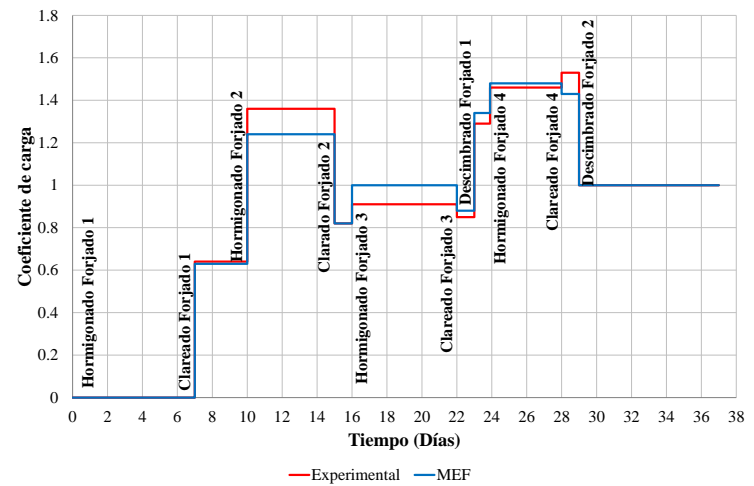

Fig. 4.5 Comparación coeficientes de carga en el forjado 1 (Forjado de losa maciza - Vano de esquina)

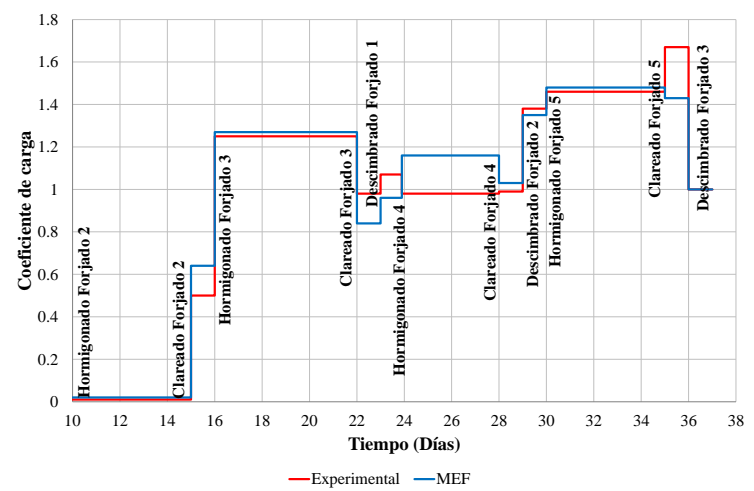

Fig. 4.7 Comparación coeficientes de carga en el forjado 2 (Forjado de losa maciza - Vano de esquina)

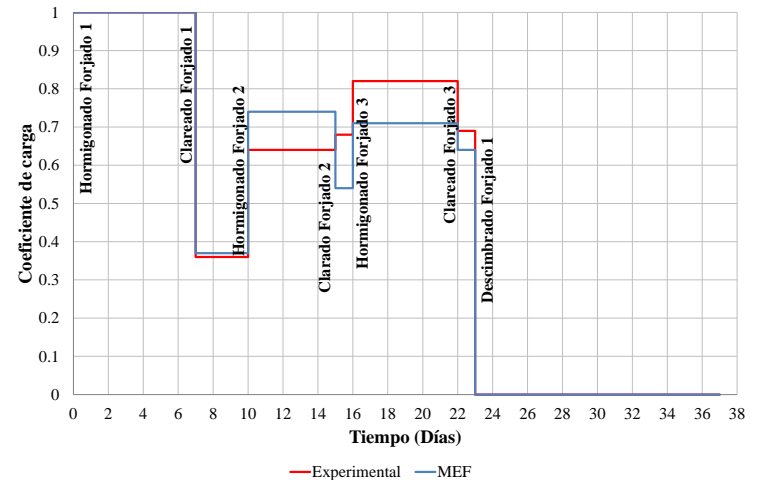

Fig. 4.6 Comparación coeficientes de carga en puntales bajo el forjado 1 (Forjado de losa maciza - Vano de esquina)

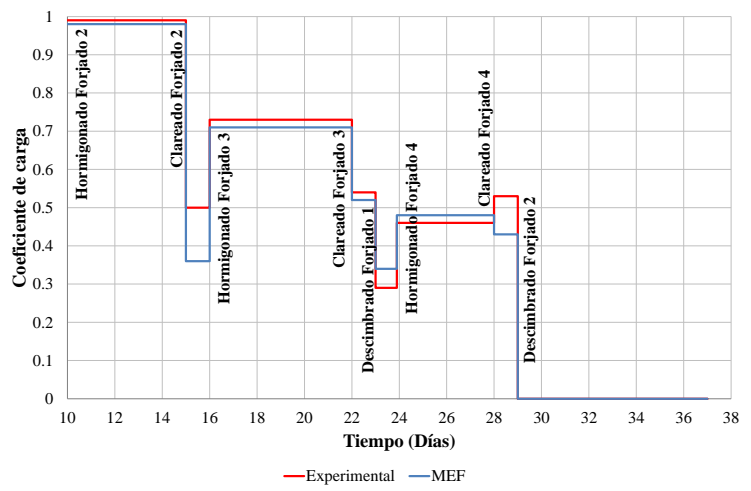

Fig. 4.8 Comparación coeficientes de carga en puntales bajo el forjado 2 (Forjado de losa maciza - Vano de esquina) 


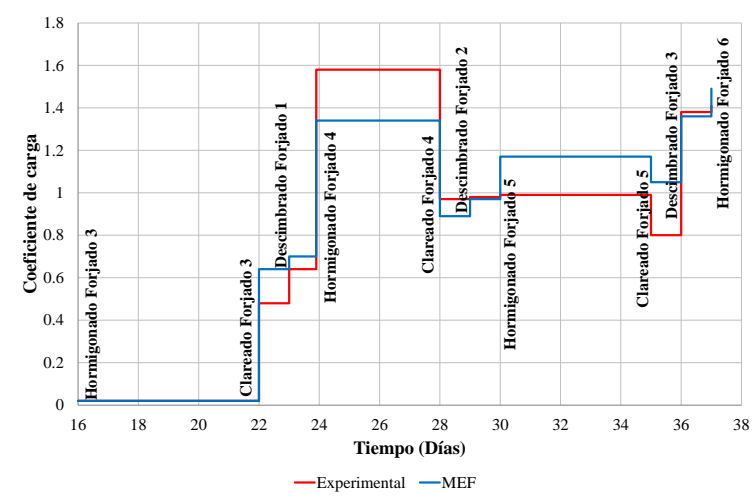

Fig. 4.9 Comparación coeficientes de carga en el forjado 3 (Forjado de losa maciza - Vano de esquina)

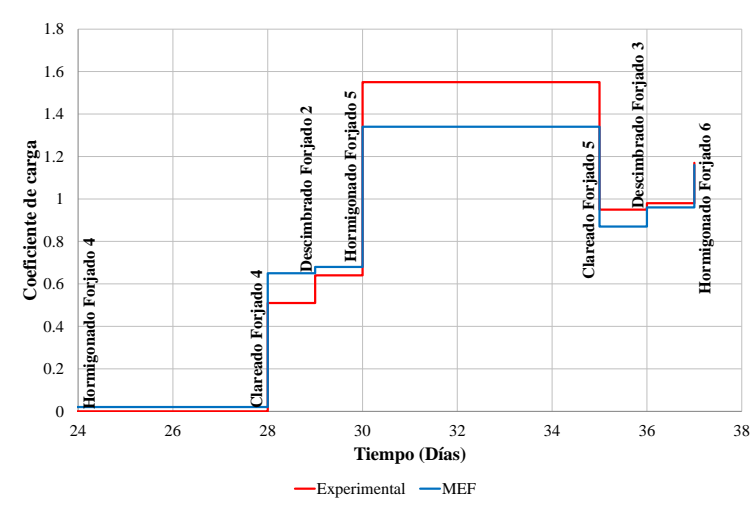

Fig. 4.11 Comparación coeficientes de carga en el forjado 4 (Forjado de losa maciza - Vano de esquina)

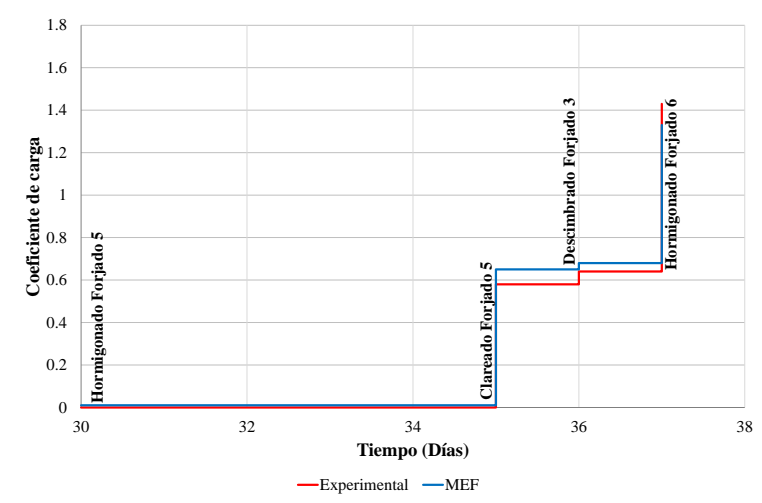

Fig. 4.13 Comparación coeficientes de carga en el forjado 5 (Forjado de losa maciza - Vano de esquina)

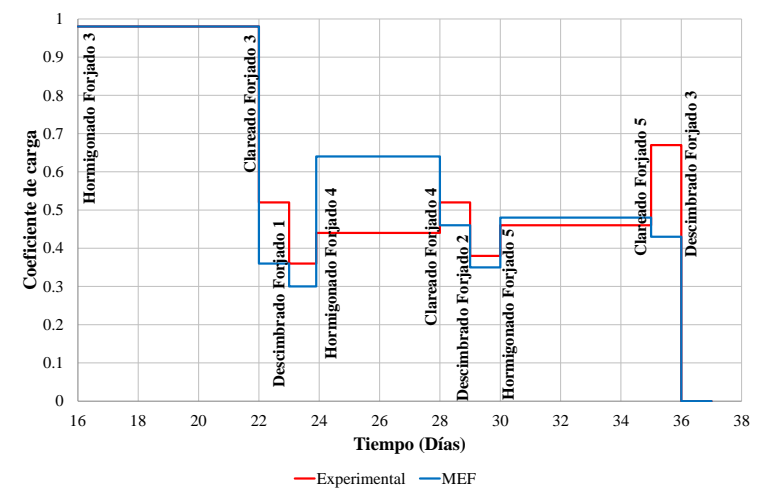

Fig. 4.10 Comparación coeficientes de carga en puntales bajo el forjado 3 (Forjado de losa maciza - Vano de esquina)

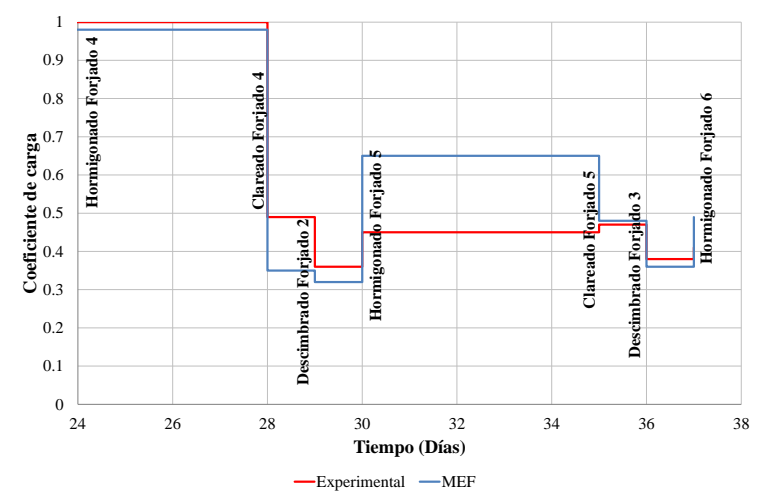

Fig. 4.12 Comparación coeficientes de carga en puntales bajo el forjado 4 (Forjado de losa maciza - Vano de esquina)

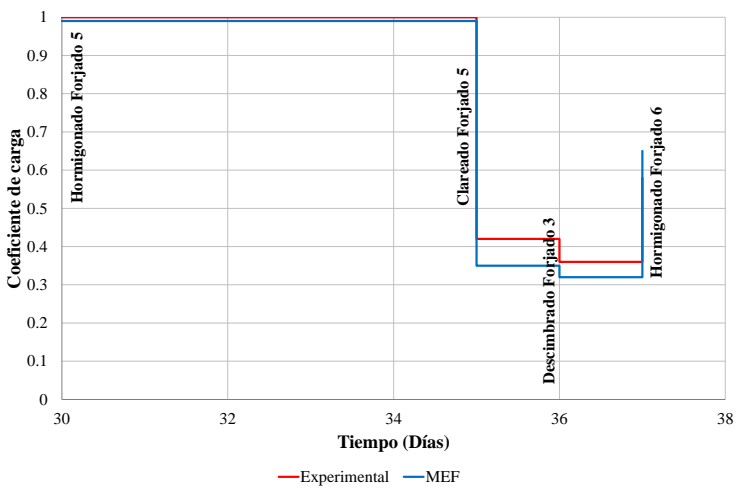

Fig. 4.14 Comparación coeficientes de carga en puntales bajo el forjado 5 (Forjado de losa maciza - Vano de esquina)

La Tabla 4.2 muestra una comparación entre los valores de la carga media en puntales obtenidos de la medición en obra $\left(q_{\text {med,exp }}\right)$ y los valores de carga media del modelo de Elementos Finitos $\left(q_{m e d, M E F}\right)$ obtenidos a partir de la carga en los puntales equivalentes a los instrumentados en obra. 
Así mismo, se comparan las cargas máximas en puntales obtenidas experimentalmente $\left(P_{\text {max,exp }}\right)$ y a partir del modelo $\left(P_{\max , M E F}\right)$.

Tabla 4.2. Comparación entre las medidas experimentales y los resultados del modelo numérico (Forjado de losa maciza Vano de esquina)

\begin{tabular}{|c|c|c|c|c|c|c|c|c|}
\hline $\begin{array}{l}\text { Paso } \\
\text { de } \\
\text { carga }\end{array}$ & Operación & Nivel & $\begin{array}{c}\text { Experimental } \\
q_{\text {med,exp }} \\
\left(\mathrm{kN} / \mathrm{m}^{2}\right)\end{array}$ & $\begin{array}{c}\text { Numérico } \\
q_{m e d, M E F} \\
\left(\mathbf{k N} / \mathbf{m}^{2}\right)\end{array}$ & $\frac{q_{\text {med,exp }}}{q_{\text {med,MEF }}}$ & $\begin{array}{c}\text { Experimental } \\
P_{\max , \exp } \\
(\mathrm{kN})\end{array}$ & $\begin{array}{c}\text { Numérico } \\
P_{\max , M E F} \\
(\mathrm{kN})\end{array}$ & $\frac{P_{\max , \exp }}{P_{\max , M E F}}$ \\
\hline 1 & $\begin{array}{l}\text { Hormigonado } \\
\text { forjado } 1\end{array}$ & 1 & 4.95 & 4.96 & 1.00 & 3.40 & 3.65 & 0.93 \\
\hline 2 & Clareado forjado 1 & 1 & 1.77 & 1.84 & 0.96 & 5.29 & 5.91 & 0.90 \\
\hline \multirow{2}{*}{3} & Hormigonado & 2 & 4.90 & 4.85 & 1.01 & 5.40 & 4.87 & 1.11 \\
\hline & forjado 2 & 1 & 3.16 & 3.69 & 0.86 & 7.01 & 11.76 & 0.60 \\
\hline \multirow{2}{*}{4} & \multirow{2}{*}{ Clareado forjado 2} & 2 & 2.50 & 1.77 & 1.41 & 7.01 & 5.47 & 1.28 \\
\hline & & 1 & 3.36 & 2.70 & 1.24 & 8.26 & 8.66 & 0.95 \\
\hline \multirow{3}{*}{5} & \multirow{3}{*}{$\begin{array}{l}\text { Hormigonado } \\
\text { forjado } 3\end{array}$} & 3 & 4.86 & 4.85 & 1.00 & 5.20 & 4.87 & 1.07 \\
\hline & & 2 & 3.61 & 3.50 & 1.03 & 10.75 & 10.77 & 1.00 \\
\hline & & 1 & 4.09 & 3.53 & 1.16 & 11.09 & 11.41 & 0.97 \\
\hline \multirow{3}{*}{6} & \multirow{3}{*}{ Clareado forjado 3} & 3 & 2.56 & 1.79 & 1.43 & 6.16 & 5.43 & 1.13 \\
\hline & & 2 & 2.68 & 2.58 & 1.04 & 7.57 & 7.95 & 0.95 \\
\hline & & 1 & 3.42 & 3.16 & 1.08 & 10.07 & 10.00 & 1.01 \\
\hline \multirow{2}{*}{7} & \multirow{2}{*}{$\begin{array}{l}\text { Descimbrado } \\
\text { forjado } 1\end{array}$} & 3 & 1.79 & 1.51 & 1.19 & 4.90 & 4.10 & 1.20 \\
\hline & & 2 & 1.44 & 1.71 & 0.84 & 4.98 & 4.10 & 1.21 \\
\hline \multirow{3}{*}{8} & \multirow{3}{*}{$\begin{array}{l}\text { Hormigonado } \\
\text { forjado } 4^{2}\end{array}$} & 4 & 5.05 & 4.85 & 1.04 & 5.27 & 4.87 & 1.08 \\
\hline & & 3 & 2.18 & 3.16 & 0.69 & 5.84 & 9.06 & 0.64 \\
\hline & & 2 & 2.28 & 2.37 & 0.96 & 6.47 & 6.00 & 1.08 \\
\hline \multirow{3}{*}{9} & \multirow{3}{*}{ Clareado forjado 4} & 4 & 2.42 & 1.75 & 1.38 & 6.38 & 5.38 & 1.19 \\
\hline & & 3 & 2.58 & 2.29 & 1.13 & 8.44 & 6.51 & 1.30 \\
\hline & & 2 & 2.63 & 2.13 & 1.23 & 7.81 & 5.15 & 1.52 \\
\hline \multirow{2}{*}{10} & \multirow{2}{*}{$\begin{array}{l}\text { Descimbrado } \\
\text { forjado } 2\end{array}$} & 3 & 1.79 & 1.59 & 1.13 & 5.00 & 4.66 & 1.07 \\
\hline & & 2 & 1.88 & 1.74 & 1.08 & 5.01 & 4.43 & 1.13 \\
\hline \multirow{3}{*}{11} & \multirow{3}{*}{$\begin{array}{l}\text { Hormigonado } \\
\text { forjado } 5\end{array}$} & 5 & 4.96 & 4.92 & 1.01 & 5.06 & 5.02 & 1.01 \\
\hline & & 4 & 2.23 & 3.22 & 0.69 & 5.84 & 9.57 & 0.61 \\
\hline & & 3 & 2.28 & 2.39 & 0.95 & 6.15 & 6.29 & 0.98 \\
\hline \multirow{3}{*}{12} & \multirow{3}{*}{ Clareado forjado $5^{2}$} & 5 & 2.09 & 1.76 & 1.19 & 7.13 & 5.38 & 1.33 \\
\hline & & 4 & 2.33 & 2.37 & 0.98 & 7.50 & 7.06 & 1.06 \\
\hline & & 3 & 3.32 & 2.15 & 1.54 & 7.18 & 5.47 & 1.31 \\
\hline \multirow{2}{*}{13} & \multirow{2}{*}{$\begin{array}{l}\text { Descimbrado } \\
\text { forjado } 3\end{array}$} & 5 & 1.79 & 1.60 & 1.12 & 4.80 & 4.62 & 1.04 \\
\hline & & 4 & 1.88 & 1.80 & 1.04 & 5.02 & 4.88 & 1.03 \\
\hline \multirow{3}{*}{14} & \multirow{3}{*}{$\begin{array}{l}\text { Hormigonado } \\
\text { forjado } 6\end{array}$} & 6 & 5.01 & 4.85 & 1.03 & 5.06 & 4.87 & 1.04 \\
\hline & & 5 & 2.88 & 3.25 & 0.89 & 8.44 & 9.58 & 0.88 \\
\hline & & 4 & 2.03 & 2.45 & 0.83 & 5.63 & 6.76 & 0.83 \\
\hline- & Media & - & - & - & 1.07 & - & - & 1.04 \\
\hline- & Desviación Típica & - & - & - & 0.19 & - & - & 0.20 \\
\hline
\end{tabular}

${ }^{2}$ Operaciones constructivas en las que el proceso constructivo sufrió algún tipo de alteración por necesidades de la obra. 


\subsubsection{Vano de medianera}

Las Figuras 4.15 y 4.16 muestran la evolución del coeficiente de carga para el forjado 1 y para los puntales bajo este forjado durante todo el proceso constructivo. Las Figuras 4.17 y 4.18 muestran la evolución del coeficiente de carga para el forjado 2 y para los puntales bajo este forjado durante todo el proceso constructivo. Las Figuras 4.19 y 4.20 muestran la evolución del coeficiente de carga para el forjado 3 y para los puntales bajo este forjado durante todo el proceso constructivo. Las Figuras $4.21 \mathrm{y}$ 4.22 muestran la evolución del coeficiente de carga para el forjado 4 y para los puntales bajo este forjado durante todo el proceso constructivo. Por último, las Figuras 4.23 y 4.24 muestran la evolución del coeficiente de carga para el forjado 5 y para los puntales bajo este forjado durante todo el proceso constructivo. No se muestra una evolución del coeficiente de carga en el forjado 6 y en los puntales bajo este forjado debido a que únicamente fue objeto de medición el hormigonado de dicho forjado (operación en la cual se terminó el estudio experimental). En todas las figuras se muestra tanto el coeficiente de carga obtenido a partir de los resultados del modelo de Elementos Finitos como el obtenido a partir de las medidas experimentales.

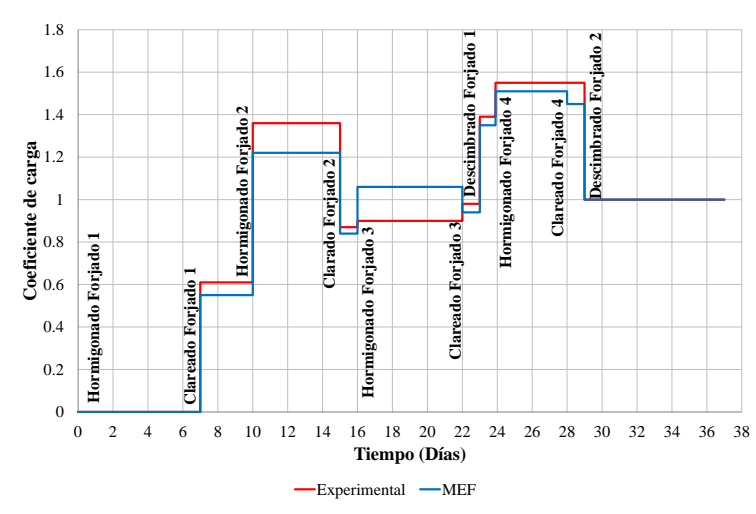

Fig. 4.15 Comparación coeficientes de carga en el forjado 1 (Forjado de losa maciza - Vano de medianera)

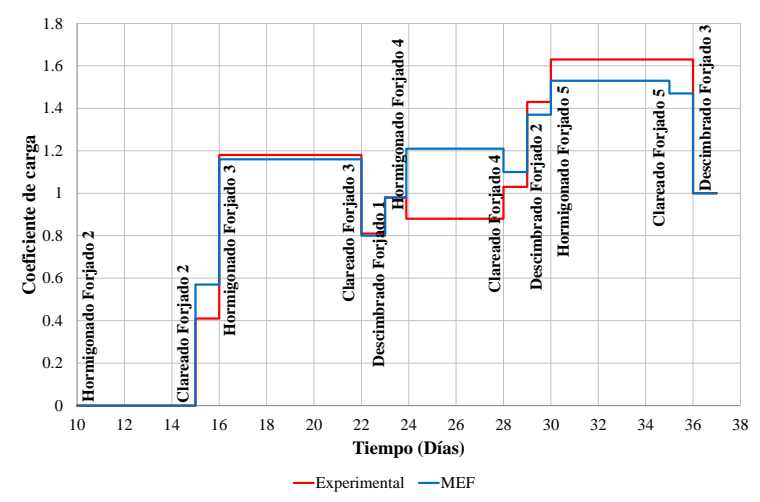

Fig. 4.17 Comparación coeficientes de carga en el forjado 2 (Forjado de losa maciza - Vano de medianera)

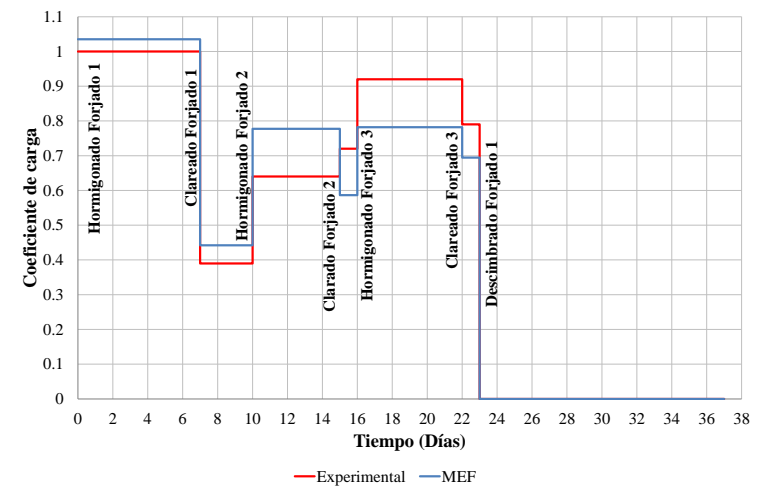

Fig. 4.16 Comparación coeficientes de carga en puntales bajo el forjado 1 (Forjado de losa maciza - Vano de medianera)

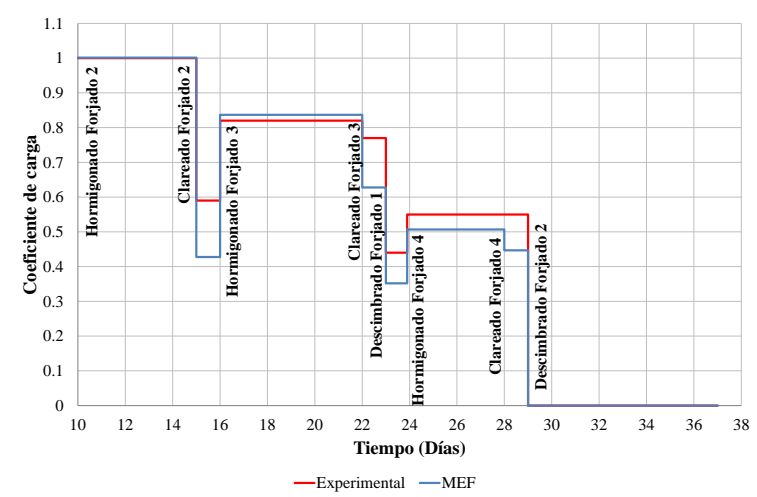

Fig. 4.18 Comparación coeficientes de carga en puntales bajo el forjado 2 (Forjado de losa maciza - Vano de medianera) 


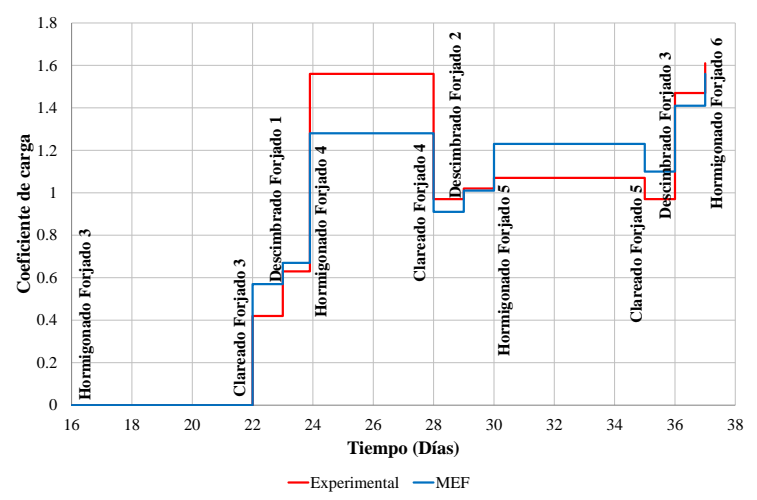

Fig. 4.19 Comparación coeficientes de carga en el forjado 3 (Forjado de losa maciza - Vano de medianera)

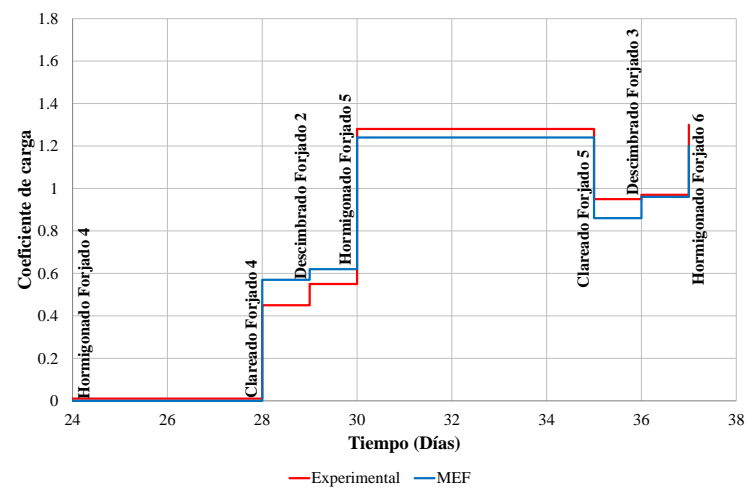

Fig. 4.21 Comparación coeficientes de carga en el forjado 4 (Forjado de losa maciza - Vano de medianera)

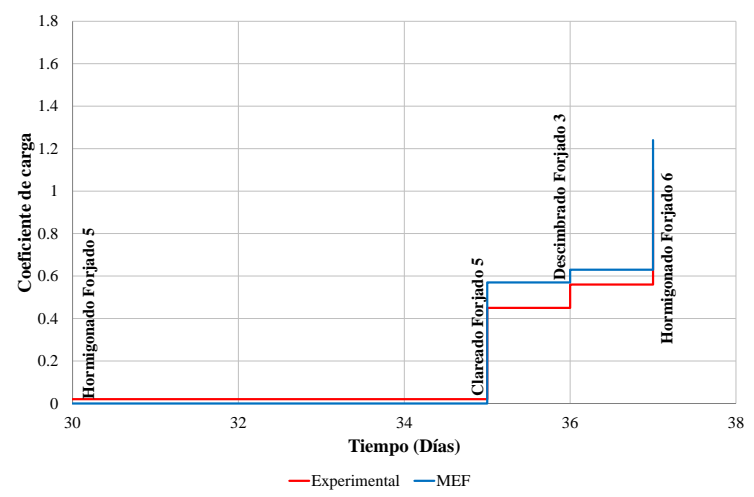

Fig. 4.23 Comparación coeficientes de carga en el forjado 5 (Forjado de losa maciza - Vano de medianera)

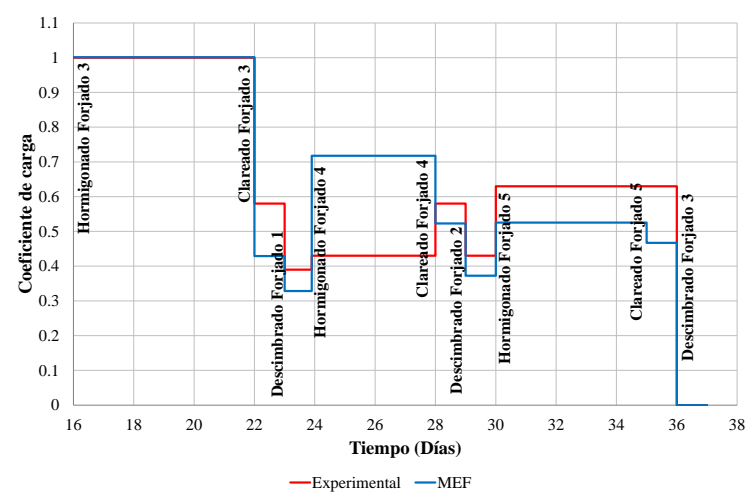

Fig. 4.20 Comparación coeficientes de carga en puntales bajo el forjado 3 (Forjado de losa maciza - Vano de medianera)

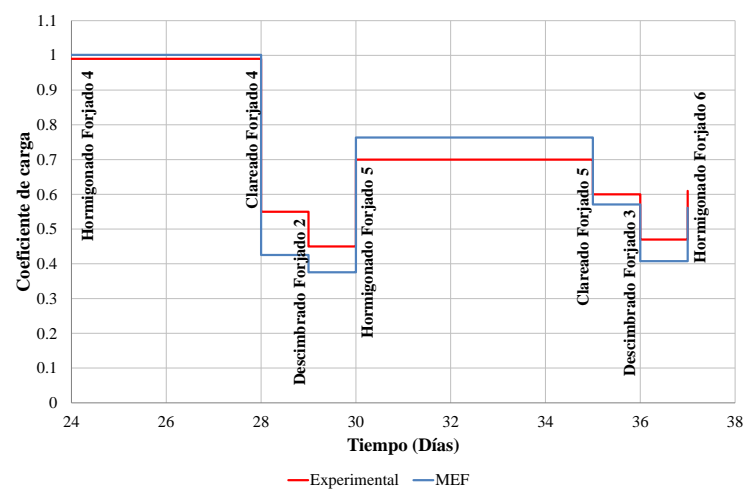

Fig. 4.22 Comparación coeficientes de carga en puntales bajo el forjado 4 (Forjado de losa maciza - Vano de medianera)

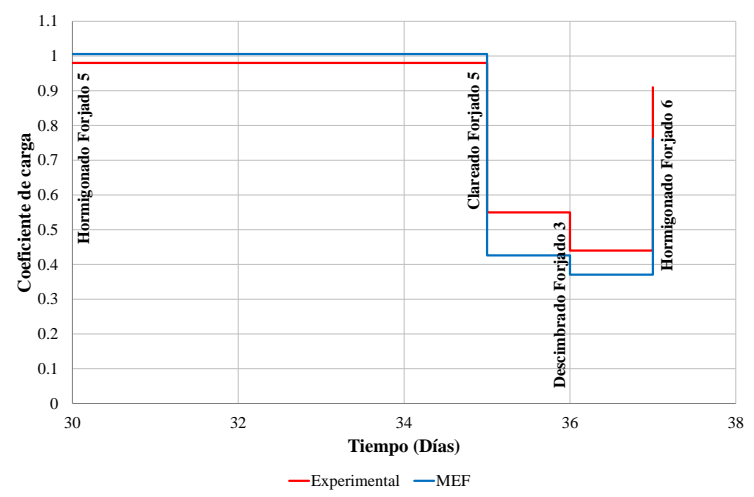

Fig. 4.24 Comparación coeficientes de carga en puntales bajo el forjado 5 (Forjado de losa maciza - Vano de medianera)

La Tabla 4.3 muestra una comparación entre los valores de la carga media en puntales obtenidos de la medición en obra $\left(q_{\text {med,exp }}\right)$ y los valores de carga media del modelo de Elementos Finitos $\left(q_{m e d, M E F}\right)$ obtenidos a partir de la carga en los puntales equivalentes a los instrumentados en obra. 
Así mismo, se comparan las cargas máximas en puntales obtenidas experimentalmente $\left(P_{\max , \text { exp }}\right)$ y a partir del modelo $\left(P_{\max , M E F}\right)$.

Tabla 4.3. Comparación entre las medidas experimentales y los resultados del modelo numérico (Forjado de losa maciza Vano de medianera)

\begin{tabular}{|c|c|c|c|c|c|c|c|c|}
\hline $\begin{array}{c}\text { Paso } \\
\text { de } \\
\text { carga }\end{array}$ & Operación & Nivel & $\begin{array}{c}\text { Experimental } \\
q_{\text {med,exp }} \\
\left(\mathrm{kN} / \mathrm{m}^{2}\right)\end{array}$ & $\begin{array}{c}\text { Numérico } \\
q_{\text {med,MEF }} \\
\left(\mathrm{kN} / \mathbf{m}^{2}\right)\end{array}$ & $\frac{q_{m e d, e x p}}{q_{m e d, M E F}}$ & $\begin{array}{c}\text { Experimental } \\
P_{\max , \exp } \\
(\mathrm{kN}) \\
\end{array}$ & $\begin{array}{c}\text { Numérico } \\
P_{\max , M E F} \\
(\mathbf{k N})\end{array}$ & $\frac{P_{\text {max }, \text { exp }}}{P_{\max , M E F}}$ \\
\hline 1 & $\begin{array}{l}\text { Hormigonado } \\
\text { forjado } 1\end{array}$ & 1 & 4.96 & 4.96 & 1.00 & 3.40 & 3.63 & 0.94 \\
\hline 2 & Clareado forjado 1 & 1 & 1.95 & 2.20 & 0.89 & 6.04 & 6.76 & 0.89 \\
\hline \multirow{2}{*}{3} & Hormigonado & 2 & 5.00 & 4.97 & 1.01 & 5.29 & 5.02 & 1.05 \\
\hline & forjado 2 & 1 & 3.17 & 3.86 & 0.82 & 10.07 & 12.89 & 0.78 \\
\hline \multirow{2}{*}{4} & \multirow{2}{*}{ Clareado forjado 2} & 2 & 2.95 & 2.12 & 1.39 & 6.87 & 6.26 & 1.10 \\
\hline & & 1 & 3.57 & 2.91 & 1.23 & 12.37 & 9.95 & 1.24 \\
\hline \multirow{3}{*}{5} & \multirow{3}{*}{$\begin{array}{l}\text { Hormigonado } \\
\text { forjado } 3\end{array}$} & 3 & 4.95 & 4.97 & 1.00 & 5.06 & 5.02 & 1.01 \\
\hline & & 2 & 4.06 & 4.15 & 0.98 & 9.22 & 12.46 & 0.74 \\
\hline & & 1 & 4.56 & 3.88 & 1.18 & 13.34 & 13.37 & 1.00 \\
\hline \multirow{3}{*}{6} & \multirow{3}{*}{ Clareado forjado 3} & 3 & 2.87 & 2.13 & 1.35 & 6.68 & 6.25 & 1.07 \\
\hline & & 2 & 3.84 & 3.12 & 1.23 & 9.79 & 9.56 & 1.02 \\
\hline & & 1 & 3.92 & 3.45 & 1.14 & 11.79 & 11.71 & 1.01 \\
\hline \multirow{2}{*}{7} & \multirow{2}{*}{$\begin{array}{l}\text { Descimbrado } \\
\text { forjado } 1\end{array}$} & 3 & 1.84 & 1.63 & 1.13 & 4.48 & 4.22 & 1.06 \\
\hline & & 2 & 1.93 & 1.75 & 1.10 & 4.42 & 4.14 & 1.07 \\
\hline \multirow{3}{*}{8} & \multirow{3}{*}{$\begin{array}{l}\text { Hormigonado } \\
\text { forjado } 4^{3}\end{array}$} & 4 & 4.91 & 4.97 & 0.99 & 5.06 & 5.02 & 1.01 \\
\hline & & 3 & 2.13 & 3.56 & 0.60 & 6.74 & 9.86 & 0.68 \\
\hline & & 2 & 2.73 & 2.52 & 1.08 & 6.44 & 6.48 & 0.99 \\
\hline \multirow{3}{*}{9} & \multirow{3}{*}{ Clareado forjado 4} & 4 & 2.72 & 2.11 & 1.29 & 8.14 & 6.11 & 1.33 \\
\hline & & 3 & 2.88 & 2.60 & 1.11 & 7.74 & 7.28 & 1.06 \\
\hline & & 2 & 2.73 & 2.22 & 1.23 & 5.96 & 5.46 & 1.09 \\
\hline \multirow{2}{*}{10} & \multirow{2}{*}{$\begin{array}{l}\text { Descimbrado } \\
\text { forjado } 2\end{array}$} & 3 & 2.23 & 1.86 & 1.20 & 5.10 & 5.25 & 0.97 \\
\hline & & 2 & 2.13 & 1.85 & 1.15 & 5.20 & 4.76 & 1.09 \\
\hline \multirow{3}{*}{11} & \multirow{3}{*}{$\begin{array}{l}\text { Hormigonado } \\
\text { forjado } 5\end{array}$} & 5 & 4.87 & 4.99 & 0.98 & 5.06 & 5.05 & 1.00 \\
\hline & & 4 & 3.47 & 3.79 & 0.92 & 7.04 & 10.85 & 0.65 \\
\hline & & 3 & 3.12 & 2.61 & 1.20 & 9.72 & 7.06 & 1.38 \\
\hline \multirow{3}{*}{12} & \multirow{3}{*}{ Clareado forjado $5^{3}$} & 5 & 2.75 & 2.11 & 1.30 & 6.63 & 6.11 & 1.09 \\
\hline & & 4 & 2.98 & 2.83 & 1.05 & 6.24 & 8.33 & 0.75 \\
\hline & & 3 & 3.12 & 2.32 & 1.34 & 8.64 & 6.10 & 1.42 \\
\hline \multirow{2}{*}{13} & \multirow{2}{*}{$\begin{array}{l}\text { Descimbrado } \\
\text { forjado } 3\end{array}$} & 5 & 2.18 & 1.84 & 1.18 & 5.14 & 5.14 & 1.00 \\
\hline & & 4 & 2.33 & 2.02 & 1.15 & 5.63 & 5.53 & 1.02 \\
\hline \multirow{3}{*}{14} & \multirow{3}{*}{$\begin{array}{l}\text { Hormigonado } \\
\text { forjado } 6\end{array}$} & 6 & 5.00 & 4.97 & 1.01 & 5.03 & 5.02 & 1.00 \\
\hline & & 5 & 4.51 & 3.78 & 1.19 & 10.52 & 10.79 & 0.97 \\
\hline & & 4 & 3.03 & 2.78 & 1.09 & 9.32 & 7.86 & 1.19 \\
\hline- & Media & - & - & - & 1.11 & - & - & 1.02 \\
\hline- & Desviación Típica & - & - & - & 0.16 & - & - & 0.17 \\
\hline
\end{tabular}

\footnotetext{
${ }^{3}$ Operaciones constructivas en las que el proceso constructivo sufrió algún tipo de alteración por necesidades de la obra.
} 


\subsubsection{Resumen}

Se puede apreciar que la media de la relación $q_{\text {med,exp }} / q_{\text {med,MEF }}$ de todas las operaciones es de 1.07 con una desviación típica de 0.19 , para el vano de esquina, y de 1.11 con una desviación típica de 0.16 para el vano de medianera.

Las diferencias más significativas se observan en el hormigonado y clareado del forjado 4 , y en el clareado del forjado 5. Esto es debido a que en las operaciones constructivas del hormigonado del forjado 4 y del clareado del forjado 5 , el proceso constructivo sufrió algunas alteraciones por necesidades de obra.

En el hormigonado del forjado 4 se aflojaron y retiraron momentáneamente algunos de los puntales de forjado 3 debido al tránsito de material en obra. Esto produce un descenso en la solicitación de carga en el forjado 2 al hormigonar el forjado 4.

En el clareado del forjado 5, los puntales del forjado 3 fueron apretados debido a que se detectó que los puntales de una sopanda se encontraban poco ajustados. Esto conlleva a un aumento de carga en los puntales del forjado 3 .

Este tipo de operaciones no previstas dentro del proceso constructivo modifican notablemente la transmisión esperada de cargas entre forjados y puntales.

Además, se comparan los valores de la carga máxima en puntales de las medidas experimentales y de los resultados del modelo de EF. La media de la relación $P_{\max , \exp } / P_{\max , M E F}$ del total de las fases de construcción es de 1.04 con una desviación típica de 0.20 , para el caso del vano de esquina, y de 1.02 con una desviación típica de 0.17 , para el vano de medianera.

\subsubsection{Comparación de los resultados de los puntales de la sopanda con los de la totalidad de puntales del vano en el FEM}

En el MEF se pueden extraer los resultados tanto de los puntales de la sopanda monitorizada en obra, como del conjunto de puntales del vano. Esto permite comparar ambos resultados y comprobar si los valores obtenidos para la sopanda son representativos del vano completo.

En la Tabla 4.4 se muestran, para ambos vanos, los resultados del modelo numérico obtenidos considerando sólo los puntales monitorizados $\left(\boldsymbol{q}_{\mathbf{m e d}, \mathbf{M E F}}\right)$ y los correspondientes a la totalidad de los puntales del vano $\left(\boldsymbol{q}_{\boldsymbol{m e d}, \boldsymbol{M E F} 2}\right)$, así como la comparación entre ambos. 
Tabla 4.4. Comparación entre los resultados del modelo numérico considerando sólo los puntales monitorizados y los correspondientes a la totalidad de puntales del vano.

\begin{tabular}{|c|c|c|c|c|c|c|c|c|}
\hline \multirow[b]{2}{*}{$\begin{array}{c}\text { Paso } \\
\text { de } \\
\text { carga }\end{array}$} & \multirow[b]{2}{*}{ Operación } & \multirow[b]{2}{*}{ Nivel } & \multicolumn{3}{|c|}{ Vano de esquina } & \multicolumn{3}{|c|}{ Vano de medianera } \\
\hline & & & $\begin{array}{c}\text { Numérico } \\
q_{\text {med,MEF }} \\
\left(\mathrm{kN} / \mathrm{m}^{2}\right)\end{array}$ & $\begin{array}{c}\text { Numérico } \\
q_{m e d, M E F 2} \\
\left(\mathrm{kN} / \mathrm{m}^{2}\right.\end{array}$ & $\frac{q_{m e d, F E M}}{q_{m e d, M E F 2}}$ & $\begin{array}{c}\text { Numérico } \\
q_{m e d, M E F} \\
\left(\mathrm{kN} / \mathbf{m}^{2}\right)\end{array}$ & $\begin{array}{c}\text { Numérico } \\
q_{m e d, M E F 2} \\
\left(\mathrm{kN} / \mathrm{m}^{2}\right.\end{array}$ & $\frac{q_{m e d, F E M}}{q_{m e d, M E F 2}}$ \\
\hline 1 & $\begin{array}{l}\text { Hormigonado } \\
\text { forjado } 1\end{array}$ & 1 & 4.96 & 4.86 & 1.06 & 4.96 & 4.76 & 1.08 \\
\hline 2 & Clareado forjado 1 & 1 & 1.84 & 2.14 & 0.86 & 2.20 & 2.21 & 0.99 \\
\hline 3 & $\begin{array}{l}\text { Hormigonado } \\
\text { forjado } 2\end{array}$ & $\begin{array}{l}2 \\
1\end{array}$ & $\begin{array}{l}4.85 \\
3.69\end{array}$ & $\begin{array}{l}4.87 \\
4.27\end{array}$ & $\begin{array}{l}1.00 \\
0.86\end{array}$ & $\begin{array}{l}4.97 \\
3.86\end{array}$ & $\begin{array}{l}4.91 \\
4.50\end{array}$ & $\begin{array}{l}1.01 \\
0.86\end{array}$ \\
\hline 4 & Clareado forjado 2 & $\begin{array}{l}2 \\
1\end{array}$ & $\begin{array}{l}1.77 \\
2.70\end{array}$ & $\begin{array}{l}1.97 \\
3.19\end{array}$ & $\begin{array}{l}0.90 \\
0.84\end{array}$ & $\begin{array}{l}2.12 \\
2.91\end{array}$ & $\begin{array}{l}2.02 \\
3.46\end{array}$ & $\begin{array}{l}1.05 \\
0.84\end{array}$ \\
\hline 5 & $\begin{array}{l}\text { Hormigonado } \\
\text { forjado } 3\end{array}$ & $\begin{array}{l}3 \\
2 \\
1\end{array}$ & $\begin{array}{l}4.85 \\
3.50 \\
3.53 \\
\end{array}$ & $\begin{array}{l}4.87 \\
3.90 \\
4.23\end{array}$ & $\begin{array}{l}1.00 \\
0.90 \\
0.84\end{array}$ & $\begin{array}{l}4.97 \\
4.15 \\
3.88 \\
\end{array}$ & $\begin{array}{l}4.91 \\
4.08 \\
4.61\end{array}$ & $\begin{array}{l}1.01 \\
1.02 \\
0.84 \\
\end{array}$ \\
\hline 6 & Clareado forjado 3 & $\begin{array}{l}3 \\
2 \\
1\end{array}$ & $\begin{array}{l}1.79 \\
2.58 \\
3.16\end{array}$ & $\begin{array}{l}1.97 \\
2.94 \\
3.74\end{array}$ & $\begin{array}{l}0.91 \\
0.88 \\
0.84\end{array}$ & $\begin{array}{l}2.13 \\
3.12 \\
3.45\end{array}$ & $\begin{array}{l}2.07 \\
3.13 \\
4.08\end{array}$ & $\begin{array}{l}1.03 \\
1.00 \\
0.84\end{array}$ \\
\hline 7 & $\begin{array}{l}\text { Descimbrado } \\
\text { forjado } 1\end{array}$ & $\begin{array}{l}3 \\
2\end{array}$ & $\begin{array}{l}1.51 \\
1.71\end{array}$ & $\begin{array}{l}1.49 \\
1.58\end{array}$ & $\begin{array}{l}1.01 \\
1.08\end{array}$ & $\begin{array}{l}1.63 \\
1.75\end{array}$ & $\begin{array}{l}1.51 \\
1.59\end{array}$ & $\begin{array}{l}1.08 \\
1.10\end{array}$ \\
\hline 8 & $\begin{array}{l}\text { Hormigonado } \\
\text { forjado } 4\end{array}$ & $\begin{array}{l}4 \\
3 \\
2 \\
\end{array}$ & $\begin{array}{l}4.85 \\
3.16 \\
2.37 \\
\end{array}$ & $\begin{array}{l}4.87 \\
3.28 \\
2.32 \\
\end{array}$ & $\begin{array}{l}1.00 \\
0.96 \\
1.02 \\
\end{array}$ & $\begin{array}{l}4.97 \\
3.56 \\
2.52 \\
\end{array}$ & $\begin{array}{l}4.91 \\
3.40 \\
2.40 \\
\end{array}$ & $\begin{array}{l}1.01 \\
1.05 \\
1.05\end{array}$ \\
\hline 9 & Clareado forjado 4 & $\begin{array}{l}4 \\
3 \\
2\end{array}$ & $\begin{array}{l}1.75 \\
2.29 \\
2.13\end{array}$ & $\begin{array}{l}1.95 \\
2.41 \\
2.03\end{array}$ & $\begin{array}{l}0.90 \\
0.95 \\
1.05\end{array}$ & $\begin{array}{l}2.11 \\
2.60 \\
2.22\end{array}$ & $\begin{array}{l}1.99 \\
2.55 \\
2.09\end{array}$ & $\begin{array}{l}1.06 \\
1.02 \\
1.06\end{array}$ \\
\hline 10 & $\begin{array}{l}\text { Descimbrado } \\
\text { forjado } 2\end{array}$ & $\begin{array}{l}3 \\
2\end{array}$ & $\begin{array}{l}1.59 \\
1.74 \\
\end{array}$ & $\begin{array}{l}1.70 \\
1.71 \\
\end{array}$ & $\begin{array}{l}0.94 \\
1.02\end{array}$ & $\begin{array}{l}1.86 \\
1.85\end{array}$ & $\begin{array}{l}1.77 \\
1.76 \\
\end{array}$ & $\begin{array}{l}1.05 \\
1.05\end{array}$ \\
\hline 11 & $\begin{array}{l}\text { Hormigonado } \\
\text { forjado } 5\end{array}$ & $\begin{array}{l}5 \\
4 \\
3\end{array}$ & $\begin{array}{l}4.92 \\
3.22 \\
2.39\end{array}$ & $\begin{array}{l}4.80 \\
3.49 \\
2.44\end{array}$ & $\begin{array}{l}1.02 \\
0.92 \\
0.98\end{array}$ & $\begin{array}{l}4.99 \\
3.79 \\
2.61\end{array}$ & $\begin{array}{l}4.90 \\
3.64 \\
2.57\end{array}$ & $\begin{array}{l}1.02 \\
1.04 \\
1.01\end{array}$ \\
\hline 12 & Clareado forjado 5 & $\begin{array}{l}5 \\
4 \\
3 \\
\end{array}$ & $\begin{array}{l}1.76 \\
2.37 \\
2.15 \\
\end{array}$ & $\begin{array}{l}1.95 \\
2.63 \\
2.16 \\
\end{array}$ & $\begin{array}{l}0.90 \\
0.90 \\
1.00\end{array}$ & $\begin{array}{l}2.11 \\
2.83 \\
2.32\end{array}$ & $\begin{array}{l}1.99 \\
2.87 \\
2.27\end{array}$ & $\begin{array}{l}1.06 \\
1.01 \\
1.02\end{array}$ \\
\hline 13 & $\begin{array}{l}\text { Descimbrado } \\
\text { forjado } 3\end{array}$ & $\begin{array}{l}5 \\
4\end{array}$ & $\begin{array}{l}1.60 \\
1.80\end{array}$ & $\begin{array}{l}1.69 \\
1.88\end{array}$ & $\begin{array}{l}0.94 \\
0.96\end{array}$ & $\begin{array}{l}1.84 \\
2.02\end{array}$ & $\begin{array}{l}1.75 \\
1.96\end{array}$ & $\begin{array}{l}1.05 \\
1.03\end{array}$ \\
\hline 14 & $\begin{array}{l}\text { Hormigonado } \\
\text { forjado } 6\end{array}$ & $\begin{array}{l}6 \\
5 \\
4\end{array}$ & $\begin{array}{l}4.85 \\
3.25 \\
2.45 \\
\end{array}$ & $\begin{array}{l}4.87 \\
3.49 \\
2.62 \\
\end{array}$ & $\begin{array}{l}1.00 \\
0.93 \\
0.94 \\
\end{array}$ & $\begin{array}{l}4.97 \\
3.78 \\
2.78 \\
\end{array}$ & $\begin{array}{l}4.91 \\
3.65 \\
2.77 \\
\end{array}$ & $\begin{array}{l}1.01 \\
1.03 \\
1.01 \\
\end{array}$ \\
\hline- & Media & - & - & - & 0.95 & - & - & 1.01 \\
\hline- & Desviación Típica & - & - & - & 0.07 & - & - & 0.07 \\
\hline
\end{tabular}

Tal y como muestra la tabla anterior, la media de la relación $\boldsymbol{q}_{\boldsymbol{m e d , M E F}} / \boldsymbol{q}_{\boldsymbol{m e d}, \boldsymbol{M E F 2}}$ de todas las operaciones en el vano de esquina es de 0.95 con una desviación típica de 0.07 , mientras que en el vano de medianera la media es de 1.01 con la misma desviación típica. Estos los resultados permiten concluir que la carga media de la sopanda se puede asimilar como la carga media del vano, tanto en el vano de esquina como en el de medianera. 


\subsection{Modelo numérico del edificio de forjado reticular de casetón recuperable}

Al igual que para la realización del modelo numérico del edificio de losa maciza, se ha utilizado el software comercial ANSYS 11.0 (2006) para la modelización de este edificio y su proceso constructivo descrito en el capítulo anterior (véase apartado 3.4 de la presente tesis). Se asume un cálculo no lineal, evolutivo que considera tanto las fases constructivas como la variación de las características mecánicas de hormigón durante cada etapa constructiva.

Debido a las dimensiones de la obra, y puesto que el análisis experimental comprende únicamente un vano de esquina y su contiguo de medianera, se ha optado por modelizar únicamente una parte del edificio. La continuidad del forjado se ha simulado mediante voladizos que producen, en la línea de pilares, un momento flector similar al que se produce, por los vanos adyacentes, en la realidad. En la Figura 4.25a y 4.25b se observa una sección del edificio completo modelizado y una planta tipo, respectivamente.

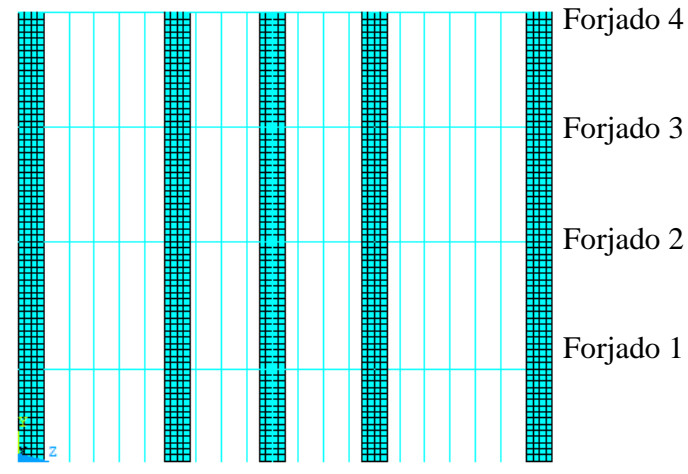

(a)

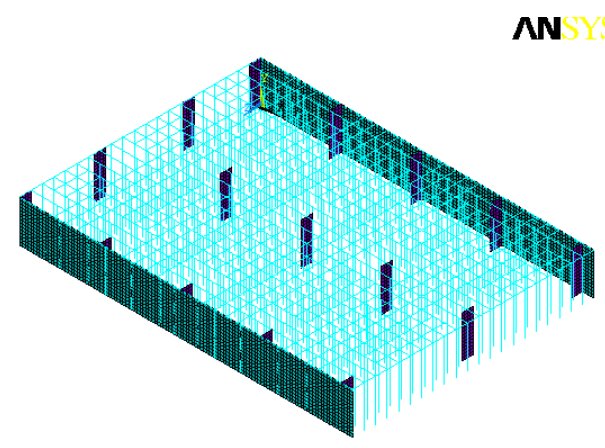

(b)

Fig. 4.25 Modelo de Elementos Finitos del edificio de forjado reticular de casetón recuperable: (a) Sección (b) Forjado tipo

\subsubsection{Hipótesis consideradas}

El proceso constructivo se ha modelizado siguiendo las fases constructivas indicadas en el capítulo anterior (véase apartado 3.4.3), mientras que las características geométricas de los elementos que forman el modelo experimental son las descritas en el apartado 3.4.1.

Las hipótesis adoptadas para realizar el modelo de EF son:

$\checkmark$ Se asume un comportamiento elástico y lineal del forjado de hormigón armado, considerando la variación de su rigidez en el tiempo.

$\checkmark$ Los pilares se simulan con un comportamiento elástico y lineal, y se considera la variación de su rigidez con respecto al tiempo. Los pilares de planta baja se consideran empotrados en su base.

$\checkmark$ Los puntales de acero son asimilados como soportes elásticos con una rigidez finita. Los puntales situados bajo planta baja tienen una sección transversal de $364 \mathrm{~mm}^{2}$, mientras que la sección 
transversal de los situados en el resto de plantas es de $289 \mathrm{~mm}^{2}$. En todos los casos el módulo de elasticidad de los puntales es de $210 \mathrm{GPa}$

$\checkmark$ Los tableros de encofrado son de madera, con un espesor de $27 \mathrm{~mm}$ y un módulo de elasticidad de $10 \mathrm{GPa}$. Estos tableros son considerados como elementos con un comportamiento elástico y lineal $\mathrm{y}$ de rigidez finita.

$\checkmark$ La cimentación se considera infinitamente rígida.

No se consideran los efectos de fluencia y retracción en el hormigón, ni los cambios de temperatura en los diferentes elementos de la estructura. Se considera que esta hipótesis es válida ya que se analizan los incrementos de carga producidos en cada fase constructiva, siendo cada una de éstas de corta duración.

\subsubsection{Descripción del modelo de Elementos Finitos}

Al igual que el modelo de EF del edificio de forjado de losa maciza, se utilizó el software comercial ANSYS 11.0 (2006) para la realización del modelo, utilizando EF tipo SHELL, BEAM y LINK (ANSYS, 2006).

Para modelizar los forjados reticulares se ha empleado la teoría del emparrillado espacial, siguiendo las recomendaciones de Regalado (2003), tanto para los nervios del forjado como para los ábacos. La sección considerada para los nervios del emparrillado es la que se muestra en la Figura 4.26. Para la zona de los ábacos se ha considerado que las barras son de sección rectangular de $0.80 \mathrm{~m}$ de ancho y $0.40 \mathrm{~m}$ de canto, mientras que las vigas perimetrales tienen una sección de 0.40 x $0.40 \mathrm{~m}$.

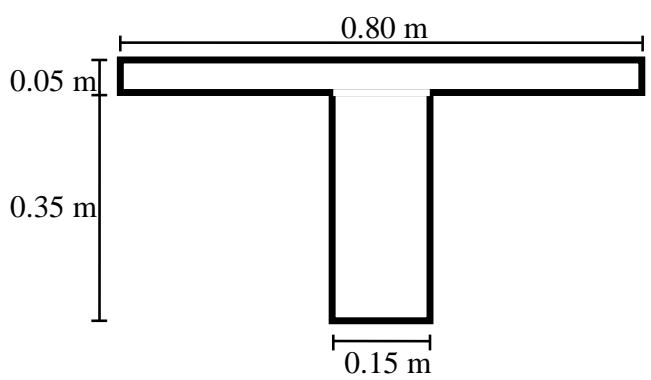

Fig. 4.26 Sección correspondiente a los nervios del emparrillado.

\subsubsection{Tipos de EF y mallado empleado}

Se han utilizado los mismos elementos que los descritos en el apartado 4.2.2.1. para el modelo numérico del edificio de forjado de losa maciza, empleando en este caso el elemento finito BEAM188 para la modelación de los nervios, ábacos y paneles de encofrado. Los puntales de acero se modelizan mediante elementos LINK10 y para modelizar los pilares apantallados de hormigón se emplean elementos SHELL63. El muro de sótano, al igual que los pilares apantallados, se modeliza mediante elementos SHELL63. 
El tamaño de la malla de los forjados está condicionado por sus dimensiones y por la distribución de los componentes del sistema de cimbrado y encofrado. Buscando obtener un grado de aproximación adecuado, el tamaño de malla de EF para los elementos de emparrillado del forjado es de $0.20 \mathrm{~m}$, al igual que para los elementos del encofrado. Para los elementos del muro, así como para los pilares apantallados, el tamaño de la malla es de $0.20 \times 0.20 \mathrm{~m}^{2}$.

\subsubsection{Simulación del proceso constructivo}

Tal y como se describe en el apartado 4.2.2.2 de la presente Tesis Doctoral, ANSYS 11.0 permite considerar la variación en el tiempo de las características mecánicas del hormigón y de las condiciones de apoyo de los distintos elementos al realizar un cálculo evolutivo a través de diferentes pasos de carga.

El módulo de elasticidad del hormigón se estima de acuerdo con la formulación propuesta en la Instrucción de Hormigón Estructural EHE-08 (2008). El Apéndice III muestra el proceso de cálculo del módulo elástico.

Los distintos pasos de carga considerados en el modelo de Elementos Finitos son los siguientes:

- Paso de carga 1: Hormigonado del forjado 1. El cálculo de este paso de carga consiste en dejar activados únicamente los elementos del forjado 1 con su sistema de cimbrado, desactivando los elementos de los forjados superiores, incluidos los puntales y encofrado.

- Paso de carga 2: Clareado del forjado 1. En este paso de carga se desactivan los elementos del encofrado y los puntales correspondientes a las sopandas intermedias correspondientes al sistema de cimbrado del forjado 1.

- Paso de carga 3: Hormigonado del forjado 2. En el paso de carga 3 se activan el conjunto de elementos del forjado 2 incluidos pilares, encofrado y puntales.

- Paso de carga 4: Clareado del forjado 2. Para el cálculo de este paso de carga se desactivan el encofrado y los puntales correspondientes a las sopandas intermedias del sistema de cimbrado del forjado 2 .

- Paso de carga 5: Descimbrado del forjado 1. En este paso de carga se desactivan los puntales situados bajo el forjado 1, quedando únicamente los puntales correspondientes a las sopandas principales situados bajo el forjado 2 .

- Paso de carga 6: Hormigonado del forjado 3. Partiendo del paso de carga 5, en este paso de carga se activan los elementos del forjado 3 , incluyendo el sistema de apuntalamiento.

- Paso de carga 7: Clareado del forjado 3. Para realizar este paso de carga, se desactivan los puntales correspondientes a las sopandas intermedias así como el encofrado del sistema de cimbrado del forjado 3 .

- Paso de carga 8: Descimbrado del forjado 2. Para simular el descimbrado del forjado 2 se desactivan los puntales bajo el forjado 2 . 
- Paso de carga 9: Hormigonado del forjado 4. En el paso de carga 9 se activan los elementos del forjado 4 incluyendo sus pilares y su sistema de cimbrado (encofrado y puntales).

En la Tabla 4.5 se muestran las edades del hormigón y los módulos de elasticidad correspondientes para cada uno de los pasos de carga. Se considera una temperatura media en obra de $22^{\circ} \mathrm{C}$.

Tabla 4.5. Edades del hormigón y módulos elásticos ${ }^{4}$ para cada paso de carga (modelo del edificio de forjado reticular de casetón recuperable).

\begin{tabular}{|c|c|c|c|c|c|}
\hline \multirow{2}{*}{ Paso de carga } & \multirow{2}{*}{ Nivel } & \multicolumn{2}{|c|}{ Forjado } & \multicolumn{2}{|c|}{ Pilares } \\
\hline & & Edad (días) & $\mathbf{E}_{\mathrm{c}, \mathrm{t}, \mathrm{f}}(\mathbf{G P a})$ & Edad (días) & 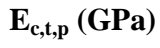 \\
\hline 1 & 1 & 0 & 0.00 & 12 & 27.32 \\
\hline 2 & 1 & 7 & 26.69 & 19 & 28.24 \\
\hline \multirow{2}{*}{3} & 2 & 0 & 0.00 & 11 & 27.32 \\
\hline & 1 & 17 & 28.10 & 29 & 28.67 \\
\hline \multirow{2}{*}{4} & 2 & 7 & 26.69 & 18 & 28.17 \\
\hline & 1 & 24 & 28.51 & 36 & 28.67 \\
\hline \multirow{2}{*}{5} & 2 & 7 & 26.69 & 18 & 28.17 \\
\hline & 1 & 24 & 28.51 & 36 & 28.67 \\
\hline \multirow{3}{*}{6} & 3 & 0 & 0.00 & 13 & 27.73 \\
\hline & 2 & 15 & 27.93 & 26 & 28.59 \\
\hline & 1 & 32 & 28.67 & 44 & 28.67 \\
\hline \multirow{3}{*}{7} & 3 & 5 & 26.00 & 18 & 28.17 \\
\hline & 2 & 20 & 28.30 & 31 & 28.67 \\
\hline & 1 & 37 & 28.67 & 49 & 28.67 \\
\hline \multirow{3}{*}{8} & 3 & 6 & 26.38 & 19 & 28.24 \\
\hline & 2 & 21 & 28.38 & 32 & 28.67 \\
\hline & 1 & 38 & 28.67 & 50 & 28.67 \\
\hline \multirow{4}{*}{9} & 4 & 0 & 0.00 & 10 & 27.32 \\
\hline & 3 & 17 & 28.10 & 30 & 28.67 \\
\hline & 2 & 32 & 28.67 & 43 & 28.67 \\
\hline & 1 & 49 & 28.67 & 61 & 28.67 \\
\hline
\end{tabular}

\subsubsection{Análisis de resultados del modelo y comparación con las medidas experimentales}

Puesto que únicamente se instrumentó una sopanda por cada vano, para realizar la comparación con las mediciones experimentales, del modelo de Elementos Finitos se han extraído únicamente los resultados correspondientes a los puntales que están situados en las mismas sopandas donde estaban los puntales instrumentados.

A continuación se muestra un resumen de los resultados obtenidos con el modelo de Elementos Finitos, validándolos con las mediciones del modelo experimental expuestas en el capítulo anterior (apartado 3.2.4).

\footnotetext{
${ }^{4}$ Para edades del hormigón superiores a 28 días se considera un módulo elástico igual al considerado a los 28 días.
} 


\subsubsection{Vano de esquina}

Las Figuras 4.27 y 4.28 muestran la evolución del coeficiente de carga para el forjado 1 y para los puntales bajo este forjado durante todo el proceso constructivo. Las Figuras 4.29 y 4.30 muestran la evolución del coeficiente de carga para el forjado 2 y para los puntales bajo este forjado durante todo el proceso constructivo. Por último, las Figuras 4.31 y 4.32 muestran la evolución del coeficiente de carga para el forjado 3 y para los puntales bajo este forjado durante todo el proceso constructivo. No se muestra una evolución del coeficiente de carga en el forjado 4 y en los puntales bajo este forjado debido a que únicamente fue objeto de medición el hormigonado de dicho forjado (operación en la cual se terminó el estudio experimental). En todas las figuras se muestra una tanto el coeficiente de carga obtenido a partir de los resultados del modelo de Elementos Finitos como el obtenido a partir de las medidas experimentales.

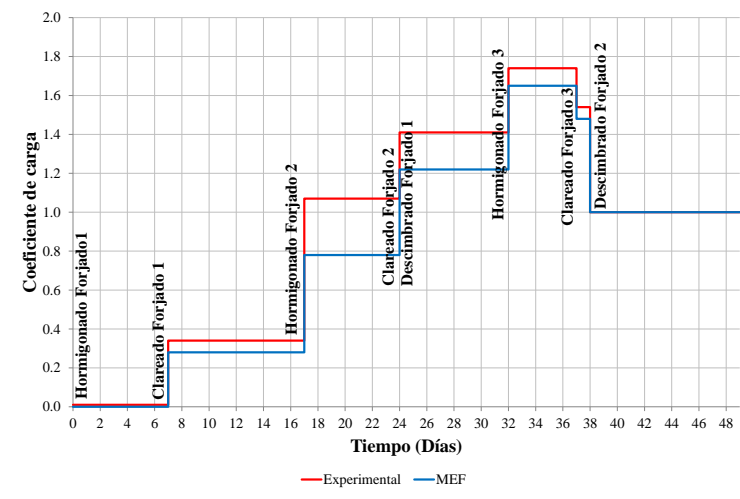

Fig. 4.27 Comparación coeficientes de carga en el forjado 1 (Forjado reticular de casetón recuperable - Vano de esquina)

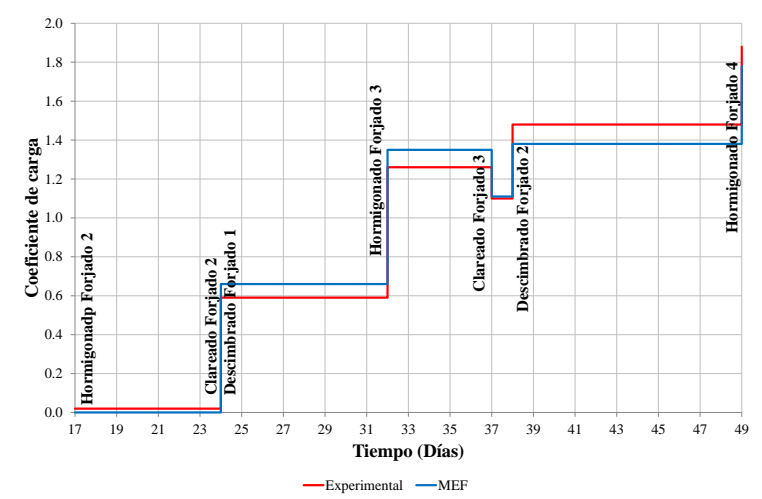

Fig. 4.29 Comparación coeficientes de carga en el forjado 2 (Forjado reticular de casetón recuperable - Vano de esquina)

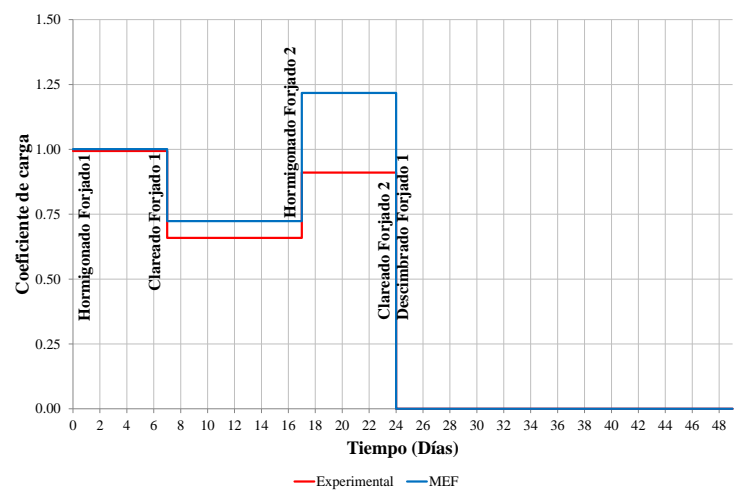

Fig. 4.28 Comparación coeficientes de carga en puntales bajo el forjado 1 (Forjado reticular de casetón recuperable Vano de esquina)

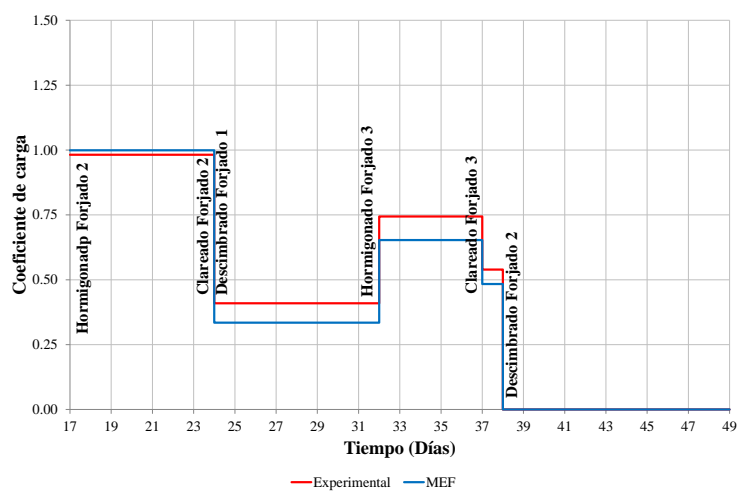

Fig. 4.30 Comparación coeficientes de carga en puntales bajo el forjado 2 (Forjado reticular de casetón recuperable Vano de esquina) 


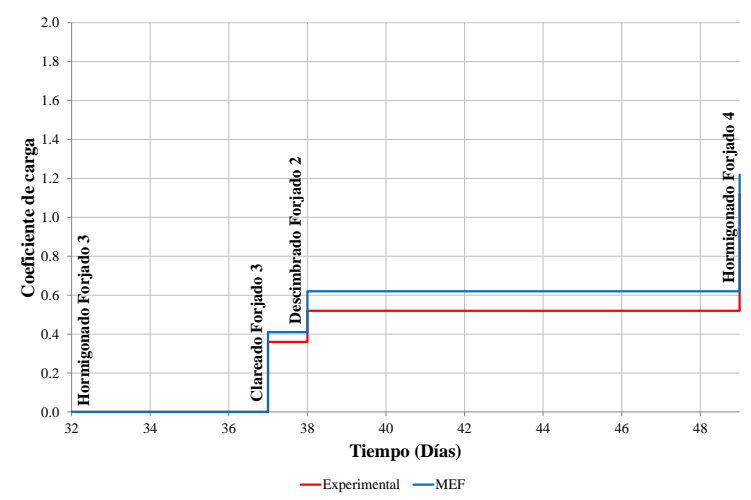

Fig. 4.31 Comparación coeficientes de carga en el forjado 3 (Forjado reticular de casetón recuperable - Vano de esquina)

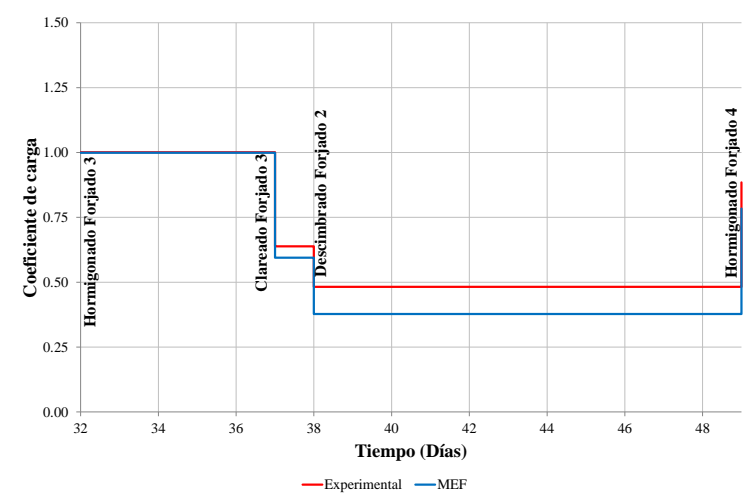

Fig. 4.32 Comparación coeficientes de carga en puntales bajo el forjado 3 (Forjado reticular de casetón recuperable Vano de esquina)

La Tabla 4.6 muestra una comparación entre los valores de la carga media en puntales obtenidos de la medición en obra $\left(q_{\text {med,exp }}\right)$ y los valores de carga media del modelo de Elementos Finitos $\left(q_{m e d, M E F}\right)$ obtenidos a partir de la carga en los puntales equivalentes a los instrumentados en obra. Así mismo, se comparan las cargas máximas en puntales obtenidas experimentalmente $\left(P_{\text {max,exp }}\right)$ y a partir del modelo $\left(P_{\max , M E F}\right)$.

Tabla 4.6. Comparación entre las medidas experimentales y los resultados del modelo numérico (Forjado reticular de casetón recuperable - Vano de esquina)

\begin{tabular}{|c|c|c|c|c|c|c|c|c|}
\hline $\begin{array}{c}\text { Paso } \\
\text { de } \\
\text { carga }\end{array}$ & Operación & Nivel & $\begin{array}{c}\text { Experimental } \\
q_{\text {med,exp }} \\
\left(\mathrm{kN} / \mathrm{m}^{2}\right) \\
\end{array}$ & $\begin{array}{c}\text { Numérico } \\
q_{\text {med,MEF }} \\
\left(\mathrm{kN} / \mathrm{m}^{2}\right) \\
\end{array}$ & $\frac{q_{m e d, e x p}}{q_{m e d, M E F}}$ & $\begin{array}{c}\text { Experimental } \\
P_{\max , \exp } \\
(\mathrm{kN}) \\
\end{array}$ & $\begin{array}{c}\text { Numérico } \\
P_{\max , M E F} \\
(\mathbf{k N})\end{array}$ & $\frac{P_{\text {max }, \text { exp }}}{P_{\max , M E F}}$ \\
\hline 1 & $\begin{array}{l}\text { Hormigonado } \\
\text { forjado } 1\end{array}$ & 1 & 5.73 & 5.77 & 0.99 & 4.80 & 4.74 & 1.01 \\
\hline 2 & Clareado forjado 1 & 1 & 3.80 & 4.17 & 0.91 & 7.19 & 7.66 & 0.94 \\
\hline \multirow{2}{*}{3} & Hormigonado & 2 & 5.66 & 5.76 & 0.98 & 7.00 & 4.74 & 1.48 \\
\hline & forjado 2 & 1 & 5.25 & 7.02 & 0.75 & 9.44 & 12.95 & 0.73 \\
\hline \multirow{2}{*}{4} & \multirow{2}{*}{ Clareado forjado $2^{5}$} & 2 & - & 3.92 & - & - & 7.18 & - \\
\hline & & 1 & - & 7.24 & - & - & 13.88 & - \\
\hline 5 & $\begin{array}{l}\text { Descimbrado } \\
\text { forjado } 1\end{array}$ & 2 & 2.36 & 1.93 & 1.22 & 5.65 & 3.29 & 1.71 \\
\hline \multirow{2}{*}{6} & Hormigonado & 3 & 5.77 & 5.76 & 1.00 & 4.97 & 4.74 & 1.05 \\
\hline & forjado 3 & 2 & 4.29 & 3.77 & 1.14 & 8.65 & 5.89 & 1.47 \\
\hline \multirow{2}{*}{7} & \multirow{2}{*}{ Clareado forjado 3} & 3 & 3.68 & 3.43 & 1.07 & 7.86 & 5.76 & 1.36 \\
\hline & & 2 & 3.11 & 2.79 & 1.12 & 5.16 & 4.28 & 1.21 \\
\hline 8 & $\begin{array}{l}\text { Descimbrado } \\
\text { forjado } 2\end{array}$ & 3 & 2.78 & 2.18 & 1.28 & 6.26 & 3.61 & 1.73 \\
\hline \multirow{2}{*}{9} & Hormigonado & 4 & 5.75 & 5.76 & 1.00 & 4.90 & 4.74 & 1.03 \\
\hline & forjado 4 & 3 & 5.10 & 4.52 & 1.13 & 10.72 & 7.71 & 1.39 \\
\hline- & Media & - & - & - & 1.05 & - & - & 1.25 \\
\hline- & Desviación Típica & - & - & - & 0.14 & - & - & 0.30 \\
\hline
\end{tabular}

\footnotetext{
${ }^{5}$ No se presentan datos experimentales del Clareado del Forjado 2, puesto que esta operación se realizó conjuntamente con el Descimbrado del Forjado 1.
} 


\subsubsection{Vano de medianera}

Las Figuras 4.33 y 4.34 muestran la evolución del coeficiente de carga para el forjado 1 y para los puntales bajo este forjado durante todo el proceso constructivo. Las Figuras 4.35 y 4.36 muestran la evolución del coeficiente de carga para el forjado 2 y para los puntales bajo este forjado durante todo el proceso constructivo. Por último, las Figuras 4.37 y 4.38 muestran la evolución del coeficiente de carga para el forjado 3 y para los puntales bajo este forjado durante todo el proceso constructivo. No se muestra una evolución del coeficiente de carga en el forjado 4 y en los puntales bajo este forjado debido a que únicamente fue objeto de medición el hormigonado de dicho forjado (operación en la cual se terminó el estudio experimental). En todas las figuras se muestra una tanto el coeficiente de carga obtenido a partir de los resultados del modelo de Elementos Finitos como el obtenido a partir de las medidas experimentales.

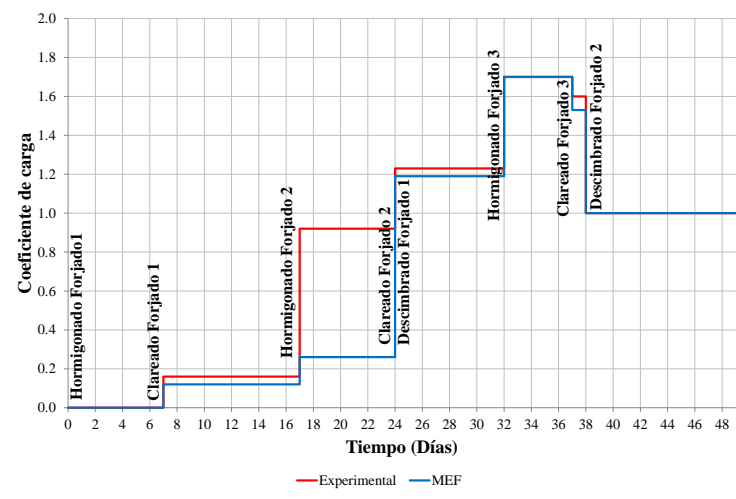

Fig. 4.33 Comparación coeficientes de carga en el forjado 1 (Forjado reticular de casetón recuperable - Vano de medianera)

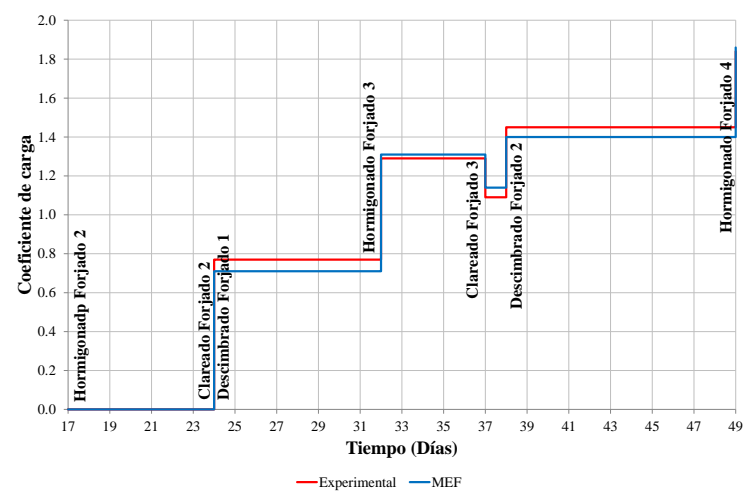

Fig. 4.35 Comparación coeficientes de carga en el forjado 2 (Forjado reticular de casetón recuperable - Vano de medianera)

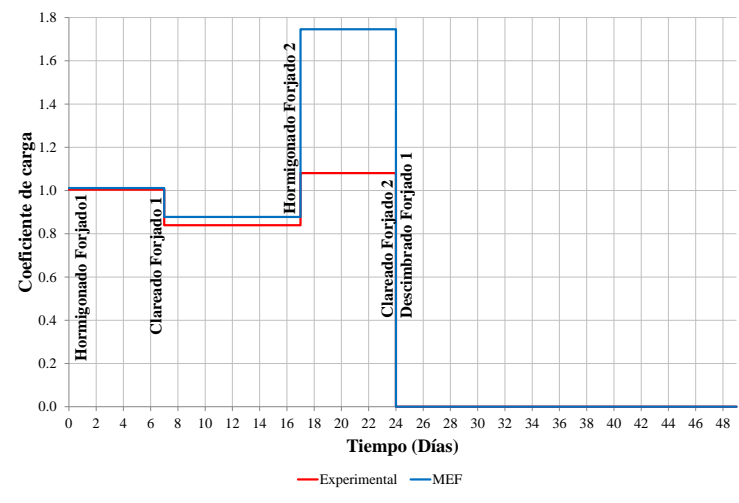

Fig. 4.34 Comparación coeficientes de carga en puntales bajo el forjado 1 (Forjado reticular de casetón recuperable Vano de medianera)

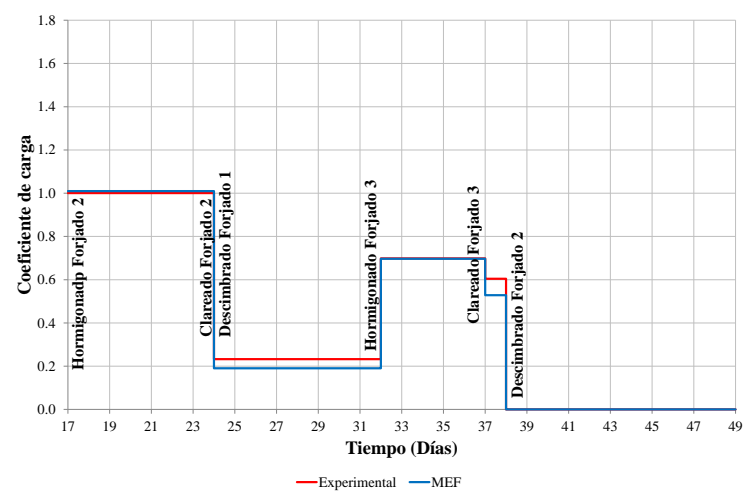

Fig. 4.36 Comparación coeficientes de carga en puntales bajo el forjado 2 (Forjado reticular de casetón recuperable Vano de medianera 


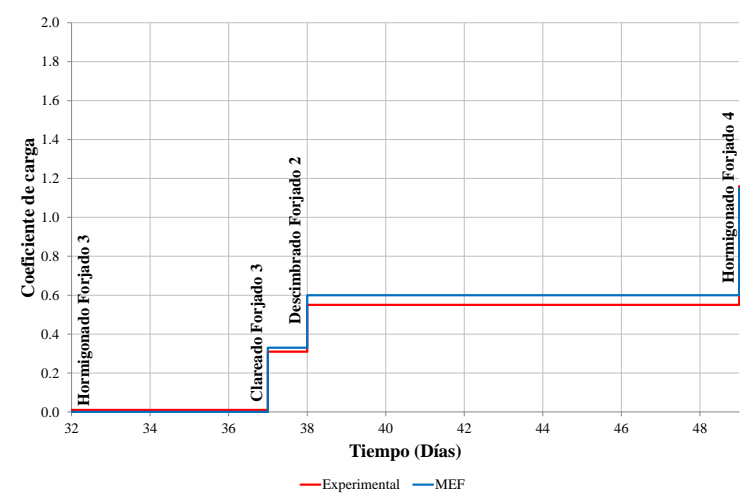

Fig. 4.37 Comparación coeficientes de carga en el forjado 3 (Forjado reticular de casetón recuperable - Vano de medianera)

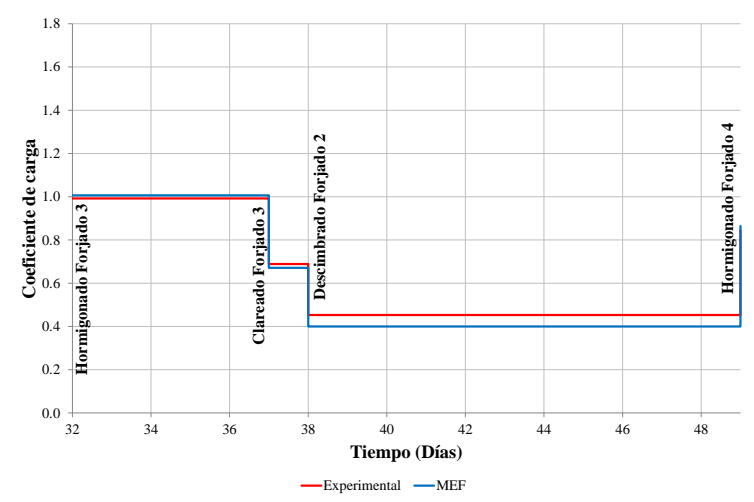

Fig. 4.38 Comparación coeficientes de carga en puntales bajo el forjado 3 (Forjado reticular de casetón recuperable Vano de medianera)

La Tabla 4.7 muestra una comparación entre los valores de la carga media en puntales obtenidos de la medición en obra $\left(q_{\text {med,exp }}\right)$ y los valores de carga media del modelo de Elementos Finitos $\left(q_{m e d, M E F}\right)$ obtenidos a partir de la carga en los puntales equivalentes a los instrumentados en obra. Así mismo, se comparan las cargas máximas en puntales obtenidas experimentalmente $\left(P_{\max , \text { exp }}\right)$ y a partir del modelo $\left(P_{\max , M E F}\right)$.

Tabla 4.7. Comparación entre las medidas experimentales y los resultados del modelo numérico (Forjado reticular de casetón recuperable - Vano de medianera)

\begin{tabular}{|c|c|c|c|c|c|c|c|c|}
\hline $\begin{array}{c}\text { Paso } \\
\text { de } \\
\text { carga }\end{array}$ & Operación & Nivel & $\begin{array}{c}\text { Experimental } \\
q_{\text {med,exp }} \\
\left(\mathrm{kN} / \mathrm{m}^{2}\right) \\
\end{array}$ & $\begin{array}{c}\text { Numérico } \\
q_{\text {med,MEF }} \\
\left(\mathrm{kN} / \mathrm{m}^{2}\right) \\
\end{array}$ & $\frac{q_{m e d, e x p}}{q_{m e d, M E F}}$ & $\begin{array}{c}\text { Experimental } \\
P_{\max , \exp } \\
(\mathrm{kN}) \\
\end{array}$ & $\begin{array}{c}\text { Numérico } \\
P_{\max , M E F} \\
(\mathbf{k N})\end{array}$ & $\frac{P_{\text {max }, \text { exp }}}{P_{\max , M E F}}$ \\
\hline 1 & $\begin{array}{l}\text { Hormigonado } \\
\text { forjado } 1\end{array}$ & 1 & 5.79 & 5.83 & 0.99 & 4.75 & 4.74 & 1.00 \\
\hline 2 & Clareado forjado 1 & 1 & 4.84 & 5.06 & 0.96 & 9.28 & 7.31 & 1.27 \\
\hline \multirow{2}{*}{3} & Hormigonado & 2 & 5.77 & 5.82 & 0.99 & 4.98 & 4.74 & 1.05 \\
\hline & forjado 2 & 1 & 6.23 & 10.07 & 0.62 & 11.92 & 14.50 & 0.82 \\
\hline \multirow{2}{*}{4} & \multirow{2}{*}{ Clareado forjado $2^{6}$} & 2 & - & 4.89 & - & - & 7.11 & - \\
\hline & & 1 & - & 9.50 & - & - & 13.55 & - \\
\hline 5 & $\begin{array}{l}\text { Descimbrado } \\
\text { forjado } 1\end{array}$ & 2 & 1.34 & 1.10 & 1.22 & 3.59 & 2.10 & 1.74 \\
\hline \multirow{2}{*}{6} & Hormigonado & 3 & 5.72 & 5.80 & 0.99 & 4.92 & 4.74 & 1.04 \\
\hline & forjado 3 & 2 & 4.03 & 4.02 & 1.00 & 9.77 & 6.54 & 1.49 \\
\hline \multirow{2}{*}{7} & \multirow{2}{*}{ Clareado forjado 3} & 3 & 3.97 & 3.87 & 1.03 & 8.11 & 5.66 & 1.43 \\
\hline & & 2 & 3.48 & 3.05 & 1.14 & 8.64 & 4.93 & 1.75 \\
\hline 8 & $\begin{array}{l}\text { Descimbrado } \\
\text { forjado } 2\end{array}$ & 3 & 2.61 & 2.31 & 1.13 & 6.74 & 3.33 & 2.02 \\
\hline \multirow{2}{*}{9} & Hormigonado & 4 & 5.75 & 5.80 & 0.99 & 4.87 & 4.74 & 1.03 \\
\hline & forjado 4 & 3 & 4.87 & 4.99 & 0.98 & 10.91 & 7.27 & 1.50 \\
\hline- & Media & - & - & - & 1.00 & - & - & 1.34 \\
\hline- & Desviación Típica & - & - & - & 0.14 & - & - & 0.35 \\
\hline
\end{tabular}

\footnotetext{
${ }^{6}$ No se presentan datos experimentales del Clareado del Forjado 2, puesto que esta operación se realizó conjuntamente con el Descimbrado del Forjado 1.
} 


\subsubsection{Resumen}

Se puede apreciar que la media de la relación $q_{m e d, e x p} / q_{m e d, M E F}$ de todas las operaciones es de 1.05, para el vano de esquina, y de 1.00 para el vano de medianera, con una desviación típica, en ambos casos, de 0.14 , obteniendo un buen grado de ajuste entre ambas medidas.

El proceso constructivo sufrió alteraciones debidas a necesidades de la obra. Así, sin haber clareado el Forjado 3, se retiraron parte de los puntales situados bajo el Forjado 2, tal y como se aprecia en la Figura 4.39. En este caso, sí que se pudo simular esta operación no controlada en el MEF puesto que se conocía el número y situación de los puntales retirados.

Este tipo de operaciones no previstas dentro del proceso constructivo modifican la transmisión esperada de cargas entre forjados y puntales.
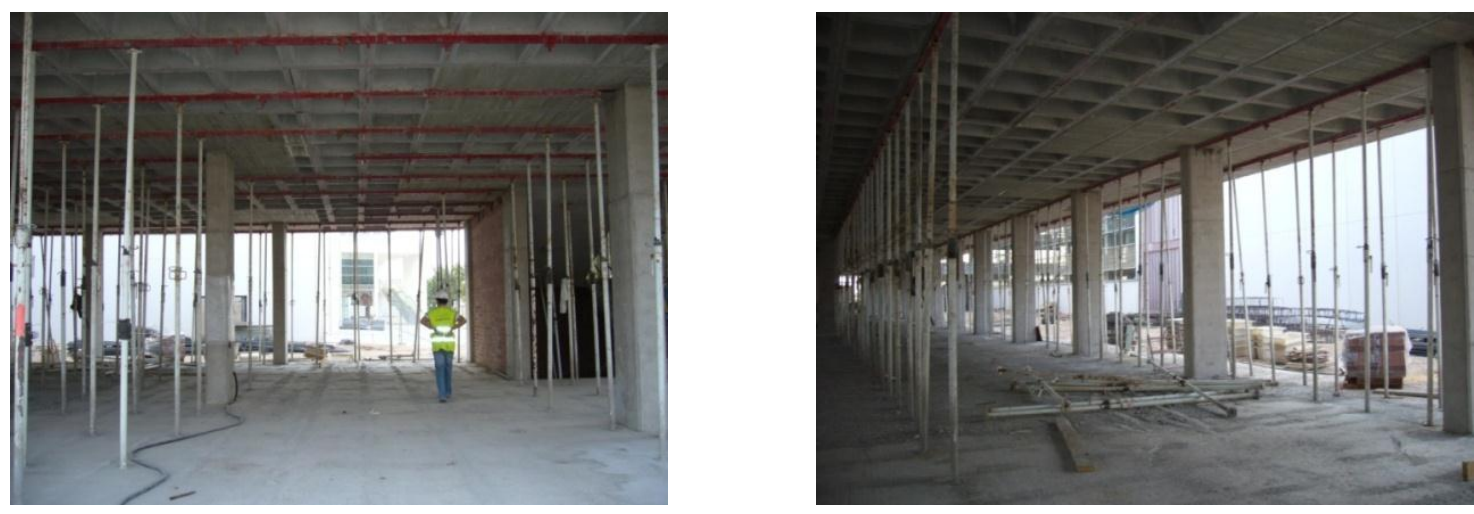

Fig. 4.39 Operación no controlada realizada antes del Clareado del Forjado 3

Además, se comparan los valores de la carga máxima en puntales de las medidas experimentales y de los resultados del modelo de EF. La media de la relación $P_{\max , \exp } / P_{\max , M E F}$ del total de las fases de construcción es de 1.25 con una desviación típica de 0.30 , para el caso del vano de esquina, y de 1.34 con una desviación típica de 0.35 , para el vano de medianera.

Las diferencias existentes entre los valores de carga máxima en puntales obtenidos experimentalmente y los del modelo de EF, son debidas a que no todos los puntales están igual de ajustados en el edificio. Por lo tanto, si un puntal se encuentra excesivamente apretado, los puntales de alrededor recibirán menos carga y viceversa. Al no conocer el grado de ajuste, este hecho no puede ser reproducido en el modelo de EF.

\subsection{Modelo numérico del edificio experimental de Alvarado (2009) considerando los efectos de la temperatura}

Tal y como se muestra en el Capítulo 2 (Apartado 2.4.4), Alvarado (2009) detectó la importancia que las variaciones de temperatura ambiente tenían sobre las cargas en los puntales durante el proceso constructivo. Estos cambios de temperatura afectaban a los diferentes elementos de la estructura durante su construcción (forjados, pilares, puntales, tableros de encofrado y sopandas), afectando finalmente a las cargas en los puntales. Es por ello, que se pretende obtener una aproximación 
numérica al efecto que producen los cambios de temperatura en la transmisión de cargas entre forjados y puntales.

Basándose en el modelo de Elementos Finitos de Alvarado et al (2010), se plantea un modelo que pretende simular el edificio experimental estudiado por Alvarado (2009), considerando los cambios de temperatura que se producen tanto en el ambiente, como en la losa, puntales y pilares.

Para poder determinar las variaciones de temperatura que se produjeron en los distintos elementos del edificio experimental, se tendrán en cuenta:

- Las medidas de temperatura ambiente, de puntales y del hormigón realizadas en el edificio experimental por Alvarado (2009).

- Las mediciones de temperatura realizadas en los edificios de forjado reticular de casetón perdido y recuperable (véase aparatados 3.3.5 y 3.4.5 de la presente Tesis Doctoral) para poder evaluar la variación de temperatura en el forjado y determinar el gradiente térmico.

Para realizar el modelo numérico se ha empleado el software comercial ANSYS 11.0 (2006). Se han considerado las características geométricas y mecánicas de cada uno de los elementos que intervienen en la construcción del edificio. Además, se ha tenido en cuenta el proceso constructivo seguido mediante un cálculo evolutivo.

\subsubsection{Breve descripción del edificio experimental de Alvarado (2009)}

El edificio experimental estaba constituido por 3 plantas. En todas las plantas el forjado estaba formado por una losa de hormigón armado de $0.25 \mathrm{~m}$ de canto, siendo la altura entre plantas de 2.75 m. Existía un sólo vano de dimensiones 6.00 × $6.00 \mathrm{~m}$ con un voladizo de $1.80 \mathrm{~m}$. El hormigón utilizado para la construcción de todos los elementos del edificio tenía una resistencia característica a compresión de $25 \mathrm{MPa}$. La Figura 4.40 muestra una vista del modelo experimental.

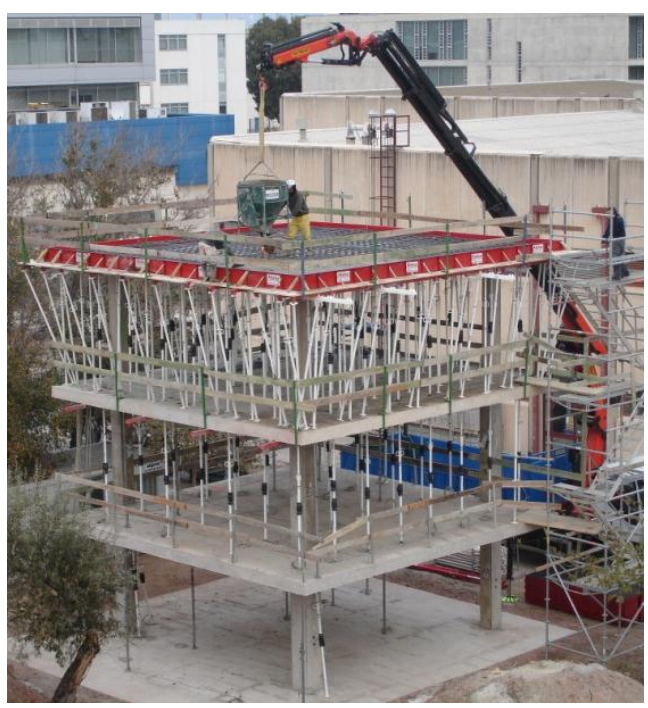

Fig. 4.40 Edificio experimental (Alvarado, 2009) 
Se instrumentaron un total de 80 puntales para poder estudiar la transmisión de cargas entre forjados y puntales. Además, se instalaron 5 captadores de desplazamiento (LVDTs) entre cada uno de los forjados, con el fin de conocer las deformaciones provocadas por el proceso constructivo.

Para poder determinar la evolución de la temperatura desde el vertido del hormigón, se instalaron 3 termopares embebidos en cada uno de los forjados. Estos termopares medían la temperatura en el centro de la sección de hormigón. Asimismo, se instalaron 2 termopares pegados a la superficie de 2 puntales y otros 2 termopares para medir la temperatura ambiente.

Con el fin de poder tratar los datos recopilados por los sistemas de adquisición se utilizaron 2 ordenadores equipados con un software desarrollado por personal de ICITECH. Estos equipos se instalaron en un edificio auxiliar, ubicado junto al edificio.

Puede encontrarse una descripción detallada del estudio experimental en Alvarado et al (2009) y Alvarado (2009).

\subsubsection{Hipótesis consideradas}

Las hipótesis adoptadas para realizar el modelo de EF son las siguientes:

$\checkmark$ Se asume un comportamiento elástico y lineal del forjado de hormigón armado, considerando la variación de su rigidez en el tiempo.

$\checkmark$ Los pilares se simulan con un comportamiento elástico y lineal, y se considera la variación de su rigidez con respecto al tiempo.

$\checkmark$ Los puntales de acero son considerados como elementos elásticos con una rigidez finita, apoyados en sus extremos. Sus características principales se muestran en la Tabla 4.8.

Tabla 4.8. Características geométricas y mecánicas de los puntales considerados en el modelo

\begin{tabular}{llll}
\hline Longitud (m) & $\begin{array}{l}\text { Diámetro del } \\
\text { cuerpo }(\mathbf{m m})\end{array}$ & $\begin{array}{l}\text { Espesor del } \\
\text { cuerpo }(\mathbf{m m})\end{array}$ & $\begin{array}{l}\text { Módulo de } \\
\text { elasticidad (GPa) }\end{array}$ \\
\hline 2.88 & 48 & 2 & 210 \\
\hline
\end{tabular}

$\checkmark$ Los tableros de encofrado son considerados como elementos con un comportamiento elástico y lineal y de rigidez finita. Los tableros son de madera, con un espesor de $27 \mathrm{~mm}$ y un módulo de elasticidad de $10 \mathrm{GPa}$.

$\checkmark$ Las sopandas son simuladas como elementos con un comportamiento elástico y lineal, con una rigidez finita. Las sopandas son de acero, con una sección transversal de $406 \mathrm{~mm}^{2}$ y un módulo de elasticidad de $210 \mathrm{GPa}$.

$\checkmark$ La cimentación se considera infinitamente rígida. Esta hipótesis se adopta a partir de establecer que el conjunto de puntales del primer forjado apoyan directamente sobre la losa de cimentación. 
$\checkmark$ Se consideran los cambios de temperatura en los diferentes elementos de la estructura. En el caso de los puntales y los pilares, se considera una temperatura uniforme en todo el elemento, mientras que en la losa se introduce el gradiente correspondiente.

$\checkmark \quad$ No se consideran los efectos de fluencia y retracción en el hormigón.

\subsubsection{Descripción del modelo de Elementos Finitos}

Para simular el proceso constructivo del edificio en el modelo de EF se considerará que las distintas condiciones de apoyo (puntales, sopandas y encofrado), las características mecánicas del hormigón, así como la temperatura de los distintos elementos, son cambiantes con el tiempo.

\subsubsection{Tipos de EF y mallado empleado}

Los elementos utilizados en este modelo son los mismos que en los adoptados en los modelos anteriormente descritos. Los forjados de hormigón y los tableros de encofrado de madera se modelizan mediante elementos bidimensionales SHELL63 Los puntales metálicos se modelizan mediante elementos unidimensionales de 2 nodos tipo LINK10 y para modelizar los pilares de hormigón y las sopandas de acero se emplean elementos tipo BEAM44.

El tamaño de la malla de los forjados está condicionado por sus dimensiones y por la distribución espacial de los componentes del sistema de cimbrado y encofrado. Así, buscando simular con un alto grado de aproximación las características de la estructura, el tamaño de malla de EF para el forjado es de $0.20 \times 0.20 \mathrm{~m}^{2}$. En el caso de los elementos del encofrado, al tener que coincidir sus nodos con los nodos de los elementos del forjado, el tamaño de la malla de EF también es de $0.20 \times 0.20 \mathrm{~m}^{2}$.

El tamaño de la malla de los pilares de hormigón es de $0.58 \mathrm{~m}$. En el caso de las sopandas, siendo necesario que los nodos coincidieran con los nodos del encofrado, el tamaño de la malla es de $0.20 \mathrm{~m}$.

\subsubsection{Temperaturas consideradas}

Durante la construcción del edificio se registró la temperatura ambiente, la de los puntales y la del hormigón de los forjados, en el centro de la sección de los forjados, embebiendo termopares en estos. Las Figuras 4.41 y 4.42 muestran la temperatura del hormigón registrada por los distintos termopares para los forjados 1 y 2 , así como la temperatura de los puntales y la ambiente. 


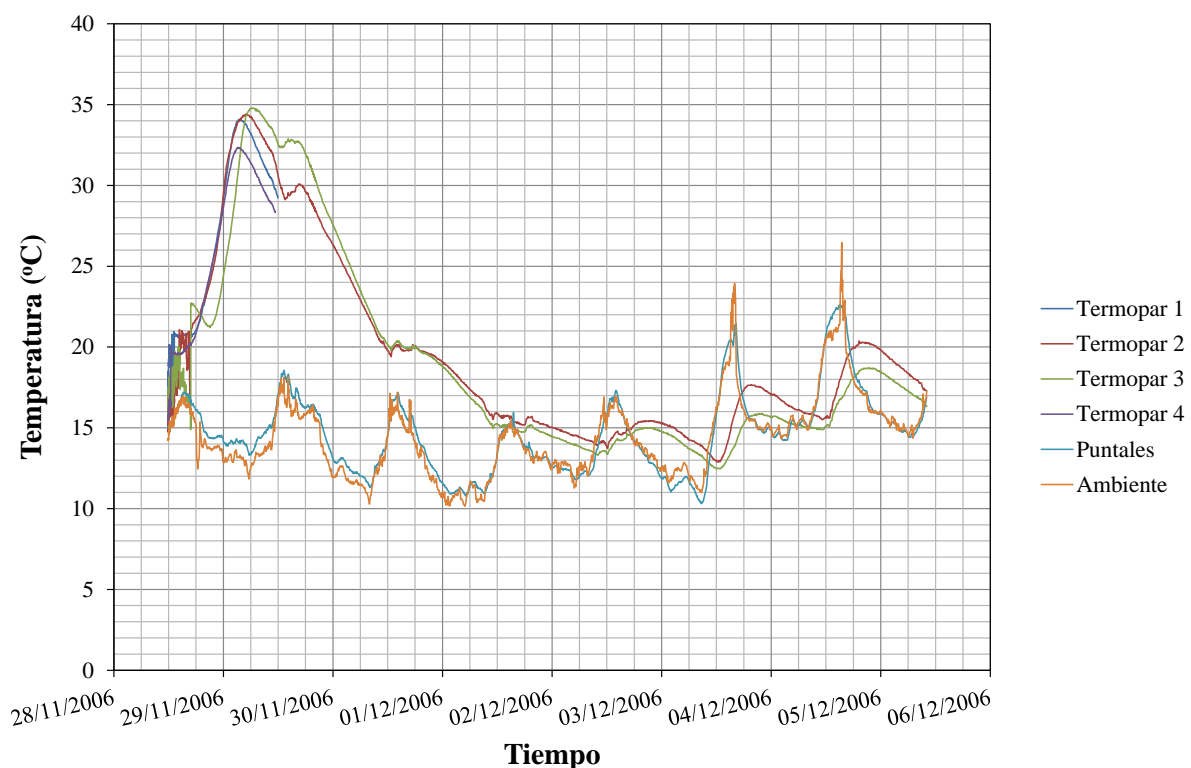

Fig. 4.41 Temperatura medida en el hormigón, puntales y ambiente para el Forjado 1 del edificio experimental. (Alvarado, 2009)

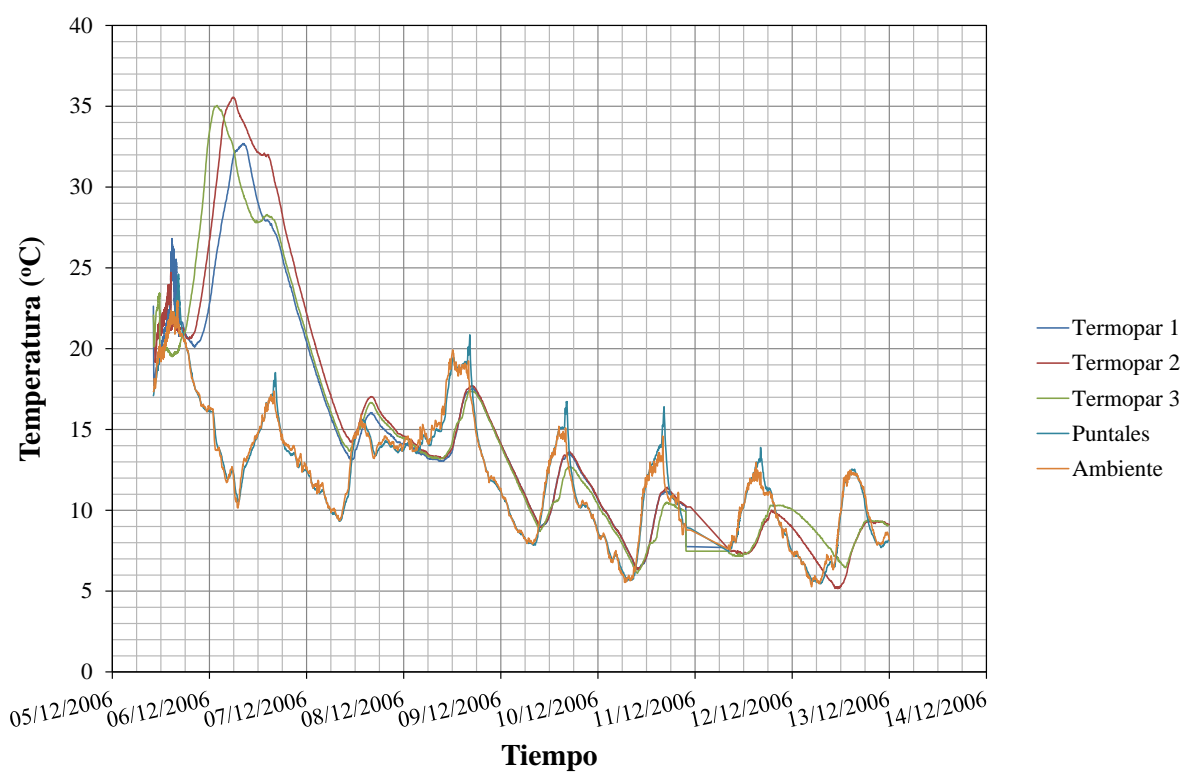

Fig. 4.42 Temperatura medida en el hormigón, puntales y ambiente para el Forjado 2 del edificio experimental. (Alvarado, 2009)

Como se observa en las figuras anteriores la temperatura de los puntales coincide con la temperatura ambiente. Por tanto, el incremento de temperatura considerado para los puntales en el modelo de EF es igual al de la temperatura ambiente. 
En los pilares, tal y como muestra Fang et al (2009b), la temperatura presenta un comportamiento similar a la temperatura ambiente, pero con incrementos menores y con un retraso en el tiempo.

En los forjados, las variaciones de temperatura consideradas en el modelo de EF vienen dadas en la Tabla 4.9. Dichos valores se han estimado a partir de las temperaturas medidas en el edificio experimental (Fig. 4.41 y 4.42) y analizando los gradientes máximos y mínimos medidos en los edificios de forjado reticular de casetón perdido y recuperable expuestos en el capítulo anterior (Tablas 3.7 y 3.10 del Capítulo 3). Se ha tenido en cuenta que la losa del edificio experimental era de $0.25 \mathrm{~m}$ de espesor y que la construcción de éste se llevó a cabo en invierno, mientras que los otros dos edificios se construyeron en primavera y verano.

Tabla 4.9. Diferencias de temperatura $\left({ }^{\circ} \mathrm{C}\right)$, máximas y mínimas, entre la cara superior e inferior de la losa consideradas en el modelo

\begin{tabular}{cccccc}
\hline \multicolumn{2}{c}{ Losa encofrada } & \multicolumn{2}{c}{$\begin{array}{c}\text { Losa desencofrada con } \\
\text { insolación directa }\end{array}$} & \multicolumn{2}{c}{$\begin{array}{c}\text { Losa desencofrada con forjado } \\
\text { superior }\end{array}$} \\
\hline Mínima & Máxima & Mínima & Máxima & Mínima & Máxima \\
\hline-0.3 & 2.4 & -0.6 & 3.0 & -0.4 & 2.0 \\
\hline
\end{tabular}

\subsubsection{Simulación del proceso constructivo}

Para poder simular el proceso constructivo del edificio en el modelo de Elementos Finitos, se ha considerado la variación en el tiempo de las características mecánicas del hormigón y de las condiciones de apoyo de los distintos elementos, así como las variaciones de temperatura en los diferentes elementos de la estructura.

ANSYS 11.0 permite considerar estas variaciones al realizar un cálculo evolutivo a través de diferentes pasos de carga. Los pasos de carga seguidos en el modelo de EF se corresponden con las diferentes fases constructivas y las variaciones de temperatura máximas y mínimas que se produjeron entre dichas fases.

La estimación de la evolución del módulo elástico se realiza aplicando la técnica de la madurez y puede verse en Alvarado (2009).

A continuación se indica las fases correspondientes a cada paso de carga:

- Paso de carga 1: Hormigonado del forjado 1 (Día 0). El cálculo de este paso de carga consiste en dejar activados únicamente los elementos del forjado 1 con su sistema de cimbrado, desactivando los elementos de los forjados superiores, incluidos los puntales y encofrado.

- Paso de carga 2-7: Variaciones de temperatura (Días 1-3). En estos pasos de carga se introducen las variaciones de temperatura en los distintos elementos, producidas por un máximo o un mínimo de temperatura.

- Paso de carga 8: Clareado del forjado 1 (Día 3). En este paso de carga se desactivan los elementos del encofrado y los puntales correspondientes a las sopandas intermedias correspondientes al 
sistema de cimbrado del forjado 1. Además se introducen, en los diferentes elementos, las variaciones de temperatura que se han producido.

- Paso de carga 9-17: Variaciones de temperatura (Días 3-6). En estos pasos de carga se introducen las variaciones de temperatura en los distintos elementos, producidas por un máximo o un mínimo de temperatura.

- Paso de carga 18: Hormigonado del forjado 2 (Día 7). En el paso de carga 3 se activan el conjunto de elementos del forjado 2 incluidos pilares, encofrado y puntales. Además se introducen, en los diferentes elementos, las variaciones de temperatura producidas.

- Paso de carga 19-29: Variaciones de temperatura (Días 7-13). En estos pasos de carga se introducen las variaciones de temperatura en los distintos elementos, producidas por un máximo o un mínimo de temperatura.

- Paso de carga 30: Clareado del forjado 2 (Día 13). Para el cálculo de este paso de carga se desactivan el encofrado y los puntales correspondientes a las sopandas intermedias del sistema de cimbrado del forjado 2. Además se introducen, en los diferentes elementos, las variaciones de temperatura registradas.

- Paso de carga 31-34: Variaciones de temperatura (Días 13-14). En estos pasos de carga se introducen las variaciones de temperatura en los distintos elementos, producidas por un máximo o un mínimo de temperatura.

- Paso de carga 35: Descimbrado del forjado 1 (Día 14). En este paso de carga se desactivan los puntales situados bajo el forjado 1, quedando únicamente los puntales correspondientes a las sopandas principales situados bajo el forjado 2. Además se introducen, en los diferentes elementos, las variaciones de temperatura que se han producido.

- Paso de carga 36-42: Variaciones de temperatura (Días 14-17). En estos pasos de carga se introducen las variaciones de temperatura en los distintos elementos, producidas por un máximo o un mínimo de temperatura.

\subsubsection{Análisis de resultados del modelo y comparación con las medidas experimentales}

Se pretende obtener una aproximación numérica al efecto que producen los cambios de temperatura en la transmisión de cargas entre forjados y puntales.

En las Figuras 4.43 y 4.44 se muestra una comparación de la evolución del incremento del coeficiente de carga en puntales medido experimentalmente y el obtenido con el método de Elementos Finitos para los forjados 1 y 2 , respectivamente. Además dichas figuras muestran la evolución diaria de los máximos y mínimos de la temperatura ambiente registrada en la obra. 


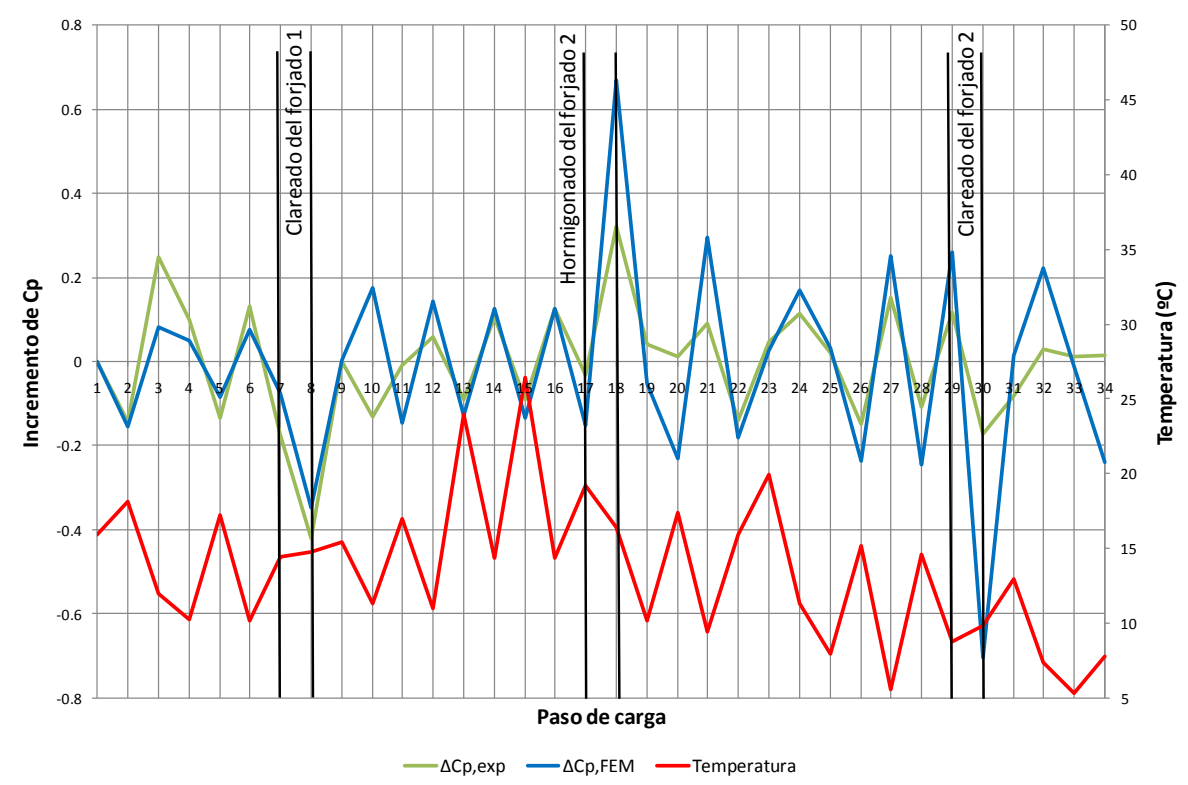

Fig. 4.43 Evolución del coeficiente de carga en puntales del forjado 1

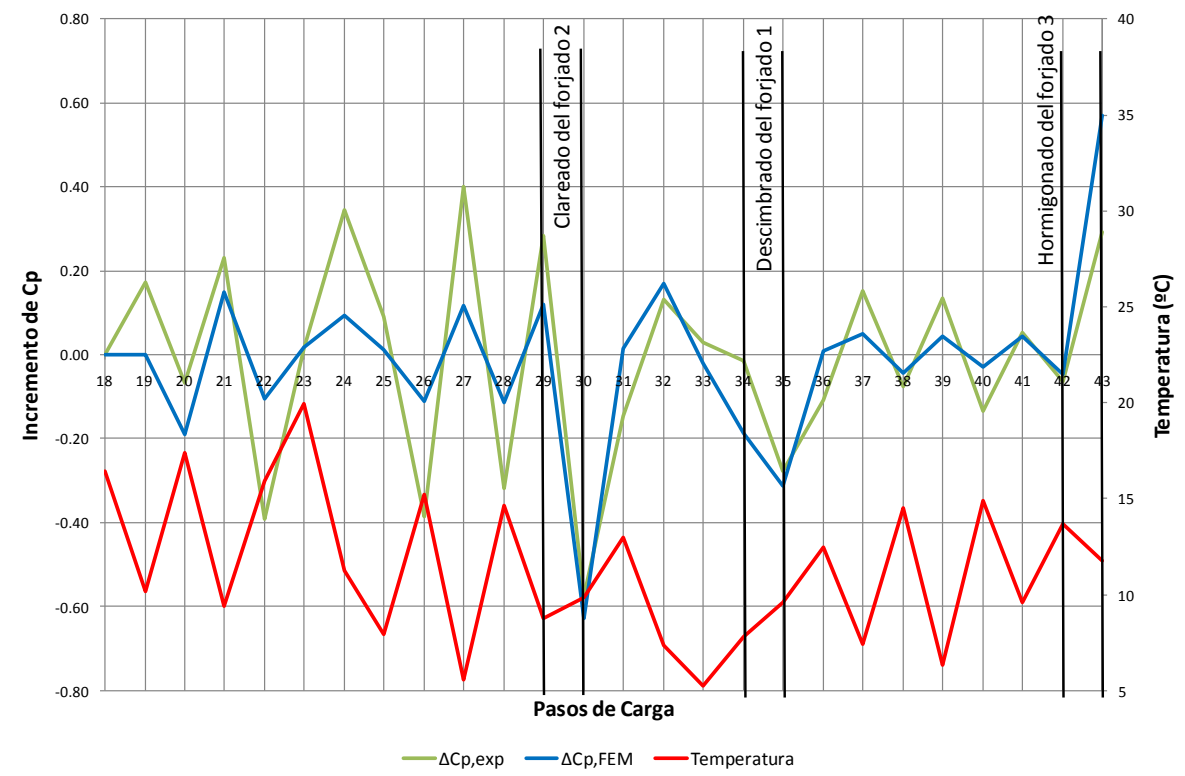

Fig. 4.44 Evolución del coeficiente de carga en puntales del forjado 2

Como se puede observar en las figuras anteriores, tanto en las medidas experimentales como en el modelo numérico se presenta la misma pauta de comportamiento frente a los cambios de temperatura; un aumento de temperatura produce un descenso de carga en los puntales y viceversa.

En el estudio experimental también se midieron las deformaciones con 5 LVDTs. En las Figuras 4.454.46 se muestra la variación de la flecha de $\operatorname{los}$ forjados 1 y 2 , respectivamente, en función de los cambios de temperatura ambiente. 


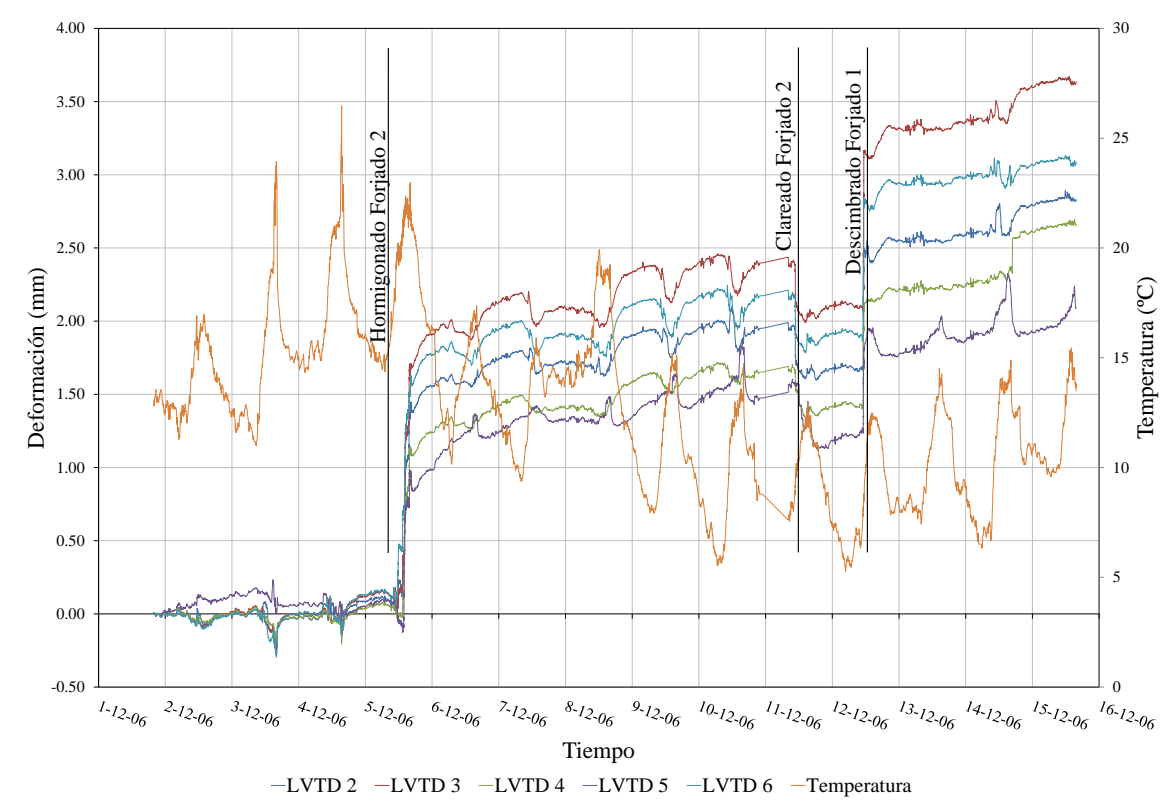

Fig. 4.45 Deformaciones medidas experimentalmente en el forjado 1 (Alvarado, 2009)

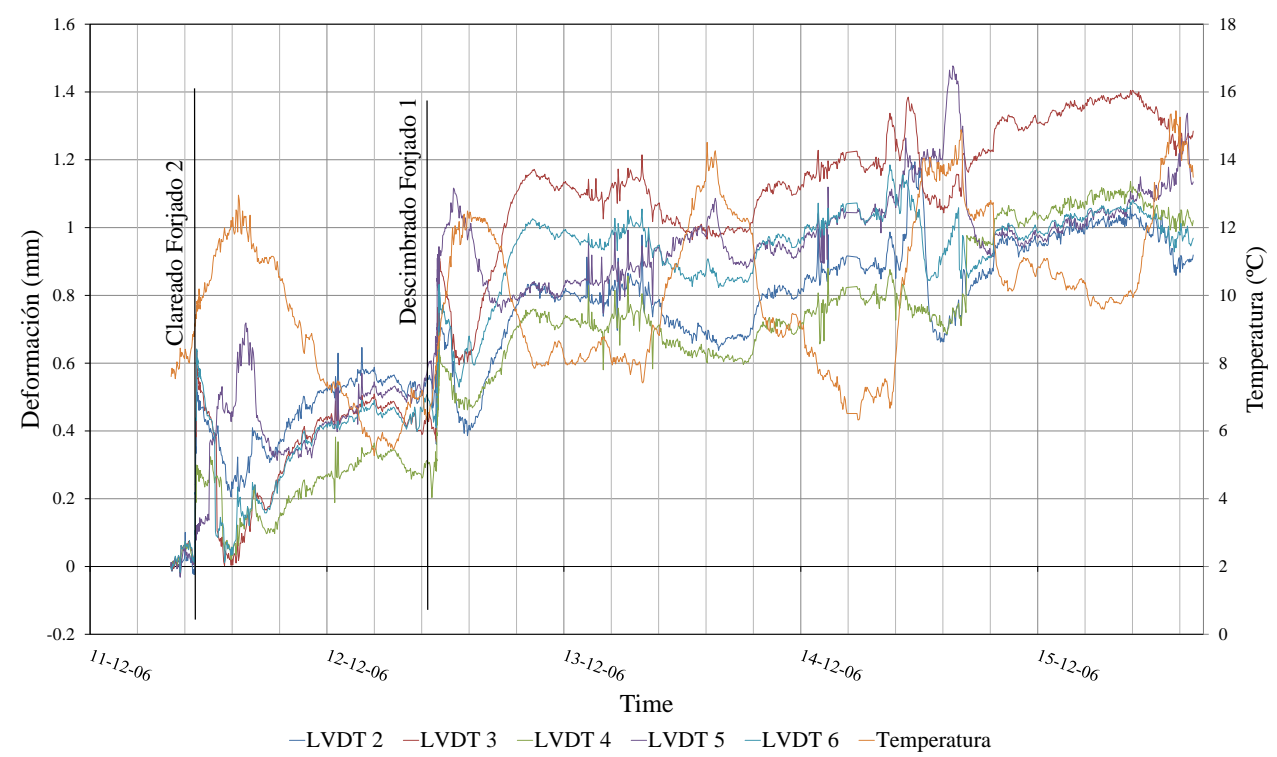

Fig. 4.46 Deformaciones medidas experimentalmente en el forjado 2 (Alvarado, 2009)

Como se puede observar, la pauta de comportamiento de dicha variación, se corresponde a un aumento en la flecha del forjado al descender la temperatura, y a una disminución de la flecha al aumentar la temperatura en las posiciones de los LVDTs 2, 3, 4 y 6 . Este comportamiento resulta ser inverso para la posición del LVDT 5 debido a que se encuentra en el borde del voladizo.

En las Figuras 4.47-4.56 se muestran, para el Forjado 1 y para los pasos de carga 8-17, las deformaciones que se presentan en el forjado debidas a los cambios de temperaturas obtenidas en el modelo de Elementos Finitos. Los pasos de carga mostrados se corresponden con el intervalo de 
tiempo entre el Clareado del Forjado 1 (paso de carga 8) y el hormigonado del Forjado 2 (paso de carga 18).

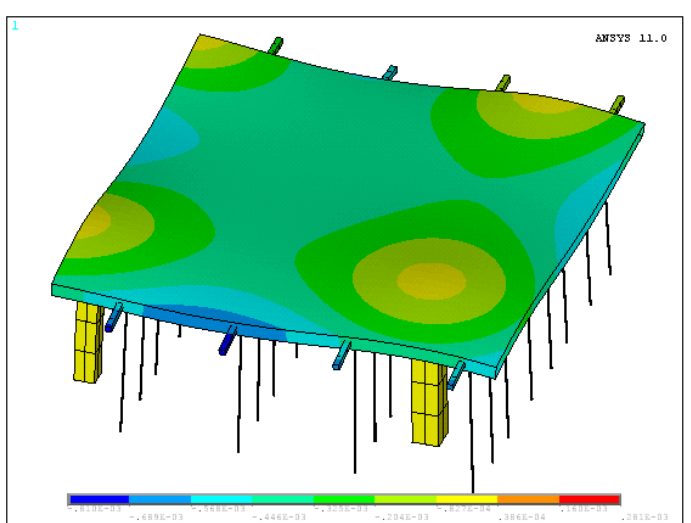

Fig. 4.47 Deformaciones que sufre el forjado en el MEF (Paso de carga 8)

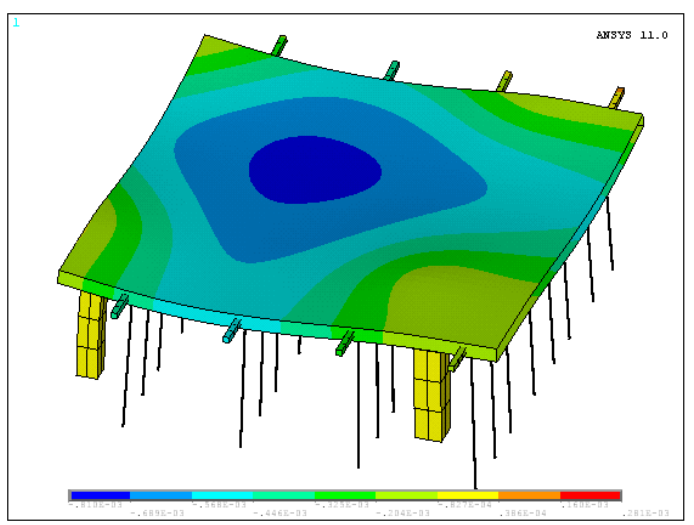

Fig. 4.49 Deformaciones que sufre el forjado en el MEF (Paso de carga 10)

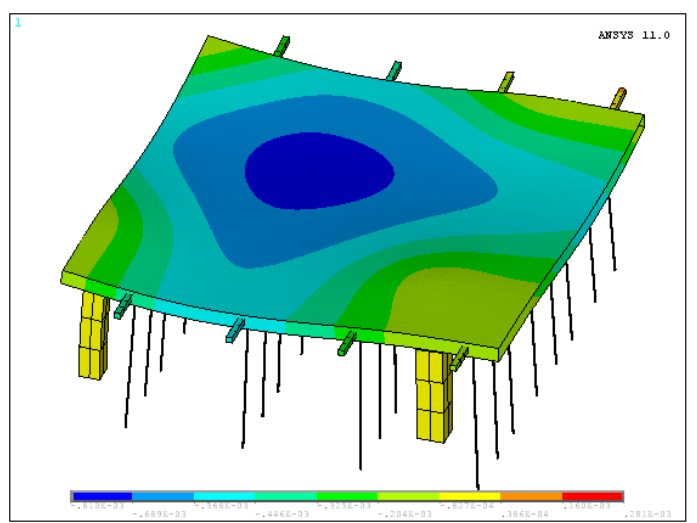

Fig. 4.51 Deformaciones que sufre el forjado en el MEF (Paso de carga 12)

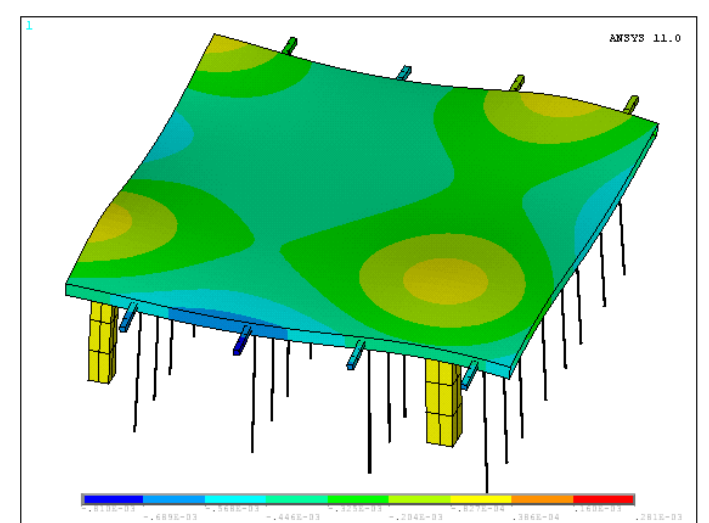

Fig. 4.48 Deformaciones que sufre el forjado en el MEF (Paso de carga 9)

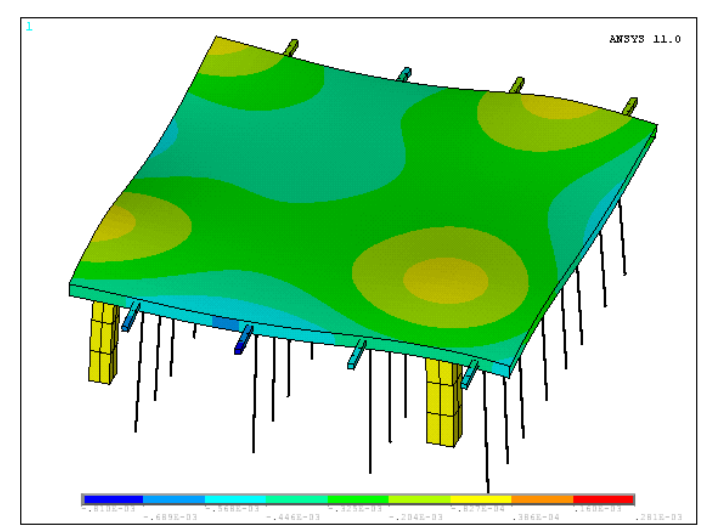

Fig. 4.50 Deformaciones que sufre el forjado en el MEF (Paso de carga 11)

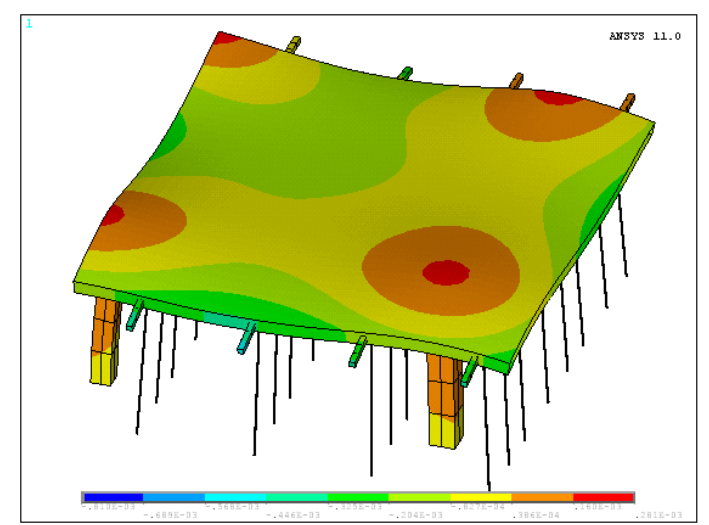

Fig. 4.52 Deformaciones que sufre el forjado en el MEF (Paso de carga 13) 


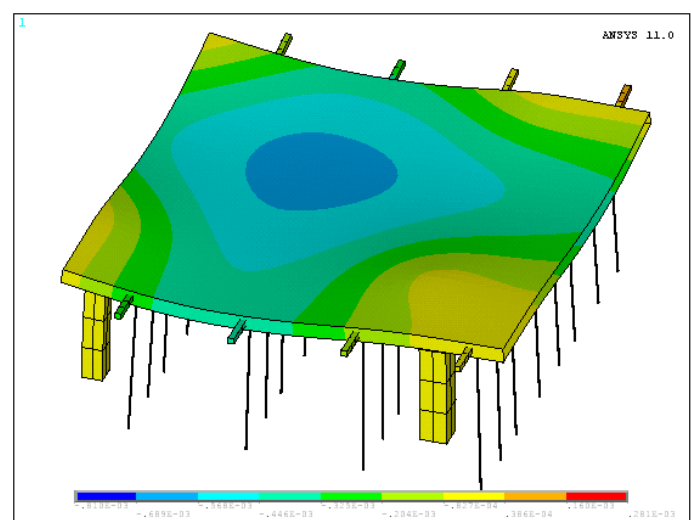

Fig. 4.53 Deformaciones que sufre el forjado en el MEF (Paso de carga 14)

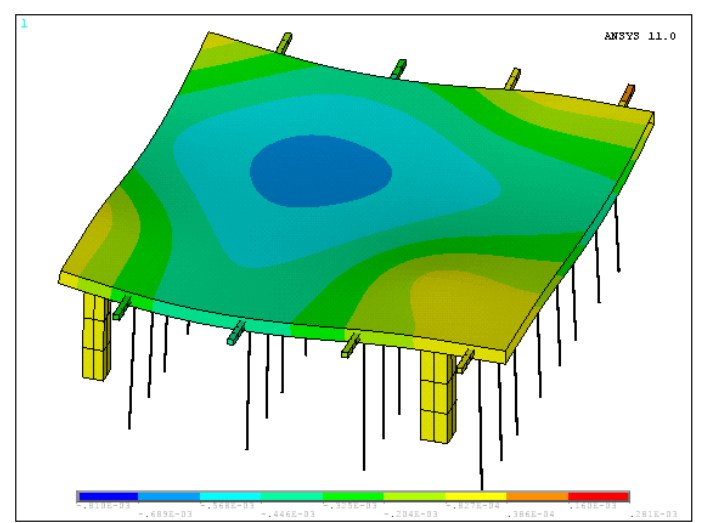

Fig. 4.55 Deformaciones que sufre el forjado en el MEF (Paso de carga 16)

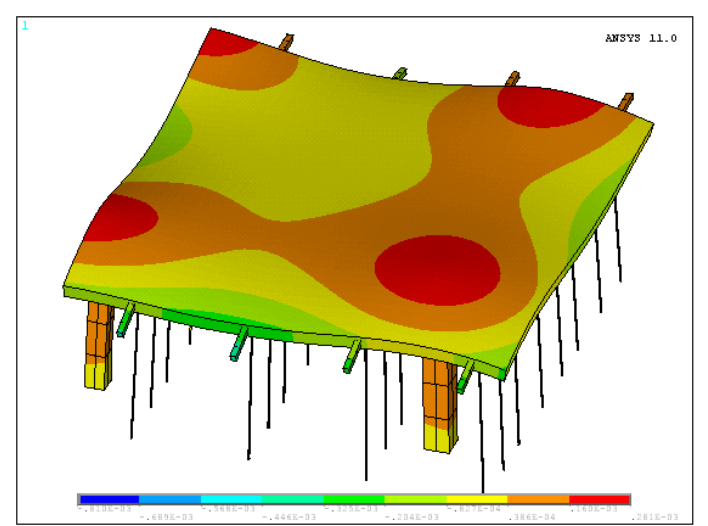

Fig. 4.54 Deformaciones que sufre el forjado en el MEF (Paso de carga 15)

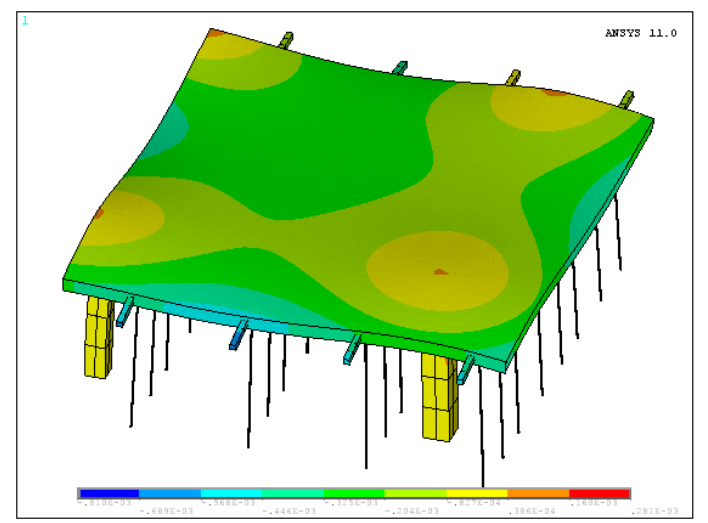

Fig. 4.56 Deformaciones que sufre el forjado en el MEF (Paso de carga 17)

En la Tabla 4.10 se muestra un resumen de las figuras anteriores, analizando la deformación que se produce, aproximadamente, en el centro de vano.

Tabla 4.10. Deformación en centro de vano según MEF para los pasos de carga 8-17.

\begin{tabular}{ccc}
\hline Paso de carga & $\begin{array}{c}\text { Temperatura } \\
\text { ambiente }\left({ }^{\circ} \mathbf{C}\right)\end{array}$ & $\begin{array}{c}\text { Deformación en centro } \\
\text { de vano }(\mathbf{m m})\end{array}$ \\
\hline 8 & 14.76 & 0.53 \\
9 & 15.42 & 0.51 \\
10 & 11.28 & 0.72 \\
11 & 16.97 & 0.39 \\
12 & 11.00 & 0.73 \\
13 & 23.95 & 0.18 \\
14 & 14.33 & 0.61 \\
15 & 26.55 & 0.03 \\
16 & 14.36 & 0.60 \\
17 & 19.18 & 0.33 \\
\hline
\end{tabular}


Como se observa, cuando se produce un descenso de la temperatura ambiente aumenta la flecha del forjado, mientras que para un aumento de la temperatura ambiente disminuye la flecha del forjado, al igual que se extraía del análisis de los resultados de los LVDT.

Con el fin de distinguir entre los efectos producidos por los cambios de temperatura en pilares y puntales, y los debidos al gradiente de temperatura en la losa, se han estudiado dichos efectos por separado, tomando para ello dos pasos de carga (el 14 y el 15) entre los que únicamente existiera un cambio de temperatura entre ellos. La Figura 4.57 muestra la deformación del forjado y los incrementos de carga en puntales debidos a los cambios de temperatura entre dichos pasos de carga.

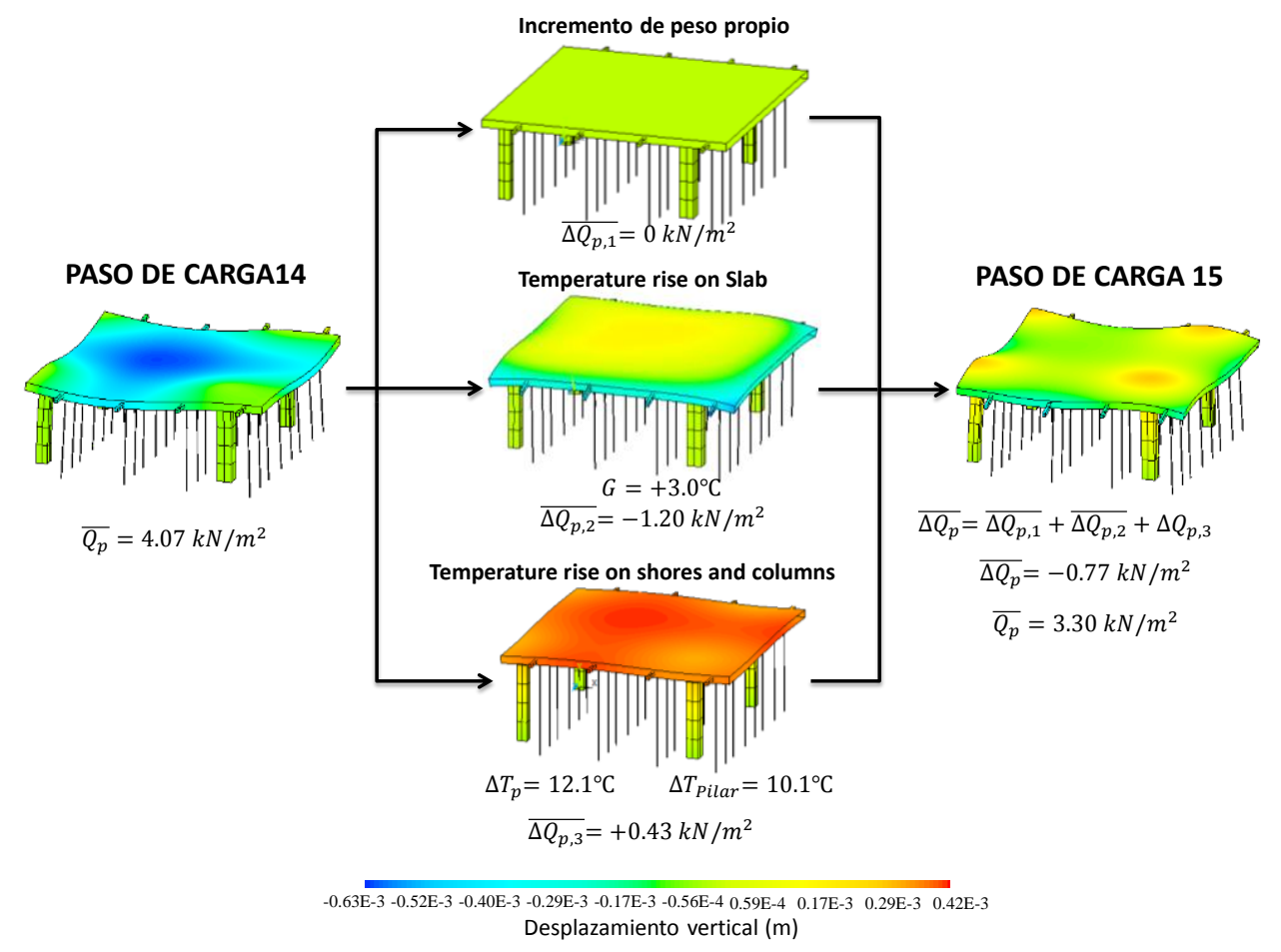

Fig. 4.57 Deformación del forjado e incrementos de carga en puntales debidos a los cambios de temperatura entre los pasos de carga 14 y 15

Entre el paso de carga 14 y 15 la temperatura experimenta los siguientes cambios:

a. Incremento de peso propio: No existe un incremento de peso propio entre los pasos de carga $14 \mathrm{y}$ 15.

b. Diferencia de temperatura entre la cara superior e inferior de la losa $(\mathrm{G})$ :

- Paso de carga $14: \mathrm{G}=-0.6^{\circ} \mathrm{C}$ (gradiente negativo: la cara inferior está más caliente que la superior)

- Paso de carga $15: \mathrm{G}=+3.0^{\circ} \mathrm{C}$ (gradiente positivo: la cara superior está más caliente que la inferior)

- Variación de temperatura entre los pasos de carga 14 y $15:+3.6^{\circ} \mathrm{C}$.

c. Aumento de temperatura en los puntales: $\quad 12.1^{\circ} \mathrm{C}$

Aumento de temperatura en los pilares: $\quad 10.1^{\circ} \mathrm{C}$ 
Como se aprecia en la Figura 4.57, estos de cambios de temperatura han producido los siguientes incrementos de carga en los puntales $\overline{\Delta Q_{p}}$ (para este cálculo se ha desactivado la tracción en los puntales):

a. Incremento de peso propio:

$\overline{\Delta Q_{p, 1}}=0.00 \mathrm{kN} / \mathrm{m}^{2}$

b. Aumento de temperatura en el forjado

(Diferencia de temperatura entre la cara superior e inferior de la losa)

$\overline{\Delta Q_{p, 2}}=-1.20 \mathrm{kN} / \mathrm{m}^{2}$

c. Aumento de temperatura en los puntales y pilares:

$\overline{\Delta Q_{p, 3}}=+0.43 \mathrm{kN} / \mathrm{m}^{2}$

Efecto de los cambios de temperatura entre los pasos de carga 14 y15:

$\overline{\Delta Q_{p}}=-0.77 \mathrm{kN} / \mathrm{m}^{2}$

\subsection{Conclusiones relativas a los modelos numéricos}

En el presente capítulo se ha calibrado un modelo numérico para el cálculo de la transmisión de cargas entre forjados y puntales durante la construcción de edificios de forjados de hormigón in situ y se ha realizado una aproximación numérica al efecto que producen los cambios de temperatura en la transmisión de cargas entre forjados y puntales.

Para la calibración del modelo de Elementos Finitos, se han desarrollado dos modelos numéricos basados en el modelo desarrollado por Alvarado et al. (2010). Estos modelos se basan en un cálculo evolutivo no lineal, donde se considera el proceso constructivo seguido en obra, así como la evolución de las propiedades del hormigón con el tiempo.

La calibración del modelo numérico se ha realizado a partir de las medidas experimentales, del edificio de forjado de losa maciza y de forjado reticular de casetón recuperable, expuestas en el Capítulo 3 de la presente Tesis Doctoral.

En el caso del edificio de forjado de losa maciza, en general, el modelo de EF presenta un buen grado de ajuste respecto a las cargas medias medidas experimentalmente. La media de la relación $q_{\text {med,exp }} / q_{m e d, M E F}$ de todas las fases de construcción es de 1.07 , con una desviación típica de 0.19 para el vano de esquina, y de 1.11 con una desviación típica de 0.16 para el vano de medianera.

Para el edificio de forjado reticular de casetón recuperable, en general, los resultados obtenidos con modelo de EF se ajustan satisfactoriamente a las mediciones en obra. La media de la relación $q_{\text {med,exp }} / q_{\text {med,MEF }}$ de todas las fases de construcción es de 1.05 , con una desviación típica de 0.14 para el vano de esquina, y de 1.00 con una desviación típica de 0.14 para el vano de medianera.

Además de la carga media, se han comparado las cargas máximas obtenidas en cada uno de los edificios, Para el edificio de forjado de losa maciza, la media de la relación $P_{\text {max,exp }} / P_{\text {max,MEF }}$ del total de las fases de construcción es de 1.04 con una desviación típica de 0.20 , para el caso del vano de esquina, y de 1.02 con una desviación típica de 0.17 , para el vano de medianera. En el caso del edificio de forjado reticular de casetón recuperable, la media de la relación $P_{\max , \exp } / P_{\max , M E F}$ es de 1.25 , para el vano de esquina, y de 1.34 para el vano de medianera, con desviaciones típicas de 0.30 y 0.35 , respectivamente. 
Las diferencias existentes entre el modelo experimental y el modelo de EF en cuanto a la carga máxima en puntales son debidas a que en el modelo experimental resulta muy difícil controlar que todos los puntales se encuentran apretados de la misma forma, y por lo tanto la carga puede variar si se encuentran más o menos apretados. Se trata de un valor mucho más sensible a las manipulaciones de obra que la carga media.

Así mismo, se han encontrado algunas diferencias entre el modelo de EF y las medidas experimentales en algunas de las fases de construcción del edificio de forjado de losa maciza. Esto es debido a las diversas alteraciones que sufrió el proceso constructivo por necesidades de obra y que no pueden reflejarse en el modelo de EF.

Por otra parte, se ha realizado una aproximación numérica al efecto que producen los cambios de temperatura en la transmisión de cargas entre forjados y puntales. Para ello se ha utilizado el modelo numérico (Alvarado et al., 2010) del edificio experimental de Alvarado (2009) pero considerando los cambios de temperatura que se producen tanto en el ambiente como en la losa, pilares y puntales.

Del análisis de resultados se puede concluir que se presenta la misma pauta de comportamiento frente a temperatura tanto en el modelo de EF como en las mediciones experimentales. Esta pauta de comportamiento, en el caso del edificio experimental estudiado, consiste en un incremento de la carga frente a un descenso de temperatura ambiente y una disminución frente a un aumento de ésta. Esta pauta se presenta en todos los forjados, independientemente de que estos estén completamente cimbrados o clareados.

En el caso de la flecha del forjado, también se observa la misma pauta de comportamiento en las medidas experimentales y en el modelo de EF. El comportamiento que se produce, para el caso estudiado, es un aumento en la flecha del forjado al descender la temperatura ambiente y una disminución de la flecha al aumentar la temperatura ambiente.

Los resultados obtenidos del modelo numérico de temperaturas muestran la importancia de las variaciones de temperatura en las cargas de puntales y forjados durante la construcción de edificios. Estos cambios en las cargas son producto de la combinación de dos efectos principales: (a) los cambios de temperatura en los pilares y los puntales y (b) la diferencia de temperatura entre las caras superior e inferior de los forjados. 



\section{CAPITULO 5. ESTUDIO COMPARATIVO DE DIVERSOS MÉTODOS SIMPLIFICADOS DE CÁLCULO DE TRANSMISIÓN DE CARGAS}

\subsection{Introducción}

En el Capítulo 4 se ha calibrado un modelo numérico que permite estimar la transmisión de cargas entre forjados y puntales durante la construcción de edificios en altura considerando la operación del clareado. El modelo de EF requiere modelar en su totalidad el edificio a estudiar. Es por ello que pese al buen grado de ajuste obtenido, la complejidad del modelo numérico hace que éste no sea práctico para los técnicos que trabajan en esta área.

En este capítulo, mediante los resultados obtenidos en los estudios experimentales, se busca validar un método simplificado que permita, mediante coeficientes de carga, evaluar la transmisión de cargas durante el proceso de cimbrado, clareado y descimbrado de edificios con forjados consecutivos de hormigón in situ.

Para poder simular la operación del clareado, es necesario que el método simplificado considere la rigidez real de los puntales, ya que el clareado no es sino una reducción de dicha rigidez. Teniendo en cuenta esta condición, los métodos simplificados que se analizarán en este capítulo son:

- Método Simplificado Mejorado (Duan y Chen, 1995)

- Método Simplificado de Fang et al. (2001a)

- Nuevo Procedimiento Simplificado (Calderón, 2011)

Las cargas estimadas por dichos métodos serán comparadas con las mediciones del estudio experimental (véase Capítulo 3) y con los resultados de los modelos numéricos (véase Capítulo 4).

\subsection{Métodos simplificados considerados}

En este apartado se resumen las hipótesis básicas de los métodos simplificados que van a ser aplicados posteriormente. Se han escogido estos métodos simplificados puesto que consideran la rigidez real de los puntales, lo cual los hace válidos para simular la operación del clareado. Los métodos que se describen a continuación están explicados con detalle el Capítulo 2. 


\subsubsection{Método Simplificado Mejorado (Duan y Chen, 1995)}

El Método Simplificado Mejorado (Duan y Chen, 1995) fue desarrollado en 1995 buscando, al igual que el Método Simplificado (Grundy y Kabaila, 1963), un procedimiento que no exigiese la utilización de ningún software de análisis estructural. La principal hipótesis de partida de este método se basa en considerar que los puntales tienen una rigidez finita, lo que permite simular la operación del clareado. Ésta es la principal diferencia con el método simplificado de Grundy y Kabaila (1963) que considera los puntales con un valor de rigidez infinita.

Las hipótesis consideradas por este método son las siguientes:

$\checkmark$ El comportamiento de los forjados se considera elástico, y su rigidez dependiente del tiempo.

$\checkmark$ Los puntales son simulados como elementos elásticos con una rigidez finita.

$\checkmark$ Los efectos de retracción y fluencia son despreciados.

$\checkmark$ Las cargas de los puntales se simulan como cargas uniformemente distribuidas sobre los forjados.

$\checkmark$ El modelo es incremental, es decir, que considera la acumulación de cargas y desplazamientos.

$\checkmark$ La cimentación se considera como infinitamente rígida.

En el apartado 2.3.1.7 de la presente Tesis Doctoral se explican detalladamente las expresiones para calcular las cargas durante el proceso constructivo correspondientes al Método Simplificado Mejorado (Duan y Chen, 1995).

\subsubsection{Método Simplificado de Fang et al. (2001a)}

En 2001, Fang et al. propusieron un nuevo método para el cálculo de la transmisión de cargas en la construcción de edificios en altura. La principal hipótesis de este nuevo método, es considerar que durante el curado del hormigón la rigidez de los elementos estructurales varía significativamente, y en consecuencia los esfuerzos en la estructura tienen que redistribuirse especialmente en forjados recién hormigonados.

El Método Simplificado de Fang et al. (2001a) considera las siguientes hipótesis:

$\checkmark$ Modelo bidimensional, considerando la unión entre puntales y forjado como una articulación.

$\checkmark$ Se considera la variación del módulo de elasticidad con el tiempo de los elementos de hormigón.

$\checkmark$ La cimentación se considera como infinitamente rígida.

$\checkmark$ Los efectos de retracción y fluencia son despreciados.

$\checkmark$ El modelo es incremental. Esto significa que considera la acumulación de cargas y desplazamientos.

$\checkmark$ El forjado recién hormigonado evoluciona desde una situación en que no soporta ninguna carga, hasta soportar parte de su peso propio, provocando una redistribución del peso propio del forjado proporcional a su ganancia de rigidez y a la rigidez del sistema de apuntalamiento. 
A partir de estas hipótesis se desarrolla una formulación basada en la relación entre la rigidez de los forjados y la rigidez de los puntales. Dicha formulación y una explicación más detallada de la aplicación de este método se recogen en el apartado 2.3.1.8 de la presente Tesis Doctoral.

\subsubsection{Nuevo Procedimiento Simplificado (Calderón et al., 2011)}

En 2011, Calderón et al. desarrollan un nuevo procedimiento simplificado que permite estimar las cargas en forjados y puntales durante la construcción de edificios de forjados consecutivos de hormigón in situ. El nuevo procedimiento simplificado, además de considerar la rigidez real del conjunto de puntales, presenta como novedades la hipótesis de que la deformación media del conjunto de puntales bajo un forjado coincide con la deformación media de dicho forjado, y la consideración de diferentes condiciones de contorno del forjado (vanos interiores, vanos extremos, vanos de esquina, etc.), estimando su deformabilidad mediante la aplicación del método de Scanlon y Murray (1982).

El Nuevo Procedimiento Simplificado (Calderón, 2011) ha sido hasta la fecha el único método empleado para estimar la transmisión de cargas entre forjados y puntales para un proceso constructivo de cimbrado, clareado y descimbrado, el cual es de uso habitual en España.

Las hipótesis consideradas en este método son las siguientes:

$\checkmark$ Se considera la variación del módulo de elasticidad con el tiempo de los elementos de hormigón.

$\checkmark$ La cimentación se considera como infinitamente rígida.

$\checkmark$ El modelo es incremental. Esto significa que considera la acumulación de cargas y desplazamientos.

$\checkmark$ Se considera a los puntales como elementos con un comportamiento elástico y de rigidez finita.

$\checkmark$ Se considera que las cargas transmitidas por los puntales a los forjados son uniformemente distribuidas.

$\checkmark$ Se considera que la deformación media del forjado coincide con la deformación media de los puntales dispuestos bajo dicho forjado.

$\checkmark$ Se consideran diferentes condiciones de contorno del forjado, estimando su deformabilidad mediante la aplicación del método de Scanlon y Murray (1982).

$\checkmark$ Se desprecian los efectos de retracción y fluencia.

La formulación del Nuevo Procedimiento Simplificado (Calderón, 2011) se encuentra detallada en el apartado 2.3.1.14 de la presente Tesis Doctoral.

\subsection{Aplicación de los métodos simplificados al edificio de forjado de losa maciza}

La geometría de la estructura y el proceso constructivo analizado son los descritos en el apartado 3.2 de la presente Tesis Doctoral. 


\subsubsection{Método Simplificado Mejorado (Duan y Chen, 1995)}

\section{$\checkmark$ Parámetros de cálculo vano de esquina}

Los diferentes parámetros para la aplicación de este método se describen en las Tablas 5.1 y 5.2 para los forjados y puntales, respectivamente.

Tabla 5.1 Parámetros del forjado para el método simplificado de Duan y Chen (1995) (Forjado losa maciza - Vano de esquina)

\begin{tabular}{cccc}
\hline $\boldsymbol{L}(\mathbf{m})$ & $\boldsymbol{E}_{\boldsymbol{j}}(\mathbf{G P a})$ & $\boldsymbol{I}\left(\mathbf{m}^{\mathbf{4}}\right)$ & $\boldsymbol{\gamma}$ \\
\hline 3.50 & Según Apéndice III & $8.873 \mathrm{E}-4$ & $1 / 185$ \\
\hline
\end{tabular}

$L$ es la longitud del vano del forjado, $E_{\mathrm{j}}$ es el módulo de elasticidad del hormigón de los forjados, $I$ el momento de inercia del forjado suponiendo un ancho de la unidad y $\gamma$ es un coeficiente que depende de las condiciones de contorno y la relación largo ancho del forjado.

Tabla 5.2 Parámetros de los puntales para el método simplificado de Duan y Chen (1995) (Forjado losa maciza - Vano de esquina)

\begin{tabular}{ccccc}
\hline Forjados & $\boldsymbol{H}(\mathbf{m})$ & $\begin{array}{c}\boldsymbol{E}_{\text {sh }} \\
(\mathbf{G P a})\end{array}$ & $\begin{array}{c}\boldsymbol{A}_{\text {Cimbrado }} \\
\left(\mathbf{m}^{\mathbf{2}}\right)\end{array}$ & $\begin{array}{c}\boldsymbol{A}_{\text {Clareado }} \\
\left.\mathbf{( m}^{2}\right)\end{array}$ \\
\hline F1 & 3.63 & 210 & $1.45 \mathrm{E}-3$ & $5.78 \mathrm{E}-4$ \\
F2 - F6 & 2.73 & 210 & $1.16 \mathrm{E}-3$ & $5.78 \mathrm{E}-4$ \\
\hline
\end{tabular}

$H$ es la altura de los puntales, $E_{s h}$ es el módulo de elasticidad de los puntales, $A_{\text {Cimbrado }}$ es la sumatoria del área de los puntales en la fase de cimbrado y $A_{\text {Clareado }}$ es la sumatoria del área de los puntales en la fase de clareado.

\section{$\checkmark$ Parámetros de cálculo vano de medianera}

Los diferentes parámetros para la aplicación de este método se describen en las Tablas 5.3 y 5.4 para los forjados y puntales, respectivamente.

Tabla 5.3 Parámetros del forjado para el método simplificado de Duan y Chen (1995) (Forjado losa maciza - Vano de medianera)

\begin{tabular}{cccc}
\hline $\boldsymbol{L}(\mathbf{m})$ & $\boldsymbol{E}_{\boldsymbol{j}}(\mathbf{G P a})$ & $\boldsymbol{I}\left(\mathbf{m}^{\mathbf{4}}\right)$ & $\boldsymbol{\gamma}$ \\
\hline 5.40 & Según Apéndice III & $8.873 \mathrm{E}-4$ & $1 / 384$ \\
\hline
\end{tabular}

$L$ es la longitud del vano del forjado, $E_{\mathrm{j}}$ es el módulo de elasticidad del hormigón de los forjados, I el momento de inercia del forjado suponiendo un ancho de la unidad y $\gamma$ es un coeficiente que depende de las condiciones de contorno y la relación largo/ancho del forjado. 
Tabla 5.4 Parámetros de los puntales para el método simplificado de Duan y Chen (1995) (Forjado losa maciza - Vano de medianera)

\begin{tabular}{ccccc}
\hline Forjados & $\boldsymbol{H}(\mathbf{m})$ & $\begin{array}{c}\boldsymbol{E}_{\text {sh }} \\
(\mathbf{G P a})\end{array}$ & $\begin{array}{c}\boldsymbol{A}_{\text {Cimbrado }} \\
\left(\mathbf{m}^{\mathbf{2}}\right)\end{array}$ & $\begin{array}{c}\boldsymbol{A}_{\text {Clareado }} \\
\left(\mathbf{m}^{\mathbf{2}}\right)\end{array}$ \\
\hline F1 & 3.63 & 210 & $2.02 \mathrm{E}-3$ & $8.67 \mathrm{E}-4$ \\
F2 - F6 & 2.73 & 210 & $1.45 \mathrm{E}-3$ & $8.67 \mathrm{E}-4$ \\
\hline
\end{tabular}

$H$ es la altura de los puntales, $E_{s h}$ es el módulo de elasticidad de los puntales, $A_{\text {Cimbrado }}$ es la sumatoria del área de los puntales en la fase de cimbrado y $A_{\text {Clareado }}$ es la sumatoria del área de los puntales en la fase de clareado.

\subsubsection{Resultados de la aplicación del método}

La Figura 5.1 muestra los resultados obtenidos aplicando el Método Simplificado Mejorado (Duan y Chen, 1995) para los vanos de esquina y medianera. Los resultados obtenidos con este método, al considerar las condiciones de contorno de los forjados, son diferentes para el vano de esquina y para el vano de medianera. Los resultados se muestran en coeficientes de carga en puntales y forjados. 

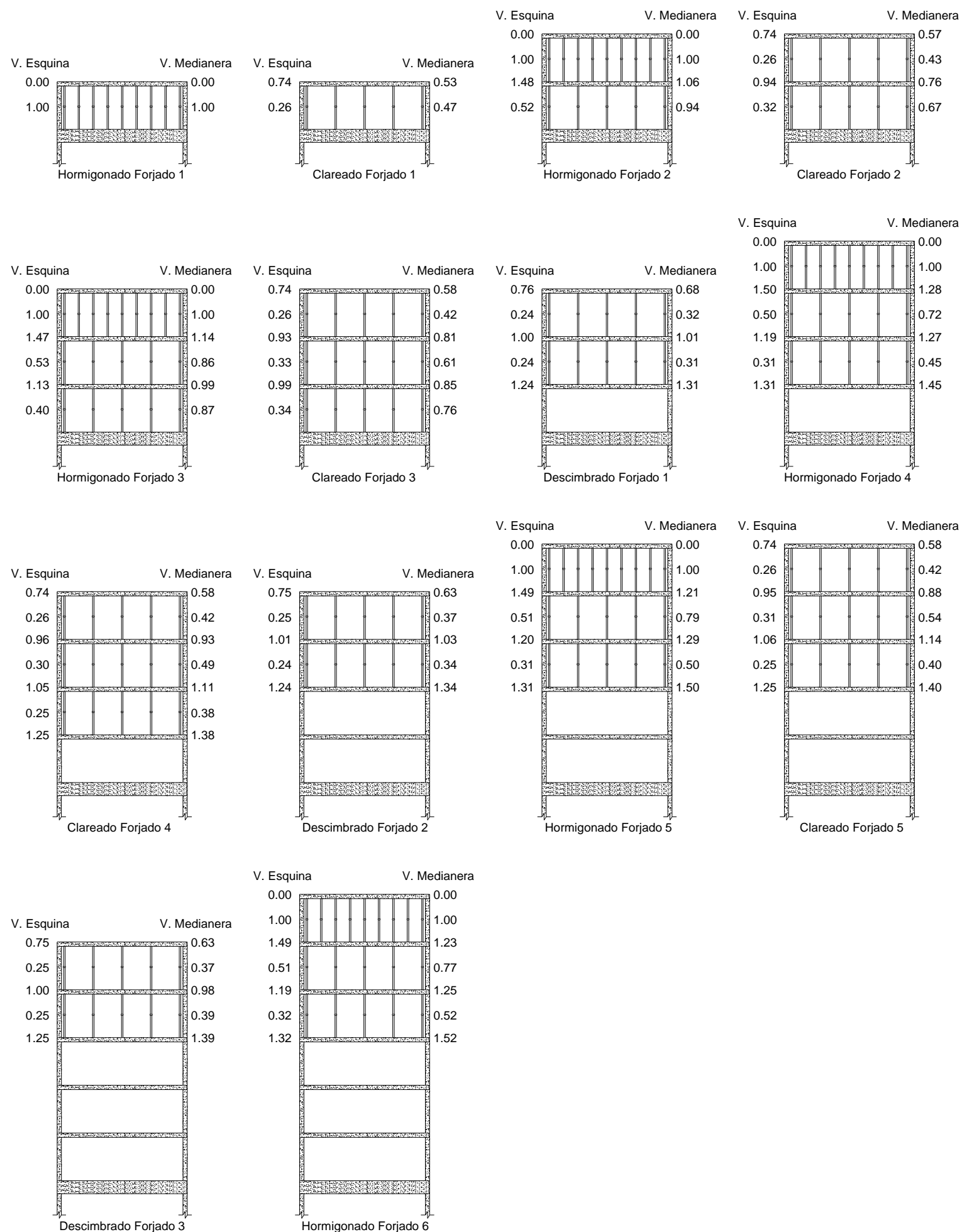

Fig. 5.1 Coeficientes de carga estimados con el método de Duan y Chen (1995) (Forjado de losa maciza) 


\subsubsection{Comparación de los resultados}

\section{$\checkmark$ Vano de esquina}

En la Tabla 5.5 se muestra una comparación de los coeficientes de carga en puntales determinados a partir del Método Simplificado Mejorado (Duan y Chen, 1995) $\left(C_{D \& C}\right)$, de las medidas del estudio experimental $\left(C_{E x p}\right)$ (véase Capítulo 3) y de los resultados del modelo de $\mathrm{EF}\left(C_{M E F}\right)$ (véase Capítulo 4), para el vano de esquina.

Tabla 5.5 Comparación entre los coeficientes de carga estimados con el método de Duan y Chen (1995) con las medidas experimentales y con los resultados del modelo de EF, para el vano de esquina (Forjado de losa maciza)

\begin{tabular}{|c|c|c|c|c|c|c|}
\hline Operación & Nivel & $C_{D \& C}$ & $C_{\text {exp }}$ & $\frac{C_{e x p}}{C_{D \& C}}$ & $C_{M E F}$ & $\frac{C_{M E F}}{C_{D \& C}}$ \\
\hline $\begin{array}{l}\text { Hormigonado } \\
\text { forjado } 1\end{array}$ & 1 & 1.00 & 1.00 & 1.00 & 0.98 & 0.98 \\
\hline Clareado forjado 1 & 1 & 0.26 & 0.36 & 1.38 & 0.43 & 1.66 \\
\hline \multirow{2}{*}{$\begin{array}{l}\text { Hormigonado } \\
\text { forjado } 2\end{array}$} & 2 & 1.00 & 0.99 & 0.99 & 0.98 & 0.98 \\
\hline & 1 & 0.52 & 0.64 & 1.23 & 0.86 & 1.66 \\
\hline \multirow{2}{*}{ Clareado forjado 2} & 2 & 0.26 & 0.50 & 1.92 & 0.40 & 1.53 \\
\hline & 1 & 0.32 & 0.68 & 2.13 & 0.64 & 2.01 \\
\hline \multirow{3}{*}{$\begin{array}{l}\text { Hormigonado } \\
\text { forjado } 3\end{array}$} & 3 & 1.00 & 0.98 & 0.98 & 0.98 & 0.98 \\
\hline & 2 & 0.53 & 0.73 & 1.38 & 0.79 & 1.49 \\
\hline & 1 & 0.40 & 0.82 & 2.05 & 0.85 & 2.13 \\
\hline \multirow{3}{*}{ Clareado forjado 3} & 3 & 0.26 & 0.52 & 2.00 & 0.40 & 1.53 \\
\hline & 2 & 0.33 & 0.54 & 1.64 & 0.59 & 1.80 \\
\hline & 1 & 0.34 & 0.69 & 2.03 & 0.76 & 2.22 \\
\hline \multirow{2}{*}{$\begin{array}{l}\text { Descimbrado } \\
\text { forjado } 1\end{array}$} & 3 & 0.24 & 0.36 & 1.50 & 0.30 & 1.25 \\
\hline & 2 & 0.24 & 0.29 & 1.21 & 0.32 & 1.33 \\
\hline \multirow{3}{*}{$\begin{array}{l}\text { Hormigonado } \\
\text { forjado } 4\end{array}$} & 4 & 1.00 & 1.02 & 1.02 & 0.98 & 0.98 \\
\hline & 3 & 0.50 & 0.44 & 0.88 & 0.66 & 1.33 \\
\hline & 2 & 0.31 & 0.46 & 1.48 & 0.47 & 1.51 \\
\hline \multirow{3}{*}{ Clareado forjado 4} & 4 & 0.26 & 0.49 & 1.88 & 0.39 & 1.51 \\
\hline & 3 & 0.30 & 0.52 & 1.73 & 0.49 & 1.62 \\
\hline & 2 & 0.25 & 0.53 & 2.12 & 0.41 & 1.64 \\
\hline \multirow{2}{*}{$\begin{array}{l}\text { Descimbrado } \\
\text { forjado } 2\end{array}$} & 3 & 0.25 & 0.36 & 1.44 & 0.34 & 1.38 \\
\hline & 2 & 0.24 & 0.38 & 1.58 & 0.34 & 1.44 \\
\hline \multirow{3}{*}{$\begin{array}{l}\text { Hormigonado } \\
\text { forjado } 5\end{array}$} & 5 & 1.00 & 1.00 & 1.00 & 0.97 & 0.97 \\
\hline & 4 & 0.51 & 0.45 & 0.88 & 0.71 & 1.38 \\
\hline & 3 & 0.31 & 0.46 & 1.48 & 0.49 & 1.59 \\
\hline \multirow{3}{*}{ Clareado forjado 5} & 5 & 0.26 & 0.42 & 1.62 & 0.39 & 1.52 \\
\hline & 4 & 0.31 & 0.47 & 1.52 & 0.53 & 1.71 \\
\hline & 3 & 0.25 & 0.67 & 2.68 & 0.44 & 1.74 \\
\hline \multirow{2}{*}{$\begin{array}{l}\text { Descimbrado } \\
\text { forjado } 3\end{array}$} & 5 & 0.25 & 0.36 & 1.44 & 0.34 & 1.37 \\
\hline & 4 & 0.25 & 0.38 & 1.52 & 0.38 & 1.52 \\
\hline \multirow{3}{*}{$\begin{array}{l}\text { Hormigonado } \\
\text { forjado } 6\end{array}$} & 6 & 1.00 & 1.01 & 1.01 & 0.98 & 0.98 \\
\hline & 5 & 0.51 & 0.58 & 1.14 & 0.71 & 1.38 \\
\hline & 4 & 0.32 & 0.41 & 1.28 & 0.53 & 1.65 \\
\hline Media & - & - & - & 1.49 & - & 1.48 \\
\hline Desviación Típica & - & - & - & 0.43 & - & 0.32 \\
\hline
\end{tabular}


Comparando las estimaciones obtenidas por el Método Simplificado Mejorado (Duan y Chen, 1995) con las medidas del modelo experimental y con los resultados del modelo de EF, se obtiene una media de los ratios $\frac{C_{\text {exp }}}{C_{D \& C}}$ y $\frac{C_{M E F}}{C_{D \& C}}$ muy similar del 49 y $48 \%$, respectivamente. Sin embargo, la desviación típica con respecto a las medidas experimentales es superior que la desviación obtenida para el caso del modelo de EF. Como muestran los resultados, la estimación que se obtiene con el Método Simplificado Mejorado (Duan y Chen, 1995), para el caso estudiado, no es buena.

\section{$\checkmark \quad$ Vano de medianera}

Tabla 5.6 Comparación entre los coeficientes de carga estimados con el método de Duan y Chen (1995) con las medidas experimentales y con los resultados del modelo de EF, para el vano de medianera (Forjado de losa maciza)

\begin{tabular}{|c|c|c|c|c|c|c|}
\hline Operación & Nivel & $C_{D \& C}$ & $C_{\text {exp }}$ & $\frac{C_{\text {exp }}}{C_{D \& C}}$ & $C_{M E F}$ & $\frac{C_{M E F}}{C_{D \& C}}$ \\
\hline $\begin{array}{l}\text { Hormigonado } \\
\text { forjado } 1\end{array}$ & 1 & 1.00 & 1.00 & 1.00 & 0.96 & 0.96 \\
\hline Clareado forjado 1 & 1 & 0.47 & 0.39 & 0.84 & 0.45 & 0.95 \\
\hline \multirow{2}{*}{$\begin{array}{l}\text { Hormigonado } \\
\text { forjado } 2\end{array}$} & 2 & 1.00 & 1.01 & 1.01 & 0.99 & 0.99 \\
\hline & 1 & 0.94 & 0.64 & 0.68 & 0.91 & 0.97 \\
\hline \multirow{2}{*}{ Clareado forjado 2} & 2 & 0.43 & 0.59 & 1.38 & 0.41 & 0.95 \\
\hline & 1 & 0.67 & 0.72 & 1.08 & 0.70 & 1.04 \\
\hline \multirow{3}{*}{$\begin{array}{l}\text { Hormigonado } \\
\text { forjado } 3\end{array}$} & 3 & 1.00 & 1.00 & 1.00 & 0.99 & 0.99 \\
\hline & 2 & 0.86 & 0.82 & 0.95 & 0.82 & 0.96 \\
\hline & 1 & 0.87 & 0.92 & 1.06 & 0.93 & 1.07 \\
\hline \multirow{3}{*}{ Clareado forjado 3} & 3 & 0.42 & 0.58 & 1.38 & 0.42 & 0.99 \\
\hline & 2 & 0.61 & 0.77 & 1.27 & 0.63 & 1.04 \\
\hline & 1 & 0.76 & 0.79 & 1.04 & 0.82 & 1.09 \\
\hline \multirow{2}{*}{$\begin{array}{l}\text { Descimbrado } \\
\text { forjado } 1\end{array}$} & 3 & 0.32 & 0.37 & 1.16 & 0.31 & 0.95 \\
\hline & 2 & 0.31 & 0.39 & 1.26 & 0.32 & 1.04 \\
\hline \multirow{3}{*}{$\begin{array}{l}\text { Hormigonado } \\
\text { forjado } 4\end{array}$} & 4 & 1.00 & 0.99 & 0.99 & 0.99 & 0.99 \\
\hline & 3 & 0.72 & 0.43 & 0.60 & 0.69 & 0.95 \\
\hline & 2 & 0.45 & 0.55 & 1.08 & 0.48 & 1.08 \\
\hline \multirow{3}{*}{ Clareado forjado 4} & 4 & 0.42 & 0.55 & 1.31 & 0.40 & 0.96 \\
\hline & 3 & 0.49 & 0.58 & 1.18 & 0.52 & 1.05 \\
\hline & 2 & 0.38 & 0.55 & 1.45 & 0.42 & 1.11 \\
\hline \multirow{2}{*}{$\begin{array}{l}\text { Descimbrado } \\
\text { forjado } 2\end{array}$} & 3 & 0.37 & 0.45 & 1.22 & 0.36 & 0.97 \\
\hline & 2 & 0.34 & 0.43 & 1.26 & 0.36 & 1.05 \\
\hline \multirow{3}{*}{$\begin{array}{l}\text { Hormigonado } \\
\text { forjado } 5\end{array}$} & 5 & 1.00 & 0.98 & 0.98 & 0.99 & 0.99 \\
\hline & 4 & 0.79 & 0.70 & 0.89 & 0.74 & 0.93 \\
\hline & 3 & 0.50 & 0.63 & 1.26 & 0.52 & 1.04 \\
\hline \multirow{3}{*}{ Clareado forjado 5} & 5 & 0.42 & 0.55 & 1.31 & 0.40 & 0.96 \\
\hline & 4 & 0.54 & 0.60 & 1.11 & 0.57 & 1.05 \\
\hline & 3 & 0.40 & 0.63 & 1.58 & 0.46 & 1.15 \\
\hline \multirow{2}{*}{$\begin{array}{l}\text { Descimbrado } \\
\text { forjado } 3\end{array}$} & 5 & 0.37 & 0.44 & 1.19 & 0.35 & 0.96 \\
\hline & 4 & 0.39 & 0.47 & 1.21 & 0.40 & 1.02 \\
\hline \multirow{3}{*}{$\begin{array}{l}\text { Hormigonado } \\
\text { forjado } 6\end{array}$} & 6 & 1.00 & 1.01 & 1.01 & 0.99 & 0.99 \\
\hline & 5 & 0.77 & 0.91 & 1.18 & 0.74 & 0.96 \\
\hline & 4 & 0.52 & 0.61 & 1.17 & 0.56 & 1.08 \\
\hline Media & - & - & - & 1.13 & - & 1.01 \\
\hline Desviación Típica & - & - & - & 0.20 & - & 0.05 \\
\hline
\end{tabular}


En la Tabla 5.6 se muestra una comparación de los coeficientes de carga en puntales determinados a partir del Método Simplificado Mejorado (Duan y Chen, 1995) $\left(C_{D \& C}\right)$, de las medidas del estudio experimental $\left(C_{E x p}\right)$ (véase Capítulo 3) y de los resultados del modelo de $\mathrm{EF}\left(C_{M E F}\right)$ (véase Capítulo 4), para el vano de medianera.

Comparando las estimaciones obtenidas por el Método Simplificado Mejorado (Duan y Chen, 1995) con las medidas del modelo experimental, se obtiene una media del ratio $\frac{C_{\text {exp }}}{C_{D \& C}}$ de 1.13 , con una desviación típica de 0.20. En cambio al realizar la comparación con los resultados del modelo de EF la media del ratio $\frac{C_{M E F}}{C_{D \& C}}$ es mucho menor (1.01) al igual que la desviación típica (0.05).

Se puede considerar que, para el caso estudiado, el Método Simplificado Mejorado (Duan y Chen, 1995) estima con un grado de ajuste bastante bueno las cargas que se presentan en puntales.

\subsubsection{Método Simplificado de Fang et al. (2001a)}

\section{$\checkmark$ Parámetros de cálculo vano de esquina}

Los diferentes parámetros para los forjados y puntales necesarios para la aplicación de este método se describen en las Tablas 5.7 y 5.8, respectivamente.

Tabla 5.7 Parámetros del forjado para el método simplificado de Fang et al. (2001a). (Forjado losa maciza - Vano de esquina)

\begin{tabular}{cccc}
\hline $\boldsymbol{L}(\mathbf{m})$ & $\boldsymbol{E}_{\boldsymbol{j}}(\mathbf{G P a})$ & $\boldsymbol{I}\left(\mathbf{m}^{\mathbf{4}}\right)$ & $\boldsymbol{\lambda}$ \\
\hline 3.50 & Según Apéndice III & $8.873 \mathrm{E}-4$ & 185 \\
\hline
\end{tabular}

$L$ es la longitud del vano del forjado, $E_{j}$ es el módulo de elasticidad del hormigón de los forjados, I el momento de inercia del forjado suponiendo un ancho de la unidad y $\lambda$ es un coeficiente que depende de las condiciones de contorno y la relación largo ancho del forjado.

Tabla 5.8 Parámetros de los puntales para el método simplificado de Fang et al. (2001a). (Forjado losa maciza - Vano de esquina)

\begin{tabular}{ccccccc}
\hline Forjados & $\begin{array}{c}\boldsymbol{L}_{\text {shore }} \\
(\mathbf{m})\end{array}$ & $\begin{array}{c}\boldsymbol{E}_{\text {shore }} \\
(\mathbf{G P a})\end{array}$ & $\begin{array}{c}\boldsymbol{A}_{\text {shore }} \\
\left(\mathbf{m}^{\mathbf{2}}\right)\end{array}$ & $\begin{array}{c}\mathbf{s} \\
(\mathbf{c i m b r a d o})\end{array}$ & $\begin{array}{c}\mathbf{s} \\
(\text { clareado) }\end{array}$ & $\boldsymbol{\rho}$ \\
\hline F1 & 3.63 & 210 & $2.89 \mathrm{E}-4$ & 5 & 2 & 1.00 \\
F2 - F6 & 2.73 & 210 & $2.89 \mathrm{E}-4$ & 4 & 2 & 1.00 \\
\hline
\end{tabular}

$L_{\text {shore }}$ es la longitud de los puntales, $E_{\text {shore, }}$ es el módulo de elasticidad de los puntales, $A_{\text {shore }}$ es el área de la sección transversal de los puntales, $\mathrm{s}$ es el número de puntales instalados en el vano considerado para cada uno de los procesos constructivos analizados y $\rho$ es el coeficiente que considera las cargas desiguales en los puntales.

\section{$\checkmark$ Parámetros de cálculo vano de medianera}

Los diferentes parámetros para los forjados y puntales necesarios para la aplicación de este método se describen en las Tablas 5.9 y 5.10 , respectivamente. 
Tabla 5.9 Parámetros del forjado para el método simplificado de Fang et al. (2001a) (Forjado losa maciza - Vano de medianera)

\begin{tabular}{cccc}
\hline $\boldsymbol{L}(\mathbf{m})$ & $\boldsymbol{E}_{\boldsymbol{j}}(\mathbf{G P a})$ & $\boldsymbol{I}\left(\mathbf{m}^{\mathbf{4}}\right)$ & $\boldsymbol{\lambda}$ \\
\hline 5.40 & Según Apéndice III & $8.873 \mathrm{E}-4$ & 384 \\
\hline
\end{tabular}

$L$ es la longitud del vano del forjado, $E_{j}$ es el módulo de elasticidad del hormigón de los forjados, I el momento de inercia del forjado suponiendo un ancho de la unidad y $\lambda$ es un coeficiente que depende de las condiciones de contorno y la relación largo ancho del forjado.

Tabla 5.10 Parámetros de los puntales para el método simplificado de Fang et al. (2001a) (Forjado losa maciza - Vano de medianera)

\begin{tabular}{|c|c|c|c|c|c|c|}
\hline Forjados & $\begin{array}{c}L_{\text {shore }} \\
\text { (m) }\end{array}$ & $\begin{array}{l}E_{\text {shore }} \\
(\mathbf{G P a})\end{array}$ & $\begin{array}{c}A_{\text {shore }} \\
\left(\mathbf{m}^{2}\right)\end{array}$ & $\begin{array}{c}\mathrm{S} \\
\text { (cimbrado) }\end{array}$ & $\begin{array}{c}\text { S } \\
\text { (clareado) }\end{array}$ & $\rho$ \\
\hline F1 & 3.63 & 210 & $2.89 \mathrm{E}-4$ & 7 & 3 & 1.00 \\
\hline $\mathrm{F} 2-\mathrm{F} 6$ & 2.73 & 210 & $2.89 \mathrm{E}-4$ & 5 & 3 & 1.00 \\
\hline
\end{tabular}

$L_{\text {shore }}$ es la longitud de los puntales, $E_{\text {shore, }}$ es el módulo de elasticidad de los puntales, $A_{\text {shore }}$ es el área de la sección transversal de los puntales, $s$ es el número de puntales instalados en el vano considerado para cada uno de los procesos constructivos analizados y $\rho$ es el coeficiente que considera las cargas desiguales en los puntales.

\subsubsection{Resultados de la aplicación del método}

En la Figura 5.2 se muestran los resultados obtenidos aplicando el Método Simplificado de Fang et al. (2001a) para los vanos de esquina y medianera. Los resultados obtenidos con el Método Simplificado de Fang et al. (2001a), al considerar las condiciones de contorno de los forjados, son diferentes para el vano de esquina y para el vano de medianera. Los resultados se muestran en coeficientes de carga en puntales y forjados. 

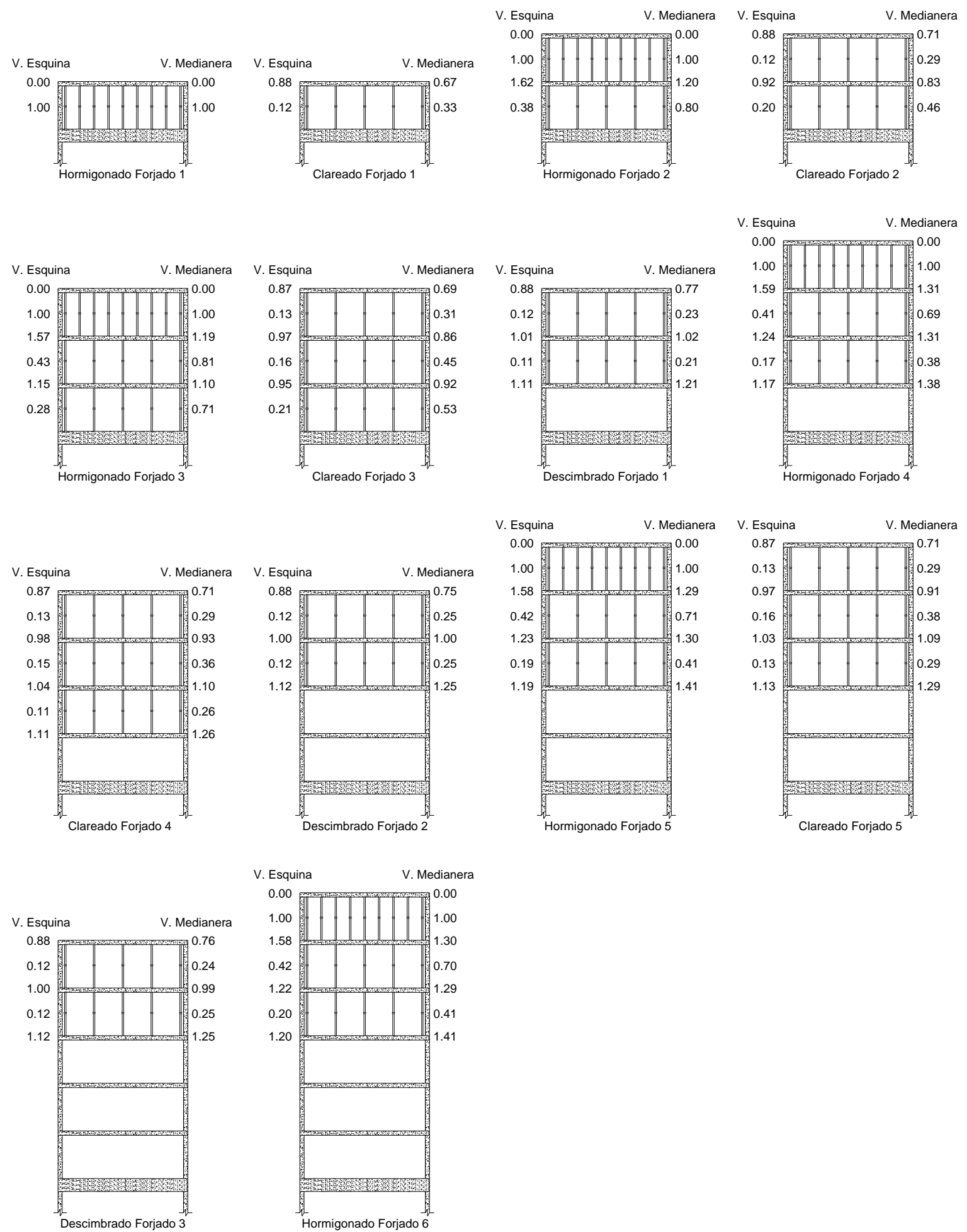

Fig. 5.2 Coeficientes de carga estimados con el método de Fang et al. (2001a) (Forjado de losa maciza) 


\subsubsection{Comparación de los resultados}

\section{$\checkmark$ Vano de esquina}

La Tabla 5.11 muestra una comparación de los coeficientes de carga en puntales determinados con el Método Simplificado de Fang et al. (2001a) $\left(C_{\text {Fang }}\right)$, con las medidas del estudio experimental $\left(C_{E x p}\right)$ (véase Capítulo 3 ) y con los resultados del modelo de $\mathrm{EF}\left(C_{M E F}\right)$ (véase Capítulo 4), para el vano de esquina.

Tabla 5.11 Comparación entre los coeficientes de carga estimados con el método de Fang et al. (2001a) con las medidas experimentales y con los resultados del modelo de EF, para el vano de esquina. (Forjado de losa maciza)

\begin{tabular}{|c|c|c|c|c|c|c|}
\hline Operación & Nivel & $C_{\text {Fang }}$ & $C_{\text {exp }}$ & $\frac{C_{\text {exp }}}{C_{\text {Fang }}}$ & $C_{M E F}$ & $\frac{C_{M E F}}{C_{F a n g}}$ \\
\hline $\begin{array}{l}\text { Hormigonado } \\
\text { forjado } 1\end{array}$ & 1 & 1.00 & 1.00 & 1.00 & 0.98 & 0.98 \\
\hline Clareado forjado 1 & 1 & 0.12 & 0.36 & 3.00 & 0.43 & 3.60 \\
\hline \multirow{2}{*}{$\begin{array}{l}\text { Hormigonado } \\
\text { forjado } 2\end{array}$} & 2 & 1.00 & 0.99 & 0.99 & 0.98 & 0.98 \\
\hline & 1 & 0.38 & 0.64 & 1.68 & 0.86 & 2.27 \\
\hline \multirow{2}{*}{ Clareado forjado 2} & 2 & 0.12 & 0.50 & 4.17 & 0.40 & 3.32 \\
\hline & 1 & 0.20 & 0.68 & 3.40 & 0.64 & 3.22 \\
\hline \multirow{3}{*}{$\begin{array}{l}\text { Hormigonado } \\
\text { forjado } 3\end{array}$} & 3 & 1.00 & 0.98 & 0.98 & 0.98 & 0.98 \\
\hline & 2 & 0.43 & 0.73 & 1.70 & 0.79 & 1.83 \\
\hline & 1 & 0.28 & 0.82 & 2.93 & 0.85 & 3.05 \\
\hline \multirow{3}{*}{ Clareado forjado 3} & 3 & 0.13 & 0.52 & 4.00 & 0.40 & 3.06 \\
\hline & 2 & 0.16 & 0.54 & 3.38 & 0.59 & 3.71 \\
\hline & 1 & 0.21 & 0.69 & 3.29 & 0.76 & 3.60 \\
\hline \multirow{2}{*}{$\begin{array}{l}\text { Descimbrado } \\
\text { forjado } 1\end{array}$} & 3 & 0.12 & 0.36 & 3.00 & 0.30 & 2.50 \\
\hline & 2 & 0.11 & 0.29 & 2.64 & 0.32 & 2.89 \\
\hline \multirow{3}{*}{$\begin{array}{l}\text { Hormigonado } \\
\text { forjado } 4\end{array}$} & 4 & 1.00 & 1.02 & 1.02 & 0.98 & 0.98 \\
\hline & 3 & 0.41 & 0.44 & 1.07 & 0.66 & 1.62 \\
\hline & 2 & 0.17 & 0.46 & 2.71 & 0.47 & 2.76 \\
\hline \multirow{3}{*}{ Clareado forjado 4} & 4 & 0.13 & 0.49 & 3.77 & 0.39 & 3.02 \\
\hline & 3 & 0.15 & 0.52 & 3.47 & 0.49 & 3.25 \\
\hline & 2 & 0.11 & 0.53 & 4.82 & 0.41 & 3.72 \\
\hline \multirow{2}{*}{$\begin{array}{l}\text { Descimbrado } \\
\text { forjado } 2\end{array}$} & 3 & 0.12 & 0.36 & 3.00 & 0.34 & 2.86 \\
\hline & 2 & 0.12 & 0.38 & 3.17 & 0.34 & 2.87 \\
\hline \multirow{3}{*}{$\begin{array}{l}\text { Hormigonado } \\
\text { forjado } 5\end{array}$} & 5 & 1.00 & 1.00 & 1.00 & 0.97 & 0.97 \\
\hline & 4 & 0.42 & 0.45 & 1.07 & 0.71 & 1.68 \\
\hline & 3 & 0.19 & 0.46 & 2.42 & 0.49 & 2.59 \\
\hline \multirow{3}{*}{ Clareado forjado 5} & 5 & 0.13 & 0.42 & 3.23 & 0.39 & 3.03 \\
\hline & 4 & 0.16 & 0.47 & 2.94 & 0.53 & 3.32 \\
\hline & 3 & 0.13 & 0.67 & 5.15 & 0.44 & 3.35 \\
\hline \multirow{2}{*}{$\begin{array}{l}\text { Descimbrado } \\
\text { forjado } 3\end{array}$} & 5 & 0.12 & 0.36 & 3.00 & 0.34 & 2.85 \\
\hline & 4 & 0.12 & 0.38 & 3.17 & 0.38 & 3.16 \\
\hline \multirow{3}{*}{$\begin{array}{l}\text { Hormigonado } \\
\text { forjado } 6\end{array}$} & 6 & 1.00 & 1.01 & 1.01 & 0.98 & 0.98 \\
\hline & 5 & 0.42 & 0.58 & 1.38 & 0.71 & 1.68 \\
\hline & 4 & 0.20 & 0.41 & 2.05 & 0.53 & 2.64 \\
\hline Media & - & - & - & 2.59 & - & 2.53 \\
\hline Desviación Típica & - & - & - & 1.17 & - & 0.91 \\
\hline
\end{tabular}


Comparando las estimaciones obtenidas por el Método Simplificado de Fang et al. (2001a) con las medidas del modelo experimental, se obtiene una media del ratio $\frac{C_{\text {exp }}}{C_{\text {Fang }}}$ de 2.59 con una desviación típica de 1.17. Si se comparan los resultados del modelo de EF con los del método de Fang et al. se obtienen resultados similares $\left(\frac{C_{M E F}}{C_{F a n g}}=2.53\right.$ y desviación típica de 0.91$)$.

Los coeficientes de carga obtenidos por el Método Simplificado de Fang et al. (2001a) difieren considerablemente de los obtenidos de forma experimental y de forma numérica. Por lo tanto, este método no resulta adecuado para predecir las cargas en puntales en este edificio y con este proceso constructivo.

\section{Vano de medianera}

La Tabla 5.12 muestra una comparación de los coeficientes de carga en puntales determinados con el Método Simplificado de Fang et al. (2001a) $\left(C_{F a n g}\right)$, con las medidas del estudio experimental $\left(C_{\text {Exp }}\right)$ (véase Capítulo 3) y con los resultados del modelo de $\mathrm{EF}\left(C_{M E F}\right)$ (véase Capítulo 4), para el vano de medianera.

Tabla 5.12 Comparación entre los coeficientes de carga estimados con el método de Fang et al. (2001a) con las medidas experimentales y con los resultados del modelo de EF, para el vano de medianera (Forjado de losa maciza)

\begin{tabular}{|c|c|c|c|c|c|c|}
\hline Operación & Nivel & $C_{\text {Fang }}$ & $C_{e x p}$ & $\frac{C_{\text {exp }}}{C_{\text {Fang }}}$ & $C_{M E F}$ & $\frac{C_{M E F}}{C_{\text {Fang }}}$ \\
\hline $\begin{array}{l}\text { Hormigonado } \\
\text { forjado } 1\end{array}$ & 1 & 1.00 & 1.00 & 1.00 & 0.96 & 0.96 \\
\hline Clareado forjado 1 & 1 & 0.33 & 0.39 & 1.19 & 0.45 & 1.35 \\
\hline \multirow{2}{*}{$\begin{array}{l}\text { Hormigonado } \\
\text { forjado } 2\end{array}$} & 2 & 1.00 & 1.01 & 1.01 & 0.99 & 0.99 \\
\hline & 1 & 0.80 & 0.64 & 0.80 & 0.91 & 1.14 \\
\hline \multirow{2}{*}{ Clareado forjado 2} & 2 & 0.29 & 0.59 & 2.05 & 0.41 & 1.40 \\
\hline & 1 & 0.46 & 0.72 & 1.57 & 0.70 & 1.52 \\
\hline \multirow{3}{*}{$\begin{array}{l}\text { Hormigonado } \\
\text { forjado } 3\end{array}$} & 3 & 1.00 & 1.00 & 1.00 & 0.99 & 0.99 \\
\hline & 2 & 0.81 & 0.82 & 1.01 & 0.82 & 1.02 \\
\hline & 1 & 0.71 & 0.92 & 1.29 & 0.93 & 1.31 \\
\hline \multirow{3}{*}{ Clareado forjado 3} & 3 & 0.31 & 0.58 & 1.86 & 0.42 & 1.35 \\
\hline & 2 & 0.45 & 0.77 & 1.72 & 0.63 & 1.41 \\
\hline & 1 & 0.53 & 0.79 & 1.49 & 0.82 & 1.56 \\
\hline \multirow{2}{*}{$\begin{array}{l}\text { Descimbrado } \\
\text { forjado } 1\end{array}$} & 3 & 0.23 & 0.37 & 1.61 & 0.31 & 1.33 \\
\hline & 2 & 0.21 & 0.39 & 1.86 & 0.32 & 1.53 \\
\hline \multirow{3}{*}{$\begin{array}{l}\text { Hormigonado } \\
\text { forjado } 4\end{array}$} & 4 & 1.00 & 0.99 & 0.99 & 0.99 & 0.99 \\
\hline & 3 & 0.69 & 0.43 & 0.62 & 0.69 & 1.00 \\
\hline & 2 & 0.38 & 0.55 & 1.45 & 0.48 & 1.28 \\
\hline \multirow{3}{*}{ Clareado forjado 4} & 4 & 0.29 & 0.55 & 1.90 & 0.40 & 1.39 \\
\hline & 3 & 0.36 & 0.58 & 1.61 & 0.52 & 1.43 \\
\hline & 2 & 0.26 & 0.55 & 2.12 & 0.42 & 1.62 \\
\hline \multirow{2}{*}{$\begin{array}{l}\text { Descimbrado } \\
\text { forjado } 2\end{array}$} & 3 & 0.25 & 0.45 & 1.80 & 0.36 & 1.43 \\
\hline & 2 & 0.25 & 0.43 & 1.72 & 0.36 & 1.43 \\
\hline \multirow{3}{*}{$\begin{array}{l}\text { Hormigonado } \\
\text { forjado } 5\end{array}$} & 5 & 1.00 & 0.98 & 0.98 & 0.99 & 0.99 \\
\hline & 4 & 0.71 & 0.70 & 0.99 & 0.74 & 1.04 \\
\hline & 3 & 0.41 & 0.63 & 1.54 & 0.52 & 1.27 \\
\hline
\end{tabular}




\begin{tabular}{ccccccc}
\hline Operación & Nivel & $\boldsymbol{C}_{\boldsymbol{F a n g}}$ & $\boldsymbol{C}_{\boldsymbol{e x p}}$ & $\frac{\boldsymbol{C}_{\boldsymbol{e x p}}}{\boldsymbol{C}_{\boldsymbol{F a n g}}}$ & $\boldsymbol{C}_{\boldsymbol{M E F}}$ & $\frac{\boldsymbol{C}_{\boldsymbol{M E F}}}{\boldsymbol{C}_{\boldsymbol{F a n g}}}$ \\
\hline \multirow{2}{*}{ Clareado forjado 5 } & 5 & 0.29 & 0.55 & 1.90 & 0.40 & 1.39 \\
& 4 & 0.38 & 0.60 & 1.58 & 0.57 & 1.50 \\
\hline Descimbrado & 5 & 0.29 & 0.63 & 2.17 & 0.46 & 1.58 \\
forjado 3 & 4 & 0.24 & 0.44 & 1.83 & 0.35 & 1.48 \\
\hline Hormigonado & 6 & 0.25 & 0.47 & 1.88 & 0.40 & 1.58 \\
forjado 6 & 5 & 0.70 & 1.01 & 1.01 & 0.99 & 0.99 \\
& 4 & 0.41 & 0.91 & 1.30 & 0.74 & 1.05 \\
\hline Media & - & - & - & 1.49 & 0.56 & 1.37 \\
\hline Desviación Típica & - & - & - & $\mathbf{0 . 4 1}$ & - & $\mathbf{1 . 2 9}$ \\
\hline
\end{tabular}

Al comparar las estimaciones obtenidas por el Método Simplificado de Fang et al. (2001a) con las medidas del modelo experimental, se obtiene una media del ratio $\frac{C_{\text {exp }}}{C_{F a n g}}$ de 1.46, con una desviación típica de 0.41. Al realizar la comparación con los resultados del modelo de EF, se obtienen resultados algo mejores, siendo la media del ratio $\frac{C_{M E F}}{C_{F a n g}}$ igual a 1.29 y la desviación típica de 0.21 . Aun así, a la vista de los resultados, se puede concluir que el Método Simplificado de Fang et al. (2001a) no es un método válido para estimar las cargas en puntales en este caso, puesto que subestima dichas cargas.

\subsubsection{Nuevo Procedimiento Simplificado (Calderón et al., 2011)}

\section{$\checkmark$ Parámetros de cálculo vano de esquina}

Los diferentes parámetros para la aplicación de este método se describen en las Tablas 5.13 y 5.14 para los forjados y puntales, respectivamente.

Tabla 5.13 Parámetros del forjado para el nuevo procedimiento simplificado de Calderón et al. (2011) (Forjado losa maciza Vano de esquina)

\begin{tabular}{cccc}
\hline $\boldsymbol{L}_{\boldsymbol{x}}(\mathbf{m})$ & $\boldsymbol{L}_{\boldsymbol{y}}(\mathbf{m})$ & $\boldsymbol{E}_{\boldsymbol{j}}(\mathbf{G P a})$ & $\boldsymbol{I}\left(\mathbf{m}^{\mathbf{4}}\right)$ \\
\hline \multirow{2}{*}{3.50} & \multirow{2}{*}{4.50} & \multirow{2}{*}{ Según Apéndice III } & $\begin{array}{c}7.76 \mathrm{E}-4 \\
\end{array}$ \\
\end{tabular}

$L_{x}$ es la luz entre cara de pilares en la dirección x (perpendicular a las sopandas), $L_{y}$ es la luz entre cara de pilares en la dirección y (dirección de las sopandas), $E_{\mathrm{j}}$ es el módulo de elasticidad del hormigón de los forjados e $I$ es el momento de inercia bruta de la sección de la banda considerada.

Tabla 5.14 Parámetros de los puntales para el nuevo procedimiento simplificado de Calderón et al. (2011) (Forjado losa maciza - Vano de esquina)

\begin{tabular}{ccccc}
\hline Forjados & $\boldsymbol{H}(\mathbf{m})$ & $\begin{array}{c}\boldsymbol{E}_{\boldsymbol{s h}} \\
(\mathbf{G P a})\end{array}$ & $\begin{array}{c}\boldsymbol{A}_{\text {Cimbrado }} \\
\left(\mathbf{m}^{\mathbf{2}}\right)\end{array}$ & $\begin{array}{c}\boldsymbol{A}_{\text {Clareado }} \\
\left(\mathbf{m}^{2}\right)\end{array}$ \\
\hline F1 & 3.63 & 210 & $1.45 \mathrm{E}-3$ & $5.78 \mathrm{E}-4$ \\
F2 - F6 & 2.73 & 210 & $1.16 \mathrm{E}-3$ & $5.78 \mathrm{E}-4$ \\
\hline
\end{tabular}


$H$ es la altura de los puntales, $E_{S h}$ es el módulo de elasticidad de los puntales, $A_{\text {Cimbrado }}$ es la sumatoria del área de los puntales en la fase de cimbrado y $A_{\text {Clareado }}$ es la sumatoria del área de los puntales en la fase de clareado.

\section{$\checkmark$ Parámetros de cálculo vano de medianera}

Los diferentes parámetros para la aplicación de este método se describen en las Tablas 5.15 y 5.16 para los forjados y puntales, respectivamente.

Tabla 5.15 Parámetros del forjado para el nuevo procedimiento simplificado de Calderón et al. (2011) (Forjado losa maciza Vano de medianera)

\begin{tabular}{cccc}
\hline $\boldsymbol{L}_{\boldsymbol{x}}(\mathbf{m})$ & $\boldsymbol{L}_{\boldsymbol{y}}(\mathbf{m})$ & $\boldsymbol{E}_{\boldsymbol{j}}(\mathbf{G P a})$ & $\boldsymbol{I}\left(\mathbf{m}^{\mathbf{4}}\right)$ \\
\hline \multirow{2}{*}{5.40} & \multirow{2}{*}{5.20} & \multirow{2}{*}{ Según Apéndice III } & $1.15 \mathrm{E}-3$ \\
& & & $1.20 \mathrm{E}-3$ \\
\hline
\end{tabular}

$L_{x}$ es la luz entre cara de pilares en la dirección x (perpendicular a las sopandas), $L_{y}$ es la luz entre cara de pilares en la dirección y (dirección de las sopandas), $E_{\mathrm{j}}$ es el módulo de elasticidad del hormigón de los forjados e $I$ es el momento de inercia bruta de la sección de la banda considerada.

Tabla 5.16 Parámetros de los puntales para el nuevo procedimiento simplificado de Calderón et al. (2011) (Forjado losa maciza - Vano de medianera)

\begin{tabular}{ccccc}
\hline Forjados & $\boldsymbol{H}(\mathbf{m})$ & $\begin{array}{c}\boldsymbol{E}_{\boldsymbol{s h}} \\
(\mathbf{G P a})\end{array}$ & $\begin{array}{c}\boldsymbol{A}_{\text {Cimbrado }} \\
\left(\mathbf{m}^{\mathbf{2}}\right)\end{array}$ & $\begin{array}{c}\boldsymbol{A}_{\text {Clareado }} \\
\left(\mathbf{m}^{2}\right)\end{array}$ \\
\hline F1 & 3.63 & 210 & $2.02 \mathrm{E}-3$ & $8.67 \mathrm{E}-4$ \\
F2 - F6 & 2.73 & 210 & $1.45 \mathrm{E}-3$ & $8.67 \mathrm{E}-4$ \\
\hline
\end{tabular}

$H$ es la altura de los puntales, $E_{s h}$ es el módulo de elasticidad de los puntales, $A_{\text {Cimbrado }}$ es la sumatoria del área de los puntales en la fase de cimbrado y $A_{\text {Clareado }}$ es la sumatoria del área de los puntales en la fase de clareado.

\subsubsection{Resultados de la aplicación del método}

La Figura 5.3 muestra los resultados obtenidos aplicando el Nuevo Procedimiento Simplificado (Calderón et al. 2011) para los vanos de esquina y medianera. Los resultados obtenidos con dicho procedimiento, al considerar las condiciones de contorno de los forjados, son diferentes para el vano de esquina y para el vano de medianera. Los resultados se muestran en coeficientes de carga en puntales y forjados. 

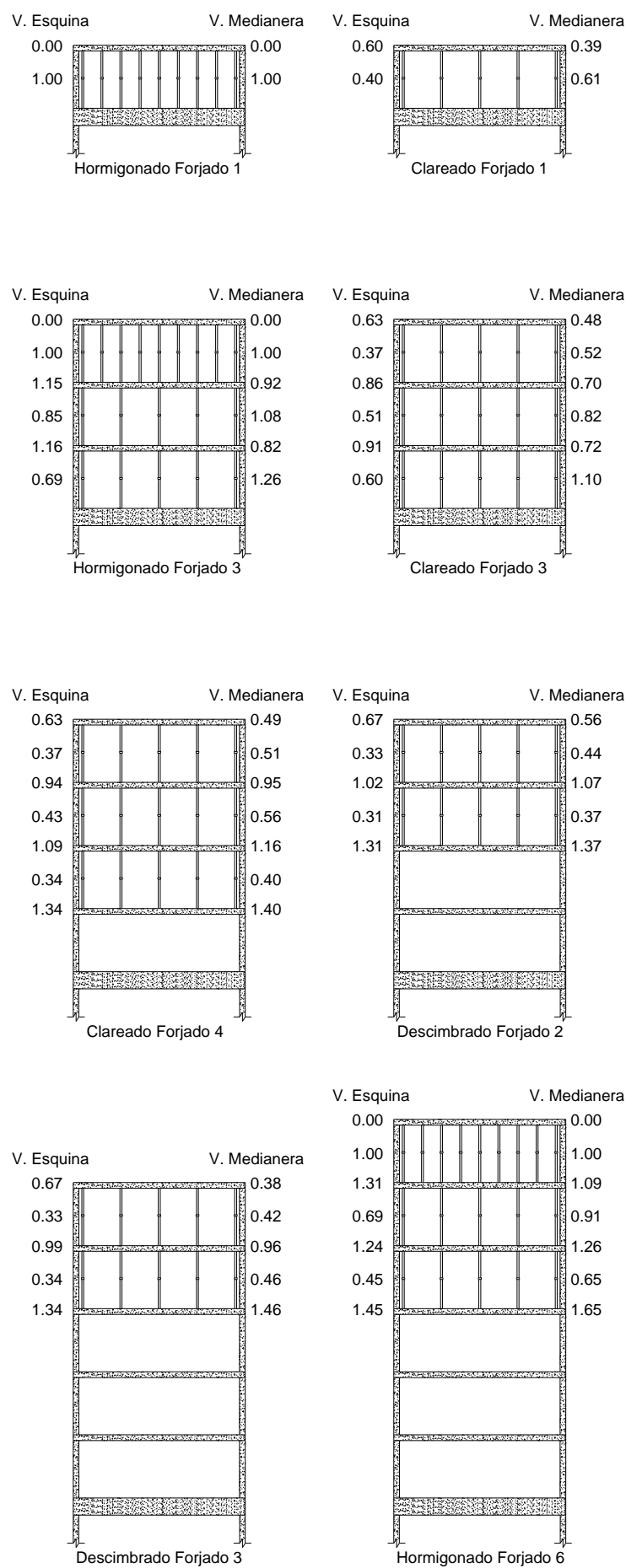
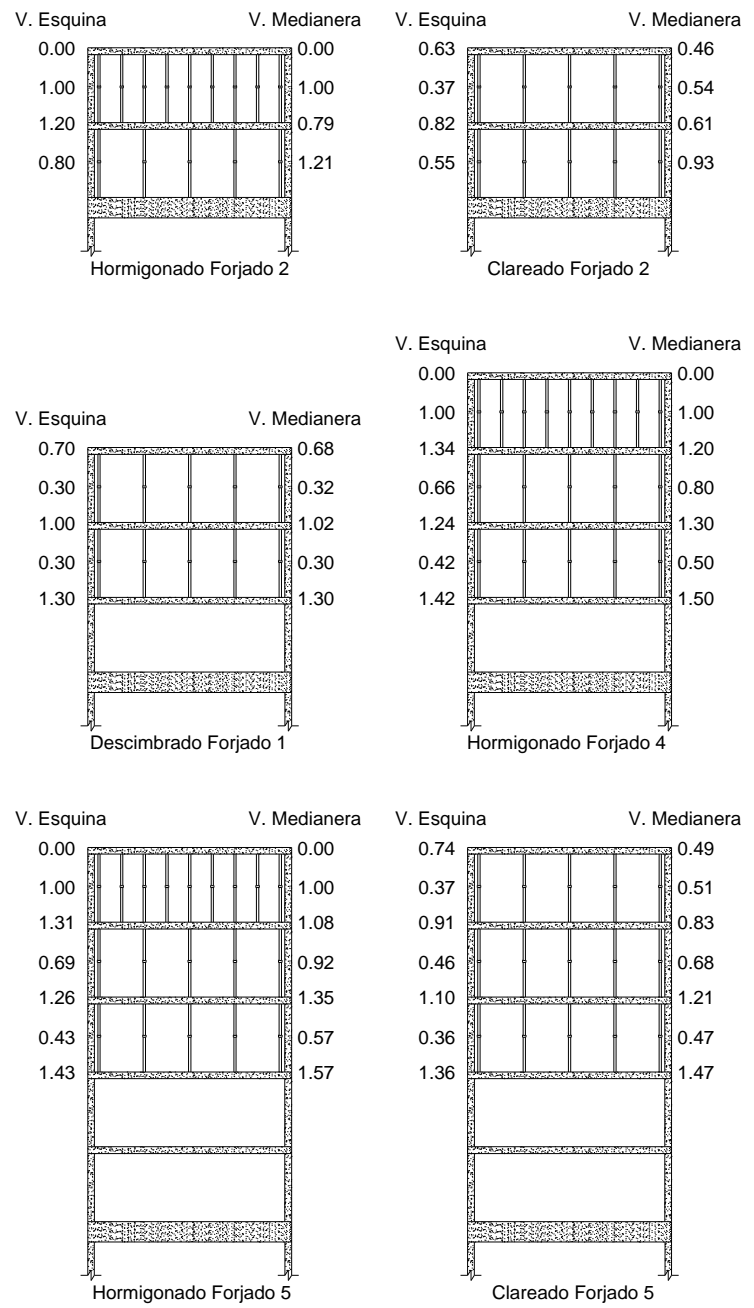

Fig. 5.3 Coeficientes de carga estimados con el método de Calderón et al. (2011) (Forjado de losa maciza) 


\subsubsection{Comparación de los resultados}

\section{$\checkmark$ Vano de esquina}

En la Tabla 5.17 se muestra una comparación de los coeficientes de carga media en puntales determinados a partir del Nuevo Procedimiento Simplificado (Calderón et al. 2011) $\left(C_{N P S}\right)$, de las medidas del estudio experimental $\left(C_{E x p}\right)$ (véase Capítulo 3) y de los resultados del modelo de EF $\left(C_{M E F}\right)$ (véase Capítulo 4$)$, para el vano de esquina.

Tabla 5.17 Comparación entre los coeficientes de carga estimados con el método de Calderón et al. (2011) con las medidas experimentales y con los resultados del modelo de EF, para el vano de esquina. (Forjado de losa maciza)

\begin{tabular}{|c|c|c|c|c|c|c|}
\hline Operación & Nivel & $C_{N P S}$ & $C_{\text {exp }}$ & $\frac{C_{\text {exp }}}{C_{N P S}}$ & $C_{M E F}$ & $\frac{C_{M E F}}{C_{N P S}}$ \\
\hline $\begin{array}{l}\text { Hormigonado } \\
\text { forjado } 1\end{array}$ & 1 & 1.00 & 1.00 & 1.00 & 0.98 & 0.98 \\
\hline Clareado forjado 1 & 1 & 0.40 & 0.36 & 0.90 & 0.43 & 1.08 \\
\hline \multirow{2}{*}{$\begin{array}{l}\text { Hormigonado } \\
\text { forjado } 2\end{array}$} & 2 & 1.00 & 0.99 & 0.99 & 0.98 & 0.98 \\
\hline & 1 & 0.80 & 0.64 & 0.80 & 0.86 & 1.08 \\
\hline \multirow{2}{*}{ Clareado forjado 2} & 2 & 0.37 & 0.50 & 1.34 & 0.40 & 1.07 \\
\hline & 1 & 0.55 & 0.68 & 1.25 & 0.64 & 1.18 \\
\hline \multirow{3}{*}{$\begin{array}{l}\text { Hormigonado } \\
\text { forjado } 3\end{array}$} & 3 & 1.00 & 0.98 & 0.98 & 0.98 & 0.98 \\
\hline & 2 & 0.85 & 0.73 & 0.98 & 0.79 & 1.06 \\
\hline & 1 & 0.69 & 0.82 & 1.19 & 0.85 & 1.24 \\
\hline \multirow{3}{*}{ Clareado forjado 3} & 3 & 0.37 & 0.52 & 1.41 & 0.40 & 1.08 \\
\hline & 2 & 0.51 & 0.54 & 1.06 & 0.59 & 1.17 \\
\hline & 1 & 0.60 & 0.69 & 1.15 & 0.76 & 1.26 \\
\hline \multirow{2}{*}{$\begin{array}{l}\text { Descimbrado } \\
\text { forjado } 1\end{array}$} & 3 & 0.30 & 0.36 & 1.19 & 0.30 & 0.99 \\
\hline & 2 & 0.30 & 0.29 & 0.96 & 0.32 & 1.06 \\
\hline \multirow{3}{*}{$\begin{array}{l}\text { Hormigonado } \\
\text { forjado } 4\end{array}$} & 4 & 1.00 & 1.02 & 1.02 & 0.98 & 0.98 \\
\hline & 3 & 0.66 & 0.44 & 0.67 & 0.66 & 1.00 \\
\hline & 2 & 0.42 & 0.46 & 1.11 & 0.47 & 1.13 \\
\hline \multirow{3}{*}{ Clareado forjado 4} & 4 & 0.37 & 0.49 & 1.33 & 0.39 & 1.06 \\
\hline & 3 & 0.43 & 0.52 & 1.20 & 0.49 & 1.13 \\
\hline & 2 & 0.34 & 0.53 & 1.55 & 0.41 & 1.20 \\
\hline \multirow{2}{*}{$\begin{array}{l}\text { Descimbrado } \\
\text { forjado } 2\end{array}$} & 3 & 0.33 & 0.36 & 1.09 & 0.34 & 1.04 \\
\hline & 2 & 0.31 & 0.38 & 1.21 & 0.34 & 1.10 \\
\hline \multirow{3}{*}{$\begin{array}{l}\text { Hormigonado } \\
\text { forjado } 5\end{array}$} & 5 & 1.00 & 1.00 & 1.00 & 0.97 & 0.97 \\
\hline & 4 & 0.69 & 0.45 & 0.65 & 0.71 & 1.02 \\
\hline & 3 & 0.43 & 0.46 & 1.07 & 0.49 & 1.15 \\
\hline \multirow{3}{*}{ Clareado forjado 5} & 5 & 0.37 & 0.42 & 1.14 & 0.39 & 1.07 \\
\hline & 4 & 0.46 & 0.47 & 1.02 & 0.53 & 1.15 \\
\hline & 3 & 0.36 & 0.67 & 1.88 & 0.44 & 1.22 \\
\hline \multirow{2}{*}{$\begin{array}{l}\text { Descimbrado } \\
\text { forjado } 3\end{array}$} & 5 & 0.33 & 0.36 & 1.09 & 0.34 & 1.03 \\
\hline & 4 & 0.34 & 0.38 & 1.12 & 0.38 & 1.12 \\
\hline \multirow{3}{*}{$\begin{array}{l}\text { Hormigonado } \\
\text { forjado } 6\end{array}$} & 6 & 1.00 & 1.01 & 1.01 & 0.98 & 0.98 \\
\hline & 5 & 0.69 & 0.58 & 0.84 & 0.71 & 1.02 \\
\hline & 4 & 0.45 & 0.41 & 0.91 & 0.53 & 1.17 \\
\hline Media & - & - & - & 1.09 & - & 1.08 \\
\hline Desviación Típica & - & - & - & 0.23 & - & 0.08 \\
\hline
\end{tabular}


Comparando las estimaciones obtenidas por el Nuevo Procedimiento Simplificado (Calderón et al., 2011) con las medidas del modelo experimental y con los resultados del modelo de EF, se obtiene una media de los ratios $\frac{C_{e x p}}{C_{N P S}}$ y $\frac{C_{M E F}}{C_{N P S}}$ muy similar del 9 y $8 \%$, respectivamente. Sin embargo, la desviación típica con respecto a las medidas experimentales es superior que la desviación obtenida para el caso del modelo de EF.

Considerando el grado de simplificación que se logra al aplicar el Nuevo Procedimiento Simplificado (Calderón et al., 2011), se puede considerar que dicho método estima con un buen grado de ajuste las cargas que se presentan en puntales para el proceso constructivo empleado en el caso estudiado.

\section{$\checkmark$ Vano de medianera}

En la Tabla 5.18 se muestra una comparación de los coeficientes de carga media en puntales determinados a partir Nuevo Procedimiento Simplificado (Calderón et al. 2011) $\left(C_{N P S}\right.$ ), de las medidas del estudio experimental $\left(C_{E x p}\right)$ (véase Capítulo 3$)$ y de los resultados del modelo de $\mathrm{EF}\left(C_{M E F}\right)$ (véase Capítulo 4), para el vano de medianera.

Tabla 5.18 Comparación entre los coeficientes de carga estimados con el método de Calderón et al. (2011) con las medidas experimentales y con los resultados del modelo de EF, para el vano de medianera. (Forjado de losa maciza)

\begin{tabular}{|c|c|c|c|c|c|c|}
\hline Operación & Nivel & $C_{N P S}$ & $C_{\text {exp }}$ & $\frac{C_{\text {exp }}}{C_{N P S}}$ & $C_{M E F}$ & $\frac{C_{M E F}}{C_{N P S}}$ \\
\hline $\begin{array}{l}\text { Hormigonado } \\
\text { forjado } 1\end{array}$ & 1 & 1.00 & 1.00 & 1.00 & 0.96 & 0.96 \\
\hline Clareado forjado 1 & 1 & 0.61 & 0.39 & 0.65 & 0.45 & 0.73 \\
\hline \multirow{2}{*}{$\begin{array}{l}\text { Hormigonado } \\
\text { forjado } 2\end{array}$} & 2 & 1.00 & 1.01 & 1.01 & 0.99 & 0.99 \\
\hline & 1 & 1.21 & 0.64 & 0.53 & 0.91 & 0.75 \\
\hline \multirow{2}{*}{ Clareado forjado 2} & 2 & 0.54 & 0.59 & 1.10 & 0.41 & 0.75 \\
\hline & 1 & 0.93 & 0.72 & 0.77 & 0.70 & 0.75 \\
\hline \multirow{3}{*}{$\begin{array}{l}\text { Hormigonado } \\
\text { forjado } 3\end{array}$} & 3 & 1.00 & 1.00 & 1.00 & 0.99 & 0.99 \\
\hline & 2 & 1.08 & 0.82 & 0.76 & 0.82 & 0.76 \\
\hline & 1 & 1.26 & 0.92 & 0.73 & 0.93 & 0.74 \\
\hline \multirow{3}{*}{ Clareado forjado 3} & 3 & 0.52 & 0.58 & 1.12 & 0.42 & 0.81 \\
\hline & 2 & 0.82 & 0.77 & 0.95 & 0.63 & 0.78 \\
\hline & 1 & 1.10 & 0.79 & 0.72 & 0.82 & 0.75 \\
\hline \multirow{2}{*}{$\begin{array}{l}\text { Descimbrado } \\
\text { forjado } 1\end{array}$} & 3 & 0.32 & 0.37 & 1.17 & 0.31 & 0.97 \\
\hline & 2 & 0.30 & 0.39 & 1.29 & 0.32 & 1.07 \\
\hline \multirow{3}{*}{$\begin{array}{l}\text { Hormigonado } \\
\text { forjado } 4\end{array}$} & 4 & 1.00 & 0.99 & 0.99 & 0.99 & 0.99 \\
\hline & 3 & 0.80 & 0.43 & 0.54 & 0.69 & 0.86 \\
\hline & 2 & 0.50 & 0.55 & 1.11 & 0.48 & 0.97 \\
\hline \multirow{3}{*}{ Clareado forjado 4} & 4 & 0.51 & 0.55 & 1.08 & 0.40 & 0.79 \\
\hline & 3 & 0.56 & 0.58 & 1.04 & 0.52 & 0.92 \\
\hline & 2 & 0.40 & 0.55 & 1.38 & 0.42 & 1.06 \\
\hline \multirow{2}{*}{$\begin{array}{l}\text { Descimbrado } \\
\text { forjado } 2\end{array}$} & 3 & 0.44 & 0.45 & 1.03 & 0.36 & 0.82 \\
\hline & 2 & 0.37 & 0.43 & 1.16 & 0.36 & 0.96 \\
\hline \multirow{3}{*}{$\begin{array}{l}\text { Hormigonado } \\
\text { forjado } 5\end{array}$} & 5 & 1.00 & 0.98 & 0.98 & 0.99 & 0.99 \\
\hline & 4 & 0.92 & 0.70 & 0.76 & 0.74 & 0.80 \\
\hline & 3 & 0.57 & 0.63 & 1.11 & 0.52 & 0.92 \\
\hline
\end{tabular}




\begin{tabular}{ccccccc}
\hline Operación & Nivel & $\boldsymbol{C}_{\boldsymbol{N P S}}$ & $\boldsymbol{C}_{\boldsymbol{e x p}}$ & $\frac{\boldsymbol{C}_{\boldsymbol{e x p}}}{\boldsymbol{C}_{\boldsymbol{N P S}}}$ & $\boldsymbol{C}_{\boldsymbol{M E F}}$ & $\frac{\boldsymbol{C}_{\boldsymbol{M E F}}}{\boldsymbol{C}_{\boldsymbol{N} P S}}$ \\
\hline \multirow{2}{*}{ Clareado forjado 5 } & 5 & 0.51 & 0.55 & 1.08 & 0.40 & 0.79 \\
& 4 & 0.68 & 0.60 & 0.88 & 0.57 & 0.84 \\
\hline Descimbrado & 5 & 0.47 & 0.63 & 1.34 & 0.46 & 0.98 \\
forjado 3 & 4 & 0.42 & 0.44 & 1.04 & 0.35 & 0.84 \\
\hline Hormigonado & 6 & 0.46 & 0.47 & 1.02 & 0.40 & 0.86 \\
forjado 6 & 5 & 0.91 & 1.01 & 1.01 & 0.99 & 0.99 \\
& 4 & 0.65 & 0.61 & 1.00 & 0.74 & 0.81 \\
\hline Media & - & - & - & $\mathbf{0 . 9 8}$ & - & 0.85 \\
\hline Desviación Típica & - & - & - & $\mathbf{0 . 2 0}$ & - & $\mathbf{0 . 8 7}$ \\
\hline
\end{tabular}

Como se observa en la Tabla 5.18, el Nuevo Procedimiento Simplificado (Calderón et al. 2011) estima con un grado de ajuste bastante bueno las cargas que se presentan en puntales para el caso estudiado. Comparando las estimaciones obtenidas por el Nuevo Procedimiento Simplificado (Calderón et al. 2011) con las medidas del modelo experimental, se obtiene una media del ratio $\frac{C_{\exp }}{C_{N P S}}$ de 0.98 , con una desviación típica de 0.20. Comparando los resultados del método con los obtenidos del modelo numérico, la media del ratio $\frac{C_{M E F}}{C_{N P S}}$ que se obtiene es de 0.87 con una desviación típica de 0.10 .

\subsection{Aplicación de los métodos simplificados al edificio de forjado reticular de casetón perdido}

En el apartado 3.3 de la presente Tesis Doctoral han quedado descritos tanto la geometría de la estructura y como el proceso constructivo analizado.

\subsubsection{Método Simplificado Mejorado (Duan y Chen, 1995)}

Los diferentes parámetros para la aplicación de este método se describen en las Tablas 5.19 y 5.20 para los forjados y puntales, respectivamente.

Tabla 5.19 Parámetros del forjado para el método simplificado de Duan y Chen (1995) (Forjado reticular de casetón perdido)

\begin{tabular}{cccc}
\hline $\boldsymbol{L}(\mathbf{m})$ & $\boldsymbol{E}_{\boldsymbol{j}}(\mathbf{G P a})$ & $\boldsymbol{I}\left(\mathbf{m}^{\mathbf{4}}\right)$ & $\boldsymbol{\gamma}$ \\
\hline 4.20 & Según Apéndice III & $9.511 \mathrm{E}-4$ & $1 / 185$ \\
\hline
\end{tabular}

$L$ es la longitud del vano del forjado, $E_{\mathrm{j}}$ es el módulo de elasticidad del hormigón de los forjados, I el momento de inercia del forjado suponiendo un ancho de la unidad y $\gamma$ es un coeficiente que depende de las condiciones de contorno y la relación largo ancho del forjado. 
Estudio de la evolución de cargas en forjados y puntales durante el proceso constructivo

Tabla 5.20 Parámetros de los puntales para el método simplificado de Duan y Chen (1995) (Forjado reticular de casetón perdido)

\begin{tabular}{ccccc}
\hline Forjados & $\boldsymbol{H}(\mathbf{m})$ & $\begin{array}{c}\boldsymbol{E}_{\boldsymbol{s h}} \\
(\mathbf{G P a})\end{array}$ & $\begin{array}{c}\boldsymbol{A}_{\text {Cimbrado }} \\
\left(\mathbf{m}^{\mathbf{2}}\right)\end{array}$ & $\begin{array}{c}\boldsymbol{A}_{\text {Clareado }} \\
\left(\mathbf{m}^{\mathbf{2}}\right)\end{array}$ \\
\hline F1 & 2.65 & 210 & $8.67 \mathrm{E}-4$ & $2.89 \mathrm{E}-4$ \\
F2 & 2.80 & 210 & $8.67 \mathrm{E}-4$ & $2.89 \mathrm{E}-4$ \\
F3 & 4.15 & 210 & $1.46 \mathrm{E}-3$ & $7.29 \mathrm{E}-4$ \\
F4 - F6 & 2.70 & 210 & $1.16 \mathrm{E}-3$ & $5.78 \mathrm{E}-4$ \\
\hline
\end{tabular}

$H$ es la altura de los puntales, $E_{s h}$ es el módulo de elasticidad de los puntales, $A_{\text {Cimbrado }}$ es la sumatoria del área de los puntales en la fase de cimbrado y $A_{\text {Clareado }}$ es la sumatoria del área de los puntales en la fase de clareado.

\subsubsection{Resultados de la aplicación del método}

La Figura 5.4 muestra los resultados obtenidos aplicando el Método Simplificado Mejorado (Duan y Chen, 1995). Los resultados se muestran en coeficientes de carga en puntales y forjados. 

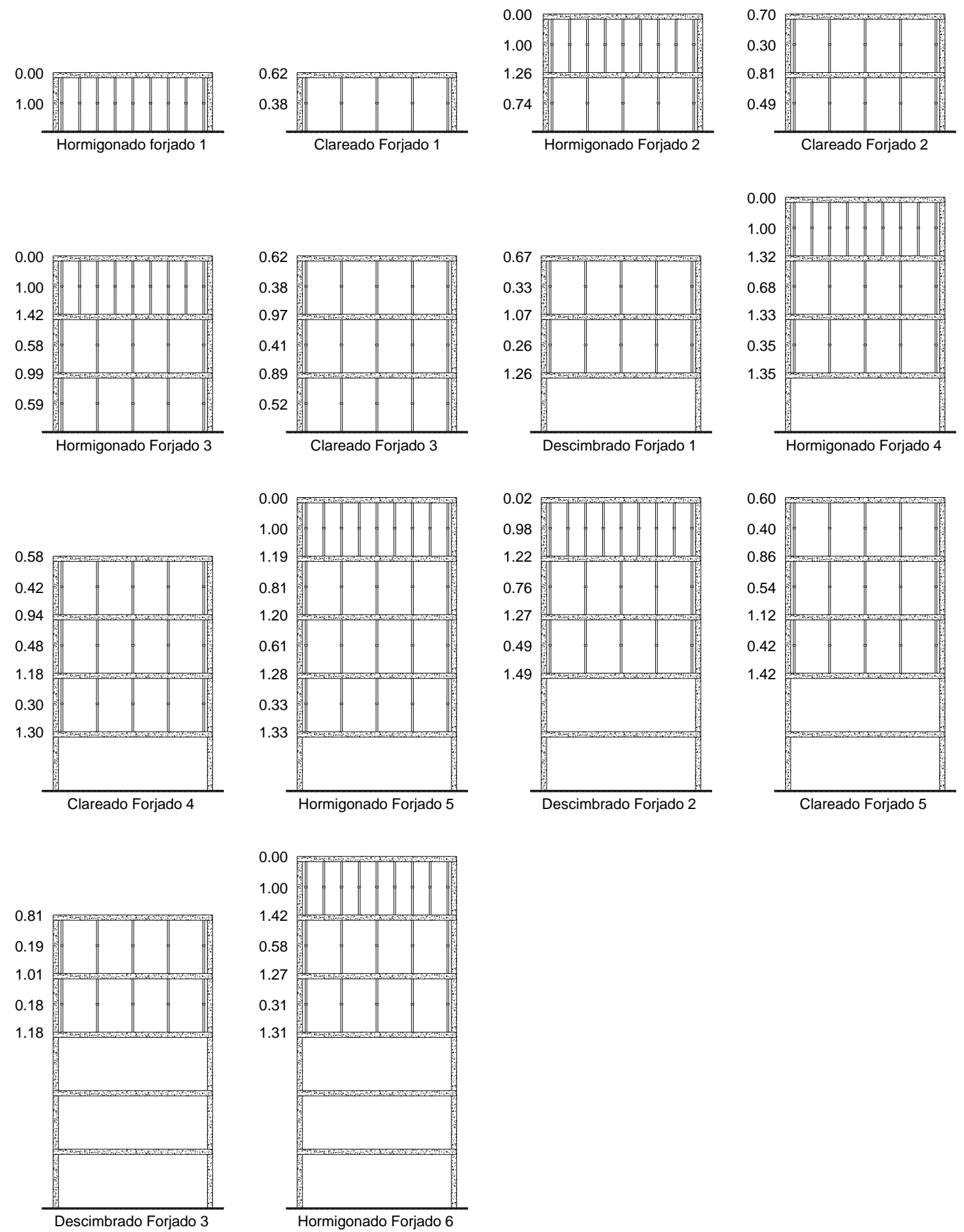

Fig. 5.4 Coeficientes de carga estimados con el método de Duan y Chen (1995) (Forjado reticular de casetón perdido) 


\subsubsection{Comparación de los resultados}

En la Tabla 5.21 se muestra una comparación de los coeficientes de carga en puntales determinados a partir del Método Simplificado Mejorado (Duan y Chen, 1995) $\left(C_{D \& C}\right)$ y de las medidas del estudio experimental $\left(C_{E x p}\right)$ (véase Capítulo 3).

Tabla 5.21 Comparación entre los coeficientes de carga estimados con el método de Duan y Chen (1995) con las medidas experimentales (Forjado reticular de casetón perdido)

\begin{tabular}{|c|c|c|c|c|}
\hline Operación & Nivel & $C_{D \& C}$ & $C_{e x p}$ & $\frac{C_{e x p}}{C_{D \& C}}$ \\
\hline $\begin{array}{l}\text { Hormigonado } \\
\text { forjado } 1\end{array}$ & 1 & 1.00 & 1.00 & 1.00 \\
\hline Clareado forjado 1 & 1 & 0.38 & 0.58 & 1.53 \\
\hline Hormigonado & 2 & 1.00 & 1.00 & 1.00 \\
\hline forjado 2 & 1 & 0.74 & 0.85 & 1.15 \\
\hline \multirow{2}{*}{ Clareado forjado 2} & 2 & 0.30 & 0.70 & 2.33 \\
\hline & 1 & 0.49 & 0.67 & 1.38 \\
\hline \multirow{3}{*}{$\begin{array}{l}\text { Hormigonado } \\
\text { forjado } 3\end{array}$} & 3 & 1.00 & 0.98 & 0.98 \\
\hline & 2 & 0.58 & 0.99 & 1.69 \\
\hline & 1 & 0.59 & 0.82 & 1.39 \\
\hline \multirow{3}{*}{ Clareado forjado 3} & 3 & 0.38 & 0.67 & 1.78 \\
\hline & 2 & 0.41 & 0.70 & 1.72 \\
\hline & 1 & 0.52 & 0.89 & 1.70 \\
\hline \multirow{2}{*}{$\begin{array}{l}\text { Descimbrado } \\
\text { forjado } 1\end{array}$} & 3 & 0.33 & 0.45 & 1.37 \\
\hline & 2 & 0.26 & 0.32 & 1.23 \\
\hline \multirow{3}{*}{$\begin{array}{l}\text { Hormigonado } \\
\text { forjado } 4\end{array}$} & 4 & 1.00 & 1.00 & 1.00 \\
\hline & 3 & 0.68 & 0.91 & 1.34 \\
\hline & 2 & 0.35 & 0.51 & 1.46 \\
\hline \multirow{3}{*}{ Clareado forjado 4} & 4 & 0.42 & 0.48 & 1.15 \\
\hline & 3 & 0.48 & 0.66 & 1.39 \\
\hline & 2 & 0.30 & 0.41 & 1.38 \\
\hline \multirow{4}{*}{$\begin{array}{l}\text { Hormigonado } \\
\text { forjado } 5\end{array}$} & 5 & 1.00 & 1.00 & 1.00 \\
\hline & 4 & 0.81 & 1.01 & 1.25 \\
\hline & 3 & 0.61 & 0.91 & 1.48 \\
\hline & 2 & 0.33 & 0.58 & 1.74 \\
\hline \multirow{3}{*}{$\begin{array}{l}\text { Descimbrado } \\
\text { forjado } 2\end{array}$} & 5 & 0.98 & 0.94 & 0.96 \\
\hline & 4 & 0.76 & 0.96 & 1.26 \\
\hline & 3 & 0.49 & 0.78 & 1.59 \\
\hline \multirow{3}{*}{ Clareado forjado 5} & 5 & 0.40 & 0.59 & 1.48 \\
\hline & 4 & 0.54 & 0.78 & 1.45 \\
\hline & 3 & 0.42 & 0.72 & 1.71 \\
\hline \multirow{2}{*}{$\begin{array}{l}\text { Descimbrado } \\
\text { forjado } 3\end{array}$} & 5 & 0.19 & 0.56 & 2.93 \\
\hline & 4 & 0.18 & 0.61 & 3.43 \\
\hline \multirow{3}{*}{$\begin{array}{l}\text { Hormigonado } \\
\text { forjado } 6\end{array}$} & 6 & 1.00 & 1.00 & 1.00 \\
\hline & 5 & 0.58 & 0.87 & 1.49 \\
\hline & 4 & 0.31 & 0.62 & 1.98 \\
\hline Media & - & - & - & 1.51 \\
\hline Desviación Típica & - & - & - & 0.52 \\
\hline
\end{tabular}


La media del ratio $\frac{C_{\text {exp }}}{C_{D \& C}}$ es de 1.51 con una desviación típica de 0.52. En este caso, el Método Simplificado Mejorado (Duan y Chen, 1995) no es adecuado para predecir las cargas en puntales durante el proceso de cimbrado, clareado y descimbrado.

\subsubsection{Método Simplificado de Fang et al. (2001a)}

Los diferentes parámetros para los forjados y puntales necesarios para la aplicación de este método se describen en las Tablas 5.22 y 5.23, respectivamente.

Tabla 5.22 Parámetros del forjado para el método simplificado de Fang et al. (2001a). (Forjado reticular de casetón perdido)

\begin{tabular}{cccc}
\hline $\boldsymbol{L}(\mathbf{m})$ & $\boldsymbol{E}_{\boldsymbol{j}}(\mathbf{G P a})$ & $\boldsymbol{I}\left(\mathbf{m}^{\mathbf{4}}\right)$ & $\boldsymbol{\lambda}$ \\
\hline 4.20 & Según Apéndice III & $9.511 \mathrm{E}-4$ & 185 \\
\hline
\end{tabular}

$L$ es la longitud del vano del forjado, $E_{j}$ es el módulo de elasticidad del hormigón de los forjados, I el momento de inercia del forjado suponiendo un ancho de la unidad y $\lambda$ es un coeficiente que depende de las condiciones de contorno y la relación largo ancho del forjado.

Tabla 5.23 Parámetros de los puntales para el método simplificado de Fang et al. (2001a). (Forjado reticular de casetón perdido)

\begin{tabular}{ccccccc}
\hline Forjados & $\begin{array}{c}\boldsymbol{L}_{\text {shore }} \\
(\mathbf{m})\end{array}$ & $\begin{array}{c}\boldsymbol{E}_{\text {shore }} \\
(\mathbf{G P a})\end{array}$ & $\begin{array}{c}\boldsymbol{A}_{\text {shore }} \\
\left(\mathbf{m}^{2}\right)\end{array}$ & $\begin{array}{c}\mathbf{s} \\
(\text { cimbrado) }\end{array}$ & $\begin{array}{c}\text { s } \\
(\text { clareado) }\end{array}$ & $\boldsymbol{\rho}$ \\
\hline F1 & 2.65 & 210 & $2.89 \mathrm{E}-4$ & 3 & 1 & 1.00 \\
F2 & 2.80 & 210 & $2.89 \mathrm{E}-4$ & 3 & 1 & 1.00 \\
F3 & 4.15 & 210 & $3.64 \mathrm{E}-4$ & 4 & 2 & 1.00 \\
F4 - F6 & 2.70 & 210 & $2.89 \mathrm{E}-4$ & 4 & 2 & 1.00 \\
\hline
\end{tabular}

$L_{\text {shore }}$ es la longitud de los puntales, $E_{\text {shore }}$, es el módulo de elasticidad de los puntales, $A_{\text {shore }}$ es el área de la sección transversal de los puntales, s es el número de puntales instalados en el vano considerado para cada uno de los procesos constructivos analizados y $\rho$ es el coeficiente que considera las cargas desiguales en los puntales.

\subsubsection{Resultados de la aplicación del método}

En la Figura 5.5 se muestran los resultados obtenidos aplicando el Método Simplificado de Fang et al. (2001a). Los resultados se muestran en coeficientes de carga en puntales y forjados. 

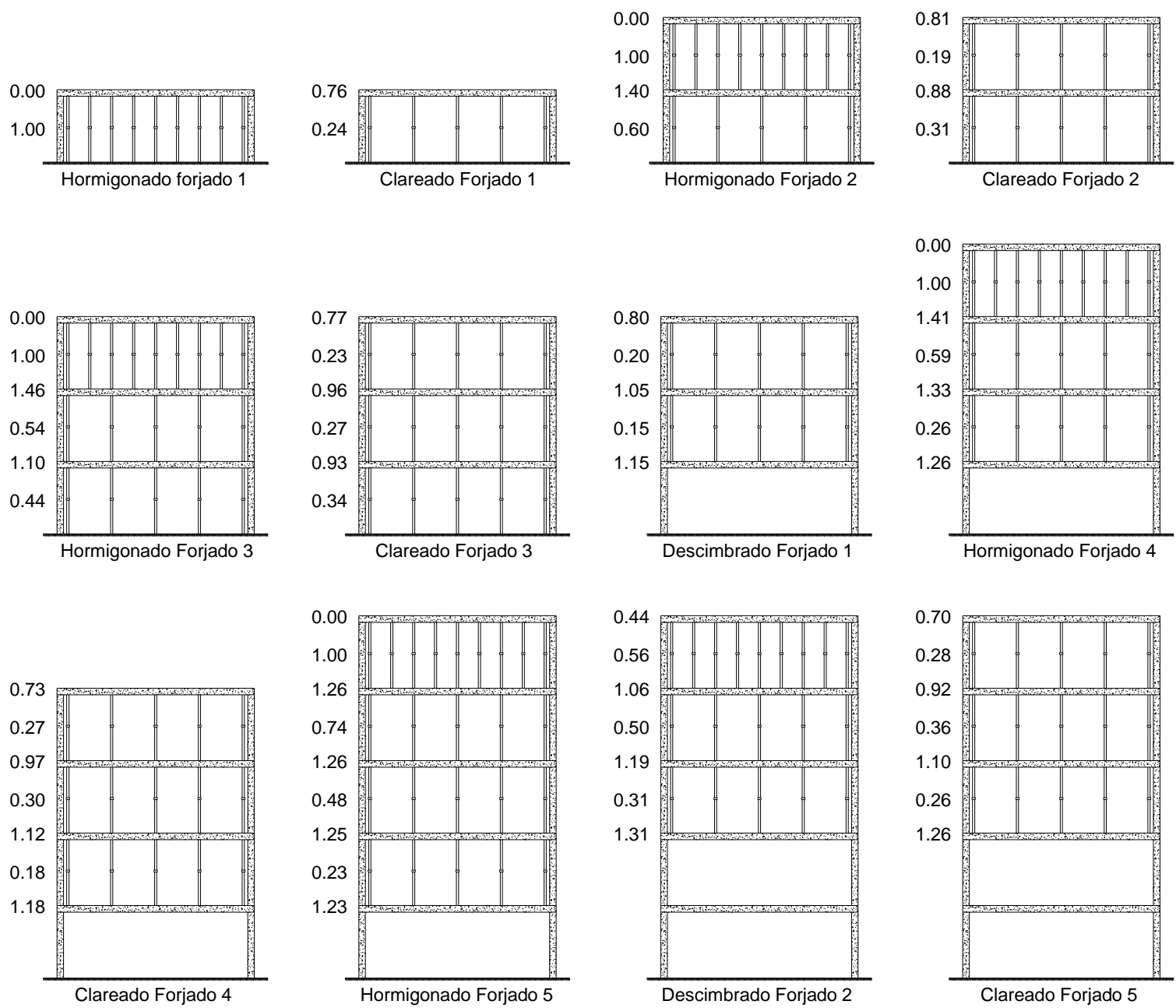
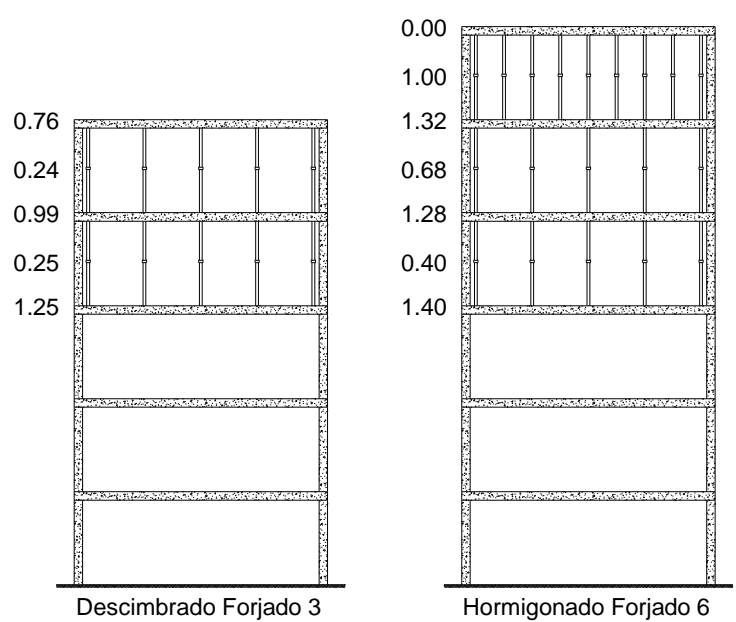

Fig. 5.5 Coeficientes de carga estimados con el método de Fang et al. (2001a) (Forjado reticular de casetón perdido) 


\subsubsection{Comparación de los resultados}

En la Tabla 5.24 se muestra una comparación de los coeficientes de carga en puntales determinados a partir del Método Simplificado de Fang et al. (2001a) $\left(C_{\text {Fang }}\right.$ ) y de las medidas del estudio experimental $\left(C_{E x p}\right)$ (véase Capítulo 3).

Tabla 5.24 Comparación entre los coeficientes de carga estimados con el método de Fang et al. (2001a) con las medidas experimentales (Forjado reticular de casetón perdido)

\begin{tabular}{|c|c|c|c|c|}
\hline Operación & Nivel & $C_{\text {Fang }}$ & $C_{\text {exp }}$ & $\frac{C_{\text {exp }}}{C_{\text {Fang }}}$ \\
\hline $\begin{array}{l}\text { Hormigonado } \\
\text { forjado } 1\end{array}$ & 1 & 1.00 & 1.00 & 1.00 \\
\hline Clareado forjado 1 & 1 & 0.24 & 0.58 & 2.37 \\
\hline \multirow{2}{*}{$\begin{array}{l}\text { Hormigonado } \\
\text { forjado } 2\end{array}$} & 2 & 1.00 & 1.00 & 1.00 \\
\hline & 1 & 0.60 & 0.85 & 1.41 \\
\hline \multirow{2}{*}{ Clareado forjado 2} & 2 & 0.19 & 0.70 & 3.71 \\
\hline & 1 & 0.31 & 0.67 & 2.15 \\
\hline \multirow{3}{*}{$\begin{array}{l}\text { Hormigonado } \\
\text { forjado } 3\end{array}$} & 3 & 1.00 & 0.98 & 0.98 \\
\hline & 2 & 0.54 & 0.99 & 1.83 \\
\hline & 1 & 0.44 & 0.82 & 1.87 \\
\hline \multirow{3}{*}{ Clareado forjado 3} & 3 & 0.23 & 0.67 & 2.88 \\
\hline & 2 & 0.27 & 0.70 & 2.59 \\
\hline & 1 & 0.34 & 0.89 & 2.61 \\
\hline \multirow{2}{*}{$\begin{array}{l}\text { Descimbrado } \\
\text { forjado } 1\end{array}$} & 3 & 0.20 & 0.45 & 2.31 \\
\hline & 2 & 0.15 & 0.32 & 2.07 \\
\hline \multirow{3}{*}{$\begin{array}{l}\text { Hormigonado } \\
\text { forjado } 4\end{array}$} & 4 & 1.00 & 1.00 & 1.00 \\
\hline & 3 & 0.59 & 0.91 & 1.55 \\
\hline & 2 & 0.26 & 0.51 & 2.00 \\
\hline \multirow{3}{*}{ Clareado forjado 4} & 4 & 0.27 & 0.48 & 1.76 \\
\hline & 3 & 0.30 & 0.66 & 2.19 \\
\hline & 2 & 0.18 & 0.41 & 2.25 \\
\hline \multirow{4}{*}{$\begin{array}{l}\text { Hormigonado } \\
\text { forjado } 5\end{array}$} & 5 & 1.00 & 1.00 & 1.00 \\
\hline & 4 & 0.74 & 1.01 & 1.37 \\
\hline & 3 & 0.48 & 0.91 & 1.89 \\
\hline & 2 & 0.23 & 0.58 & 2.54 \\
\hline \multirow{3}{*}{$\begin{array}{l}\text { Descimbrado } \\
\text { forjado } 2\end{array}$} & 5 & 0.56 & 0.94 & 1.67 \\
\hline & 4 & 0.50 & 0.96 & 1.93 \\
\hline & 3 & 0.31 & 0.78 & 2.53 \\
\hline \multirow{3}{*}{ Clareado forjado 5} & 5 & 0.28 & 0.59 & 2.12 \\
\hline & 4 & 0.36 & 0.78 & 2.14 \\
\hline & 3 & 0.26 & 0.72 & 2.76 \\
\hline \multirow{2}{*}{$\begin{array}{l}\text { Descimbrado } \\
\text { forjado } 3\end{array}$} & 5 & 0.24 & 0.56 & 2.35 \\
\hline & 4 & 0.25 & 0.61 & 2.46 \\
\hline \multirow{3}{*}{$\begin{array}{l}\text { Hormigonado } \\
\text { forjado } 6\end{array}$} & 6 & 1.00 & 1.00 & 1.00 \\
\hline & 5 & 0.68 & 0.87 & 1.27 \\
\hline & 4 & 0.40 & 0.62 & 1.54 \\
\hline Media & - & - & - & 1.95 \\
\hline Desviación Típica & - & - & - & 0.64 \\
\hline
\end{tabular}


Como se puede observar, los coeficientes de cargas obtenidos por el Método Simplificado de Fang et al. (2001a) difieren considerablemente de los obtenidos experimentalmente. La media del ratio $\frac{C_{\text {exp }}}{C_{\text {Fang }}}$ es de 1.95, con una desviación típica de 0.64. Por lo tanto, para el caso estudiado, este método no se podría considerar como un método válido para estimar las cargas en puntales durante el proceso constructivo.

\subsubsection{Nuevo Procedimiento Simplificado (Calderón et al., 2011)}

Los diferentes parámetros para la aplicación de este método se describen en las Tablas 5.25 y 5.26 para los forjados y puntales, respectivamente.

Tabla 5.25 Parámetros del forjado para el nuevo procedimiento simplificado de Calderón et al. (2011) (Forjado reticular de casetón perdido)

\begin{tabular}{cccc}
\hline $\boldsymbol{L}_{\boldsymbol{x}}(\mathbf{m})$ & $\boldsymbol{L}_{\boldsymbol{y}}(\mathbf{m})$ & $\boldsymbol{E}_{\boldsymbol{j}}(\mathbf{G P a})$ & $\boldsymbol{I}\left(\mathbf{m}^{\mathbf{4}}\right)$ \\
\hline \multirow{2}{*}{4.20} & \multirow{2}{*}{6.70} & \multirow{2}{*}{ Según Apéndice III } & $1.40 \mathrm{E}-3$ \\
& & & $2.23 \mathrm{E}-3$ \\
\hline
\end{tabular}

$L_{x}$ es la luz entre cara de pilares en la dirección x (perpendicular a las sopandas), $L_{y}$ es la luz entre cara de pilares en la dirección y (dirección de las sopandas), $E_{\mathrm{j}}$ es el módulo de elasticidad del hormigón de los forjados e $I$ es el momento de inercia bruta de la sección de la banda considerada.

Tabla 5.26 Parámetros de los puntales para el nuevo procedimiento simplificado de Calderón et al. (2011) (Forjado reticular de casetón perdido)

\begin{tabular}{ccccc}
\hline Forjados & $\boldsymbol{H}(\mathbf{m})$ & $\begin{array}{c}\boldsymbol{E}_{\boldsymbol{s h}} \\
(\mathbf{G P a})\end{array}$ & $\begin{array}{c}\boldsymbol{A}_{\text {Cimbrado }} \\
\left(\mathbf{m}^{\mathbf{2}}\right)\end{array}$ & $\begin{array}{c}\boldsymbol{A}_{\text {Clareado }} \\
\left(\mathbf{m}^{\mathbf{2}}\right)\end{array}$ \\
\hline F1 & 2.65 & 210 & $8.67 \mathrm{E}-4$ & $2.89 \mathrm{E}-4$ \\
F2 & 2.80 & 210 & $8.67 \mathrm{E}-4$ & $2.89 \mathrm{E}-4$ \\
F3 & 4.15 & 210 & $1.46 \mathrm{E}-3$ & $7.29 \mathrm{E}-4$ \\
F4 - F6 & 2.70 & 210 & $1.16 \mathrm{E}-3$ & $5.78 \mathrm{E}-4$ \\
\hline
\end{tabular}

$H$ es la altura de los puntales, $E_{s h}$ es el módulo de elasticidad de los puntales, $A_{\text {Cimbrado }}$ es la sumatoria del área de los puntales en la fase de cimbrado y $A_{\text {Clareado }}$ es la sumatoria del área de los puntales en la fase de clareado.

\subsubsection{Resultados de la aplicación del método}

La Figura 5.6 muestra los resultados obtenidos aplicando el Nuevo Procedimiento Simplificado (Calderón et al. 2011). Los resultados se muestran en coeficientes de carga en puntales y forjados. 

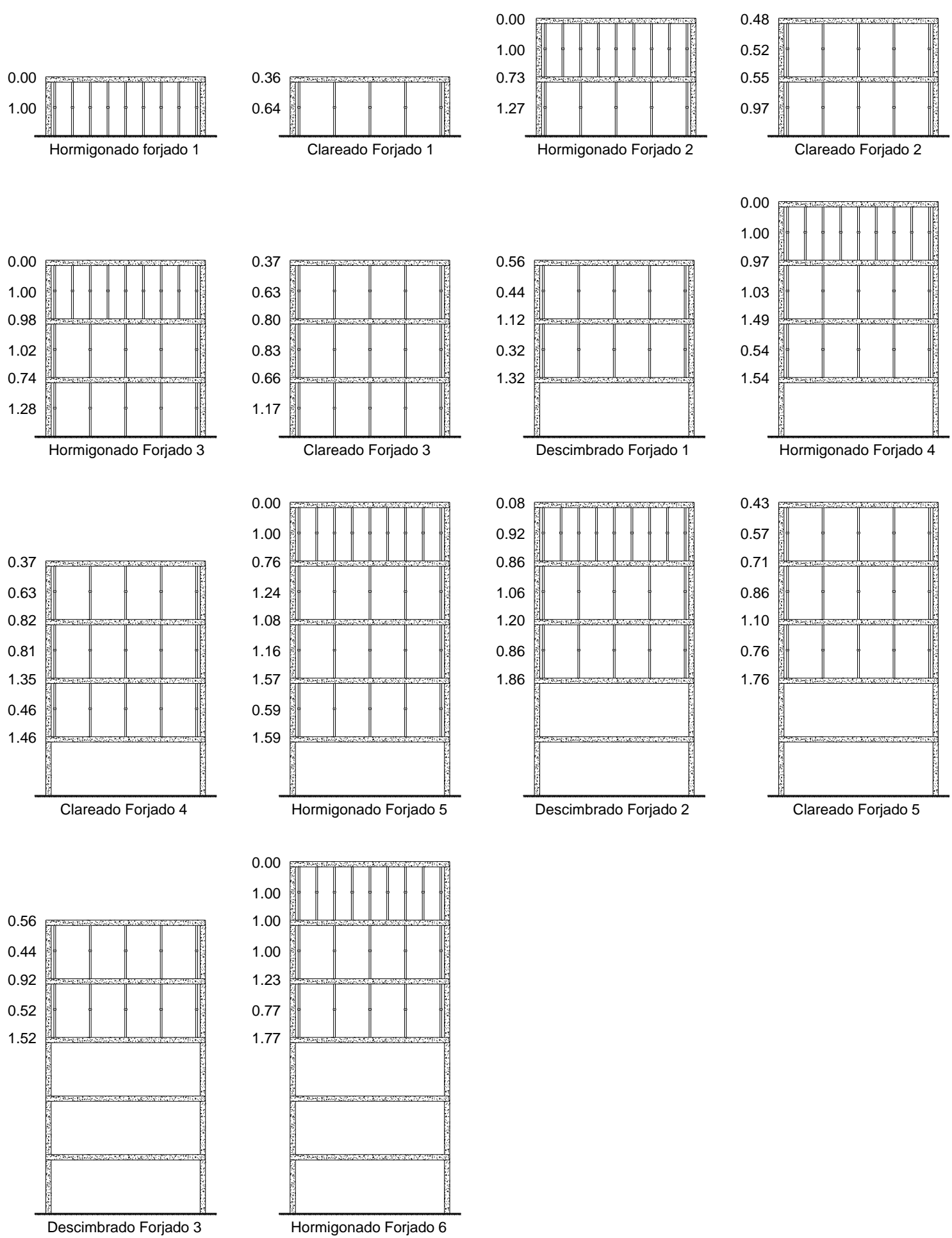

Fig. 5.6 Coeficientes de carga estimados con el método de Calderón et al. (2011) (Forjado reticular de casetón perdido) 


\subsubsection{Comparación de los resultados}

La Tabla 5.27 muestra una comparación de los coeficientes de carga media en puntales determinados a partir del Nuevo Procedimiento Simplificado (Calderón et al. 2011) $\left(C_{N P S}\right)$ y de las medidas del estudio experimental $\left(C_{E x p}\right)$ (véase Capítulo 3$)$.

Tabla 5.27 Comparación entre los coeficientes de carga estimados con el método de Calderón et al. (2011) y con las medidas experimentales. (Forjado reticular de casetón perdido)

\begin{tabular}{|c|c|c|c|c|}
\hline Operación & Nivel & $C_{N P S}$ & $C_{\text {exp }}$ & $\frac{C_{\text {exp }}}{C_{N P S}}$ \\
\hline $\begin{array}{l}\text { Hormigonado } \\
\text { forjado } 1\end{array}$ & 1 & 1.00 & 1.00 & 1.00 \\
\hline Clareado forjado 1 & 1 & 0.64 & 0.58 & 0.90 \\
\hline Hormigonado & 2 & 1.00 & 1.00 & 1.00 \\
\hline forjado 2 & 1 & 1.27 & 0.85 & 0.67 \\
\hline \multirow{2}{*}{ Clareado forjado 2} & 2 & 0.52 & 0.70 & 1.35 \\
\hline & 1 & 0.97 & 0.67 & 0.69 \\
\hline \multirow{3}{*}{$\begin{array}{l}\text { Hormigonado } \\
\text { forjado } 3\end{array}$} & 3 & 1.00 & 0.98 & 0.98 \\
\hline & 2 & 1.02 & 0.99 & 0.97 \\
\hline & 1 & 1.28 & 0.82 & 0.64 \\
\hline \multirow{3}{*}{ Clareado forjado 3} & 3 & 0.63 & 0.67 & 1.06 \\
\hline & 2 & 0.83 & 0.70 & 0.84 \\
\hline & 1 & 1.17 & 0.89 & 0.76 \\
\hline \multirow{2}{*}{$\begin{array}{l}\text { Descimbrado } \\
\text { forjado } 1\end{array}$} & 3 & 0.44 & 0.45 & 1.01 \\
\hline & 2 & 0.32 & 0.32 & 1.00 \\
\hline \multirow{3}{*}{$\begin{array}{l}\text { Hormigonado } \\
\text { forjado } 4\end{array}$} & 4 & 1.00 & 1.00 & 1.00 \\
\hline & 3 & 1.03 & 0.91 & 0.89 \\
\hline & 2 & 0.54 & 0.51 & 0.94 \\
\hline \multirow{3}{*}{ Clareado forjado 4} & 4 & 0.63 & 0.48 & 0.76 \\
\hline & 3 & 0.81 & 0.66 & 0.81 \\
\hline & 2 & 0.46 & 0.41 & 0.89 \\
\hline \multirow{4}{*}{$\begin{array}{l}\text { Hormigonado } \\
\text { forjado } 5\end{array}$} & 5 & 1.00 & 1.00 & 1.00 \\
\hline & 4 & 1.24 & 1.01 & 0.82 \\
\hline & 3 & 1.16 & 0.91 & 0.78 \\
\hline & 2 & 0.59 & 0.58 & 0.98 \\
\hline \multirow{3}{*}{$\begin{array}{l}\text { Descimbrado } \\
\text { forjado } 2\end{array}$} & 5 & 0.92 & 0.94 & 1.02 \\
\hline & 4 & 1.06 & 0.96 & 0.90 \\
\hline & 3 & 0.86 & 0.78 & 0.91 \\
\hline \multirow{3}{*}{ Clareado forjado 5} & 5 & 0.57 & 0.59 & 1.04 \\
\hline & 4 & 0.86 & 0.78 & 0.91 \\
\hline & 3 & 0.76 & 0.72 & 0.94 \\
\hline \multirow{2}{*}{$\begin{array}{l}\text { Descimbrado } \\
\text { forjado } 3\end{array}$} & 5 & 0.44 & 0.56 & 1.28 \\
\hline & 4 & 0.52 & 0.61 & 1.15 \\
\hline \multirow{3}{*}{$\begin{array}{l}\text { Hormigonado } \\
\text { forjado } 6\end{array}$} & 6 & 1.00 & 1.00 & 1.00 \\
\hline & 5 & 1.00 & 0.87 & 0.87 \\
\hline & 4 & 0.77 & 0.62 & 0.81 \\
\hline Media & - & - & - & 0.93 \\
\hline Desviación Típica & - & - & - & 0.15 \\
\hline
\end{tabular}


Comparando las estimaciones obtenidas por el Nuevo Procedimiento Simplificado (Calderón et al., 2011) con las medidas del modelo experimental, se obtiene una media del ratio $\frac{C_{\text {exp }}}{C_{N P S}}$ del 0.93 con una desviación típica de 0.15 .

Considerando el grado de simplificación que se logra al aplicar el Nuevo Procedimiento Simplificado (Calderón et al., 2011), se puede considerar que dicho método estima, con un buen grado de ajuste, las cargas que se presentan en puntales para el proceso constructivo empleado en el caso estudiado.

\subsection{Aplicación de los métodos simplificados al edificio de forjado reticular de casetón recuperable}

El proceso constructivo analizado y la geometría de la estructura quedan descritos en el apartado 3.4 de la presente Tesis Doctoral.

\subsubsection{Método Simplificado Mejorado (Duan y Chen, 1995)}

\section{$\checkmark$ Parámetros de cálculo vano de esquina}

Los diferentes parámetros para la aplicación de este método se describen en las Tablas 5.28 y 5.29 para los forjados y puntales, respectivamente.

Tabla 5.28 Parámetros del forjado para el método simplificado de Duan y Chen (1995) (Forjado reticular de casetón recuperable - Vano de esquina)

\begin{tabular}{cccc}
\hline $\boldsymbol{L}(\mathbf{m})$ & $\boldsymbol{E}_{\boldsymbol{j}}(\mathbf{G P a})$ & $\boldsymbol{I}\left(\mathbf{m}^{\mathbf{4}}\right)$ & $\boldsymbol{\gamma}$ \\
\hline 5.00 & Según Apéndice III & $1.987 \mathrm{E}-3$ & $1 / 185$ \\
\hline
\end{tabular}

$L$ es la longitud del vano del forjado, $E_{\mathrm{j}}$ es el módulo de elasticidad del hormigón de los forjados, I el momento de inercia del forjado suponiendo un ancho de la unidad y $\gamma$ es un coeficiente que depende de las condiciones de contorno y la relación largo ancho del forjado.

Tabla 5.29 Parámetros de los puntales para el método simplificado de Duan y Chen (1995) (Forjado reticular de casetón recuperable - Vano de esquina)

\begin{tabular}{ccccc}
\hline Forjados & $\boldsymbol{H}(\mathbf{m})$ & $\begin{array}{c}\boldsymbol{E}_{\text {sh }} \\
(\mathbf{G P a})\end{array}$ & $\begin{array}{c}\boldsymbol{A}_{\text {Cimbrado }} \\
\left(\mathbf{m}^{\mathbf{2}}\right)\end{array}$ & $\begin{array}{c}\boldsymbol{A}_{\text {Clareado }} \\
\left(\mathbf{m}^{2}\right)\end{array}$ \\
\hline F1 & 2.90 & 210 & $2.02 \mathrm{E}-3$ & $1.16 \mathrm{E}-3$ \\
F2 & 4.00 & 210 & $2.55 \mathrm{E}-3$ & $1.46 \mathrm{E}-3$ \\
F3 - F4 & 3.60 & 210 & $2.02 \mathrm{E}-3$ & $1.16 \mathrm{E}-3$ \\
\hline
\end{tabular}

$H$ es la altura de los puntales, $E_{s h}$ es el módulo de elasticidad de los puntales, $A_{\text {Cimbrado }}$ es la sumatoria del área de los puntales en la fase de cimbrado y $A_{\text {Clareado }}$ es la sumatoria del área de los puntales en la fase de clareado. 


\section{$\checkmark$ Parámetros de cálculo vano de medianera}

Los diferentes parámetros para la aplicación de este método se describen en las Tablas 5.30 y 5.31 para los forjados y puntales, respectivamente.

Tabla 5.30 Parámetros del forjado para el método simplificado de Duan y Chen (1995) (Forjado reticular de casetón recuperable - Vano de medianera)

\begin{tabular}{cccc}
\hline $\boldsymbol{L}(\mathbf{m})$ & $\boldsymbol{E}_{\boldsymbol{j}}(\mathbf{G P a})$ & $\boldsymbol{I}\left(\mathbf{m}^{\mathbf{4}}\right)$ & $\boldsymbol{\gamma}$ \\
\hline 8.00 & Según Apéndice III & $1.987 \mathrm{E}-3$ & $1 / 185$ \\
\hline
\end{tabular}

$L$ es la longitud del vano del forjado, $E_{\mathrm{j}}$ es el módulo de elasticidad del hormigón de los forjados, I el momento de inercia del forjado suponiendo un ancho de la unidad y $\gamma$ es un coeficiente que depende de las condiciones de contorno y la relación largo ancho del forjado.

Tabla 5.31 Parámetros de los puntales para el método simplificado de Duan y Chen (1995) (Forjado reticular de casetón recuperable - Vano de medianera)

\begin{tabular}{ccccc}
\hline Forjados & $\boldsymbol{H}(\mathbf{m})$ & $\begin{array}{c}\boldsymbol{E}_{\boldsymbol{s h}} \\
(\mathbf{G P a})\end{array}$ & $\begin{array}{c}\boldsymbol{A}_{\text {Cimbrado }} \\
\left(\mathbf{m}^{\mathbf{2}}\right)\end{array}$ & $\begin{array}{c}\boldsymbol{A}_{\text {Clareado }} \\
\left(\mathbf{m}^{2}\right)\end{array}$ \\
\hline F1 & 2.90 & 210 & $3.18 \mathrm{E}-3$ & $1.73 \mathrm{E}-3$ \\
F2 & 4.00 & 210 & $4.01 \mathrm{E}-3$ & $2.19 \mathrm{E}-3$ \\
F3 - F4 & 3.60 & 210 & $3.18 \mathrm{E}-3$ & $1.73 \mathrm{E}-3$ \\
\hline
\end{tabular}

$H$ es la altura de los puntales, $E_{S h}$ es el módulo de elasticidad de los puntales, $A_{\text {Cimbrado }}$ es la sumatoria del área de los puntales en la fase de cimbrado y $A_{\text {Clareado }}$ es la sumatoria del área de los puntales en la fase de clareado.

\subsubsection{Resultados de la aplicación del método}

La Figura 5.7 muestra los resultados obtenidos aplicando el Método Simplificado Mejorado (Duan y Chen, 1995) para los vanos de esquina y medianera. Los resultados obtenidos con este método, al considerar las condiciones de contorno de los forjados, son diferentes para el vano de esquina y para el vano de medianera. Los resultados se muestran en coeficientes de carga en puntales y forjados. 

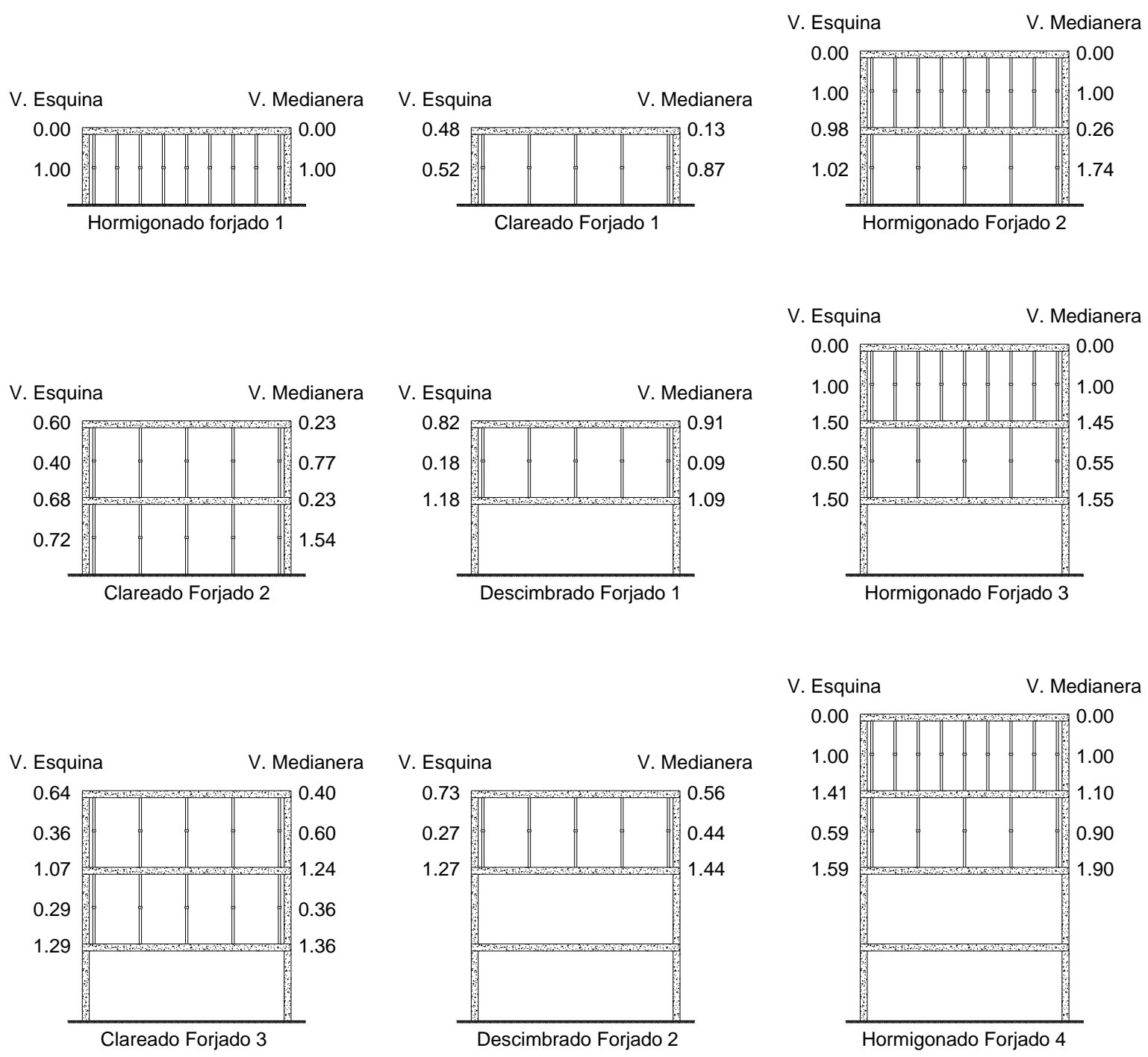

Fig. 5.7 Coeficientes de carga estimados con el método de Duan y Chen (1995) (Forjado reticular de casetón recuperable)

\subsubsection{Comparación de los resultados}

\section{$\checkmark$ Vano de esquina}

En la Tabla 5.32 se muestra una comparación de los coeficientes de carga en puntales determinados a partir del Método Simplificado Mejorado (Duan y Chen, 1995) $\left(C_{D \& C}\right)$, de las medidas del estudio experimental $\left(C_{E x p}\right)$ (véase Capítulo 3) y de los resultados del modelo de $\mathrm{EF}\left(C_{M E F}\right)$ (véase Capítulo 4), para el vano de esquina.

Comparando las medidas del modelo experimental con las estimaciones obtenidas por el Método Simplificado Mejorado (Duan y Chen, 1995), se obtiene una media de los ratios $\frac{C_{\text {exp }}}{C_{D \& C}}$ y $\frac{C_{M E F}}{C_{D \& C}}$ de 1.40 , en ambos casos. Siendo también las desviaciones típicas muy similares. Como se observa el error obtenido con el Método Simplificado Mejorado (Duan y Chen, 1995) es bastante elevado, por lo tanto, para el caso estudiado, este método no es adecuado para la estimación de cargas en puntales durante el proceso constructivo. 
Estudio de la evolución de cargas en forjados y puntales durante el proceso constructivo

Tabla 5.32 Comparación entre los coeficientes de carga estimados con el método de Duan y Chen (1995) con las medidas experimentales y con los resultados del modelo de EF, para el vano de esquina (Forjado reticular de casetón recuperable)

\begin{tabular}{|c|c|c|c|c|c|c|}
\hline Operación & Nivel & $C_{D \& C}$ & $C_{e x p}$ & $\frac{C_{\text {exp }}}{C_{D \& C}}$ & $C_{M E F}$ & $\frac{C_{M E F}}{C_{D \& C}}$ \\
\hline $\begin{array}{l}\text { Hormigonado } \\
\text { forjado } 1\end{array}$ & 1 & 1.00 & 0.99 & 0.99 & 1.00 & 1.00 \\
\hline Clareado forjado 1 & 1 & 0.52 & 0.66 & 1.28 & 0.60 & 1.16 \\
\hline \multirow{2}{*}{$\begin{array}{l}\text { Hormigonado } \\
\text { forjado } 2\end{array}$} & 2 & 1.00 & 0.98 & 0.98 & 0.99 & 0.99 \\
\hline & 1 & 1.02 & 0.91 & 0.89 & 1.18 & 1.16 \\
\hline \multirow{2}{*}{ Clareado forjado 2} & 2 & 0.40 & - & - & 0.68 & 1.70 \\
\hline & 1 & 0.72 & - & - & 1.04 & 1.45 \\
\hline $\begin{array}{l}\text { Descimbrado } \\
\text { forjado } 1\end{array}$ & 2 & 0.18 & 0.41 & 2.34 & 0.35 & 2.00 \\
\hline \multirow{2}{*}{$\begin{array}{l}\text { Hormigonado } \\
\text { forjado } 3\end{array}$} & 3 & 1.00 & 1.00 & 1.00 & 0.99 & 0.99 \\
\hline & 2 & 0.50 & 0.74 & 1.48 & 0.83 & 1.65 \\
\hline \multirow{2}{*}{ Clareado forjado 3} & 3 & 0.36 & 0.64 & 1.76 & 0.60 & 1.65 \\
\hline & 2 & 0.29 & 0.54 & 1.84 & 0.65 & 2.22 \\
\hline $\begin{array}{l}\text { Descimbrado } \\
\text { forjado } 2\end{array}$ & 3 & 0.27 & 0.48 & 1.76 & 0.37 & 1.35 \\
\hline \multirow{2}{*}{$\begin{array}{l}\text { Hormigonado } \\
\text { forjado } 4\end{array}$} & 4 & 1.00 & 1.00 & 1.00 & 0.98 & 0.98 \\
\hline & 3 & 0.59 & 0.88 & 1.51 & 0.78 & 1.33 \\
\hline Media & - & - & - & 1.40 & - & 1.40 \\
\hline Desviación Típica & - & - & - & 0.44 & - & 0.38 \\
\hline
\end{tabular}

\section{$\checkmark$ Vano de medianera}

En la Tabla 5.33 se muestra una comparación de los coeficientes de carga en puntales determinados a partir del Método Simplificado Mejorado (Duan y Chen, 1995) $\left(C_{D \& C}\right)$, de las medidas del estudio experimental $\left(C_{E x p}\right)$ (véase Capítulo 3$)$ y de los resultados del modelo de $\mathrm{EF}\left(C_{M E F}\right)$ (véase Capítulo 4), para el vano de medianera.

Tabla 5.33 Comparación entre los coeficientes de carga estimados con el método de Duan y Chen (1995) con las medidas experimentales y con los resultados del modelo de EF, para el vano de medianera (Forjado reticular de casetón recuperable)

\begin{tabular}{ccccccc}
\hline Operación & Nivel & $\boldsymbol{C}_{\boldsymbol{D} \& \boldsymbol{C}}$ & $\boldsymbol{C}_{\boldsymbol{e x p}}$ & $\frac{\boldsymbol{C}_{\boldsymbol{e x p}}}{\boldsymbol{C}_{\boldsymbol{D} \& \boldsymbol{C}}}$ & $\boldsymbol{C}_{\boldsymbol{M E F}}$ & $\frac{\boldsymbol{C}_{\boldsymbol{M E F}}}{\boldsymbol{C}_{\boldsymbol{D} \& \boldsymbol{C}}}$ \\
\hline $\begin{array}{c}\text { Hormigonado } \\
\text { forjado 1 }\end{array}$ & 1 & 1.00 & 1.00 & 1.00 & 1.00 & 1.00 \\
\hline $\begin{array}{c}\text { Clareado forjado 1 } \\
\text { Hormigonado }\end{array}$ & 1 & 0.87 & 0.84 & 0.96 & 0.79 & 0.91 \\
\hline forjado 2 & 1 & 1.00 & 1.00 & 1.00 & 1.00 & 1.00 \\
\hline $\begin{array}{c}\text { Clareado forjado 2 } \\
\text { Descimbrado }\end{array}$ & 1 & 1.74 & 1.08 & 0.62 & 1.57 & 0.90 \\
\hline forjado 1 & 2 & 1.54 & - & - & 0.79 & 1.02 \\
\hline $\begin{array}{c}\text { Hormigonado } \\
\text { forjado 3 }\end{array}$ & 3 & 0.09 & 0.23 & 2.64 & 0.23 & 2.61 \\
\hline
\end{tabular}




\begin{tabular}{ccccccc}
\hline Operación & Nivel & $\boldsymbol{C}_{\boldsymbol{D} \& \boldsymbol{C}}$ & $\boldsymbol{C}_{\boldsymbol{e x p}}$ & $\frac{\boldsymbol{C}_{\boldsymbol{e x p}}}{\boldsymbol{C}_{\boldsymbol{D} \& \boldsymbol{C}}}$ & $\boldsymbol{C}_{\boldsymbol{M E F}}$ & $\frac{\boldsymbol{C}_{\boldsymbol{M E F}}}{\boldsymbol{C}_{\boldsymbol{D} \& \boldsymbol{C}}}$ \\
\hline Clareado forjado 3 & 3 & 0.60 & 0.69 & 1.15 & 0.65 & 1.09 \\
\hline $\begin{array}{c}\text { Descimbrado } \\
\text { forjado 2 }\end{array}$ & 3 & 0.36 & 0.60 & 1.66 & 0.56 & 1.53 \\
\hline $\begin{array}{c}\text { Hormigonado } \\
\text { forjado 4 }\end{array}$ & 4 & 1.00 & 1.00 & 1.00 & 1.00 & 0.98 \\
\hline Media & - & 0.90 & 0.84 & 0.94 & 0.89 & 0.99 \\
\hline Desviación Típica & - & - & - & $\mathbf{1 . 1 9}$ & - & $\mathbf{1 . 1 6}$ \\
\hline
\end{tabular}

La media de los ratios $\frac{C_{\text {exp }}}{C_{D \& C}}$ y $\frac{C_{M E F}}{C_{D \& C}}$ de las comparaciones mostradas en la Tabla 5.33 son próximas 1.00. Sin embargo, la desviación típica es bastante alta. Siendo de 0.49 para la comparación con las medidas del estudio experimental y de 0.43 para la comparación con los resultados del modelo de EF. Por lo tanto, el Método Simplificado Mejorado (Duan y Chen, 1995) no consigue un grado de ajuste suficiente para el caso estudiado.

\subsubsection{Método Simplificado de Fang et al. (2001a)}

\section{$\checkmark$ Parámetros de cálculo vano de esquina}

Los diferentes parámetros para los forjados y puntales necesarios para la aplicación de este método se describen en las Tablas 5.34 y 5.35, respectivamente.

Tabla 5.34 Parámetros del forjado para el método simplificado de Fang et al. (2001a). (Forjado reticular de casetón recuperable - Vano de esquina)

\begin{tabular}{cccc}
\hline $\boldsymbol{L}(\mathbf{m})$ & $\boldsymbol{E}_{\boldsymbol{j}}(\mathbf{G P a})$ & $\boldsymbol{I}\left(\mathbf{m}^{\mathbf{4}}\right)$ & $\boldsymbol{\lambda}$ \\
\hline 5.00 & Según Apéndice III & $1.987 \mathrm{E}-3$ & 185 \\
\hline
\end{tabular}

$L$ es la longitud del vano del forjado, $E_{j}$ es el módulo de elasticidad del hormigón de los forjados, I el momento de inercia del forjado suponiendo un ancho de la unidad y $\lambda$ es un coeficiente que depende de las condiciones de contorno y la relación largo ancho del forjado.

Tabla 5.35 Parámetros de los puntales para el método simplificado de Fang et al. (2001a). (Forjado reticular de casetón recuperable - Vano de esquina)

\begin{tabular}{ccccccc}
\hline Forjados & $\begin{array}{c}\boldsymbol{L}_{\text {shore }} \\
(\mathbf{m})\end{array}$ & $\begin{array}{c}\boldsymbol{E}_{\text {shore }} \\
(\mathbf{G P a})\end{array}$ & $\begin{array}{c}\boldsymbol{A}_{\text {shore }} \\
\left(\mathbf{m}^{2}\right)\end{array}$ & $\begin{array}{c}\mathbf{S} \\
(\mathbf{c i m b r a d o})\end{array}$ & $\begin{array}{c}\text { s } \\
(\text { clareado) }\end{array}$ & $\boldsymbol{\rho}$ \\
\hline F1 & 2.90 & 210 & $2.89 \mathrm{E}-4$ & 7 & 4 & 1.00 \\
F2 & 4.00 & 210 & $3.64 \mathrm{E}-4$ & 7 & 4 & 1.00 \\
F3 - F4 & 3.60 & 210 & $2.89 \mathrm{E}-4$ & 7 & 4 & 1.00 \\
\hline
\end{tabular}

$L_{\text {shore }}$ es la longitud de los puntales, $E_{\text {shore, }}$ es el módulo de elasticidad de los puntales, $A_{\text {shore }}$ es el área de la sección transversal de los puntales, $\mathrm{s}$ es el número de puntales instalados en el vano 
considerado para cada uno de los procesos constructivos analizados y $\rho$ es el coeficiente que considera las cargas desiguales en los puntales.

\section{$\checkmark$ Parámetros de cálculo vano de medianera}

Los diferentes parámetros para los forjados y puntales necesarios para la aplicación de este método se describen en las Tablas 5.36 y 5.37, respectivamente.

Tabla 5.36 Parámetros del forjado para el método simplificado de Fang et al. (2001a) (Forjado reticular de casetón recuperable - Vano de medianera)

\begin{tabular}{cccc}
\hline $\boldsymbol{L}(\mathbf{m})$ & $\boldsymbol{E}_{\boldsymbol{j}}(\mathbf{G P a})$ & $\boldsymbol{I}\left(\mathbf{m}^{\mathbf{4}}\right)$ & $\boldsymbol{\lambda}$ \\
\hline 8.00 & Según Apéndice III & $1.987 \mathrm{E}-3$ & 384 \\
\hline
\end{tabular}

$L$ es la longitud del vano del forjado, $E_{j}$ es el módulo de elasticidad del hormigón de los forjados, I el momento de inercia del forjado suponiendo un ancho de la unidad y $\lambda$ es un coeficiente que depende de las condiciones de contorno y la relación largo ancho del forjado.

Tabla 5.37 Parámetros de los puntales para el método simplificado de Fang et al. (2001a) (Forjado reticular de casetón recuperable - Vano de medianera)

\begin{tabular}{ccccccc}
\hline Forjados & $\begin{array}{c}\boldsymbol{L}_{\text {shore }} \\
(\mathbf{m})\end{array}$ & $\begin{array}{c}\boldsymbol{E}_{\text {shore }} \\
(\mathbf{G P a})\end{array}$ & $\begin{array}{c}\boldsymbol{A}_{\text {shore }} \\
\left(\mathbf{m}^{2}\right)\end{array}$ & $\begin{array}{c}\mathbf{s} \\
(\text { cimbrado) }\end{array}$ & $\begin{array}{c}\text { s } \\
(\text { clareado) }\end{array}$ & $\boldsymbol{\rho}$ \\
\hline F1 & 2.90 & 210 & $2.89 \mathrm{E}-4$ & 11 & 6 & 1.00 \\
F2 & 4.00 & 210 & $3.64 \mathrm{E}-4$ & 11 & 6 & 1.00 \\
F3 - F4 & 3.60 & 210 & $2.89 \mathrm{E}-4$ & 11 & 6 & 1.00 \\
\hline
\end{tabular}

$L_{\text {shore }}$ es la longitud de los puntales, $E_{\text {shore, }}$ es el módulo de elasticidad de los puntales, $A_{\text {shore }}$ es el área de la sección transversal de los puntales, $s$ es el número de puntales instalados en el vano considerado para cada uno de los procesos constructivos analizados y $\rho$ es el coeficiente que considera las cargas desiguales en los puntales.

\subsubsection{Resultados de la aplicación del método}

En la Figura 5.8 se muestran los resultados obtenidos aplicando el Método Simplificado de Fang et al. (2001a) para los vanos de esquina y medianera. Los resultados obtenidos con el Método Simplificado de Fang et al. (2001a), al considerar las condiciones de contorno de los forjados, son diferentes para el vano de esquina y para el vano de medianera. Los resultados se muestran en coeficientes de carga en puntales y forjados. 

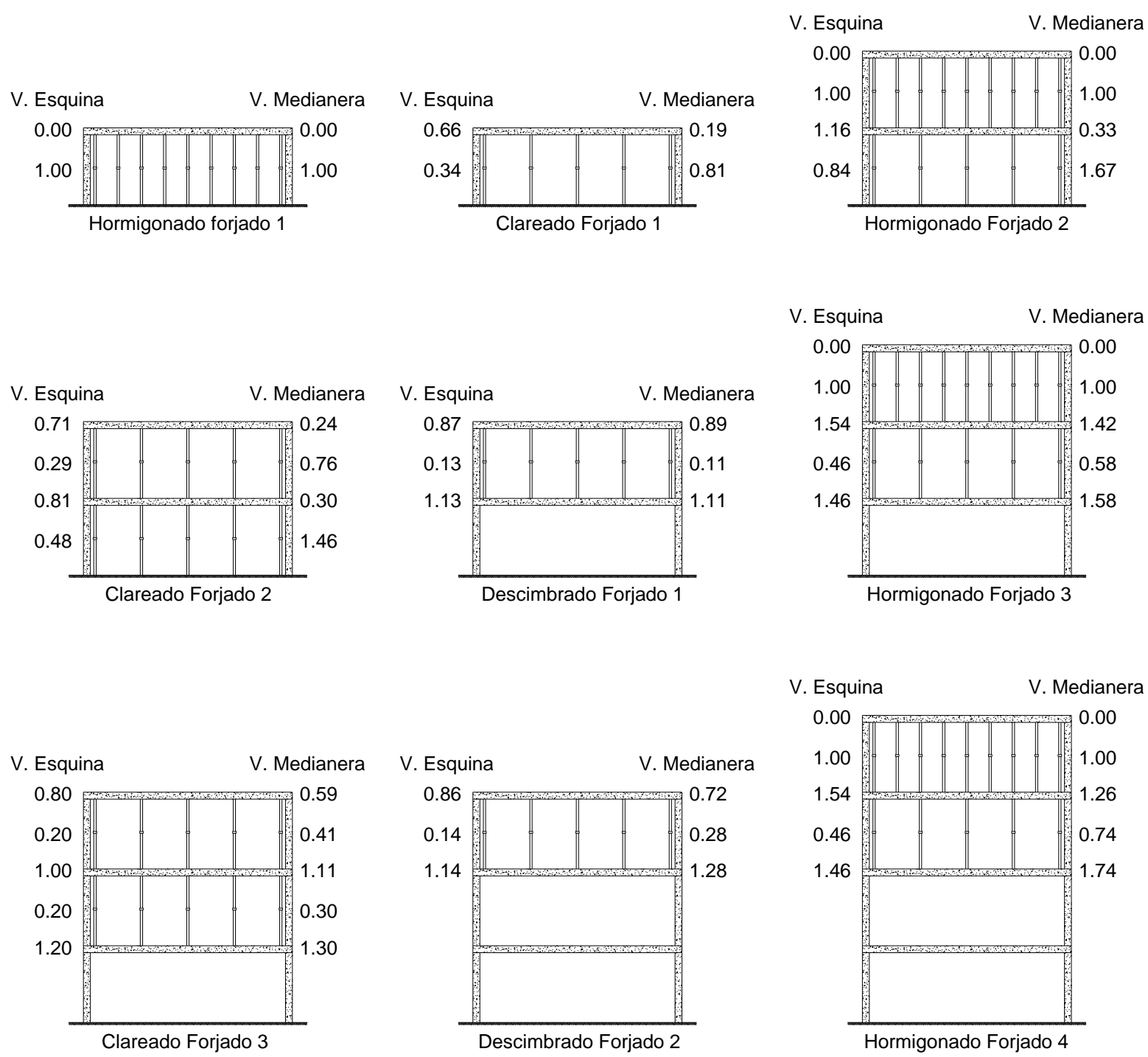

Fig. 5.8 Coeficientes de carga estimados con el método de Fang et al. (2001a) (Forjado reticular de casetón recuperable)

\subsubsection{Comparación de los resultados}

\section{Vano de esquina}

La Tabla 5.38 muestra una comparación de los coeficientes de carga en puntales determinados con el Método Simplificado de Fang et al. (2001a) $\left(C_{\text {Fang }}\right)$, con las medidas del estudio experimental $\left(C_{E x p}\right)$ (véase Capítulo 3 ) y con los resultados del modelo de $\mathrm{EF}\left(C_{M E F}\right)$ (véase Capítulo 4), para el vano de esquina.

Como se observa en la Tabla 5.38 la media de los ratios $\frac{C_{\text {exp }}}{C_{F a n g}}$ y $\frac{C_{F E M}}{C_{F a n g}}$ es del $90 \%$ en ambos casos, siendo mayor la desviación típica con respecto a las medidas experimentales.

Los coeficientes de carga obtenidos por el Método Simplificado de Fang et al. (2001a) difieren considerablemente de los obtenidos de forma experimental y de forma numérica. Por lo tanto, este 
método no resulta adecuado para predecir las cargas en puntales durante el proceso constructivo para el caso estudiado.

Tabla 5.38 Comparación entre los coeficientes de carga estimados con el método de Fang et al. (2001a) con las medidas experimentales y con los resultados del modelo de EF, para el vano de esquina. (Forjado reticular de casetón recuperable)

\begin{tabular}{|c|c|c|c|c|c|c|}
\hline Operación & Nivel & $C_{F a n g}$ & $C_{e x p}$ & $\frac{C_{\text {exp }}}{C_{\text {Fang }}}$ & $C_{M E F}$ & $\frac{C_{\text {MEF }}}{C_{\text {Fang }}}$ \\
\hline $\begin{array}{l}\text { Hormigonado } \\
\text { forjado } 1\end{array}$ & 1 & 1.00 & 0.99 & 0.99 & 1.00 & 1.00 \\
\hline Clareado forjado 1 & 1 & 0.34 & 0.66 & 1.96 & 0.60 & 1.79 \\
\hline Hormigonado & 2 & 1.00 & 0.98 & 0.98 & 0.99 & 0.99 \\
\hline forjado 2 & 1 & 0.84 & 0.91 & 1.08 & 1.18 & 1.41 \\
\hline \multirow{2}{*}{ Clareado forjado 2} & 2 & 0.29 & - & - & 0.68 & 2.37 \\
\hline & 1 & 0.48 & - & - & 1.04 & 2.17 \\
\hline $\begin{array}{l}\text { Descimbrado } \\
\text { forjado } 1\end{array}$ & 2 & 0.13 & 0.41 & 3.04 & 0.35 & 2.59 \\
\hline \multirow{2}{*}{$\begin{array}{l}\text { Hormigonado } \\
\text { forjado } 3\end{array}$} & 3 & 1.00 & 1.00 & 1.00 & 0.99 & 0.99 \\
\hline & 2 & 0.46 & 0.74 & 1.60 & 0.83 & 1.79 \\
\hline \multirow{2}{*}{ Clareado forjado 3} & 3 & 0.20 & 0.64 & 3.14 & 0.60 & 2.94 \\
\hline & 2 & 0.20 & 0.54 & 2.68 & 0.65 & 3.23 \\
\hline $\begin{array}{l}\text { Descimbrado } \\
\text { forjado } 2\end{array}$ & 3 & 0.14 & 0.48 & 3.36 & 0.37 & 2.59 \\
\hline Hormigonado & 4 & 1.00 & 1.00 & 1.00 & 0.98 & 0.98 \\
\hline forjado 4 & 3 & 0.46 & 0.88 & 1.93 & 0.78 & 1.71 \\
\hline Media & - & - & - & 1.90 & - & 1.90 \\
\hline Desviación Típica & - & - & - & 0.90 & - & 0.74 \\
\hline
\end{tabular}

\section{Vano de medianera}

La Tabla 5.39 muestra una comparación de los coeficientes de carga en puntales determinados con el Método Simplificado de Fang et al. (2001a) $\left(C_{F a n g}\right)$, con las medidas del estudio experimental $\left(C_{E x p}\right)$ (véase Capítulo 3) y con los resultados del modelo de EF ( $C_{M E F}$ ) (véase Capítulo 4), para el vano de medianera.

Tabla 5.39 Comparación entre los coeficientes de carga estimados con el método de Fang et al. (2001a) con las medidas experimentales y con los resultados del modelo de EF, para el vano de medianera (Forjado reticular de casetón recuperable)

\begin{tabular}{ccccccc}
\hline Operación & Nivel & $\boldsymbol{C}_{\text {Fang }}$ & $\boldsymbol{C}_{\boldsymbol{e x p}}$ & $\frac{\boldsymbol{C}_{\text {exp }}}{\boldsymbol{C}_{\text {Fang }}}$ & $\boldsymbol{C}_{\boldsymbol{M E F}}$ & $\frac{\boldsymbol{C}_{\boldsymbol{M E F}}}{\boldsymbol{C}_{\boldsymbol{F a n g}}}$ \\
\hline $\begin{array}{c}\text { Hormigonado } \\
\text { forjado 1 }\end{array}$ & 1 & 1.00 & 1.00 & 1.00 & 1.00 & 1.00 \\
\hline Clareado forjado 1 & 1 & 0.81 & 0.84 & 1.04 & 0.79 & 0.98 \\
\hline $\begin{array}{c}\text { Hormigonado } \\
\text { forjado 2 }\end{array}$ & 2 & 1.00 & 1.00 & 1.00 & 1.00 & 1.00 \\
\hline $\begin{array}{c}\text { Clareado forjado 2 } \\
\text { Descimbrado } \\
\text { forjado 1 }\end{array}$ & 1 & 1.67 & 1.08 & 0.65 & 1.57 & 0.94 \\
\hline
\end{tabular}




\begin{tabular}{|c|c|c|c|c|c|c|}
\hline Operación & Nivel & $C_{\text {Fang }}$ & $C_{\text {exp }}$ & $\frac{C_{\text {exp }}}{C_{\text {Fang }}}$ & $C_{M E F}$ & $\frac{C_{M E F}}{C_{F a n g}}$ \\
\hline \multirow{2}{*}{$\begin{array}{l}\text { Hormigonado } \\
\text { forjado } 3\end{array}$} & 3 & 1.00 & 0.99 & 0.99 & 1.00 & 1.00 \\
\hline & 2 & 0.58 & 0.70 & 1.22 & 0.72 & 1.25 \\
\hline \multirow{2}{*}{ Clareado forjado 3} & 3 & 0.41 & 0.69 & 1.70 & 0.65 & 1.60 \\
\hline & 2 & 0.30 & 0.60 & 2.01 & 0.56 & 1.88 \\
\hline $\begin{array}{l}\text { Descimbrado } \\
\text { forjado } 2\end{array}$ & 3 & 0.28 & 0.45 & 1.63 & 0.43 & 1.56 \\
\hline \multirow{2}{*}{$\begin{array}{l}\text { Hormigonado } \\
\text { forjado } 4\end{array}$} & 4 & 1.00 & 1.00 & 1.00 & 1.00 & 1.00 \\
\hline & 3 & 0.74 & 0.84 & 1.14 & 0.89 & 1.21 \\
\hline Media & - & - & - & 1.29 & - & 1.25 \\
\hline Desviación Típica & - & - & - & 0.44 & - & 0.36 \\
\hline
\end{tabular}

Comparando las estimaciones obtenidas por el Método Simplificado de Fang et al. (2001a) con las medidas del modelo experimental, se obtiene una media de los ratio $\frac{C_{e x p}}{C_{F a n g}}$ y $\frac{C_{M E F}}{C_{F a n g}}$ muy similares, de 1.29 y 1.25 , respectivamente, siendo la desviación típica en ambos casos bastante elevada ( 0.44 y 0.36 , respectivamente). Esto implica que el Método Simplificado de Fang et al. (2001a) no permite estimar correctamente las cargas en puntales en el caso estudiado.

\subsubsection{Nuevo Procedimiento Simplificado (Calderón et al., 2011)}

\section{$\checkmark$ Parámetros de cálculo vano de esquina}

Los diferentes parámetros para la aplicación de este método se describen en las Tablas 5.40 y 5.41 para los forjados y puntales, respectivamente.

Tabla 5.40 Parámetros del forjado para el nuevo procedimiento simplificado de Calderón et al. (2011) (Forjado reticular de casetón recuperable - Vano de esquina)

\begin{tabular}{cccc}
\hline $\boldsymbol{L}_{\boldsymbol{x}}(\mathbf{m})$ & $\boldsymbol{L}_{\boldsymbol{y}}(\mathbf{m})$ & $\boldsymbol{E}_{\boldsymbol{j}}(\mathbf{G P a})$ & $\boldsymbol{I}\left(\mathbf{m}^{\mathbf{4}}\right)$ \\
\hline \multirow{2}{*}{5.00} & \multirow{2}{*}{5.50} & \multirow{2}{*}{ Según Apéndice III } & $\begin{array}{c}2.48 \mathrm{E}-3 \\
2.78 \mathrm{E}-3\end{array}$ \\
\hline
\end{tabular}

$L_{x}$ es la luz entre cara de pilares en la dirección x (perpendicular a las sopandas), $L_{y}$ es la luz entre cara de pilares en la dirección y (dirección de las sopandas), $E_{\mathrm{j}}$ es el módulo de elasticidad del hormigón de los forjados e $I$ es el momento de inercia bruta de la sección de la banda considerada.

Tabla 5.41 Parámetros de los puntales para el nuevo procedimiento simplificado de Calderón et al. (2011) (Forjado reticular de casetón recuperable - Vano de esquina)

\begin{tabular}{|c|c|c|c|c|}
\hline Forjados & $\boldsymbol{H}(\mathbf{m})$ & $\begin{array}{c}E_{\text {sh }} \\
(\mathbf{G P a})\end{array}$ & $\begin{array}{c}A_{\text {Cimbrado }} \\
\left(\mathbf{m}^{2}\right)\end{array}$ & $\begin{array}{c}A_{\text {Clareado }} \\
\left(\mathbf{m}^{2}\right)\end{array}$ \\
\hline $\mathrm{F} 1$ & 2.90 & 210 & $2.02 \mathrm{E}-3$ & $1.16 \mathrm{E}-3$ \\
\hline F2 & 4.00 & 210 & $2.55 \mathrm{E}-3$ & $1.46 \mathrm{E}-3$ \\
\hline $\mathrm{F} 3-\mathrm{F} 4$ & 3.60 & 210 & $2.02 \mathrm{E}-3$ & $1.16 \mathrm{E}-3$ \\
\hline
\end{tabular}


$H$ es la altura de los puntales, $E_{s h}$ es el módulo de elasticidad de los puntales, $A_{\text {Cimbrado }}$ es la sumatoria del área de los puntales en la fase de cimbrado y $A_{\text {Clareado }}$ es la sumatoria del área de los puntales en la fase de clareado.

\section{$\checkmark$ Parámetros de cálculo vano de medianera}

Los diferentes parámetros para la aplicación de este método se describen en las Tablas 5.42 y 5.43 para los forjados y puntales, respectivamente.

Tabla 5.42 Parámetros del forjado para el nuevo procedimiento simplificado de Calderón et al. (2011) (Forjado reticular de casetón recuperable - Vano de medianera)

\begin{tabular}{cccc}
\hline $\boldsymbol{L}_{\boldsymbol{x}}(\mathbf{m})$ & $\boldsymbol{L}_{\boldsymbol{y}}(\mathbf{m})$ & $\boldsymbol{E}_{\boldsymbol{j}}(\mathbf{G P a})$ & $\boldsymbol{I}\left(\mathbf{m}^{\mathbf{4}}\right)$ \\
\hline \multirow{2}{*}{8.00} & \multirow{2}{*}{5.50} & Según Apéndice III & $\begin{array}{c}2.73 \mathrm{E}-3 \\
4.01 \mathrm{E}-3\end{array}$ \\
\hline
\end{tabular}

$L_{x}$ es la luz entre cara de pilares en la dirección x (perpendicular a las sopandas), $L_{y}$ es la luz entre cara de pilares en la dirección y (dirección de las sopandas), $E_{\mathrm{j}}$ es el módulo de elasticidad del hormigón de los forjados e $I$ es el momento de inercia bruta de la sección de la banda considerada.

Tabla 5.43 Parámetros de los puntales para el nuevo procedimiento simplificado de Calderón et al. (2011) (Forjado reticular de casetón recuperable - Vano de medianera)

\begin{tabular}{ccccc}
\hline Forjados & $\boldsymbol{H}(\mathbf{m})$ & $\begin{array}{c}\boldsymbol{E}_{\boldsymbol{s h}} \\
(\mathbf{G P a})\end{array}$ & $\begin{array}{c}\boldsymbol{A}_{\text {Cimbrado }} \\
\left(\mathbf{m}^{\mathbf{2}}\right)\end{array}$ & $\begin{array}{c}\boldsymbol{A}_{\text {Clareado }} \\
\left(\mathbf{m}^{2}\right)\end{array}$ \\
\hline F1 & 2.90 & 210 & $3.18 \mathrm{E}-3$ & $1.73 \mathrm{E}-3$ \\
F2 & 4.00 & 210 & $4.01 \mathrm{E}-3$ & $2.19 \mathrm{E}-3$ \\
F3 - F4 & 3.60 & 210 & $3.18 \mathrm{E}-3$ & $1.73 \mathrm{E}-3$ \\
\hline
\end{tabular}

$H$ es la altura de los puntales, $E_{s h}$ es el módulo de elasticidad de los puntales, $A_{\text {Cimbrado }}$ es la sumatoria del área de los puntales en la fase de cimbrado y $A_{\text {Clareado }}$ es la sumatoria del área de los puntales en la fase de clareado.

\subsubsection{Resultados de la aplicación del método}

La Figura 5.9 muestra los resultados obtenidos aplicando el Nuevo Procedimiento Simplificado (Calderón et al. 2011) para los vanos de esquina y medianera. Los resultados obtenidos con dicho procedimiento, al considerar las condiciones de contorno de los forjados, son diferentes para el vano de esquina y para el vano de medianera. Los resultados se muestran en coeficientes de carga en puntales y forjados. 

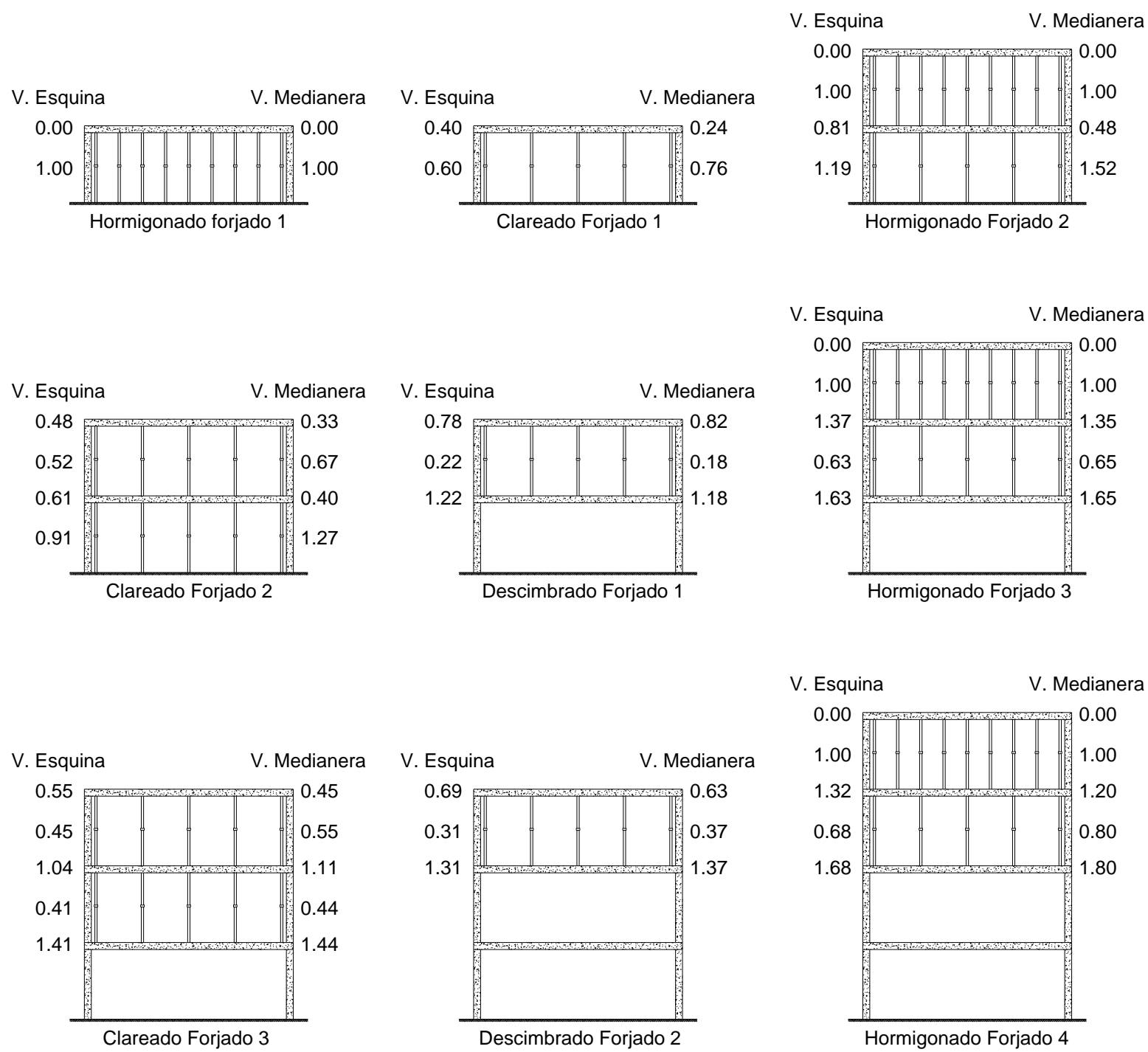

Fig. 5.9 Coeficientes de carga estimados con el método de Calderón et al. (2011) (Forjado reticular de casetón recuperable)

\subsubsection{Comparación de los resultados}

\section{Vano de esquina}

En la Tabla 5.44 se muestra una comparación de los coeficientes de carga media en puntales determinados a partir del Nuevo Procedimiento Simplificado (Calderón et al. 2011) $\left(C_{N P S}\right)$, de las medidas del estudio experimental $\left(C_{E x p}\right)$ (véase Capítulo 3) y de los resultados del modelo de $\mathrm{EF}$ $\left(C_{M E F}\right)$ (véase Capítulo 4$)$, para el vano de esquina.

Comparando las estimaciones obtenidas por el Nuevo Procedimiento Simplificado (Calderón et al., 2011) con las medidas del modelo experimental y con los resultados del modelo de EF, se obtiene una media de los ratios $\frac{C_{e x p}}{C_{N P S}}$ y $\frac{C_{M E F}}{C_{N P S}}$ de 1.20 y 1.18 , respectivamente, siendo la desviación típica muy similar en ambos casos (0.29 y 0.20). 
Tabla 5.44 Comparación entre los coeficientes de carga estimados con el método de Calderón et al. (2011) con las medidas experimentales y con los resultados del modelo de EF, para el vano de esquina. (Forjado reticular de casetón recuperable)

\begin{tabular}{|c|c|c|c|c|c|c|}
\hline Operación & Nivel & $C_{N P S}$ & $C_{e x p}$ & $\frac{C_{\text {exp }}}{C_{N P S}}$ & $C_{M E F}$ & $\frac{C_{M E F}}{C_{N P S}}$ \\
\hline $\begin{array}{l}\text { Hormigonado } \\
\text { forjado } 1\end{array}$ & 1 & 1.00 & 0.99 & 0.99 & 1.00 & 1.00 \\
\hline Clareado forjado 1 & 1 & 0.60 & 0.66 & 1.10 & 0.60 & 1.00 \\
\hline Hormigonado & 2 & 1.00 & 0.98 & 0.98 & 0.99 & 0.99 \\
\hline forjado 2 & 1 & 1.19 & 0.91 & 0.76 & 1.18 & 0.99 \\
\hline \multirow{2}{*}{ Clareado forjado 2} & 2 & 0.52 & - & - & 0.68 & 1.30 \\
\hline & 1 & 0.91 & - & - & 1.04 & 1.15 \\
\hline $\begin{array}{l}\text { Descimbrado } \\
\text { forjado } 1\end{array}$ & 2 & 0.22 & 0.41 & 1.83 & 0.35 & 1.56 \\
\hline \multirow{2}{*}{$\begin{array}{l}\text { Hormigonado } \\
\text { forjado } 3\end{array}$} & 3 & 1.00 & 1.00 & 1.00 & 0.99 & 0.99 \\
\hline & 2 & 0.63 & 0.74 & 1.18 & 0.83 & 1.31 \\
\hline \multirow{2}{*}{ Clareado forjado 3} & 3 & 0.45 & 0.64 & 1.41 & 0.60 & 1.33 \\
\hline & 2 & 0.41 & 0.54 & 1.32 & 0.65 & 1.59 \\
\hline $\begin{array}{l}\text { Descimbrado } \\
\text { forjado } 2\end{array}$ & 3 & 0.31 & 0.48 & 1.57 & 0.37 & 1.21 \\
\hline Hormigonado & 4 & 1.00 & 1.00 & 1.00 & 0.98 & 0.99 \\
\hline forjado 4 & 3 & 0.68 & 0.88 & 1.31 & 0.78 & 1.15 \\
\hline Media & - & - & - & 1.20 & - & 1.18 \\
\hline Desviación Típica & - & - & - & 0.29 & - & 0.20 \\
\hline
\end{tabular}

Utilizando el Nuevo Procedimiento Simplificado (Calderón et al. 2011) se consigue una aceptable aproximación en la estimación de cargas en los puntales para el caso estudiado. El grado de ajuste no es mayor debido a que el vano estudiado es un vano irregular cuya geometría no se puede considerar en toda su complejidad en este método simplificado.

\section{$\checkmark \quad$ Vano de medianera}

La Tabla 5.45 muestra una comparación de los coeficientes de carga media en puntales determinados a partir Nuevo Procedimiento Simplificado (Calderón et al. 2011) $\left(C_{N P S}\right)$, de las medidas del estudio experimental $\left(C_{E x p}\right)$ (véase Capítulo 3$)$ y de los resultados del modelo de $\mathrm{EF}\left(C_{M E F}\right)$ (véase Capítulo 4), para el vano de medianera.

Comparando las estimaciones obtenidas por el Nuevo Procedimiento Simplificado (Calderón et al. 2011) con las medidas del modelo experimental y con los resultados del modelo de EF, se obtiene una media de los ratios $\frac{C_{\text {exp }}}{C_{N P S}}$ y $\frac{C_{M E F}}{C_{N P S}}$ muy similar del 9 y $11 \%$, respectivamente. Sin embargo, la desviación típica con respecto a las medidas experimentales es mayor que la desviación obtenida para el caso del modelo de EF. 
Tabla 5.45 Comparación entre los coeficientes de carga estimados con el método de Calderón et al. (2011) con las medidas experimentales y con los resultados del modelo de EF, para el vano de medianera. (Forjado reticular de casetón recuperable)

\begin{tabular}{|c|c|c|c|c|c|c|}
\hline Operación & Nivel & $C_{N P S}$ & $C_{e x p}$ & $\frac{C_{\text {exp }}}{C_{N P S}}$ & $C_{M E F}$ & $\frac{C_{M E F}}{C_{N P S}}$ \\
\hline $\begin{array}{l}\text { Hormigonado } \\
\text { forjado } 1\end{array}$ & 1 & 1.00 & 1.00 & 1.00 & 1.00 & 1.00 \\
\hline Clareado forjado 1 & 1 & 0.76 & 0.84 & 1.10 & 0.79 & 1.03 \\
\hline \multirow{2}{*}{$\begin{array}{l}\text { Hormigonado } \\
\text { forjado } 2\end{array}$} & 2 & 1.00 & 1.00 & 1.00 & 1.00 & 1.00 \\
\hline & 1 & 1.52 & 1.08 & 0.71 & 1.57 & 1.03 \\
\hline \multirow{2}{*}{ Clareado forjado 2} & 2 & 0.67 & - & - & 0.79 & 1.18 \\
\hline & 1 & 1.27 & - & - & 1.46 & 1.15 \\
\hline $\begin{array}{l}\text { Descimbrado } \\
\text { forjado } 1\end{array}$ & 2 & 0.18 & 0.23 & 1.27 & 0.23 & 1.25 \\
\hline \multirow{2}{*}{$\begin{array}{l}\text { Hormigonado } \\
\quad \text { forjado } 3\end{array}$} & 3 & 1.00 & 0.99 & 0.99 & 1.00 & 1.00 \\
\hline & 2 & 0.65 & 0.70 & 1.08 & 0.72 & 1.11 \\
\hline \multirow{2}{*}{ Clareado forjado 3} & 3 & 0.55 & 0.69 & 1.25 & 0.65 & 1.17 \\
\hline & 2 & 0.44 & 0.60 & 1.38 & 0.56 & 1.28 \\
\hline $\begin{array}{l}\text { Descimbrado } \\
\text { forjado } 2\end{array}$ & 3 & 0.37 & 0.45 & 1.22 & 0.43 & 1.16 \\
\hline Hormigonado & 4 & 1.00 & 1.00 & 1.00 & 1.00 & 1.00 \\
\hline forjado 4 & 3 & 0.80 & 0.84 & 1.06 & 0.89 & 1.11 \\
\hline Media & - & - & - & 1.09 & - & 1.11 \\
\hline Desviación Típica & - & - & - & 0.17 & - & 0.09 \\
\hline
\end{tabular}

Considerando el grado de simplificación que se logra al aplicar el Nuevo Procedimiento Simplificado (Calderón et al., 2011), se puede considerar que dicho método estima con un buen grado de ajuste las cargas que se presentan en puntales para el proceso constructivo empleado en el caso estudiado.

\subsection{Conclusiones}

En el presente capítulo se han comparado, para cada uno de los edificios objeto de estudio, los resultados de diferentes métodos simplificados con las medidas experimentales recogidas en el Capítulo 3 y con los resultados de los modelos numéricos mostrados en el Capítulo 4. En las siguientes figuras se muestra un resumen de dichas comparaciones. 


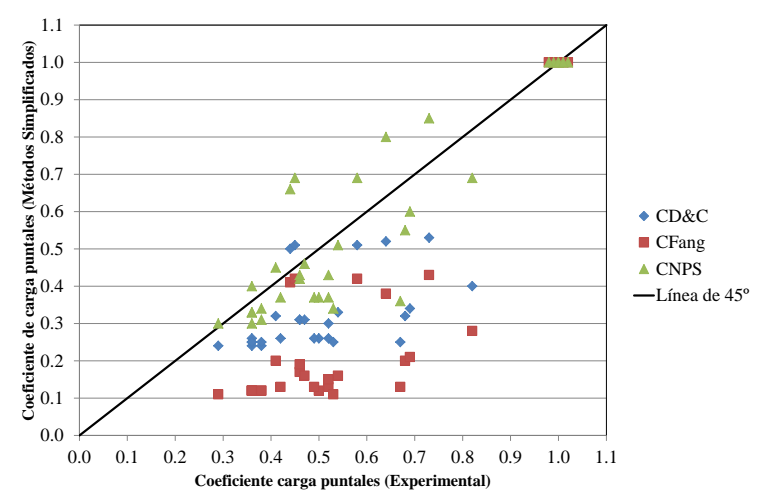

Fig. 5.10 Comparación entre los métodos simplificados y las medidas experimentales (Edificio de forjado de losa maciza - vano de esquina)
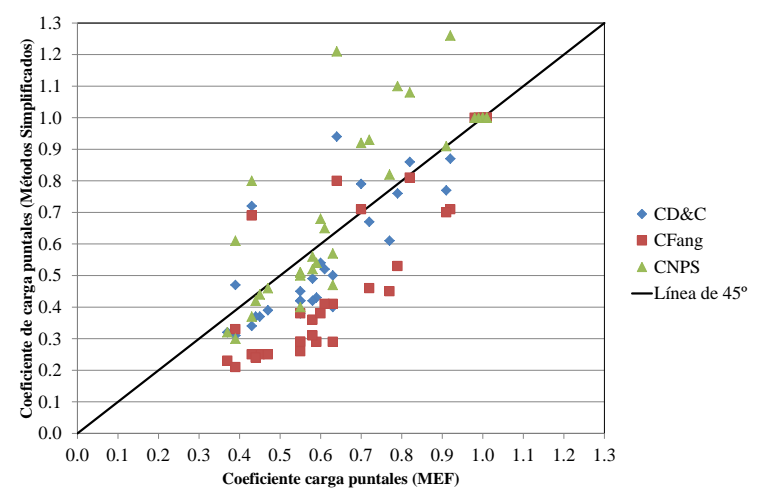

Fig. 5.12 Comparación entre los métodos simplificados y las medidas experimentales (Edificio de forjado de losa maciza - vano de medianera)

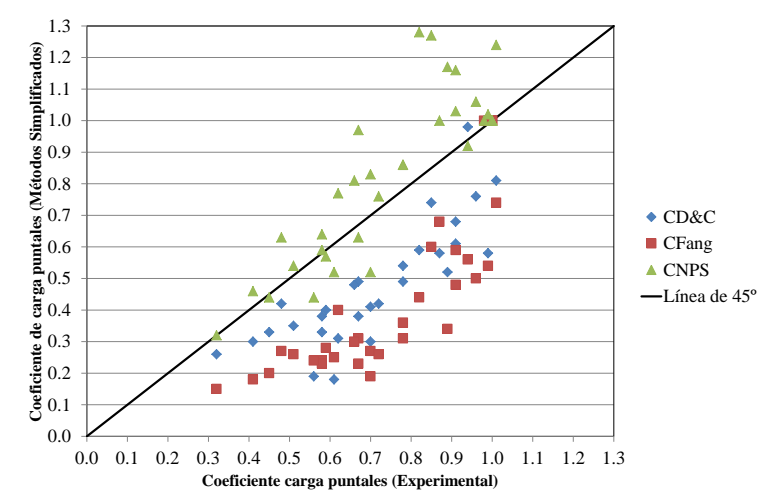

Fig. 5.14 Comparación entre los métodos simplificados y las medidas experimentales (Edificio de reticular de casetón perdido)

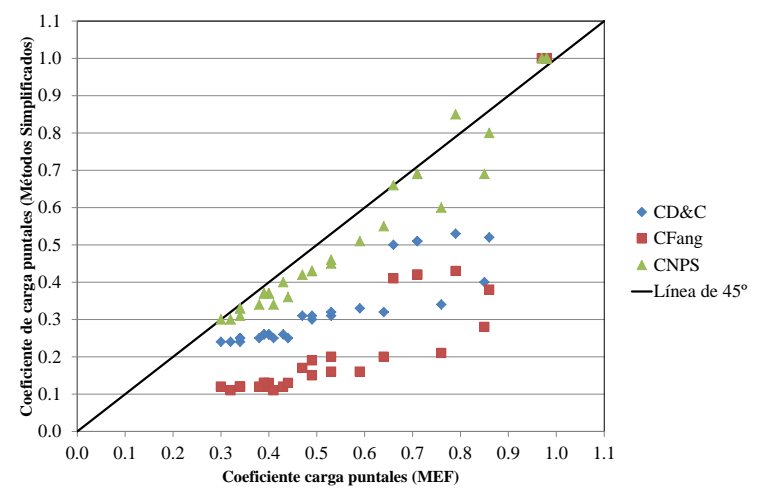

Fig. 5.11 Comparación entre los métodos simplificados y los resultados del MEF (Edificio de forjado de losa maciza vano - de esquina)

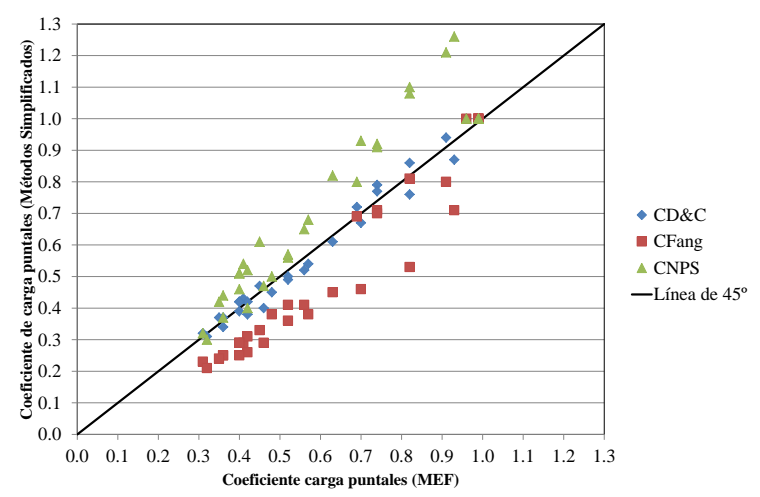

Fig. 5.13 Comparación entre los métodos simplificados y los resultados del MEF (Edificio de forjado de losa maciza vano - de medianera) 


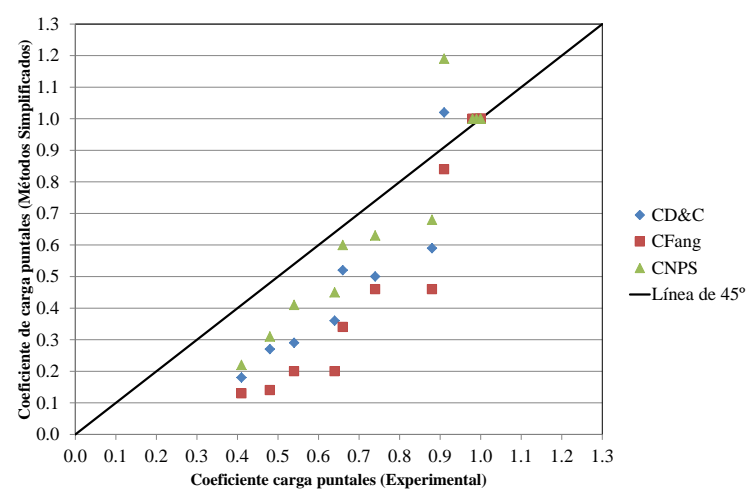

Fig. 5.15 Comparación entre los métodos simplificados y las medidas experimentales (Edificio de reticular de casetón recuperable - vano de esquina)

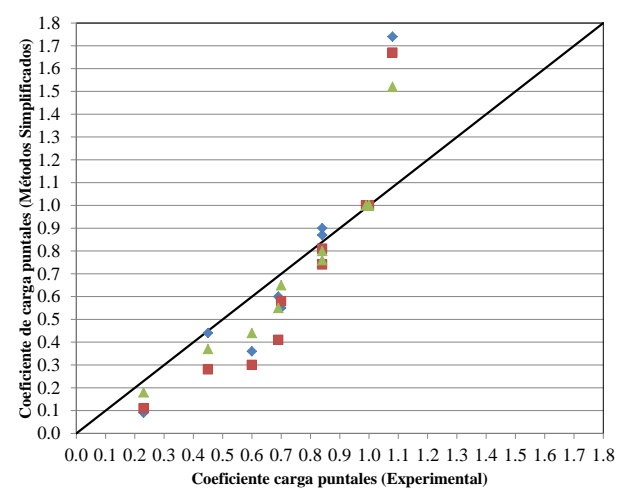

Fig. 5.17 Comparación entre los métodos simplificados y las medidas experimentales (Edificio de reticular de casetón recuperable - vano de medianera)

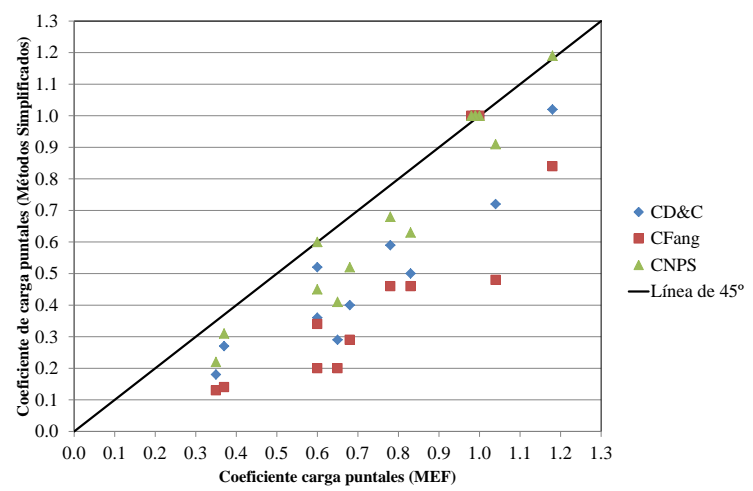

Fig. 5.16 Comparación entre los métodos simplificados y los resultados del MEF (Edificio de reticular de casetón recuperable - vano de esquina)

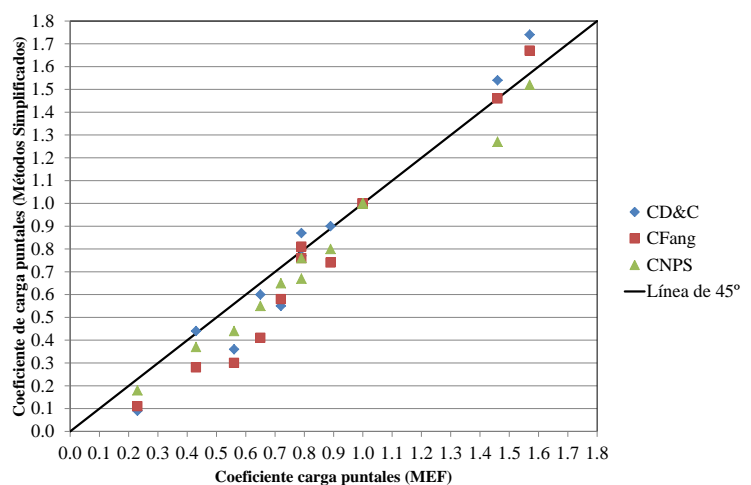

Fig. 5.18 Comparación entre los métodos simplificados y los resultados del MEF (Edificio de reticular de casetón recuperable - vano de medianera)

El primer método analizado es el Método Simplificado Mejorado (Duan y Chen, 1995). Los resultados obtenidos aplicando este método, sólo son satisfactorios en uno de los casos estudiados, en concreto para el vano de medianera del edificio de losa maciza, donde las medias de los ratios $\frac{C_{e x p}}{C_{D \& C}}$ y $\frac{C_{M E F}}{C_{D \& C}}$ son de 1.13 y 1.01 , respectivamente y las desviaciones típicas son de 0.20 y 0.05 .

En el caso del vano de medianera del edificio de forjado reticular de casetón recuperable, las medias de los ratios $\frac{C_{\text {exp }}}{C_{D \& C}}$ y $\frac{C_{M E F}}{C_{D \& C}}$ son bastante cercanas a 1.00 (1.19 y 1.16 , respectivamente) pero los valores de las desviaciones típicas son muy elevados (0.49 y 0.43$)$.

Para el resto de casos estudiados, la relación de los ratios $\frac{C_{\text {exp }}}{C_{D \& C}}$ y $\frac{C_{M E F}}{C_{D \& C}}$ es superior a 1.40 con desviaciones típicas también muy elevadas.

En general, el grado de ajuste obtenido con el Método Simplificado Mejorado (Duan y Chen, 1995) no es bueno y por lo tanto este método no resulta adecuado para estimar las cargas en puntales durante un proceso constructivo similar a los estudiados, donde se realiza la operación de clareado. Este método subestima la carga de los puntales, llevando a sobreestimar la carga de los forjados. 
El segundo método analizado es el Método Simplificado de Fang et al. (2001a). Aplicando este método a los diferentes casos estudiados no se obtiene un grado de ajuste aceptable para ninguno de ellos. La media del ratio $\frac{C_{\text {exp }}}{C_{\text {Fang }}}$ es siempre superior a 1.29, llegando a ser de 2.59 en uno de los casos. Las desviaciones típicas obtenidas con respecto a las medidas experimentales son superiores a 0.40 en todos los casos. Comparando los resultados del método con los obtenidos con el modelo numérico se obtiene que la media del ratio $\frac{C_{M E F}}{C_{F a n g}}$ es, en todos los casos, superior al 25\%, con desviaciones típicas que varían entre 0.21 y 0.91. Al igual Método Simplificado Mejorado (Duan y Chen, 1995), este método subestima la carga de los puntales, sobreestimando así la carga de los forjado.

En vista de lo anterior, se puede concluir que el Método Simplificado de Fang et al. (2001a) no es un método válido para estimar las cargas en puntales durante el proceso de cimbrado, clareado y descimbrado.

El último método estudiado es el Nuevo Procedimiento Simplificado (Calderón et al., 2011). Comparando los resultados obtenidos con este método con los obtenidos experimentalmente, se obtiene que la media del ratio $\frac{C_{\exp }}{C_{N P S}}$ varía entre un $2 \%$ y un $20 \%$, con unas desviaciones típicas inferiores a 0.30 . El caso donde menos se ajusta el método a las medidas experimentales es en el vano de esquina del edificio de forjado reticular de casetón recuperable. Esto es debido a la irregularidad del vano, cuya geometría no se puede considerar en toda su complejidad en este método simplificado. Si se excluye este caso, la media del ratio $\frac{C_{\text {exp }}}{C_{N P S}}$ oscila entre un $2 \%$ y $9 \%$, siendo las desviaciones típicas inferiores a 0.23 .

Por otro lado, al comparar los resultados obtenidos con el Nuevo Procedimiento Simplificado (Calderón et al., 2011) con los obtenidos con los modelos numéricos, se obtiene que la media del ratio $\frac{C_{M E F}}{C_{N P S}}$ varía entre un $8 \%$ y un $18 \%$, siendo la desviación típica máxima de 0.20 .

Se puede considerar, por tanto que el Nuevo Procedimiento Simplificado (Calderón et al., 2011) presenta un buen grado de ajuste tanto con las medidas experimentales como con los modelos numéricos.

Por lo tanto, se puede concluir que el Nuevo Procedimiento Simplificado (Calderón et al., 2011) es el método que mejor estima la transmisión de cargas entre forjados y puntales durante un proceso constructivo de cimbrado, clareado y descimbrado de edificios con forjados consecutivos de hormigón in situ. 


\section{CAPITULO 6. CONCLUSIONES Y FUTURAS LÍNEAS DE INVESTIGACIÓN}

\subsection{Conclusiones}

En la presente Tesis Doctoral se ha estudiado, de forma experimental y numérica, la transmisión de cargas entre forjados y puntales durante un proceso de cimbrado, clareado y descimbrado en las diferentes tipologías de forjados más comunes en edificación. Así mismo, se ha desarrollado un estudio experimental y teórico para conocer el comportamiento frente a variaciones de temperatura de los distintos elementos de la estructura durante su construcción y determinar su influencia en la transmisión de cargas.

En el presente apartado se exponen las conclusiones obtenidas en esta Tesis Doctoral. Primero se detallan las conclusiones extraídas de los estudios experimentales, tanto los relativos a la transmisión de cargas como a los efectos que producen los cambios de temperatura ambiente en los distintos elementos. Posteriormente se presentan las conclusiones relativas a la verificación y calibración de los modelos numéricos, para finalizar con las conclusiones sobre la validez de los distintos métodos simplificados de transmisión de cargas..

\subsubsection{Medidas experimentales de la transmisión de cargas entre puntales y forjados}

Se han realizado mediciones experimentales en edificios con tipologías estructurales distintas y en vanos con diferentes condiciones de contorno obteniendo conclusiones generales similares.

Esta medición experimental realizada durante la construcción de los edificios se basa en medidas instantáneas. La medición instantánea consiste en tomar medidas antes y después de cada una de las operaciones constructivas (hormigonado, clareado y descimbrado). Dichas medidas permiten conocer los incrementos de carga en puntales y forjados debido a la ejecución de cada una de las operaciones constructivas. Del estudio experimental se pueden extraer las siguientes conclusiones:

$\checkmark$ El reparto de cargas entre puntales no es uniforme. En general en los puntales de centro de vano se presentan los valores de carga máxima para cada una de las operaciones constructivas.

$\checkmark$ Cuando, durante el proceso constructivo, se producen operaciones no previstas, se observa una notable modificación de la transmisión de cargas esperada entre forjados y puntales

$\checkmark \quad$ En cada una de las operaciones constructivas (hormigonado, clareado y descimbrado), tanto para el vano de esquina como para el vano de medianera y para las distintas tipologías de forjado, se observan unas pautas generales de comportamiento muy marcadas. 
- Al hormigonar cada forjado, la totalidad de la carga es transmitida a los puntales.

- Al realizar la operación de clareado, los forjados clareados asumen una fracción importante de carga.

- Edificio de forjado de losa maciza.

- Vano de esquina: $48-64 \%$ del peso propio del forjado.

- Vano de medianera: $41-61 \%$ del peso propio del forjado.

- Edificio de forjado reticular de casetón perdido:

- Vano de esquina (forjados 1 y 2): 30-42\% del peso propio del forjado

- Vano extremo con voladizo (resto de forjados): $33-52 \%$ del peso propio del forjado

- Edificio de forjado reticular de casetón recuperable.

- Vano de esquina: 34 - 36\% del peso propio del forjado.

- Vano de medianera: $16-31 \%$ del peso propio del forjado.

- Al hormigonar un forjado superior sobre forjados inferiores ya clareados, una fracción importante de carga es asumida por el forjado sobre el que se apoyan los puntales del forjado hormigonado.

- Edificio de forjado de losa maciza.

- Vano de esquina: $72-94 \%$ del peso propio del forjado

- Vano de medianera: 54 - 93\% del peso propio del forjado

- Edificio de forjado reticular de casetón perdido.

- Vano de esquina (forjados 1 y 2): $69-73 \%$ del peso propio del forjado

- Vano extremo con voladizo (resto de forjados): 47-69\% del peso propio del forjado

- Edificio de forjado reticular de casetón recuperable.

- Vano de esquina: 60 - $73 \%$ del peso propio del forjado.

- Vano de medianera: $53-76 \%$ del peso propio del forjado.

- Al retirar los puntales de un forjado o descimbrarlo, la carga que asumían dichos puntales se reparte entre los forjados superiores conectados por puntales. La carga asumida por el forjado inmediatamente superior al forjado descimbrado varió entre:

- Edificio de forjado de losa maciza.

- Vano de esquina: 64 - 87\% de la carga que tenían los puntales retirados.

- Vano de medianera: 52 - 79\% de la carga que tenían los puntales retirados.

- Edificio de forjado reticular de casetón perdido.

- Vano de esquina (forjados 1 y 2): 57-67\% de la carga que tenían los puntales retirados.

- Vano extremo con voladizo (resto de forjados): $76 \%$ de la carga que tenían los puntales retirados.

- Edificio de forjado reticular de casetón recuperable. 
- Vano de esquina: $70 \%$ de la carga que tenían los puntales retirados.

- Vano de medianera: $60 \%$ de la carga que tenían los puntales retirados.

$\checkmark$ Las medidas experimentales han evidenciado que la transmisión de cargas entre forjados y puntales es diferente según el vano analizado. Esto se debe a que las condiciones de contorno y geometría del vano hacen particular la deformabilidad y/o la rigidez de cada uno de los vanos del forjado.

\subsubsection{Medidas experimentales de los cambios de temperatura en los distintos elementos}

Además de las mediciones de carga en puntales, en dos de los edificios se han realizado medidas experimentales de temperatura. Se ha medido tanto la evolución de la temperatura ambiente como las variaciones de temperatura que se producían en el espesor de los forjados, observando la magnitud e importancia de los gradientes de temperatura en el forjado. De estas mediciones se concluye que:

$\checkmark$ Como pauta general, se aprecia que por la noche y a primera hora de la mañana, cuando la temperatura ambiente es menor, la cara inferior del forjado tiene mayor temperatura que la superior. Conforme va aumentando la temperatura ambiente, este fenómeno se invierte, quedando la cara superior del forjado con una temperatura mayor que la cara inferior.

$\checkmark$ Se aprecia asimismo que las variaciones de temperatura son distintas dependiendo de si el forjado se encuentra encofrado o desencofrado, y de si recibe o no insolación directa. En la Tabla 6.1 se muestra un resumen de las variaciones de temperatura, máximas y mínimas, entre la cara superior e inferior del forjado registradas en cada uno de los casos. En ambos edificios se registró una diferencia máxima de temperatura ambiente en torno a los $12^{\circ} \mathrm{C}$.

Tabla 6.1 Incrementos de temperatura $\left({ }^{\circ} \mathrm{C}\right)$, máximos y mínimos, entre la cara superior e inferior del forjado.

\begin{tabular}{ccccccc}
\hline & \multicolumn{3}{c}{ Forjado encofrado } & \multicolumn{2}{c}{ Forjado desencofrado } \\
\hline & \multicolumn{1}{c}{$\begin{array}{c}\text { Incremento } \\
\text { min }\end{array}$} & $\begin{array}{c}\text { Incremento } \\
\text { máx }\end{array}$ & $\begin{array}{c}\text { Incremento } \\
\text { min }\end{array}$ & $\begin{array}{c}\text { Incremento } \\
\text { máx }\end{array}$ & $\begin{array}{c}\text { Incremento } \\
\text { min }\end{array}$ & $\begin{array}{c}\text { Incremento } \\
\text { máx }\end{array}$ \\
\hline Losa 0.20 m & -0.35 & 1.49 & -0.77 & 3.79 & - & - \\
Ábaco 0.32 m & -1.21 & 2.77 & -1.87 & 5.80 & - & - \\
Nervio 0.40 m & -2.96 & 6.94 & -3.86 & 9.56 & -1.31 & 7.32 \\
\hline
\end{tabular}

\subsubsection{Verificación y calibración de los modelos numéricos de EF}

\subsubsection{Transmisión de cargas por operaciones constructivas}

Se han desarrollado dos modelos numéricos basados en el modelo desarrollado por Alvarado et al. (2010) para la calibración de éste, ajustándolo a diferentes tipologías estructurales. Estos modelos se 
basan en un cálculo evolutivo no lineal, donde se considera el proceso constructivo seguido en obra, así como la evolución de las propiedades del hormigón con el tiempo.

La calibración del modelo numérico se ha realizado a partir de las medidas experimentales, del edificio de forjado de losa maciza y de forjado reticular de casetón recuperable. De los modelos numéricos puede extraerse que:

Los resultados obtenidos de los modelos de EF se ajustan satisfactoriamente a las mediciones experimentales.

- En el caso del edificio de forjado de losa maciza, la media de la relación $q_{\text {med,exp }} / q_{\text {med,MEF }}$ de todas las fases de construcción es de 1.07 , con una desviación típica de 0.19 para el vano de esquina, y de 1.11 con una desviación típica de 0.16 para el vano de medianera

- Para el edificio de forjado reticular de casetón recuperable, la media de la relación $q_{\text {med,exp }} / q_{\text {med,MEF }}$ de todas las fases de construcción es de 1.05 , para el vano de esquina, y de 1.00, para el vano de medianera. En ambos casos la desviación típica es de 0.14

- En cuanto a la comparación de las cargas máximas medidas experimentalmente con las obtenidas del modelo numérico, destacar que se obtienen mayores diferencias que en el caso de la carga media. Esto es debido a que en el modelo experimental resulta muy difícil controlar que todos los puntales se encuentran apretados de la misma forma, y por lo tanto la carga puede variar si se encuentran más o menos apretados. Se trata de un valor mucho más sensible a las manipulaciones de obra que la carga media.

\subsubsection{Efectos de los cambios de temperatura en la transmisión de cargas}

Además, se ha realizado una aproximación numérica al efecto que producen los cambios de temperatura en la transmisión de cargas entre forjados y puntales utilizando el modelo numérico (Alvarado et al., 2010) del edificio experimental de Alvarado (2009) pero considerando los cambios de temperatura que se producen tanto en el ambiente como en la losa, pilares y puntales. Las conclusiones que se obtienen de dicha aproximación son las siguientes:

$\checkmark$ Se ha observado que tanto el modelo de EF como los resultados obtenidos experimentalmente, muestran las mismas pautas de comportamiento frente a cambios de temperatura. Este comportamiento consiste, para el edificio estudiado, en que un aumento de temperatura produce una descarga en puntales, y un descenso de temperatura provoca un aumento de la carga de los mismos. Esta pauta se presenta en todos los forjados, independientemente de que estos estén completamente cimbrados o clareados.

$\checkmark$ En el caso de la flecha del forjado, también se observa la misma pauta de comportamiento en las medidas experimentales y en el modelo de EF. El comportamiento que se produce es un aumento en la flecha del forjado al descender la temperatura ambiente y una disminución de la flecha al aumentar la temperatura ambiente. 
$\checkmark$ Los resultados obtenidos del modelo numérico de temperaturas muestran la importancia de las variaciones de temperatura en las cargas de puntales y forjados durante la construcción de edificios. Estos cambios en las cargas son producto de la combinación de dos efectos principales: (a) los cambios de temperatura en los pilares y los puntales y (b) la diferencia de temperatura entre las caras superior e inferior de los forjados

\subsubsection{Comprobación de la validez de los métodos simplificados de determinación de transmisión de cargas.}

Por último se ha buscado validar un método simplificado que permita, mediante coeficientes de carga, evaluar la transmisión de cargas durante el proceso de cimbrado, clareado y descimbrado de edificios con forjados consecutivos de hormigón in situ.

Para realizar el estudio comparativo de diversos métodos simplificados de cálculo de transmisión de cargas, se han considerado el Método Simplificado Mejorado (Duan y Chen, 1995), el Método Simplificado de Fang et al. (2001a) y el Nuevo Procedimiento Simplificado (Calderón, 2011), puesto que son métodos que tienen en cuenta la rigidez real de los puntales y por lo tanto permiten simular la operación del clareado. De dicho estudio se concluye que:

$\checkmark$ En general, tanto el Método Simplificado Mejorado (Duan y Chen, 1995) como el Método Simplificado de Fang et al. (2001a) subestiman la carga de los puntales, llevando a sobreestimar la carga de los forjados. Además, el grado de ajuste obtenido no es bueno y por lo tanto no pueden considerarse métodos válidos para estimar las cargas en puntales durante un proceso constructivo similar a los estudiados, donde se realiza la operación de clareado.

$\checkmark$ El Nuevo Procedimiento Simplificado (Calderón et al., 2011) es el método que mejor grado de ajuste presenta tanto con las medidas experimentales como con los modelos numéricos. Se puede considerar que es un buen método para estimar la transmisión de cargas entre forjados y puntales durante un proceso constructivo de cimbrado, clareado y descimbrado de edificios con forjados consecutivos de hormigón in situ.

\subsection{Aportación original de la Tesis Doctoral}

Dentro del avance en el conocimiento aportado, son de destacar las siguientes aportaciones:

Se han realizado estudios experimentales en tres edificios de tres tipologías de forjado diferentes, con distintas condiciones de contorno, tomando mediadas durante el proceso de cimbrado, clareado y descimbrado. De las mediciones experimentales se ha obtenido que, independientemente del tipo de forjado, al realizar la operación de clareado los forjados asumen una fracción importante de carga.

$\checkmark$ Se han instrumentado tres forjados de distinto espesor con termopares a distintas profundidades para conocer el comportamiento que presentan los forjados frente a variaciones de temperatura ambiente. Se ha obtenido una pauta de comportamiento muy marcada y se ha observado la magnitud e importancia de los gradientes de temperatura en la losa. 
$\checkmark$ Se ha calibrado el modelo numérico desarrollado por Alvarado et al. (2010) ajustándolo a diferentes tipologías estructurales de las cuales se conoce su comportamiento experimental a través de las medidas de cargas en puntales tomadas en obra.

$\checkmark$ Se ha realizado una aproximación numérica al efecto que producen los cambios de temperatura en la transmisión de cargas entre forjados y puntales utilizando el modelo numérico (Alvarado et al., 2010) del edificio experimental de Alvarado (2009) pero considerando los cambios de temperatura que se producen tanto en el ambiente como en la losa, pilares y puntales, obteniendo el mismo comportamiento tanto experimental como numéricamente.

$\checkmark$ Se ha validado el Nuevo Procedimiento Simplificado como método simplificado que permite, mediante coeficientes de carga, evaluar la transmisión de cargas durante el proceso de cimbrado, clareado y descimbrado de edificios con forjados consecutivos de hormigón in situ.

\subsection{Producción científica}

Como consecuencia de los trabajos relacionados con esta Tesis Doctoral, hasta la fecha, se ha generado una producción científica que se plasma en forma de publicaciones, presentaciones en congresos científicos y proyectos de investigación financiados con fondos de instituciones públicas o privadas y que se detalla a continuación.

\subsubsection{Publicaciones}

Gasch, I.; Alvarado, Y.A.; Calderón, P.A. Temperature effects on load transmission between slabs and shores. Engineering Structures (2012), doi: 10.1016/j.engstruct.2012.02.004

Gasch, I.; Alvarado, Y.A.; Calderón, P.A.; Ivorra S. Construction loads using a shoring-clearingstriking process. Structures and Buildings. (En fase de revisión)

\subsubsection{Congresos}

Autores: Yezid A. Alvarado; Pedro A. Calderón; Isabel Gasch; José M. Adam; Jordi García; Francesc Moret

Título: Aplicación del nuevo procedimiento simplificado en la estimación de cargas en forjados y puntales durante la construcción de forjados consecutivos

Tipo de participación: Artículo

Congreso: V Congreso de ACHE

Lugar celebración: Barcelona, España

Fecha: Octubre 2011

Autores: Isabel Gasch; Yezid A. Alvarado; Pedro A. Calderón; Benjamín Torres

Título: Efecto de la temperatura en la transmisión de cargas entre forjados y puntales

Tipo de participación: Artículo

Congreso: V Congreso de ACHE

Lugar celebración: Barcelona, España

Fecha: Octubre 2011 


\subsubsection{Proyectos de investigación}

Título del contrato/proyecto: Optimización heurística del proceso constructivo de forjados hormigonados in situ mediante operaciones de cimbrado, clareado, recimbrado y descimbrado de plantas. (2009).

Entidad financiadora: Universidad Politécnica de Valencia

Duración, desde: 01/12/11 hasta: 01/12/13

Investigador responsable: Adam Martínez, José Miguel

Número de investigadores participantes: 5

Cuantía de la subvención: $9.000 €$

Título del contrato/proyecto: Desarrollo de una nueva herramienta informática de cálculo, simulación y monitorización de los procesos de cimbrado-descimbrado para estructuras de hormigón armado.

Tipo de contrato: $\mathrm{I}+\mathrm{D}$ contratada/conveniada

Empresa/Administración financiadora: Encofrados J. Alsina, S.A.

Entidades participantes: Universidad Politécnica de Valencia

Duración, desde: 14/12/10 hasta: 14/01/12

Investigador responsable: Calderón Garcia, Pedro Antonio

Número de investigadores participantes: 3

Precio total del proyecto: $43.200 €$

Título del contrato/proyecto: Investigación sobre la transmisión de cargas entre forjados y puntales para optimizar costes y rendimientos durante el proceso constructivo de forjados sucesivos de hormigón in situ (CDTI 2010)

Tipo de contrato: $\mathrm{I}+\mathrm{D}$ contratada/convenida

Empresa/Administración financiadora: SACYR, S.A.

Entidades participantes: Universidad Politécnica de Valencia

Duración, desde: 02/07/09 hasta: 02/03/11

Investigador responsable: Calderón Garcia, Pedro Antonio

Número de investigadores participantes: 8

Precio total del proyecto: $55.000 €$

Título del contrato/proyecto: Desarrollo de una aplicación informática que estime la transmisión de cargas en forjados y puntales durante la construcción de forjados hormigonados in-situ para un proceso de cimbrado, clareado y descimbrado

Tipo de contrato: I+D contratada/conveniada

Empresa/Administración financiadora: Encofrados J. Alsina, S.A.

Entidades participantes: Universidad Politécnica de Valencia

Duración, desde: 13/10/08 hasta: 13/09/09

Investigador responsable: Calderón Garcia, Pedro Antonio

Número de investigadores participantes: 5

Precio total del proyecto: $35.000 €$ 
Título del contrato/proyecto: Estudio experimental del proceso de clareado para diferentes tipologías de forjados de hormigón in-situ

Tipo de contrato: Consultorías, estudios técnicos y asesoramiento

Empresa/Administración financiadora: Encofrados J. Alsina, S.A.

Entidades participantes: Universidad Politécnica de Valencia

Duración, desde: 29/09/08 hasta: 29/09/09

Investigador responsable: Calderón Garcia, Pedro Antonio

Número de investigadores participantes: 4

Precio total del proyecto: $15.110 €$

Título del proyecto: Desarrollo de un método para el diseño de la construcción de forjados hormigonados in situ empleando el clareado en procesos de cimbrado: estudio numérico y experimental (GVPRE/2008/284)

Entidad financiadora: Generalitat Valenciana

Entidades participantes: Universidad Politécnica de Valencia

Duración, desde: 01/01/08 hasta: 01/01/09

Investigador responsable: Pellicer Armiñana, Teresa María

Número de investigadores participantes: 5

Cuantía de la subvención: $12.213 €$

\subsection{Futuras líneas de investigación}

Después del desarrollo de la presente Tesis Doctoral, se evidencia la necesidad de realizar nuevas investigaciones relacionadas con la distribución de cargas entre forjados y puntales en la construcción de edificios de hormigón in situ. Las posibles investigaciones futuras, relacionadas con el tema, podrían ser las que se exponen a continuación.

$\checkmark$ La mejora del plazo y economía del proceso constructivo, estriba en recuperar la mayor parte de las estructuras auxiliares en el menor tiempo posible. Dicha recuperación depende del sistema de cimbrado, el proceso constructivo empleado, las características de los materiales del edificio, las condiciones de temperatura y humedad en la obra, entre otros. De estos condicionantes la elección del proceso constructivo resulta ser fundamental para la mejora del plazo y la economía de ejecución de la estructura. Por tanto, sería interesante desarrollar una aplicación informática que, basada en técnicas de optimización heurística y en estimaciones de la transmisión de cargas entre forjados y puntales, permita determinar el proceso constructivo óptimo en la construcción de edificios de forjados consecutivos de hormigón in situ.

$\checkmark$ Actualmente al estimar las cargas que se presentan en los puntales, durante el proceso constructivo, se adopta como valor de carga, para elegir el puntal a utilizar en toda una planta, el máximo que se presenta en cualquiera de los vanos de dicha planta y para la operación constructiva más crítica. Esto lleva a utilizar un tipo de puntal en todo un forjado que cumpla los requisitos de resistencia que se presentan en un único punto de un vano lo cual no resulta ser óptimo con respecto al coste de ejecución del forjado pero dicha ejecución permite estar del lado de la seguridad frente a las cargas que se presentan en la mayoría de los puntales. Sería necesario desarrollar un elemento que siendo parte del puntal permita una redistribución de la carga máxima, 
que se presenta en el punto de mayor deformabilidad del forjado, en los puntales de su alrededor y optimizar de esta forma el tipo de puntal a utilizar en la ejecución de todo el forjado con su correspondiente reducción del coste de ejecución de éste.

$\checkmark$ En la presente Tesis Doctoral se ha estudiado el efecto de la temperatura en la transmisión de cargas entre forjados y puntales en un edificio concreto, pero sería necesario realizar un estudio más a fondo. Tendrían que tenerse en cuenta diferentes configuraciones estructurales y deberían ser evaluados diferentes tipos de variación de temperatura (p. ej. mayor inercia térmica en los pilares podría llevar a mayores diferencias entre la temperatura de los pilares y los puntales) para observar cuál es el rango esperado de incrementos de carga debido a los cambios de temperatura.

$\checkmark$ Autores como Serrà (1994) y Marí (1995) han determinado la influencia que tiene el descimbrar elementos de hormigón a edades jóvenes sobre la deformabilidad diferida. Por lo tanto, sería de un gran interés plantear un estudio en el que se analizase la influencia que la operación de clareado pueda tener sobre la deformabilidad diferida en los forjados. 



\section{REFERENCIAS BIBLIOGRÁFICAS}

ACI Committee 347 (1988). "Guide to formwork for concrete", American Concrete Institute, Detroit, Michigan.

ACI Committee 318 (1989). "Buildings code requirements for reinforced concrete", American Concrete Institute, Detroit, Michigan.

Agarwal RK, Gardner NJ (1974). "Form and shore requirements for multi-story flat slab type buildings", ACI Journal Proceedings, 71(11), 559-569.

ALSINA (2009). “Catálogo general de productos y servicios".

Alvarado YA. (2009) "Estudio experimental y numérico de la construcción de forjados hormigonados in situ mediante procesos de cimbrado, clareado y descimbrado de plantas consecutivas", Tesis Doctoral, Universidad Politécnica de Valencia, Valencia. http://hdl.handle.net/10251/7285.

Alvarado YA, Calderón PA, Adam JM, Payá IJ, Pellicer T, Pallares FJ, Moragues JJ, (2009). “An experimental study into the evolution of loads on shores and slabs during construction of multistory buildings using partial striking", Engineering Structures, 31(9), 2132-2140.

Alvarado YA, Calderón PA, Gasch I, Adam J, (2010). "A numerical study into the evolution of loads on shores and slabs during construction of multistorey buildings. Comparison of partial striking with other techniques”. Engineering Structures, 32(10), 3093-3102.

Álvarez R (1983). "Comportamiento de las estructuras de hormigón en edificación durante el proceso constructivo", Hormigón y Acero, 152, 25-37.

Ambrose TP, Huston DR, Fuhr PL, Devino EA, Werner MP (1994). "Shoring systems for construction load monitoring", Smart Materials and Structures, 3, 26-34.

ANSYS Inc. (2006). “ANSYS 11.0. Theory reference”.

ANSYS Inc. (2006). “ANSYS 11.0. Element reference”.

ASTM (1999). "Standard practice for estimating concrete strength by the maturity method. ASTM C 1074-98”, Philadelphia.

Azkune M (2007). "Transmisión de cargas en la ejecución de edificios de hormigón: mediciones en obra y análisis teórico", Tesis Doctoral, Universidad de Navarra, San Sebastián. 
Azkune M, Puente I, Insausti A (2007). "Effect to ambient temperature on the redistribution of loads during construction of multi-storey concrete structures", Engineering Structures, 29(6), 933941.

Beeby AW (2001a). "Criteria for the loading of slabs during construction", Proceedings of the Institution of Civil Engineers - Structures and Buildings, 146(2), 195-202.

Beeby AW (2001b). "The forces in backprops during construction of flat slab structures", Proceedings of the Institution of Civil Engineers - Structures and Buildings, 146(3), 307-317.

CEB-FIP (1991). "Model code 90”, Lausanne.

Calderón PA, Alvarado YA, Adam JM, (2011). "A new simplified procedure to estimate loads on slabs and shoring during the construction of multistorey buildings". Engineering Structures, 33(5), $1565-1575$.

Catalá J, Moragues JJ, Salort V, Sirvent PL (1992). "Transmisión de cargas entre forjados durante el proceso constructivo: Medidas realizadas en obra", Valencia.

Díaz J (2008). “Criterios técnicos para el descimbrado de estructuras de hormigón”, Tesis Doctoral, Universidad Politécnica de Madrid, Madrid.

Duan MZ, Chen WF (1995). "Improved simplified method for slab and shore load analysis during construction”, Project Report CE-STR-95-24, West Lafayette, Ind.

Duan MZ, Chen WF (1996). "Design guidelines for safe concrete construction", Concrete International, 18(10), 44-49.

El-Shahhat AM, Chen WF (1992). "Improved analysis of shore-slab interaction", ACI Structural Journal, 89(5), 528-537.

El-Shahhat AM, Rosowsky DV, Chen WF (1993). "Construction safety of multistory concrete buildings", ACI Structural Journal, 90(4), 335-341.

El-Shahhat AM, Rosowsky DV, Chen WF (1994). "Partial factor design for reinforced concrete buildings during construction", ACI Structural Journal, 91(4), 475-485.

Eldukair ZA, Ayyub BM (1991). "Analysis of recent U.S. structural and construction failures", Journal of Performance of Constructed Facilities, 5(1), 57-73.

ENV 1992-1-1 (Eurocode No 2) (1991). "Design of concrete structures. Part 1: General rules and rules for Buildings".

Epaarachchi DC, Stewart MG, Rosowsky DV (2002). "Structural reliability of multistory buildings during construction", Structural Engineering, 128(2), 205-213.

Fang DP, Geng CD, Zhu HY, Liu XL (2001a). "Floor load distribution in reinforced concrete buildings during construction", ACI Structural Journal, 98(2), 149-156. 
Fang DP, Zhu HY, Geng CD, Liu XL (2001b). "On site measurement of load distribution in reinforced concrete buildings during construction", ACI Structural Journal, 98(2), 157-163.

Fang DP, Xi H, Wang X, Zhang Ch, Zhao T, (2009a). "Load distribution assessment of reinforced concrete buildings during construction with structural characteristic parameter approach". Tsinghua Science and Technology, 14(6), 746-755.

Fang DP, Xi H, Wang X, Zhang Ch, (2009b). "Influences of shrinkage, creep, and temperature on the load distributions in reinforced concrete buildings during construction". Tsinghua Science and Technology, 14(6), 756-764.

Feld J, Carper K (1997). “Construction Failure”, John Wiley and Sons.

Freisleben H, Pedersen EJ (1977). "Maleinstrument til kontrol of betons haerdning”, Nordisk Betong, 1, 21-25.

Grundy P, Kabaila A (1963). "Construction loads on slabs with shored formwork in multistory buildings", ACI Structural proceedings, 60(12), 1729-1738.

Guo C (1989). "Maturity of concrete: method for predicting early-stage strength", ACI Materials Journal, 86(4), 341, 353.

Huston D, Fuhr P, Rosowsky D, Chen WF, Kirmani M (1999) Structures Congress - Proceedings, 715-718, New Orleans

Kaminetzky D, Stivaros P (1994). "Early-Age Concrete: Construction Loads, Behavior, and failures", Concrete International, 16(1), 58-62.

Kwak HG, Kim JK (2006). "Determination of efficient shoring system in RC frame structures", Building and Enviornment 41(12), 1913-1923.

Laplante P, Boulay C (1994). "Evolution du coefficient de dilatation thermique du béton en fonction de sa maturité aux tout premiers ages", Materials and structures, Springer Netherlands.

Lasisi M, Ng SF (1979). "Construction loads imposed on high-rise floor slabs", Concrete International, 1(2), 24-29.

Lee TG, Kim SY, Yi ST (2004) "Distribution of construction loads in columns and shores during construction of reinforced concrete structures", Magazine od Concrete Research, 56 (6), 347-358.

Liu XL, Chen WF, Bowman MD (1985). "Construction load analysis for concrete structures", Journal of Structural Engineering, 111(5), 1019-1036.

Liu XL, Chen WF, Bowman MD (1985). "Construction loads on supporting floors", Concrete International, 7(12), 21-26.

Liu XL, Chen WF, Bowman MD (1986). "Shore-slab interaction in concrete buildings", Journal of Construction Engineering and Management, 112(2), 227-244. 
Liu XL, Chen WF (1987). "Probability distribution of maximum wooden shore loads in multistory R/C buildings", Structural Safety, 4, 197-215.

Marí AR, Serrà I (1995). "Criterios para la determinación de plazos de descimbrado en estructuras de hormigón armado solicitadas a flexión”, Hormigón y Acero, 197, 41-55.

Ministerio de Fomento (2008). "Instrucción de hormigón estructural. EHE-08”, Madrid.

Moragues JJ (1992). "Algunas mediciones reales en cimbrados de plantas consecutivas realizadas en España”, Valencia.

Moragues JJ, Catalá J, Pellicer E (1994). "Mediciones en obra y análisis teórico de estructuras de edificación, de hormigón armado, durante el proceso de cimbrado consecutivo de forjados", Hormigón y Acero, 190, 83-91.

Moragues JJ, Catalá J, Pellicer E (1996). “An analysis of concrete framed structures during the construction process", Concrete International, 18(11), 44-48.

Mosallam K, Chen WF (1990). "Design considerations for formwork in multistory concrete buildings", Engineering Structures, 12(3), 163-172.

Mosallam K, Chen WF (1991). "Determining shoring loads for reinforced concrete construction", ACI Structural Journal, 88(3), 340-350.

Mosallam K, Chen WF (1992). "Construction load distributions for laterally braced formwork", ACI Structural Journal, 89(4), 415-424.

Nielsen, K. (1952) "Loads on reinforced concrete floor slabs and their deformations during construction", Bulletin, 15, Final Report, Swedish Cement and Concrete Research Institute, Royal Institute Technology, Stockholm.

Pallett P (2001). "Guide to flat slab formwork and falsework”, CONSTRUCT, Berkshire.

Pintado XC; Carlton RJ (2007). "Modelling prop loads during concrete slab construction", Structures and Buildings, 160(SB4), 221-229

Puente I, Azkune M, Insausti A (2007). "Shore-slab interaction in multistory reinforced concrete buildings during construction: An experimental approach", Engineering Structures, 29(5), 731741.

Regalado F. (2003) "Los forjados reticulares: diseño, análisis, construcción y patología”. CYPE Ingenieros, Alicante.

Rosowsky DV, Philbrick TW, Huston DR (1997). "Observations from shore load measurements during concrete construction", Journal of Performance of Constructed Facilities, 11(1), 18-23.

Scanlon A, Murray DB. (1982). "Practical calculation of two-way slab deflection", Concrete International, Design and Construction, American Concrete Institute, Detroit. 
Serrà I, Marí AR, Lopez F (1993). "Estudio experimental del comportamiento de las vigas de hormigón armado, descimbradas a tempranas edades", Hormigón y Acero, 189, 93-105.

Serrà I (1994). "Estudio experimental del comportamiento de vigas de hormigón armado descimbradas a tempranas edades", Tesis Doctoral, Universidad Politécnica de Cataluña, Cataluña.

Stivaros P, Halvorsen G (1990). "Shoring reshoring operations for multistory buildings", ACI Structural Journal, 87(5), 589-596.

Stivaros P, Halvorsen G (1991). "Equivalent frame analysis of concrete buildings during construction", Concrete International, 13(8), 57-62.

Taylor PJ (1967). "Effects of formwork stripping time on deflections of flat slabs and plates", Australian civil engineering and construction, 8(2), 31-35.

Vollum R.L. (2003). "Investigation into backprop forces and deflections at St George Wharf", Magazine for Concrete Research, 55, 449-460. 



\section{APÉNDICE I. RESULTADOS DE LOS ESTUDIOS EXPERIMENTALES}

\section{I.1. Introducción}

En el Capítulo 3 de la presente Tesis Doctoral se han expuesto los diferentes estudios experimentales llevados a cabo. El primero de ellos se realizó en un edificio de forjado de losa maciza situado en Madrid, donde se instrumentaron 2 vanos consecutivos, uno de esquina y otro de medianera, con 6 puntales instrumentados por cada vano. La medición se realizó desde el hormigonado del forjado correspondiente a planta baja (forjado 1), hasta el hormigonado del forjado correspondiente al techo de la quinta planta (forjado 6).

El siguiente estudio experimental se llevó en Sabadell (Barcelona), en un edificio de forjado reticular de casetón perdido. Se instrumentaron 2 sopandas principales por planta, pertenecientes ambas al mismo vano, con un total de 8 puntales instrumentados por sopanda. Se tomaron medidas de carga desde el hormigonado del forjado de techo de sótano 2 (forjado 1) hasta el hormigonado del forjado correspondiente al techo de la tercera planta (forjado 6).

El último de los estudios experimentales se realizó en un edificio de forjado reticular de casetón recuperable situado en la Universidad Politécnica de Valencia. Se instrumentaron dos vanos consecutivos, uno de esquina y otro de medianera, con un total de 11 puntales por planta. La monitorización se realizó desde el hormigonado del forjado de techo del sótano (forjado 1) hasta el hormigonado del forjado de techo de la segunda planta (forjado 4).

En el presente apéndice se muestran los resultados de la medición instantánea de carga. Con el fin de representar la transmisión de cargas durante la construcción de la estructura, los resultados son expresados gráficamente usando la siguiente notación:

$\checkmark \quad W_{f}$ : peso propio del forjado $\left(\mathrm{kN} / \mathrm{m}^{2}\right)$

- Edificio losa maciza: Valor teórico estimado en $4.96 \mathrm{kN} / \mathrm{m}^{2}$.

- Edificio losa maciza: Valor teórico estimado en $3.39 \mathrm{kN} / \mathrm{m}^{2}$.

- Edificio losa maciza: Valor teórico estimado en $5.76 \mathrm{kN} / \mathrm{m}^{2}$.

$\checkmark Q_{p}$ : carga media en puntales $\left(\mathrm{kN} / \mathrm{m}^{2}\right)$. Valor obtenido de la medida de cargas en puntales.

$\checkmark Q_{f}$ : carga media en el forjado $\left(W_{f}-Q_{p}\right)\left(\mathrm{kN} / \mathrm{m}^{2}\right)$.

$\checkmark C_{f}$ : coeficiente de carga en forjados que resulta de la relación entre la carga media del forjado y el peso propio del forjado $\left(Q_{f} / W_{f}\right)$. 
$\checkmark \quad C_{p}$ : coeficiente de carga en puntales que resulta de la relación entre la carga media en puntales y el peso propio del forjado $\left(Q_{p} / W_{f}\right)$.

$\checkmark A_{t}$ : área tributaria del puntal considerado $\left(\mathrm{m}^{2}\right)$.

$\checkmark A_{\text {total }}$ : área del forjado instrumentada $\left(\mathrm{m}^{2}\right)$.

$\checkmark \quad P_{i}$ : carga instantánea en el puntal “ $i$ " $(\mathrm{kN})$.

$\checkmark \quad P_{\text {max }}$ : axil del puntal más cargado $(\mathrm{kN})$.

$\checkmark \quad q_{\max }$ : axil del puntal más cargado por unidad de superficie $\left(P_{\max } / A_{t}\right)\left(\mathrm{kN} / \mathrm{m}^{2}\right)$.

$\checkmark q_{m e d}$ : carga media en puntales por unidad de superficie que resulta de la relación entre la sumatoria de las cargas en puntales y el área del forjado instrumentada $\left(\sum P_{i} / A_{\text {total }}\right)\left(\mathrm{kN} / \mathrm{m}^{2}\right)$.

\section{I.2. Resultados del estudio experimental de un edificio de forjado de losa maciza}

\section{I.2.1. Hormigonado forjado 1}

El hormigonado del forjado 1 se realizó el 8 de Junio de 2009. Las Figuras I.1 y I.2 muestran un resumen de las medidas instantáneas para cada uno de los vanos instrumentados.

\section{Vano de esquina}

$$
\begin{aligned}
& \boldsymbol{C}_{\boldsymbol{f}}=0.00 \\
& \boldsymbol{C}_{\boldsymbol{p}}=1.00
\end{aligned}
$$

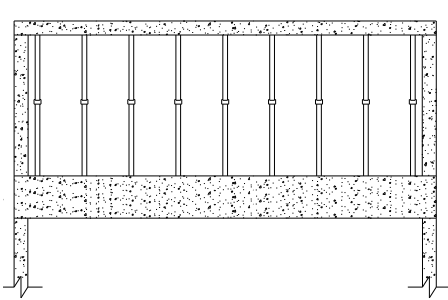

$$
\begin{array}{cc}
\text { Número de puntales } & \text { Puntal más cargado } \\
5 & \text { Puntal 5 } \\
\boldsymbol{A}_{\text {total }}=3.33 \mathrm{~m}^{2} & \boldsymbol{A}_{\boldsymbol{t}}=0.66 \mathrm{~m}^{2} \\
\boldsymbol{q}_{\text {med }}=4.95 \mathrm{kN} / \mathrm{m}^{2} & \boldsymbol{P}_{\text {max }}=3.40 \mathrm{kN} \\
& \boldsymbol{q}_{\text {max }}=5.10 \mathrm{kN} / \mathrm{m}^{2}
\end{array}
$$

Fig. I.1 Resultados vano de esquina (forjado de losa maciza). Hormigonado del forjado 1

\section{Vano de medianera}

$$
\begin{aligned}
& \boldsymbol{C}_{\boldsymbol{f}}=0.00 \\
& \boldsymbol{C}_{\boldsymbol{p}}=1.00
\end{aligned}
$$

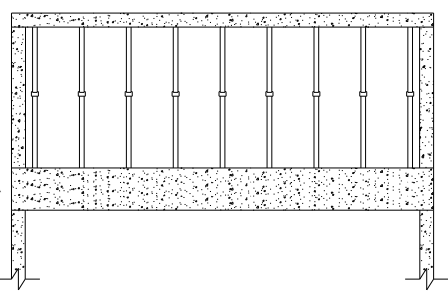

$$
\begin{array}{cc}
\text { Número de puntales } & \text { Puntal más cargado } \\
5 & \text { Puntal } 9 \\
\boldsymbol{A}_{\text {total }}=3.33 \mathrm{~m}^{2} & \boldsymbol{A}_{\boldsymbol{t}}=0.66 \mathrm{~m}^{2} \\
\boldsymbol{q}_{\text {med }}=4.95 \mathrm{kN} / \mathrm{m}^{2} & \boldsymbol{P}_{\text {max }}=3.40 \mathrm{kN} \\
& \boldsymbol{q}_{\text {max }}=5.10 \mathrm{kN} / \mathrm{m}^{2}
\end{array}
$$

Fig. I.2 Resultados vano de medianera (forjado de losa maciza). Hormigonado del forjado 1

Como era esperable, una vez hormigonado el forjado la carga total fue asumida por el sistema de apuntalamiento. 


\section{I.2.2. Clareado forjado 1}

El clareado del forjado 1 se realizó el 15 de Junio de 2009, 7 días después de su hormigonado. En las Figuras I.3 y I.4 se muestra un resumen de las medidas instantáneas una vez realizado el clareado.

Vano de esquina

$$
\begin{aligned}
& \boldsymbol{C}_{\boldsymbol{f}}=0.64 \\
& \boldsymbol{C}_{\boldsymbol{p}}=0.36
\end{aligned}
$$

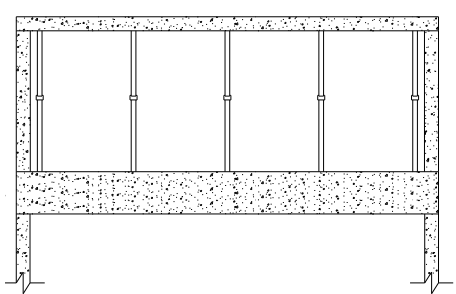

Fig. I.3 Resultados vano de esquina (forjado de losa maciza). Clareado del forjado 1

\section{Vano de medianera}

$$
\begin{aligned}
& \boldsymbol{C}_{\boldsymbol{f}}=0.61 \\
& \boldsymbol{C}_{\boldsymbol{p}}=0.39
\end{aligned}
$$

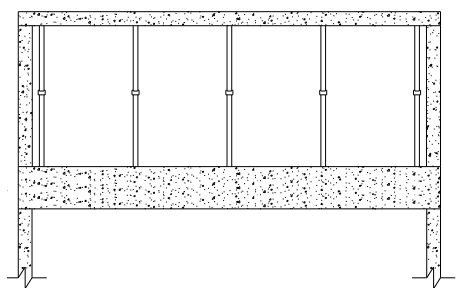

Número de puntales 5

$A_{\text {total }}=10.50 \mathrm{~m}^{2}$

$\boldsymbol{q}_{\text {med }}=1.77 \mathrm{kN} / \mathrm{m}^{2}$

Puntal más cargado Puntal 3

$\boldsymbol{A}_{\boldsymbol{t}}=2.10 \mathrm{~m}^{2}$

$\boldsymbol{P}_{\text {max }}=5.29 \mathrm{kN}$

$\boldsymbol{q}_{\max }=2.52 \mathrm{kN} / \mathrm{m}^{2}$

Fig. I.4 Resultados vano de medianera (forjado de losa maciza). Clareado del forjado 1

Al realizar la operación del clareado, el forjado asume entre un $61 \%$ y un $64 \%$ de carga en relación a su peso propio, presentándose una reducción en la carga media de los puntales. Este valor de carga asumido por los puntales confirma que una vez realizado el clareado o descimbrado parcial, el forjado comienza a soportar una fracción importante de su carga.

\section{I.2.3. Hormigonado forjado 2}

El hormigonado del forjado 2 se llevó a cabo el 18 de Junio de 2009, 10 días después del hormigonado de la primera planta. Las Figuras I.5 y I.6 muestran resumidamente las medidas instantáneas obtenidas. 


\section{Vano de esquina}

$$
\begin{aligned}
& \boldsymbol{C}_{\boldsymbol{f}}=0.01 \\
& \boldsymbol{C}_{\boldsymbol{p}}=0.99 \\
& \boldsymbol{C}_{\boldsymbol{f}}=1.36 \\
& \boldsymbol{C}_{\boldsymbol{p}}=0.64
\end{aligned}
$$

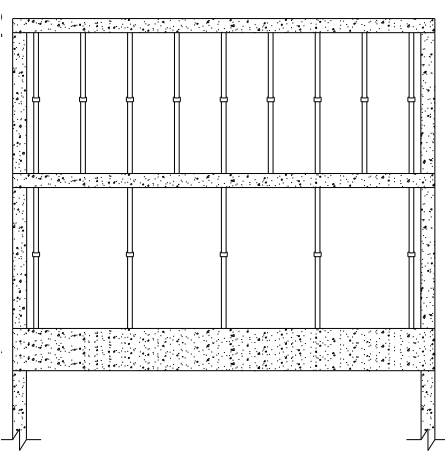

$$
\begin{aligned}
& \text { Número de puntales Puntal más cargado } \\
& 5 \quad \text { Puntal } 3 \\
& \boldsymbol{A}_{\text {total }}=5.00 \mathrm{~m}^{2} \quad \boldsymbol{A}_{\boldsymbol{t}}=1.00 \mathrm{~m}^{2} \\
& \boldsymbol{q}_{\text {med }}=4.90 \mathrm{kN} / \mathrm{m}^{2} \quad \boldsymbol{P}_{\text {max }}=5.40 \mathrm{kN} \\
& \text { Número de puntales } \\
& 5 \\
& \boldsymbol{q}_{\text {max }}=5.40 \mathrm{kN} / \mathrm{m}^{2} \\
& \text { Puntal más cargado } \\
& \text { Puntal } 1 \\
& \boldsymbol{A}_{\text {total }}=10.50 \mathrm{~m}^{2} \\
& \boldsymbol{q}_{\text {med }}=3.16 \mathrm{kN} / \mathrm{m}^{2} \\
& \boldsymbol{A}_{\boldsymbol{t}}=2.10 \mathrm{~m}^{2} \\
& P_{\text {max }}=7.01 \mathrm{kN} \\
& \boldsymbol{q}_{\text {max }}=3.34 \mathrm{kN} / \mathrm{m}^{2}
\end{aligned}
$$

Fig. I.5 Resultados vano de esquina (forjado de losa maciza). Hormigonado del forjado 2

\section{Vano de medianera}

$$
\begin{aligned}
& C_{\boldsymbol{f}}=0.00 \\
& \boldsymbol{C}_{\boldsymbol{p}}=1.01 \\
& \boldsymbol{C}_{\boldsymbol{f}}=1.36 \\
& \boldsymbol{C}_{\boldsymbol{p}}=0.64
\end{aligned}
$$

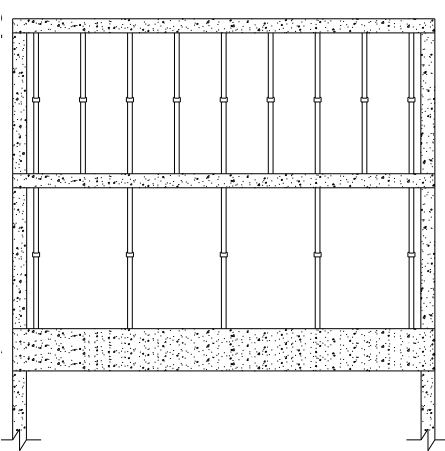

$$
\begin{array}{cc}
\text { Número de puntales } & \text { Puntal más cargado } \\
5 & \text { Puntal 10 } \\
\boldsymbol{A}_{\text {total }}=5.00 \mathrm{~m}^{2} & \boldsymbol{A}_{\boldsymbol{t}}=1.00 \mathrm{~m}^{2} \\
\boldsymbol{q}_{\text {med }}=5.00 \mathrm{kN} / \mathrm{m}^{2} & \boldsymbol{P}_{\text {max }}=5.29 \mathrm{kN} \\
& \boldsymbol{q}_{\text {max }}=5.29 \mathrm{kN} / \mathrm{m}^{2} \\
\text { Número de puntales } & \text { Puntal más cargado } \\
5 & \text { Puntal } 8 \\
\boldsymbol{A}_{\text {total }}=10.00 \mathrm{~m}^{2} & \boldsymbol{A}_{\boldsymbol{t}}=2.00 \mathrm{~m}^{2} \\
\boldsymbol{q}_{\text {med }}=3.17 \mathrm{kN} / \mathrm{m}^{2} & \boldsymbol{P}_{\text {max }}=10.07 \mathrm{kN} \\
& \boldsymbol{q}_{\text {max }}=5.04 \mathrm{kN} / \mathrm{m}^{2}
\end{array}
$$

Fig. I.6 Resultados vano de medianera (forjado de losa maciza). Hormigonado del forjado 2

De la misma forma que al hormigonar el forjado 1, el sistema de apuntalamiento soporta toda la carga del forjado 2 recién hormigonado.

La carga transmitida por los puntales que se encuentran bajo el forjado 2 es soportada en gran parte por el forjado 1, sólo transmitiendo un $25-28 \%$ de esta carga a los puntales que se encuentran bajo este forjado.

\section{I.2.4. Clareado forjado 2}

El clareado del forjado 2 se realizó el 23 de Junio de 2009, 5 días después de su hormigonado. Las Figura I.7 y I.8 muestran un resumen de las medidas instantáneas posteriores al clareado del forjado 2. 
Vano de esquina

$$
\begin{aligned}
& C_{f}=0.50 \\
& C_{p}=0.50 \\
& C_{f}=0.82 \\
& C_{p}=0.68
\end{aligned}
$$

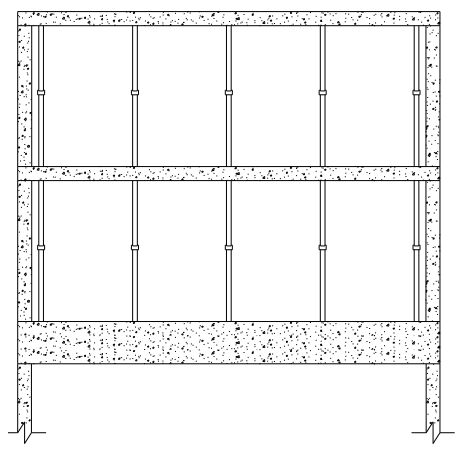

$$
\begin{array}{cc}
\text { Número de puntales } & \text { Puntal más cargado } \\
5 & \text { Puntal } 2 \\
A_{\text {total }}=10.50 \mathrm{~m}^{2} & A_{t}=2.10 \mathrm{~m}^{2} \\
q_{\text {med }}=2.50 \mathrm{kN} / \mathrm{m}^{2} & P_{\text {max }}=7.01 \mathrm{kN} \\
& q_{\text {max }}=3.34 \mathrm{kN} / \mathrm{m}^{2} \\
\text { Número de puntales } & \text { Puntal más cargado } \\
5 & \text { Puntal } 2 \\
A_{\text {total }}=10.50 \mathrm{~m}^{2} & A_{t}=2.10 \mathrm{~m}^{2} \\
q_{\text {med }}=3.36 \mathrm{kN} / \mathrm{m}^{2} & P_{\text {max }}=8.26 \mathrm{kN} \\
& q_{\text {max }}=3.93 \mathrm{kN} / \mathrm{m}^{2}
\end{array}
$$

Fig. I.7 Resultados vano de esquina (forjado de losa maciza). Clareado del forjado 2

\section{Vano de medianera}

$$
\begin{aligned}
& C_{f}=0.41 \\
& C_{p}=0.59 \\
& C_{f}=0.87 \\
& C_{p}=0.72
\end{aligned}
$$

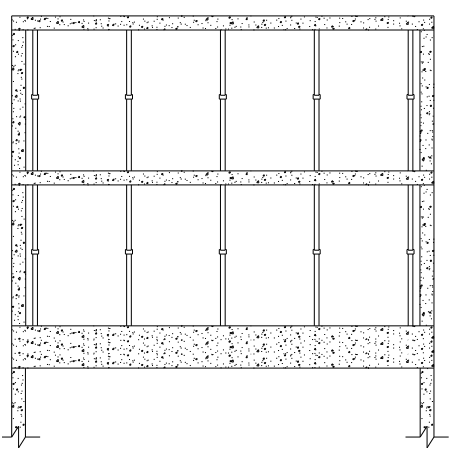

$$
\begin{array}{cc}
\text { Número de puntales } & \text { Puntal más cargado } \\
5 & \text { Puntal } 9 \\
A_{\text {total }}=10.00 \mathrm{~m}^{2} & A_{t}=2.00 \mathrm{~m}^{2} \\
q_{\text {med }}=2.95 \mathrm{kN} / \mathrm{m}^{2} & P_{\text {max }}=6.87 \mathrm{kN} \\
& q_{\text {max }}=3.43 \mathrm{kN} / \mathrm{m}^{2} \\
& \text { Puntal más cargado } \\
\text { Número de puntales } & \text { Puntal } 8 \\
5 & A_{t}=2.00 \mathrm{~m}^{2} \\
A_{\text {total }}=10.00 \mathrm{~m}^{2} & P_{\text {max }}=12.37 \mathrm{kN} \\
q_{\text {med }}=3.57 \mathrm{kN} / \mathrm{m}^{2} & q_{\text {max }}=6.18 \mathrm{kN} / \mathrm{m}^{2}
\end{array}
$$

Fig. I.8 Resultados vano de medianera (forjado de losa maciza). Clareado del forjado 2

Al realizar la operación de clareado en el forjado 2, éste asume el 50\% de carga en relación a su peso propio, en el caso del vano de esquina y el $41 \%$ en el caso del vano de medianera.

\section{I.2.5. Hormigonado forjado 3}

El hormigonado del forjado 3 se hizo el 24 de Junio de 2009. Las Figuras I.9 y I.10 muestran un resumen de las cargas instantáneas. 


\section{Vano de esquina}

$$
\begin{aligned}
& C_{f}=0.02 \\
& C_{p}=0.98 \\
& C_{f}=1.25 \\
& C_{p}=0.73 \\
& C_{f}=0.91 \\
& C_{p}=0.82
\end{aligned}
$$

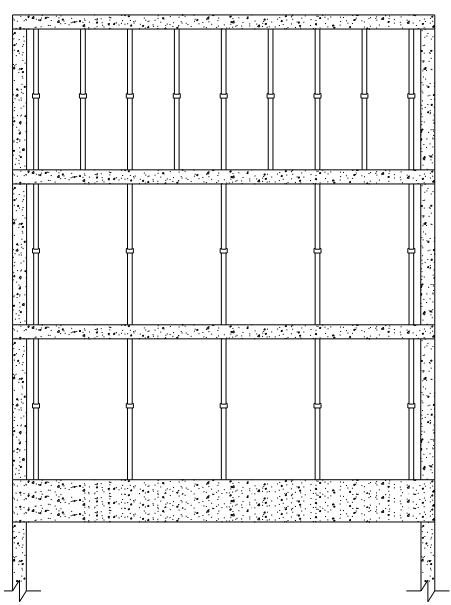

$$
\begin{array}{cc}
\text { Número de puntales } & \text { Puntal más cargado } \\
5 & \text { Puntal } 3 \\
A_{\text {total }}=5.00 \mathrm{~m}^{2} & A_{t}=1.00 \mathrm{~m}^{2} \\
q_{\text {med }}=4.86 \mathrm{kN} / \mathrm{m}^{2} & P_{\text {max }}=5.20 \mathrm{kN} \\
& q_{\text {max }}=5.20 \mathrm{kN} / \mathrm{m}^{2} \\
\text { Número de puntales } & \text { Puntal más cargado } \\
5 & \text { Puntal } 5 \\
A_{\text {total }}=10.50 \mathrm{~m}^{2} & A_{t}=2.10 \mathrm{~m}^{2} \\
q_{\text {med }}=3.61 \mathrm{kN} / \mathrm{m}^{2} & P_{\text {max }}=10.75 \mathrm{kN} \\
& q_{\text {max }}=5.12 \mathrm{kN} / \mathrm{m}^{2} \\
\text { Número de puntales } & \text { Puntal más cargado } \\
5 & \text { Puntal } 3 \\
A_{\text {total }}=10.50 \mathrm{~m}^{2} & A_{t}=2.10 \mathrm{~m}^{2} \\
q_{\text {med }}=4.09 \mathrm{kN} / \mathrm{m}^{2} & P_{\text {max }}=11.09 \mathrm{kN} \\
& q_{\text {max }}=5.28 \mathrm{kN} / \mathrm{m}^{2}
\end{array}
$$

Fig. I.9 Resultados vano de esquina (forjado de losa maciza). Hormigonado del forjado 3

\section{Vano de medianera}

$$
\begin{aligned}
& C_{f}=0.00 \\
& C_{p}=1.00 \\
& C_{f}=1.18 \\
& C_{p}=0.82 \\
& C_{f}=0.90 \\
& C_{p}=0.92
\end{aligned}
$$

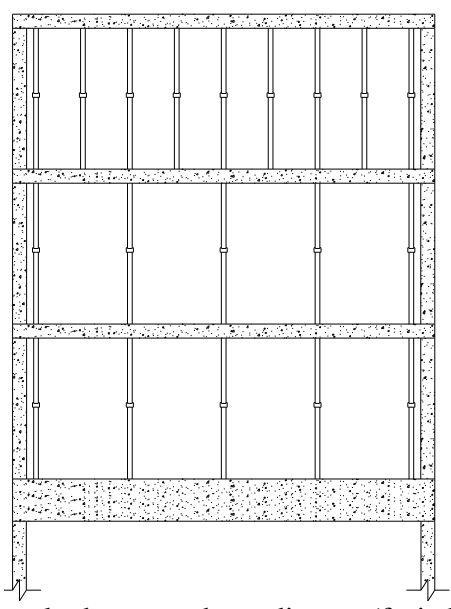

$$
\begin{array}{cc}
\text { Número de puntales } & \text { Puntal más cargado } \\
5 & \text { Puntal } 7 \\
A_{\text {total }}=5.00 \mathrm{~m}^{2} & A_{t}=1.00 \mathrm{~m}^{2} \\
q_{\text {med }}=4.95 \mathrm{kN} / \mathrm{m}^{2} & P_{\max }=5.06 \mathrm{kN} \\
& q_{\max }=5.06 \mathrm{kN} / \mathrm{m}^{2} \\
\text { Número de puntales } & \text { Puntal más cargado } \\
5 & \text { Puntal } 9 \\
A_{\text {total }}=10.00 \mathrm{~m}^{2} & A_{t}=2.00 \mathrm{~m}^{2} \\
q_{\text {med }}=4.06 \mathrm{kN} / \mathrm{m}^{2} & P_{\text {max }}=9.22 \mathrm{kN} \\
& q_{\text {max }}=4.61 \mathrm{kN} / \mathrm{m}^{2} \\
\text { Número de puntales } & \text { Puntal más cargado } \\
5 & \text { Puntal } 8 \\
A_{\text {total }}=10.00 \mathrm{~m}^{2} & A_{t}=2.00 \mathrm{~m} \mathrm{~m}^{2} \\
q_{\text {med }}=4.56 \mathrm{kN} / \mathrm{m}^{2} & P_{\text {max }}=13.34 \mathrm{kN} \\
& q_{\text {max }}=6.67 \mathrm{kN} / \mathrm{m}^{2}
\end{array}
$$

Fig. I.10 Resultados vano de medianera (forjado de losa maciza). Hormigonado del forjado 3

Al igual que en el hormigonado de los forjados 1 y 2, la carga al hormigonar el forjado 3 es soportada en su totalidad por los puntales. La carga correspondiente al forjado 3 se reparte, para el caso del vano de esquina, en un $75 \%$ en el forjado 2 , en un $9 \%$ forjado 1 y el $14 \%$ restante al forjado de planta baja. En el caso del vano de medianera la carga del forjado 3 se reparte en un $77 \%$ en el forjado 2, en un $3 \%$ en el forjado 1 y el $20 \%$ restante en el forjado de planta baja.

\section{I.2.6. Clareado forjado 3}

Después de 6 días de su hormigonado se llevó a cabo el clareado del forjado 3 (30 de Junio de 2009). La medición de cargas instantáneas a modo de resumen se muestra en las Figuras I.11 y I.12. 
Vano de esquina

$$
\begin{aligned}
& C_{f}=0.48 \\
& C_{p}=0.52 \\
& C_{f}=0.98 \\
& C_{p}=0.54 \\
& C_{f}=0.85 \\
& C_{p}=0.69
\end{aligned}
$$

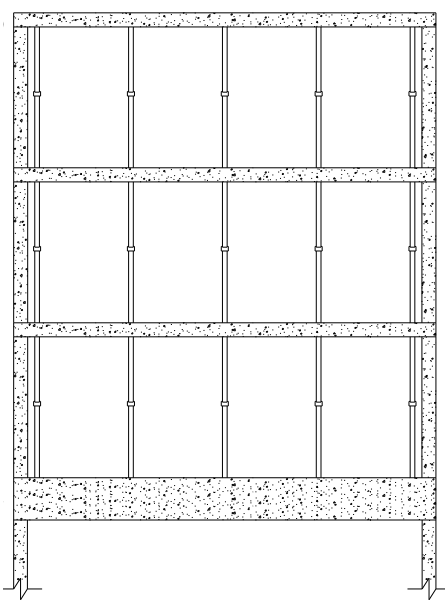

Número de puntales

$$
5
$$

$A_{\text {total }}=10.50 \mathrm{~m}^{2}$

$q_{\text {med }}=2.56 \mathrm{kN} / \mathrm{m}^{2}$

Número de puntales 5

$A_{\text {total }}=10.50 \mathrm{~m}^{2}$

$q_{\text {med }}=2.68 \mathrm{kN} / \mathrm{m}^{2}$

Número de puntales 5

$A_{\text {total }}=10.50 \mathrm{~m}^{2}$

$q_{\text {med }}=3.42 \mathrm{kN} / \mathrm{m}^{2}$
Puntal más cargado

Puntal 2

$A_{t}=2.10 \mathrm{~m}^{2}$

$P_{\text {max }}=6.16 \mathrm{kN}$

$q_{\text {max }}=2.94 \mathrm{kN} / \mathrm{m}^{2}$

Puntal más cargado Puntal 1

$A_{t}=2.10 \mathrm{~m}^{2}$

$P_{\max }=7.57 \mathrm{kN}$

$q_{\max }=3.61 \mathrm{kN} / \mathrm{m}^{2}$

Puntal más cargado

Puntal 5

$A_{t}=2.10 \mathrm{~m}^{2}$

$P_{\text {max }}=10.07 \mathrm{kN}$

$q_{\max }=4.80 \mathrm{kN} / \mathrm{m}^{2}$

Fig. I.11 Resultados vano de esquina (forjado de losa maciza). Clareado del forjado 3

\section{Vano de medianera}

$$
\begin{aligned}
& C_{f}=0.42 \\
& C_{p}=0.58 \\
& C_{f}=0.81 \\
& C_{p}=0.77 \\
& C_{f}=0.98 \\
& C_{p}=0.79
\end{aligned}
$$

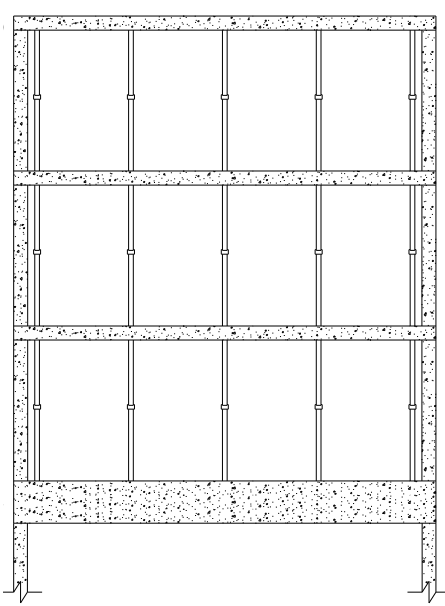

Número de puntales

$$
5
$$

$A_{\text {total }}=10.00 \mathrm{~m}^{2}$

$q_{\text {med }}=2.87 \mathrm{kN} / \mathrm{m}^{2}$

Número de puntales 5

$A_{\text {total }}=10.00 \mathrm{~m}^{2}$

$q_{\text {med }}=3.84 \mathrm{kN} / \mathrm{m}^{2}$

Número de puntales 5

$A_{\text {total }}=10.00 \mathrm{~m}^{2}$

$q_{\text {med }}=3.91 \mathrm{kN} / \mathrm{m}^{2}$
Puntal más cargado

Puntal 11

$A_{t}=2.00 \mathrm{~m}^{2}$ $P_{\text {max }}=6.68 \mathrm{kN}$

$q_{\max }=3.34 \mathrm{kN} / \mathrm{m}^{2}$

Puntal más cargado Puntal 9

$A_{t}=2.00 \mathrm{~m}^{2}$

$P_{\text {max }}=9.79 \mathrm{kN}$

$q_{\max }=4.89 \mathrm{kN} / \mathrm{m}^{2}$

Puntal más cargado Puntal 11

$A_{t}=2.00 \mathrm{~m}^{2}$

$P_{\text {max }}=11.79 \mathrm{kN}$

$q_{\max }=5.90 \mathrm{kN} / \mathrm{m}^{2}$

Fig. I.12 Resultados vano de medianera (forjado de losa maciza). Clareado del forjado 3

Al realizar el clareado del forjado 3, dicho forjado asumió el $48 \%$ de la carga para el vano de esquina y el $42 \%$ de la carga para el vano de medianera en relación a su peso propio. En los forjados inferiores se observó una disminución de la solicitación de carga.

\section{I.2.7. Descimbrado forjado 1}

El descimbrado del forjado 1 se realizó el 1 de Julio de 2009. Los resultados obtenidos de las medidas instantáneas se muestran en las Figuras I.13 y I.14. 


\section{Vano de esquina}

$$
\begin{aligned}
& C_{f}=0.64 \\
& C_{p}=0.36 \\
& C_{f}=1.07 \\
& C_{p}=0.29 \\
& C_{f}=1.29
\end{aligned}
$$

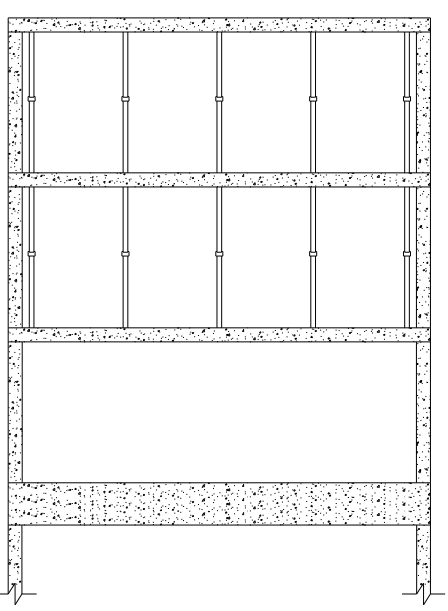

$$
\begin{array}{cc}
\text { Número de puntales } & \text { Puntal más cargado } \\
5 & \text { Puntal } 4 \\
A_{\text {total }}=10.50 \mathrm{~m}^{2} & A_{t}=2.10 \mathrm{~m}^{2} \\
q_{\text {med }}=1.78 \mathrm{kN} / \mathrm{m}^{2} & P_{\max }=4.90 \mathrm{kN} \\
& q_{\max }=2.33 \mathrm{kN} / \mathrm{m}^{2} \\
\text { Número de puntales } & \text { Puntal más cargado } \\
5 & \text { Puntal } 5 \\
A_{\text {total }}=10.50 \mathrm{~m}^{2} & A_{t}=2.10 \mathrm{~m}^{2} \\
q_{\text {med }}=1.44 \mathrm{kN} / \mathrm{m}^{2} & P_{\text {max }}=4.98 \mathrm{kN} \\
& q_{\text {max }}=2.37 \mathrm{kN} / \mathrm{m}^{2}
\end{array}
$$

Fig. I.13 Resultados vano de esquina (forjado de losa maciza). Descimbrado del forjado 1

\section{Vano de medianera}

$$
\begin{aligned}
& C_{f}=0.63 \\
& C_{p}=0.37 \\
& C_{f}=0.98 \\
& C_{p}=0.39 \\
& C_{f}=1.39
\end{aligned}
$$

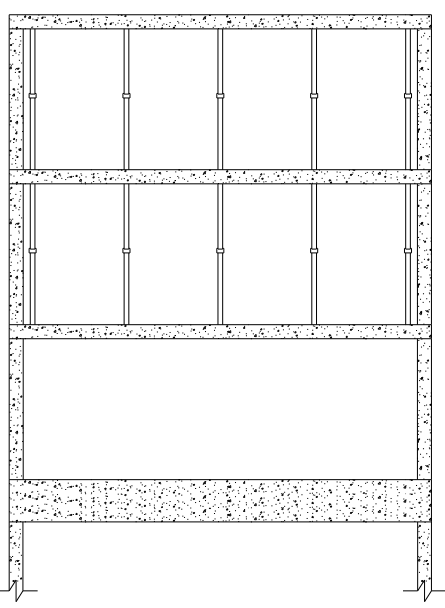

$$
\begin{array}{cc}
\text { Número de puntales } & \text { Puntal más cargado } \\
5 & \text { Puntal } 11 \\
A_{\text {total }}=10.00 \mathrm{~m}^{2} & A_{t}=2.00 \mathrm{~m}^{2} \\
q_{\text {med }}=1.84 \mathrm{kN} / \mathrm{m}^{2} & P_{\text {max }}=4.48 \mathrm{kN} \\
& q_{\text {max }}=2.24 \mathrm{kN} / \mathrm{m}^{2} \\
\text { Número de puntales } & \text { Puntal más cargado } \\
5 & \text { Puntal } 9 \\
A_{\text {total }}=10.00 \mathrm{~m}^{2} & A_{t}=2.00 \mathrm{~m}^{2} \\
q_{\text {med }}=1.93 \mathrm{kN} / \mathrm{m}^{2} & P_{\text {max }}=4.42 \mathrm{kN} \\
& q_{\text {max }}=2.21 \mathrm{kN} / \mathrm{m}^{2}
\end{array}
$$

Fig. I.14 Resultados vano de medianera (forjado de losa maciza). Descimbrado del forjado 1

En la operación de descimbrado del forjado 1, la carga que asumían los puntales de dicho forjado fue asumida por los forjados superiores en un orden de:

- Vano de esquina: $23 \%$ el forjado $3 ; 13 \%$ el forjado 2 y $64 \%$ el forjado 1.

- Vano de medianera: $24 \%$ el forjado 3; $18 \%$ el forjado 2 y $58 \%$ el forjado 1.

\section{I.2.8. Hormigonado forjado 4}

El día 1 de Julio de 2009 se realizó el hormigonado del forjado 4. Antes de realizar el hormigonado del forjado 4 se informó por parte del encargado de la obra que algunos de los puntales bajo el forjado 3 fueron aflojados (los únicos no aflojados según el encargado de obra fueron los puntales instrumentados), lo cual produce un efecto de recimbrado parcial que se ve reflejado en una reducción 
de carga en los forjados 2 y 1 antes del hormigonado del forjado 4. Los resultados obtenidos de las medidas instantáneas se muestran en las Figuras I.15 y I.16.

Vano de esquina

$$
\begin{aligned}
& C_{f}=0.00 \\
& C_{p}=1.02 \\
& C_{f}=1.58 \\
& C_{p}=0.44 \\
& C_{f}=0.98 \\
& C_{p}=0.46 \\
& C_{f}=1.46
\end{aligned}
$$

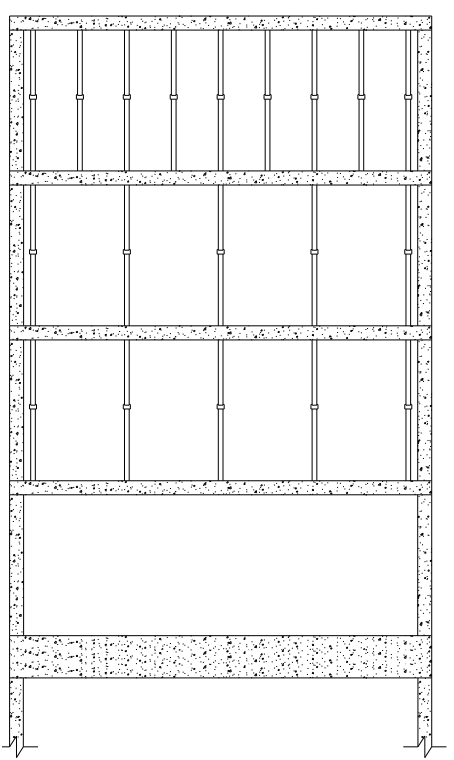

$$
\begin{array}{cc}
\text { Número de puntales } & \text { Puntal más cargado } \\
5 & \text { Puntal } 5 \\
A_{\text {total }}=5.00 \mathrm{~m}^{2} & A_{t}=1.00 \mathrm{~m}^{2} \\
q_{\text {med }}=5.05 \mathrm{kN} / \mathrm{m}^{2} & P_{\text {max }}=5.27 \mathrm{kN} \\
& q_{\text {max }}=5.27 \mathrm{kN} / \mathrm{m}^{2} \\
\text { Número de puntales } & \text { Puntal más cargado } \\
5 & \text { Puntal } 5 \\
A_{\text {total }}=10.50 \mathrm{~m}^{2} & A_{t}=2.10 \mathrm{~m}^{2} \\
q_{\text {med }}=2.18 \mathrm{kN} / \mathrm{m}^{2} & P_{\text {max }}=5.84 \mathrm{kN} \\
& q_{\text {max }}=2.78 \mathrm{kN} / \mathrm{m}^{2} \\
\text { Número de puntales } & \text { Puntal más cargado } \\
5 & \text { Puntal 1 } \\
5 & A_{t}=2.10 \mathrm{~m}^{2} \\
A_{\text {total }}=10.50 \mathrm{~m}^{2} & P_{\text {max }}=6.47 \mathrm{kN} \\
q_{\text {med }}=2.28 \mathrm{kN} / \mathrm{m}^{2} & q_{\text {max }}=3.08 \mathrm{kN} / \mathrm{m}^{2}
\end{array}
$$

Fig. I.15 Resultados vano de esquina (forjado de losa maciza). Hormigonado del forjado 4

\section{Vano de medianera}

$$
\begin{aligned}
& C_{f}=0.01 \\
& C_{p}=0.99 \\
& C_{f}=1.56 \\
& C_{p}=0.43 \\
& C_{f}=0.88 \\
& C_{p}=0.55 \\
& C_{f}=1.55
\end{aligned}
$$

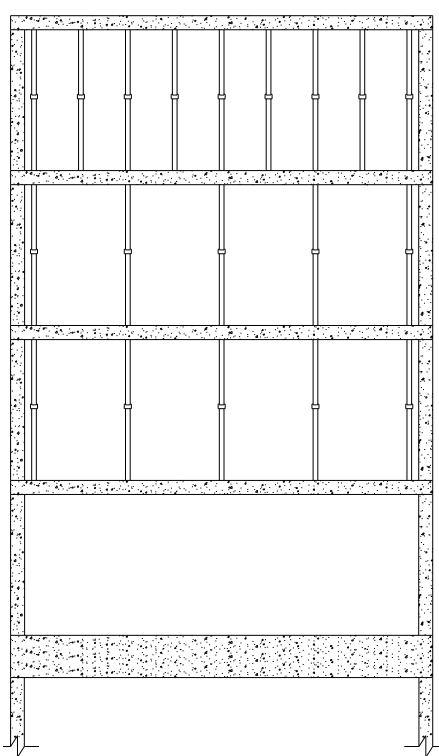

$$
\begin{array}{cc}
\text { Número de puntales } & \text { Puntal más cargado } \\
5 & \text { Puntal } 10 \\
A_{\text {total }}=5.00 \mathrm{~m}^{2} & A_{t}=1.00 \mathrm{~m}^{2} \\
q_{\text {med }}=4.91 \mathrm{kN} / \mathrm{m}^{2} & P_{\text {max }}=5.06 \mathrm{kN} \\
& q_{\text {max }}=5.06 \mathrm{kN} / \mathrm{m}^{2} \\
\text { Número de puntales } & \text { Puntal más cargado } \\
5 & \text { Puntal } 9 \\
A_{\text {total }}=10.00 \mathrm{~m}^{2} & A_{t}=2.00 \mathrm{~m}^{2} \\
q_{\text {med }}=2.13 \mathrm{kN} / \mathrm{m}^{2} & P_{\text {max }}=6.74 \mathrm{kN} \\
& q_{\text {max }}=3.37 \mathrm{kN} / \mathrm{m}^{2} \\
\text { Número de puntales } & \text { Puntal más cargado } \\
5 & \text { Puntal } 9 \\
A_{\text {total }}=10.00 \mathrm{~m}^{2} & A_{t}=2.00 \mathrm{~m}^{2} \\
q_{\text {med }}=2.73 \mathrm{kN} / \mathrm{m}^{2} & P_{\text {max }}=6.44 \mathrm{kN} \\
& q_{\text {max }}=3.22 \mathrm{kN} / \mathrm{m}^{2}
\end{array}
$$

Fig. I.16 Resultados vano de medianera (forjado de losa maciza). Hormigonado del forjado 4

Debido al recimbrado parcial efectuado en los puntales bajo el forjado 3, en el forjado 2 se evidencia un descenso en la solicitación de carga, lo cual altera la transmisión de cargas entre forjados y puntales para esta operación y para operaciones constructivas posteriores. 


\section{I.2.9. Clareado forjado 4}

Después de 5 días de su hormigonado se llevó a cabo el clareado del forjado 4 (6 de Julio de 2009). La medición de cargas instantáneas a modo de resumen se muestra en las Figuras I.17 y I.18.

\section{Vano de esquina}

$$
\begin{aligned}
& C_{f}=0.51 \\
& C_{p}=0.49 \\
& C_{f}=0.97 \\
& C_{p}=0.52 \\
& C_{f}=0.99 \\
& C_{p}=0.53 \\
& C_{f}=1.53
\end{aligned}
$$

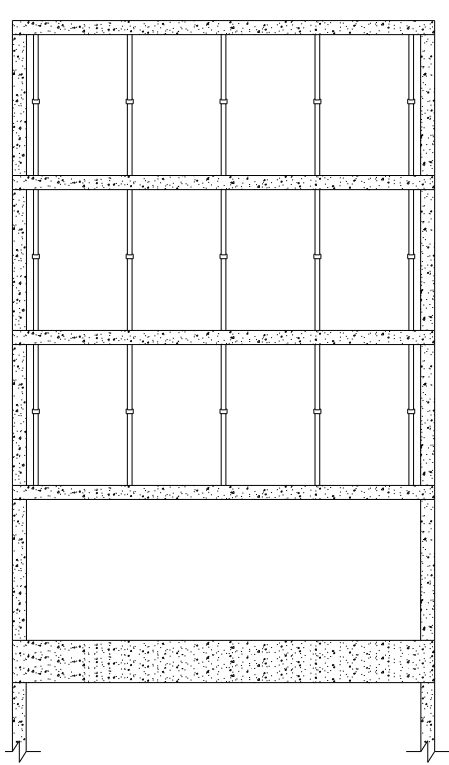

$$
\begin{array}{cc}
\text { Número de puntales } & \text { Puntal más cargado } \\
5 & \text { Puntal } 5 \\
A_{\text {total }}=10.50 \mathrm{~m}^{2} & A_{t}=2.10 \mathrm{~m}^{2} \\
q_{\text {med }}=2.42 \mathrm{kN} / \mathrm{m}^{2} & P_{\max }=6.38 \mathrm{kN} \\
& q_{\text {max }}=3.04 \mathrm{kN} / \mathrm{m}^{2} \\
\text { Número de puntales } & \text { Puntal más cargado } \\
5 & \text { Puntal } 1 \\
A_{\text {total }}=10.50 \mathrm{~m}^{2} & A_{t}=2.10 \mathrm{~m}^{2} \\
q_{\text {med }}=2.58 \mathrm{kN} / \mathrm{m}^{2} & P_{\text {max }}=8.44 \mathrm{kN} \\
& q_{\text {max }}=4.02 \mathrm{kN} / \mathrm{m}^{2} \\
\text { Número de puntales } & \text { Puntal más cargado } \\
5 & \text { Puntal } 1 \\
A_{\text {total }}=10.50 \mathrm{~m}^{2} & A_{t}=2.10 \mathrm{~m}{ }^{2} \\
q_{\text {med }}=2.63 \mathrm{kN} / \mathrm{m}^{2} & P_{\text {max }}=7.81 \mathrm{kN} \\
& q_{\text {max }}=3.72 \mathrm{kN} / \mathrm{m}^{2}
\end{array}
$$

Fig. I.17 Resultados vano de esquina (forjado de losa maciza). Clareado del forjado 4

\section{Vano de medianera}

$$
\begin{aligned}
& C_{f}=0.45 \\
& C_{p}=0.55 \\
& C_{f}=0.97 \\
& C_{p}=0.58 \\
& C_{f}=1.03 \\
& C_{p}=0.55 \\
& C_{f}=1.55
\end{aligned}
$$

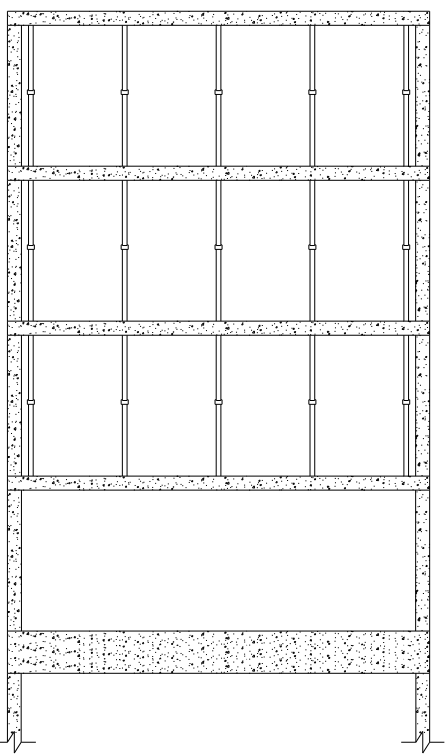

Número de puntales 5

$A_{\text {total }}=10.00 \mathrm{~m}^{2}$ $q_{\text {med }}=2.72 \mathrm{kN} / \mathrm{m}^{2}$

Número de puntales 5

$A_{\text {total }}=10.00 \mathrm{~m}^{2}$ $q_{\text {med }}=2.88 \mathrm{kN} / \mathrm{m}^{2}$

Número de puntales 5

$A_{\text {total }}=10.00 \mathrm{~m}^{2}$ $q_{\text {med }}=2.73 \mathrm{kN} / \mathrm{m}^{2}$
Puntal más cargado Puntal 11 $A_{t}=2.00 \mathrm{~m}^{2}$ $P_{\max }=8.14 \mathrm{kN}$ $q_{\max }=4.07 \mathrm{kN} / \mathrm{m}^{2}$ Puntal más cargado Puntal 9 $A_{t}=2.00 \mathrm{~m}^{2}$ $P_{\text {max }}=7.74 \mathrm{kN}$ $q_{\max }=3.87 \mathrm{kN} / \mathrm{m}^{2}$ Puntal más cargado Puntal 9 $A_{t}=2.00 \mathrm{~m}^{2}$ $P_{\max }=5.96 \mathrm{kN}$ $q_{\max }=2.98 \mathrm{kN} / \mathrm{m}^{2}$

Fig. I.18 Resultados vano de medianera (forjado de losa maciza). Clareado del forjado 4 
Una vez clareado el forjado 4, dicho forjado asumió una fracción importante de carga como se muestra a continuación:

- Vano de esquina: el forjado 4 una vez realizada la operación de clareado asumió el 51\% de su peso propio.

- Vano de medianera: el forjado 4 una vez realizada la operación de clareado asumió el 45\% de su peso propio.

Estos valores resultan muy similares a los clareados de los forjados 2 y 3 .

\section{I.2.10. Descimbrado forjado 2}

El descimbrado del forjado 2 se realizó el 7 de Julio de 2009. Los resultados obtenidos de las medidas instantáneas se muestran en las Figuras I.19 y I.20.

\section{Vano de esquina}

$$
\begin{aligned}
& C_{f}=0.64 \\
& C_{p}=0.36 \\
& C_{f}=0.98 \\
& C_{p}=0.38 \\
& C_{f}=1.38
\end{aligned}
$$

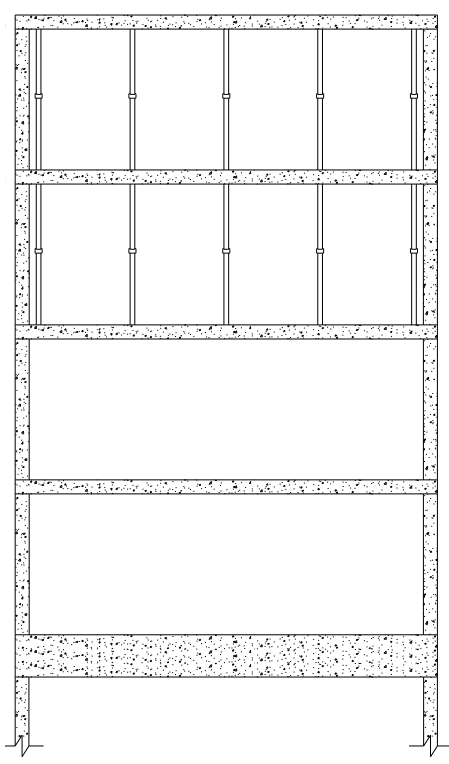

$$
\begin{array}{cc}
\text { Número de puntales } & \text { Puntal más cargado } \\
5 & \text { Puntal } 5 \\
A_{\text {total }}=10.50 \mathrm{~m}^{2} & A_{t}=2.10 \mathrm{~m}^{2} \\
q_{\text {med }}=1.78 \mathrm{kN} / \mathrm{m}^{2} & P_{\text {max }}=5.00 \mathrm{kN} \\
& q_{\text {max }}=2.38 \mathrm{kN} / \mathrm{m}^{2} \\
\text { Número de puntales } & \text { Puntal más cargado } \\
5 & \text { Puntal } 4 \\
A_{\text {total }}=10.50 \mathrm{~m}^{2} & A_{t}=2.10 \mathrm{~m}^{2} \\
q_{\text {med }}=1.88 \mathrm{kN} / \mathrm{m}^{2} & P_{\text {max }}=5.01 \mathrm{kN} \\
& q_{\text {max }}=2.39 \mathrm{kN} / \mathrm{m}^{2}
\end{array}
$$

Fig. I.19 Resultados vano de esquina (forjado de losa maciza). Descimbrado del forjado 2 


\section{Vano de medianera}

$$
\begin{aligned}
& C_{f}=0.55 \\
& C_{p}=0.45 \\
& C_{f}=1.02 \\
& C_{p}=0.43 \\
& C_{f}=1.43
\end{aligned}
$$

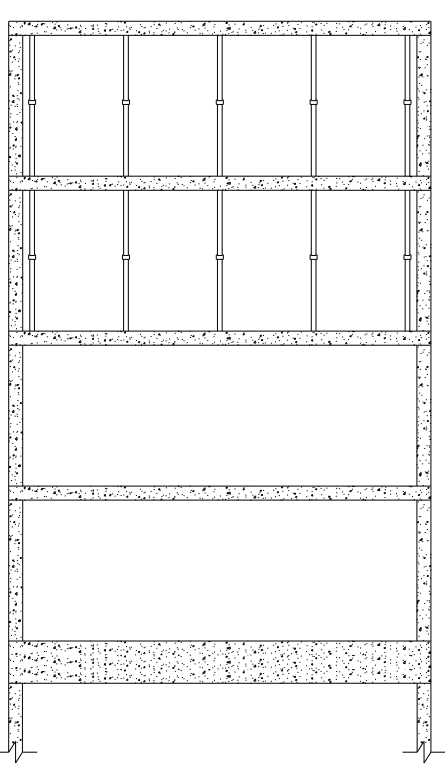

$$
\begin{array}{cc}
\text { Número de puntales } & \text { Puntal más cargado } \\
5 & \text { Puntal } 11 \\
A_{\text {total }}=10.00 \mathrm{~m}^{2} & A_{t}=2.00 \mathrm{~m}^{2} \\
q_{\text {med }}=2.23 \mathrm{kN} / \mathrm{m}^{2} & P_{\text {max }}=5.10 \mathrm{kN} \\
& q_{\text {max }}=2.55 \mathrm{kN} / \mathrm{m}^{2} \\
\text { Número de puntales } & \text { Puntal más cargado } \\
5 & \text { Puntal } 10 \\
A_{\text {total }}=10.00 \mathrm{~m}^{2} & A_{t}=2.00 \mathrm{~m}^{2} \\
q_{\text {med }}=2.13 \mathrm{kN} / \mathrm{m}^{2} & P_{\text {max }}=5.20 \mathrm{kN} \\
& q_{\text {max }}=2.60 \mathrm{kN} / \mathrm{m}^{2}
\end{array}
$$

Fig. I.20 Resultados vano de medianera (forjado de losa maciza). Descimbrado del forjado 2

En la operación de descimbrado del forjado 2, la carga que asumían los puntales de dicho forjado fue asumida por los forjados superiores en un orden de:

- Vano de esquina: $17 \%$ el forjado 4; $18 \%$ el forjado 3 y $65 \%$ el forjado 2.

- Vano de medianera: $11 \%$ el forjado $4 ; 4 \%$ el forjado 3 y $85 \%$ el forjado 2.

\section{I.2.11. Hormigonado forjado 5}

El día 8 de Julio de 2009 se realizó el hormigonado del forjado 5. Los resultados obtenidos de las medidas instantáneas se muestran en las Figuras I.21 y I.22. 


\section{Vano de esquina}

$$
\begin{aligned}
& C_{f}=0.00 \\
& C_{p}=1.00 \\
& C_{f}=1.55 \\
& C_{p}=0.45 \\
& C_{f}=0.99 \\
& C_{p}=0.46 \\
& C_{f}=1.46
\end{aligned}
$$

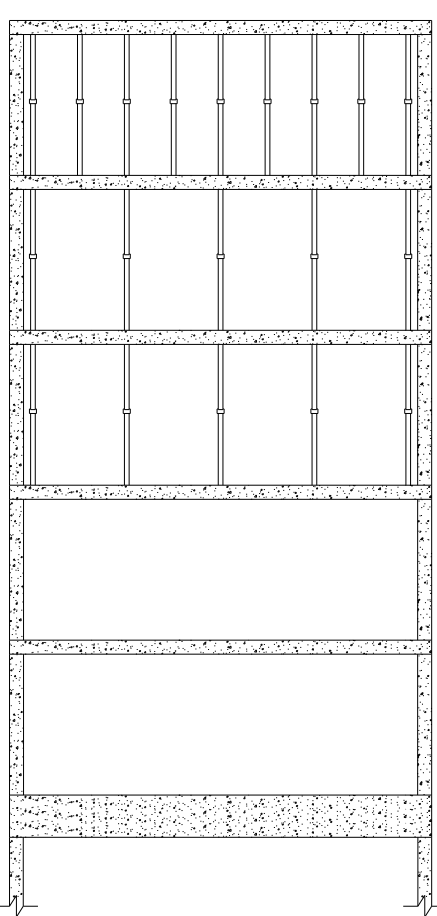

Número de puntales

$$
5
$$

$A_{\text {total }}=5.00 \mathrm{~m}^{2}$

$q_{\text {med }}=4.96 \mathrm{kN} / \mathrm{m}^{2}$

Número de puntales 5

$A_{\text {total }}=10.50 \mathrm{~m}^{2}$

$q_{\text {med }}=2.23 \mathrm{kN} / \mathrm{m}^{2}$

Número de puntales 5

$A_{\text {total }}=10.50 \mathrm{~m}^{2}$

$q_{\text {med }}=2.28 \mathrm{kN} / \mathrm{m}^{2}$
Puntal más cargado

Puntal 3

$A_{t}=1.00 \mathrm{~m}^{2}$ $P_{\text {max }}=5.06 \mathrm{kN}$

$q_{\text {max }}=5.06 \mathrm{kN} / \mathrm{m}^{2}$

Puntal más cargado Puntal 5

$A_{t}=2.10 \mathrm{~m}^{2}$

$P_{\max }=5.84 \mathrm{kN}$

$q_{\max }=2.78 \mathrm{kN} / \mathrm{m}^{2}$

Puntal más cargado Puntal 4

$A_{t}=2.10 \mathrm{~m}^{2}$

$P_{\text {max }}=6.15 \mathrm{kN}$

$q_{\max }=2.93 \mathrm{kN} / \mathrm{m}^{2}$

Fig. I.21 Resultados vano de esquina (forjado de losa maciza). Hormigonado del forjado 5

\section{Vano de medianera}

$$
\begin{aligned}
& C_{f}=0.02 \\
& C_{p}=0.98 \\
& C_{f}=1.28 \\
& C_{p}=0.70 \\
& C_{f}=1.07 \\
& C_{p}=0.63 \\
& C_{f}=1.63
\end{aligned}
$$

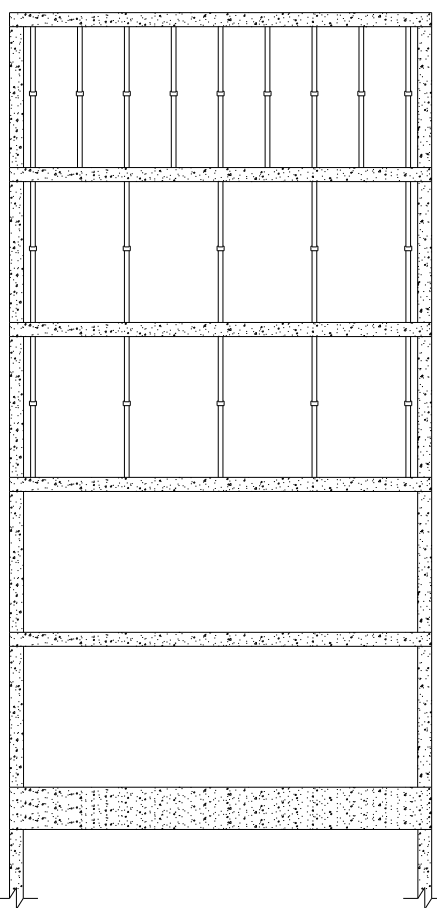

Número de puntales 5

$A_{\text {total }}=5.00 \mathrm{~m}^{2}$

$q_{\text {med }}=4.87 \mathrm{kN} / \mathrm{m}^{2}$

Número de puntales

$A_{\text {total }}=10.00 \mathrm{~m}^{2}$ $q_{\text {med }}=3.47 \mathrm{kN} / \mathrm{m}^{2}$

Número de puntales 5

$A_{\text {total }}=10.00 \mathrm{~m}^{2}$ $q_{\text {med }}=3.12 \mathrm{kN} / \mathrm{m}^{2}$
Puntal más cargado Puntal 11

$A_{t}=1.00 \mathrm{~m}^{2}$

$$
P_{\text {max }}=5.06 \mathrm{kN}
$$

$q_{\max }=5.06 \mathrm{kN} / \mathrm{m}^{2}$

Puntal más cargado Puntal 11 $A_{t}=2.00 \mathrm{~m}^{2}$ $P_{\max }=7.04 \mathrm{kN}$

$q_{\max }=3.52 \mathrm{kN} / \mathrm{m}^{2}$

Puntal más cargado Puntal 9 $A_{t}=2.00 \mathrm{~m}^{2}$ $P_{\max }=9.72 \mathrm{kN}$ $q_{\max }=4.86 \mathrm{kN} / \mathrm{m}^{2}$

Fig. I.22 Resultados vano de medianera (forjado de losa maciza). Hormigonado del forjado 5 
Al hormigonar el forjado 5, su peso propio se repartió entre los forjados inferiores conectados por puntales. Dicho reparto fue medido como sigue:

- Vano de esquina: $91 \%$ el forjado 4; $1 \%$ el forjado 3 y el $8 \%$ restante el forjado 2.

- Vano de medianera: $75 \%$ el forjado $4 ; 5 \%$ el forjado 3 y el $20 \%$ restante el forjado 2.

\section{I.2.12. Clareado forjado 5}

El día 13 de Julio de 2009 se procedió con el clareado del forjado 5, cinco días después del hormigonado de dicho forjado. Los resultados obtenidos de las medidas instantáneas se muestran en las Figuras I.23 y I.24.

\section{Vano de esquina}

$$
\begin{aligned}
& C_{f}=0.58 \\
& C_{p}=0.42 \\
& C_{f}=0.95 \\
& C_{p}=0.47 \\
& C_{f}=0.80 \\
& C_{p}=0.67 \\
& C_{f}=1.67
\end{aligned}
$$

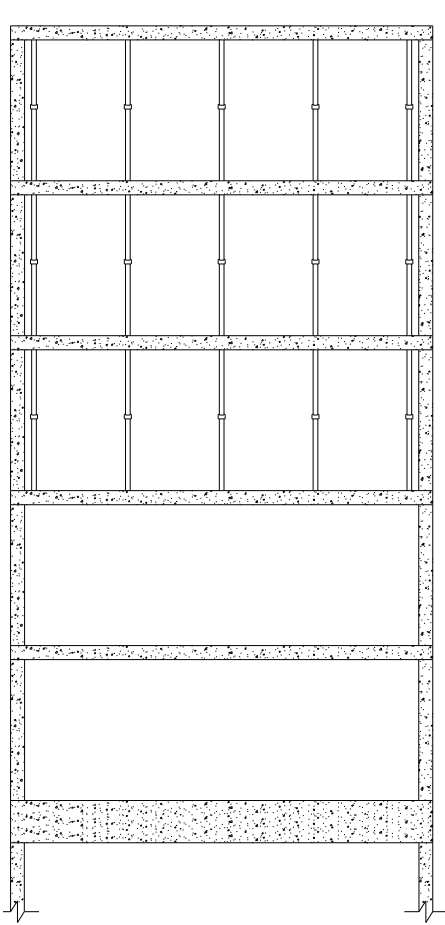

Fig. I.23 Resultados vano de esquina (forjado de losa maciza). Clareado del forjado 5 
Vano de medianera

$$
\begin{aligned}
& C_{f}=0.45 \\
& C_{p}=0.55 \\
& C_{f}=0.95 \\
& C_{p}=0.60 \\
& C_{f}=0.97 \\
& C_{p}=0.63 \\
& C_{f}=1.63
\end{aligned}
$$

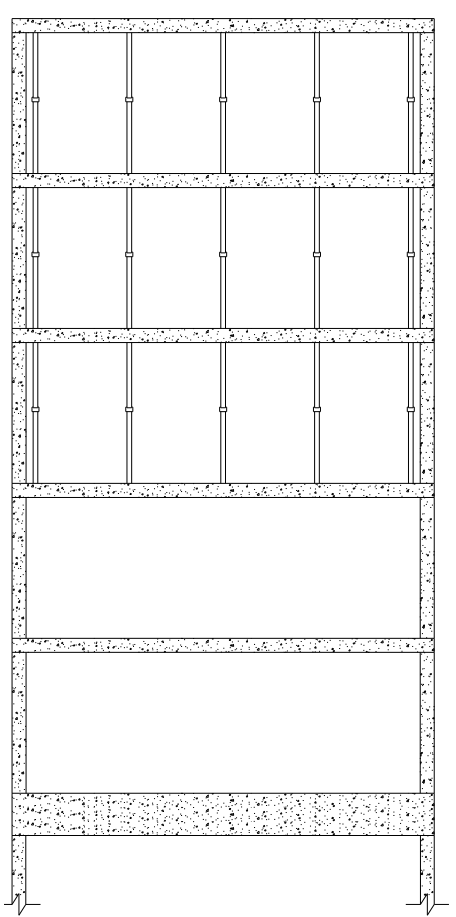

Número de puntales

$$
\begin{gathered}
5 \\
A_{\text {total }}=10.00 \mathrm{~m}^{2}
\end{gathered}
$$$$
q_{\text {med }}=2.75 \mathrm{kN} / \mathrm{m}^{2}
$$

Número de puntales 5

$A_{\text {total }}=10.00 \mathrm{~m}^{2}$

$q_{\text {med }}=2.98 \mathrm{kN} / \mathrm{m}^{2}$

Número de puntales 5

$A_{\text {total }}=10.00 \mathrm{~m}^{2}$

$q_{\text {med }}=3.12 \mathrm{kN} / \mathrm{m}^{2}$

Puntal más cargado

Puntal 11

$A_{t}=2.00 \mathrm{~m}^{2}$

$P_{\text {max }}=6.63 \mathrm{kN}$

$q_{\max }=3.32 \mathrm{kN} / \mathrm{m}^{2}$

Puntal más cargado Puntal 9

$A_{t}=2.00 \mathrm{~m}^{2}$

$P_{\text {max }}=6.24 \mathrm{kN}$

$q_{\max }=3.12 \mathrm{kN} / \mathrm{m}^{2}$

Puntal más cargado

Puntal 9

$A_{t}=2.00 \mathrm{~m}^{2}$

$P_{\text {max }}=8.64 \mathrm{kN}$

$q_{\max }=4.32 \mathrm{kN} / \mathrm{m}^{2}$

Fig. I.24 Resultados vano de medianera (forjado de losa maciza). Clareado del forjado 5

Durante el clareado del forjado 5, se informó por parte del encargado de obra, que los puntales del forjado 3 (inclusive los puntales instrumentados) fueron apretados debido a que se detectó que los puntales de una de las sopandas se encontraban poco ajustados, por lo cual se evidencia un aumento de la carga en los puntales del forjado 3 .

Al realizar la operación de clareado del forjado 5 éste asumió un $58 \%$ de su peso propio en el vano de esquina y un $45 \%$ de su peso propio en el vano de medianera.

\section{I.2.13. Descimbrado forjado 3}

El día 14 de Julio de 2009 se hizo el descimbrado del forjado 3. Los resultados obtenidos de las medidas instantáneas se muestran en las Figuras I.25 y I.26. 


\section{Vano de esquina}

$$
\begin{aligned}
& C_{f}=0.64 \\
& C_{p}=0.36 \\
& C_{f}=0.98 \\
& C_{p}=0.38 \\
& C_{f}=1.38
\end{aligned}
$$

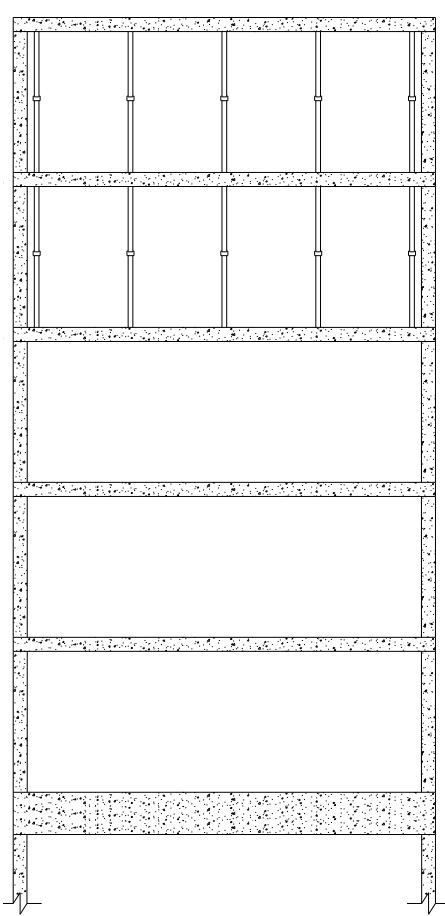

Número de puntales

$A_{\text {total }}=10.50 \mathrm{~m}^{2}$

$q_{\text {med }}=1.78 \mathrm{kN} / \mathrm{m}^{2}$

Número de puntales 5

$A_{\text {total }}=10.50 \mathrm{~m}^{2}$

$q_{\text {med }}=1.88 \mathrm{kN} / \mathrm{m}^{2}$
Puntal más cargado

$$
\text { Puntal } 4
$$

$A_{t}=2.10 \mathrm{~m}^{2}$

$P_{\text {max }}=4.80 \mathrm{kN}$

$q_{\max }=2.29 \mathrm{kN} / \mathrm{m}^{2}$

Puntal más cargado Puntal 5

$A_{t}=2.10 \mathrm{~m}^{2}$

$P_{\max }=5.02 \mathrm{kN}$

$q_{\max }=2.39 \mathrm{kN} / \mathrm{m}^{2}$

Fig. I.25 Resultados vano de esquina (forjado de losa maciza). Descimbrado del forjado 3

\section{Vano de medianera}

$$
\begin{aligned}
& C_{f}=0.56 \\
& C_{p}=0.44 \\
& C_{f}=0.97 \\
& C_{p}=0.47 \\
& C_{f}=1.47
\end{aligned}
$$

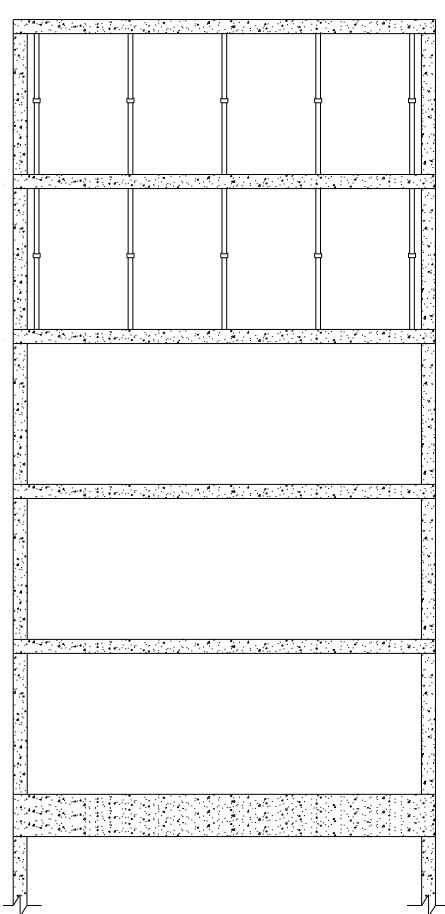

Número de puntales 5

$A_{\text {total }}=10.00 \mathrm{~m}^{2}$

$q_{\text {med }}=2.18 \mathrm{kN} / \mathrm{m}^{2}$

Número de puntales 5

$A_{\text {total }}=10.00 \mathrm{~m}^{2}$

$q_{\text {med }}=2.33 \mathrm{kN} / \mathrm{m}^{2}$

Puntal más cargado Puntal 11

$A_{t}=2.00 \mathrm{~m}^{2}$

$P_{\text {max }}=5.14 \mathrm{kN}$

$q_{\max }=2.57 \mathrm{kN} / \mathrm{m}^{2}$

Puntal más cargado

Puntal 11

$A_{t}=2.00 \mathrm{~m}^{2}$

$P_{\text {max }}=5.63 \mathrm{kN}$

$q_{\max }=2.82 \mathrm{kN} / \mathrm{m}^{2}$ 
En la operación de descimbrado del forjado 3, la carga que asumían los puntales de dicho forjado se repartió en los forjados superiores en un orden de:

- Vano de esquina: $7 \%$ el forjado 5; $19 \%$ el forjado 4 y $74 \%$ el forjado 3.

- Vano de medianera: $14 \%$ el forjado 5; $9 \%$ el forjado 4 y $77 \%$ el forjado 3.

\section{I.2.14. Hormigonado forjado 6}

El día 15 de Julio de 2009 se realizó el hormigonado del forjado 6, concluyendo así la medición experimental. Los resultados obtenidos de las medidas instantáneas se muestran en las Figuras I.27 y I.28.

\section{Vano de esquina}

$$
\begin{aligned}
& C_{f}=0.00 \\
& C_{p}=1.01 \\
& C_{f}=1.43 \\
& C_{p}=0.58 \\
& C_{f}=1.17 \\
& C_{p}=0.41 \\
& C_{f}=1.41
\end{aligned}
$$

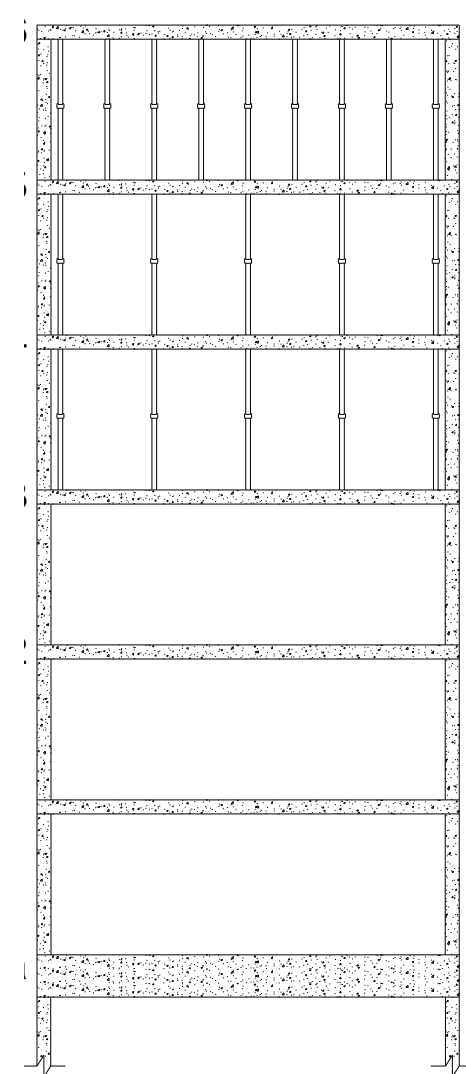

$$
\begin{array}{cc}
\text { Número de puntales } & \text { Puntal más cargado } \\
5 & \text { Puntal } 3 \\
A_{\text {total }}=5.00 \mathrm{~m}^{2} & A_{t}=1.00 \mathrm{~m}^{2} \\
q_{\text {med }}=5.01 \mathrm{kN} / \mathrm{m}^{2} & P_{\text {max }}=5.06 \mathrm{kN} \\
& q_{\text {max }}=5.06 \mathrm{kN} / \mathrm{m}^{2} \\
\text { Número de puntales } & \text { Puntal más cargado } \\
5 & \text { Puntal } 3 \\
A_{\text {total }}=10.50 \mathrm{~m}^{2} & A_{t}=2.10 \mathrm{~m}^{2} \\
q_{\text {med }}=2.88 \mathrm{kN} / \mathrm{m}^{2} & P_{\text {max }}=8.44 \mathrm{kN} \\
& q_{\text {max }}=4.02 \mathrm{kN} / \mathrm{m}^{2} \\
\text { Número de puntales } & \text { Puntal más cargado } \\
5 & \text { Puntal } 5 \\
& A_{t}=2.10 \mathrm{~m}^{2} \\
A_{\text {total }}=10.50 \mathrm{~m}^{2} & P_{\text {max }}=5.63 \mathrm{kN} \\
q_{\text {med }}=2.03 \mathrm{kN} / \mathrm{m}^{2} & q_{\text {max }}=2.68 \mathrm{kN} / \mathrm{m}^{2}
\end{array}
$$

Fig. I.27 Resultados vano de esquina (forjado de losa maciza). Hormigonado del forjado 6 
Vano de medianera

$$
\begin{aligned}
& C_{f}=0.00 \\
& C_{p}=1.01 \\
& C_{f}=1.10 \\
& C_{p}=0.91 \\
& C_{f}=1.30 \\
& C_{p}=0.61 \\
& C_{f}=1.61
\end{aligned}
$$

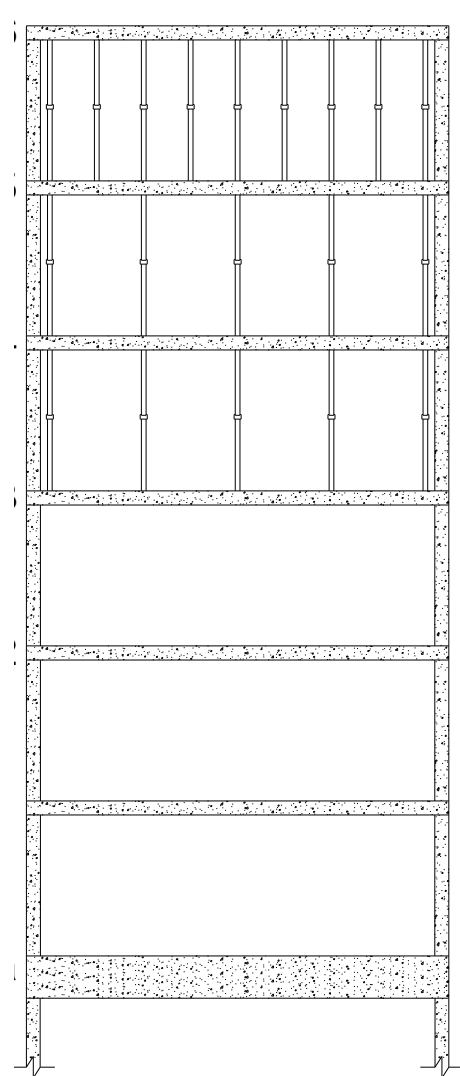

$$
\begin{array}{cc}
\text { Número de puntales } & \text { Puntal más cargado } \\
5 & \text { Puntal } 9 \\
A_{\text {total }}=5.00 \mathrm{~m}^{2} & A_{t}=1.00 \mathrm{~m}^{2} \\
q_{\text {med }}=5.00 \mathrm{kN} / \mathrm{m}^{2} & P_{\text {max }}=5.03 \mathrm{kN} \\
& q_{\text {max }}=5.03 \mathrm{kN} / \mathrm{m}^{2} \\
\text { Número de puntales } & \text { Puntal más cargado } \\
5 & \text { Puntal } 8 \\
A_{\text {total }}=10.00 \mathrm{~m}^{2} & A_{t}=2.00 \mathrm{~m}^{2} \\
q_{\text {med }}=4.51 \mathrm{kN} / \mathrm{m}^{2} & P_{\text {max }}=10.52 \mathrm{kN} \\
& q_{\text {max }}=5.26 \mathrm{kN} / \mathrm{m}^{2} \\
\text { Número de puntales } & \text { Puntal más cargado } \\
5 & \text { Puntal } 11 \\
A_{\text {total }}=10.00 \mathrm{~m}^{2} & A_{t}=2.00 \mathrm{~m}^{2} \\
q_{\text {med }}=3.03 \mathrm{kN} / \mathrm{m}^{2} & P_{\text {max }}=9.32 \mathrm{kN} \\
& q_{\text {max }}=4.66 \mathrm{kN} / \mathrm{m}^{2}
\end{array}
$$

Fig. I.28 Resultados vano de medianera (forjado de losa maciza). Hormigonado del forjado 6

Al hormigonar el forjado 6, su peso propio se repartió entre los forjados inferiores conectados por puntales. Dicho reparto fue medido como sigue:

- Vano de esquina: $79 \%$ el forjado 5; $18 \%$ el forjado 4 y el 3\% restante el forjado 3 .

- Vano de medianera: $54 \%$ el forjado 5; $33 \%$ el forjado 4 y el $14 \%$ restante el forjado 3.

\section{I.3. Resultados del estudio experimental de un edificio de forjado reticular de casetón perdido}

\section{I.3.1. Hormigonado forjado 1}

El hormigonado del forjado 1 se realizó el 4 de Diciembre de 2009. La Figura I.29 muestra un resumen de las medidas instantáneas para cada uno de los vanos instrumentados.

$$
\begin{aligned}
& \boldsymbol{C}_{\boldsymbol{f}}=0.00 \\
& \boldsymbol{C}_{\boldsymbol{p}}=1.00
\end{aligned}
$$

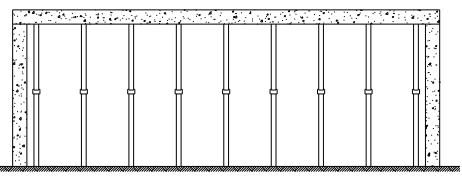

$$
\begin{array}{cc}
\text { Número de puntales } & \text { Puntal más cargado } \\
15 & \text { Puntal } 13 \\
\boldsymbol{A}_{\text {total }}=13.85 \mathrm{~m}^{2} & \boldsymbol{A}_{\boldsymbol{t}}=1.02 \mathrm{~m}^{2} \\
\boldsymbol{q}_{\text {med }}=3.40 \mathrm{kN} / \mathrm{m}^{2} & \boldsymbol{P}_{\text {max }}=3.69 \mathrm{kN} \\
& \boldsymbol{q}_{\text {max }}=3.62 \mathrm{kN} / \mathrm{m}^{2}
\end{array}
$$

Fig. I.29 Resultados Hormigonado del forjado 1 (forjado reticular de casetón perdido) 
Como era esperable, una vez hormigonado el forjado la carga total fue asumida por el sistema de apuntalamiento.

\section{I.3.2. Clareado forjado 1}

El clareado del forjado 1 se realizó el 10 de Diciembre de 2009, 6 días después de su hormigonado. En la Figura I.30 se muestra un resumen de las medidas instantáneas una vez realizado el clareado.

$$
\begin{aligned}
& \boldsymbol{C}_{\boldsymbol{f}}=0.42 \\
& \boldsymbol{C}_{\boldsymbol{p}}=0.58
\end{aligned}
$$

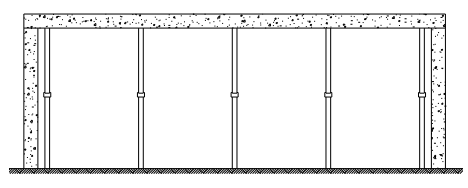

$$
\begin{array}{cc}
\text { Número de puntales } & \text { Puntal más cargado } \\
15 & \text { Puntal 5 } \\
\boldsymbol{A}_{\text {total }}=27.53 \mathrm{~m}^{2} & \boldsymbol{A}_{\boldsymbol{t}}=1.97 \mathrm{~m}^{2} \\
\boldsymbol{q}_{\text {med }}=1.97 \mathrm{kN} / \mathrm{m}^{2} & \boldsymbol{P}_{\text {max }}=4.98 \mathrm{kN} \\
& \boldsymbol{q}_{\text {max }}=2.52 \mathrm{kN} / \mathrm{m}^{2}
\end{array}
$$

Fig. I.30 Resultados Clareado del forjado 1 (forjado reticular de casetón perdido)

Al realizar la operación del clareado, el forjado asume un $42 \%$ de carga en relación a su peso propio, presentándose una reducción en la carga media de los puntales. Este valor de carga asumido por los puntales confirma que una vez realizado el clareado o descimbrado parcial, el forjado comienza a soportar una fracción importante de su carga.

\section{I.3.3. Hormigonado forjado 2}

El hormigonado del forjado 2 se llevó a cabo el 26 de Enero de 2010. La Figuras I.31 muestra resumidamente las medidas instantáneas obtenidas.

$$
\begin{aligned}
& \boldsymbol{C}_{\boldsymbol{f}}=0.00 \\
& \boldsymbol{C}_{\boldsymbol{p}}=1.00 \\
& \boldsymbol{C}_{\boldsymbol{f}}=1.15 \\
& \boldsymbol{C}_{\boldsymbol{p}}=0.85
\end{aligned}
$$

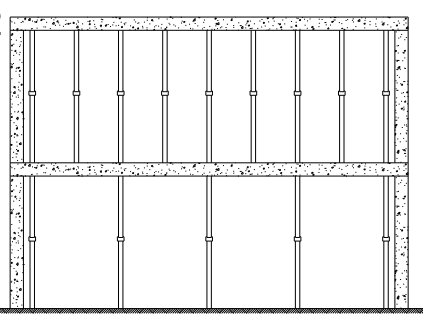

$$
\begin{array}{cc}
\text { Número de puntales } & \text { Puntal más cargado } \\
15 & \text { Puntal } 12 \\
\boldsymbol{A}_{\text {total }}=13.98 \mathrm{~m}^{2} & \boldsymbol{A}_{\boldsymbol{t}}=1.04 \mathrm{~m}^{2} \\
\boldsymbol{q}_{\boldsymbol{m} \boldsymbol{\text { ed }}}=3.40 \mathrm{kN} / \mathrm{m}^{2} & \boldsymbol{P}_{\boldsymbol{m a x}}=3.55 \mathrm{kN} \\
& \boldsymbol{q}_{\text {max }}=3.41 \mathrm{kN} / \mathrm{m}^{2} \\
\text { Número de puntales } & \text { Puntal más cargado } \\
15 & \text { Puntal } 13 \\
\boldsymbol{A}_{\text {total }}=27.53 \mathrm{~m}^{2} & \boldsymbol{A}_{\boldsymbol{t}}=2.03 \mathrm{~m}^{2} \\
\boldsymbol{q}_{\text {med }}=2.88 \mathrm{kN} / \mathrm{m}^{2} & \boldsymbol{P}_{\text {max }}=8.03 \mathrm{kN} \\
& \boldsymbol{q}_{\text {max }}=3.96 \mathrm{kN} / \mathrm{m}^{2}
\end{array}
$$

Fig. I.31 Resultados Hormigonado del forjado 2 (forjado reticular de casetón perdido)

De la misma forma que al hormigonar el forjado 1, el sistema de apuntalamiento soporta toda la carga del forjado 2 recién hormigonado.

La carga transmitida por los puntales que se encuentran bajo el forjado 2 es soportada en gran parte por el forjado 1, sólo transmitiendo un $27 \%$ de esta carga a los puntales que se encuentran bajo este forjado.

\section{I.3.4. Clareado forjado 2}

El clareado del forjado 2 se realizó el 1 de Febrero de 2010, 6 días después de su hormigonado. La Figura I.32 muestra un resumen de las medidas instantáneas posteriores al clareado del forjado 2. 


$$
\begin{aligned}
& C_{f}=0.30 \\
& C_{p}=0.70 \\
& C_{f}=1.03 \\
& C_{p}=0.67
\end{aligned}
$$

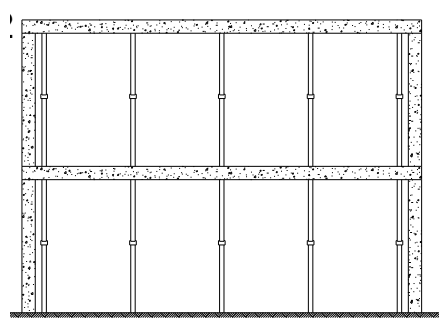

$$
\begin{array}{cc}
\text { Número de puntales } & \begin{array}{c}
\text { Puntal más cargado } \\
15
\end{array} \\
\text { Puntal } 11 \\
A_{\text {total }}=26.82 \mathrm{~m}^{2} & A_{t}=2.04 \mathrm{~m}^{2} \\
q_{\text {med }}=2.37 \mathrm{kN} / \mathrm{m}^{2} & P_{\text {max }}=6.84 \mathrm{kN} \\
& q_{\text {max }}=3.35 \mathrm{kN} / \mathrm{m}^{2} \\
\text { Número de puntales } & \text { Puntal más cargado } \\
5 & \text { Puntal } 13 \\
A_{\text {total }}=27.53 \mathrm{~m}^{2} & A_{t}=2.03 \mathrm{~m}^{2} \\
q_{\text {med }}=2.27 \mathrm{kN} / \mathrm{m}^{2} & P_{\text {max }}=6.48 \mathrm{kN} \\
& q_{\text {max }}=3.19 \mathrm{kN} / \mathrm{m}^{2}
\end{array}
$$

Fig. I.32 Resultados Clareado del forjado 2 (forjado reticular de casetón perdido)

Al realizar la operación de clareado en el forjado 2, éste asume el 30\% de carga en relación a su peso propio.

\section{I.3.5. Hormigonado forjado 3}

El hormigonado del forjado 3 se realizó el 26 de Febrero de 2010. La Figura I.33 muestra un resumen de las cargas instantáneas.

$$
\begin{aligned}
& C_{f}=0.02 \\
& C_{p}=0.98 \\
& C_{f}=0.99 \\
& C_{p}=0.99 \\
& C_{f}=1.17 \\
& C_{p}=0.82
\end{aligned}
$$

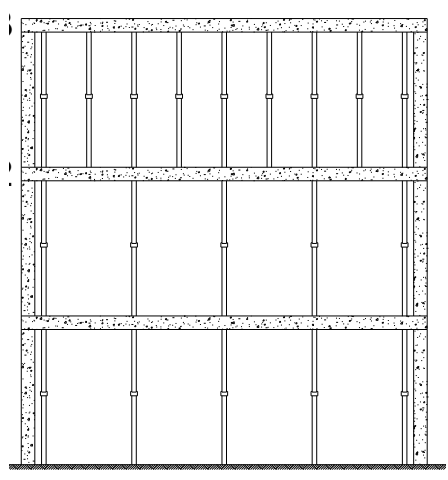

$$
\begin{gathered}
\text { Número de puntales } \\
16 \\
A_{\text {total }}=16.44 \mathrm{~m}^{2} \\
q_{\text {med }}=3.32 \mathrm{kN} / \mathrm{m}^{2} \\
\text { Número de puntales } \\
15 \\
A_{\text {total }}=26.82 \mathrm{~m}^{2} \\
q_{\text {med }}=3.36 \mathrm{kN} / \mathrm{m}^{2} \\
\text { Número de puntales } \\
15 \\
A_{\text {total }}=27.53 \mathrm{~m}^{2} \\
q_{\text {med }}=2.78 \mathrm{kN} / \mathrm{m}^{2}
\end{gathered}
$$

Puntal más cargado Puntal 13

$A_{t}=1.16 \mathrm{~m}^{2}$

$P_{\text {max }}=3.90 \mathrm{kN}$

$q_{\max }=3.38 \mathrm{kN} / \mathrm{m}^{2}$

Puntal más cargado

Puntal 11

$A_{t}=2.04 \mathrm{~m}^{2}$

$P_{\max }=10.52 \mathrm{kN}$

$q_{\max }=5.16 \mathrm{kN} / \mathrm{m}^{2}$

Puntal más cargado

$$
\text { Puntal } 11
$$

$A_{t}=2.12 \mathrm{~m}^{2}$

$P_{\max }=7.56 \mathrm{kN}$

$q_{\max }=3.56 \mathrm{kN} / \mathrm{m}^{2}$

Fig. I.33 Resultados Hormigonado del forjado 3 (forjado reticular de casetón perdido)

Al igual que en el hormigonado de los forjados 1 y 2, la carga al hormigonar el forjado 3 es soportada en su totalidad por los puntales.

La carga correspondiente al forjado 3 se reparte, en un $69 \%$ en el forjado 2, en un $14 \%$ forjado 1 y el $17 \%$ a los puntales bajo el forjado 1 .

\section{I.3.6. Clareado forjado 3}

Después de 5 días de su hormigonado se llevó a cabo el clareado del forjado 3 (3 de Marzo de 2010). La medición de cargas instantáneas a modo de resumen se muestra en la Figura I.34. 


$$
\begin{aligned}
& C_{f}=0.33 \\
& C_{p}=0.67 \\
& C_{f}=0.97 \\
& C_{p}=0.70 \\
& C_{f}=0.81 \\
& C_{p}=0.89
\end{aligned}
$$

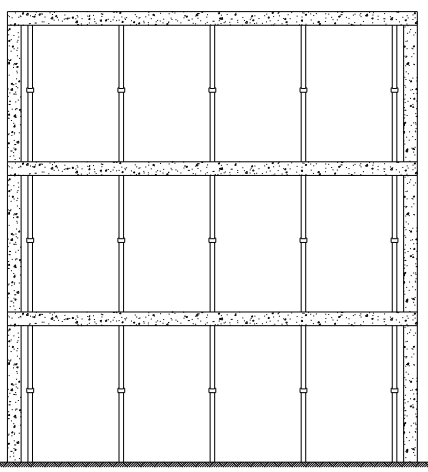

$$
\begin{array}{cc}
\text { Número de puntales } & \begin{array}{c}
\text { Puntal más cargado } \\
16
\end{array} \\
\text { Puntal } 13 \\
A_{\text {total }}=31.33 \mathrm{~m}^{2} & A_{t}=2.02 \mathrm{~m}^{2} \\
q_{\text {med }}=2.27 \mathrm{kN} / \mathrm{m}^{2} & P_{\text {max }}=6.58 \mathrm{kN} \\
& q_{\text {max }}=3.25 \mathrm{kN} / \mathrm{m}^{2} \\
\text { Número de puntales } & \text { Puntal más cargado } \\
15 & \text { Puntal } 11 \\
A_{\text {total }}=26.82 \mathrm{~m}^{2} & A_{t}=2.04 \mathrm{~m}^{2} \\
q_{\text {med }}=2.37 \mathrm{kN} / \mathrm{m}^{2} & P_{\text {max }}=8.14 \mathrm{kN} \\
& q_{\text {max }}=3.99 \mathrm{kN} / \mathrm{m}^{2} \\
\text { Número de puntales } & \text { Puntal más cargado } \\
15 & \text { Puntal } 11 \\
A_{\text {total }}=27.53 \mathrm{~m}^{2} & A_{t}=2.12 \mathrm{~m}{ }^{2} \\
q_{\text {med }}=3.02 \mathrm{kN} / \mathrm{m}^{2} & P_{\text {max }}=8.47 \mathrm{kN} \\
& q_{\text {max }}=4.00 \mathrm{kN} / \mathrm{m}^{2}
\end{array}
$$

Fig. I.34 Resultados Clareado del forjado 3 (forjado reticular de casetón perdido)

Al realizar el clareado del forjado 3, dicho forjado asumió el 33\% de la en relación a su peso propio. En los forjados inferiores se observó una disminución de la solicitación de carga.

\section{I.3.7. Descimbrado forjado 1}

El descimbrado del forjado 1 se realizó el 25 de Marzo de 2010. Los resultados obtenidos de las medidas instantáneas se muestran en la Figura I.35.

$$
\begin{aligned}
& C_{f}=0.55 \\
& C_{p}=0.45 \\
& C_{f}=1.13 \\
& C_{p}=0.32 \\
& C_{f}=1.32
\end{aligned}
$$

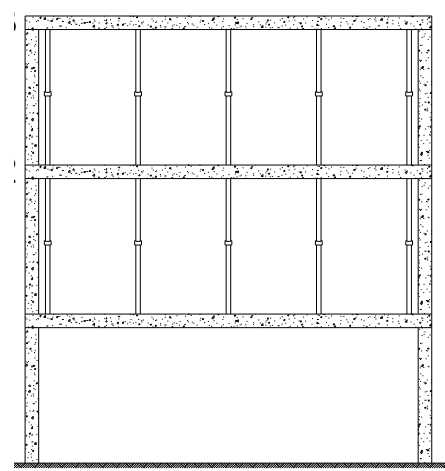

$$
\begin{array}{cc}
\text { Número de puntales } & \text { Puntal más cargado } \\
16 & \text { Puntal } 13 \\
A_{\text {total }}=31.33 \mathrm{~m}^{2} & A_{t}=2.02 \mathrm{~m}^{2} \\
q_{\text {med }}=1.53 \mathrm{kN} / \mathrm{m}^{2} & P_{\text {max }}=5.56 \mathrm{kN} \\
& q_{\text {max }}=2.75 \mathrm{kN} / \mathrm{m}^{2} \\
\text { Número de puntales } & \text { Puntal más cargado } \\
15 & \text { Puntal } 11 \\
A_{\text {total }}=26.82 \mathrm{~m}^{2} & A_{t}=2.04 \mathrm{~m}^{2} \\
q_{\text {med }}=1.08 \mathrm{kN} / \mathrm{m}^{2} & P_{\text {max }}=5.04 \mathrm{kN} \\
& q_{\text {max }}=2.47 \mathrm{kN} / \mathrm{m}^{2}
\end{array}
$$

Fig. I.35 Resultados Descimbrado del forjado 1 (forjado reticular de casetón perdido)

En la operación de descimbrado del forjado 1, la carga que asumían los puntales de dicho forjado fue asumida por los forjados superiores. El forjado 1 asumió un 57\% de dicha carga, el forjado 2 un $18 \%$ y el forjado 3 un $25 \%$.

\section{I.3.8. Hormigonado forjado 4}

El 25 de Marzo de 2010 se realizó el hormigonado del forjado 4. Los resultados obtenidos de las medidas instantáneas se muestran en las Figura I.36. 


$$
\begin{aligned}
& C_{f}=0.00 \\
& C_{p}=1.00 \\
& C_{f}=1.09 \\
& C_{p}=0.91 \\
& C_{f}=1.40 \\
& C_{p}=0.51 \\
& C_{f}=1.51
\end{aligned}
$$

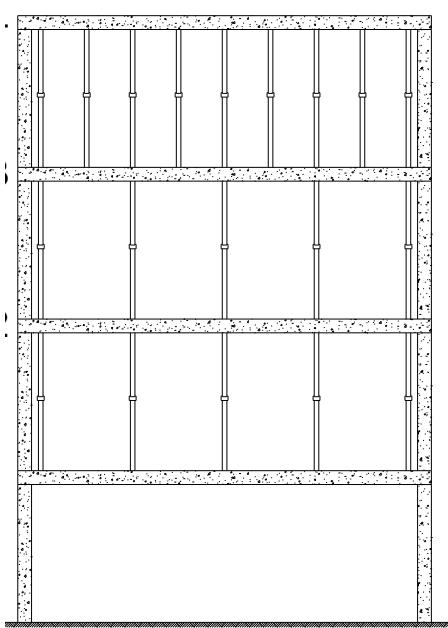

Número de puntales 16

$A_{\text {total }}=16.70 \mathrm{~m}^{2}$

$q_{\text {med }}=3.39 \mathrm{kN} / \mathrm{m}^{2}$

Número de puntales 16

$A_{\text {total }}=31.33 \mathrm{~m}^{2}$

$q_{\text {med }}=3.03 \mathrm{kN} / \mathrm{m}^{2}$

Número de puntales 15

$A_{\text {total }}=26.82 \mathrm{~m}^{2}$

$q_{\text {med }}=1.73 \mathrm{kN} / \mathrm{m}^{2}$
Puntal más cargado

Puntal 13

$A_{t}=1.05 \mathrm{~m}^{2}$

$P_{\max }=3.60 \mathrm{kN}$

$q_{\max }=3.43 \mathrm{kN} / \mathrm{m}^{2}$

Puntal más cargado Puntal 13

$A_{t}=2.02 \mathrm{~m}^{2}$

$P_{\text {max }}=8.77 \mathrm{kN}$

$q_{\max }=4.34 \mathrm{kN} / \mathrm{m}^{2}$

Puntal más cargado

Puntal 11

$A_{t}=2.04 \mathrm{~m}^{2}$

$P_{\text {max }}=3.94 \mathrm{kN}$

$q_{\max }=1.93 \mathrm{kN} / \mathrm{m}^{2}$

Fig. I.36 Resultados Hormigonado del forjado 4 (forjado reticular de casetón perdido)

Al igual que sucedía en hormigonados anteriores, la totalidad de la carga del forjado 4 es asumida por los puntales. Estos puntales transmiten la carga al forjado 3 que asume un 54\% de la carga, el forjado 2 asume un $27 \%$ y el $19 \%$ restante es asumido por el forjado 1.

\section{I.3.9. Clareado forjado 4}

Después de 4 días de su hormigonado se llevó a cabo el clareado del forjado 4 (29 de Marzo de 2010). La medición de cargas instantáneas a modo de resumen se muestra en la Figura I.37.

$$
\begin{aligned}
& C_{f}=0.52 \\
& C_{p}=0.48 \\
& C_{f}=0.82 \\
& C_{p}=0.66 \\
& C_{f}=1.25 \\
& C_{p}=0.41 \\
& C_{f}=1.41
\end{aligned}
$$

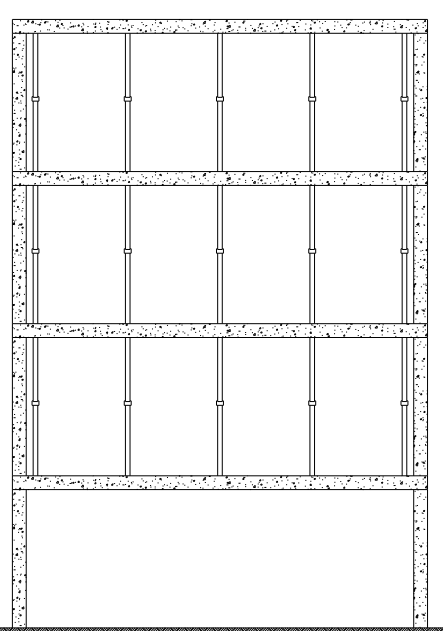

Número de puntales

$$
16
$$

$A_{\text {total }}=30.34 \mathrm{~m}^{2}$

$q_{\text {med }}=1.62 \mathrm{kN} / \mathrm{m}^{2}$

Número de puntales 16

$A_{\text {total }}=31.33 \mathrm{~m}^{2}$

$q_{\text {med }}=2.24 \mathrm{kN} / \mathrm{m}^{2}$

Número de puntales 15

$A_{\text {total }}=26.28 \mathrm{~m}^{2}$

$q_{\text {med }}=1.39 \mathrm{kN} / \mathrm{m}^{2}$
Puntal más cargado

$$
\text { Puntal } 3
$$

$A_{t}=2.18 \mathrm{~m}^{2}$

$P_{\text {max }}=4.68 \mathrm{kN}$

$q_{\max }=2.15 \mathrm{kN} / \mathrm{m}^{2}$

Puntal más cargado Puntal 13

$A_{t}=2.02 \mathrm{~m}^{2}$

$P_{\max }=4.93 \mathrm{kN}$

$q_{\max }=2.44 \mathrm{kN} / \mathrm{m}^{2}$

Puntal más cargado

Puntal 11

$A_{t}=2.04 \mathrm{~m}^{2}$

$P_{\text {max }}=3.88 \mathrm{kN}$

$q_{\max }=1.90 \mathrm{kN} / \mathrm{m}^{2}$

Fig. I.37 Resultados Clareado del forjado 4 (forjado reticular de casetón perdido)

Una vez clareado el forjado 4, dicho forjado asumió una fracción importante de carga correspondiente a un $52 \%$ de carga en relación con su peso propio. 


\section{I.3.10. Hormigonado forjado 5}

El día 20 de Abril de 2010 se realizó el hormigonado del forjado 5. Los resultados obtenidos de las medidas instantáneas se muestran en la Figura I.38. En el forjado 5 sólo se instrumentaron 13 puntales correspondientes a los puntales 2-7 y 9-15.

$$
\begin{aligned}
& C_{f}=0.00 \\
& C_{p}=1.00 \\
& C_{f}=0.99 \\
& C_{p}=1.01 \\
& C_{f}=1.10 \\
& C_{p}=0.91 \\
& C_{f}=1.33 \\
& C_{p}=0.58 \\
& C_{f}=1.58
\end{aligned}
$$

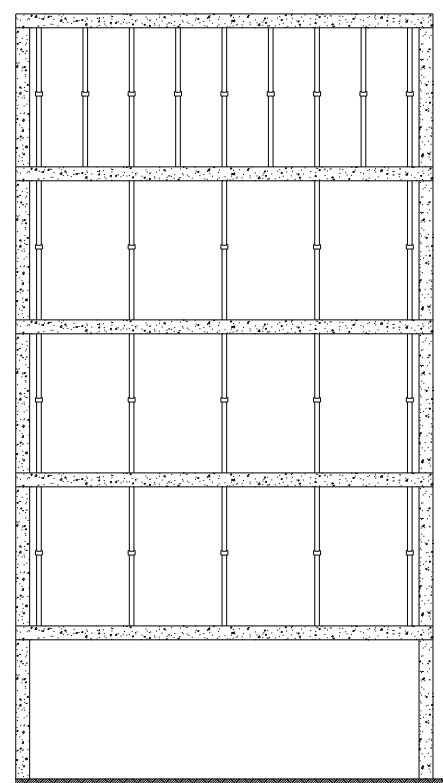

$$
\begin{array}{cc}
\text { Número de puntales } & \begin{array}{c}
\text { Puntal más cargado } \\
13
\end{array} \\
\text { Puntal } 14 \\
A_{\text {total }}=13.00 \mathrm{~m}^{2} & A_{t}=1.00 \mathrm{~m}^{2} \\
q_{\text {med }}=3.40 \mathrm{kN} / \mathrm{m}^{2} & P_{\text {max }}=3.45 \mathrm{kN} \\
& q_{\text {max }}=3.45 \mathrm{kN} / \mathrm{m}^{2} \\
\text { Número de puntales } & \text { Puntal más cargado } \\
16 & \text { Puntal } 3 \\
A_{\text {total }}=30.34 \mathrm{~m}^{2} & A_{t}=2.13 \mathrm{~m}^{2} \\
q_{\text {med }}=3.41 \mathrm{kN} / \mathrm{m}^{2} & P_{\text {max }}=9.13 \mathrm{kN} \\
& q_{\text {max }}=4.28 \mathrm{kN} / \mathrm{m}^{2} \\
\text { Número de puntales } & \text { Puntal más cargado } \\
16 & \text { Puntal } 2 \\
A_{\text {total }}=31.33 \mathrm{~m}^{2} & A_{t}=2.07 \mathrm{~m} \mathrm{~m}^{2} \\
q_{\text {med }}=3.08 \mathrm{kN} / \mathrm{m}^{2} & P_{\text {max }}=7.22 \mathrm{kN} \\
& q_{\text {max }}=3.49 \mathrm{kN} / \mathrm{m}^{2} \\
\text { Número de puntales } & \text { Puntal más cargado } \\
15 & \text { Puntal } 11 \\
A_{\text {total }}=26.28 \mathrm{~m}^{2} & A_{t}=2.04 \mathrm{~m}{ }^{2} \\
q_{\text {med }}=1.97 \mathrm{kN} / \mathrm{m}^{2} & P_{\text {max }}=4.18 \mathrm{kN} \\
& q_{\text {max }}=2.05 \mathrm{kN} / \mathrm{m}^{2}
\end{array}
$$

Fig. I.38 Resultados Hormigonado del forjado 5 (forjado reticular de casetón perdido)

$\mathrm{Al}$ hormigonar el forjado 5, su peso propio se repartió entre los forjados inferiores conectados por puntales. Dicho reparto fue medido como sigue: $47 \%$ el forjado $4 ; 28 \%$ el forjado $3,8 \%$ el forjado 2 y el $17 \%$ restante el forjado 1.

En este caso, y por necesidades de la obra, se realizó el hormigonado del forjado 5 sin haber descimbrado el forjado 1, quedando 4 plantas consecutivas cimbradas (3 clareadas y 1 completamente cimbrada).

\section{I.3.11. Descimbrado forjado 2}

El descimbrado del forjado 2 se realizó el 26 de Abril de 2010. Los resultados obtenidos de las medidas instantáneas se muestran en la Figura I.39. 


$$
\begin{aligned}
& C_{f}=0.06 \\
& C_{p}=0.94 \\
& C_{f}=0.98 \\
& C_{p}=0.96 \\
& C_{f}=1.26 \\
& C_{p}=0.78 \\
& C_{f}=1.78
\end{aligned}
$$

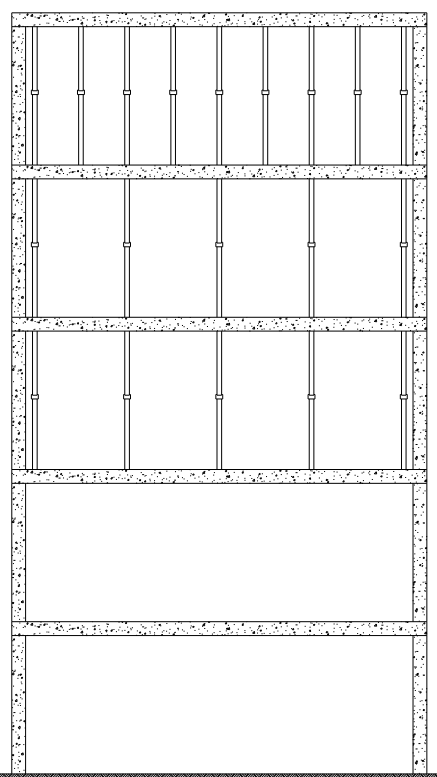

Número de puntales 13

$A_{\text {total }}=13.00 \mathrm{~m}^{2}$

$q_{\text {med }}=3.20 \mathrm{kN} / \mathrm{m}^{2}$

Número de puntales 16

$A_{\text {total }}=30.34 \mathrm{~m}^{2}$

$q_{\text {med }}=3.27 \mathrm{kN} / \mathrm{m}^{2}$

Número de puntales 16

$A_{\text {total }}=31.33 \mathrm{~m}^{2}$

$q_{\text {med }}=2.38 \mathrm{kN} / \mathrm{m}^{2}$
Puntal más cargado Puntal 6

$A_{t}=1.00 \mathrm{~m}^{2}$

$P_{\max }=4.43 \mathrm{kN}$

$q_{\max }=4.43 \mathrm{kN} / \mathrm{m}^{2}$

Puntal más cargado Puntal 3

$A_{t}=2.13 \mathrm{~m}^{2}$

$P_{\text {max }}=8.22 \mathrm{kN}$

$q_{\max }=3.86 \mathrm{kN} / \mathrm{m}^{2}$

Puntal más cargado

$$
\text { Puntal } 2
$$

$A_{t}=2.07 \mathrm{~m}^{2}$

$P_{\text {max }}=6.10 \mathrm{kN}$

$q_{\max }=2.95 \mathrm{kN} / \mathrm{m}^{2}$

Fig. I.39 Resultados Descimbrado del forjado 2 (forjado reticular de casetón perdido)

En la operación de descimbrado del forjado 2, la carga que asumían los puntales de dicho forjado fue asumida por los forjados superiores en un orden de: $67 \%$ el forjado $2 ; 24 \%$ el forjado $3,0 \%$ el forjado 4 y el $9 \%$ restante el forjado 5 .

\section{I.3.12. Clareado forjado 5}

El día 26 de Abril de 2010 se procedió con el clareado del forjado 5, seis días después del hormigonado de dicho forjado. Los resultados obtenidos de las medidas instantáneas se muestran en la Figura I.40.

$$
\begin{aligned}
& C_{f}=0.41 \\
& C_{p}=0.59 \\
& C_{f}=0.81 \\
& C_{p}=0.78 \\
& C_{f}=1.06 \\
& C_{p}=0.72 \\
& C_{f}=1.72
\end{aligned}
$$

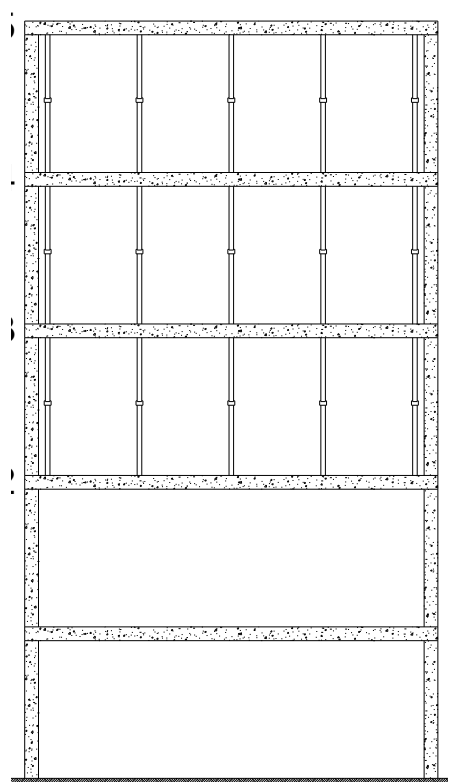

Número de puntales

$$
13
$$

$A_{\text {total }}=23.78 \mathrm{~m}^{2}$

$q_{\text {med }}=2.00 \mathrm{kN} / \mathrm{m}^{2}$

Número de puntales 16

$A_{\text {total }}=30.34 \mathrm{~m}^{2}$

$q_{\text {med }}=2.64 \mathrm{kN} / \mathrm{m}^{2}$

Número de puntales 16

$A_{\text {total }}=31.33 \mathrm{~m}^{2}$

$q_{\text {med }}=2.44 \mathrm{kN} / \mathrm{m}^{2}$
Puntal más cargado

Puntal 14

$A_{t}=1.70 \mathrm{~m}^{2}$

$P_{\text {max }}=5.89 \mathrm{kN}$

$q_{\text {max }}=3.47 \mathrm{kN} / \mathrm{m}^{2}$

Puntal más cargado Puntal 10

$A_{t}=1.73 \mathrm{~m}^{2}$

$P_{\text {max }}=6.92 \mathrm{kN}$

$q_{\max }=3.99 \mathrm{kN} / \mathrm{m}^{2}$

Puntal más cargado

Puntal 2

$A_{t}=2.07 \mathrm{~m}^{2}$

$P_{\text {max }}=5.34 \mathrm{kN}$

$q_{\max }=2.58 \mathrm{kN} / \mathrm{m}^{2}$

Fig. I.40 Resultados Clareado del forjado 5 (forjado reticular de casetón perdido) 
Al realizar la operación de clareado del forjado 5, éste asumió un $41 \%$ de su peso propio.

\section{I.3.13. Descimbrado forjado 3}

El día 13 de Mayo de 2010 se realizó el descimbrado del forjado 3. Los resultados obtenidos de las medidas instantáneas se muestran en la Figuras I.41.

$$
\begin{aligned}
& C_{f}=0.44 \\
& C_{p}=0.56 \\
& C_{f}=0.95 \\
& C_{p}=0.61 \\
& C_{f}=1.61
\end{aligned}
$$

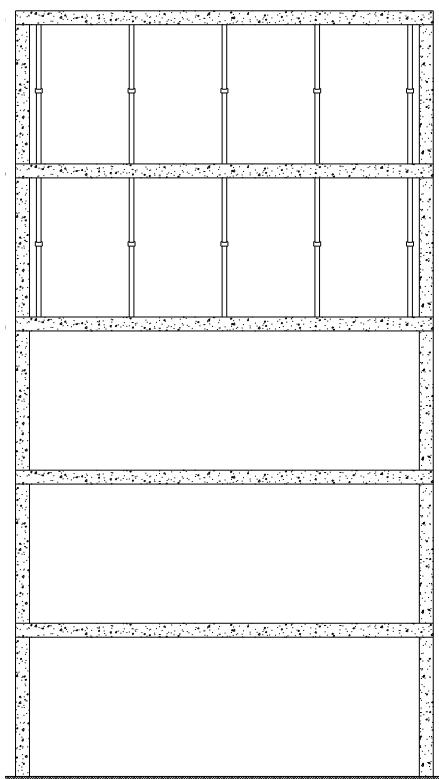

$$
\begin{array}{cc}
\text { Número de puntales } & \text { Puntal más cargado } \\
13 & \text { Puntal } 14 \\
A_{\text {total }}=23.78 \mathrm{~m}^{2} & A_{t}=1.70 \mathrm{~m}^{2} \\
q_{\text {med }}=1.91 \mathrm{kN} / \mathrm{m}^{2} & P_{\max }=6.03 \mathrm{kN} \\
& q_{\text {max }}=3.54 \mathrm{kN} / \mathrm{m}^{2} \\
& \text { Puntal más cargado } \\
\text { Número de puntales } & \text { Puntal } 10 \\
16 & A_{t}=1.73 \mathrm{~m}^{2} \\
A_{\text {total }}=30.34 \mathrm{~m}^{2} & P_{\text {max }}=8.59 \mathrm{kN} \\
q_{\text {med }}=2.08 \mathrm{kN} / \mathrm{m}^{2} & q_{\text {max }}=4.96 \mathrm{kN} / \mathrm{m}^{2}
\end{array}
$$

Fig. I.41 Resultados Descimbrado del forjado 3 (forjado reticular de casetón perdido)

Una vez descimbrado del forjado 3 , la carga que soportaban los puntales retirados fue asumida en un $76 \%$ por el forjado 3 , un $19 \%$ por el forjado 4 y un $5 \%$ por el forjado 5.

\section{I.3.14. Hormigonado forjado 6}

El día 13 de Mayo de 2010 se realizó el hormigonado del forjado 6, concluyendo así la medición experimental. Los resultados obtenidos de las medidas instantáneas se muestran en la Figura I.42. 


$$
\begin{aligned}
& C_{f}=0.00 \\
& C_{p}=1.00 \\
& C_{f}=1.13 \\
& C_{p}=0.87 \\
& C_{f}=1.25 \\
& C_{p}=0.62 \\
& C_{f}=1.62
\end{aligned}
$$

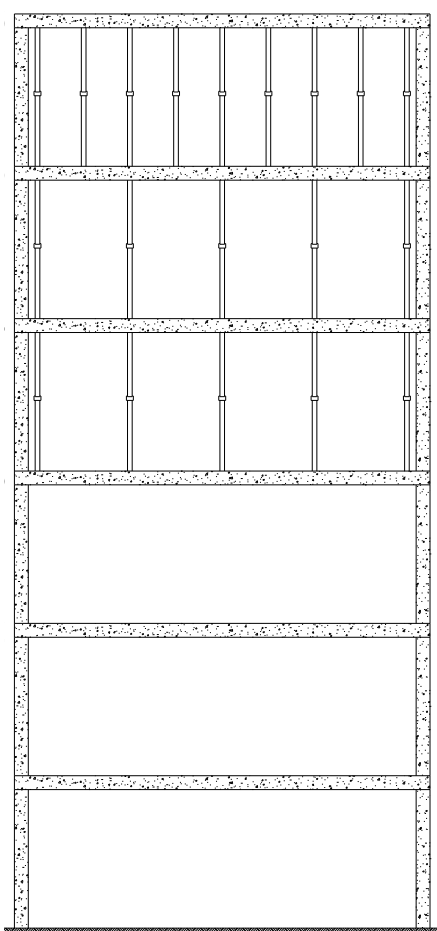

Número de puntales 16

$A_{\text {total }}=15.85 \mathrm{~m}^{2}$

$q_{\text {med }}=3.40 \mathrm{kN} / \mathrm{m}^{2}$

Número de puntales 13

$A_{\text {total }}=23.78 \mathrm{~m}^{2}$

$q_{\text {med }}=2.96 \mathrm{kN} / \mathrm{m}^{2}$

Número de puntales 16

$A_{\text {total }}=30.34 \mathrm{~m}^{2}$

$q_{\text {med }}=2.09 \mathrm{kN} / \mathrm{m}^{2}$
Puntal más cargado

Puntal 13

$A_{t}=1.00 \mathrm{~m}^{2}$

$P_{\text {max }}=3.48 \mathrm{kN}$

$q_{\max }=3.48 \mathrm{kN} / \mathrm{m}^{2}$

Puntal más cargado Puntal 2

$A_{t}=1.99 \mathrm{~m}^{2}$

$P_{\text {max }}=8.01 \mathrm{kN}$

$q_{\max }=4.01 \mathrm{kN} / \mathrm{m}^{2}$

Puntal más cargado

$$
\text { Puntal } 7
$$

$A_{t}=2.04 \mathrm{~m}^{2}$

$P_{\text {max }}=5.06 \mathrm{kN}$

$q_{\max }=2.48 \mathrm{kN} / \mathrm{m}^{2}$

Fig. I.42 Resultados Hormigonado del forjado 6 (forjado reticular de casetón perdido)

Al hormigonar el forjado 6, su peso propio se repartió entre los forjados inferiores conectados por puntales, asumiendo un $69 \%$ el forjado 5 ; un $30 \%$ el forjado 4 y el $1 \%$ restante el forjado 3.

\section{I.4. Resultados del estudio experimental de un edificio de forjado reticular de casetón recuperable}

\section{I.4.1. Hormigonado forjado 1}

El hormigonado del forjado 1 se realizó el 14 de Junio de 2010. Las Figuras I.43 y I.44 muestran un resumen de las medidas instantáneas para cada uno de los vanos instrumentados.

\section{Vano de esquina}

$$
\begin{aligned}
& \boldsymbol{C}_{\boldsymbol{f}}=0.01 \\
& \boldsymbol{C}_{\boldsymbol{p}}=0.99
\end{aligned}
$$

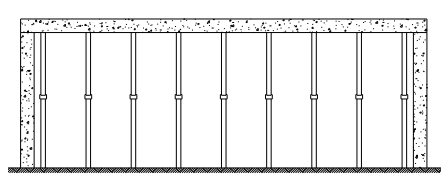

$$
\begin{gathered}
\text { Número de puntales } \\
5 \\
\boldsymbol{A}_{\text {total }}=3.63 \mathrm{~m}^{2} \\
\boldsymbol{q}_{\text {med }}=5.73 \mathrm{kN} / \mathrm{m}^{2}
\end{gathered}
$$

Puntal más cargado Puntal 5

$\boldsymbol{A}_{\boldsymbol{t}}=0.83 \mathrm{~m}^{2}$

$\boldsymbol{P}_{\text {max }}=4.80 \mathrm{kN}$

$\boldsymbol{q}_{\max }=5.78 \mathrm{kN} / \mathrm{m}^{2}$

Fig. I.43 Resultados vano de esquina (forjado reticular de casetón recuperable). Hormigonado del forjado 1 
Vano de medianera

$$
\begin{aligned}
& \boldsymbol{C}_{\boldsymbol{f}}=0.00 \\
& \boldsymbol{C}_{\boldsymbol{p}}=1.00
\end{aligned}
$$

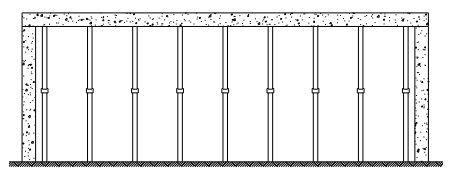

$$
\begin{array}{cc}
\text { Número de puntales } & \text { Puntal más cargado } \\
6 & \text { Puntal } 8 \\
\boldsymbol{A}_{\text {total }}=4.15 \mathrm{~m}^{2} & \boldsymbol{A}_{\boldsymbol{t}}=0.83 \mathrm{~m}^{2} \\
\boldsymbol{q}_{\text {med }}=5.79 \mathrm{kN} / \mathrm{m}^{2} & \boldsymbol{P}_{\text {max }}=4.75 \mathrm{kN} \\
& \boldsymbol{q}_{\text {max }}=5.72 \mathrm{kN} / \mathrm{m}^{2}
\end{array}
$$

Fig. I.44 Resultados vano de medianera (forjado reticular de casetón recuperable). Hormigonado del forjado 1

Como cabía esperar, una vez hormigonado el forjado la carga total fue asumida, en su totalidad, por el sistema de apuntalamiento.

\section{I.4.2. Clareado forjado 1}

El clareado del forjado 1 se realizó el 21 de Junio de 2010, 7 días después de su hormigonado. En las Figuras I.45 y I.46 se muestra un resumen de las medidas instantáneas una vez realizado el clareado.

\section{Vano de esquina}

$$
\begin{aligned}
& \boldsymbol{C}_{\boldsymbol{f}}=0.34 \\
& \boldsymbol{C}_{\boldsymbol{p}}=0.66
\end{aligned}
$$

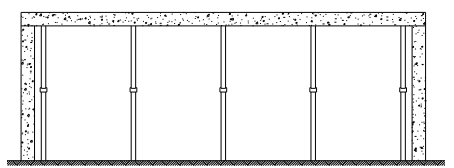

$$
\begin{array}{cc}
\text { Número de puntales } & \text { Puntal más cargado } \\
5 & \text { Puntal 5 } \\
\boldsymbol{A}_{\text {total }}=7.26 \mathrm{~m}^{2} & \boldsymbol{A}_{\boldsymbol{t}}=1.66 \mathrm{~m}^{2} \\
\boldsymbol{q}_{\text {med }}=3.80 \mathrm{kN} / \mathrm{m}^{2} & \boldsymbol{P}_{\text {max }}=7.19 \mathrm{kN} \\
& \boldsymbol{q}_{\text {max }}=4.33 \mathrm{kN} / \mathrm{m}^{2}
\end{array}
$$

Fig. I.45 Resultados vano de esquina (forjado reticular de casetón recuperable). Clareado del forjado 1

\section{Vano de medianera}

$$
\begin{aligned}
& \boldsymbol{C}_{\boldsymbol{f}}=0.16 \\
& \boldsymbol{C}_{\boldsymbol{p}}=0.84
\end{aligned}
$$

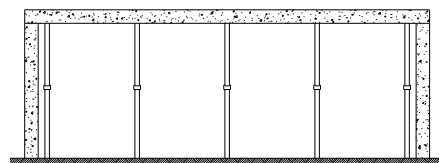

$$
\begin{array}{cc}
\text { Número de puntales } & \text { Puntal más cargado } \\
6 & \text { Puntal } 9 \\
\boldsymbol{A}_{\text {total }}=8.30 \mathrm{~m}^{2} & \boldsymbol{A}_{\boldsymbol{t}}=1.66 \mathrm{~m}^{2} \\
\boldsymbol{q}_{\text {med }}=4.84 \mathrm{kN} / \mathrm{m}^{2} & \boldsymbol{P}_{\text {max }}=9.28 \mathrm{kN} \\
& \boldsymbol{q}_{\text {max }}=5.59 \mathrm{kN} / \mathrm{m}^{2}
\end{array}
$$

Fig. I.46 Resultados vano de medianera (forjado reticular de casetón recuperable). Clareado del forjado 1

Al realizar la operación del clareado, el forjado asume un 34\% de carga en relación a su peso propio, en el caso del vano de esquina, y un $16 \%$, en el caso del vano de medianera.

\section{I.4.3. Hormigonado forjado 2}

El hormigonado del forjado 2 se llevó a cabo el 01 de Junio de 2010, 17 días después del hormigonado de la primera planta. Las Figuras I.47 y I.48 muestran resumidamente las medidas instantáneas obtenidas. 


\section{Vano de esquina}

$$
\begin{aligned}
& \boldsymbol{C}_{\boldsymbol{f}}=0.02 \\
& \boldsymbol{C}_{\boldsymbol{p}}=0.98 \\
& \boldsymbol{C}_{\boldsymbol{f}}=1.07 \\
& \boldsymbol{C}_{\boldsymbol{p}}=0.91
\end{aligned}
$$

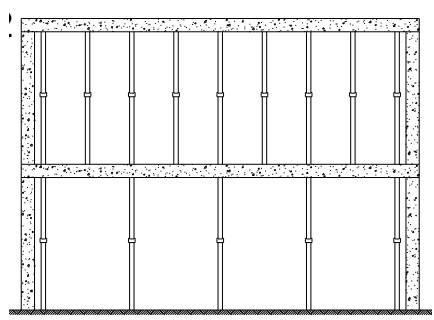

$$
\begin{array}{cc}
\text { Número de puntales } & \text { Puntal más cargado } \\
5 & \text { Puntal 1 } \\
\boldsymbol{A}_{\text {total }}=4.57 \mathrm{~m}^{2} & \boldsymbol{A}_{\boldsymbol{t}}=1.25 \mathrm{~m}^{2} \\
\boldsymbol{q}_{\boldsymbol{m} \boldsymbol{e \boldsymbol { d }}}=5.66 \mathrm{kN} / \mathrm{m}^{2} & \boldsymbol{P}_{\text {max }}=7.00 \mathrm{kN} \\
& \boldsymbol{q}_{\text {max }}=5.62 \mathrm{kN} / \mathrm{m}^{2} \\
\text { Número de puntales } & \text { Puntal más cargado } \\
5 & \text { Puntal 5 } \\
\boldsymbol{A}_{\text {total }}=7.26 \mathrm{~m}^{2} & \boldsymbol{A}_{\boldsymbol{t}}=1.66 \mathrm{~m}^{2} \\
\boldsymbol{q}_{\text {med }}=5.25 \mathrm{kN} / \mathrm{m}^{2} & \boldsymbol{P}_{\text {max }}=9.44 \mathrm{kN} \\
& \boldsymbol{q}_{\text {max }}=5.69 \mathrm{kN} / \mathrm{m}^{2}
\end{array}
$$

Fig. I.47 Resultados vano de esquina (forjado reticular de casetón recuperable). Hormigonado del forjado 2

\section{Vano de medianera}

$$
\begin{aligned}
& \boldsymbol{C}_{\boldsymbol{f}}=0.00 \\
& \boldsymbol{C}_{\boldsymbol{p}}=1.00 \\
& \boldsymbol{C}_{\boldsymbol{f}}=0.92 \\
& \boldsymbol{C}_{\boldsymbol{p}}=1.08
\end{aligned}
$$

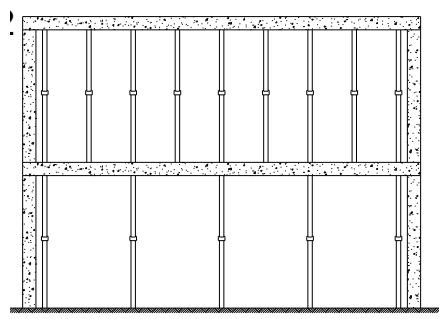

$$
\begin{gathered}
\text { Número de puntales } \\
6 \\
\boldsymbol{A}_{\text {total }}=4.57 \mathrm{~m}^{2} \\
\boldsymbol{q}_{\text {med }}=5.77 \mathrm{kN} / \mathrm{m}^{2} \\
\text { Número de puntales } \\
6 \\
\boldsymbol{A}_{\text {total }}=8.30 \mathrm{~m}^{2} \\
\boldsymbol{q}_{\text {med }}=6.23 \mathrm{kN} / \mathrm{m}^{2}
\end{gathered}
$$

Puntal más cargado Puntal 6 $\boldsymbol{A}_{\boldsymbol{t}}=0.83 \mathrm{~m}^{2}$ $\boldsymbol{P}_{\text {max }}=4.98 \mathrm{kN}$ $\boldsymbol{q}_{\max }=6.01 \mathrm{kN} / \mathrm{m}^{2}$ Puntal más cargado Puntal 9 $\boldsymbol{A}_{\boldsymbol{t}}=1.66 \mathrm{~m}^{2}$ $\boldsymbol{P}_{\text {max }}=11.92 \mathrm{kN}$ $\boldsymbol{q}_{\text {max }}=7.18 \mathrm{kN} / \mathrm{m}^{2}$

Fig. I.48 Resultados vano de medianera (forjado reticular de casetón recuperable). Hormigonado del forjado 2

De la misma forma que al hormigonar el forjado 1, el sistema de apuntalamiento soporta toda la carga del forjado 2 recién hormigonado.

La carga transmitida por los puntales que se encuentran bajo el forjado 2 es soportada en gran parte por el forjado 1 , sólo transmitiendo un $24-25 \%$ de esta carga a los puntales que se encuentran bajo este forjado.

\section{I.4.4. Clareado forjado 2 - Descimbrado forjado 1}

Por necesidades de la obra, las operaciones de clareado del forjado 2 y descimbrado del forjado 1 se realizaron simultáneamente el 8 de Julio de 2010. Sólo se obtuvo una medición, que se realizó al finalizar ambas operaciones. Los resultados obtenidos de dichas medidas instantáneas se muestran en las Figuras I.49 y I.50. 


\section{Vano de esquina}

$$
\begin{aligned}
& C_{f}=0.59 \\
& C_{p}=0.41 \\
& C_{f}=1.41
\end{aligned}
$$

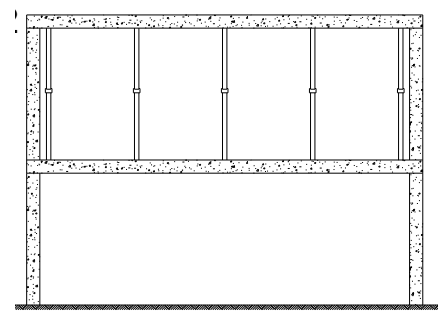

$$
\begin{array}{cc}
\text { Número de puntales } & \text { Puntal más cargado } \\
5 & \text { Puntal 1 } \\
A_{\text {total }}=9.13 \mathrm{~m}^{2} & A_{t}=2.49 \mathrm{~m}^{2} \\
q_{\text {med }}=2.36 \mathrm{kN} / \mathrm{m}^{2} & P_{\text {max }}=5.65 \mathrm{kN} \\
& q_{\text {max }}=2.27 \mathrm{kN} / \mathrm{m}^{2}
\end{array}
$$

Fig. I.49 Resultados vano de esquina (forjado reticular de casetón recuperable). Descimbrado del forjado

\section{Vano de medianera}

$$
\begin{aligned}
& C_{f}=0.77 \\
& C_{p}=0.23 \\
& C_{f}=1.23
\end{aligned}
$$

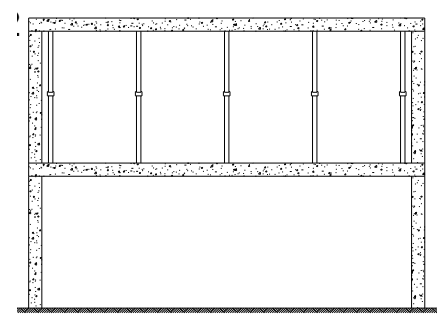

$$
\begin{array}{cc}
\text { Número de puntales } & \text { Puntal más cargado } \\
6 & \text { Puntal } 9 \\
A_{\text {total }}=9.96 \mathrm{~m}^{2} & A_{t}=1.66 \mathrm{~m}^{2} \\
q_{\text {med }}=1.34 \mathrm{kN} / \mathrm{m}^{2} & P_{\text {max }}=3.59 \mathrm{kN} \\
& q_{\text {max }}=2.16 \mathrm{kN} / \mathrm{m}^{2}
\end{array}
$$

Fig. I.50 Resultados vano de medianera (forjado reticular de casetón recuperable). Descimbrado del forjado 1

En la operación conjunta de clareado del forjado 2 y descimbrado del forjado 1, la carga que asumían los puntales de dicho forjado fue asumida por los forjados superiores en un orden de:

- Vano de esquina: $63 \%$ el forjado 2 y $37 \%$ el forjado 1 .

- Vano de medianera: $68 \%$ el forjado 2 y $32 \%$ el forjado 1 .

\section{I.4.5. Hormigonado forjado 3}

El hormigonado del forjado 3 se hizo el 16 de Julio de 2010. Las Figuras I.51 y I.52 muestran un resumen de las cargas instantáneas. 


\section{Vano de esquina}

$$
\begin{aligned}
& C_{f}=0.00 \\
& C_{p}=1.00 \\
& C_{f}=1.26 \\
& C_{p}=0.74 \\
& C_{f}=1.74
\end{aligned}
$$

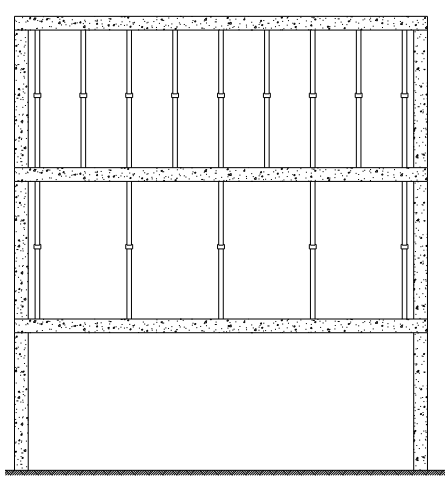

$$
\begin{array}{cc}
\text { Número de puntales } & \text { Puntal más cargado } \\
5 & \text { Puntal } 5 \\
A_{\text {total }}=4.15 \mathrm{~m}^{2} & A_{t}=0.83 \mathrm{~m}^{2} \\
q_{\text {med }}=5.66 \mathrm{kN} / \mathrm{m}^{2} & P_{\text {max }}=4.97 \mathrm{kN} \\
& q_{\text {max }}=5.99 \mathrm{kN} / \mathrm{m}^{2} \\
& \text { Puntal más cargado } \\
\text { Número de puntales } & \text { Puntal } 3 \\
5 & A_{t}=1.66 \mathrm{~m}^{2} \\
A_{\text {total }}=9.13 \mathrm{~m}^{2} & P_{\text {max }}=8.65 \mathrm{kN} \\
q_{\text {med }}=5.25 \mathrm{kN} / \mathrm{m}^{2} & q_{\text {max }}=5.21 \mathrm{kN} / \mathrm{m}^{2}
\end{array}
$$

Fig. I.51 Resultados vano de esquina (forjado reticular de casetón recuperable). Hormigonado del forjado

\section{Vano de medianera}

$$
\begin{aligned}
& C_{f}=0.01 \\
& C_{p}=0.99 \\
& C_{f}=1.29 \\
& C_{p}=0.70 \\
& C_{f}=1.70
\end{aligned}
$$

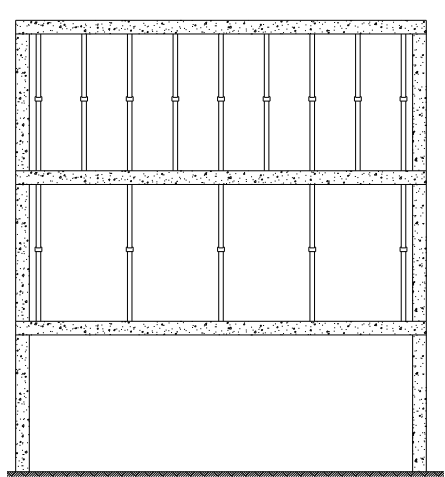

$$
\begin{array}{cc}
\text { Número de puntales } & \text { Puntal más cargado } \\
6 & \text { Puntal } 9 \\
A_{\text {total }}=4.15 \mathrm{~m}^{2} & A_{t}=0.83 \mathrm{~m}^{2} \\
q_{\text {med }}=5.72 \mathrm{kN} / \mathrm{m}^{2} & P_{\text {max }}=4.92 \mathrm{kN} \\
& q_{\text {max }}=5.93 \mathrm{kN} / \mathrm{m}^{2} \\
\text { Número de puntales } & \text { Puntal más cargado } \\
6 & \text { Puntal } 10 \\
A_{\text {total }}=9.96 \mathrm{~m}^{2} & A_{t}=1.66 \mathrm{~m}^{2} \\
q_{\text {med }}=4.03 \mathrm{kN} / \mathrm{m}^{2} & P_{\text {max }}=9.77 \mathrm{kN} \\
& q_{\text {max }}=5.89 \mathrm{kN} / \mathrm{m}^{2}
\end{array}
$$

Fig. I.52 Resultados vano de medianera (forjado reticular de casetón recuperable). Hormigonado del forjado 3

Al igual que en el hormigonado de los forjados 1 y 2, la carga al hormigonar el forjado 3 es soportada en su totalidad por los puntales. La carga correspondiente al forjado 3 se reparte, para el caso del vano de esquina, en un $67 \%$ en el forjado 2 y en un 33\% forjado 1 . En el caso del vano de medianera la carga del forjado 3 se reparte en un 53\% en el forjado 2 y el $47 \%$ restante en el forjado 1

\section{I.4.6. Clareado forjado 3}

Después de 5 días de su hormigonado se llevó a cabo el clareado del forjado 3 (21 de Julio de 2010). Por parte de la obra, se informó que el día anterior fue necesaria la retirada de diversos puntales del forjado 2. Esto supone que en el vano de esquina de dicho forjado sólo quedara un puntal instrumentado. La medición de cargas instantáneas a modo de resumen se muestra en las Figuras I.53 y I.54. 
Vano de esquina

$$
\begin{aligned}
& C_{f}=0.36 \\
& C_{p}=0.64 \\
& C_{f}=1.10 \\
& C_{p}=0.54 \\
& C_{f}=1.54
\end{aligned}
$$

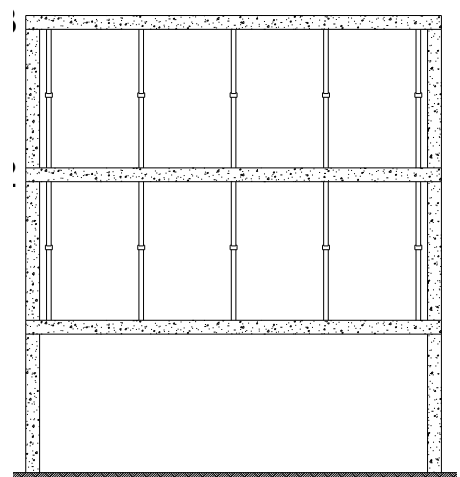

Número de puntales

$$
\begin{gathered}
5 \\
A_{\text {total }}=8.30 \mathrm{~m}^{2}
\end{gathered}
$$$$
q_{\text {med }}=3.68 \mathrm{kN} / \mathrm{m}^{2}
$$

Puntal más cargado

Puntal 4

$A_{t}=1.66 \mathrm{~m}^{2}$

$P_{\text {max }}=7.86 \mathrm{kN}$

$q_{\max }=4.73 \mathrm{kN} / \mathrm{m}^{2}$

Número de puntales

Puntal más cargado Puntal 5

$A_{\text {total }}=1.66 \mathrm{~m}^{2}$

$A_{t}=1.66 \mathrm{~m}^{2}$

$q_{\text {med }}=3.11 \mathrm{kN} / \mathrm{m}^{2}$

$P_{\text {max }}=5.16 \mathrm{kN}$

$q_{\max }=3.11 \mathrm{kN} / \mathrm{m}^{2}$

Fig. I.53 Resultados vano de esquina (forjado reticular de casetón recuperable). Clareado del forjado 3

\section{Vano de medianera}

$$
\begin{aligned}
& C_{f}=0.31 \\
& C_{p}=0.69 \\
& C_{f}=1.09 \\
& C_{p}=0.60 \\
& C_{f}=1.60
\end{aligned}
$$

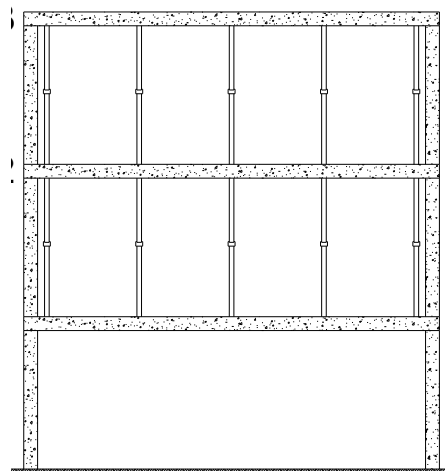

$$
\begin{array}{cc}
\text { Número de puntales } & \text { Puntal más cargado } \\
6 & \text { Puntal } 8 \\
A_{\text {total }}=8.30 \mathrm{~m}^{2} & A_{t}=1.66 \mathrm{~m}^{2} \\
q_{\text {med }}=3.97 \mathrm{kN} / \mathrm{m}^{2} & P_{\text {max }}=8.11 \mathrm{kN} \\
& q_{\text {max }}=4.89 \mathrm{kN} / \mathrm{m}^{2} \\
\text { Número de puntales } & \text { Puntal más cargado } \\
6 & \text { Puntal } 10 \\
A_{\text {total }}=9.96 \mathrm{~m}^{2} & A_{t}=1.66 \mathrm{~m}^{2} \\
q_{\text {med }}=3.48 \mathrm{kN} / \mathrm{m}^{2} & P_{\text {max }}=8.64 \mathrm{kN} \\
& q_{\text {max }}=5.20 \mathrm{kN} / \mathrm{m}^{2}
\end{array}
$$

Fig. I.54 Resultados vano de medianera (forjado reticular de casetón recuperable). Clareado del forjado 3

Al realizar el clareado del forjado 3, dicho forjado asumió el 36\% de la carga para el vano de esquina y el $31 \%$ de la carga para el vano de medianera en relación a su peso propio. En los forjados inferiores se observó una disminución de la carga.

\section{I.4.7. Descimbrado forjado 2}

El descimbrado del forjado 2 se realizó el 22 de Julio de 2010. La medición de cargas instantáneas a modo de resumen se muestra en las Figuras I.55 y I.56. 


\section{Vano de esquina}

$$
\begin{aligned}
& C_{f}=0.52 \\
& C_{p}=0.48 \\
& C_{f}=1.48
\end{aligned}
$$

$$
\begin{array}{cc}
\text { Número de puntales } & \text { Puntal más cargado } \\
5 & \text { Puntal } 3 \\
A_{\text {total }}=8.30 \mathrm{~m}^{2} & A_{t}=1.66 \mathrm{~m}^{2} \\
q_{\text {med }}=2.78 \mathrm{kN} / \mathrm{m}^{2} & P_{\text {max }}=6.26 \mathrm{kN} \\
& q_{\text {max }}=3.77 \mathrm{kN} / \mathrm{m}^{2}
\end{array}
$$

Fig. I.55 Resultados vano de esquina (forjado reticular de casetón recuperable). Descimbrado del forjado

\section{Vano de medianera}

$$
\begin{aligned}
C_{f} & =0.55 \\
C_{p} & =0.45 \\
C_{f} & =1.45
\end{aligned}
$$

$$
\begin{array}{cc}
\text { Número de puntales } & \text { Puntal más cargado } \\
6 & \text { Puntal } 6 \\
A_{\text {total }}=9.96 \mathrm{~m}^{2} & A_{t}=1.66 \mathrm{~m}^{2} \\
q_{\text {med }}=2.61 \mathrm{kN} / \mathrm{m}^{2} & P_{\max }=6.74 \mathrm{kN} \\
& q_{\max }=4.06 \mathrm{kN} / \mathrm{m}^{2}
\end{array}
$$

Fig. I.56 Resultados vano de medianera (forjado reticular de casetón recuperable). Descimbrado del forjado 2

En la operación de descimbrado del forjado 2, la carga que asumían los puntales de dicho forjado fue asumida por los forjados superiores en un orden de:

- Vano de esquina: $30 \%$ el forjado 3 y $70 \%$ el forjado 2 .

- Vano de medianera: $40 \%$ el forjado 3 y $60 \%$ el forjado 2 .

\section{I.4.8. Hormigonado forjado 4}

El día 2 de Agosto de 2010 se realizó el hormigonado del forjado 4. Los resultados obtenidos de las medidas instantáneas se muestran en las Figuras I.57 y I.58. 
Vano de esquina

$$
\begin{aligned}
& C_{f}=0.00 \\
& C_{p}=1.00 \\
& C_{f}=1.12 \\
& C_{p}=0.88 \\
& C_{f}=1.88
\end{aligned}
$$

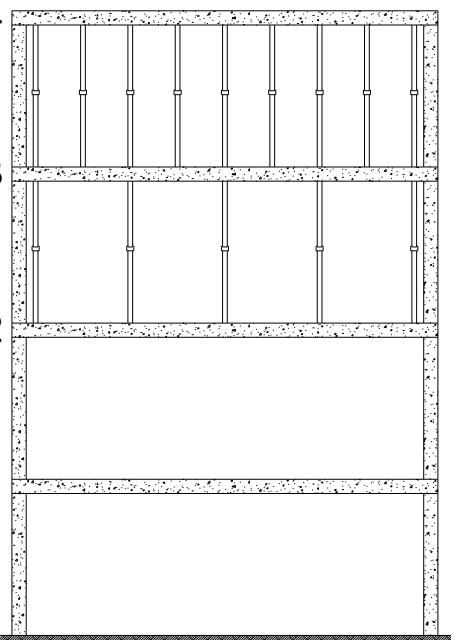

Número de puntales 5 $A_{\text {total }}=4.15 \mathrm{~m}^{2}$ $q_{\text {med }}=5.75 \mathrm{kN} / \mathrm{m}^{2}$

Número de puntales 5

$A_{\text {total }}=8.30 \mathrm{~m}^{2}$

$q_{\text {med }}=5.10 \mathrm{kN} / \mathrm{m}^{2}$
Puntal más cargado

Puntal 5

$A_{t}=0.83 \mathrm{~m}^{2}$

$P_{\text {max }}=4.90 \mathrm{kN}$

$q_{\text {max }}=5.90 \mathrm{kN} / \mathrm{m}^{2}$

Puntal más cargado Puntal 4

$A_{t}=1.66 \mathrm{~m}^{2}$

$P_{\text {max }}=10.72 \mathrm{kN}$

$q_{\max }=6.46 \mathrm{kN} / \mathrm{m}^{2}$

Fig. I.57 Resultados vano de esquina (forjado reticular de casetón recuperable). Hormigonado del forjado

\section{Vano de medianera}

$$
\begin{aligned}
& C_{f}=0.00 \\
& C_{p}=1.00 \\
& C_{f}=1.16 \\
& C_{p}=0.84 \\
& C_{f}=1.84
\end{aligned}
$$

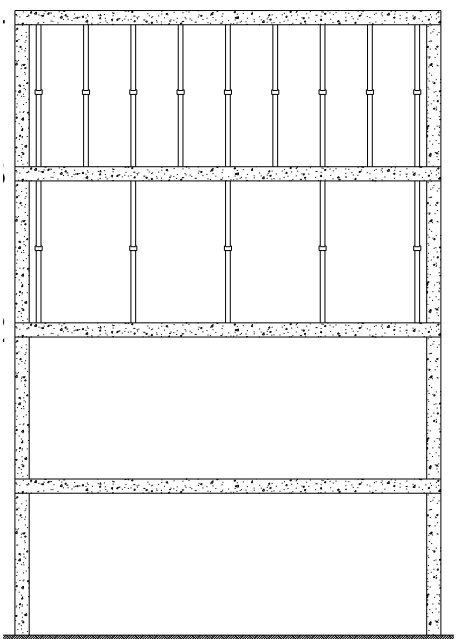

Número de puntales 6

$A_{\text {total }}=4.15 \mathrm{~m}^{2}$

$q_{\text {med }}=5.75 \mathrm{kN} / \mathrm{m}^{2}$

Número de puntales

$A_{\text {total }}=9.96 \mathrm{~m}^{2}$

$q_{\text {med }}=4.87 \mathrm{kN} / \mathrm{m}^{2}$
Puntal más cargado

$$
\text { Puntal } 9
$$

$A_{t}=0.83 \mathrm{~m}^{2}$

$P_{\max }=4.87 \mathrm{kN}$

$q_{\max }=5.87 \mathrm{kN} / \mathrm{m}^{2}$

Puntal más cargado

Puntal 6

$A_{t}=1.66 \mathrm{~m}^{2}$

$P_{\text {max }}=10.91 \mathrm{kN}$

$q_{\max }=6.57 \mathrm{kN} / \mathrm{m}^{2}$

Fig. I.58 Resultados vano de medianera (forjado reticular de casetón recuperable). Hormigonado del forjado 4

Al hormigonar el forjado 4, su peso propio se repartió entre los forjados inferiores conectados por puntales. Dicho reparto fue medido como sigue:

- Vano de esquina: $60 \%$ el forjado 3 y el $40 \%$ restante el forjado 2.

- Vano de medianera: $61 \%$ el forjado 3 y el 39\% restante el forjado 2. 



\section{APÉNDICE II. RESULTADOS DE LOS MODELOS NUMÉRICOS}

\section{II.1. Introducción}

En el Capítulo 4 de la presente Tesis Doctoral se han expuesto los diferentes modelos numéricos realizados. El primero de ellos es el modelo correspondiente al edificio de forjado de losa maciza situado en Madrid, donde se instrumentaron 2 vanos consecutivos, uno de esquina y otro de medianera, con 6 puntales instrumentados por cada vano. Se ha modelizado el proceso constructivo correspondiente a la monitorización, desde el hormigonado del forjado 1, hasta el hormigonado del forjado 6 .

El otro modelo numérico se corresponde al del edificio de forjado reticular de casetón recuperable situado en la Universidad Politécnica de Valencia, donde se instrumentaron dos vanos consecutivos, uno de esquina y otro de medianera, con un total de 11 puntales por planta. El proceso constructivo modelizado comprende desde el hormigonado del forjado 1 hasta el hormigonado del forjado 4 .

En el presente apéndice se muestran los resultados obtenidos con los modelos numéricos y su comparación con los de la medición experimental.

\section{II.2. Resultados del estudio experimental del edificio de forjado de losa maciza}

\section{II.2.1. Paso de carga 1 (Hormigonado forjado 1)}

Vano de esquina

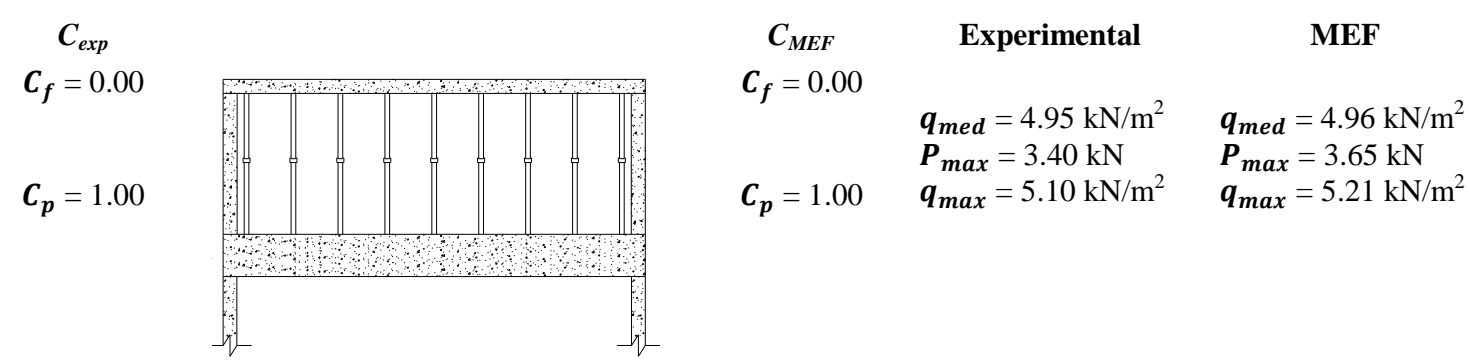

Fig. II.1 Resultados vano de esquina (forjado de losa maciza). Paso de carga 1 (Hormigonado del forjado 1) 
Vano de medianera

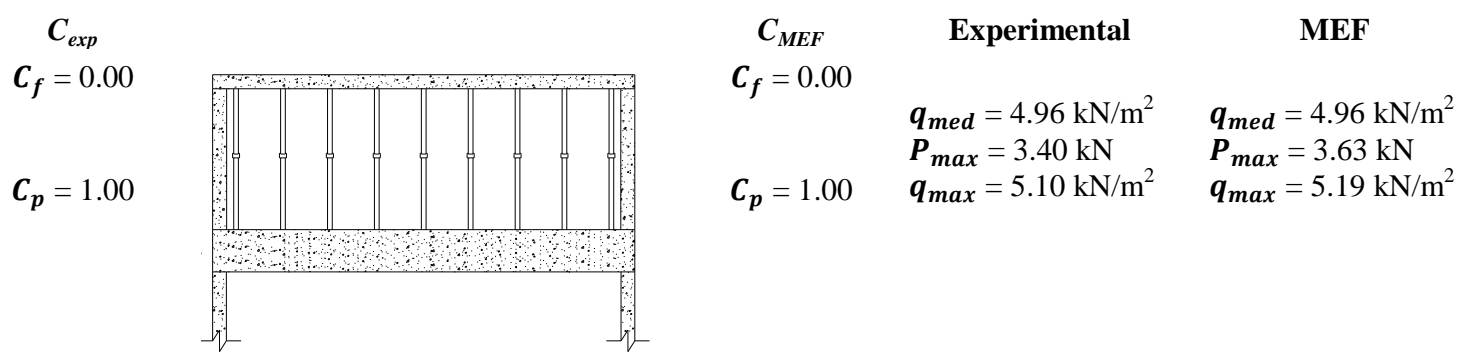

Fig. II.2 Resultados vano de medianera (forjado de losa maciza). Paso de carga 1 (Hormigonado del forjado 1)

Las Figuras II.1 y II.2 muestra los resultados obtenidos del modelo de EF comparados con las mediciones del estudio experimental. Una vez hormigonado el forjado la carga total es asumida por el sistema de apuntalamiento. Se observa que la relación entre las cargas medias experimental y numérica $\left(q_{\text {med,exp }} / q_{\text {med,MEF }}\right)$ es de 1.00 , para ambos vanos, lo que muestra un alto grado de ajuste entre los resultados del modelo de EF y las mediciones experimentales

\section{II.2.2. Paso de carga 2 (Clareado forjado 1)}

En las Figuras II.3 y II.4 se muestra una comparación entre los resultados del método de EF y las medidas experimentales para el paso de carga 2.

\section{Vano de esquina}

$C_{\text {exp }}$

$C_{f}=0.64$

$\boldsymbol{C}_{\boldsymbol{p}}=0.36$

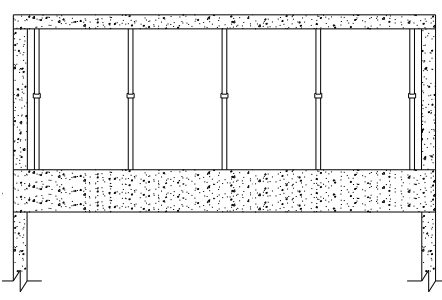

Experimental

$\boldsymbol{C}_{\boldsymbol{f}}=0.63$

$\boldsymbol{C}_{\boldsymbol{p}}=0.37$ $\boldsymbol{q}_{\boldsymbol{m} \text { ed }}=1.77 \mathrm{kN} / \mathrm{m}^{2}$

$\boldsymbol{P}_{\text {max }}=5.29 \mathrm{kN}$

$\boldsymbol{q}_{\max }=2.52 \mathrm{kN} / \mathrm{m}^{2}$

$\boldsymbol{q}_{\text {med }}=1.84 \mathrm{kN} / \mathrm{m}^{2}$

$\boldsymbol{P}_{\text {max }}=5.91 \mathrm{kN}$

$\boldsymbol{q}_{\max }=2.96 \mathrm{kN} / \mathrm{m}^{2}$

Fig. II.3 Resultados vano de esquina (forjado de losa maciza). Paso de carga 2 (Clareado del forjado 1)

\section{Vano de medianera}

$$
\begin{gathered}
C_{\text {exp }} \\
\boldsymbol{C}_{\boldsymbol{f}}=0.61 \\
\boldsymbol{C}_{\boldsymbol{p}}=0.39
\end{gathered}
$$

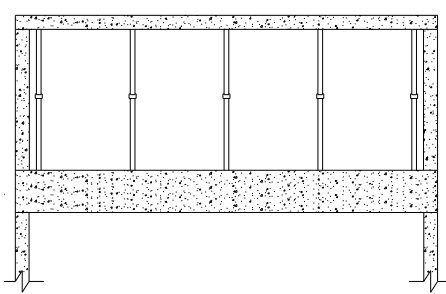

$C_{\text {MEF }}$

$C_{f}=0.56$

$$
\boldsymbol{C}_{\boldsymbol{p}}=0.44
$$

MEF

$\boldsymbol{q}_{\text {med }}=2.20 \mathrm{kN} / \mathrm{m}^{2}$

$\boldsymbol{P}_{\text {max }}=6.76 \mathrm{kN}$

$\boldsymbol{q}_{\max }=3.38 \mathrm{kN} / \mathrm{m}^{2}$

Fig. II.4 Resultados vano de medianera (forjado de losa maciza). Paso de carga 2 (Clareado del forjado 1) 
Al realizar la operación del clareado, el forjado asume entre una gran parte de carga en relación a su peso propio, presentándose una reducción en la carga media de los puntales. Al igual que en el paso de carga 1, en este paso de carga existe un alto grado de ajuste entre los valores experimentales y numéricos. Siendo la relación $q_{m e d, e x p} / q_{m e d, M E F}$ igual a 0.96 , en el vano de esquina, y 0.89 en el vano de medianera.

\section{II.2.3. Paso de carga 3 (Hormigonado forjado 2)}

\section{Vano de esquina}

$$
\begin{gathered}
\boldsymbol{C}_{\text {exp }} \\
C_{f}=0.01 \\
C_{p}=0.99 \\
C_{f}=1.36 \\
C_{p}=0.64
\end{gathered}
$$

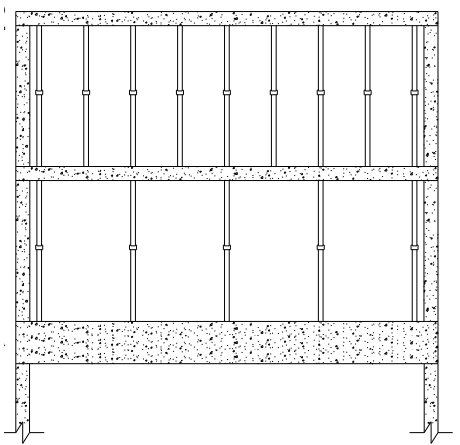

$$
\begin{array}{cll}
\boldsymbol{C}_{\text {MEF }} & \multicolumn{1}{c}{\text { Experimental }} & \multicolumn{1}{c}{\text { MEF }} \\
C_{f}=0.02 & & \\
& q_{\text {med }}=4.90 \mathrm{kN} / \mathrm{m}^{2} & \boldsymbol{q}_{\text {med }}=4.85 \mathrm{kN} / \mathrm{m}^{2} \\
C_{p}=0.98 & P_{\text {max }}=5.40 \mathrm{kN} & \boldsymbol{P}_{\text {max }}=4.87 \mathrm{kN} \\
& q_{\text {max }}=5.40 \mathrm{kN} / \mathrm{m}^{2} & q_{\text {max }}=4.87 \mathrm{kN} / \mathrm{m}^{2} \\
C_{f}=1.24 & & \\
& & \\
C_{p}=0.74 & q_{\text {med }}=3.16 \mathrm{kN} / \mathrm{m}^{2} & \boldsymbol{q}_{\text {med }}=3.69 \mathrm{kN} / \mathrm{m}^{2} \\
& P_{\text {max }}=7.01 \mathrm{kN} & \boldsymbol{P}_{\text {max }}=11.76 \mathrm{kN} \\
& q_{\text {max }}=3.34 \mathrm{kN} / \mathrm{m}^{2} & q_{\text {max }}=5.88 \mathrm{kN} / \mathrm{m}^{2}
\end{array}
$$

Fig. II.5 Resultados vano de esquina (forjado de losa maciza). Paso de carga 3 (Hormigonado del forjado 2)

\section{Vano de medianera}

$$
\begin{gathered}
\boldsymbol{C}_{\text {exp }} \\
C_{f}=0.00 \\
C_{p}=1.01 \\
C_{f}=1.36 \\
C_{p}=0.64
\end{gathered}
$$

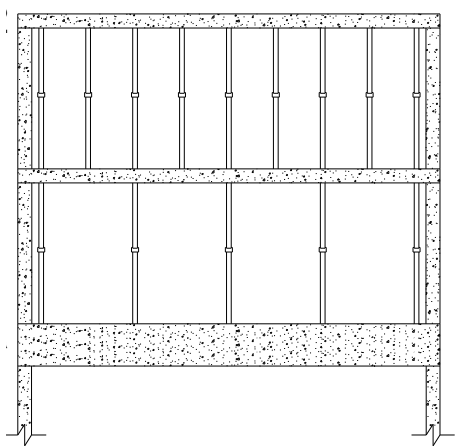

$$
\begin{array}{cll}
\boldsymbol{C}_{\text {MEF }} & \multicolumn{1}{c}{\text { Experimental }} & \multicolumn{1}{c}{\text { MEF }} \\
C_{f}=0.00 & & \\
& q_{\text {med }}=5.00 \mathrm{kN} / \mathrm{m}^{2} & \boldsymbol{q}_{\text {med }}=4.97 \mathrm{kN} / \mathrm{m}^{2} \\
C_{p}=1.00 & P_{\text {max }}=5.29 \mathrm{kN} & \boldsymbol{P}_{\text {max }}=5.02 \mathrm{kN} \\
& q_{\text {max }}=5.29 \mathrm{kN} / \mathrm{m}^{2} & q_{\text {max }}=5.02 \mathrm{kN} / \mathrm{m}^{2} \\
C_{f}=1.22 & & \\
& & \\
C_{p}=0.78 & q_{\text {med }}=3.17 \mathrm{kN} / \mathrm{m}^{2} & \boldsymbol{q}_{\text {med }}=3.86 \mathrm{kN} / \mathrm{m}^{2} \\
& P_{\text {max }}=10.07 \mathrm{kN} & \boldsymbol{P}_{\text {max }}=12.89 \mathrm{kN} \\
& q_{\text {max }}=5.04 \mathrm{kN} / \mathrm{m}^{2} & q_{\text {max }}=6.44 \mathrm{kN} / \mathrm{m}^{2}
\end{array}
$$

Fig. II.6 Resultados vano de medianera (forjado de losa maciza). Paso de carga 3 (Hormigonado del forjado 2)

El paso de carga 3 simula el hormigonado del forjado 2 (véase Figuras II.5 y II.6). El grado de ajuste entre las medidas experimentales y los resultados del modelo, para los puntales del forjado 2, es muy alto, siendo la relación $q_{m e d, e x p} / q_{m e d, M E F}$ de 1.01 para ambos vanos. En el caso de los puntales situados bajo el forjado 1, dicha relación es igual a 0.86 en el caso del vano de esquina y 0.82 en el vano de medianera. 


\section{II.2.4. Paso de carga 4 (Clareado forjado 2)}

Vano de esquina

$$
\begin{gathered}
C_{\text {exp }} \\
C_{f}=0.50 \\
C_{p}=0.50 \\
C_{f}=0.82 \\
C_{p}=0.68
\end{gathered}
$$

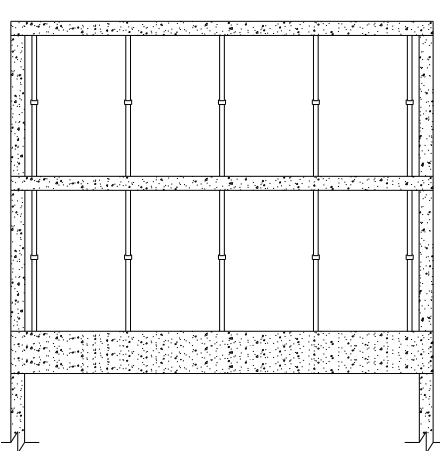

Fig. II.7 Resultados vano de esquina (forjado de losa maciza). Paso de carga 4 (Clareado del forjado 2)

\section{Vano de medianera}

$$
\begin{gathered}
\boldsymbol{C}_{\text {exp }} \\
C_{f}=0.41 \\
C_{p}=0.59 \\
C_{f}=0.87 \\
C_{p}=0.72
\end{gathered}
$$

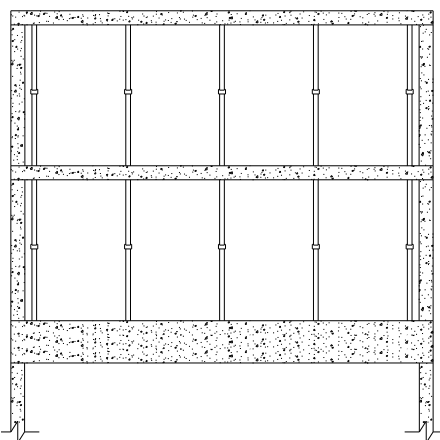

\section{MEF}

$\boldsymbol{q}_{\text {med }}=2.12 \mathrm{kN} / \mathrm{m}^{2}$

$\boldsymbol{P}_{\text {max }}=6.26 \mathrm{kN}$

$q_{\max }=3.13 \mathrm{kN} / \mathrm{m}^{2}$

$C_{f}=0.84$

$C_{p}=0.59$

$q_{\text {med }}=3.57 \mathrm{kN} / \mathrm{m}^{2}$

$P_{\max }=12.37 \mathrm{kN}$

$q_{\max }=6.18 \mathrm{kN} / \mathrm{m}^{2}$

Fig. II.8 Resultados vano de medianera (forjado de losa maciza). Paso de carga 4 (Clareado del forjado 2)

Las Figura II.7 y II.8 muestran los resultados, tanto experimentales como del modelo numérico, de paso de carga correspondiente al clareado del forjado 2. En este caso, el ajuste no es tan bueno como en los pasos de carga anteriores. Para los puntales del forjado 2, la relación $q_{\text {med,exp }} / q_{\text {med,MEF }}$ es igual a 1.41 para el vano de esquina y 1.39 para el vano de medianera. En los puntales del forjado 1, se producen errores del $24 \%$ (vano de esquina) y $23 \%$ (vano de medianera).

\section{II.2.5. Paso de carga 5 (Hormigonado forjado 3)}

En las Figuras II.9 y II.10 se muestran los resultados del paso de carga 5 que representa el hormigonado del forjado 3 . 


\section{Vano de esquina}

$$
\begin{gathered}
\boldsymbol{C}_{\text {exp }} \\
C_{f}=0.02 \\
C_{p}=0.98 \\
C_{f}=1.25 \\
C_{p}=0.73 \\
C_{f}=0.91 \\
C_{p}=0.82
\end{gathered}
$$

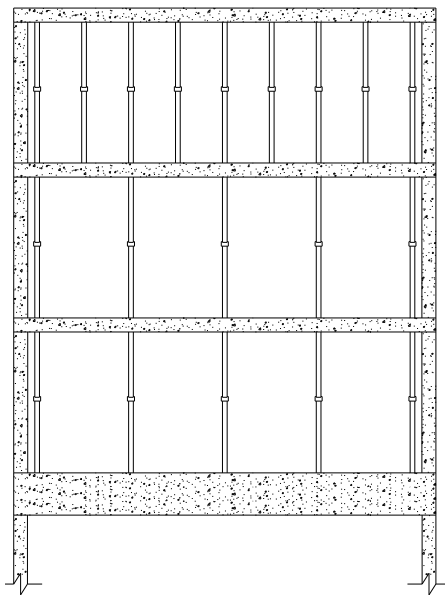

Fig. II.9 Resultados vano de esquina (forjado de losa maciza). Paso de carga 5 (Hormigonado del forjado 3 )

\section{Vano de medianera}

$$
\begin{gathered}
C_{\text {exp }} \\
C_{f}=0.00 \\
C_{p}=1.00 \\
C_{f}=1.18 \\
C_{p}=0.82 \\
C_{f}=0.90 \\
C_{p}=0.92
\end{gathered}
$$

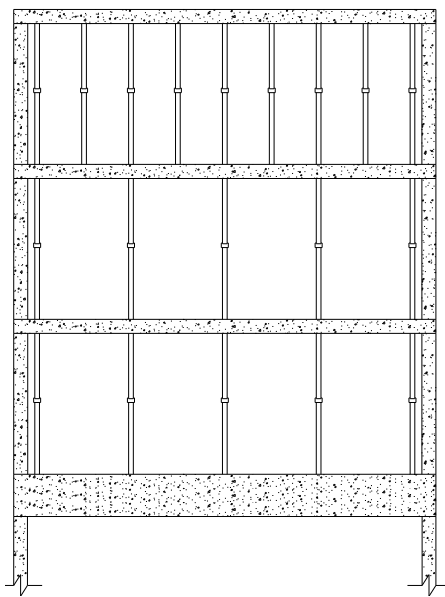

$$
\begin{aligned}
& C_{\text {MEF }} \\
& C_{f}=0.00 \\
& C_{p}=1.00 \\
& C_{f}=1.16 \\
& C_{p}=0.84 \\
& q_{\text {med }}=4.06 \mathrm{kN} / \mathrm{m}^{2} \\
& P_{\text {max }}=9.22 \mathrm{kN} \\
& C_{f}=1.06 \\
& q_{\max }=4.61 \mathrm{kN} / \mathrm{m}^{2} \\
& \boldsymbol{q}_{\text {med }}=4.15 \mathrm{kN} / \mathrm{m}^{2} \\
& \boldsymbol{P}_{\text {max }}=12.46 \mathrm{kN} \\
& C_{p}=0.78
\end{aligned}
$$

Fig. II.10 Resultados vano de medianera (forjado de losa maciza). Paso de carga 5 (Hormigonado del forjado 3)

Se obtiene un muy buen grado de ajuste para los puntales de todos los forjados en ambos vanos. La relación $q_{m e d, e x p} / q_{m e d, M E F}$ para cada caso es:

- Vano de esquina: 1.00 en los puntales del forjado 3; 1.03 en los del forjado 2 y 1.16 en los del forjado 1.

- Vano de medianera: 1.00 en los puntales del forjado 3; 0.98 en los del forjado 2 y 1.18 en los del forjado 1. 


\section{II.2.6. Paso de carga 6 (Clareado forjado 3)}

\section{Vano de esquina}

$$
\begin{gathered}
\boldsymbol{C}_{\text {exp }} \\
C_{f}=0.48 \\
C_{p}=0.52 \\
C_{f}=0.98 \\
C_{p}=0.54 \\
C_{f}=0.85 \\
C_{p}=0.69
\end{gathered}
$$

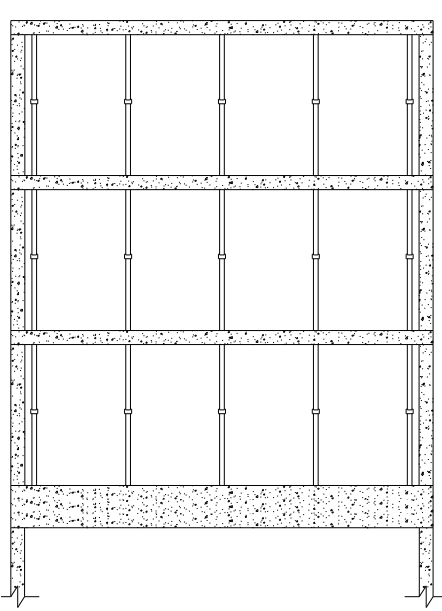

Experimental

$$
C_{f}=0.64
$$$$
C_{p}=0.36
$$$$
C_{f}=0.84
$$$$
C_{p}=0.52
$$$$
C_{f}=0.88
$$$$
q_{\text {med }}=2.68 \mathrm{kN} / \mathrm{m}^{2}
$$$$
P_{\max }=7.57 \mathrm{kN}
$$$$
q_{\text {med }}=2.56 \mathrm{kN} / \mathrm{m}^{2}
$$$$
P_{\text {max }}=6.16 \mathrm{kN}
$$$$
q_{\max }=2.94 \mathrm{kN} / \mathrm{m}^{2}
$$$$
\boldsymbol{q}_{\text {med }}=1.79 \mathrm{kN} / \mathrm{m}^{2}
$$$$
\boldsymbol{P}_{\text {max }}=5.43 \mathrm{kN}
$$$$
q_{\max }=2.71 \mathrm{kN} / \mathrm{m}^{2}
$$$$
C_{p}=0.64
$$$$
q_{\max }=3.61 \mathrm{kN} / \mathrm{m}^{2}
$$

$\boldsymbol{q}_{\text {med }}=2.58 \mathrm{kN} / \mathrm{m}^{2}$

$\boldsymbol{P}_{\text {max }}=7.95 \mathrm{kN}$

$q_{\max }=3.98 \mathrm{kN} / \mathrm{m}^{2}$

$$
\begin{aligned}
& q_{\text {med }}=3.42 \mathrm{kN} / \mathrm{m}^{2} \\
& P_{\text {max }}=10.07 \mathrm{kN} \\
& q_{\text {max }}=4.80 \mathrm{kN} / \mathrm{m}^{2}
\end{aligned}
$$

Fig. II.11 Resultados vano de esquina (forjado de losa maciza). Paso de carga 6 (Clareado del forjado 3)

\section{Vano de medianera}

$$
\begin{gathered}
\boldsymbol{C}_{\text {exp }} \\
C_{f}=0.42 \\
C_{p}=0.58 \\
C_{f}=0.81 \\
C_{p}=0.77 \\
C_{f}=0.98 \\
C_{p}=0.79
\end{gathered}
$$

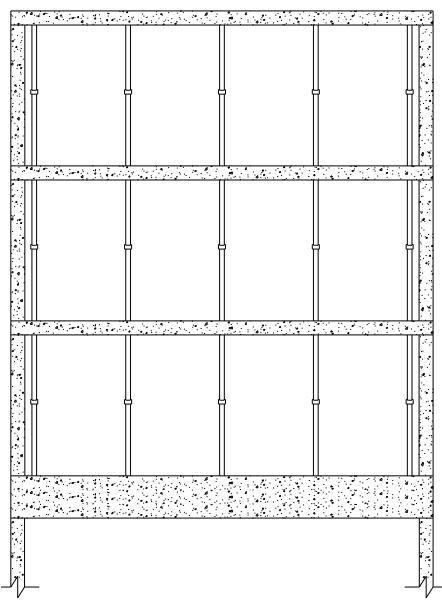

Experimental

MEF

$C_{f}=0.57$

$$
C_{p}=0.43
$$$$
C_{f}=0.80
$$

$$
C_{p}=0.63
$$$$
C_{f}=0.94
$$

$q_{\text {med }}=2.87 \mathrm{kN} / \mathrm{m}^{2}$

$$
P_{\max }=6.68 \mathrm{kN}
$$$$
q_{\max }=3.34 \mathrm{kN} / \mathrm{m}^{2}
$$

$\boldsymbol{q}_{\text {med }}=2.13 \mathrm{kN} / \mathrm{m}^{2}$

$P_{\text {max }}=6.25 \mathrm{kN}$
$q_{\text {max }}=3.12 \mathrm{kN} / \mathrm{m}^{2}$

$q^{2}(x)$

$\begin{aligned} q_{\text {med }} & =3.84 \mathrm{kN} / \mathrm{m}^{2} \\ P_{\text {max }} & =9.79 \mathrm{kN} \\ q_{\text {max }} & =4.89 \mathrm{kN} / \mathrm{m}^{2}\end{aligned}$

$\boldsymbol{q}_{\text {med }}=3.12 \mathrm{kN} / \mathrm{m}^{2}$

$\boldsymbol{P}_{\text {max }}=9.56 \mathrm{kN}$

$q_{\max }=4.78 \mathrm{kN} / \mathrm{m}^{2}$

$C_{p}=0.69$ $\boldsymbol{q}_{\text {med }}=3.45 \mathrm{kN} / \mathrm{m}^{2}$

$\boldsymbol{P}_{\text {max }}=11.71 \mathrm{kN}$

$q_{\max }=5.86 \mathrm{kN} / \mathrm{m}^{2}$

Fig. II.12 Resultados vano de medianera (forjado de losa maciza). Paso de carga 6 (Clareado del forjado 3)

Las Figuras II.11 y II.12 muestran los resultados del paso de carga 6 comparados con las medidas experimentales una vez clareado el forjado 3. El grado de ajuste entre ambos resultados es mayor en el caso de los puntales bajo los forjados 1 y 2, donde el error varía entre un $4 \%$ y un $22 \%$. En los puntales bajo el forjado 3 , la relación $q_{m e d, e x p} / q_{m e d, M E F}$ es igual a 1.43 para el vano de esquina y 1.35 para el vano de medianera. 


\section{II.2.7. Paso de carga 7 (Descimbrado forjado 1)}

\section{Vano de esquina}

$$
\begin{gathered}
\boldsymbol{C}_{\text {exp }} \\
C_{f}=0.64 \\
C_{p}=0.36 \\
C_{f}=1.07 \\
C_{p}=0.29 \\
C_{f}=1.29
\end{gathered}
$$

\begin{tabular}{|c|c|c|}
\hline$C_{M E F}$ & Experimental & MEF \\
\hline$C_{f}=0.70$ & $q_{\text {med }}=1.79 \mathrm{kN} / \mathrm{m}^{2}$ & $\boldsymbol{q}_{\text {med }}=1.51 \mathrm{kN} / \mathrm{m}^{2}$ \\
\hline$C_{p}=0.30$ & $\begin{array}{l}P_{\max }=4.90 \mathrm{kN} \\
q_{\max }=2.33 \mathrm{kN} / \mathrm{m}^{2}\end{array}$ & $\begin{array}{l}\boldsymbol{P}_{\text {max }}=4.10 \mathrm{kN} \\
q_{\text {max }}=2.05 \mathrm{kN} / \mathrm{m}^{2}\end{array}$ \\
\hline$C_{f}=0.96$ & & \\
\hline$C_{p}=0.34$ & $\begin{array}{l}q_{\text {med }}=1.44 \mathrm{kN} / \mathrm{m}^{2} \\
P_{\text {max }}=4.98 \mathrm{kN}\end{array}$ & $\begin{array}{l}\boldsymbol{q}_{\text {med }}=1.71 \mathrm{kN} / \mathrm{m}^{2} \\
\boldsymbol{P}_{\text {max }}=4.10 \mathrm{kN}\end{array}$ \\
\hline$C_{f}=1.34$ & $q_{\max }=2.37 \mathrm{kN} / \mathrm{m}^{2}$ & $q_{\max }=2.05 \mathrm{kN} / \mathrm{m}^{2}$ \\
\hline
\end{tabular}

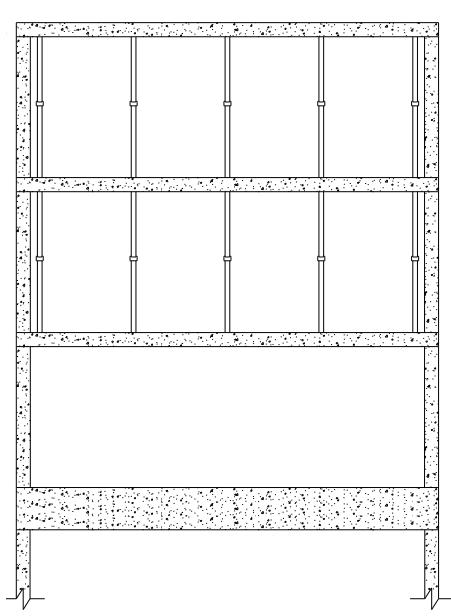

Fig. II.13 Resultados vano de esquina (forjado de losa maciza). Paso de carga 7 (Descimbrado del forjado 1)

\section{Vano de medianera}

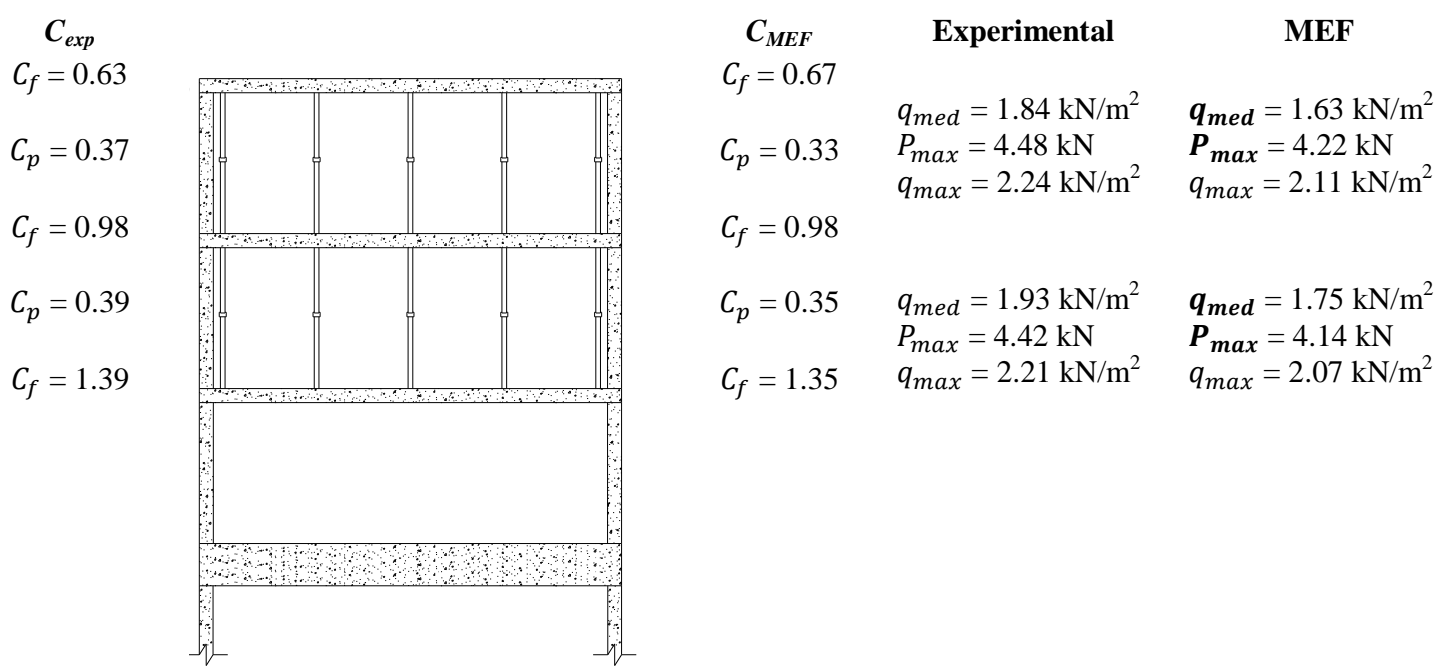

Fig. II.14 Resultados vano de medianera (forjado de losa maciza). Paso de carga 7 (Descimbrado del forjado 1)

En el descimbrado del forjado 1 se obtiene un buen grado de ajuste entre las medidas experimentales y los resultados del modelo numérico (véase Figuras II.13 y II.14). El error obtenido no es superior al $19 \%$ en ninguno de los casos. 


\section{II.2.8. Paso de carga 8 (Hormigonado forjado 4)}

\section{Vano de esquina}

$$
\begin{gathered}
\boldsymbol{C}_{\text {exp }} \\
C_{f}=0.00 \\
C_{p}=1.02 \\
C_{f}=1.58 \\
C_{p}=0.44 \\
C_{f}=0.98 \\
C_{p}=0.46 \\
C_{f}=1.46
\end{gathered}
$$

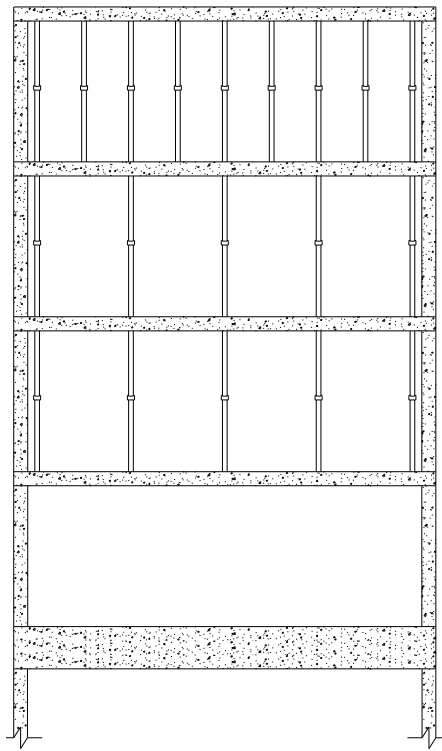

Fig. II.15 Resultados vano de esquina (forjado de losa maciza). Paso de carga 8 (Hormigonado del forjado 4)

\section{Vano de medianera}

$$
\begin{gathered}
\boldsymbol{C}_{\text {exp }} \\
C_{f}=0.01 \\
C_{p}=0.99 \\
C_{f}=1.56 \\
C_{p}=0.43 \\
C_{f}=0.88 \\
C_{p}=0.55 \\
C_{f}=1.55
\end{gathered}
$$
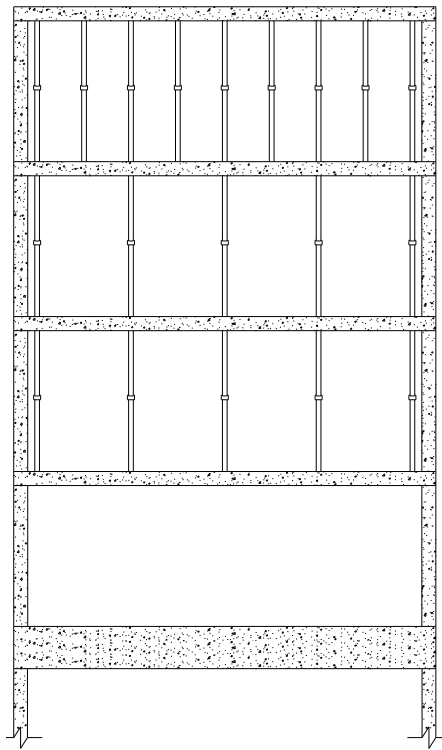

Experimental

$q_{\text {med }}=5.05 \mathrm{kN} / \mathrm{m}^{2}$

$P_{\text {max }}=5.27 \mathrm{kN}$

$q_{\max }=5.27 \mathrm{kN} / \mathrm{m}^{2}$

$C_{f}=1.34$

$C_{p}=0.64$

$C_{f}=1.16$

$q_{m e d}=2.18 \mathrm{kN} / \mathrm{m}^{2}$

$P_{\max }=5.84 \mathrm{kN}$

$q_{\max }=2.78 \mathrm{kN} / \mathrm{m}^{2}$

$C_{p}=0.48$

$C_{f}=1.48$

$q_{\text {med }}=2.28 \mathrm{kN} / \mathrm{m}^{2}$

$P_{\max }=6.47 \mathrm{kN}$

$q_{\max }=3.08 \mathrm{kN} / \mathrm{m}^{2}$
MEF

$\boldsymbol{q}_{\text {med }}=4.85 \mathrm{kN} / \mathrm{m}^{2}$

$\boldsymbol{P}_{\max }=4.87 \mathrm{kN}$

$q_{\max }=4.87 \mathrm{kN} / \mathrm{m}^{2}$

$\boldsymbol{q}_{\text {med }}=3.16 \mathrm{kN} / \mathrm{m}^{2}$

$\boldsymbol{P}_{\text {max }}=9.06 \mathrm{kN}$

$q_{\max }=4.53 \mathrm{kN} / \mathrm{m}^{2}$

$\boldsymbol{q}_{\text {med }}=2.37 \mathrm{kN} / \mathrm{m}^{2}$

$\boldsymbol{P}_{\text {max }}=6.00 \mathrm{kN}$

$q_{\max }=3.00 \mathrm{kN} / \mathrm{m}^{2}$

$$
\begin{aligned}
& C_{M E F} \quad \text { Experimental MEF } \\
& C_{f}=0.00 \\
& C_{p}=1.00 \\
& q_{\text {med }}=4.91 \mathrm{kN} / \mathrm{m}^{2} \\
& P_{\max }=5.06 \mathrm{kN} \\
& \boldsymbol{q}_{\text {med }}=4.97 \mathrm{kN} / \mathrm{m}^{2} \\
& \boldsymbol{P}_{\text {max }}=5.02 \mathrm{kN} \\
& C_{f}=1.63 \\
& q_{\max }=5.06 \mathrm{kN} / \mathrm{m}^{2} \\
& q_{\max }=4.97 \mathrm{kN} / \mathrm{m}^{2} \\
& C_{p}=0.37 \quad q_{\text {med }}=2.13 \mathrm{kN} / \mathrm{m}^{2} \\
& P_{\text {max }}=6.74 \mathrm{kN} \\
& C_{f}=0.86 \\
& q_{\max }=3.37 \mathrm{kN} / \mathrm{m}^{2} \\
& \boldsymbol{q}_{\text {med }}=3.56 \mathrm{kN} / \mathrm{m}^{2} \\
& \boldsymbol{P}_{\text {max }}=9.86 \mathrm{kN} \\
& C_{p}=0.51 \\
& C_{f}=1.51 \\
& q_{\text {med }}=2.73 \mathrm{kN} / \mathrm{m}^{2} \\
& P_{\text {max }}=6.44 \mathrm{kN} \\
& q_{\max }=3.22 \mathrm{kN} / \mathrm{m}^{2} \\
& \boldsymbol{q}_{\text {med }}=2.52 \mathrm{kN} / \mathrm{m}^{2} \\
& \boldsymbol{P}_{\text {max }}=6.48 \mathrm{kN} \\
& q_{\max }=3.24 \mathrm{kN} / \mathrm{m}^{2}
\end{aligned}
$$

Fig. II.16 Resultados vano de medianera (forjado de losa maciza). Paso de carga 8 (Hormigonado del forjado 4)

Los resultados obtenidos del modelo de EF así como las mediciones experimentales se muestran en las Figuras II.15 y II.16. En el caso de los puntales del forjado 2 y 4 el ajuste obtenido es muy bueno, no 
siendo así para los puntales del forjado 3. Esto es debido al recimbrado parcial efectuado en los puntales bajo el forjado 3 durante la ejecución de esta fase constructiva.

La relación $q_{m e d, e x p} / q_{m e d, M E F}$ para cada caso es:

- Vano de esquina: 1.04 en los puntales del forjado 4; 0.69 en los del forjado 3 y 0.96 en los del forjado 2.

- Vano de medianera: 0.99 en los puntales del forjado 4; 0.60 en los del forjado 3 y 1.08 en los del forjado 2.

\section{II.2.9. Paso de carga 9 (Clareado forjado 4)}

El paso de carga 9 consistió en modelar el clareado del forjado 4. Las Figuras II.17 y II.18muestran los resultados de dicho paso de carga.

\section{Vano de esquina}

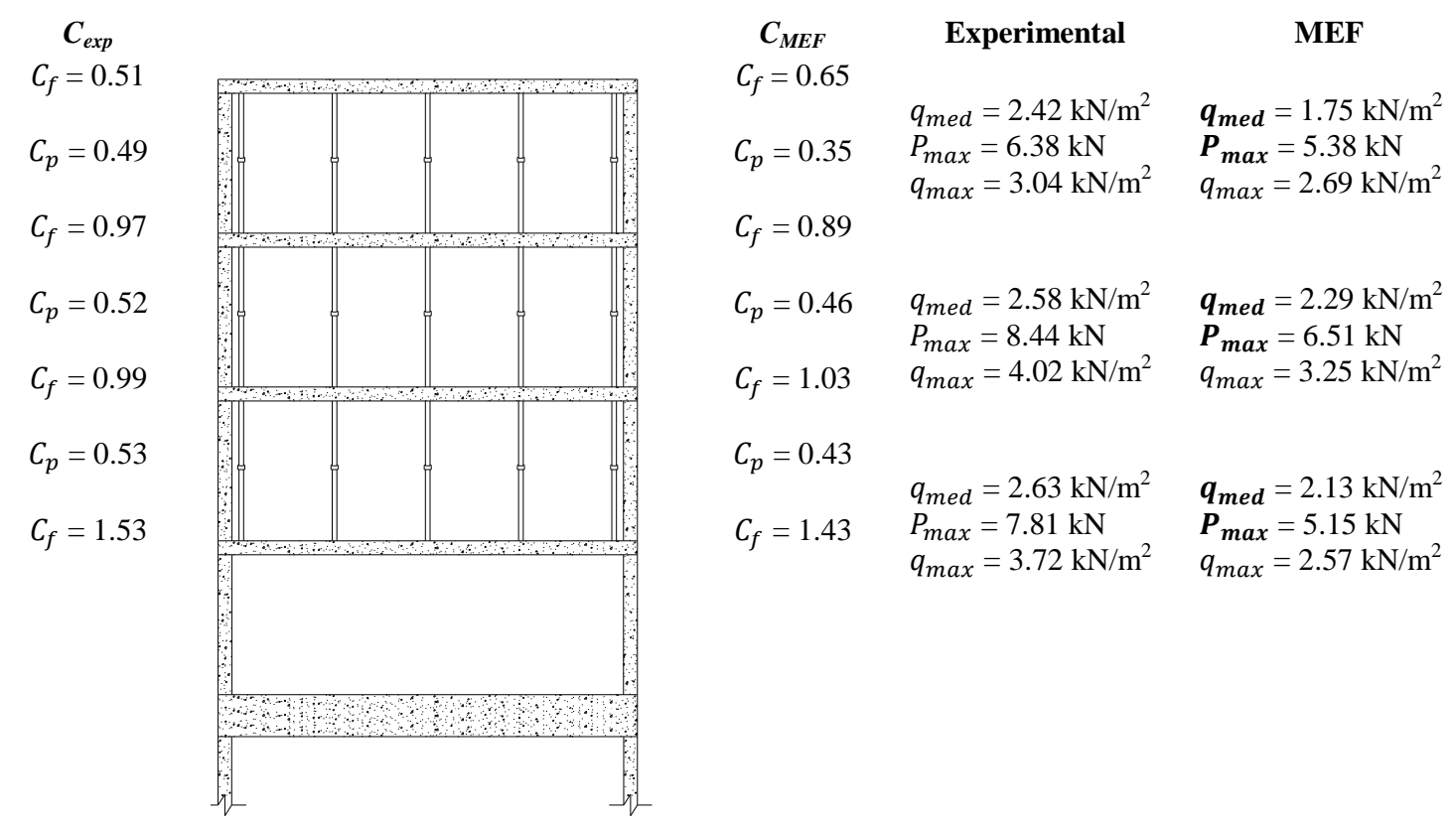

Fig. II.17 Resultados vano de esquina (forjado de losa maciza). Paso de carga 9 (Clareado del forjado 4) 


\section{Vano de medianera}

$$
\begin{aligned}
C_{\text {exp }} \\
C_{f}=0.45 \\
C_{p}=0.55 \\
C_{f}=0.97 \\
C_{p}=0.58 \\
C_{f}=1.03 \\
C_{p}=0.55 \\
C_{f}=1.55
\end{aligned}
$$
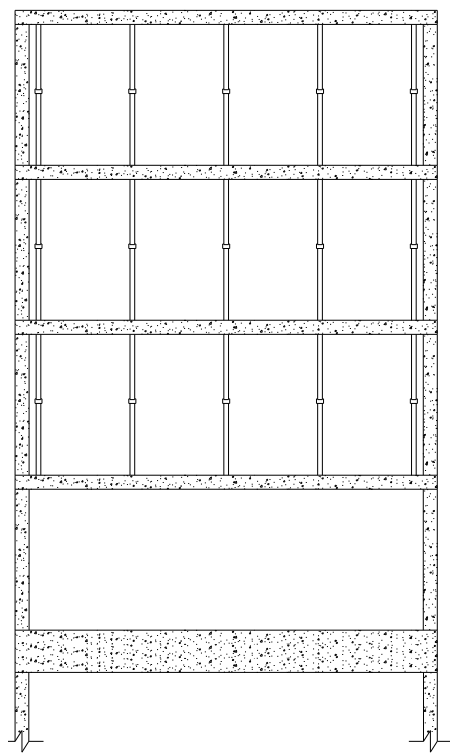

$$
\begin{array}{cll}
\boldsymbol{C}_{\text {MEF }} & \multicolumn{1}{c}{\text { Experimental }} & \multicolumn{1}{c}{\text { MEF }} \\
C_{f}=0.57 & & \\
& q_{\text {med }}=2.72 \mathrm{kN} / \mathrm{m}^{2} & \boldsymbol{q}_{\text {med }}=2.11 \mathrm{kN} / \mathrm{m}^{2} \\
C_{p}=0.43 & P_{\text {max }}=8.14 \mathrm{kN} & \boldsymbol{P}_{\text {max }}=6.11 \mathrm{kN} \\
& q_{\text {max }}=4.07 \mathrm{kN} / \mathrm{m}^{2} & q_{\text {max }}=3.05 \mathrm{kN} / \mathrm{m}^{2} \\
C_{f}=0.91 & & \\
& & \\
C_{p}=0.52 & q_{\text {med }}=2.88 \mathrm{kN} / \mathrm{m}^{2} & \boldsymbol{q}_{\text {med }}=2.60 \mathrm{kN} / \mathrm{m}^{2} \\
& P_{\text {max }}=7.74 \mathrm{kN} & \boldsymbol{P}_{\text {max }}=7.28 \mathrm{kN} \\
C_{f}=1.07 & q_{\text {max }}=3.87 \mathrm{kN} / \mathrm{m}^{2} & q_{\text {max }}=3.64 \mathrm{kN} / \mathrm{m}^{2} \\
& & \\
C_{p}=0.45 & & \\
& q_{\text {med }}=2.73 \mathrm{kN} / \mathrm{m}^{2} & \boldsymbol{q}_{\text {med }}=2.22 \mathrm{kN} / \mathrm{m}^{2} \\
C_{f}=1.45 & P_{\text {max }}=5.96 \mathrm{kN} & \boldsymbol{P}_{\text {max }}=5.46 \mathrm{kN} \\
& q_{\text {max }}=2.98 \mathrm{kN} / \mathrm{m}^{2} & q_{\text {max }}=2.73 \mathrm{kN} / \mathrm{m}^{2}
\end{array}
$$

Fig. II.18 Resultados vano de medianera (forjado de losa maciza). Paso de carga 9 (Clareado del forjado 4)

La relación $q_{m e d, e x p} / q_{m e d, M E F}$ para cada caso es:

- Vano de esquina: 1.38 en los puntales del forjado 4; 1.13 en los del forjado 3 y 1.23 en los del forjado 2 .

- Vano de medianera: 1.29 en los puntales del forjado 4; 1.11 en los del forjado 3 y 1.23 en los del forjado 2.

Los errores que se producen en este paso de carga vienen originados por el recimbrado parcial efectuado en los puntales bajo el forjado 3 durante el hormigonado del forjado 4 .

\section{II.2.10. Paso de carga 10 (Descimbrado forjado 2)}

En las Figuras II.19 y II.20 se muestra una comparación entre las medidas experimentales y los resultados obtenidos del modelo numérico para el paso de carga 10. Se puede observar que el error, para los puntales, que se produce entre ambos resultados no es superior a un $20 \%$. 


\section{Vano de esquina}

$$
\begin{gathered}
C_{\text {exp }} \\
C_{f}=0.64 \\
C_{p}=0.36 \\
C_{f}=0.98 \\
C_{p}=0.38 \\
C_{f}=1.38
\end{gathered}
$$
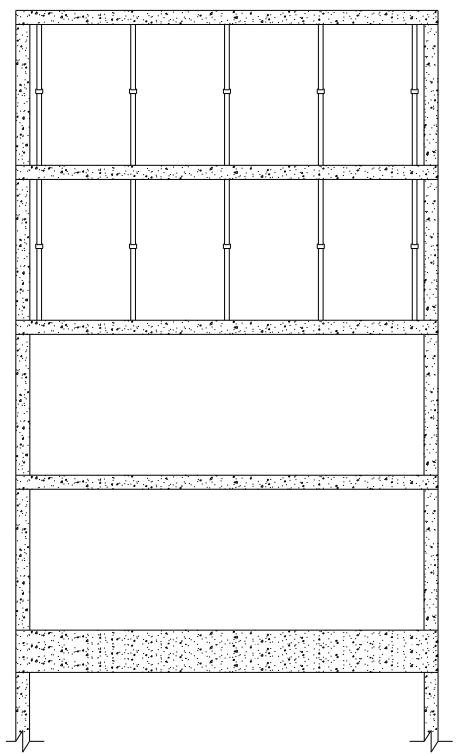

Fig. II.19 Resultados vano de esquina (forjado de losa maciza). Paso de carga 10 (Descimbrado del forjado 2)

\begin{tabular}{cll}
$\boldsymbol{C}_{\text {MEF }}$ & \multicolumn{1}{c}{ Experimental } & \multicolumn{1}{c}{ MEF } \\
$C_{f}=0.68$ & & \\
& $q_{\text {med }}=1.79 \mathrm{kN} / \mathrm{m}^{2}$ & $\boldsymbol{q}_{\text {med }}=1.59 \mathrm{kN} / \mathrm{m}^{2}$ \\
$C_{p}=0.32$ & $P_{\text {max }}=5.00 \mathrm{kN}$ & $\boldsymbol{P}_{\text {max }}=4.66 \mathrm{kN}$ \\
& $q_{\text {max }}=2.38 \mathrm{kN} / \mathrm{m}^{2}$ & $q_{\text {max }}=2.33 \mathrm{kN} / \mathrm{m}^{2}$ \\
$C_{f}=0.97$ & & \\
& & \\
$C_{p}=0.35$ & $q_{\text {med }}=1.88 \mathrm{kN} / \mathrm{m}^{2}$ & $\boldsymbol{q}_{\text {med }}=1.74 \mathrm{kN} / \mathrm{m}^{2}$ \\
& $P_{\text {max }}=5.01 \mathrm{kN}$ & $\boldsymbol{P}_{\text {max }}=4.43 \mathrm{kN}$ \\
$C_{f}=1.35$ & $q_{\text {max }}=2.39 \mathrm{kN} / \mathrm{m}^{2}$ & $q_{\text {max }}=2.22 \mathrm{kN} / \mathrm{m}^{2}$
\end{tabular}

\section{Vano de medianera}

$C_{\text {exp }}$

$C_{f}=0.55$

$C_{p}=0.45$

$C_{f}=1.02$

$C_{p}=0.43$

$C_{f}=1.43$
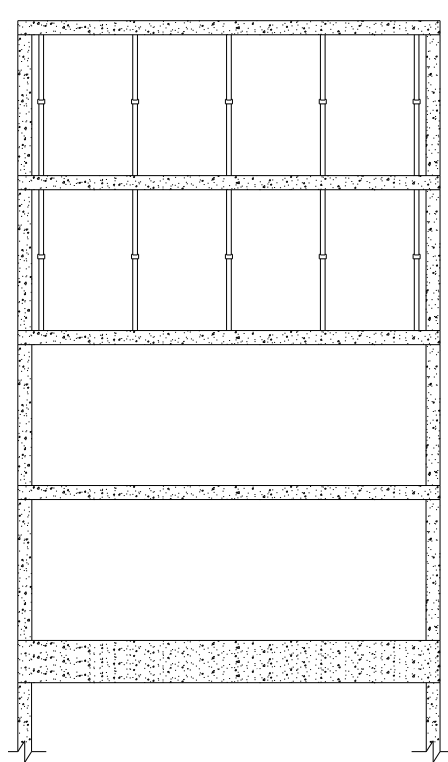

Fig. II.20 Resultados vano de medianera (forjado de losa maciza). Paso de carga 10 (Descimbrado del forjado 2)

\begin{tabular}{cll}
$\boldsymbol{C}_{\text {MEF }}$ & Experimental & \multicolumn{1}{c}{ MEF } \\
$C_{f}=0.62$ & & \\
& $q_{\text {med }}=2.23 \mathrm{kN} / \mathrm{m}^{2}$ & $\boldsymbol{q}_{\text {med }}=1.86 \mathrm{kN} / \mathrm{m}^{2}$ \\
$C_{p}=0.38$ & $P_{\text {max }}=5.10 \mathrm{kN}$ & $\boldsymbol{P}_{\text {max }}=5.25 \mathrm{kN}$ \\
& $q_{\text {max }}=2.55 \mathrm{kN} / \mathrm{m}^{2}$ & $q_{\text {max }}=2.63 \mathrm{kN} / \mathrm{m}^{2}$ \\
$C_{f}=1.01$ & & \\
& & \\
$C_{p}=0.37$ & $q_{\text {med }}=2.13 \mathrm{kN} / \mathrm{m}^{2}$ & $\boldsymbol{q}_{\text {med }}=1.85 \mathrm{kN} / \mathrm{m}^{2}$ \\
& $P_{\text {max }}=5.20 \mathrm{kN}$ & $\boldsymbol{P}_{\text {max }}=4.76 \mathrm{kN}$ \\
$C_{f}=1.37$ & $q_{\text {max }}=2.60 \mathrm{kN} / \mathrm{m}^{2}$ & $q_{\text {max }}=2.38 \mathrm{kN} / \mathrm{m}^{2}$
\end{tabular}




\section{II.2.11. Paso de carga 11 (Hormigonado forjado 5)}

El paso de carga 11 se corresponde con el hormigonado del forjado 5 (véase Figuras II.21 y II.22). La relación $q_{m e d, e x p} / q_{m e d, M E F}$ para cada caso es:

- Vano de esquina: 1.01 en los puntales del forjado 5; 0.69 en los del forjado 4 y 0.95 en los del forjado 3.

- Vano de medianera: 0.98 en los puntales del forjado 5; 0.92 en los del forjado 4 y 1.20 en los del forjado 3.

\section{Vano de esquina}

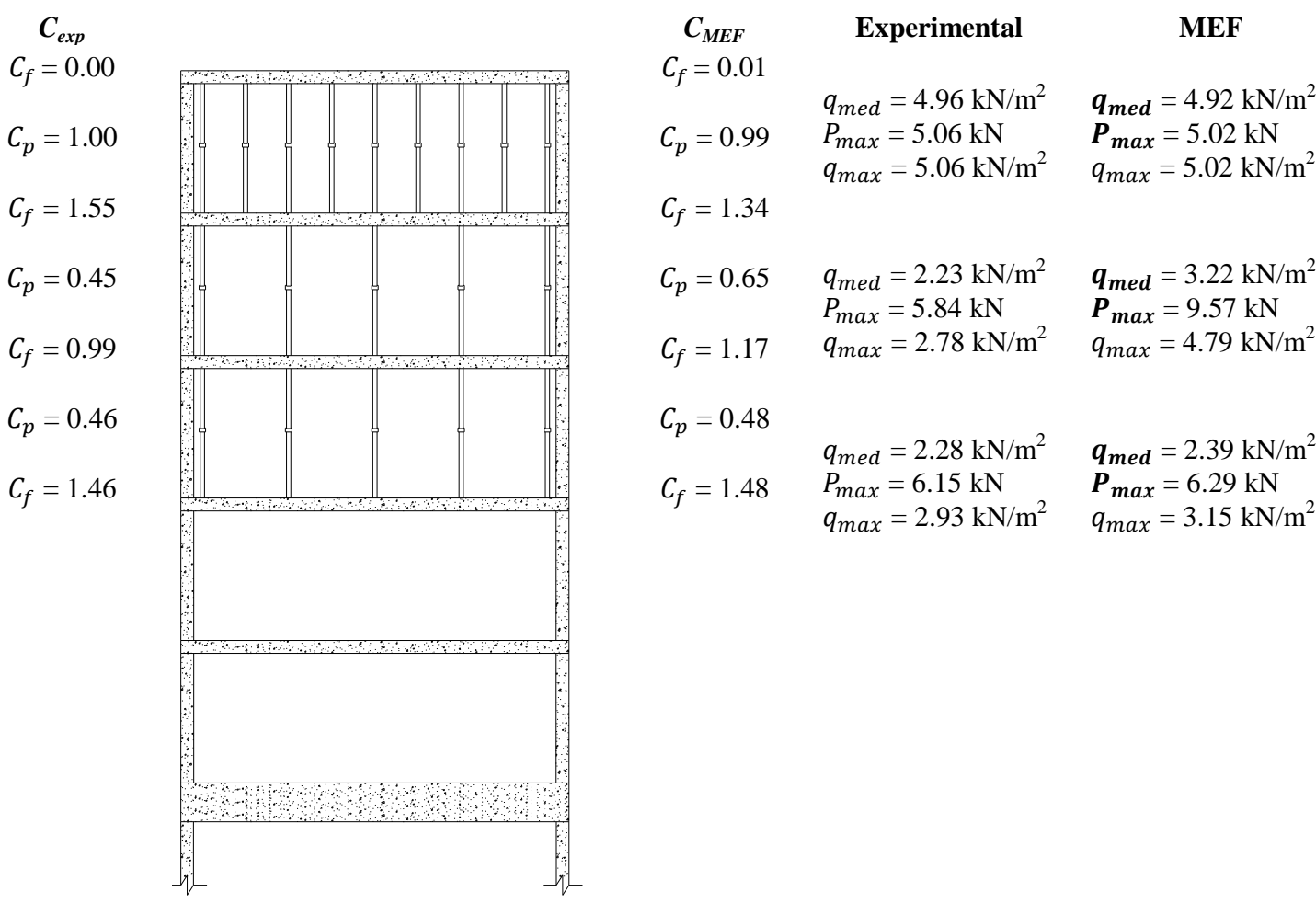

Fig. II.21 Resultados vano de esquina (forjado de losa maciza). Paso de carga 11 (Hormigonado del forjado 5) 
Vano de medianera

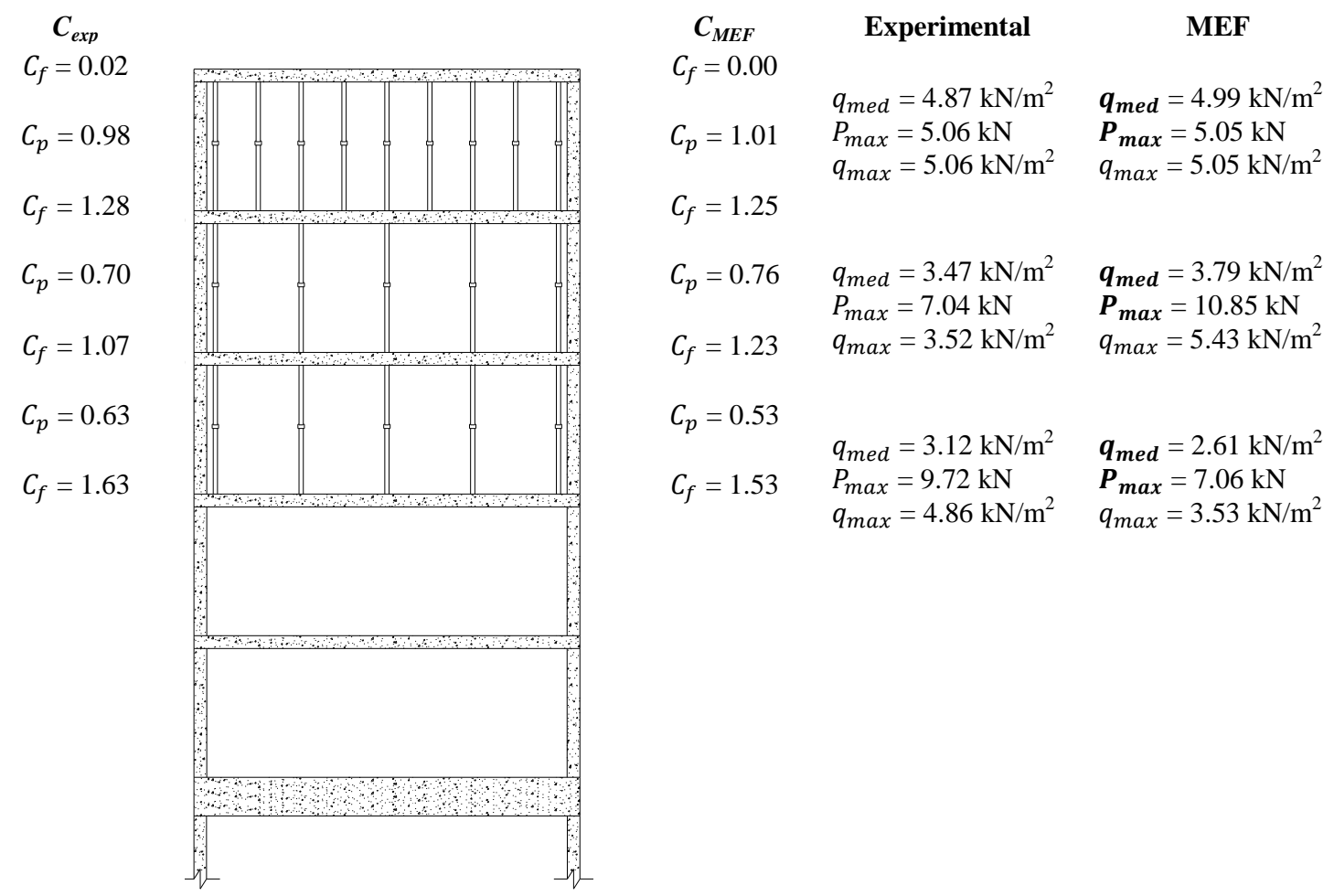

Fig. II.22 Resultados vano de medianera (forjado de losa maciza). Paso de carga 11 (Hormigonado del forjado 5)

\section{II.2.12. Paso de carga 12 (Clareado forjado 5)}

Las Figuras II.23 y II.24 muestran los resultados del paso de carga 12 comparados con las medidas experimentales tomadas en el clareado del forjado5. El error entre ambas medidas es mayor en el caso de los puntales del forjado 3 debido a que, en obra, los puntales del forjado 3 (inclusive los puntales instrumentados) fueron apretados durante el clareado del forjado 5.

La relación $q_{m e d, e x p} / q_{m e d, M E F}$ para cada caso es:

- Vano de esquina: 1.19 en los puntales del forjado 5; 0.98 en los del forjado 4 y 1.54 en los del forjado 3.

- Vano de medianera: 1.30 en los puntales del forjado 5; 1.05 en los del forjado 4 y 1.34 en los del forjado 3. 


\section{Vano de esquina}

$C_{\text {exp }}$

$C_{f}=0.58$

$C_{p}=0.42$

$C_{f}=0.95$

$C_{p}=0.47$

$C_{f}=0.80$

$C_{p}=0.67$

$C_{f}=1.67$
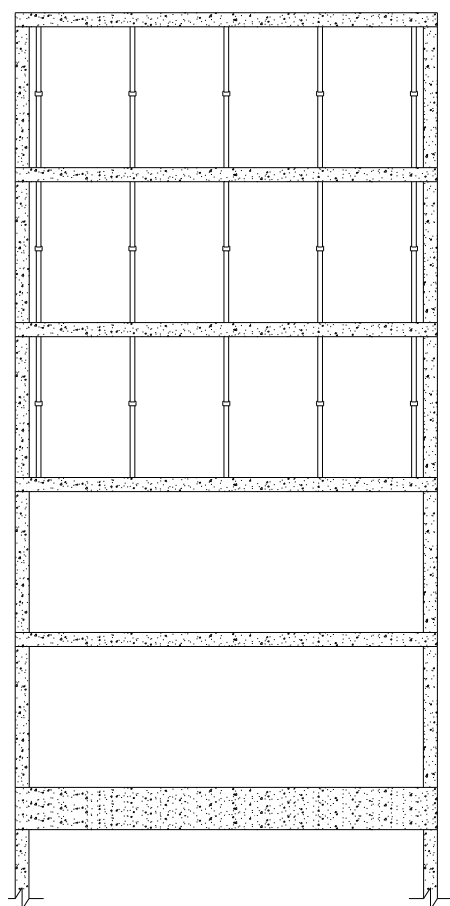

Fig. II.23 Resultados vano de esquina (forjado de losa maciza). Paso de carga 12 (Clareado del forjado 5)

\begin{tabular}{|c|c|c|}
\hline $\begin{array}{c}C_{M E F} \\
C_{f}=0.65\end{array}$ & Experimental & MEF \\
\hline$C_{p}=0.35$ & $\begin{array}{l}q_{\text {med }}=2.09 \mathrm{kN} / \mathrm{m}^{2} \\
P_{\text {max }}=7.13 \mathrm{kN} \\
q_{\text {max }}=3.39 \mathrm{kN} / \mathrm{m}^{2}\end{array}$ & $\begin{array}{l}\boldsymbol{q}_{\text {med }}=1.76 \mathrm{kN} / \mathrm{m}^{2} \\
\boldsymbol{P}_{\text {max }}=5.38 \mathrm{kN} \\
q_{\max }=2.69 \mathrm{kN} / \mathrm{m}^{2}\end{array}$ \\
\hline$C_{f}=0.87$ & & \\
\hline$C_{p}=0.48$ & $\begin{array}{l}q_{\text {med }}=2.33 \mathrm{kN} / \mathrm{m}^{2} \\
P_{\text {max }}=7.50 \mathrm{kN}\end{array}$ & $\begin{array}{l}\boldsymbol{q}_{\text {med }}=2.37 \mathrm{kN} / \mathrm{m}^{2} \\
\boldsymbol{P}_{\text {max }}=7.06 \mathrm{kN}\end{array}$ \\
\hline$C_{f}=1.05$ & $q_{\max }=3.57 \mathrm{kN} / \mathrm{m}^{2}$ & $q_{\max }=3.53 \mathrm{kN} / \mathrm{m}^{2}$ \\
\hline$C_{p}=0.43$ & & \\
\hline$C_{f}=1.43$ & $\begin{array}{l}q_{\text {med }}=3.32 \mathrm{kN} / \mathrm{m}^{2} \\
P_{\text {max }}=7.18 \mathrm{kN} \\
q_{\text {max }}=3.42 \mathrm{kN} / \mathrm{m}^{2}\end{array}$ & $\begin{array}{l}\boldsymbol{q}_{\text {med }}=2.15 \mathrm{kN} / \mathrm{m}^{2} \\
\boldsymbol{P}_{\text {max }}=5.47 \mathrm{kN} \\
q_{\text {max }}=2.73 \mathrm{kN} / \mathrm{m}^{2}\end{array}$ \\
\hline
\end{tabular}

$C_{M E F}$

$q_{\max }=3.42 \mathrm{kN} / \mathrm{m}^{2}$ 
Vano de medianera

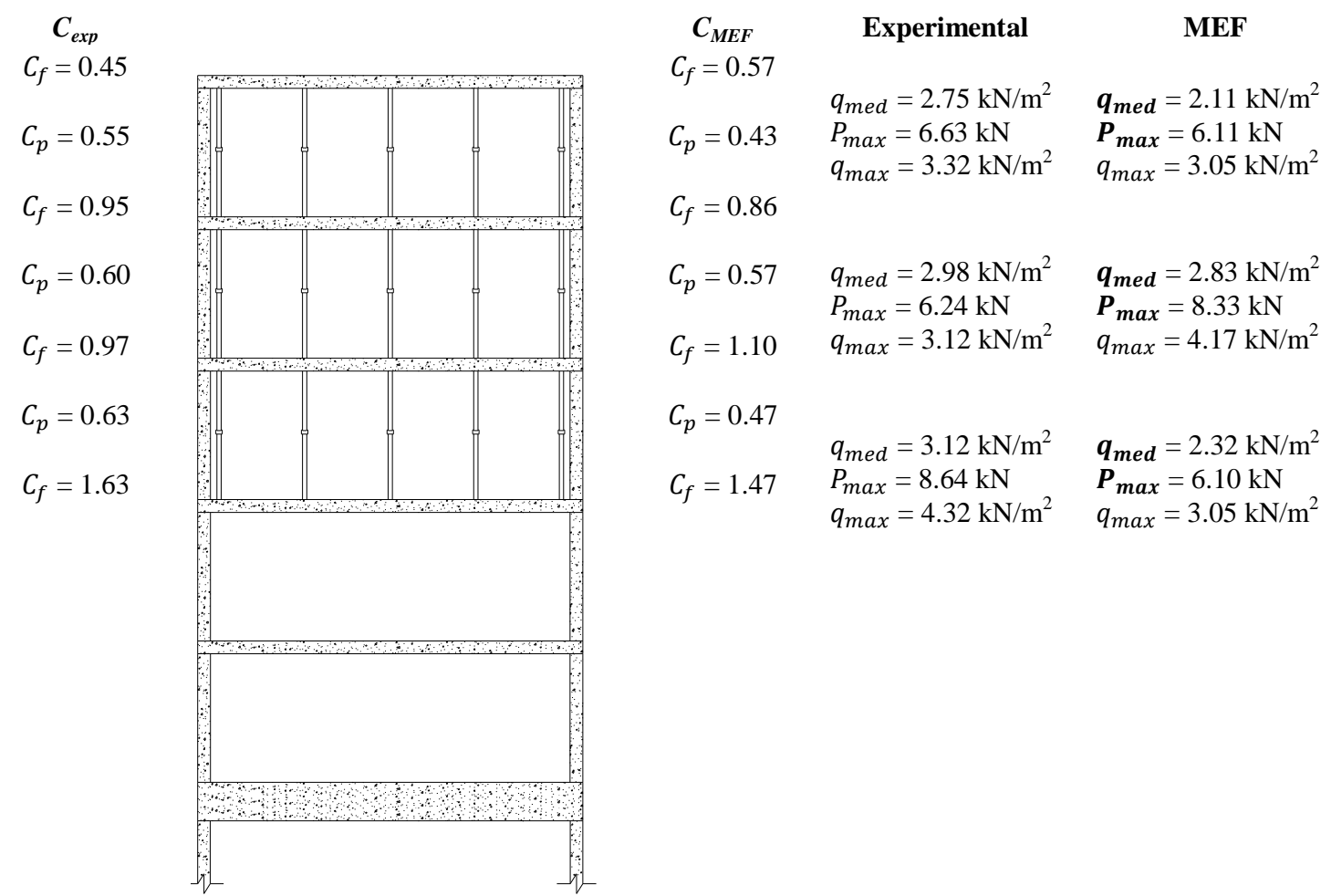

Fig. II.24 Resultados vano de medianera (forjado de losa maciza). Paso de carga 12 (Clareado del forjado 5)

\section{II.2.13. Paso de carga 13 (Descimbrado forjado 3)}

En las Figuras II.25 y II.26 se muestran los resultados del paso de carga 13 correspondiente al descimbrado del forjado 2 . Se observa que para los puntales del forjado 5 el ajuste entre las medidas experimentales y los resultados del modelo numérico es bastante bueno $\left(q_{\text {med,exp }} / q_{\text {med,MEF }}=1.12\right.$, en el vano de esquina y $q_{\text {med,exp }} / q_{m e d, M E F}=1.18$, en el vano de medianera). En el caso de los puntales del forjado 4 el ajuste es algo mejor, siendo la relación $q_{\text {med,exp }} / q_{m e d, M E F}$ igual a 1.04 , para el vano de esquina, y 1.15 para el de medianera. 


\section{Vano de esquina}

$C_{\text {exp }}$

$C_{f}=0.64$

$C_{p}=0.36$

$C_{f}=0.98$

$C_{p}=0.38$

$C_{f}=1.38$
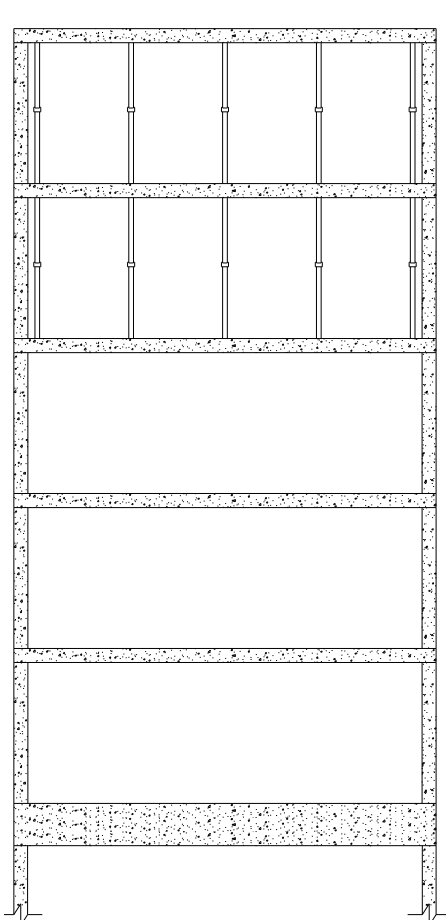

Experimental

MEF

$C_{f}=0.68$

$C_{p}=0.32$

$q_{\text {med }}=1.79 \mathrm{kN} / \mathrm{m}^{2}$

$P_{\text {max }}=4.80 \mathrm{kN}$

$q_{\max }=2.29 \mathrm{kN} / \mathrm{m}^{2}$

$\boldsymbol{q}_{\boldsymbol{m e d}}=1.60 \mathrm{kN} / \mathrm{m}^{2}$

$\boldsymbol{P}_{\text {max }}=4.62 \mathrm{kN}$

$C_{f}=0.96$

$C_{p}=0.36$

$q_{\text {med }}=1.88 \mathrm{kN} / \mathrm{m}^{2}$

$P_{\text {max }}=5.02 \mathrm{kN}$

$q_{\text {max }}=2.31 \mathrm{kN} / \mathrm{m}^{2}$

$C_{f}=1.36$

$q_{\max }=2.39 \mathrm{kN} / \mathrm{m}^{2}$

$\boldsymbol{q}_{\text {med }}=1.88 \mathrm{kN} / \mathrm{m}^{2}$

$\boldsymbol{P}_{\text {max }}=4.88 \mathrm{kN}$

$q_{\max }=2.44 \mathrm{kN} / \mathrm{m}^{2}$

Fig. II.25 Resultados vano de esquina (forjado de losa maciza). Paso de carga 13 (Descimbrado del forjado 3) 
Vano de medianera

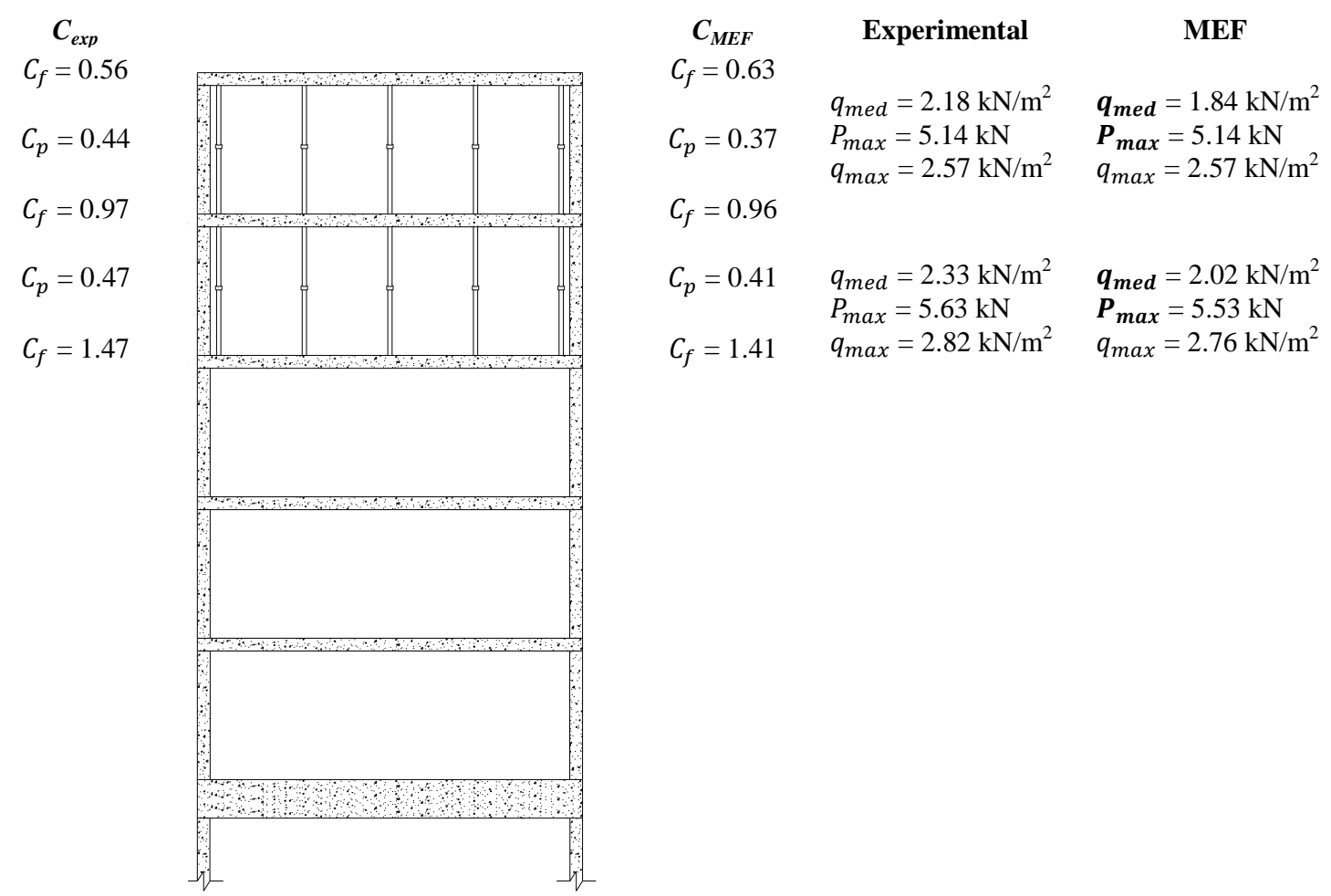

Fig. II.26 Resultados vano de medianera (forjado de losa maciza). Paso de carga 13 (Descimbrado del forjado 3)

\section{II.2.14. Paso de carga 14 (Hormigonado forjado 6)}

El último paso de carga simula el hormigonado del forjado 6 (véase Figuras II.27 y II.28). En este paso de carga se consigue un buen grado de ajuste entre las medidas experimentales y los resultados obtenidos del modelo de EF.

La relación $q_{m e d, e x p} / q_{m e d, M E F}$ para cada caso es:

- Vano de esquina: 1.03 en los puntales del forjado 6; 0.89 en los del forjado 5 y 0.83 en los del forjado 4.

- Vano de medianera: 1.01 en los puntales del forjado 6; 1.19 en los del forjado 5 y 1.09 en los del forjado 4. 


\section{Vano de esquina}

$C_{\text {exp }}$

$C_{f}=0.00$

$C_{p}=1.01$

$C_{f}=1.43$

$C_{p}=0.58$

$C_{f}=1.17$

$C_{p}=0.41$

$C_{f}=1.41$
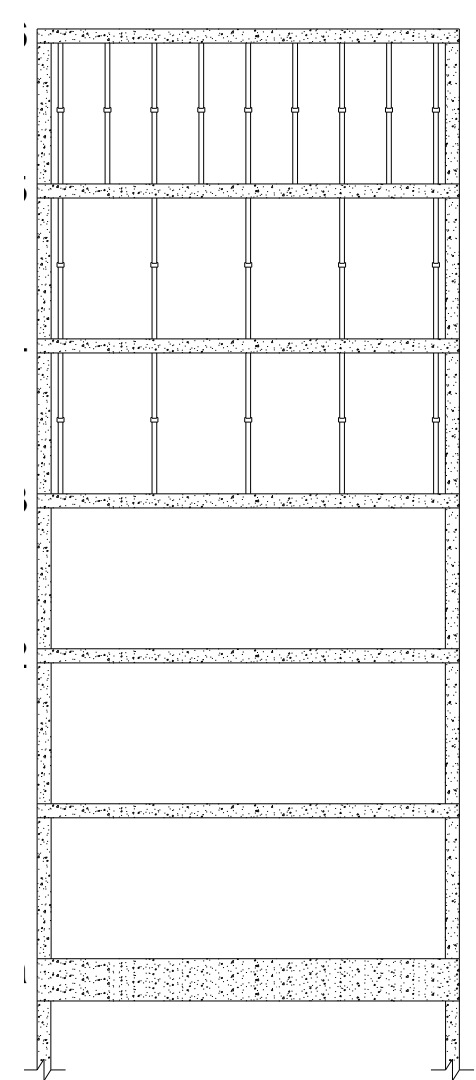

Fig. II.27 Resultados vano de esquina (forjado de losa maciza). Paso de carga 14 (Hormigonado del forjado 6)

\begin{tabular}{|c|c|c|}
\hline $\begin{array}{c}\boldsymbol{C}_{\boldsymbol{M E F}} \\
C_{f}=0.00\end{array}$ & Experimental & MEF \\
\hline$C_{p}=1.00$ & $\begin{array}{l}q_{\text {med }}=5.01 \mathrm{kN} / \mathrm{m}^{2} \\
P_{\text {max }}=5.06 \mathrm{kN} \\
q_{\text {max }}=5.06 \mathrm{kN} / \mathrm{m}^{2}\end{array}$ & $\begin{array}{l}\boldsymbol{q}_{\text {med }}=4.85 \mathrm{kN} / \mathrm{m}^{2} \\
\boldsymbol{P}_{\text {max }}=4.87 \mathrm{kN} \\
q_{\text {max }}=4.87 \mathrm{kN} / \mathrm{m}^{2}\end{array}$ \\
\hline$C_{f}=1.35$ & & \\
\hline$C_{p}=0.65$ & $\begin{array}{l}q_{\text {med }}=2.88 \mathrm{kN} / \mathrm{m}^{2} \\
P_{\text {max }}=8.44 \mathrm{kN}\end{array}$ & $\begin{array}{l}\boldsymbol{q}_{\text {med }}=3.25 \mathrm{kN} / \mathrm{m}^{2} \\
\boldsymbol{P}_{\text {max }}=9.58 \mathrm{kN}\end{array}$ \\
\hline$C_{f}=1.16$ & $q_{\max }=4.02 \mathrm{kN} / \mathrm{m}^{2}$ & $q_{\max }=4.79 \mathrm{kN} / \mathrm{m}^{2}$ \\
\hline$C_{p}=0.49$ & & \\
\hline$C_{f}=1.49$ & $\begin{array}{l}q_{\text {med }}=2.03 \mathrm{kN} / \mathrm{m}^{2} \\
P_{\text {max }}=5.63 \mathrm{kN} \\
q_{\text {max }}=2.68 \mathrm{kN} / \mathrm{m}^{2}\end{array}$ & $\begin{array}{l}\boldsymbol{q}_{\text {med }}=2.45 \mathrm{kN} / \mathrm{m}^{2} \\
\boldsymbol{P}_{\text {max }}=6.76 \mathrm{kN} \\
q_{\text {max }}=3.38 \mathrm{kN} / \mathrm{m}^{2}\end{array}$ \\
\hline
\end{tabular}

$C_{M E F}$

$q_{\max }=2.68 \mathrm{kN} / \mathrm{m}^{2}$

$q_{\max }=3.38 \mathrm{kN} / \mathrm{m}^{2}$ 
Vano de medianera

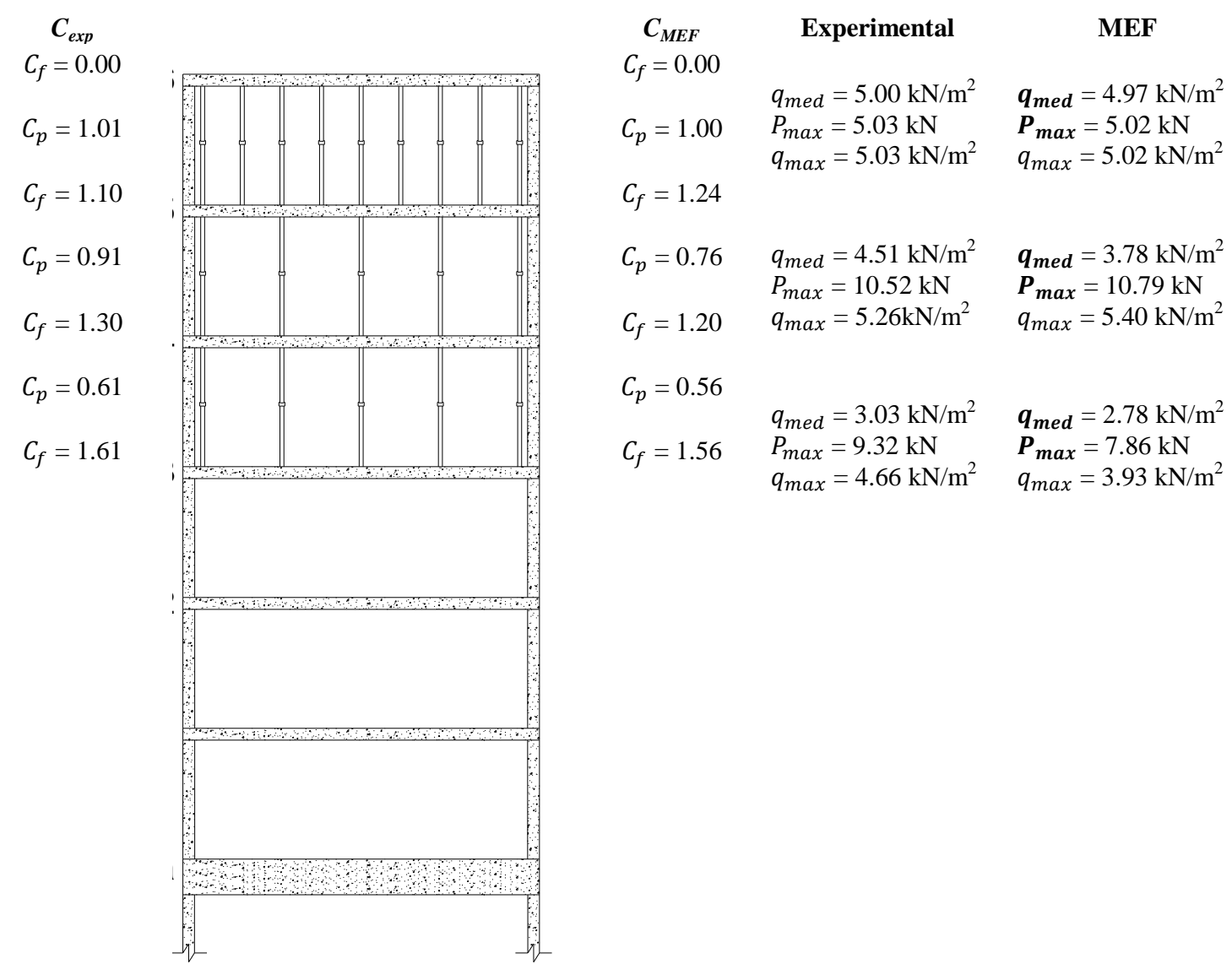

Fig. II.28 Resultados vano de medianera (forjado de losa maciza). Paso de carga 14 (Hormigonado del forjado 6)

\section{II.3. Resultados del estudio experimental del edificio de forjado reticular de casetón recuperable}

\section{II.3.1. Paso de carga 1 (Hormigonado forjado 1)}

Vano de esquina

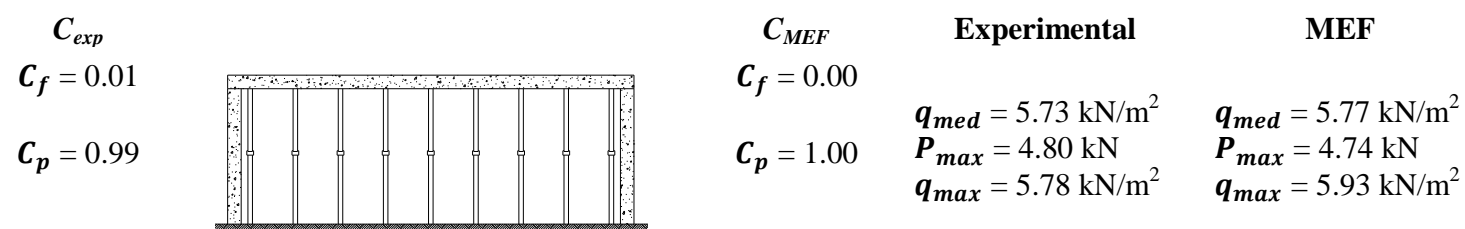

Fig. II.29 Resultados vano de esquina (forjado reticular de casetón recuperable). Paso de carga 1 (Hormigonado del forjado 1) 
Vano de medianera

$$
\begin{gathered}
\boldsymbol{C}_{\text {exp }} \\
\boldsymbol{C}_{\boldsymbol{f}}=0.00 \\
\boldsymbol{C}_{\boldsymbol{p}}=1.00
\end{gathered}
$$

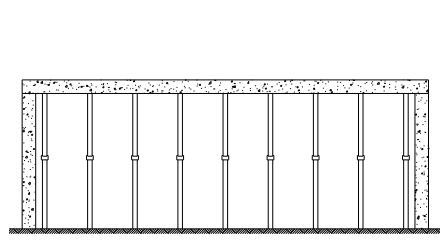

$$
\begin{gathered}
\boldsymbol{C}_{\text {MEF }} \\
\boldsymbol{C}_{\boldsymbol{f}}=0.00 \\
\boldsymbol{C}_{\boldsymbol{p}}=1.01
\end{gathered}
$$$$
\text { Experimental }
$$

MEF

$\boldsymbol{q}_{\text {med }}=5.79 \mathrm{kN} / \mathrm{m}^{2}$
$\boldsymbol{P}_{\text {max }}=4.75 \mathrm{kN}$
$\boldsymbol{q}_{\text {max }}=5.72 \mathrm{kN} / \mathrm{m}^{2}$

$\boldsymbol{q}_{\text {med }}=5.83 \mathrm{kN} / \mathrm{m}^{2}$

$\boldsymbol{P}_{\text {max }}=4.74 \mathrm{kN}$

$\boldsymbol{q}_{\max }=5.93 \mathrm{kN} / \mathrm{m}^{2}$

Fig. II.30 Resultados vano de medianera (forjado reticular de casetón recuperable). Paso de carga 1 (Hormigonado del forjado 1)

Las Figuras II.29 y II.30 muestran los resultados obtenidos del modelo numérico para este paso de

\begin{tabular}{|c|c|c|c|}
\hline$C_{e x p}$ & $C_{M E F}$ & Experimental & MEF \\
\hline$C_{f}=0.34$ & $C_{f}=0.28$ & & \\
\hline$C_{p}=0.66$ & $C_{p}=0.72$ & $\begin{array}{l}\boldsymbol{q}_{\text {med }}=3.80 \mathrm{kN} / \mathrm{m}^{2} \\
\boldsymbol{P}_{\text {max }}=7.19 \mathrm{kN} \\
\boldsymbol{q}_{\text {max }}=4.33 \mathrm{kN} / \mathrm{m}^{2}\end{array}$ & $\begin{array}{l}\boldsymbol{q}_{\text {med }}=4.17 \mathrm{kN} / \mathrm{m}^{2} \\
\boldsymbol{P}_{\text {max }}=7.66 \mathrm{kN} \\
\boldsymbol{q}_{\text {max }}=4.79 \mathrm{kN} / \mathrm{m}^{2}\end{array}$ \\
\hline
\end{tabular}
carga en comparación con las medidas experimentales. El grado de ajuste entre las cargas medias experimental y numérica es muy buena, obteniéndose una relación entre ambas $\left(q_{\text {med,exp }} / q_{\text {med,MEF }}\right)$ de 0.99 para ambos vanos.

\section{II.3.2. Paso de carga 2 (Clareado forjado 1)}

\section{Vano de esquina}

Fig. II.31 Resultados vano de esquina (forjado reticular de casetón recuperable). Paso de carga 2(Clareado del forjado 1)

Vano de medianera

$$
\begin{gathered}
\boldsymbol{C}_{\text {exp }} \\
\boldsymbol{C}_{\boldsymbol{f}}=0.16 \\
\boldsymbol{C}_{\boldsymbol{p}}=0.84
\end{gathered}
$$

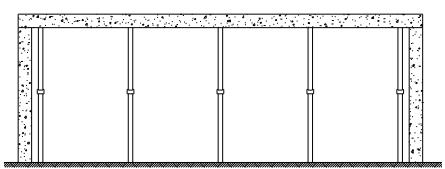

$$
\begin{gathered}
C_{M E F} \\
C_{\boldsymbol{f}}=0.12 \\
\boldsymbol{C}_{\boldsymbol{p}}=0.88
\end{gathered}
$$

Experimental

MEF

$\boldsymbol{q}_{\text {med }}=4.84 \mathrm{kN} / \mathrm{m}^{2}$

$\boldsymbol{P}_{\text {max }}=9.28 \mathrm{kN}$

$\boldsymbol{q}_{\max }=5.59 \mathrm{kN} / \mathrm{m}^{2}$

$\boldsymbol{q}_{\text {med }}=5.06 \mathrm{kN} / \mathrm{m}^{2}$

$\boldsymbol{P}_{\text {max }}=7.31 \mathrm{kN}$

$\boldsymbol{q}_{\max }=4.57 \mathrm{kN} / \mathrm{m}^{2}$

Fig. II.32 Resultados vano de medianera (forjado reticular de casetón recuperable). Paso de carga 2 (Clareado del forjado 1)

El paso de carga 2 se corresponde con el clareado del forjado 1 (véase Figuras II.31 y II.32). Al igual que en el paso de carga 1, existe un alto grado de ajuste entre los valores experimentales y los numéricos, siendo la relación $q_{m e d, e x p} / q_{m e d, M E F}$ igual a 0.91 en el vano de esquina y 0.96 en el vano de medianera. 


\section{II.3.3. Paso de carga 3 (Hormigonado forjado 2)}

Las Figuras II.33 y II.34 muestran una comparación entre las medidas experimentales y los resultados del modelo de EF para el paso de carga 3.

Vano de esquina

$$
\begin{gathered}
\boldsymbol{C}_{\text {exp }} \\
C_{f}=0.02 \\
C_{p}=0.98 \\
C_{f}=1.07 \\
C_{p}=0.91
\end{gathered}
$$

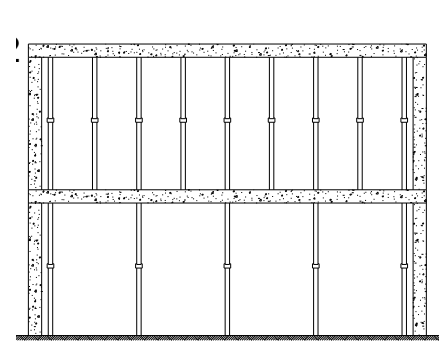

$$
\begin{array}{cll}
\boldsymbol{C}_{\text {MEF }} & \multicolumn{1}{c}{\text { Experimental }} & \multicolumn{1}{c}{\text { MEF }} \\
C_{f}=0.00 & & \\
& q_{\text {med }}=5.66 \mathrm{kN} / \mathrm{m}^{2} & \boldsymbol{q}_{\text {med }}=5.76 \mathrm{kN} / \mathrm{m}^{2} \\
C_{p}=1.00 & P_{\text {max }}=7.00 \mathrm{kN} & \boldsymbol{P}_{\text {max }}=4.74 \mathrm{kN} \\
& q_{\text {max }}=5.62 \mathrm{kN} / \mathrm{m}^{2} & q_{\text {max }}=5.92 \mathrm{kN} / \mathrm{m}^{2} \\
C_{f}=0.78 & & \\
& & \\
C_{p}=1.22 & q_{\text {med }}=5.25 \mathrm{kN} / \mathrm{m}^{2} & \boldsymbol{q}_{\text {med }}=7.02 \mathrm{kN} / \mathrm{m}^{2} \\
& P_{\text {max }}=9.44 \mathrm{kN} & \boldsymbol{P}_{\text {max }}=12.95 \mathrm{kN} \\
& q_{\text {max }}=5.69 \mathrm{kN} / \mathrm{m}^{2} & q_{\text {max }}=8.09 \mathrm{kN} / \mathrm{m}^{2}
\end{array}
$$

Fig. II.33 Resultados vano de esquina (forjado reticular de casetón recuperable). Paso de carga 3 (Hormigonado del forjado 2)

\section{Vano de medianera}

$$
\begin{gathered}
\boldsymbol{C}_{\text {exp }} \\
C_{f}=0.00 \\
C_{p}=1.00 \\
C_{f}=0.92 \\
C_{p}=1.08
\end{gathered}
$$

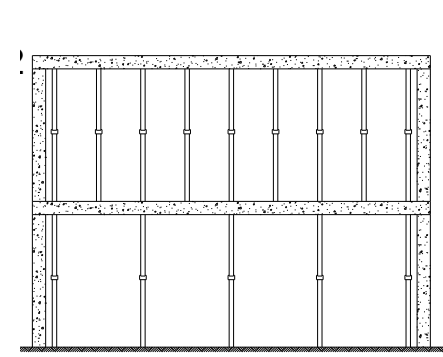

$$
\begin{aligned}
& C_{M E F} \quad \text { Experimental } \quad \text { MEF } \\
& C_{f}=0.00 \\
& q_{\text {med }}=5.77 \mathrm{kN} / \mathrm{m}^{2} \quad \boldsymbol{q}_{\text {med }}=5.82 \mathrm{kN} / \mathrm{m}^{2} \\
& C_{p}=1.01 \quad P_{\text {max }}=4.98 \mathrm{kN} \quad \boldsymbol{P}_{\text {max }}=4.74 \mathrm{kN} \\
& C_{f}=0.26 \\
& q_{\max }=6.01 \mathrm{kN} / \mathrm{m}^{2} \quad q_{\max }=5.92 \mathrm{kN} / \mathrm{m}^{2} \\
& C_{p}=1.75 \quad q_{\text {med }}=6.23 \mathrm{kN} / \mathrm{m}^{2} \quad \boldsymbol{q}_{\text {med }}=10.07 \mathrm{kN} / \mathrm{m}^{2} \\
& P_{\max }=11.92 \mathrm{kN} \quad \boldsymbol{P}_{\max }=14.50 \mathrm{kN} \\
& q_{\max }=7.18 \mathrm{kN} / \mathrm{m}^{2} \quad q_{\max }=9.06 \mathrm{kN} / \mathrm{m}^{2}
\end{aligned}
$$

Fig. II.34 Resultados vano de medianera (forjado reticular de casetón recuperable). Paso de carga 3 (Hormigonado del forjado 2)

El grado de ajuste entre las medidas experimentales y los resultados numéricos de las cargas en los puntales del forjado 1 es muy alto. La relación $q_{m e d, e x p} / q_{m e d, M E F}$ es 0.98 en el caso del vano de esquina y 0.99 en el de medianera. Sin embargo, en los puntales del forjado 1 se obtiene un error bastante alto $\left(q_{\text {med,exp }} / q_{\text {med,MEF }}=0.75\right.$, vano de esquina; $q_{\text {med,exp }} / q_{m e d, M E F}=0.62$, vano de medianera) De la misma forma que al hormigonar el forjado 1, el sistema de apuntalamiento soporta toda la carga del forjado 2 recién hormigonado.

\section{II.3.4. Paso de carga 4 (Clareado forjado 2 - Descimbrado forjado 1)}

Las operaciones de clareado del forjado 2 y descimbrado del forjado 1 se realizaron conjuntamente. En las Figuras II.35 y II.36 se muestran tanto las mediciones experimentales como los resultados numéricos para esta fase constructiva. 


\section{Vano de esquina}

$$
\begin{gathered}
C_{\text {exp }} \\
C_{f}=0.59 \\
C_{p}=0.41 \\
C_{f}=1.41
\end{gathered}
$$

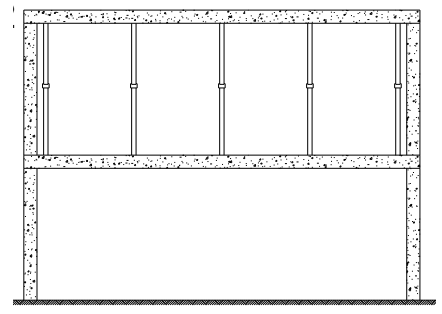

$$
\begin{array}{cll}
\boldsymbol{C}_{\text {MEF }} & \multicolumn{1}{c}{\text { Experimental }} & \multicolumn{1}{c}{\text { MEF }} \\
C_{f}=0.66 & & \\
& q_{\text {med }}=2.36 \mathrm{kN} / \mathrm{m}^{2} & \boldsymbol{q}_{\text {med }}=1.93 \mathrm{kN} / \mathrm{m}^{2} \\
C_{p}=0.33 & P_{\text {max }}=5.65 \mathrm{kN} & \boldsymbol{P}_{\text {max }}=3.29 \mathrm{kN} \\
& q_{\max }=2.27 \mathrm{kN} / \mathrm{m}^{2} & q_{\text {max }}=2.28 \mathrm{kN} / \mathrm{m}^{2} \\
C_{f}=1.33 & &
\end{array}
$$

Fig. II.35 Resultados vano de esquina (forjado reticular de casetón recuperable). Paso de carga 4 (Descimbrado del forjado 1)

\section{Vano de medianera}

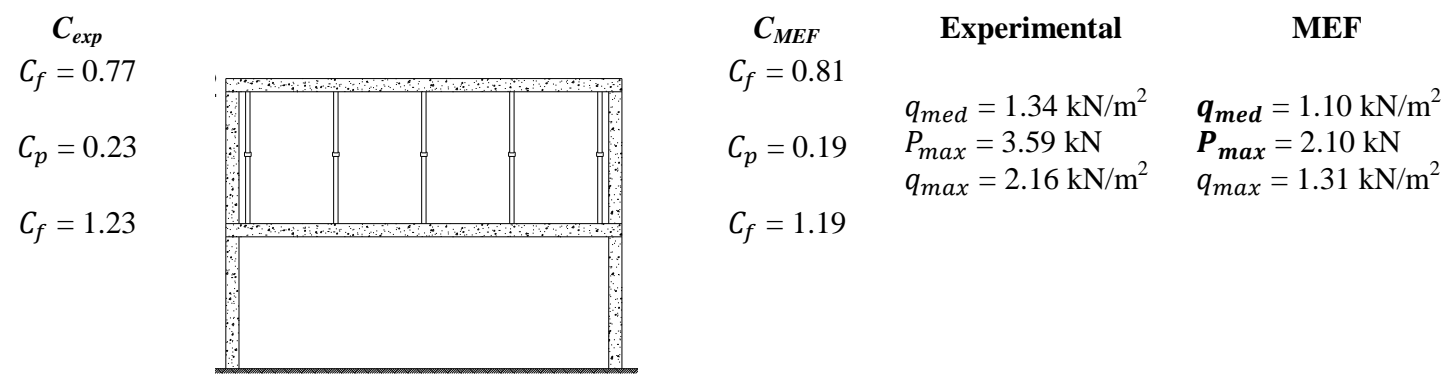

Fig. II.36 Resultados vano de medianera (forjado reticular de casetón recuperable). Paso de carga 4 (Descimbrado del forjado 1)

Para ambos vanos la relación entre las medidas experimentales y los resultado numéricos $\left(q_{m e d, e x p} / q_{m e d, M E F}\right)$ es de 1.22 .

\section{II.3.5. Paso de carga 5 (Hormigonado forjado 3)}

El paso de carga 5 consistió en modelar el hormigonado del forjado 3. Las Figuras II.37 y II.38 muestran los resultados de dicho paso de carga. Se observa que el grado de ajuste entre las medidas experimentales y los resultados del modelo de EF es alto, siendo el error máximo del $14 \%$.

La relación $q_{m e d, e x p} / q_{m e d, M E F}$ para cada caso es:

- Vano de esquina: 1.00 en los puntales del forjado 3y 1.14 en los del forjado 2.

- Vano de medianera: 0.99 en los puntales del forjado 3y 1.00 en los del forjado 2. 


\section{Vano de esquina}

$$
\begin{gathered}
\boldsymbol{C}_{\text {exp }} \\
C_{f}=0.00 \\
C_{p}=1.00 \\
C_{f}=1.26 \\
C_{p}=0.74 \\
C_{f}=1.74
\end{gathered}
$$

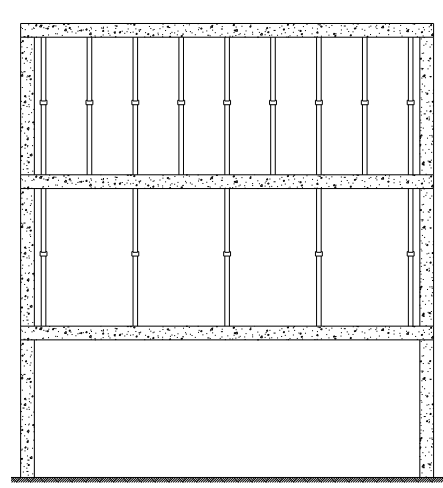

$$
\begin{array}{cll}
\boldsymbol{C}_{\text {MEF }} & \multicolumn{1}{c}{\text { Experimental }} & \text { MEF } \\
C_{f}=0.00 & & \\
& q_{\text {med }}=5.77 \mathrm{kN} / \mathrm{m}^{2} & \boldsymbol{q}_{\text {med }}=5.76 \mathrm{kN} / \mathrm{m}^{2} \\
C_{p}=1.00 & P_{\text {max }}=4.97 \mathrm{kN} & \boldsymbol{P}_{\text {max }}=4.74 \mathrm{kN} \\
& q_{\text {max }}=5.99 \mathrm{kN} / \mathrm{m}^{2} & q_{\text {max }}=5.93 \mathrm{kN} / \mathrm{m}^{2} \\
C_{f}=1.35 & & \\
& & \\
C_{p}=0.65 & q_{\text {med }}=4.29 \mathrm{kN} / \mathrm{m}^{2} & \boldsymbol{q}_{\text {med }}=3.77 \mathrm{kN} / \mathrm{m}^{2} \\
& P_{\text {max }}=8.65 \mathrm{kN} & \boldsymbol{P}_{\text {max }}=5.89 \mathrm{kN} \\
C_{f}=1.65 & q_{\text {max }}=5.21 \mathrm{kN} / \mathrm{m}^{2} & q_{\text {max }}=3.68 \mathrm{kN} / \mathrm{m}^{2}
\end{array}
$$

Fig. II.37 Resultados vano de esquina (forjado reticular de casetón recuperable). Paso de carga 5 (Hormigonado del forjado 3)

\section{Vano de medianera}

$$
\begin{gathered}
\boldsymbol{C}_{\text {exp }} \\
C_{f}=0.01 \\
C_{p}=0.99 \\
C_{f}=1.29 \\
C_{p}=0.70 \\
C_{f}=1.70
\end{gathered}
$$

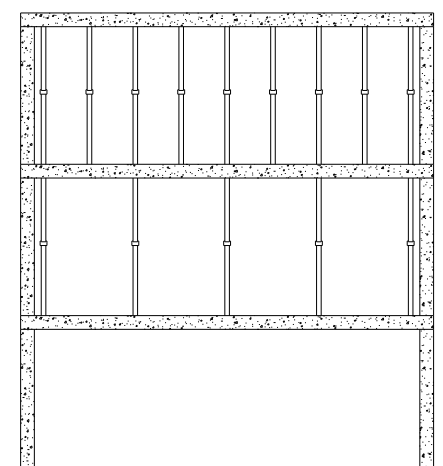

$C_{M E F}$

$C_{f}=0.00$

$C_{p}=1.01$

$C_{f}=1.31$

$C_{p}=0.70$

$C_{f}=1.70$
Experimental

$$
q_{\text {med }}=5.72 \mathrm{kN} / \mathrm{m}^{2}
$$$$
P_{\max }=4.92 \mathrm{kN}
$$$$
q_{\max }=5.93 \mathrm{kN} / \mathrm{m}^{2}
$$

$\boldsymbol{q}_{\text {med }}=5.80 \mathrm{kN} / \mathrm{m}^{2}$

$\boldsymbol{P}_{\text {max }}=4.74 \mathrm{kN}$

$q_{\max }=5.93 \mathrm{kN} / \mathrm{m}^{2}$

$q_{\text {med }}=4.03 \mathrm{kN} / \mathrm{m}^{2}$

$P_{\text {max }}=9.77 \mathrm{kN}$

$q_{\max }=5.89 \mathrm{kN} / \mathrm{m}^{2}$

$\boldsymbol{q}_{\text {med }}=4.02 \mathrm{kN} / \mathrm{m}^{2}$

$\boldsymbol{P}_{\text {max }}=6.54 \mathrm{kN}$

$q_{\max }=4.09 \mathrm{kN} / \mathrm{m}^{2}$

Fig. II.38 Resultados vano de medianera (forjado reticular de casetón recuperable). Paso de carga 5 (Hormigonado del forjado 3)

\section{II.3.6. Paso de carga 6 (Clareado forjado 3)}

En las Figuras II.39 y II.40 se muestra una comparación entre las medidas experimentales y los resultados del modelo numérico para el clareado del forjado 3. Se obtiene un buen grado de ajuste entre ambas medidas. La relación $q_{m e d, e x p} / q_{m e d, M E F}$ para cada caso es:

- Vano de esquina: 1.07 en los puntales del forjado 3y 1.12 en los del forjado 2.

- Vano de medianera: 1.03 en los puntales del forjado 3y 1.14 en los del forjado 2. 


\section{Vano de esquina}

$$
\begin{gathered}
C_{\text {exp }} \\
C_{f}=0.36 \\
C_{p}=0.64 \\
C_{f}=1.10 \\
C_{p}=0.54 \\
C_{f}=1.54
\end{gathered}
$$

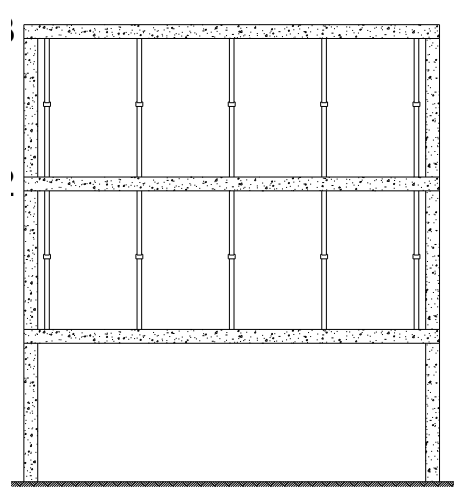

\begin{tabular}{|c|c|c|}
\hline$C_{M E F}$ & Experimental & MEF \\
\hline$C_{f}=0.33$ & & \\
\hline$C_{p}=0.67$ & $\begin{array}{l}q_{\text {med }}=3.97 \mathrm{kN} / \mathrm{m}^{2} \\
P_{\text {max }}=8.11 \mathrm{kN} \\
q_{\text {max }}=4.89 \mathrm{kN} / \mathrm{m}^{2}\end{array}$ & $\begin{aligned} \boldsymbol{q}_{\text {med }} & =3.87 \mathrm{kN} / \mathrm{m}^{2} \\
\boldsymbol{P}_{\text {max }} & =5.66 \mathrm{kN} \\
q_{\text {max }} & =3.54 \mathrm{kN} / \mathrm{m}^{2}\end{aligned}$ \\
\hline \multicolumn{3}{|l|}{$C_{f}=1.14$} \\
\hline$C_{p}=0.53$ & $\begin{array}{l}q_{\text {med }}=3.48 \mathrm{kN} / \mathrm{m}^{2} \\
P_{\text {max }}=8.64 \mathrm{kN}\end{array}$ & $\begin{array}{l}\boldsymbol{q}_{\text {med }}=3.05 \mathrm{kN} / \mathrm{m}^{2} \\
\boldsymbol{P}_{\text {max }}=4.93 \mathrm{kN}\end{array}$ \\
\hline$C_{f}=1.53$ & $q_{\max }=5.20 \mathrm{kN} / \mathrm{m}^{2}$ & $q_{\max }=3.08 \mathrm{kN} / \mathrm{m}^{2}$ \\
\hline
\end{tabular}

$$
\begin{aligned}
& C_{M E F} \quad \text { Experimental } \quad \text { MEF } \\
& C_{f}=0.41 \\
& q_{\text {med }}=3.68 \mathrm{kN} / \mathrm{m}^{2} \quad \boldsymbol{q}_{\text {med }}=3.43 \mathrm{kN} / \mathrm{m}^{2} \\
& C_{p}=0.59 \quad P_{\text {max }}=7.86 \mathrm{kN} \quad \boldsymbol{P}_{\max }=5.76 \mathrm{kN} \\
& C_{f}=1.11 \\
& C_{p}=0.48 \quad q_{\text {med }}=3.11 \mathrm{kN} / \mathrm{m}^{2} \quad \boldsymbol{q}_{\text {med }}=2.79 \mathrm{kN} / \mathrm{m}^{2} \\
& \begin{array}{ll}
P_{\text {max }}=5.16 \mathrm{kN} & \boldsymbol{P}_{\text {max }}=4.28 \mathrm{kN} \\
q_{\text {max }}=3.11 \mathrm{kN} / \mathrm{m}^{2} & q_{\text {max }}=2.68 \mathrm{kN} / \mathrm{m}^{2}
\end{array}
\end{aligned}
$$

Fig. II.39 Resultados vano de esquina (forjado reticular de casetón recuperable). Paso de carga 6 (Clareado del forjado 3)

\section{Vano de medianera}

$$
\begin{gathered}
\boldsymbol{C}_{\text {exp }} \\
C_{f}=0.31 \\
C_{p}=0.69 \\
C_{f}=1.09 \\
C_{p}=0.60 \\
C_{f}=1.60
\end{gathered}
$$

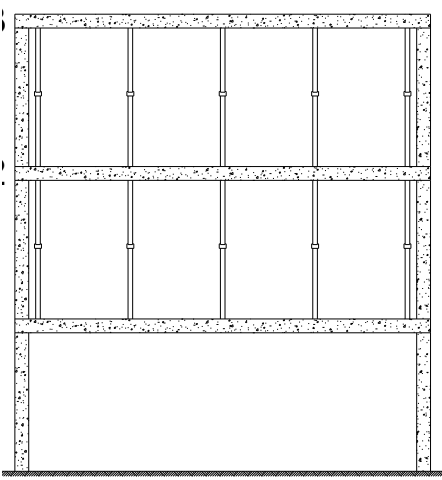

Fig. II.40 Resultados vano de medianera (forjado reticular de casetón recuperable). Paso de carga 6 (Clareado del forjado 3)

\section{II.3.7. Paso de carga 7 (Descimbrado forjado 2)}

El descimbrado del forjado 2 se modeló en el paso de carga 7 (véase Figuras II.41 y II.42). La relación entre la carga media experimental y numérica de los puntales del forjado 3 es de 1.28, en el caso del vano de esquina, y 1.14 , en el caso del vano de medianera. 
Vano de esquina

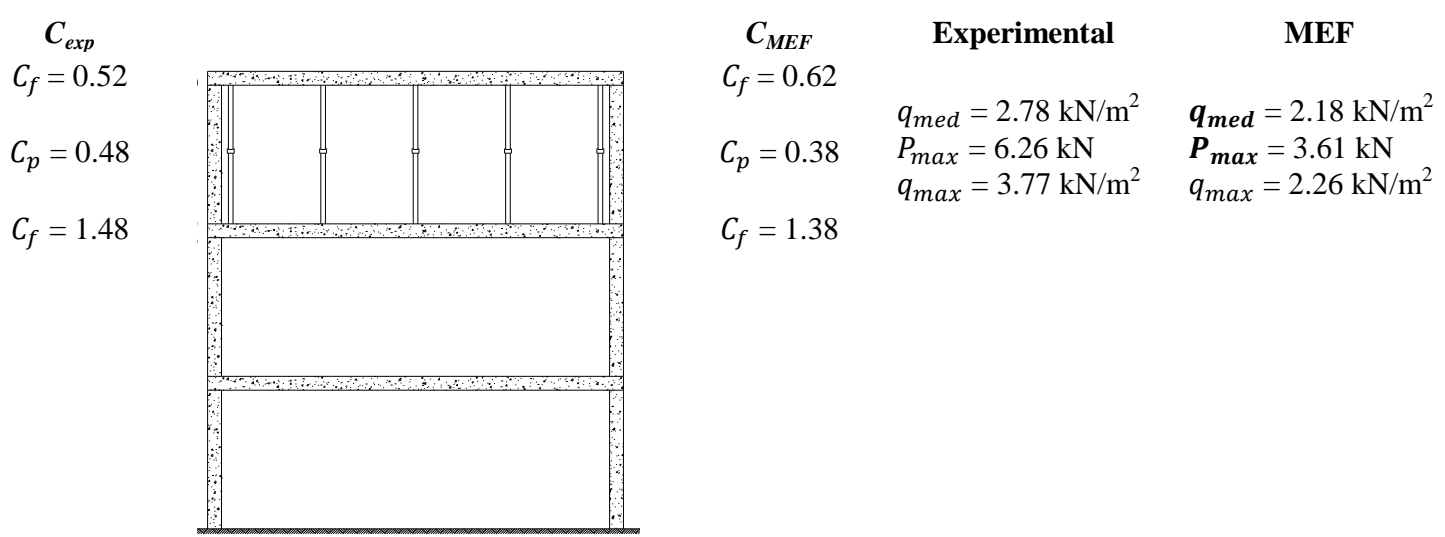

Fig. II.41 Resultados vano de esquina (forjado reticular de casetón recuperable). Paso de carga 7 (Descimbrado del forjado 2)

\section{Vano de medianera}

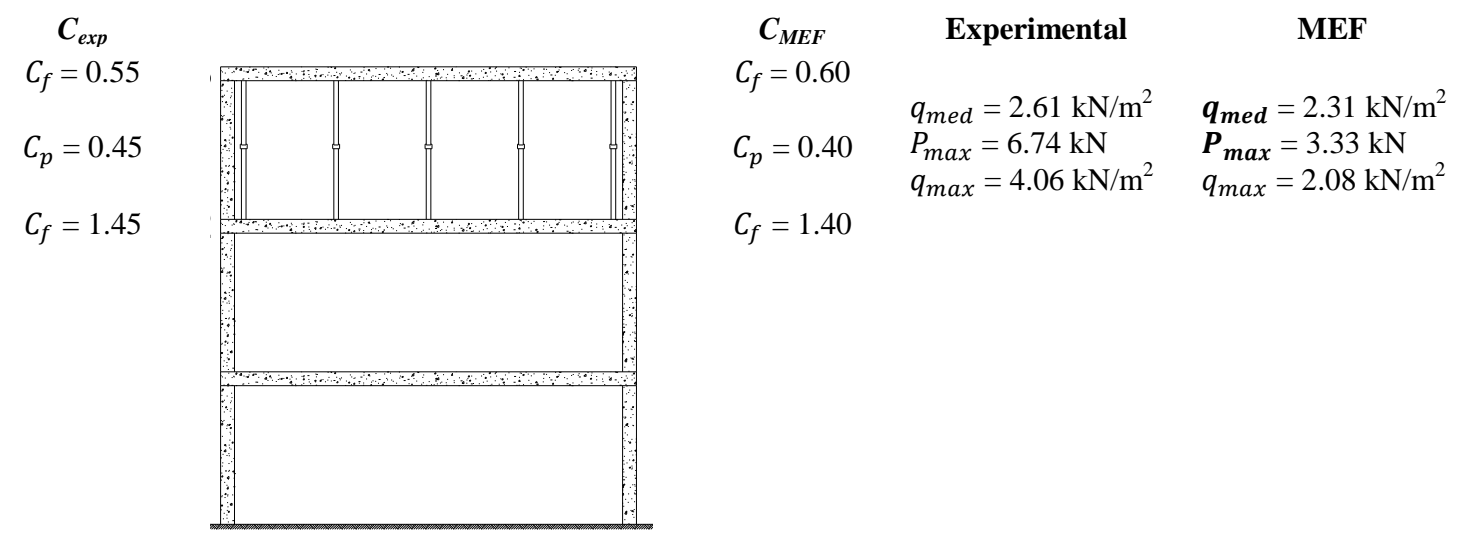

Fig. II.42 Resultados vano de medianera (forjado reticular de casetón recuperable). Paso de carga 7 (Descimbrado del forjado 2)

\section{II.3.8. Paso de carga 8 (Hormigonado forjado 4)}

El último paso de carga se corresponde con el hormigonado del forjado 4 (Figuras II.43 y II.44). En este paso de carga se obtiene un grado de ajuste muy bueno entre las medidas experimentales y los resultados del modelo de EF. La relación $q_{m e d, e x p} / q_{m e d, M E F}$ para cada caso es:

- Vano de esquina: 1.00 en los puntales del forjado 4y 1.13 en los del forjado 3.

- Vano de medianera: 0.99 en los puntales del forjado 4y 0.98 en los del forjado 3. 


\section{Vano de esquina}

$$
\begin{gathered}
\boldsymbol{C}_{\text {exp }} \\
C_{f}=0.00 \\
C_{p}=1.00 \\
C_{f}=1.12 \\
C_{p}=0.88 \\
C_{f}=1.88
\end{gathered}
$$

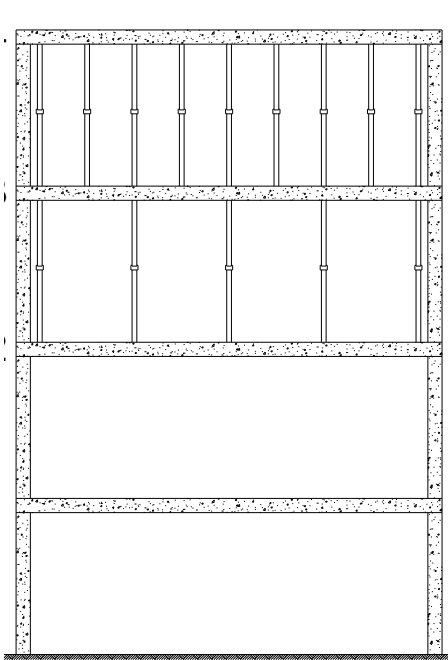

\section{Experimental}

$$
C_{f}=0.00
$$

$C_{f}=0.00$

$C_{p}=1.00$

$C_{f}=1.22$

$C_{p}=0.78$

$C_{f}=1.78$

$P_{\max }=4.90 \mathrm{kN}$

$P_{\text {max }}=10.72 \mathrm{kN}$ $q_{\text {med }}=5.75 \mathrm{kN} / \mathrm{m}^{2}$

$q_{\max }=5.90 \mathrm{kN} / \mathrm{m}^{2}$

$=5.76 \mathrm{kN} / \mathrm{m}^{2}$

$\boldsymbol{P}_{\max }=4.74 \mathrm{kN}$

$q_{\max }=5.93 \mathrm{kN} / \mathrm{m}^{2}$

$q_{\text {med }}=5.10 \mathrm{kN} / \mathrm{m}^{2}$

$q_{\max }=6.46 \mathrm{kN} / \mathrm{m}^{2}$

$\boldsymbol{q}_{\text {med }}=4.52 \mathrm{kN} / \mathrm{m}^{2}$

$\boldsymbol{P}_{\text {max }}=7.71 \mathrm{kN}$

$q_{\max }=4.82 \mathrm{kN} / \mathrm{m}^{2}$

\section{Vano de medianera}

$C_{\text {exp }}$

$C_{f}=0.00$

$C_{p}=1.00$

$C_{f}=1.16$

$C_{p}=0.84$

$C_{f}=1.84$

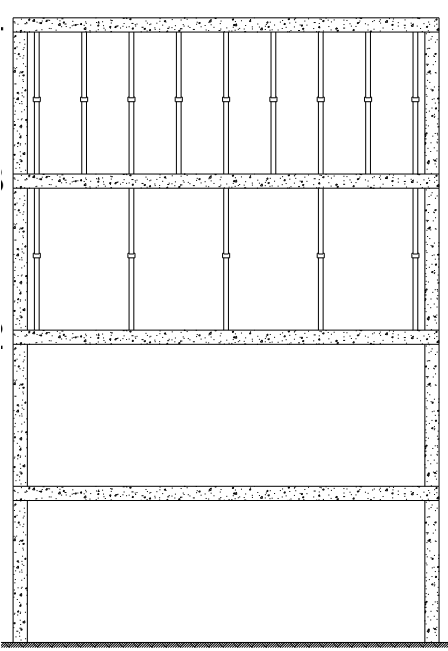

$C_{\text {MEF }}$

$C_{f}=0.00$

$C_{p}=1.01$

$C_{f}=1.15$

$C_{p}=0.86$

$C_{f}=1.86$
Experimental

$q_{\text {med }}=5.75 \mathrm{kN} / \mathrm{m}^{2}$

$P_{\text {max }}=4.87 \mathrm{kN}$

$q_{\max }=5.87 \mathrm{kN} / \mathrm{m}^{2}$

$\boldsymbol{q}_{\text {med }}=5.80 \mathrm{kN} / \mathrm{m}^{2}$

$\boldsymbol{P}_{\text {max }}=4.74 \mathrm{kN}$

$q_{\max }=5.93 \mathrm{kN} / \mathrm{m}^{2}$

$q_{\text {med }}=4.87 \mathrm{kN} / \mathrm{m}^{2} \quad \boldsymbol{q}_{\text {med }}=4.99 \mathrm{kN} / \mathrm{m}^{2}$

$P_{\text {max }}=10.91 \mathrm{kN} \quad \boldsymbol{P}_{\max }=7.27 \mathrm{kN}$

$q_{\max }=6.57 \mathrm{kN} / \mathrm{m}^{2} \quad q_{\max }=4.54 \mathrm{kN} / \mathrm{m}^{2}$

Fig. II.44 Resultados vano de medianera (forjado reticular de casetón recuperable). Paso de carga 8 (Hormigonado del forjado 4) 


\section{APÉNDICE III. ESTIMACIÓN DEL MÓDULO DE ELASTICIDAD DEL HORMIGON}

\section{III.1. Introducción}

En el modelo de Elementos Finitos planteado en el Capítulo 4 se realiza un cálculo no lineal, evolutivo que considera la variación de las características mecánicas del hormigón durante cada etapa constructiva. Esto hace que sea necesario conocer la evolución del módulo de elasticidad del hormigón en función del tiempo.

Para poder determinar el módulo elástico del hormigón a diferentes edades se utilizará de formulación propuesta en la Instrucción de Hormigón Estructural EHE-08 (2008) y se tendrá en cuenta la edad teórica del hormigón dependiendo de la temperatura media medida en obra. En el presente Apéndice se calculan los valores del módulo de elasticidad considerados para los elementos de hormigón integrados en el modelo numérico.

\section{III.2. Estimación del módulo de elasticidad}

De acuerdo con la Instrucción de Hormigón Estructural EHE-08 (2008) se puede determinar el módulo de elástico a edades diferentes de los 28 días a partir de la siguiente expresión:

$$
E_{c m}(t)=\left(\frac{f_{c m}(t)}{f_{c m}}\right)^{0.3} \cdot E_{c m}
$$

donde:

$E_{c m}(t)$ Módulo elástico a los $t$ días.

$E_{c m} \quad$ Módulo elástico a los 28 días. Según la expresión:

$$
E_{c m}=8500 \cdot \sqrt[3]{f_{c m}}
$$

$f_{c m} \quad$ Resistencia media a compresión a los 28 días que puede calcularse como $f_{c m}=f_{c k}+8$

$f_{c m}(t)$ Resistencia media a compresión a los $t$ días. Calculada a partir de la expresión:

$$
f_{c m}(t)=\beta_{c c}(t) \cdot f_{c m}
$$


con:

$$
\beta_{c c}(t)=\exp \left\{s\left[1-\left(\frac{28}{t}\right)^{1 / 2}\right]\right\}
$$

siendo:

Coeficiente que depende del cemento:

0.2 para cementos de alta resistencia y endurecimiento rápido (CEM 42.5R, CEM 52.5R)

0.25 para cementos normales y endurecimiento rápido (CEM 32.5R, CEM 42.5)

0.38 para cementos de endurecimiento lento (CEM 32.25)

\section{III.2.1.1. Cálculo del tiempo equivalente}

El tiempo equivalente o edad teórica se puede definir como el número j de días (o de horas) necesario, a una temperatura de referencia $T_{R} \mathrm{~T}_{\mathrm{R}}$, para que la madurez de la mezcla se iguale a la alcanzada con temperaturas distintas a la de referencia, aplicadas durante un periodo de tiempo t (ASTM, 1999). Con base en la ley de Arrhenius (Ec. III.5) (Guo, 1989 y Laplante, 1994), P. Freiesleben Hansen y E.J. Pedersen en 1977 propusieron la Ecuación III.6 de tiempo equivalente (CEB 1991).

$$
k=A \cdot e^{\frac{-E}{R \cdot T}}
$$

Donde, $k$ es la constante de velocidad (1/s para una reacción de primer orden, $A$ la constante denominada factor de frecuencia (1/s para un reacción de primer orden), $E$ la energía de activación (independiente de la temperatura), $T$ la temperatura en grados kelvin y $R$ la constante de los gases perfectos $\left(8.3144 \mathrm{~J} /{ }^{\circ} \mathrm{K} \mathrm{mol}\right)$.

$$
j=\sum_{i=0}^{i=t}\left(e^{\frac{E}{R} \cdot\left(\frac{1}{273+T_{R}}-\frac{1}{273+T_{i}}\right)} \cdot \Delta t_{i}\right)
$$

Siendo, $j$ el tiempo equivalente en días, $E$ la energía de activación aparente $(\mathrm{J} / \mathrm{mol}), T_{R}$ la temperatura de referencia y $T_{i}$ la temperatura en el intervalo de tiempo $\Delta t_{i}$ en grados centígrados.

Habitualmente se suele utilizar un valor único para la energía de activación aparente. Según propuesta del Código Modelo CEB-FIP 1990 (CEB-FIP 1991), coincidente con la del anejo B de la propuesta de modificación del Eurocódigo 2, se puede considerar para el hormigón una energía aparente de activación constante e igual a $33258 \mathrm{~J} / \mathrm{mol}$ y una temperatura de referencia de $20^{\circ} \mathrm{C}$. De esta forma el tiempo equivalente se puede expresar como muestra la Ecuación III.7.

$$
j=\sum_{i=0}^{i=t}\left(e^{\left(13.65 \cdot \frac{4000}{273+T_{i}}\right)} \cdot \Delta t_{i}\right)
$$

El campo de aplicación de este modelo se extiende entre las temperaturas de $0^{\circ} \mathrm{C}$ y $60^{\circ} \mathrm{C}$ y con cementos con contenidos casi nulos o relativamente reducidos de adiciones (tipos CEM I y CEM II) (fib 1999). 


\section{III.2.1.2. Edificio de forjado de losa maciza}

La temperatura media medida en obra fue de $25.3^{\circ} \mathrm{C}$. Empleando la ecuación III.7 se puede determinar el tiempo equivalente para dicha temperatura (ver Tabla III.1). Obtenido el tiempo equivalente para el hormigón, se estima la evolución del módulo de elasticidad empleando la Ecuación III.1 (ver Tabla III.1), sabiendo que el hormigón utilizado en la construcción del edificio tenía una resistencia característica a compresión de $25 \mathrm{MPa}$.

\begin{tabular}{|c|c|c|}
\hline $\begin{array}{c}\text { Tiempo } \\
\text { (Días) }\end{array}$ & $\begin{array}{c}\text { Tiempo } \\
\text { Equivalente (Días) }\end{array}$ & $\begin{array}{c}\text { Módulo Elástico } \\
\text { (MPa) }\end{array}$ \\
\hline 1 & 1.27 & 20.66 \\
\hline 2 & 2.54 & 22.91 \\
\hline 3 & 3.81 & 23.98 \\
\hline 4 & 5.08 & 24.64 \\
\hline 5 & 6.35 & 25.10 \\
\hline 6 & 7.62 & 25.45 \\
\hline 7 & 8.88 & 25.72 \\
\hline 8 & 10.15 & 25.95 \\
\hline 9 & 11.42 & 26.13 \\
\hline 10 & 12.69 & 26.29 \\
\hline 11 & 13.96 & 26.43 \\
\hline 12 & 15.23 & 26.55 \\
\hline 13 & 16.50 & 26.65 \\
\hline 14 & 17.77 & 26.75 \\
\hline 15 & 19.04 & 26.83 \\
\hline 16 & 20.31 & 26.91 \\
\hline 17 & 21.58 & 26.98 \\
\hline 18 & 22.85 & 27.05 \\
\hline 19 & 24.12 & 27.11 \\
\hline 20 & 25.39 & 27.16 \\
\hline 21 & 26.65 & 27.21 \\
\hline 22 & 27.92 & 27.26 \\
\hline 23 & 29.19 & 27.31 \\
\hline 24 & 30.46 & 27.35 \\
\hline 25 & 31.73 & 27.39 \\
\hline 26 & 33.00 & 27.43 \\
\hline 27 & 34.27 & 27.46 \\
\hline 28 & 35.54 & 27.49 \\
\hline
\end{tabular}

La Figura III.I muestra la evolución del módulo de elasticidad del hormigón del edificio de forjado de losa maciza. 


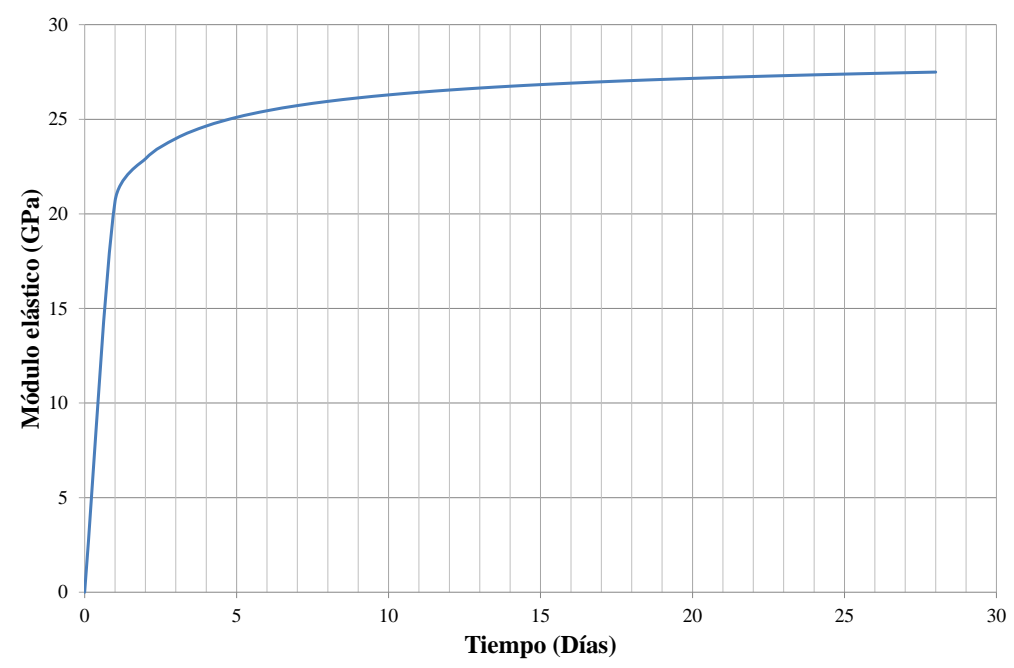

Fig. III.1 Estimación del módulo de elasticidad del edificio de forjado de losa maciza

\section{III.2.1.3. Edificio de forjado reticular de casetón perdido}

La temperatura media medida en obra fue de $22^{\circ} \mathrm{C}$. Empleando la ecuación III.7 se puede determinar el tiempo equivalente para dicha temperatura (ver Tabla III.2). Obtenido el tiempo equivalente para el hormigón, se estima la evolución del módulo de elasticidad empleando la Ecuación III.1 (ver Tabla III.2), sabiendo que el hormigón utilizado en la construcción del edificio tenía una resistencia característica a compresión de 30MPa.

Tabla III.2 Estimación del módulo de elasticidad del edificio de forjado reticular de casetón recuperable

\begin{tabular}{ccc}
\hline $\begin{array}{c}\text { Tiempo } \\
\text { (Días) }\end{array}$ & $\begin{array}{c}\text { Tiempo } \\
\text { Equivalente (Días) }\end{array}$ & $\begin{array}{c}\text { Módulo Elástico } \\
\text { (MPa) }\end{array}$ \\
\hline 1 & 1.09 & 21.08 \\
2 & 2.19 & 23.56 \\
3 & 3.28 & 24.74 \\
4 & 4.38 & 25.48 \\
5 & 5.47 & 26.00 \\
6 & 6.57 & 26.38 \\
7 & 7.66 & 26.69 \\
8 & 8.76 & 26.94 \\
9 & 9.85 & 27.14 \\
10 & 10.95 & 27.32 \\
11 & 12.04 & 27.47 \\
12 & 13.14 & 27.61 \\
13 & 14.23 & 27.73 \\
14 & 15.33 & 27.83 \\
15 & 16.42 & 27.93 \\
16 & 17.52 & 28.02 \\
17 & 18.61 & 28.10 \\
18 & 19.71 & 28.17 \\
19 & 20.80 & 28.24 \\
20 & 21.90 & 28.30 \\
21 & 22.99 & 28.36 \\
22 & 24.09 & 28.41 \\
23 & 25.18 & 28.46 \\
24 & 26.28 & 28.51 \\
25 & 27.37 & 28.55 \\
\hline
\end{tabular}




\begin{tabular}{ccc}
\hline $\begin{array}{c}\text { Tiempo } \\
\text { (Días) }\end{array}$ & $\begin{array}{c}\text { Tiempo } \\
\text { Equivalente (Días) }\end{array}$ & $\begin{array}{c}\text { Módulo Elástico } \\
\text { (MPa) }\end{array}$ \\
\hline 26 & 28.47 & 28.59 \\
27 & 29.56 & 28.63 \\
28 & 30.66 & 28.67 \\
\hline
\end{tabular}

La Figura III.2 muestra la evolución del módulo de elasticidad del hormigón del edificio de forjado reticular de casetón recuperable.

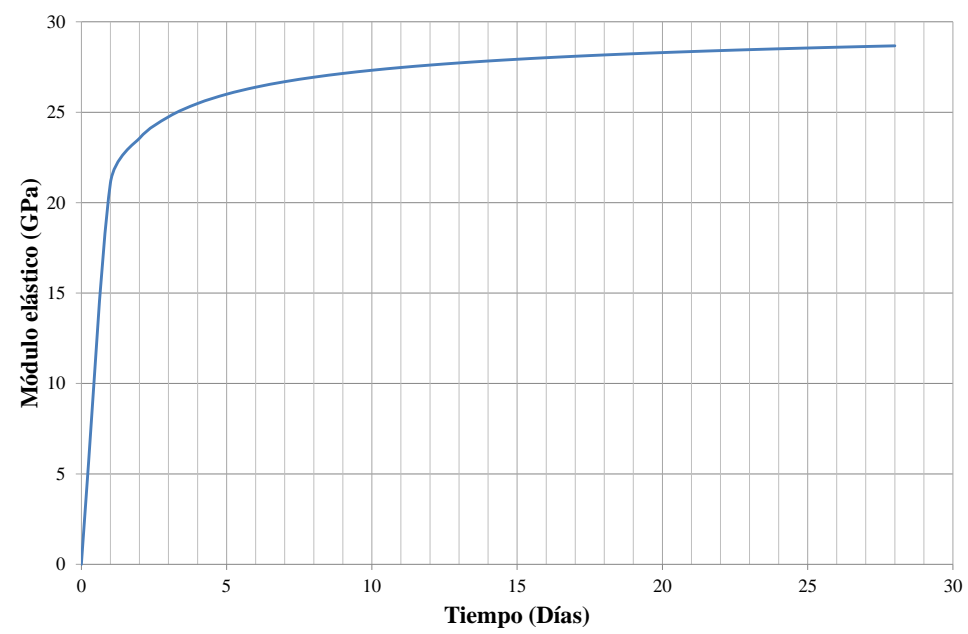

Fig. III.2 Estimación del módulo de elasticidad del edificio de forjado reticular de casetón recuperable 
